\title{
KRYPTOGAMENFLORA
} FÜR ANFÄNGER Bd. 2,1

).

\section{DIE MIKROSKOPISCHEN PILZE VON}

PROF. DR. G. LINDAU 


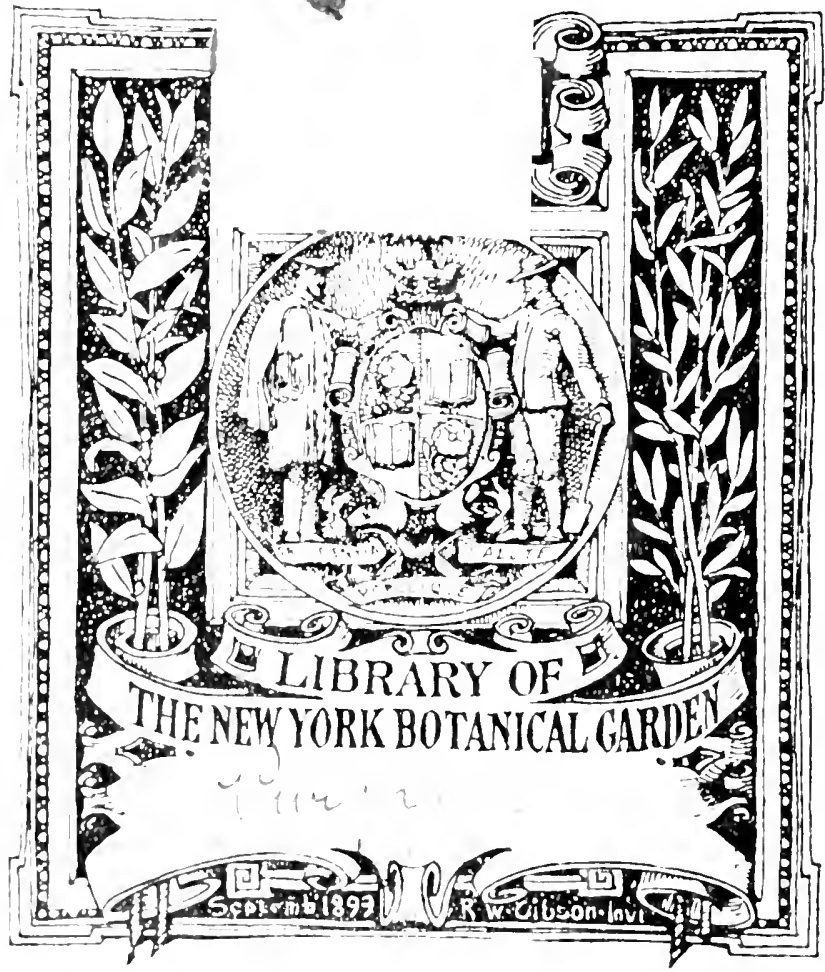




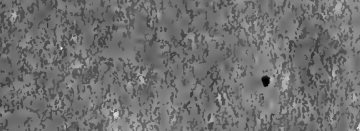

s.

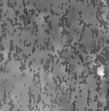

it

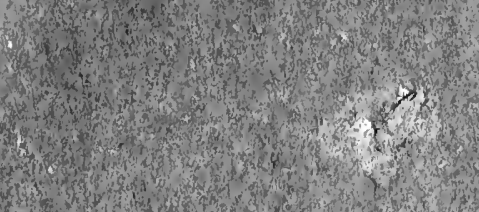

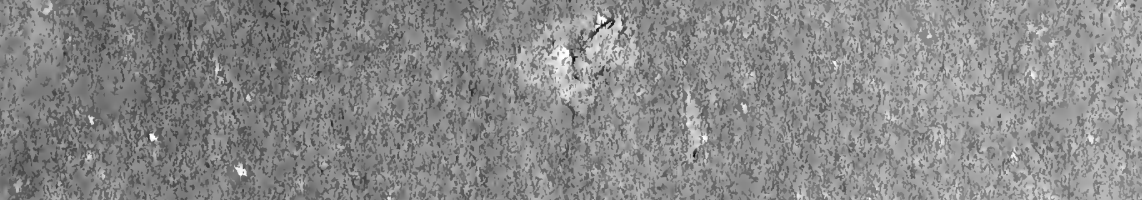

$+\frac{1}{2}+\frac{1}{2}$

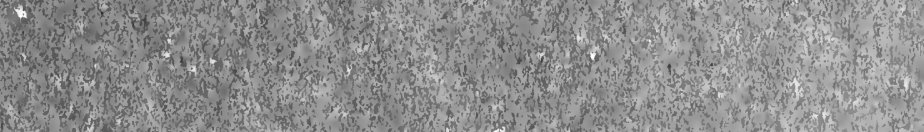

(1)

a)

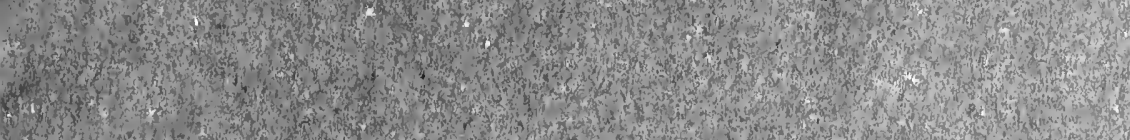

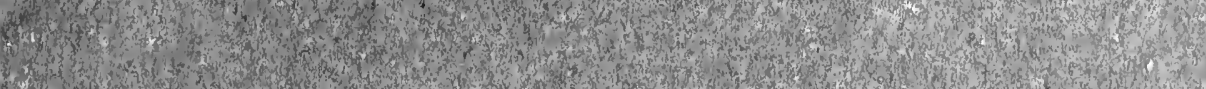

10
1

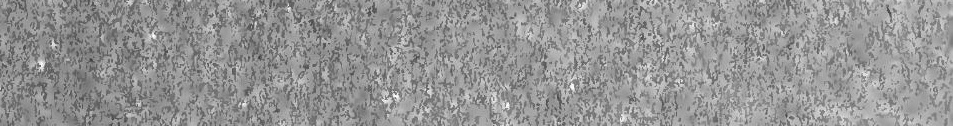

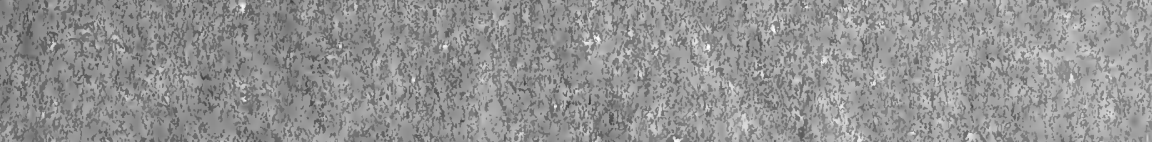

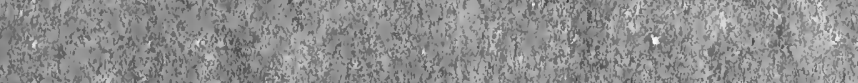

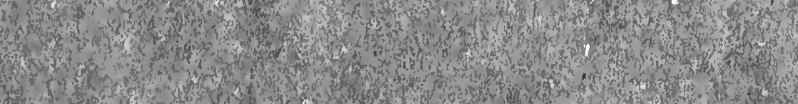

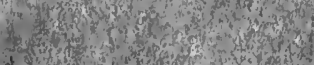

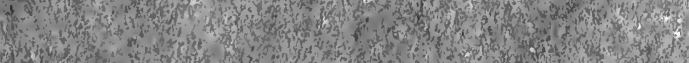

ting

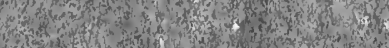

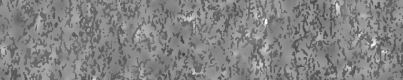

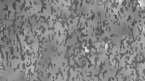

(x)

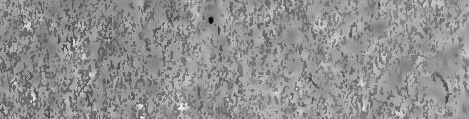

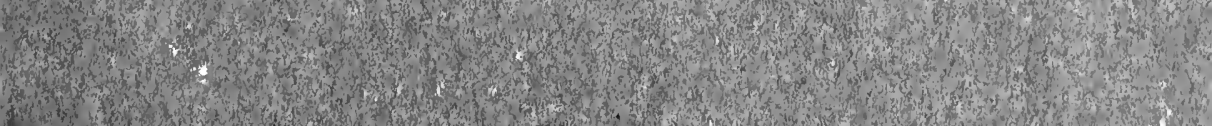

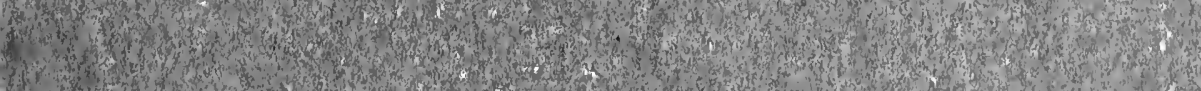

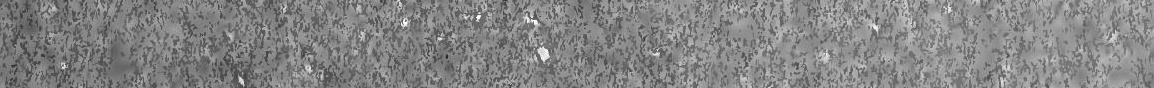
8

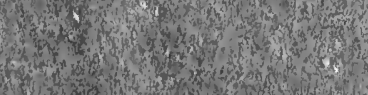

(18)

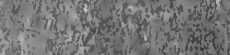

ing

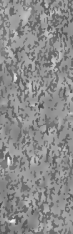

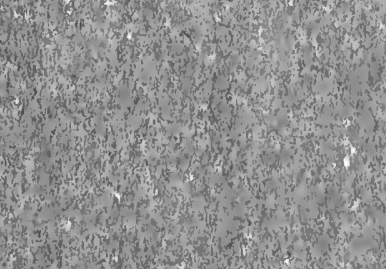

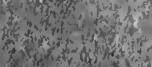

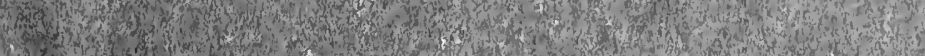
3 to a. 




\title{
Kryptogamenflora fǜ Infä̈nger
}

\author{
Eine Einfïiln'mg \\ in das studium dor blïtenlosen Gewäche \\ fiir studierende und Liebhaber
}

Heriusgegehen ron

Mr. (iustar I imdau

a. ii. l'roiesor an der luiversitat Berlin

litutos am Butall. Iluseam zal bablem

Zweiter Band. 1. Abteilung

Die mikroskopiscluen Pilze

(Mrxomyceten. Phycomyceten

und Ascomyceten)

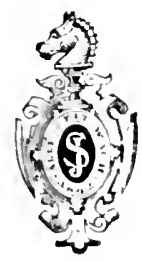

Berlin

Vorlang rou Juliusstringer

$1 \div \div 2$ 


\title{
Die \\ mikroskopischen Pilze
}

(Myxomyceten, Phycomyceten und Ascomyceten)

\author{
Von
}

\section{Dr. (justar Lindau}

a. ö. Professor an der Lniversität Berlin

Kustos am Botan. Museum zu Dahlem

Zweite, durchgesehene Auflage

Mit 400 Figuren im Text

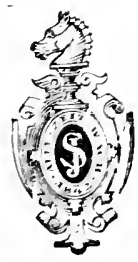

Berlin

Verlag ron Julius Springer 1929 


\section{$? \cdots, 1$}

Alle Rechte. insirendere das der

l'bersetzung in fremde sprachen. woblatten. 


\section{Vorwort zur ersten Auflage.}

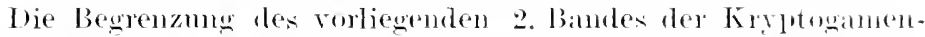
flora für Anfänger gevehah nach rein praktivchen cesichtopmkten, indem hier alle diejenigen l'ilze behondelt werden, fïr deren bewertumg der Gebranch des Vikroskopes eine merlälitiehe Vorbedingmg ist. Das richtige llals darin zn finden, wie weit man in des Beschreibung der Arten zu gehen hat, bot die gäl.sten sohwierigkeiten. dem der Anfänger soll nicht spezialstudien treihen, somblern sich erst in die Fomenkreise einatheiten mul einlehen. Fie behamllung der

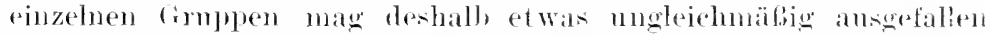
sein, was beunders den spezialisten anffallen wirl. Albe ich habe mach reiflicher C̈berlegung verschiedene (implen, namentlich die der

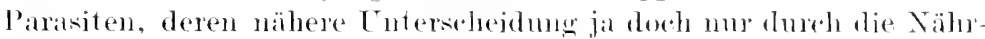
pflanzen möglich ist, weniger eingelent in bezng anf ihre mikm. skopischen dlen kmale behandelt. Anch gröbere fattmogen der Prenumyceten, deren Asten mur dem spezialforscher klar vor Angen stehen,

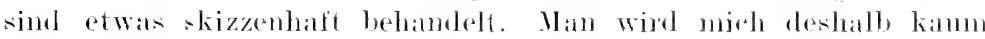
tarkelu kïmnen, da eine eingehende lreatheitung weit iiber den ge sterkten Rahmen hinansgegangen witre mol dem Anfänges doch nicht die volle Klärmng gebracht häte. Will sich also jemand näher mit einzolnen Gimplen befissen, so mub er die spezialliteratur herürksichtigen, wolür ioh einge llinweise in den einleitenten Kapiteln gegeben habe.

Die sogenannten Fungi innerfecti habe ith nicht behandelt, weil datureh der Enfang des bantes allznseh" angeschwollen wäre. sollte sich das bedürfnis, anch diese Pilzformen den Anfänger zngänglich zu machen, heraustellen, so kann das später immer noch geschehen.

Herr Prof. Dr. Jaln hat anf meine bitte sieh ter Miihe miterzogen, die Hyxonyceten in Mannskipt durchzusehen, wo[ür ich ihn meinen Dank ansistreche.

Dem Anfänger, der diesen Band benutzt, mödhte ich besontlers sagen, dab die hier behandelten Pilzabteihngen in der Wissenschaft moch durchans nicht in allen Punkten geklärt sind. Oh das jetzt angenmumene system ïberall der spateren Kritik standhält, diurlte 


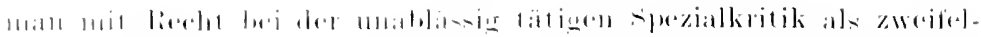

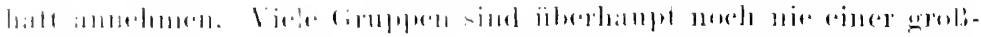

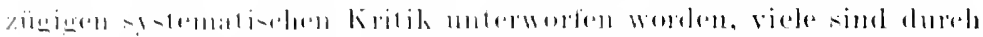

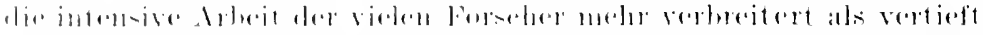

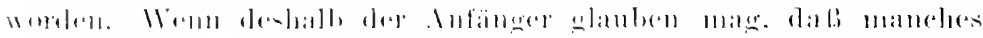

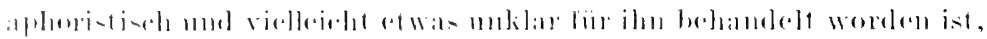

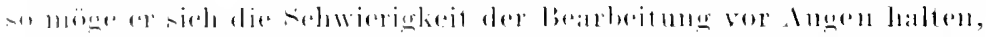

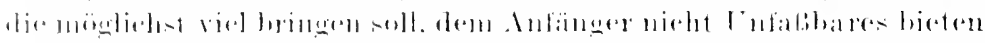

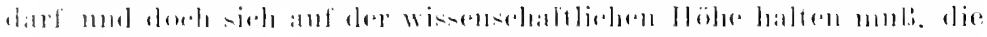

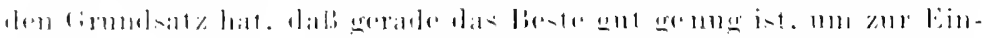

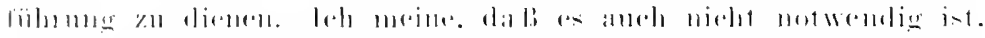

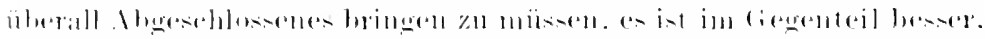

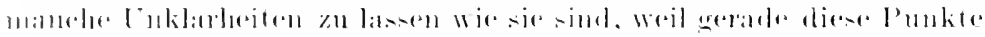

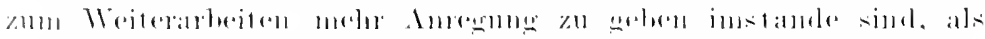

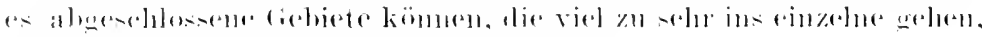

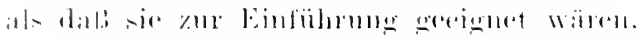

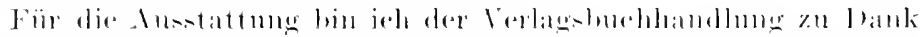

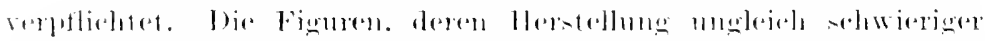

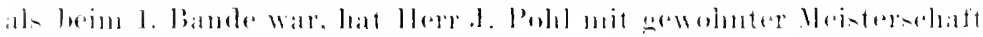

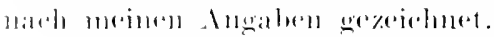

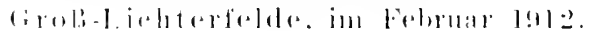

\section{Ai. Lindall.}

\section{Vorwort zar zweiten Iullage.}

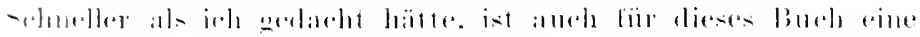

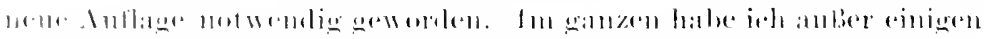

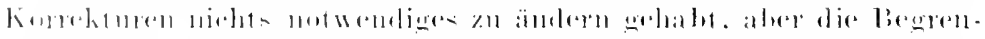

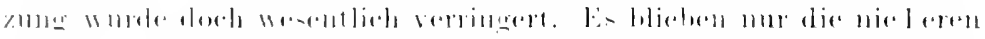

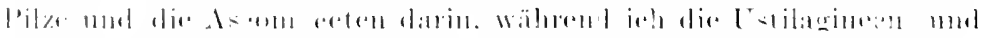

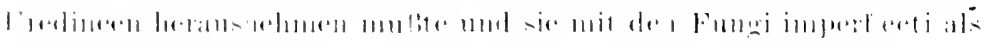

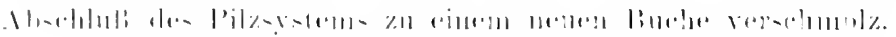

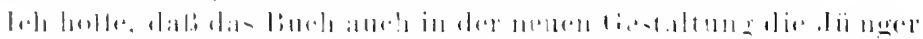

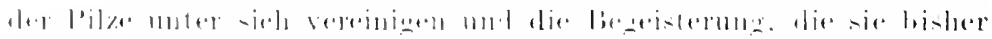

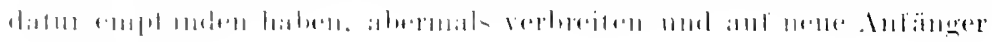

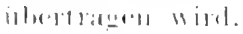

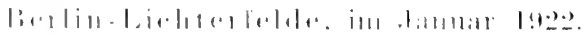

\section{li. Iindau.}




\section{Inhaltsverzeichnis.}

A. Allgemeiner Teil. - eite

I. Die mikroskopische Untersuchung . . . . . . . . . . (1)

II. Die Schleimpilze (Myxomyceten) . . . . . . . . . . . (3)

III. Tie Algenpilze (Phycomyceten) . . . . . . . . . . . . (5)

IV. Die parasitischen Pilze Syuchytriaceen, Clalochỵtriaceen. Peronoporineen). . . . . . . . . . . . . . (s)

V. Die Sehlauchpilze (Ascomyceten) . . . . . . . . . (10)

VI. System und Bestimmungstabelle der Hanltgruplen. . (16)

VII. Erklärung der wichtigsten Kunstausdrïclie. . . . . . (19)

B. Spezieller Teil.

Schizonycetes . . . . . . . . . . . . . . . . . . . 1

Myromycetes . . . . . . . . . . . . . . . . . . . . 4

Ennycetes. . . . . . . . . . . . . . . . . . . . $\geq t$

Oomycetes. . . . . . . . . . . . . . . . . 24

Zygonycetes . . . . . . . . . . . . . . . . . .

Asconycetes . . . . . . . . . . . . . . . . . 64

Verzeichnis der Gattungen, Arten und Abbildungen . . . . 205 


\title{
Lryptowamenflora \\ fïr Anfänger.
}

\author{
Von l'rof. I)r. li. Jindum.
}

I. Band. Die höheren Pilze. \%write, durchueschene Auflage Mit dot Toxtfiguren. 1917. geh. M. Sto.

II. Band. Die mikrokopischen Pibe. Zweite. durchgesehene Auflige.

1. Alteilmu: Myxomycetn, l'hyomyceten und Ascompecten. Mit 400 Figuren im Text.

¿. Aloteilung: I'stilagineen, Credineen, Inugi imperfecti.

lin Vorliereitung.

III. Band. Dje Fiechten. Mit Biti 'Textfiguren. 1919. M. -, -

IV. Band. Erste Hteilung. Die Algen. Mit 4=9 Tratfiguren. $1 ! 1] 4$

11..,.-

IV. Band. Zweite Alseilumg. Die Algen. Mit l:T Trextiguren. 1914. II $\quad$ i.tio

1V. Band. Dritte Abteilnug. Die Meerealgen. Vun Prof. Mr. Robert l'ilger. Jit jo: Textfiguren. 1916. M. 5.40.

I. Pand. Die laubmose. Von I)r. Wilhelm Lorch. Mit 2ti.; Jextfiguren. 13]:?. M. 7,-

V1. Pand. Dir. Torf-mel Lehermonse. Von Dr. Wilhelm Lorell.

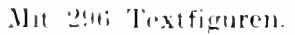

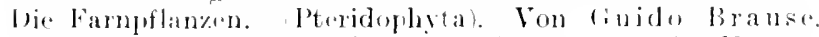

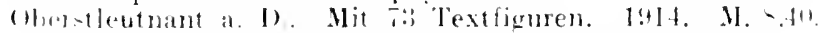

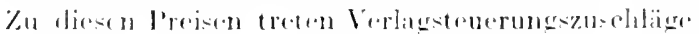

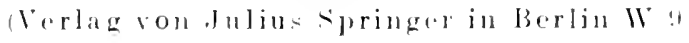




\section{Die mikroskopische Cntersuchung.}

In ersten Bande dieser Flora war bereits kurz drant hingerwesen worlen, in weleher Weise der Anfänger sich die notwentigen kemetnisse in Mikrosknpieren und in der mikrosknfischen Twebnik aneignen kann. In allgemeinen kommt or lei den höheren Pilzen. namentlich bei den lut lörnigen Basidiomyerten, mit den elementarstru Kenntnissen aus. Anders num wirt es bei den mikroskopischen Formen der Pilze. Hier hänfen sieh für den Anfïnger dieschwierigkeiten dadureh.

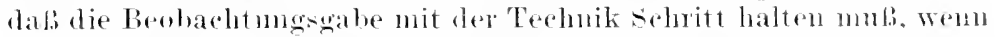
äberhanpt die Bestimmung gelingen soll. In erster linic also gebört ein etwas geschulter Blick dazu, mm alles sehen za könuen, was für die einzeluen Gruppen in Betracht kommt. Diese CHombg wird wohl jeder bald bekommen, der etwas last mol liebe zur sache mitbringt.

Ancers ater steht es mit der l'äramationstechnik. Bei allen niederen l'ilzen wollen die Objekte orst zur Benbachtmig hergerichtet sein. Ditse Präparation erfordert urobe L'bunes, aber der Anfänger lasse sich dureh anfängliche Vilerfolge nicht absehrecken. 11 änfig wird ein grofer Folnter genacht, inden versueht wird, rin bestimmtes rorliegendesobjekt nach allen Richtmugen einwandfei zu präparieren, so dali able Vorhälnisse daran hervortreten. Das möge der Geübter. machen, der Antänger dagegen darf sich darauf nirht rinlassen, sondern für iln mus als llanptregel gelten, dab er znerst überhaupt ein. mal etwas sieht. Wenn er also bei einer Art nicht sofort das ( harakteristische findet. so nögre er lieber eine andere mutersurhen. Sehlielslich wirl er doreh finden, was er sehen möchte mud sehen muli, nud dann wind es ilun pin loichtes sein, aucl an den ersten objekt das Gewïnschte zn selhen.

Berom nan hei den miknokopischen Pilzen an das genane L'ntersuchem. Keichnen mol bestimmen geht, empfiehlt es sich auberordentlieh, erst cine vorlänlige Lutersmehmog anzustellen. Diese soll den Kwerk haben, festzustellen, wh das erforderliche Reifestadimm bereits rorhandun ist. Sind die Exemplare nech nicht reif, was sich bei einiges îbung sofort benteilen läbt, so kann man sie zmm Naehroiten auslegen, also etwa Ilolzstüke mit Aseomyceten oder Hyxomyceten im Garten, Wasserpilze in riner Glassehale oder Aquarium nsw., woron weiter muten noch die liede sein wirl.

Lindau Kiyptogamenfora H. 1. 2. Aut. 


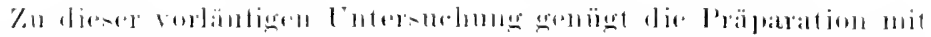

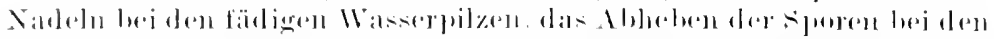

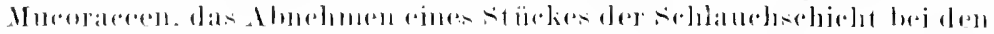

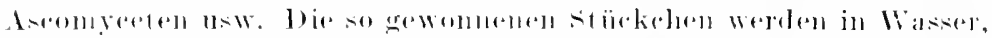

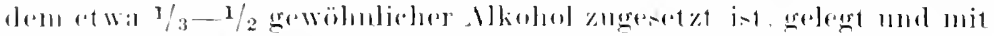

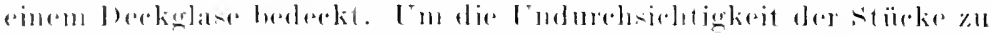

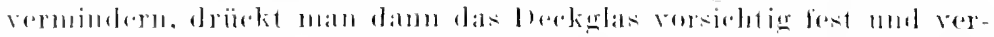

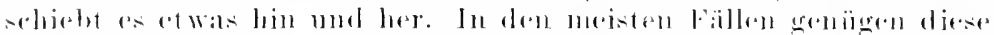

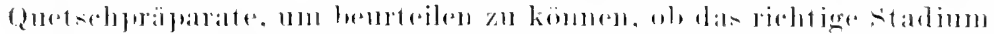

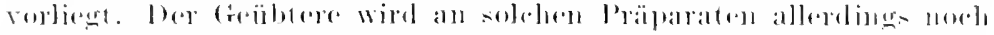

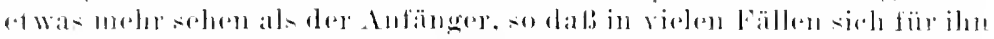

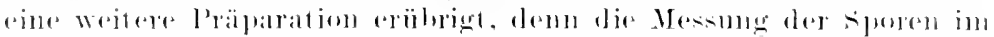

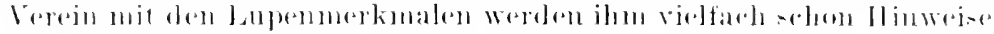

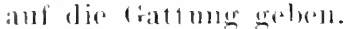

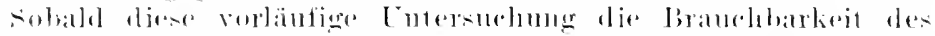

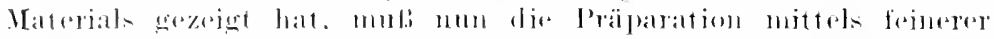

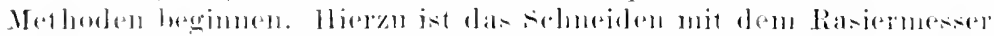

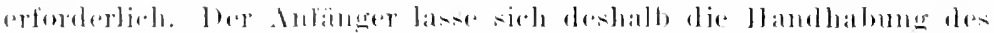

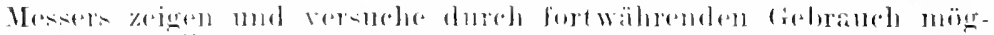

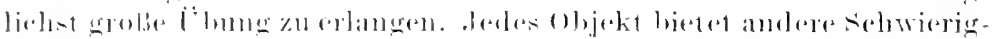

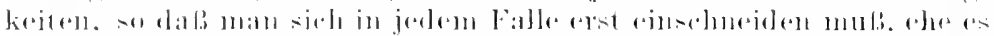

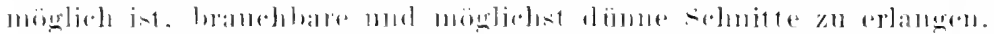

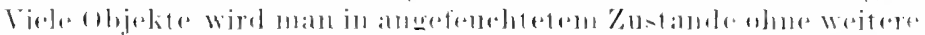

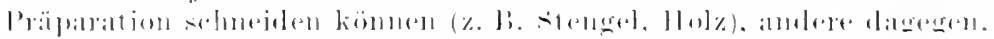

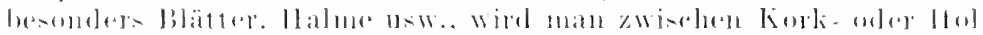

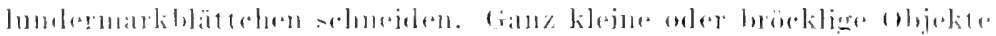

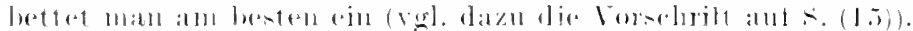

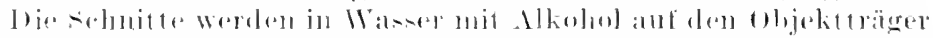

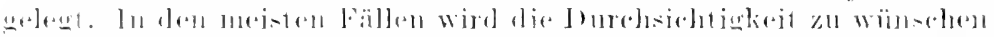

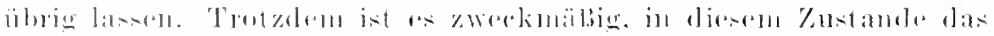

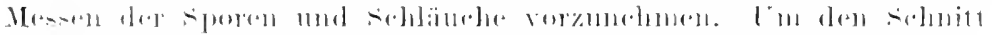

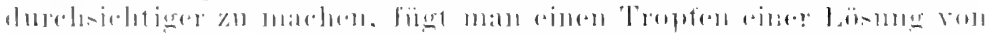

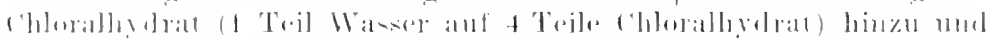

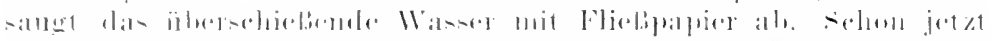

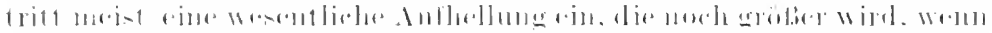

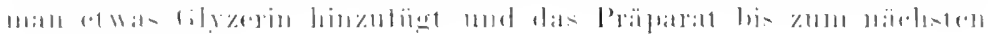

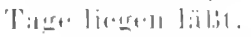

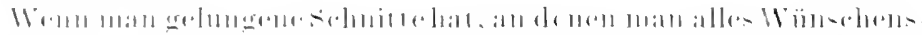

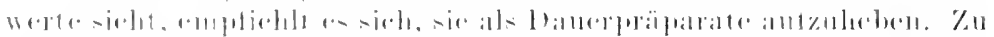

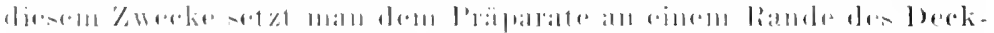

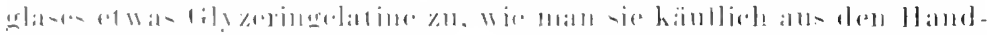

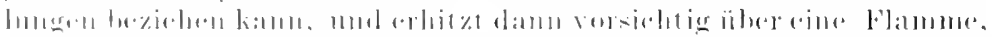

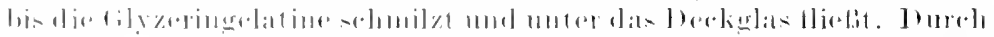

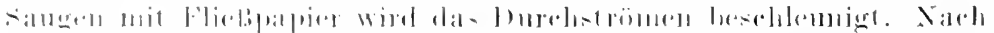

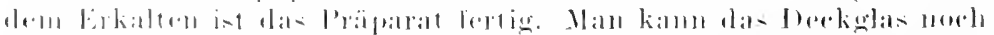

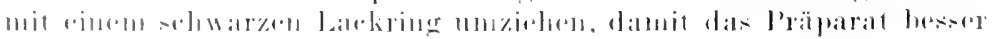

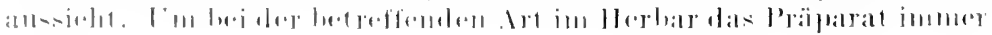


zur Hand zu haben. legt man es in kleine, käufliche Pappkästehen, die man den Exemplaren gleieh beifïgt. Das Anlegen einer besonderen Präparatensammlung empfehle ich nicht.

Ebenso wiehtigist, faß der Anfänger von vornherein alles zeichnet. was er sieht mul sich sofort dahej die Maße notiert. Auch farbige skizzen werden dem Gedächtuis besonders dam zu Hilfe kommen. wenn, wie etwa bej Iniscomyceten. the Exemplare durch das Eintrocknen sich rerfärben mul rerändern. Bei genanen Zejchnungen nach mikroskopischen Präparaten ist ein Zeichenapparat notwendig, in dessen Gebraun nan sich dureh einen Geübteren einfïhren lassen nigere.

Wie ich sehon in der Einlejtung zum ersten Bancle hervorhob. muls sich der Anfänger zuerst einem Geübteren anschliefen, der ilm die gewönliehsten Formen und die Technik ihrer Lntersuchmeg zeigt. Il at man rom jeler Gruppe erst eine Form miter Anleitmog morsucht und hestimmt, so wirl es nicht sehwer, die einzelnen Gruplen wiederzuerkennen. 'Zweifollos wird das sofortige Erkennen der Ordnung wler Reihe den Anfänger an schwersten fallen, denn die Formenfïlle wird ihn ̈̈herraschen mol dic Besclureibmngen ihn hänfig da verlassen. wo seine Fnsicherheit sich moch an sie anklammert. Das läst sich abed nicht änderus da es numöglich int, die grolien Abteilungen nach allen Richtungen hin erschöpfend zu diagnostizieren.

Es wäre ja selur w

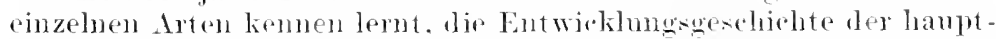
sachlichsen Typen studieren könnte. Eine schildemug darom. so wünscluenswert sic anch wäre. kann hier nicht in rinzeluen gegeben werden, denn sie wiole den $T^{+}$mfang des Buches zu seln anschwellen

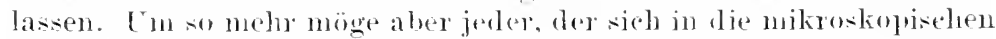
Pilze vertiefen will. hemiilnt sein, sich durels Lekt ïre mol selbständige Futersmehmogn diese breitere Basis anzueignen. Der Zanber, der sich um diese stmolien solingt, lat norle jerlen geparkt, der mit offenem tuge und regem lutereses sich diesen l'ormenkreisen zugrwendet hat.

\section{Die Schleimpilze (Myomyceten).}

Trotz ihrer meist selur geringen trähe gehören die sibleinupilze zu den zierlichsten organisehen Gobiden, die wir kennen. Inferlich erscheint jhr Bau sehr einfach, denn die meisten bilden mestaltete Lager oler besitzen anf kurzem stiel einen kngligen oder länglichen Kopt. Erst bei der Präparation sehen wir dam miter dem Mikroskop den feinen Ban des Kapillitinns, Her Kalkinkrustatimon, Floren nsw. Ans den sporen, die in den sporangien gebildet werken, driechen kleint Anubben herans, die sich nach kurzer Zeit zn eimen l'lasmodinm vereinigen. Dieses ernäht sich eine Zeitlang. indem es anf orler in den substrat herumkriecht, mol schrejtet dam zur Frohtbildung. D)i. einzehnen zusammengeflossenen Amöben, die sich noch geteilt haben.

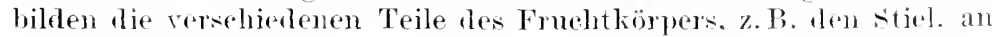




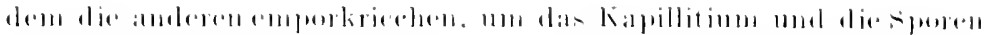

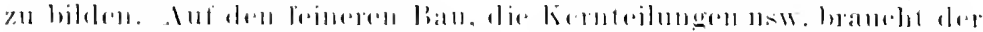

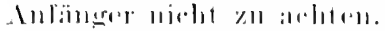

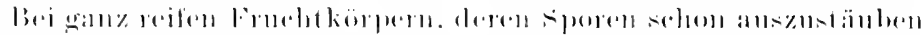

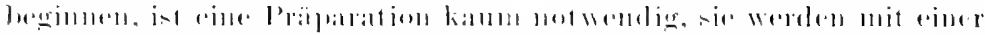

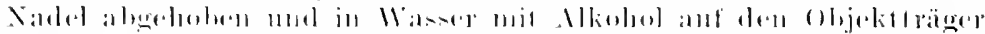

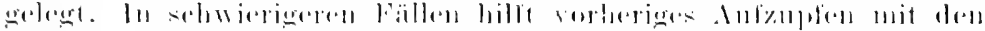

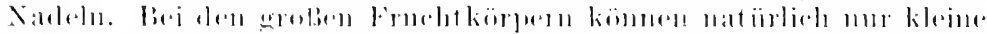

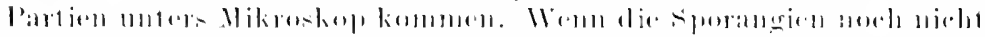

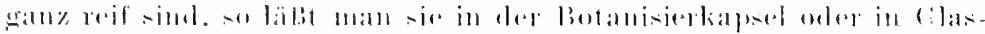

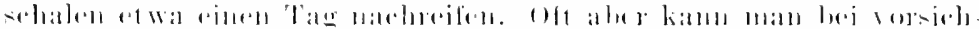

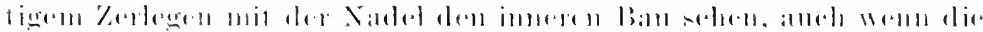

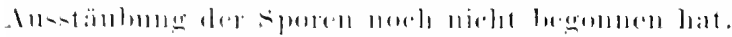

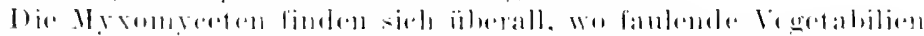

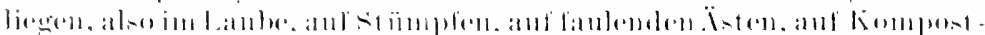

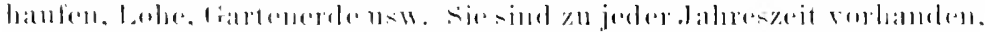

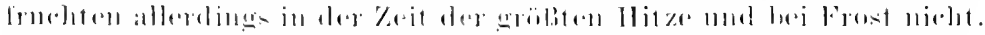

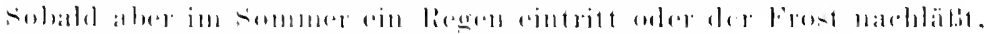

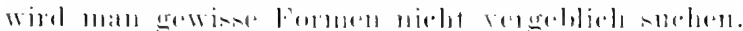

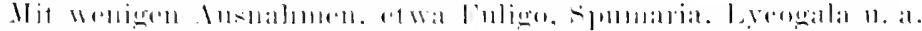

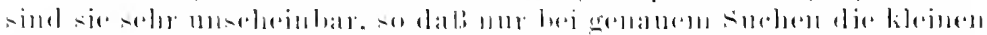

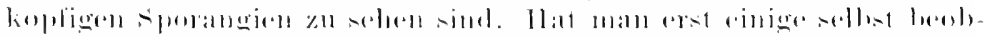

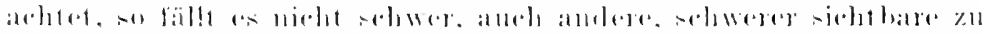

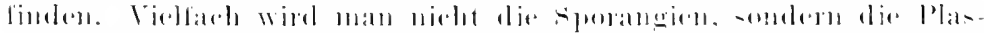

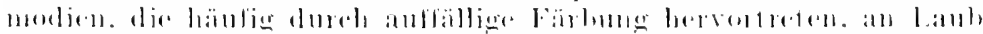

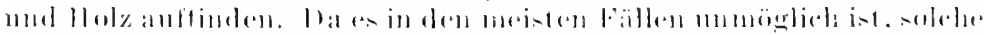

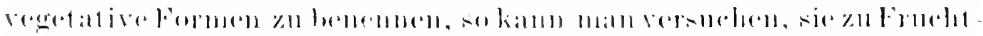

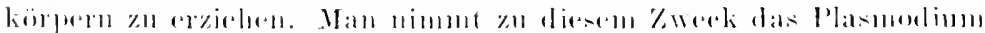

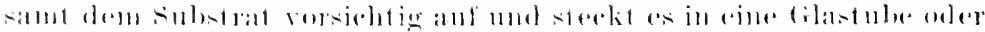

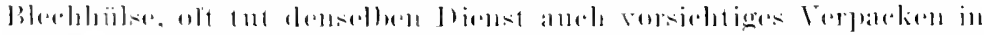

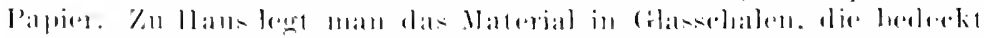

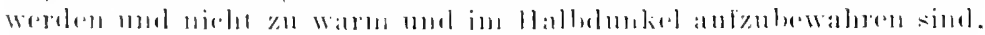

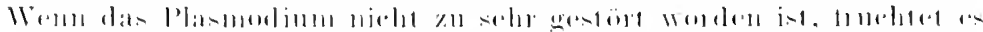

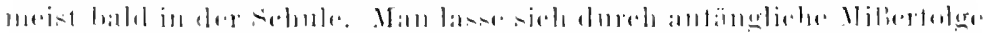

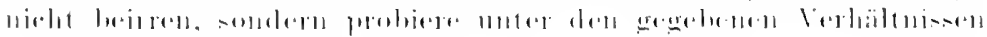

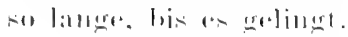

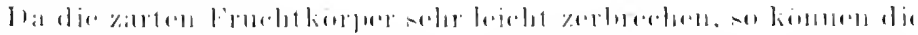

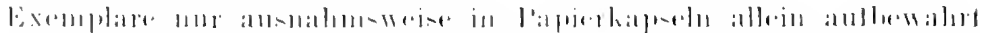

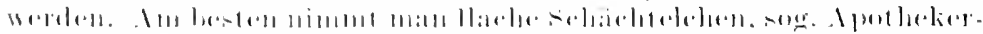

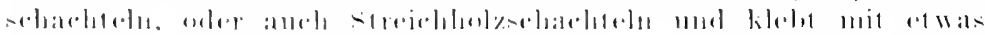

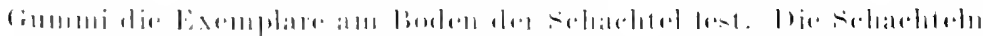

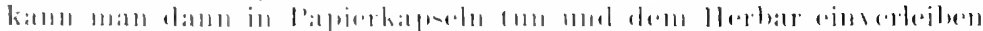

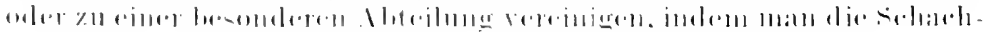

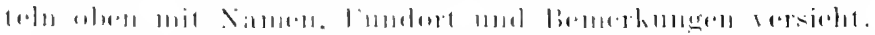

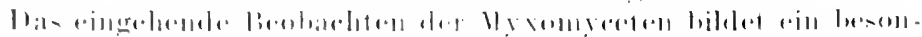

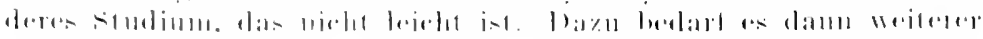

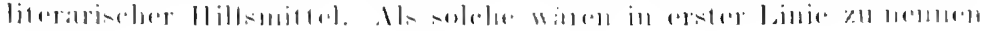


die Bearbeitung ron schroeter in der Schlesischen Kryptogamenflora im 1. Bande der Pilze nud die Monographie von Lister, A mono. sraph of the Xrcetozoa, London 1894 , mit Abbildnngen fast aller Arten der Welt (2. Antl, 1911).

\section{Die Algenpilze (Phycom yeeten).}

Zı den hier zu besprechenden Formen gehören die gesamten Phycompceten (vgl. die Übersicht $\mathrm{S}$. (17)), ich trenne aber ans $\mathrm{Z}$ weekmäßigkeitsgründen die 'eronosporeen, Synchytrinm und die Cladochytriaceen ab und weise sie dem näehsten Kapitel zu, weil sie als Parasiten von Landjflanzen besser dort mit behandelt werden.

Wenden wir uns zuerst den Wasserformen der Chytridineen, Ancylistineen, Mombblepharidineen mul saprolegniaceen zu, so muls voransgesehickt werden, daf mit Ausmahme etwa von Leptomitus keine einzige Art makroskopisch auftällig in die Erscheinmog tritt. Freilich können gewisse Saprolegniaceen an Holz, Fiselıen, Insekten als zarte weiße Räschen anch mit blobem Ange noch gerade gesehen werden, aber die übrigen Formen sind meist aneh mit der buje unsichtbar und das suchen mul, deshalb, namentlich heim liegimn des sturlinms mit dem Mikroskop gesehehen. Ilat man erst die nötige Übung. so wejl man, wo man zu stchen hat wud wird anch bei diesen Formen nielit mehr anf den blinden Zufall angewiesen sein.

Die Chytristiaceen (ebenso die Aneylistineen mol Momoblepharidincen, die weiterhin nicht besonders erwhut werlensollen) finden sich hauptsächlich an allen möglichen Wasseralgen. Man nehme also Algenasen in Glastuben mit und untersuche zn Hans, ob sich diese Parasiten daran finden. IIänig wirl man zuelst nichts entdecken, aber wonn man die Algen eine Zeitlang anfhewaht, so stellen sich häufig diese Pilze noch ein. Nan werfe deshalb eine mitgenommene Algenprobe nach negativen liefmule nie sofort weg, sondern halte sie in Wasser in einer Kulturshale noch einige Zeit im halhimblen zimmer.

Wenn man Chytridincen sicher bestimmen will, so geln̈̈t dazu die Kenntuis des gesanten bntwiekhngaganges von der Keimmug des Sclnwämers an bis wieder zur Sporangien-oded Danersporenbildung. Oft läbt sich die ganze Entwickhung innerhall, wenige 'Tage verfolgen, bisweilen aber bleiben die Beobachtumeren lüekenhalt, so das dann häufig die Bestimmung mmöglich oder moscher wiod. Man darf sich dadmeh nicht abschrecken lassen, denn die Eigenart der Beobachtung belohnt reichlieh die Mïhe, wenn aurh sehlieblich sich kein sicherer Xame ergibt. Vor alken Dingen zeichne man bei jeder heobachtum mol marhe sich Präparate. Beides dient oft dazu, eine drt doch norh später bestimmen zu können, wenn sie ge. legentlich wied(r aufgefunden wirl und damn die fehlenden stadieu zeigt.

Man hat vielfarh versucht, diese l'ilge ainzufangen und zu linlti. 


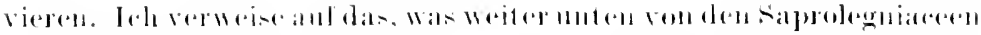
zil sagroll ist.

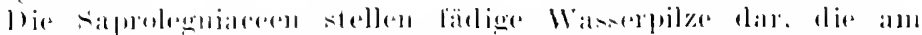

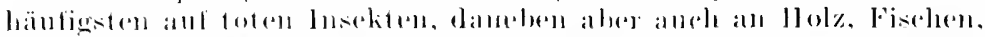

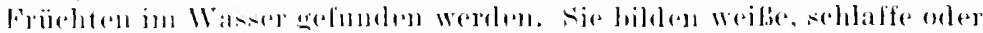

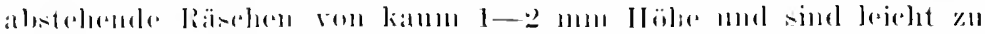

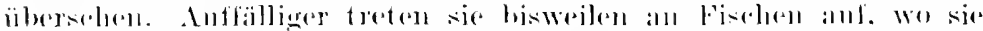

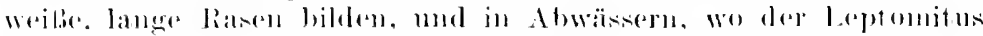

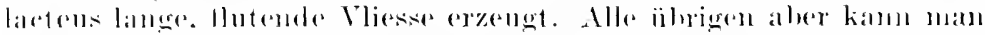

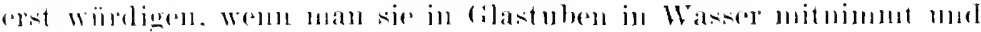

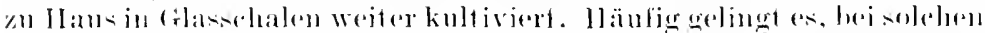

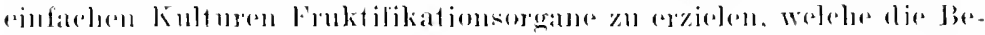

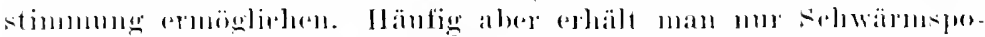

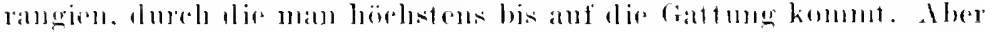

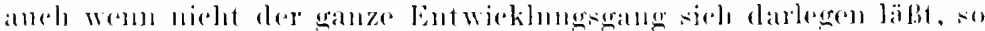

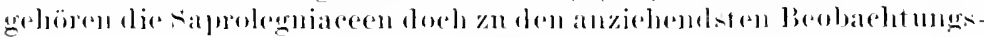

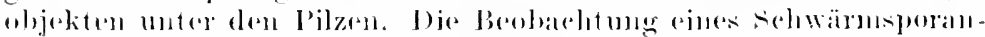

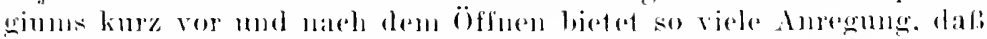

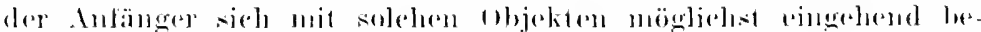

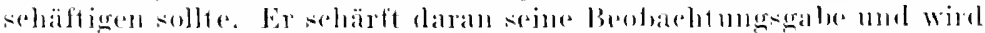

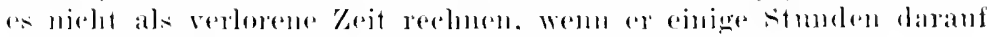

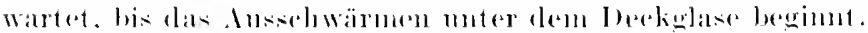

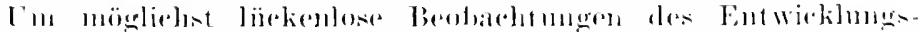
gallges

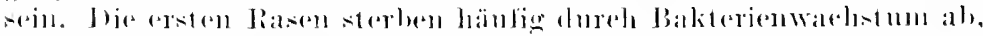

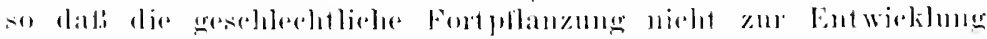

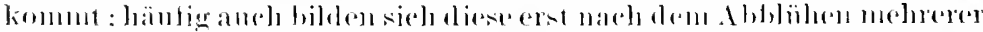

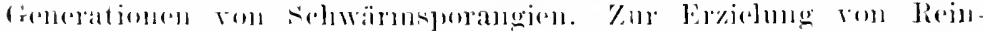

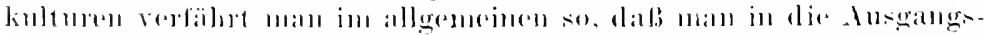

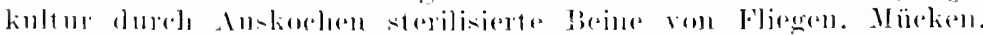

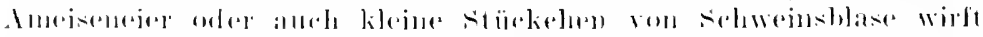

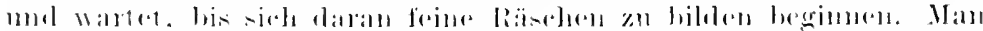

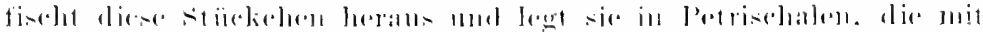

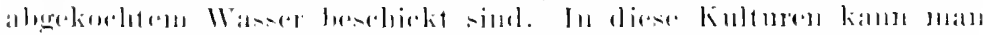

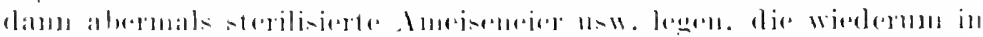

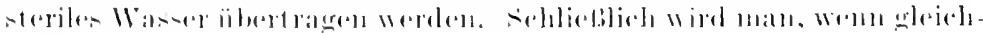

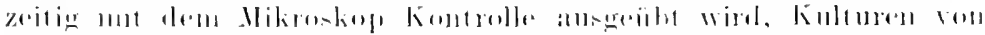

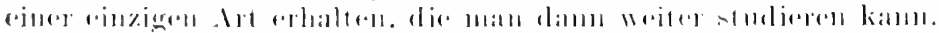

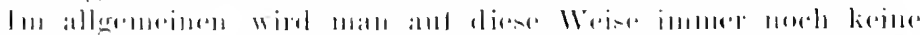

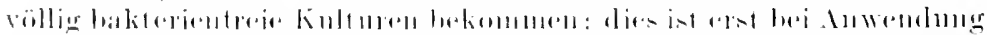

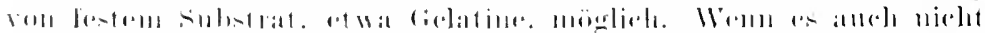

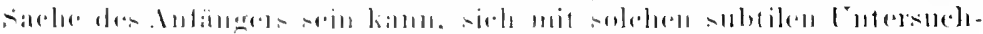

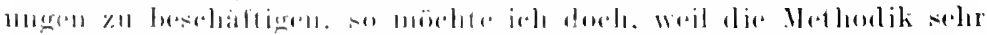

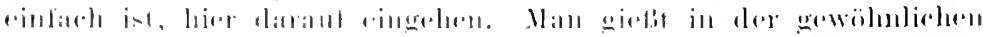

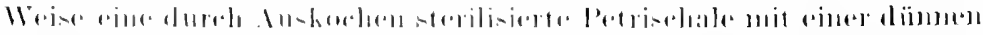

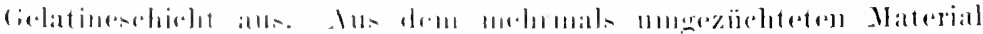

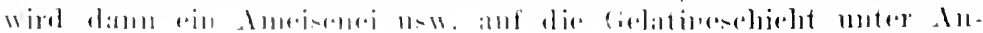


wendnng ron möglichst aseptischer Methodik (sterilisierte Nadel, möglichst schmelles $\dot{\mathrm{U}}^{\prime}$ bertragen, geringes Lüften des Deckels der Petrischale usw.) ïbertragen. Sehon nach kurzer Zeit wächst ein großer Rasen um das Substratstückehen. Aber auch dann werden noch Bakterien im Rasen sich finden und ihn in kurzer Zeit zerstören. Man verfährt dann weiter so, daß man die Petrischale senkrecht stellt, Finden sich noch Bakterien, so wird die von ihnen verflüssigte Gelatine nach unten sinken und die nach oben wachsenden Saprolegnienfäden werden rein bleiben. Man schneidet dann ron diesem remen Teil nit sterilem Messer ein kleines Gelatinestückehen herans nnd ïberträgt anf eine sterile Petrischale. Sollte der Rasen dam noch nicht rein sein, so verfährt man, wenn er erwachsen ist, noch eimmal in derselben Weise. So kann man innerhalb von wenigen Tagen zn absolut reinen Kulturen gelangen.

Voransssetzung für die oben geschilderte Methode war, dab bereits voll ausgewachsene Rasen als Ausgangsmaterial dienten. Man kamn nun aber anch von einzehen Schwärmern, wie sie sich in jedem Wasser, besonders aber von Teichen, Gräben usw. vorfinden, ausgehen. Man nimmt sich etwas Wasser von einem solchen standort mit, tut es in eine sterilisierte schale mol wirft sterile Ameiseneier, Fliegenbeine usw. hinein. Dann wird man ebenfalls nach einigen Tagen saprolegnienrasen erhalten und kam num von diesem, meist viel reinerem Naterial ans mit derseiben Mrothodik zu Reinkulturen gelangen. Anch Chytridineen kann man oft auf solche Weise erlangen, wenn man winzige Apfelstückchen als Köder benutzt.

Da die ganze Methode nur einfacher IIilfsmittel bedarf, so wird derjenige, der sich für Wasserpilze interessiert, sie auch ohne den Apparat eines Laboratoriums zur Anwendung bringen können. Die geringe Mühe wird ihn reichlich gelohnt thuch das anziehende und lehreiche Studinm, das er diesen Pilzen widnen kann.

Der andere Zweig der Phycomyceten, der sich dem Landleben ansichließlich angepaßt hat, nmfaßt die Mucorineen und Entonophthorineen. Für das stmlium der ersteren Gruppe geht der Anfänger zweckmäßig von Kulturen aus, die er sich mit Pferdemist einrichtet.

Unter eine größere Glocke wird mögliehst frischer und feuchter Pferdemist gelegt. Am besten legt man die schale oben und unten mit Fließpapier ans, tas man je nach Bedarf mit Wasser anfenchtet, um immer einen dampfgesätigten Ranm zu haben. Schon nach wenigen Tagen wirl sich der gemeine kopfschimmed zeigen (Ifucor mucedo), bald treten die verschiedenen anf ihm parasitisch lebenden Arten von Thanmidinm, Chaetocladium u, a. auf, den Beschlub bilden Piptorephalis, Syncephalis u. a. Nicht jede Kultur verläuft mit gleichem Artenreiehtum, aber in allgemeinen wird man inmer 5-6 verschiedene Arten auf ihr beobarhten können. Wenn dann die Coprinns-Arten und die Sordariaceen oder Ascobolaceen erscheinen, ist die Mueorineenflora erschöpft.

stellt man in gleicher Weise stark befomehtete brotscheibun 


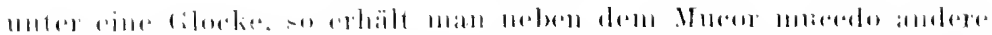

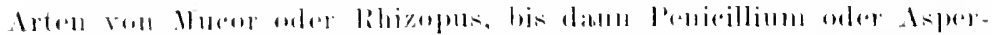

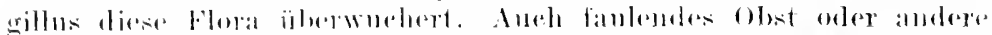

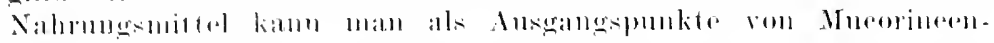

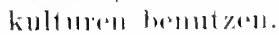

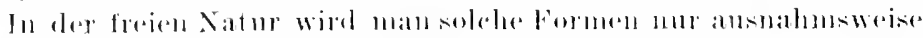

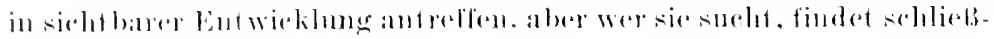
lien doele matrelites.

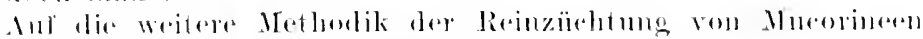

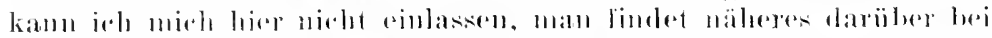

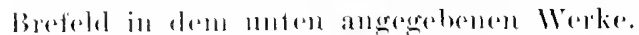

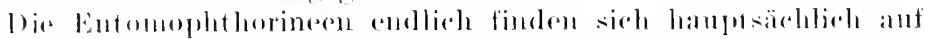

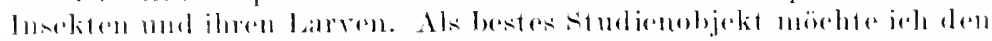

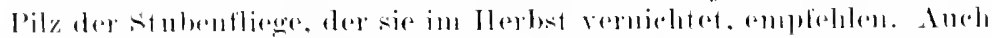

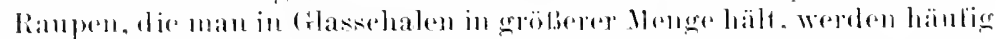
voll solelien larasiten befallen.

Dir literatur ïber die in diesem Kapitel belandelten l'ilze ist

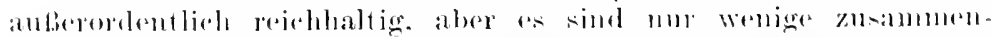

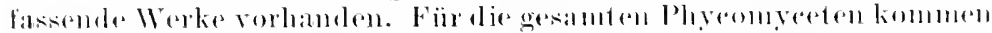

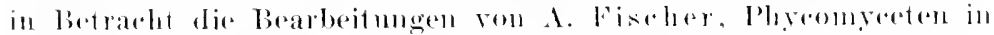

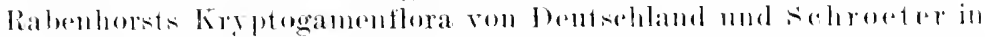

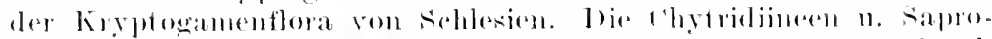

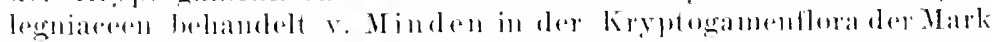

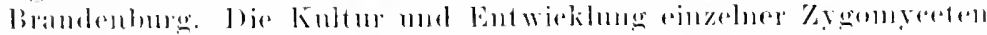

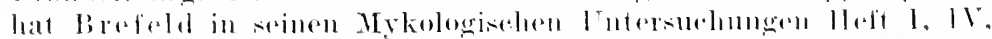

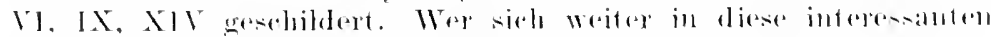

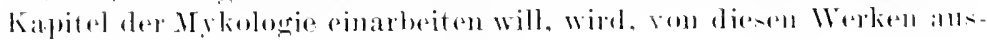
enelend, die weitire literatme finders.

\section{Die palasitischea Pilza.}

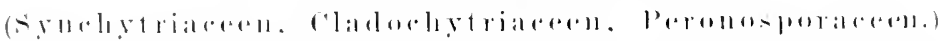

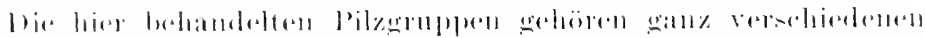

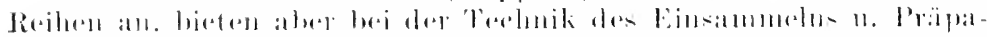

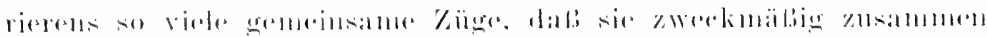

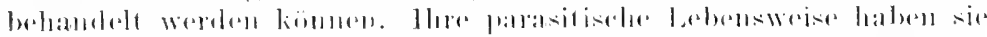

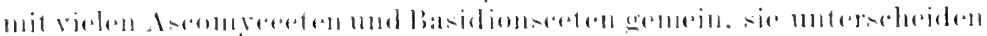

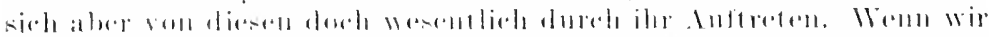

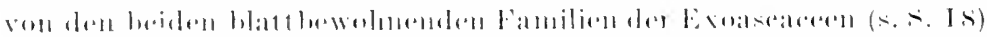

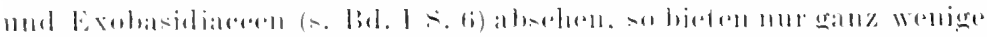

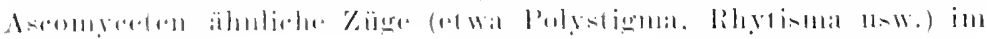
11 al 1,i11,

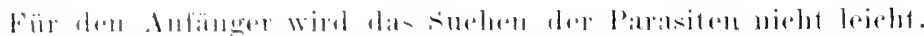

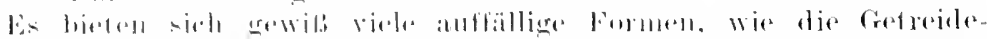

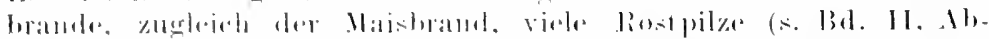

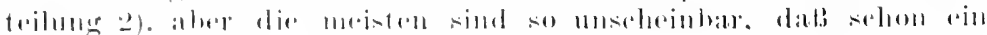

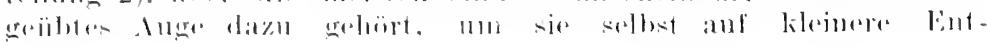


fermmgen zu sehen. Dazu kommt noch, dafs die allemeisten jhre etwas anffäligeren Fortpflanzungsorgane anf der Unterseite der Blätter ansbilden. Tnd dreh bietet gerade tas suchen solcher Formen die gröbte Abwechslmg und die meiste Befriedignng, demn der sammler findet während der Vegetationslaner stets reichste binte.

Für den Anfänger ist das suchen der Parasiten in Anfang eine schwierige Sache. Es gibt zwar viele Arten, wie Chytrilim taraxaci, ('h. anrenm, viele [roplulyetis-Arten, saprolegniaceen mul gewisse Albugo- nnd Peronospora-Arten, die sich leicht an den Flecken anf den Nährpflanzen, an Terbildnngen des Wirtes, an schimmelartigem Wachstum auf ten Unterlagen erkemen lassen, aber die Ilanptzaht der Arten lätst sich mur mikroskopiselı exkemmen. Deshalb verweise bols anf die Algenpilze (s. (5)), bei denen das mejste sehon gesagt ist. aber diejenigen Pilze, die hier erörtert werden sollen, greifen die l'tlanzen, die an das landleben angepalit sind, ganz besonder's an.

II anptsächlich kommen die Gat tungen Syuchytrim. Physoderma, Trophlyetis mod die Peomosporineae in Betracht, dic hamptsächlich in ihren Nährptlanzen von diesen Pilzen bewohnt werten. Die sirnehytrien kommen in ihren Fortpflanzmngsorganen besonelers anf simpobewolmenden Pflanzen vor. Die Oogonien nisten in slen Blätlem an gelben oder misfarbenen Flecken in Immern der Ptlanzen mud treten ander der Färbung der Blatt-oder Zweigstellen nicht weiter hervor. Die Peronosporaceen bedecken die Bläter ofler die Zwoige mit einem granen, meist sehr dontlich sichtbaren Rasen, während die Oogmien und Antheridien im Imern verborgen bleiben.

Fiir die synehytrien genïgt ex, die Blätter vou den gesammelten thanerogamed in Wasser zu legen. Weun die Pilze ziemlich ausgeroift simd, so genügen sehon wenige stmden, wm ihre Schwärmsporen frei zn maehen. Um die Entwicklumg derselben ma die Mycelbihlung in den Xährpflanzen zn sehen, dazn gehören allerdings Vorrichtmogen, ïber die der Anfänges nieht verfügen kann. Bei I'hysoderma mu Trophlyetis dïrfte die Entwicklmng nicht einfach sein, dem bisher ist von der Fontwicklnng mor weugg gesehen worden, weshalb die Rücksehlïsse anf die Fntwickhng ans den anatomisehen 'Tatsachen gefolgert worden sind.

Bei den Peronosporaceen sind die änferen Entwicklumgsongane leicht zu sehen, dem es genügt ein Absehaben mit dem Messes oder einer Nadel vollstindig. num die Konidienträger anf das dentlichste zи bemerken.

Schwieriger dïrfte es sein, die Oogonien und Autheridien so $z$ päparieren, dali sie nach jeder Rirhtmig hin zu sehen sind. Es ge nügen dazn im allgeneinen anatomische Schnitte, welche die Grane zeigen. Dazn gehört aber ein längeres Suchen mal beobachten, das nicht gleieh ju Beginue der studien zol machen ist. Im besten ist, wenn der Anlänger hier die geschickte tIand eines Geäbten brancht und einen Kursus in Präparieren nimmt. Schon nach knrzer Zeit 


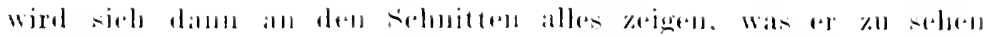
wiinselit.

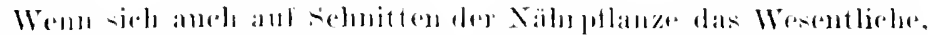

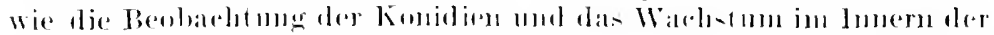

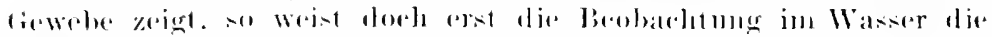

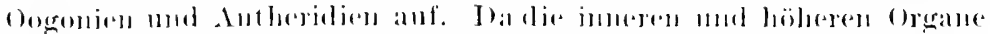

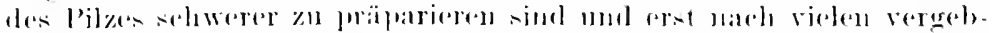

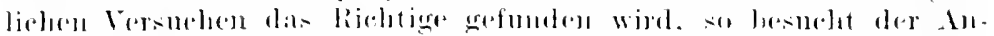

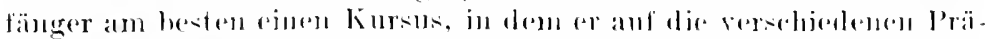

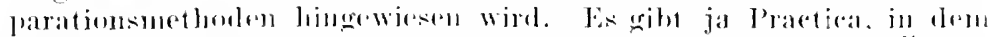

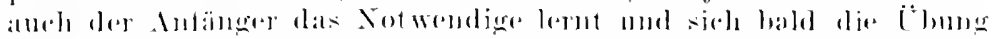

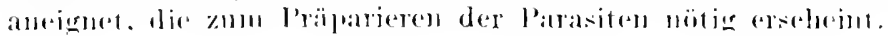

\section{Dir Schlauchpilze (Ascumyecten).}

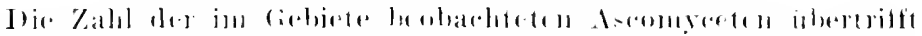

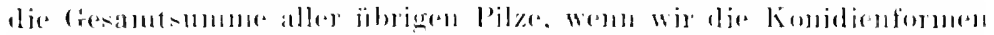

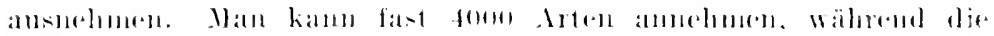

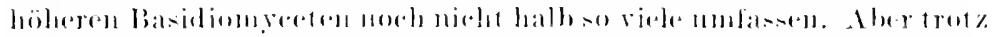

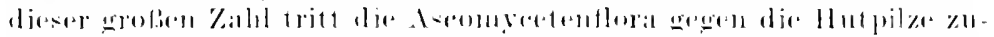

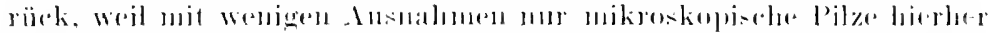

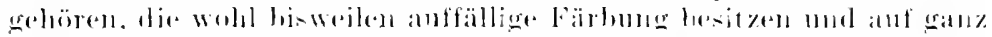

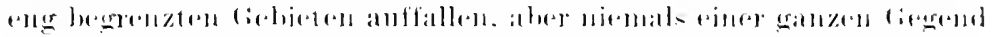

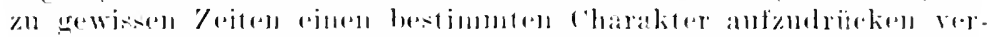

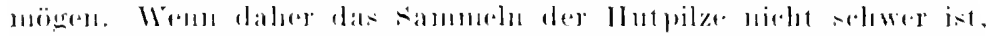

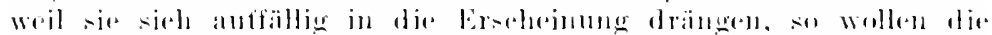

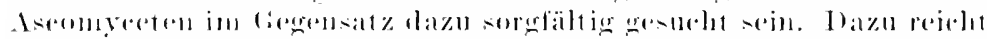

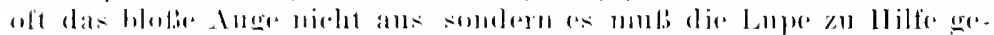

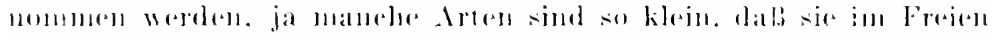

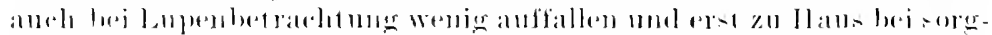

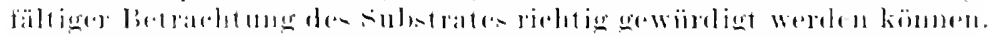

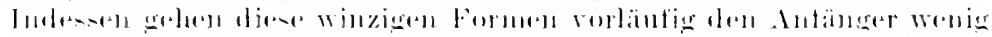

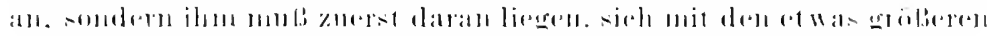

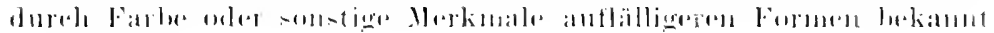
\%11 III:1r+11+?!1.

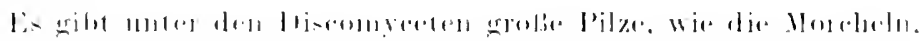

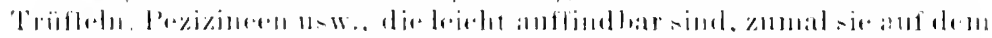

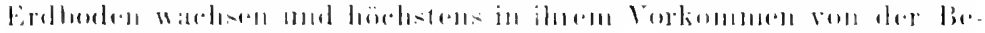

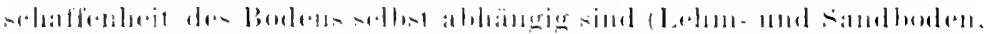

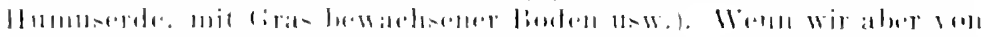

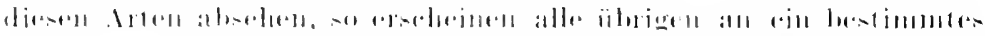

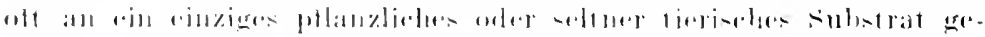

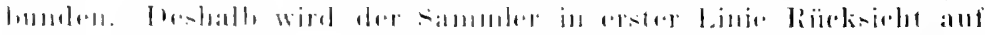

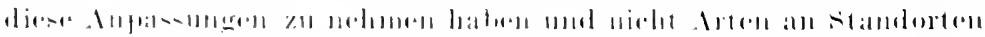

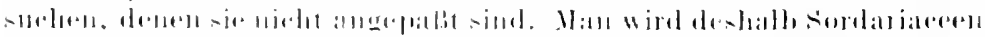

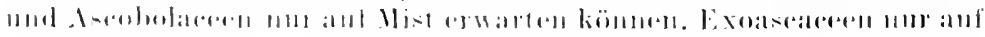

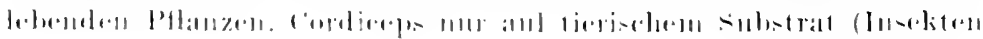


und ihren Larven), viele stromatischen Pvrenomveten nur auf faulem Holz, Myeosphaerellacen nur auf stengel und Blättern usw.

Wenn hier ganz in allgemeinen von Aseomyceten gesprochen wird, so ist darunter nur die Schlauchform als die höehst ausgebildete und den Entwicklungskreis abschliebende Fruchtform zu verstehen. Bei den meisten gehen aber nech niedrigere Fruchtformen (Konidien mit allen ihren rerschiedenen Trpen) voraus. Wenn wir auch von den meisten Schlauchformen noch nieht wissen, mit welchen Konilienformen sie zusammenlängen, so kennen wir doch wenigstens von vielen ihren Entwickhungskreis und wissen, welche andere Fruchtformen zn ihmen gehören. Erleichtert wirl dies Erkenntnis, wenn die Konidienbehälter oder -lager sich auf demselben Stroma wie die schlanchfrüchte finden (Valsaceen und rerwandte Familien). Als ganz allgemeine Regeln kömmen wir feststellen, daß mit ganz wenigen Ausnahmin die Schlanehfrichte sich stets im oder am toten substrat finden, höehst selten sehon in der lebenden Pflanze. Viele Konidienfruchtformen dagegen kommen nur anf der lebenden Pflanze vor. Wil hahen also hier die eigentiunliehe Erseheinumg, dali eine Art während des ersten Teiles jhres Entwieklungsganges parasitisch wächst: das Myzel lebt also im lebenden Blatt-oher Stengelgewebe nud bringt hier Konidien hervor. Wenn das Substrat dam aligestorben ist. wächst das Myzel im toten Gewebe weiter und kringt als Abschluf die schlanchfrüchte hervor. In zweiten Teile des Lebenskreises wird also der Pilz zum Saprophyten und in diesem Zustande lernen wir ihn remn anch gewöhnlich kennen. Als besonders anffälliges Beispiel für dieses Verhalten neme ich die bekannten schwarzen Flecken der Mhornbläter. die dureh Rhytisma acerinum verusacht werchen. Bis zum Abfallen der Blätter finden sich nur die Konilienlager, erst im Frühjahr kommen dam bei den am Boden liegenden, vernoderten Blättem die sohlanehfiüehte zur Reife.

Wir sehen aus diesem Beispiele, dem sich noch viele andere anfïgen lieben, das bej solchen parasitisch-saprophyytischen Arten die Schläuche erst im Frühjahr reif werten, wenn die sporen Gelegenheit haben. wieder junge Bläter zu infizieren. Die schlanchformen alles dieser Pilze, die auf Blättern mod stengehn vorkommen, wird man deshalb vielfach erst im Frïhjahr reif antreffen.

Bei den ausschließlich saprophytischen Holzformen findet meist die Utberwinterung der reifen Fruchitörper statt. Deshall, trifft man reife Pyremonyceten und Diseomyceten besonders im llerbst bui fenchter mnd warmer Witterung. Bei vielen aber scheint die Entwieklung wälrend des Winters still zu stehen und erst im Frühjahr wieder einzusetzen. Man findet sie daher in schönster Entwicklung in Frühjahr, besonders die alpinen Formen, bej denen der lange IIinter die Fortentwicklung muterbricht. Für die meisten Arten sind diese bohogisehen, Terhältnisse noch nubekannt, daher bietet sich selbst dem Antänger, sobald er nur einige Formen sicher kennt, nocls cin reiches Feld der beobachtmug. 


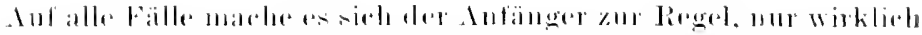

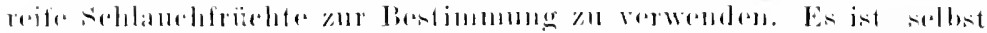

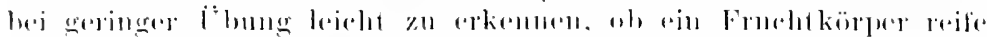

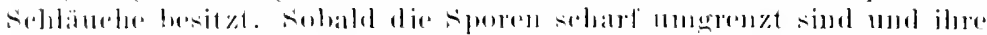

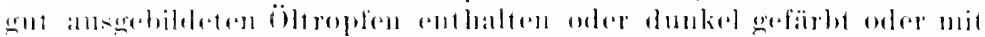

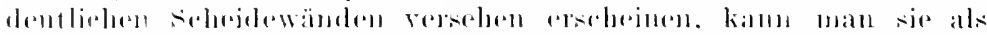

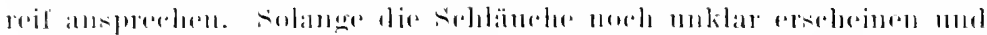

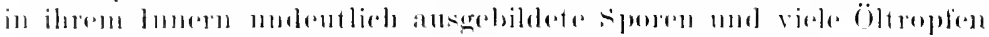

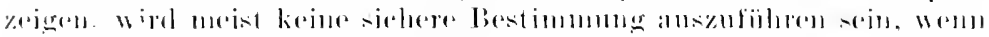

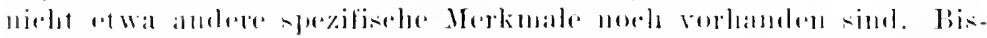

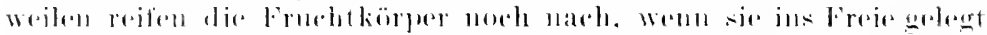

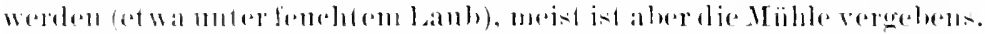

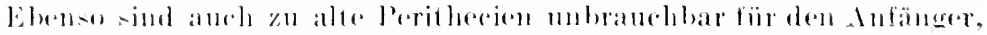

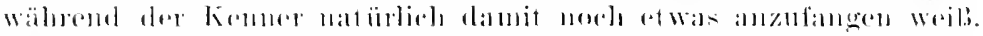

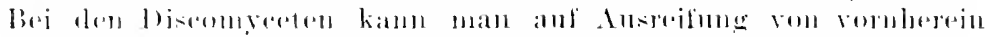

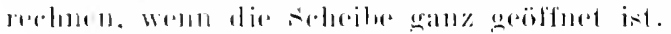

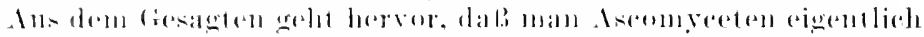

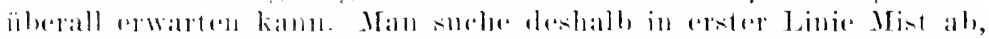

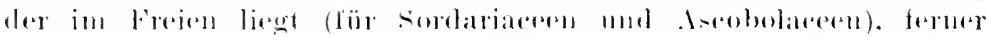

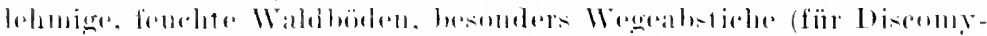

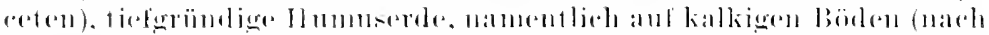

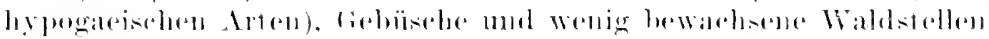

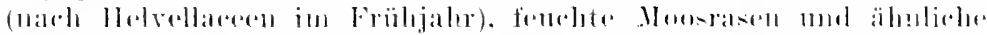

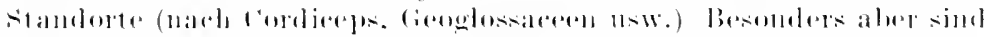

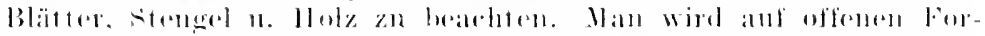

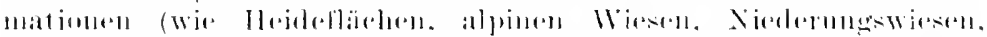
1)

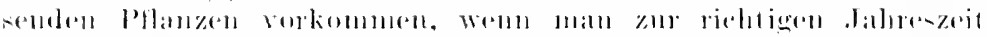

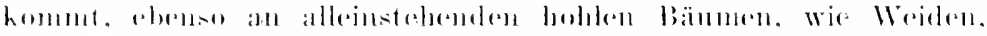
latplels

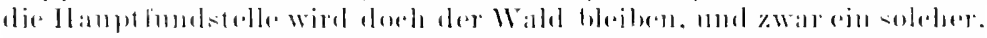

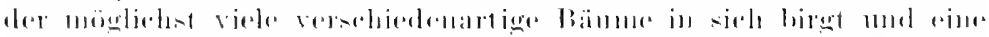

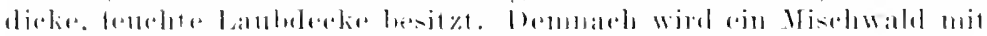

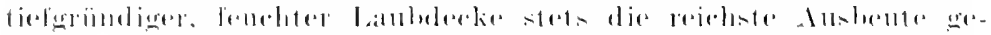

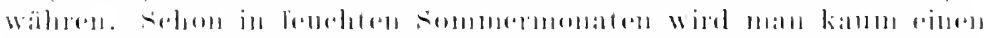

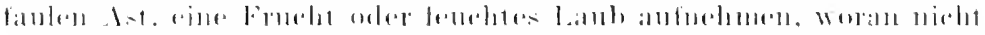

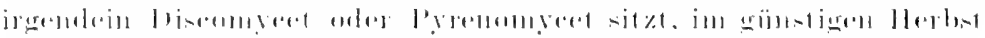

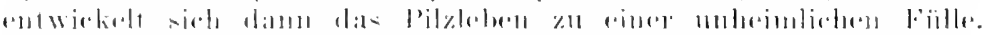
II

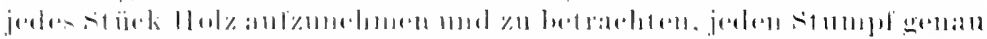

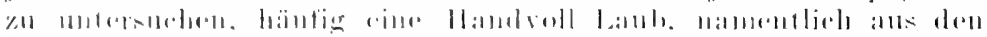

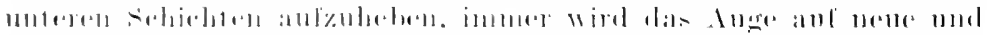

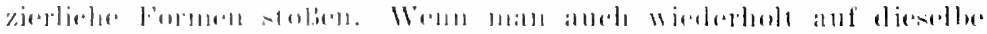

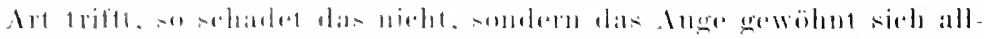

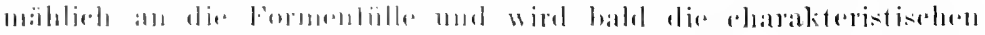

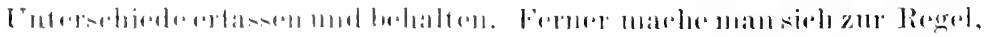

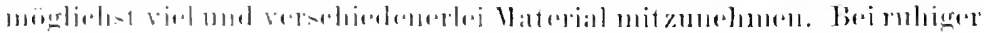


Lntersuchung zn Hans giht sieh doeh manche, vielleicht einer anderen anberlich gleichsehende Art als etwas Versehiedenes zil erkenuen, nach der Entersuehumg kam man dann das Material immer noch vernichten. Anch sammle man nie zu wenig Material, somblern suche möglichst reichlich ron derseblben drt zn erlangen, danit man für die [ntersuchung und Sammlung zu IIans das Beste anssuchen kamm.

Znm Transport anf der Exkursion wickle man jedes Exemplar in papier. Wenn grobe u. zarte Fruehtkörper von Discmureeten in Frage kommen, so kann man sie zweekmäBig in Moos rerparken. Grobere Zweige kann man an Ort und Stelle mit einem starken Messer (am besten Gärtnerhipłe) zmechtsehneiden. Bei den allermeisten Objekten braweht man keine besonclere sorgfalt anf das Eimpacken zu verwenden. Die Papjerkonvolute mag man dann in eine Butanisierkapsel oder aneh in die Taschestreken. Zweekmälig ist s. sirh an Ort mondstelle Jotizen zn marhen und diese gleieh nit in das laketehen zu legen. Wiehtig ist vor allen bingen die feststellumg der llolzart. Dies läbt sich im Walde meist lejeht vornehmen, da man die in der Nähe des Fundortes warlsonden Bänme sieht. Schwirig bleibt es immer, einen entrindeten Ast sicher zu bestimmen. Viele Il chanten. haben ja sehr eharakteristisehe anatomische Nerkmale, aber es ist oft sehr zeitranbend, ans diesen Merkmalen allein die Banmart festzustellen. Deshalb möge man besonders daranf achtell. möglichst berindete stiucke mitzmehmen, weil sich durch die limenumerkmale gewöhnlich die Holzart le ichter ansmachen lädst, besonders wenn man festgestellt hat, welehe Ilölzer an der Fumbstelle rorhamlen sind. sammelt man stengel, so wird man danach surhen müssen, rom welehen pflanzen sie stammen. Das wird oft lejeht soin, aber im Frühjahr wird es doch seine schwierigkejten haben mod man wird olt gezwungen sein, den Fundort während der Vegatalionszeit der Kränter noch einmal zu besurhen, nm die Art zweifelsfrei festzustellen. Deshalb möge gerade dre Anfänger alle diese Punkte beachten, weil ladureh alie Beobachtmosabe gestäkt und die spätere bestimmung erleichtert wirl.

Da das Einsammeln mul Beobachten in Freien eine grobe seistige Inspamung bedeutet, so mache man namentlich in Infange des stmdinms niemals örtheh und zeitlieh zu ansgedehnte Exkursonen. Eine intensive, zweist ündige Exkmrsion genügt allermeist, namentlich wenn es sich nm Lokalitäten handelt, tie man bequem von einem standort erreichen kann. Dafür aber kam man nm so öfter gehen, wenn man Aseomyceten sueht, da das Material nieht sofort bearbeitet zu werden braucht. Hat man gen̈̈gendus Mlaterial in lorbst angehänft, so kann man die Winternonate. in denen nur wenig zu finden ist, für die [ntersuchung verwenden.

Vie schon oben hervorgehoben wurde, kann man mureites Iaterial in Freien oler unter Glasglocken in kïllen lamme zum Nachreifen anslegen, wenn anch bei manehen Arten der Erfolg ansbleiben wirl. bej mistbewohnenden Formen wird man dies zur lienol 


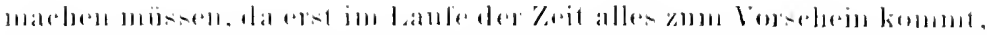

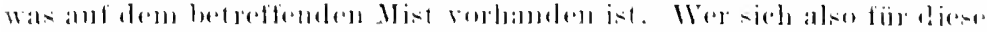

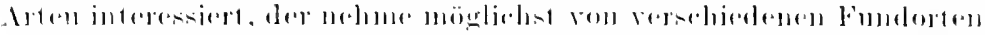

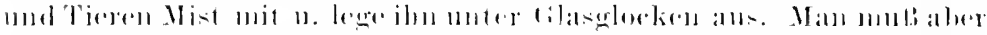

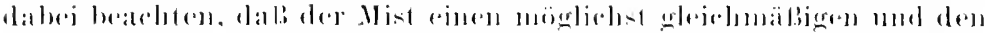

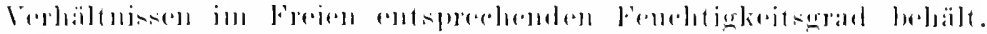

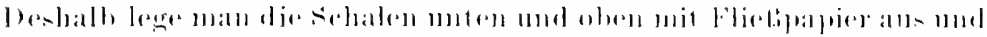

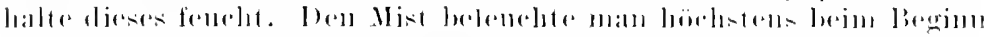

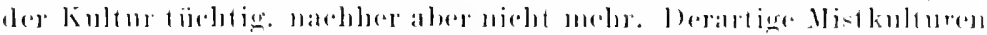

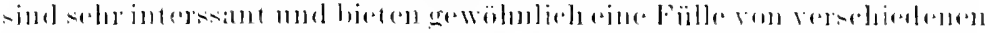

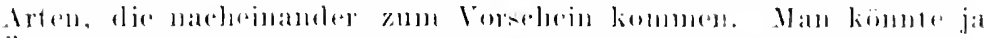

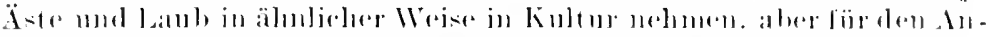

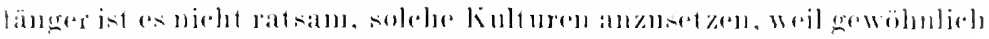

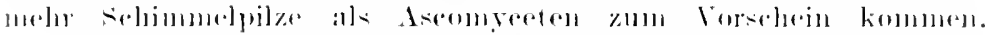

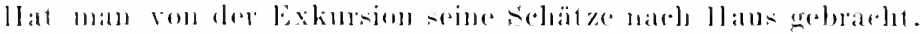

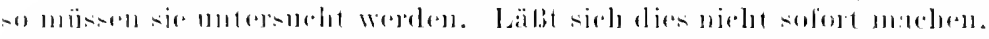

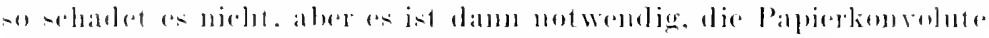

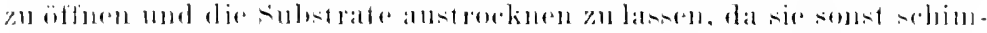

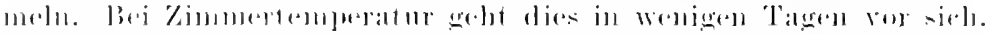

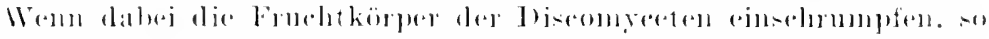

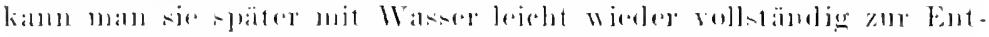

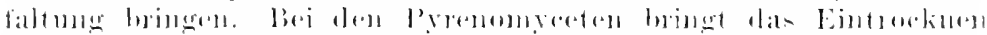

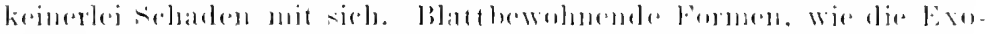

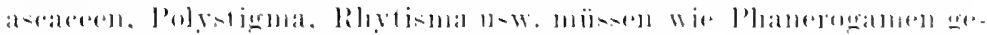

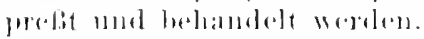

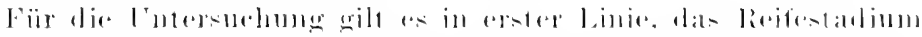

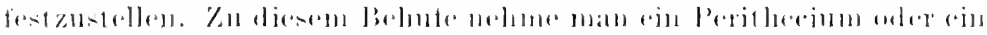

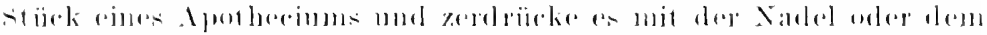

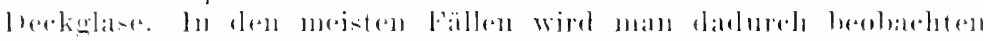

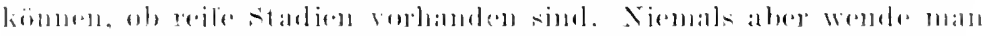

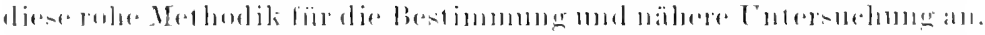

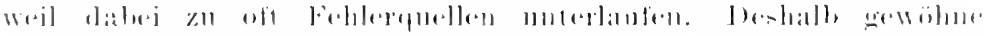

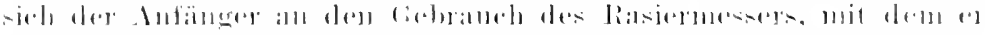

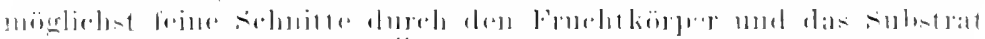

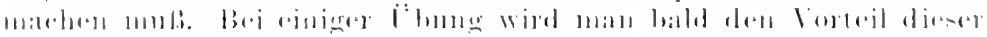

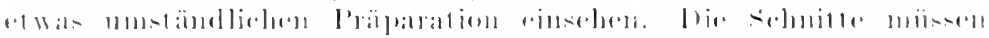

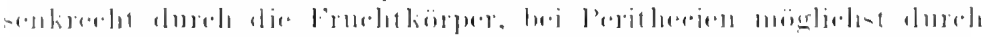

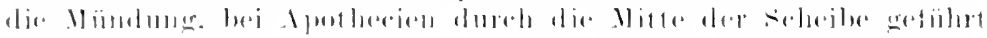

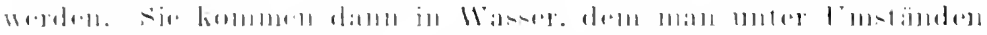

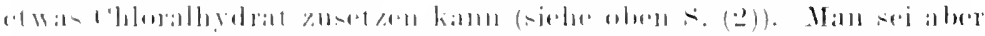

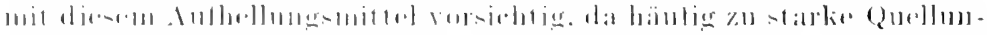

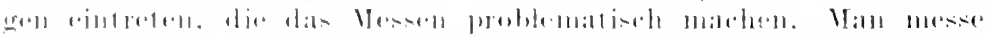

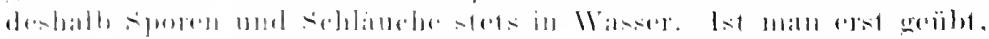

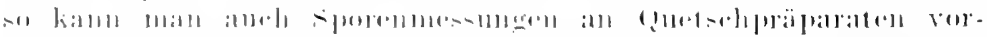

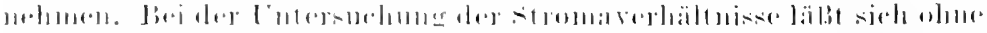

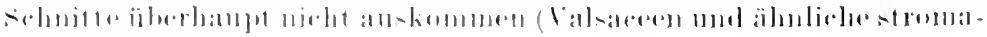

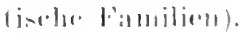


Will man trockenes Material zm Präparation verwenten, so mu? es vorher mit Wassej aufgewejcht werden. Man kann dem Wasser ron vormherein etwas Alkohol zusetzen oder die Fruchtköruer esst in Alkohol n. dam in reines Wasser legen. Da mun hänfig, namentlich bei Discontyceten nut in der Rinde nistenden Prrenomyceten, das Material sehr bröcklig wird 11 . beim Schneislen ausspringen würde, so kann man es mit Gummi arabicmm anf dümme kleine Korkstïckchen anfkleben. Man nimmf die zu schnejdenten, in Wasser mit Alkohol huftrei gemachten Fruchtkïrper oder substratstioke nud klebt sie mit Gummi arabicum anf Kork fest. Kweckmäligr bereitet man sieh dazu cine wässerige Lösmmg ans feinstem Gmmmi arabienu, wie es gepnlvert in jeder Inogenhandlumg zn haben ist, mud setzt einige Trupten Glyzerin zu, nm zu verhindsun, dal, das frummi zu spröle wird. Bereitet man sich eine grobere Menge vor so empfehlo ich, 11 das schimmeh zu verhüten, len Kusatz von einem Tropfon l'henol oflej h,ysol. Man numb ansprobieren, wieviel Glyzerin man zu-

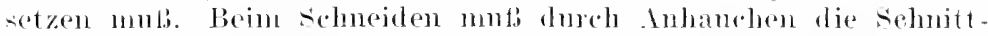
thähe jerlesmal angefenchtet werden. Das zu schnejelenelr Material muli ganz in Gummi ejugehettet sein. Die schnitte werden znerst in einen groben Tropfen Wasser gedegt, das muter Tustanden mehr.

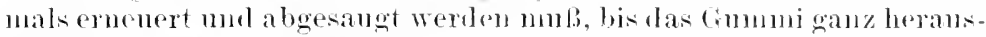
gräst ist. Wem das Material vou rounherein brocklig ist, nimmot man diese Prozedur unter dem Derekglas vor.

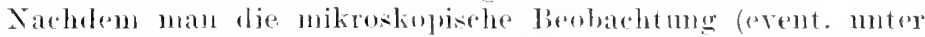

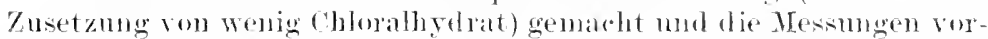

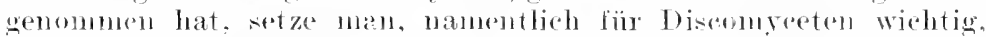

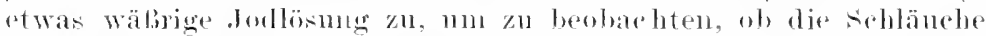

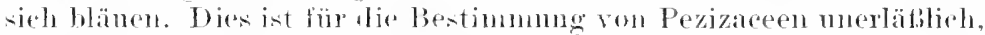

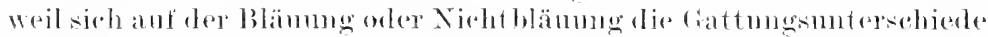
anfbanen. In 'Text int liese lieaktion' dureh J torker I - be7 irehnet.

Für die sammlums bedart es keines weiteren lräparation, als daf. man die \%weige oder llolzat incke spaltet oder zurechtselmejdet, damit se nicht allzusehr anftragen. Dis Exemplare werlens an

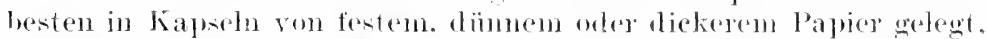
die damn dem llerbar einverleibt werken. Nan athte ja darante dalis die Exemplase ganz steril jus llerbar kommen, da hänfig in ltoly

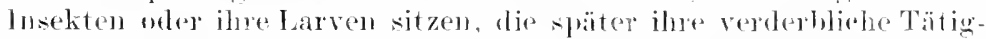
lejt entfalten. Es mïsen deshall, die Exemplare veregiftet werden mol zway an sehmellsten mol sichersten nach der jun 1. Bande s. (12)

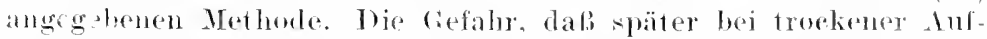

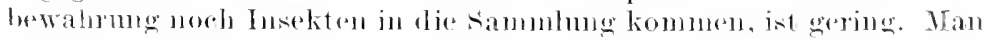
tut an hosten, woun man gleich nach der Sterilisionum ain wenig Naphthatin in jold Kapsel oder aber in einter Kapsel einc gö̈bere Monge in jede Mappe hineintut. Sollte sioh trotzdem einmal Fralis zeigen, so muls der Prozes in der Vergiltumgskiste wiederlunt werten: 


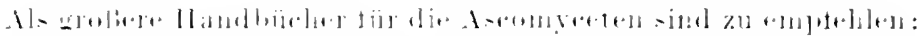

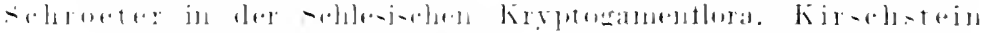

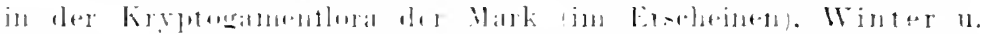

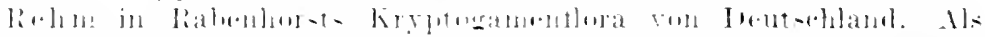

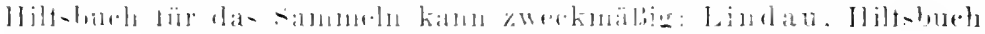

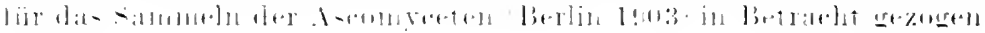
wallinl.

\section{System und Bestimmmostaholle dor Hanpteruppent.}

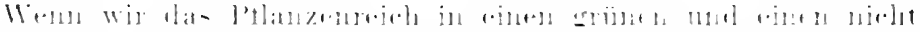

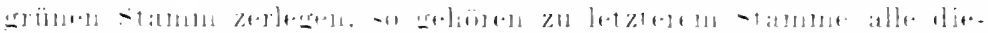

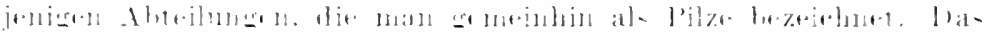

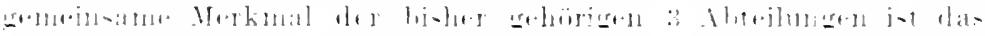

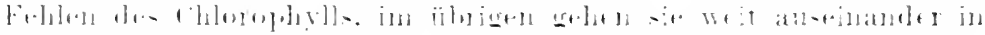

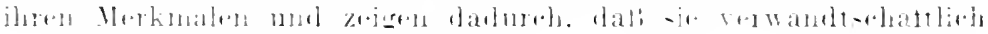

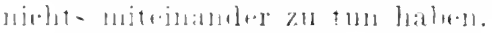

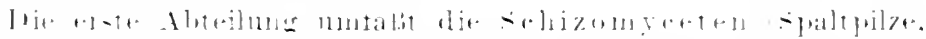

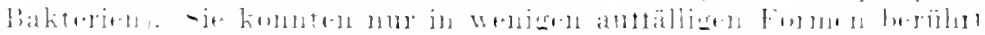

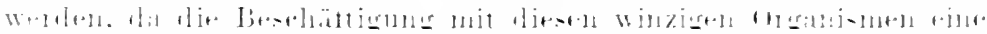

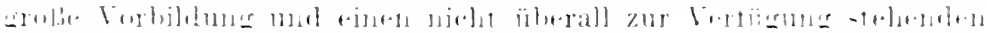

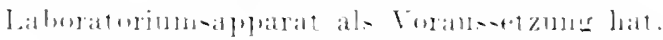

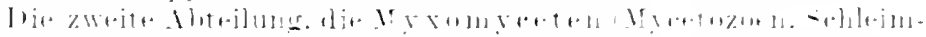

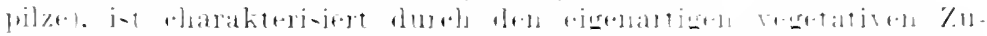

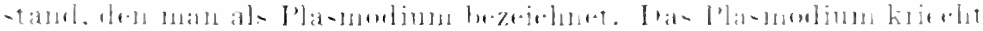

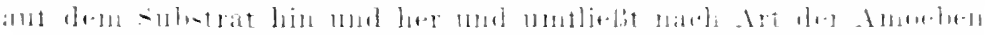

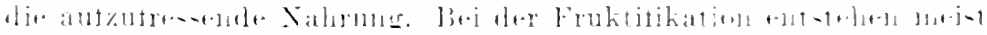

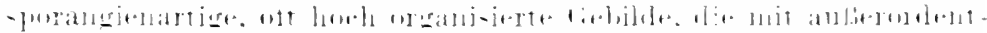

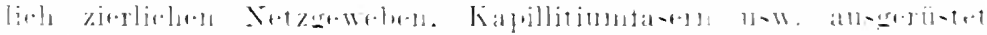

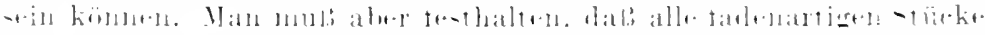

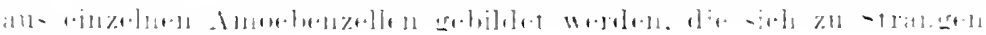

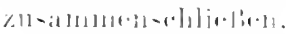

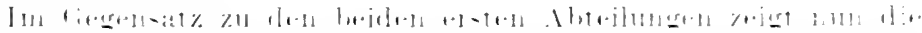

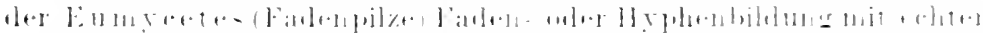

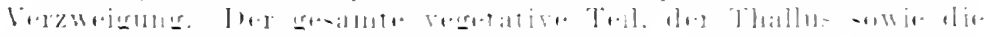

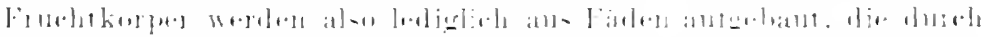

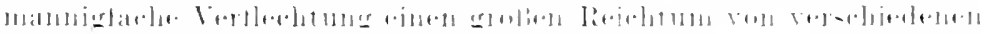

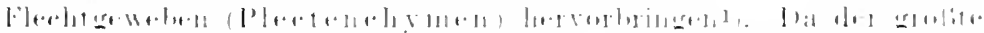

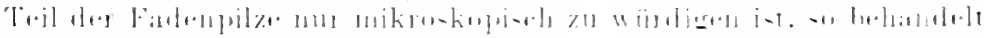

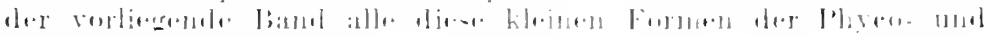

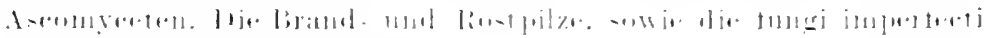

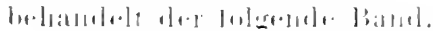

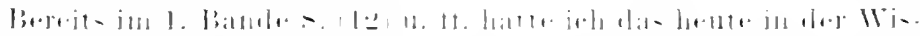

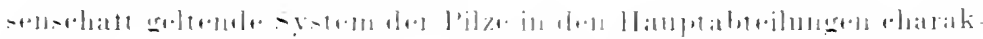

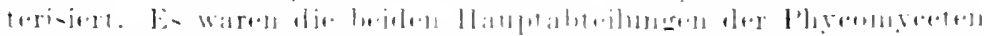
numl If

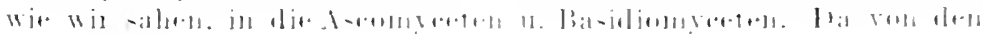




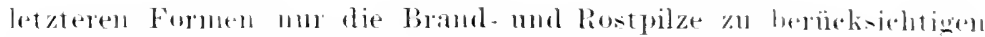

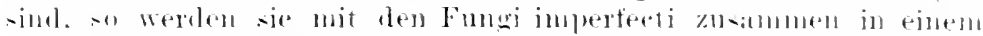

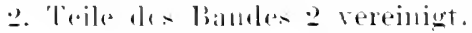

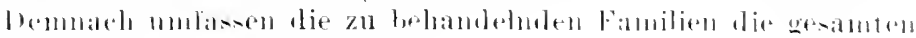

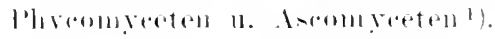

\section{Klasse: Phyounterom.}

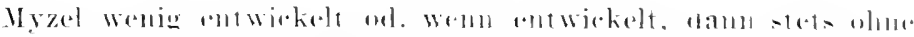

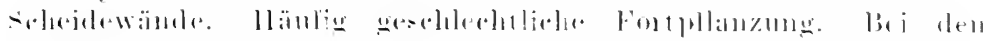

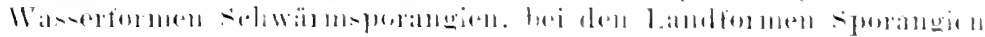
whrs kintilient.

\section{I'merklians: Gomyretes.}

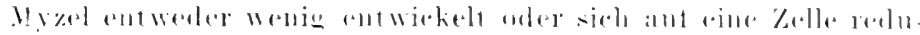

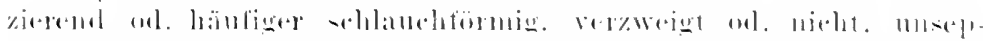

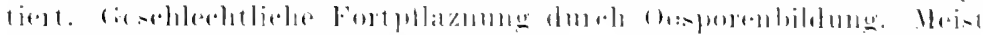

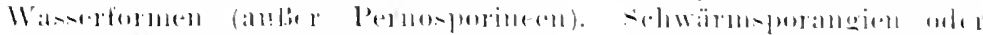

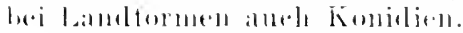

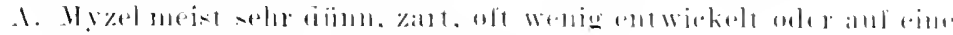

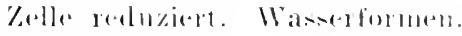

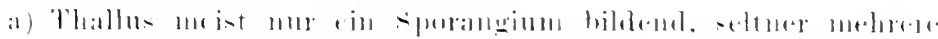

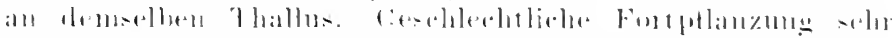

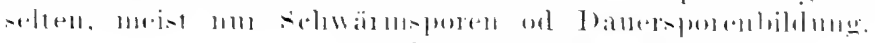

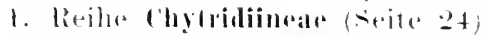

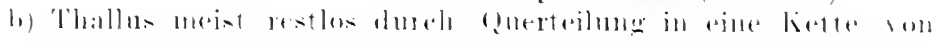

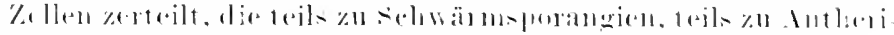

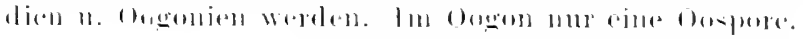

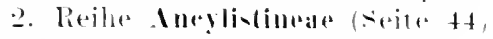

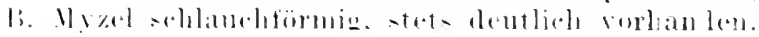

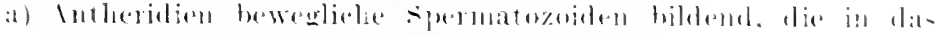

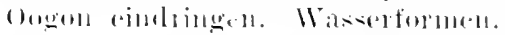

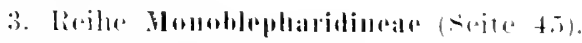

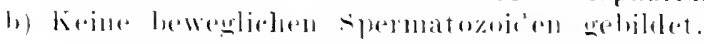

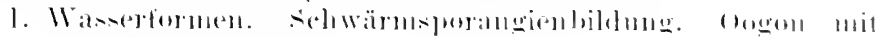
methreren lizellen.

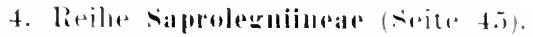

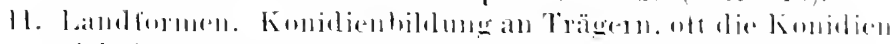

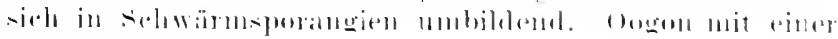
liiselle.

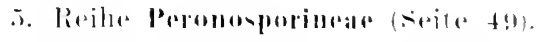

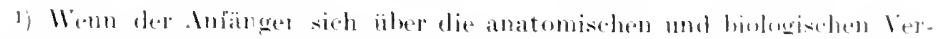

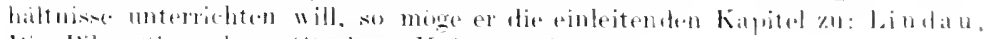

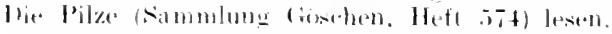

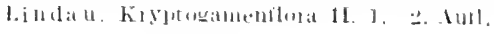




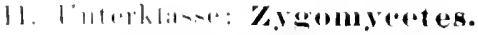

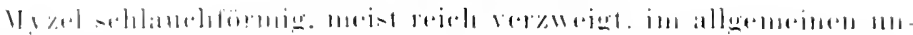

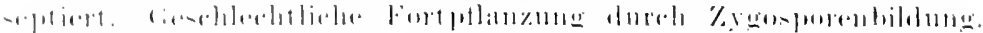

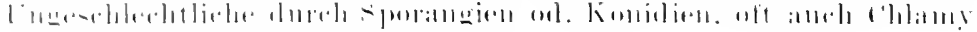

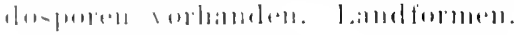

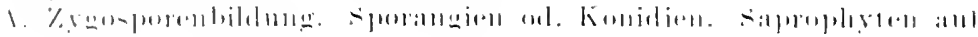

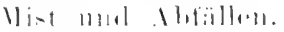

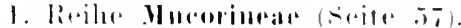

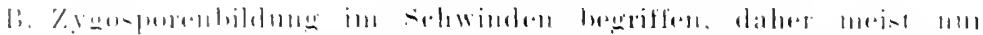

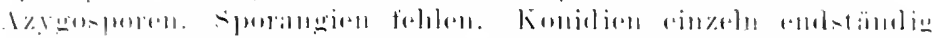

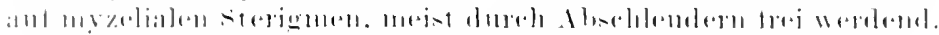

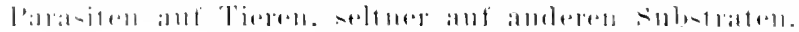

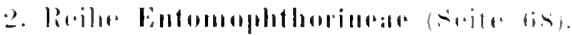

\section{Klasse: Mreoningentm.}

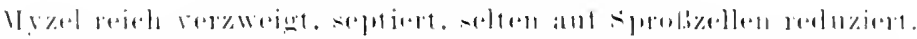

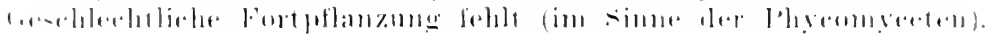

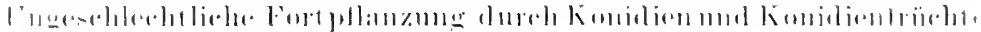

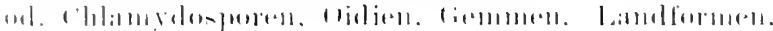

\section{Intrikling: Ascompenter.}

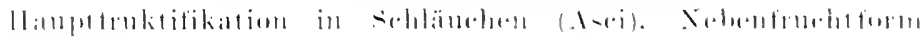

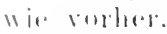

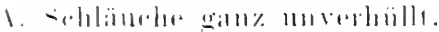

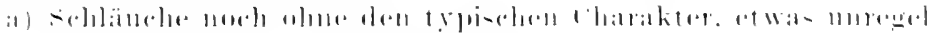

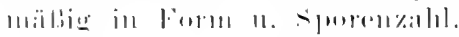

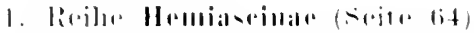

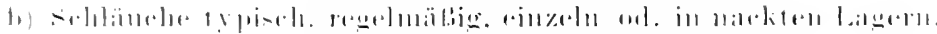

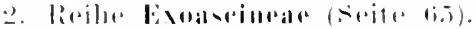

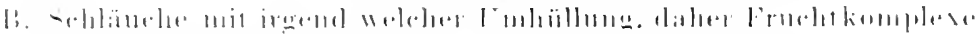

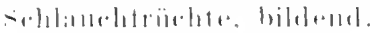

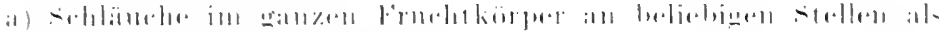

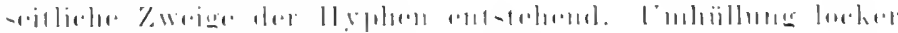

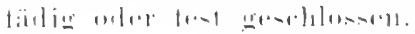

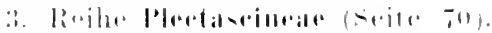

h) - shlämela

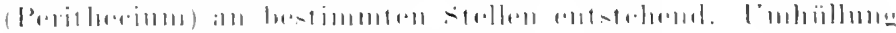

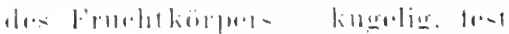

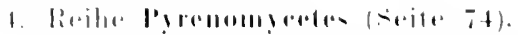

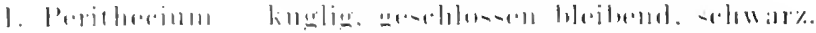

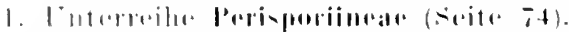

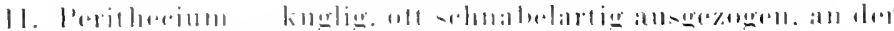

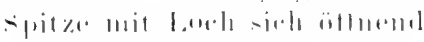

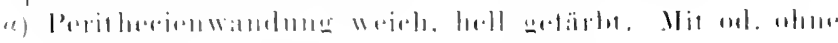
2110111:1.

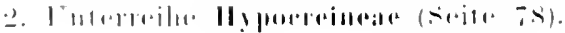




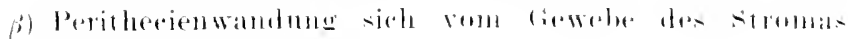
sirite ablueberial.

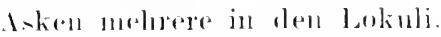

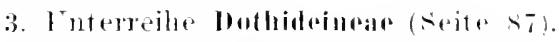

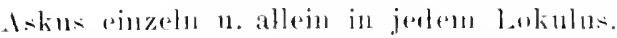

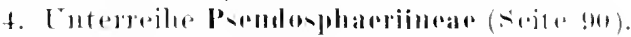

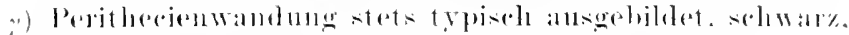
lestrig his brïchige kohlig. Jit otl. olute stroma.

万. Interseilar Spharriamear (seite !no).

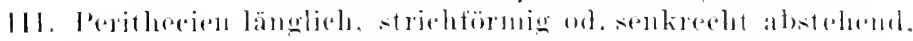

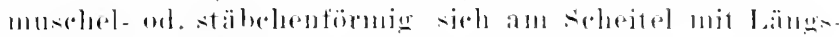
rili, cifluendl, stlwarz.

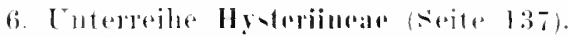

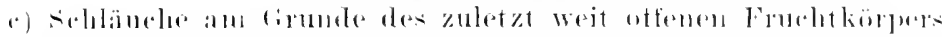

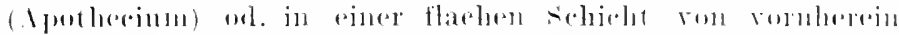

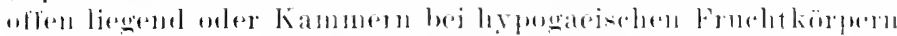

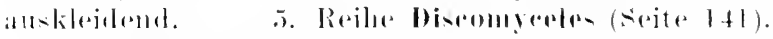

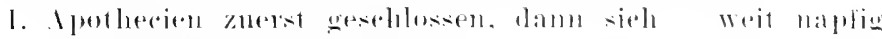
al. selsibselfösules öfnemel.

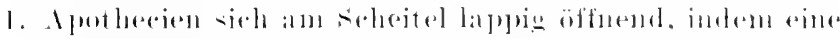

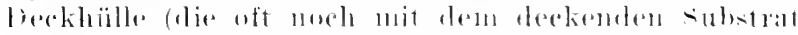

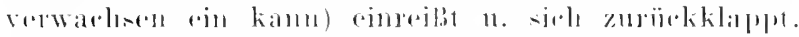

t. Ioterrejhe Phareilionoar (seite 14l).

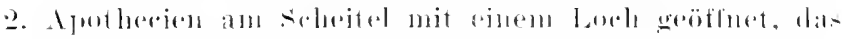

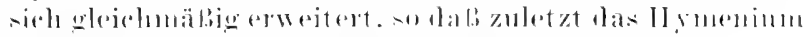

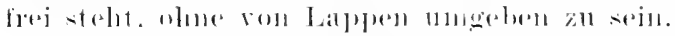

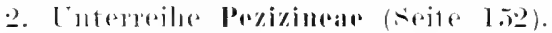

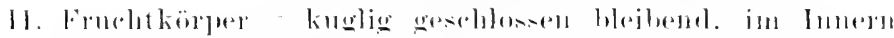

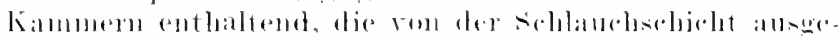

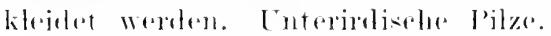

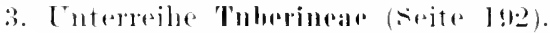

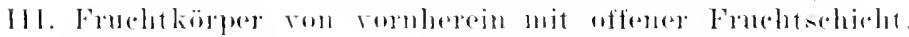
meint gexilelt.

4. Entereshe Holvellimeare (seite t!)

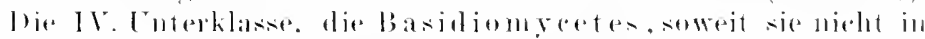

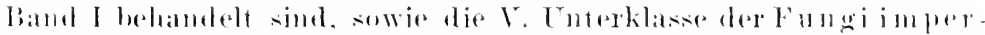

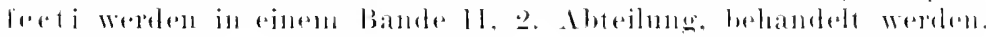

\section{EMklärmon dep wichtiesten Kunstausdlü̈cke.}

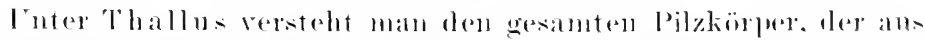

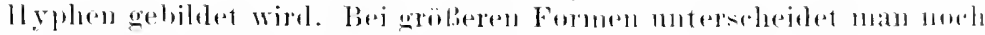

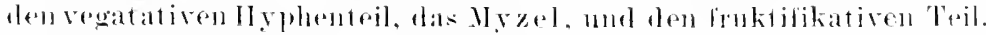

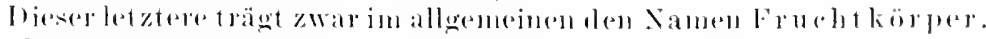

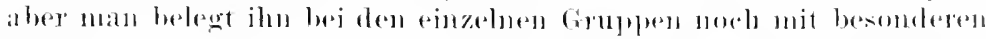

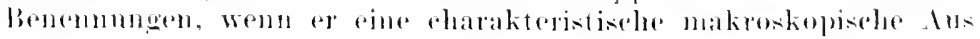

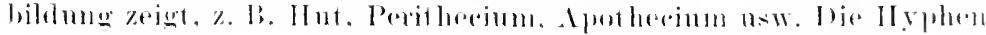




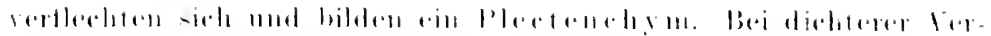

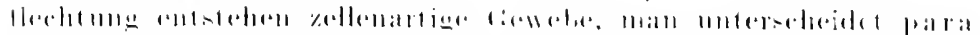

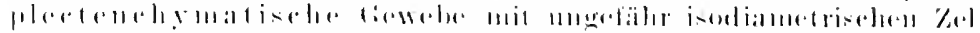

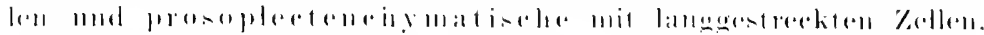

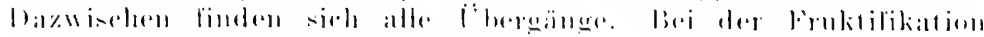

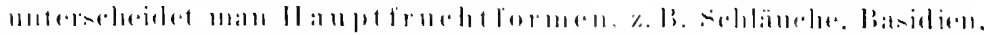

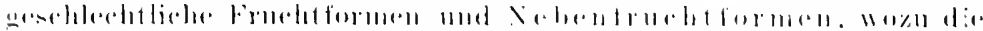

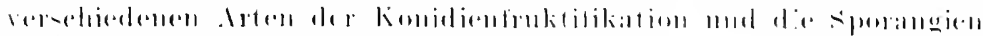

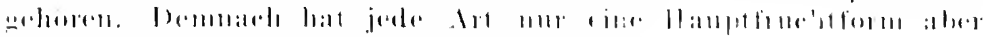

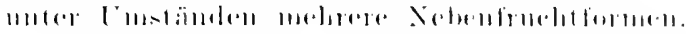

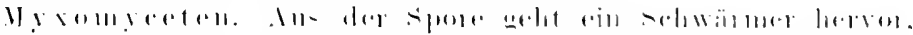

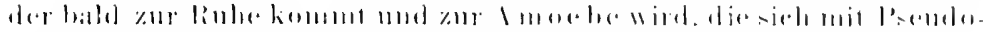

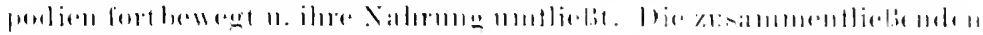

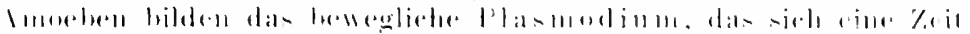

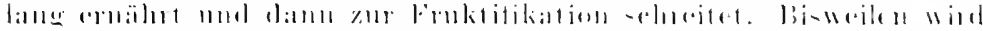

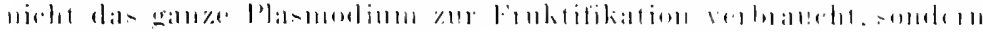

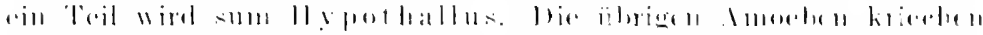

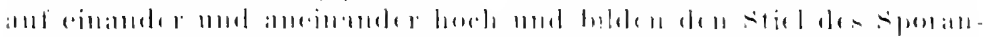

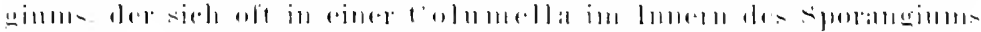

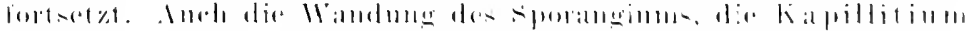

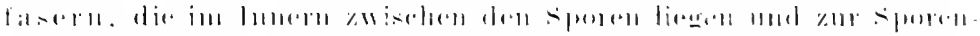

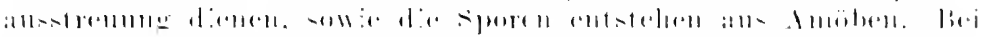

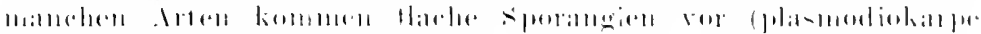

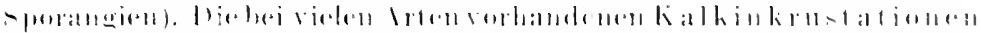

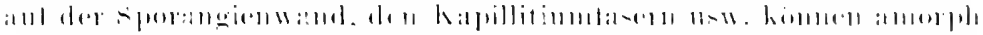

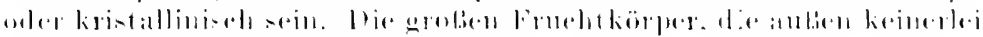

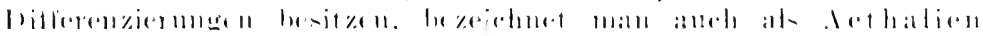
(\%) R. $|(1)|-11)$.

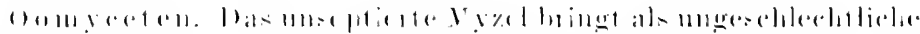

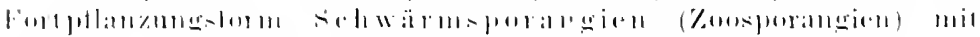
l,

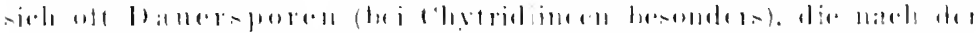

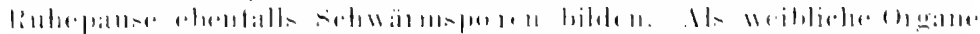

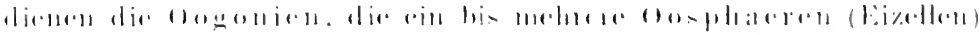

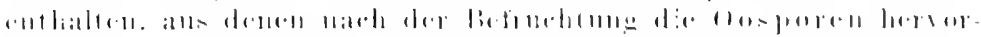

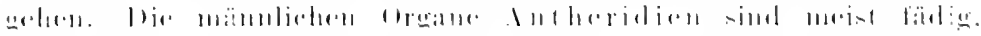

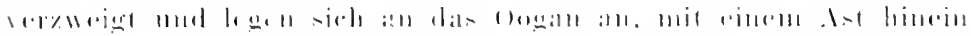

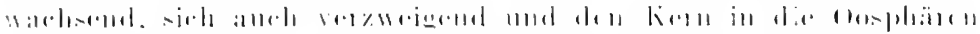

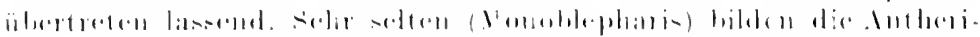

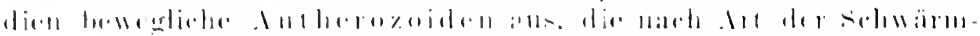

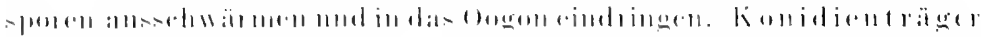

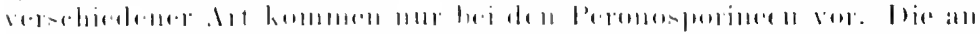

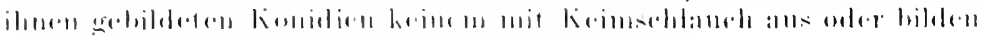

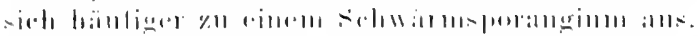

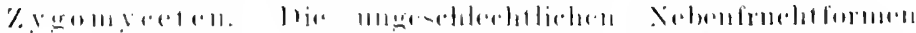

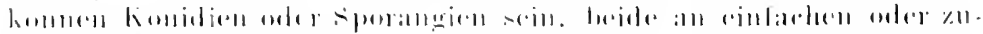

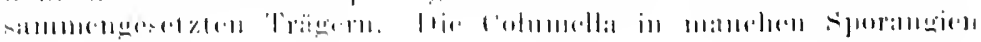


entsteht hier dureh einfache Einstïlpung ver seheidewand, die das eigentliehe sporangimm von dem stiel trennt. Selten kommen daeben anf Trägern gebildete Myzelkonidien vor, die zn den Chlamy. dosporen ejuen Ưbergang bilken. An Myzel finden sieh hänfig Daucrzellen, Chlamydosporen ofler Genmen, von denen ersters ruhende Frochtstände sind, da sie sofort in sporangien anskeimen (vel. machher bei den Uredineen). Die gesehlechtliche Fortptlanzmeg entsteht, inden 2 soitenzweige gegeneinander wachsen (suspen. soren): von diesen teilen sich die beiden Enden dureh seheide. want ab (Zygouten) nud bilden dureh Vereinigumg die Zygospore. lläug sind Azygosporen, bei denen der eine Entstelumgsast fort fällt. Die Keinmmg der Zygospore erfolgt dmeh Keimschlaneh, of mit unnitelbarer billumg eines sporanginms.

Ascomyeeten. Ans der keimenden sohlanchspore ol Kondie geht ein septiertes llyzel hervor, das in substrat (parasitiseh ofle saprophytisch) wärhst. Beivielen Gattungen wird, bevordie bruchtkïrperbildmur vor sich geht, ein festes, aus dicht verdochtenen 11 yphen bestehendes Gewebe erzengt, has stroma genamint wird. In ond ant

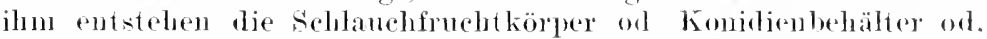
-laner. Ant die versehiedenen Arten der Stromata kinn hier nieht eingerangen werden. Tiel seltener (z. B. Clavierels) werdrn Sklerot ien gebildet, die ebenfalls aus direkt verfochtenen Il y phen bestehen,

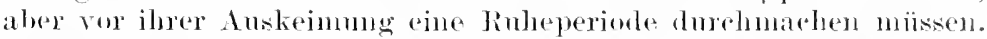

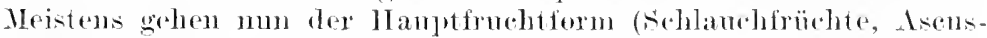
früchte) Sobenfuehtformen vorans, tie ans Konidienlagern odex Konilienbehälnissen (Pykniden mit Pyknosporen) bestehen können. Mannement diese Ersebeinmme Pleomorphie ar. Pleomorphismus.

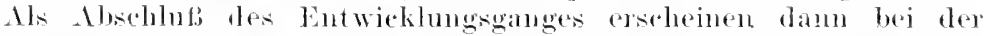
Prenomycetenreihe aie Perithecien, bei der Discomycetenreihe die Apothecien. Wis Perithecien sind geschlossene Fruchtlörper. dio von enem festen Gehäuss (von sehr verschiedener Konsistenz je

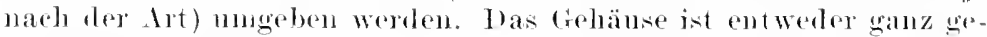
schlosien orl. oben mit eines lochartigen od. noln weniger habartier vorgezogenen Miundump (Ostiolum) verselest. In Inuern werden an der Basis, wo das Gehänse oft w, besonders in der Jugrnd motalbrochen ist mod mit drem öbrigen Nyzel in Verbindumg stelit, die schläuche ans dem ascogenen trewebe erzengt. Dor Aseus (sehlanch) ist ein in allen seinen Teilen regelmäligg gewordenes storanginm. Twischen die sehlänche eingemiseht stehen meist Paraphysen, pinfache uh. verzweigte zarte Fäden. An der Möndmog stehen oft nach innen hin zarte Fäden (Periphysen). Wie Kahl der sporen

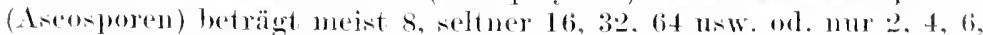
ist aher komstant fïr die Art. Das 1 pothecium ist win Frmelitkörpere, ler zwar angiokarp entsteht, aber zuletzt weit gröffuet ist m. die.

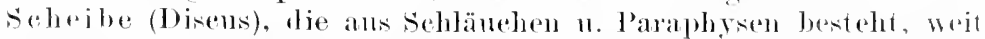

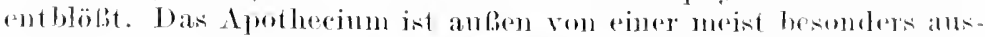

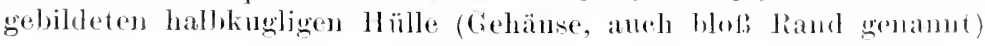




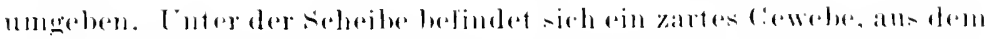

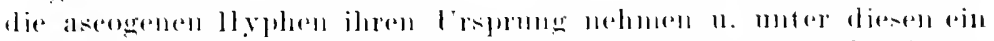

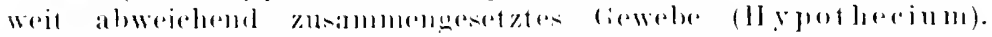

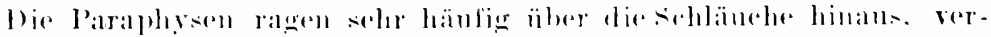

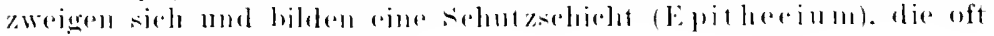
rharakteristioch geföght ist.

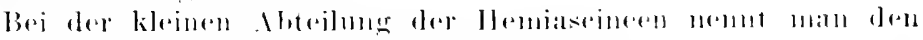

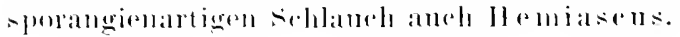




\section{Abkiirzungen im Text.}

\begin{tabular}{|c|c|}
\hline lkk. = Fruehtkörper. & 11. = Herbst. \\
\hline Th. = Thallus. & W. = Winter. \\
\hline$=-$ törmig. & Laubholz, lanb. \\
\hline$=$ breit. & Nol. = Nadelholz, Nadel. \\
\hline$=\operatorname{lang}$ & $\mathrm{u} . \quad=$ und. \\
\hline $\begin{array}{l}\mathrm{F} . \quad=\text { Frülijalı. } \\
\therefore . \quad \text { sommer. }\end{array}$ & $\begin{array}{l}=\text { oder. } \\
=\text { mehr wl. wrniger. }\end{array}$ \\
\hline
\end{tabular}

\section{Abteilung: Schizomrcetes (Bakterien, Spaltpilze).}

Selu kleine, farblose Organismen, die sich ron den cehten P'ilzen nur dureh das Fehlen des Zellkernes sicher unterscheiden lassen. zollen einzeln, versehieden gestaltet od. in Fädlen zusammenhängend, die mverzweigt sind od. sogen. falsebe Verzweigmugen besitzen. Die Zellen wachsen bis zn einer gewissen Gröbe heran mud teilen sich dann in zwei. sie besitzen Gejbeln od. sind bewegungstos. Sporenbildumg im Innern der Zellen. - Von den zahllosen Arten, die sich überall finden, kömon hier nur wenige auffallende berürksiehtigt werden, da die weitere Untersheidmog nur dureh Kultur- nnd Färbmgsmethoden mögliel ist, was ein s'pezialstudimm extordert.

Übersieht der Familien und wichtigsten Gattungen

A. Zellen kuglig, selten über $1-2$ " grol. bewegungstos und ohne sporenbildung.

Fam. Coceaceate.

a) Teilnng der Zellen immer' in der' selben Rielitung, so dafs perlselmurartige Fäden entstehen.

streptoeoceus.

b) Teilung der Kellen abwechselnd in zwei anf einander senkreehten Riehtungen einer Ebene, so daf. Zellplatton entstehen.

\section{Microeoerous.}

() Teilung in 3 zueinander senkrechten Richtungen des Rammes, so daP Zollpakete orl. unregelmälige Zellhaufen entstehen.

Sarrina.

Lindan, Kryptotamenflo:a II, 1. 2. Aufl. 


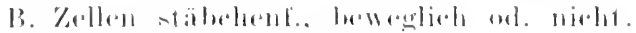

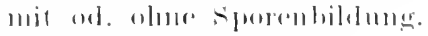

a) Zellen hewernomestos.

i.) Zallen bewergliels.

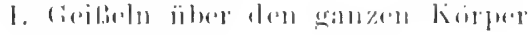

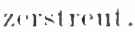

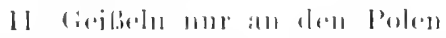

Fall1.: Ballarialealu.

Barterinur.

Barlilla-.

Prollomolllar.

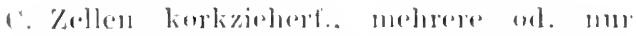

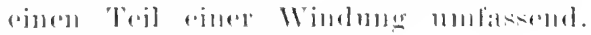

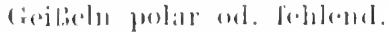

a) $/$ allum

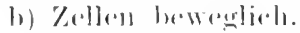

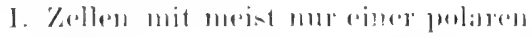
Givilial.

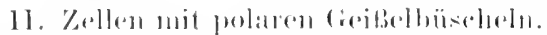

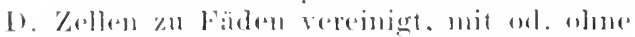

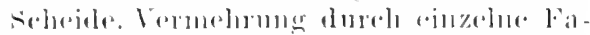

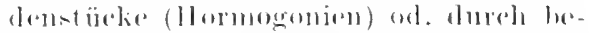

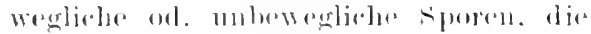

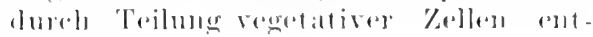
(toline.

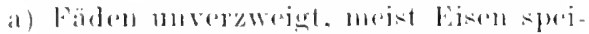

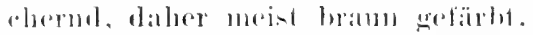

I. Fäden nur selur dïnn, Jänhteles einige "lick.

a) Füblen fast stets gerrade.

B) Finden schraubig gewmulen.

11. Fialon, mindestens im mberen Teil, 10 13. melir "li dirk

I'blamylothrix.

(iallionollas.

renothrix.

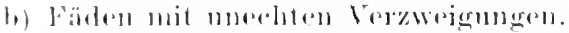

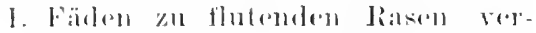
lmulen, wentig verzweigl, in stalk

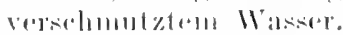

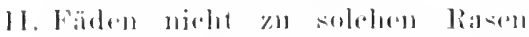

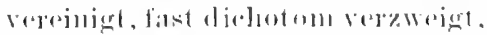
in reineme 11 asiorer.

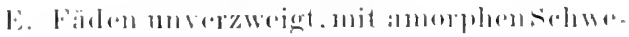

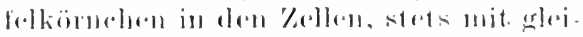

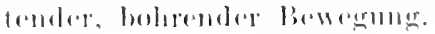

Falm.: ('hlamuglohatelerialonale.

Mirroprira.
Spirillum.

nifrithrt.

Fallu. : Sirillarenar.

Plipunamil.

\section{spharrotilu.}

\section{Chulothrix.}

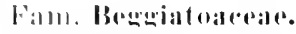 \\ Brewatiatoil.}

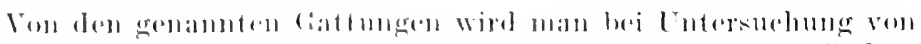

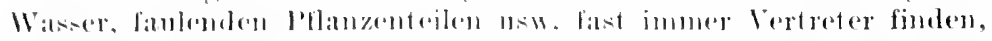

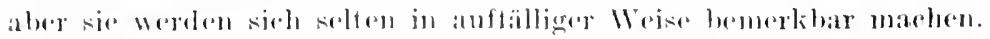

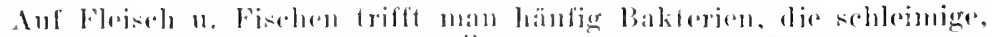

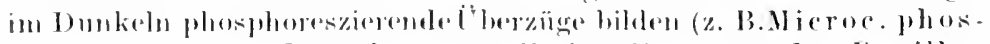

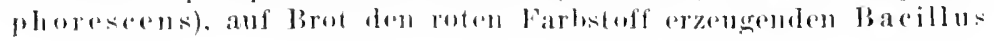


prodigiosns. in faulenden Flüsigkeiten bäntig neben Kukken u. stäbchon spirillun undula. Auffäliger sind die fadenf. Chlanydo. bacteriaceen, von denen einige drten genannt sein mögen.

('blamydothrix oeloracaea (Kïtz.). Fäden mit scheide, nur weng ̈̈ber 1 "l dick, zuerst farblos, dann durel Einlagerung von Eisenoxyd mit branner scheide. In eisenhaltigen frund-mol crabenwässeru, häufiğ.

Chlamylothrix epipluytiat Mig. Fäden kurz, nit dicker gallertiges scheide, ant Wascralgen festritzend. Hänfig.

Gallionella ferruginca Ehrenb. Fäden e. 1 "dick. schaubig um u. in einander gewnulen. lı eisenhaltigen Wässen, häntig.

fremothrix polyspora (olm. Fäden wenige mun le.. untem bis

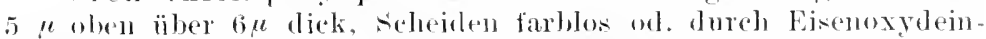
lagerungen bram. Dicke Rasen in Wasserlejtungsöhren. Brmmen. Göblun nsw. bildend, oft sehr hänfig und lästig.

sphaerotilus natans kïtz. Fäden festsitzend, mit schlej-

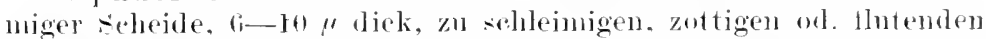
Rasen rereingt, von Leptomitus leieht mikoskojpisch mutersheidhar. Sehr häntiu in stark bewegten n. vejechnutzten Wasselüufen, Rieseluräben, ruckerfabrikabwäsern nsw. festsitzend an llolz. Wassejptlanzen nкw. (Fin. 1.)

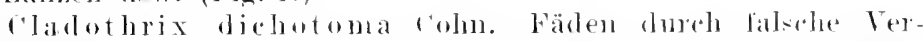

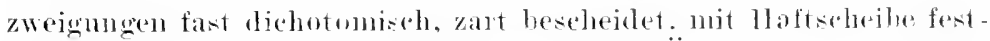

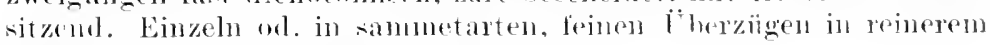
Wassel auf Ptlanzenteilen, bäutie.

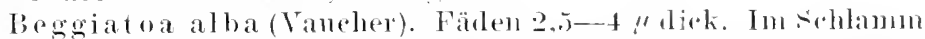

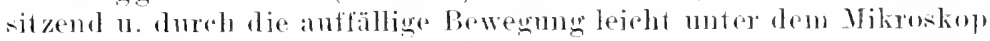
zur sluen, liänti心.

lieggiatoa leptomitiformis (Menegh.). Wie ror. Mt. aber die Fäden $110 \mathrm{r} 1,5-2,5 \mu$ dick.

lu rerschmutzten Wässern findet man an llolz, Schilf usw. häufig lie Zoogloea ramigera ltzigs. Sic stellt geweilartig verzweigte Gallertbäumehen von $1-1,5$ mm Länge dar, die zahllose in schleju gehettete stäbchen enthalten. Die Zugehörigkeit ist mbekannt.

Eine \%wischenstellung zwisehen den eigentliehen schizonucoten umb den derasineen nehmen die

\section{Myxobacteriaceae}

rin. In regetativen Zustande bestehen sie ans pinem sedwarm bon stäbelıen, der von einer selıleimbülle mugeben ist. Im fruktitikativen \%uslande kriechen sie ïbereinander n. bilken Häntohen od. gestielte wh.

Restimmumgestabolle der Gattungen.

1. Vegetativestäbehen sich rerkürzendu. in kngelt. Sporen mmwandelud. Die Fk. bestehen aus dulüulungen von sporem, dje in schleim eingebettet simb.

1. Hyxorocents. 


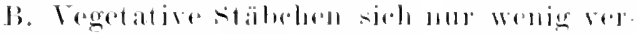

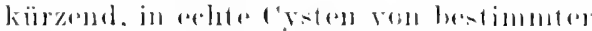

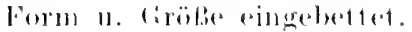

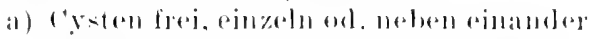

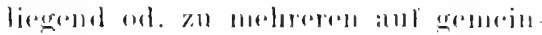
salltell $\rightarrow$ idel.

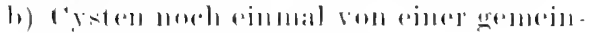

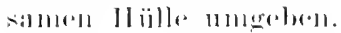

\section{‥ Chemblomitas.}

:3. Polyameimu.

1. Niattumer: Myxomerem, Thaxter.

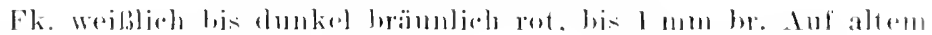
Mist voll Pflanzenflessedn, häulige,

11. IแIm (1'olu)

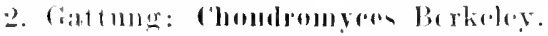

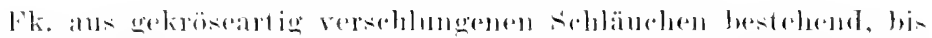

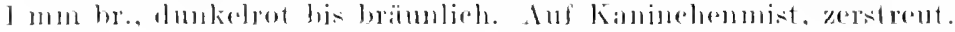

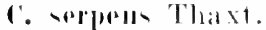

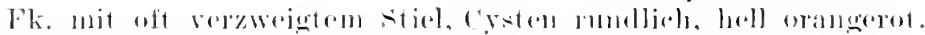

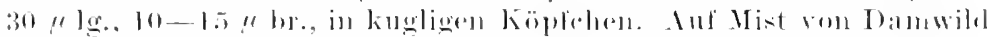

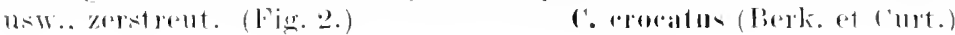

\section{Cratlungr: Polyangium limk.}

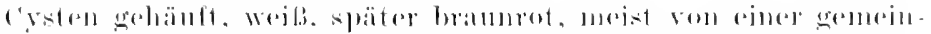

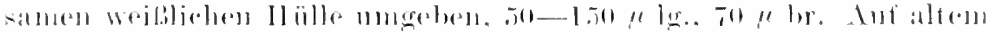
Mist. lüulier.

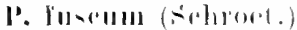

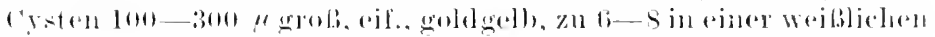

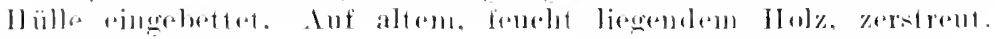
(Figr. 3.)

I. vitrllimmm Liuk

\section{Abteilung: Mrxomycotes Schleimpilze).}

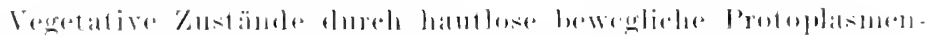

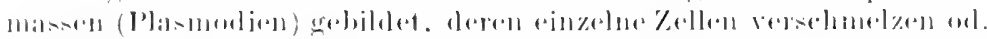

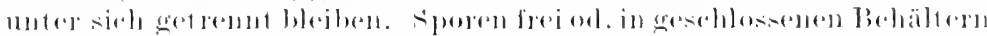

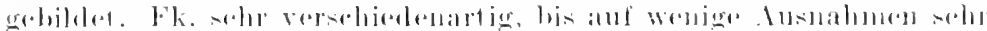

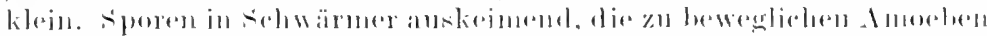

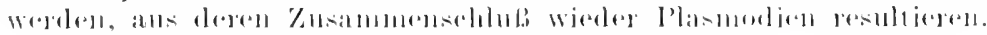

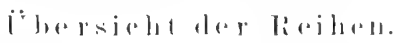

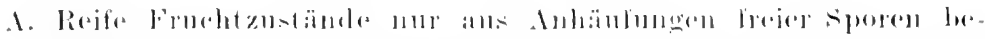
starist.

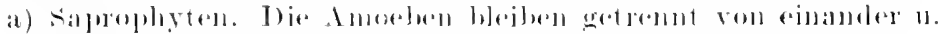

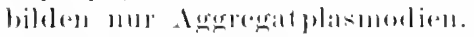

1. Irravinae.

b) larasiten int Jumern ron l'flan\%(11.

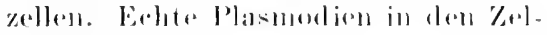
len bilalenel.

\section{II. l'hytomyxinae.}


B. Sporen in geschlossenem Fk. gebildet. Echte Plasmodien, die meist oberflächlich leben

III. Myxugasteres.

\section{Reihe: Acrasiinae.}

Die Amoeben treten zu Plasmodien zusammen, versohmelzen aber nicht. Sporen in Ballen gehildet, die hiillenlos sind u hänlig von stielen getragen werken.

\section{Bestimmungstabelle der Gattumgen.}

1. Sporenhanfen mugesticlt ofl. kaum ge-

stielt. (Fam. Guttulinaceae).

a) Anoeben mit lappigen Psendopodien. 1. Guttulinnpsis.

b) Anoeben ohne Psendopodien. O. (intulina.

13. Fporenhanfen dentlin gestielt. (Fam. Dirtyosteliaccale).

a) Stiale nicht od. nur wenig n. mregel-

mälig verzweigt.

b) stiele seln reichlich u. - regeluäbig verzwoigt.

3. Dirtyostelimm.

4. Pulysplumbylium.

1. Gattung: (intulinopsis Olive.

sporenhanfen oft etwas gestielt. Sporen moregelmälig kuglig, die des stiels mejst etwas länglich.

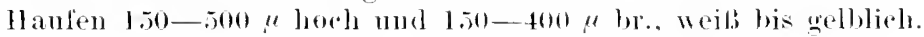
Ant Tiemist. zerstreut.

(i. valuaris Olive.

2. Crattumg: (iuttulina Link.

Kleine, tröjplohenähliehe Schleimklumpen die sich später zu sponen umbilden u. van einem kurzen stiel getragen werden.

Rote. kanm I mm grobe Köpfehen mit kurzem stiel. Anf fanlem Holz, zerstrent.

r. resea Liuk.

3. Gattung: Dictyontelium Bret.

Fk. weib, lang gestielt. Stiele selten etwas resweigt, schammig netzartig anselrend.

stiel 3-s num lang. Sporenhäufohen kuglig. Iuf altem Mist nicht selten. (lig. 4.)

1). IIrearoidss Brefl.

\section{Cattumg: Polysphomblimm Bref.}

Fls. violett, lg. gestielt n. verzweigt. Sporen in lïpfehen am Eude der iste n. des stioles.

stiel bis l em la.. von der Mitte ans mit wirteligen Östen. Anf

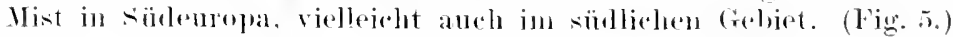

P. violacemm Biet. 


\section{Reihe: Phytomyximate.}

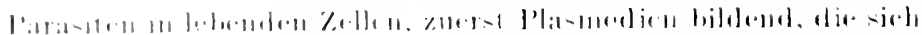

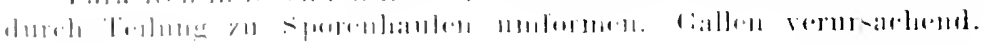

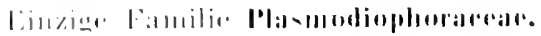

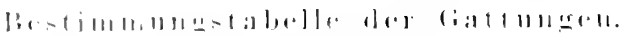

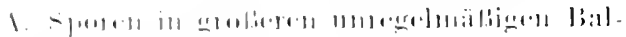

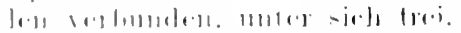

\section{P'I-IInoliopluora.}

li. - -

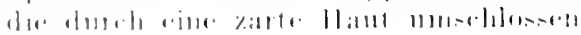
malden.

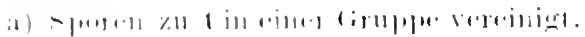

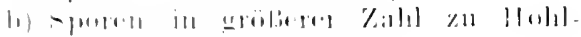

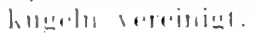

\section{‥ IPlramyxa.}

3. Nilloyharara.

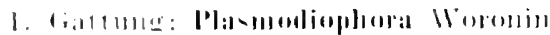

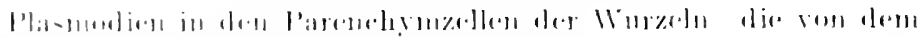

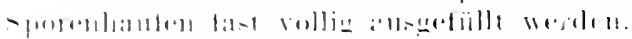

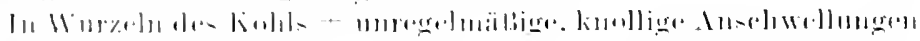

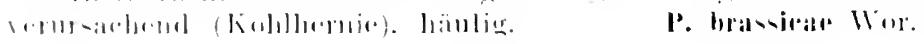

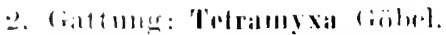

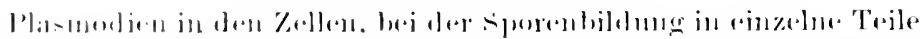

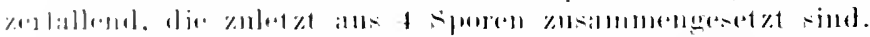

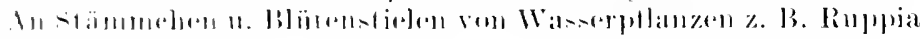

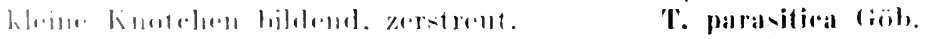

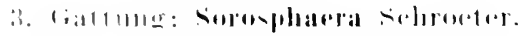

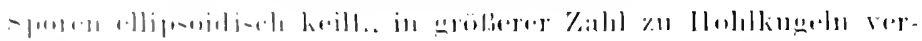
limirlente.

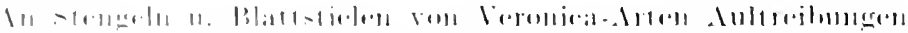

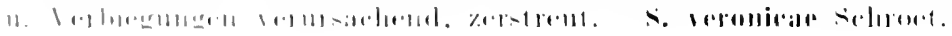

\section{Reilie: Myvomasteres.}

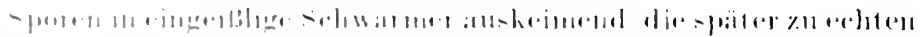

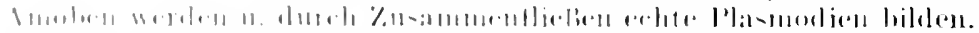

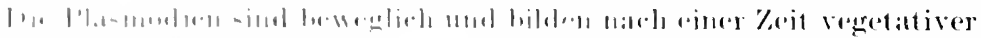

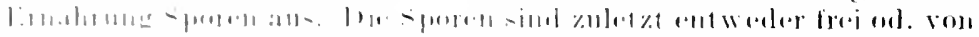

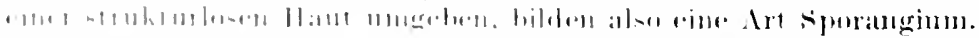

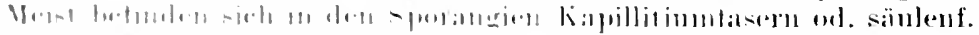

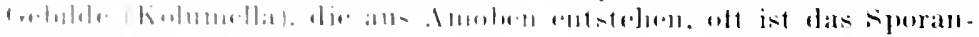

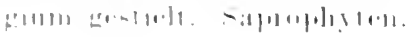




$$
\text { Bestimmungstabelle der Familien. }
$$

A. sporen frei entstehend, nicht in sporangien (Exosporeae).

1. Fann.: Cruatiomyxaceac.

B. Sporen imerhalb eines sporangiums entstehend (Lndosporeate).

a) sporen rerschieden gefärbt, aber niemals dunkel violett.

I. Kapillitim ganz fellend od. kein system von ganz gleichmäbigen Fäden bildend.

1. Sporangien gestielt od. nicht. stets getrennt von einander. einzehn stehend od. zu Gruppren rerbunden, aber nirlit zu gleicht. Äthalien vereinigt.

a) Sporangienmembran häutig. \$ Sporangienmembran mit mikroskopischen rundlichen Köruchen besetzt. sporangien einzeln (exkl. lindbladia u. Cribraria argillacea)

2. Fann. Heterodermataceae.

ş sporangienmembran mackt. sporangien dicht gehäuft

3. Fant.: 'Tubulinateace.

B) Sporangienmemliran knorpelig, härter, Sporangien einzelı

4. Fann.: Lierareae.

2. Sporangien zu einen gleich. mäßigen Äthalium zusammenfliefend.

II. Kapillitium stets rorhanden. ein Geflecht von gleichmäbigen Fäden bildend.

1. Sporangien zu rinem gleichmäßigen Äthalium zusammenfliefend. Kapillitiunfasem glatt od. mnregelmälig schrmmpfig.

2. Sporangien kein Äthalium bil6. Fam.: Lyengalareace. dend. Kapjillitiumfäden mit spiraligen od. ringf. od. stach. ligen Verlickungen.

j. Fam.: Reticulariacear. 
(4) Kapillitim mil spiral.

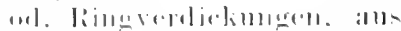

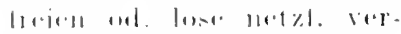

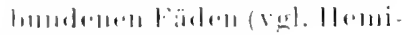

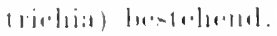

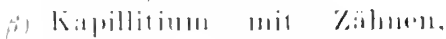

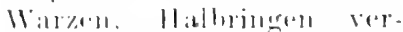

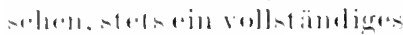

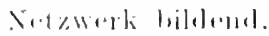

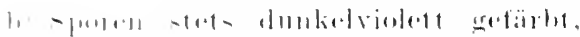

7. Fant.: Trirluiaterar.

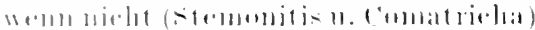

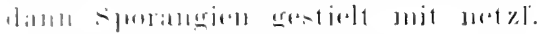
kingillitimm.

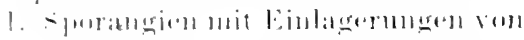
huhlensandell kalk rersthen.

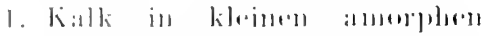
kivindelu.

2. Kalli in liri-talli-iorten MhlateJullinell.

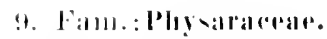

11. Fam1. I Iılymiaraile.

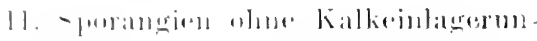
[r.t11.

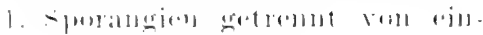

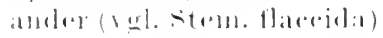

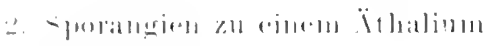
lareiniert.

S. Fam, Ireyriarear.

11. Fill1.: Strollunitarease.

\section{l.). Fan11.: Imanuro- rhaltetilraite.}

\section{Fatmilir: Crratiomyaterar.}

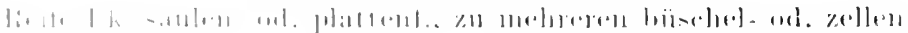

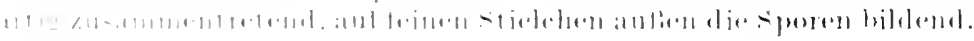

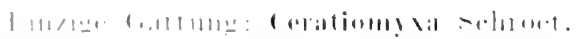

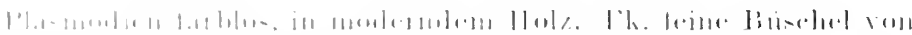

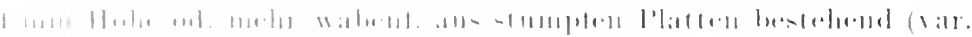

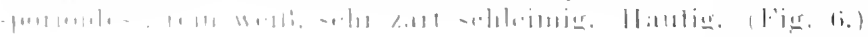

l. Inureidal (l'in's)

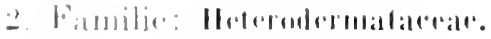

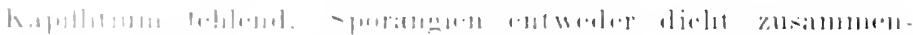

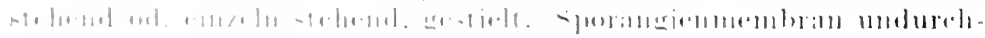

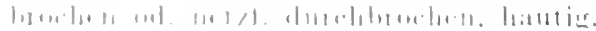

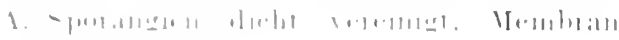

I. I.imllilarlial. 
B. Sporangien einzeln, gestielt, Membran feil durchbrochen.

a) sporangienwand in obern Teil zart netzt. durchbrochen.

1) sporangienwand bis zum Grunde in zarte Parallelrippen anfgelöst, die durch teine Fädchen verbunden werden.

\section{Cribraria.}

\section{Dirtydium.}

\section{Gattung: Lindbladia Fries.}

sporangien zu einem äthalienartigen, polstert. od. ansuebreiteten Gebilde vereinigl, $1-10 \mathrm{~mm}$ dick. Membran ganz, gebbram, mit. dunklen Körnchen besetzt. Auf moderndem IIolz, selten. (Fig. T.)

L. effusa (Elmbe.)

\section{Gattumg: Crihraria Pers.}

sporangien kuglig od. fast limf'., gestielt. Sponangienwandung in der unteren II alfte ganz, in der oberen zuletzt ein foines Netzwerk mit Knoten in den Eeken bildend.

1. Kuoten des Notzwerkes nicht ausgedelunt. 2.

Kunten des Netzwerlies ansgedehnt.

.. Sporangien lehonfarben, knglig, nit stiel bis 1,5 mul lg. Ant altem Ilolz, zerstreut. (Fig. s.) f. argillacea leos.

sporangien rothram, fast linglig od. kreiselt. nit stiol bis : mm lg. Auf altem llolz. zersilent. ('. rula (liotli)

$\therefore$ Fporangien nubbrant.

4.

sporangien purpur - od. rotbrant.

i.

4. [nterer Teil der sporangienwandung ganz bleibent, une oben nach

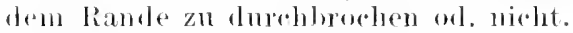

Tnterer 'Teil der sporangienwandmug bis zum Grumde rippent. durchbrohen, Netzknoten br. Simorangien knglig, nit stiel $1.5 \mathrm{~mm}$ hoch. Anf faulem Tammenholz, selten.

$$
\text { c. splendens lers. }
$$

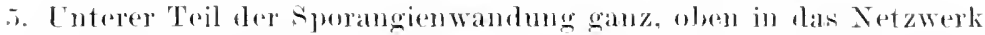
mit feinen Strängen übergehend, Netzknoten verbeitert, eckig, sirh verzweigent $u$. in dis teinen stränge ïhergehend. Sporangien kuglig, mit stiel 1-2 mm hoch, hesdig. Anf fandem Tammenholz, nicht selten. (Fig. 9.)

(1. anrantiaca sichrarl.

Unterer Teil dor siporangienwandung an oberen liand dne'bbrochen 11. allü̈hlich in das Netz übrogelend, Netzkuoten verloveitert, verzweigt. sporangion knolig od. kreiself., 2 num hor h mit stiul. Anf foulen Tamuenholz, seltent.

C. maceoearla śchlarl.

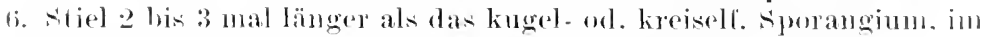
sanzell 1-1.7 mm horh. Anf fanlem Tammenholz, selten.

(. pirifornis solnat. 


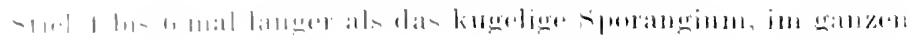

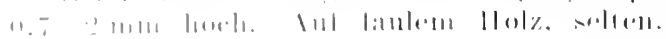

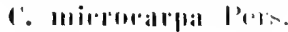

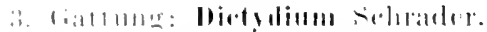

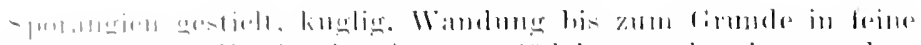

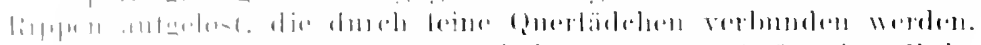

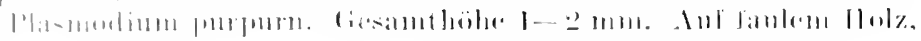

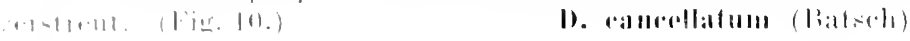

\section{Familie: Tubulinaceare.}

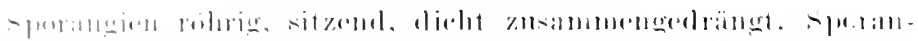

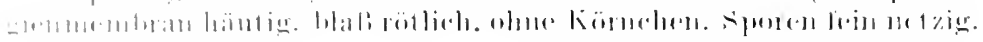
kiprillinim lahlend.

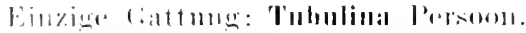

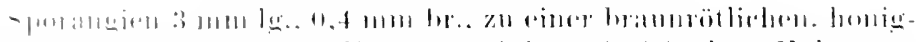

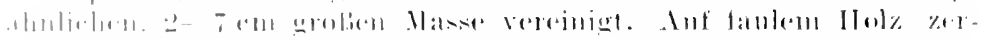
$=110111 . \quad 10 j, 1\}$.

'T. Pracilormiv l'trir.

\section{Familie: Liceacear.}

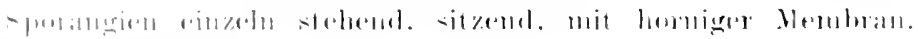

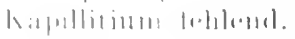

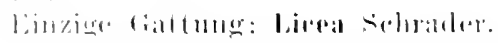

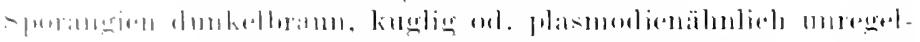
Intiliigr.

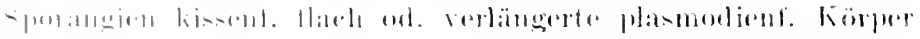

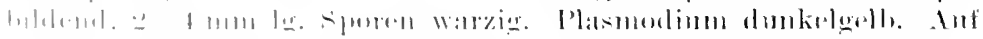

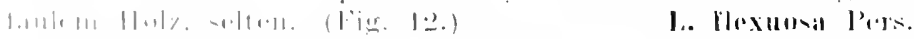

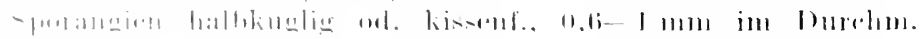

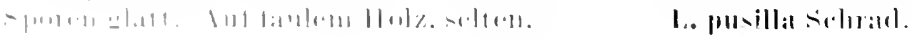

\section{万. Fandilin: Rolirularialerar.}

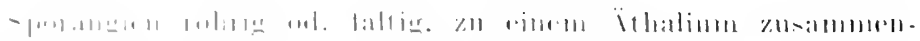

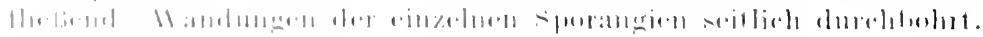

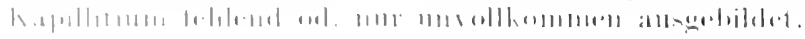

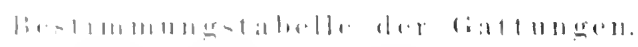

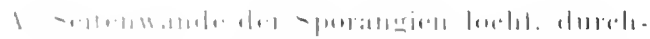

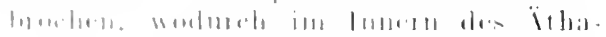

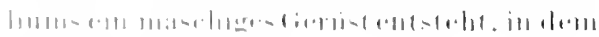

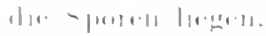

\section{Vinferidium.}

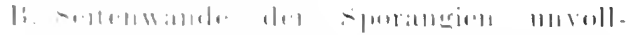

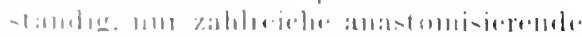

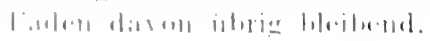

உ. Rulirularia. 
1. Gattung: Euterilium Ehrenh.

sporangien gewunden. Kapillitim fehlend. Sporen mrist in lest verbundenen Ballen.

Plasmorlinm rosenrot. Ithalium $1-3 \mathrm{~cm}$ br.. dunkel olivengrion. glatt ol. ranh. Auf fanlem IIolz, zerstrent. (Fig. 13.)

E. olivarenm Elırenl,

\section{Gattung: Reticularia Bulliarl.}

Äthalien ans gewmodenen, dicht verwebten sporangien ent stehend, deren Seitenwände z. T. versehwinden, z. 'I', als kapillitimmartige Fasern bleiben. Sporen einzeln, warzig.

Plasmodien weil. Ähalien ב-firm br., kissenf.. ron einer silberglänzenden Hant mmgeben, dunkelbrann. Anf totem lIolz, ïber Moosen, besonders ant stimmten, gemein. (Fig. 14.)

R. lyeoperdon Bull.

\section{Familie: Lycogalaceac.}

Sporangien zn einem Ithalimu zusammenfliefend. Kapillitinufasem ans glatten od. schmmpfigen, rerzweigten Röhron bestehend.

\section{Einzige Gattmog: Lyeogala Micheli.}

Ithalimm fast kuglig, oft mehrere dicht beisammonstehend.

Ithalien abgermulet, sitzend orl. kurz gestielt, anden glatt or. fein areoliert, $2-5 \mathrm{~cm}$ in Durchun., ocker-od. purpurbram. Anf fanlem IIolz. selten.

L. flavofuscum (I'ers.)

Plasmorimm rot. Ithalien fast knglig, sitzend, meist herdig, 0.2-1 1 $1 \mathrm{~m}$ im Durelum., anden warzig, graugrïn, gelb-ok. rothram. Auf faulem Holz, hesonders anf stimpfen, häufig. (Figr. 23.)

1. epidendrum (L.) .

\section{Familie: Trichiaceac.}

Sporangien einzeln. Kapillitinu aus freien Fäden bestehend od. zu enem Netzwerk verbunden, mit Spiral-od. Ringrerdickungen.

\section{Bestimmungstabelle der Gattungen.}

A. Kapillitimufasern frei.

a) Kapillitimmfasern mit regelmäßigen Spiralverdickungen.

\section{Trichi:ı.}

b) Kapillitiumfasern mit umvollständigen u. unregehmäBigen Spiralverlickungen

\section{Olignnemi.}

13. Kapillitimmlasern zu eincm Netzwerk verbuuden
a) Mit Spiralverdiekmugen
3. Homilni('hia.
b) Mil Ringverdickmogen.
4. Cormuta. 


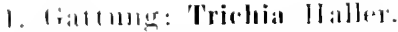

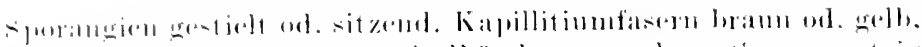

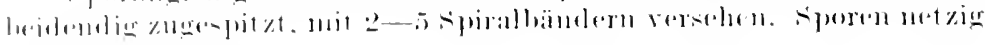
i11. 11 ill\%iu.

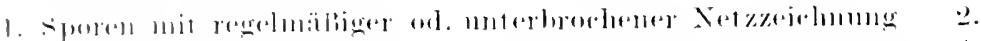

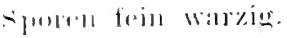

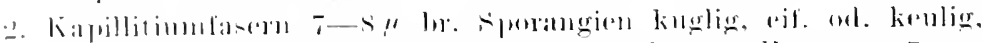

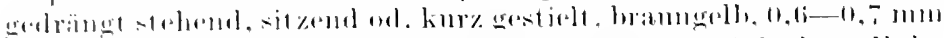

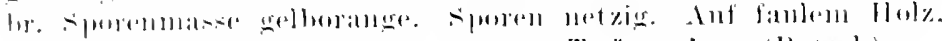

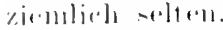

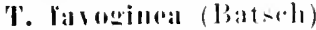

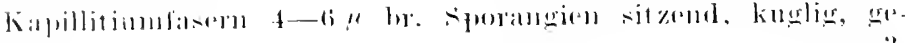
hiinl1.

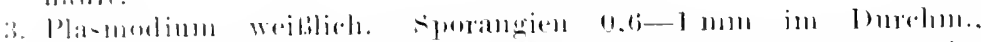

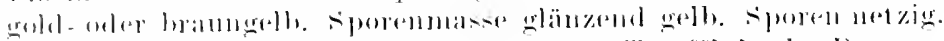
Auf finlen IIol\%, seltril.

T. allinis de liy

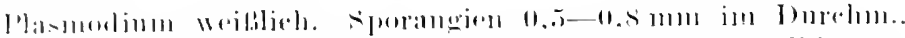

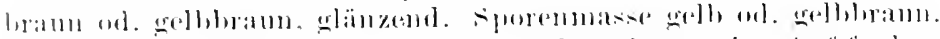

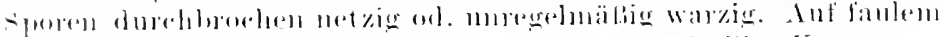

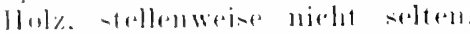

T. prominiliv Karst.

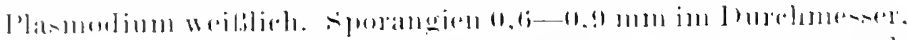

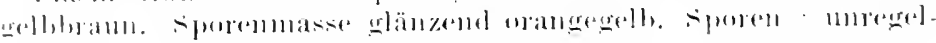

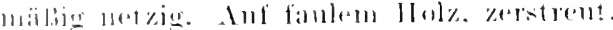

T. Maliat lintal.

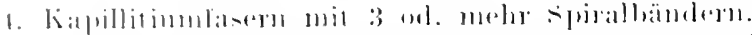

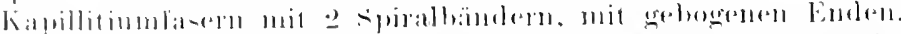

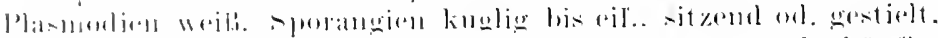

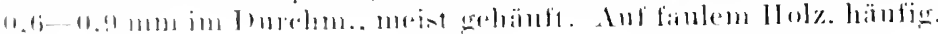
liv. 1 .

'l'. rarial l'ers.

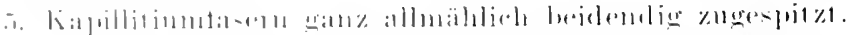

ii.

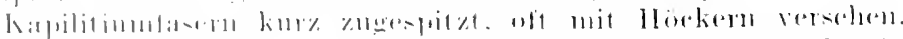

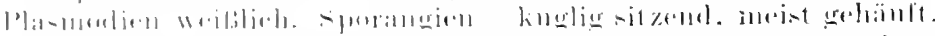

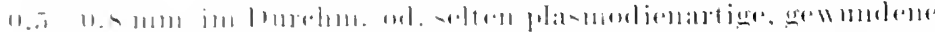

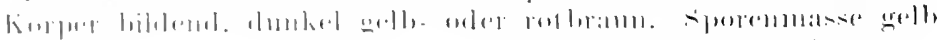

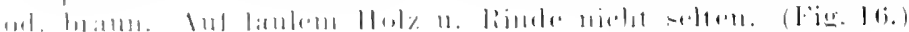

I'. ronlolla (1)itm.)

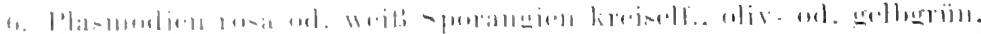

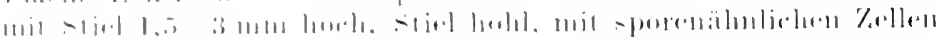

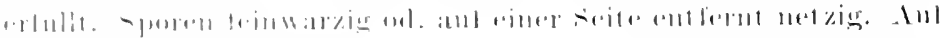

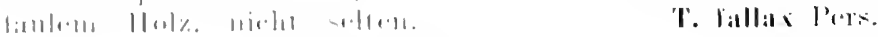

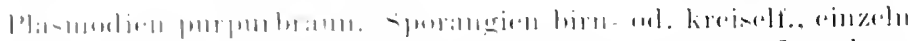

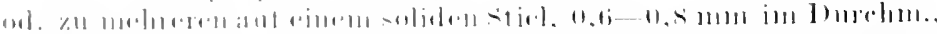

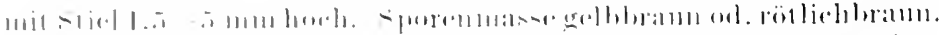

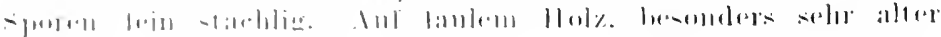

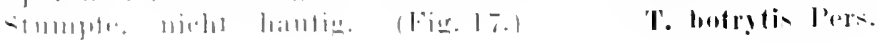


2. Gattung: Oligomema Rostafinski.

Sporangien dicht gehänft, sitzent. Kapillitimufasern mit un. regelmäbigen od. undentlichen spiralverdickungen. Sporen engnetzig.

Sporoangien $0,3-0,4 \mathrm{~mm}$ im Dnrehns, gelb od. grinlichgelb. Anf faulem Holz, selten.

0. nitens (Lib.)

\section{Gattung: Hemitrichia Rostafimski.}

sporangien gestielt od. sitzend. Kapillitimn ain Netzwerk ron tverzweigten Fäden mit $2-6$ spiralbändem bilkend. Sporen fein warzig od, netzig.

1. Sporen fast glatt od. fein warzig.

sporen netzig. Siporangien langliclue, gewundene, oft rerzweigto

Körper bildend, $0.4-0,6 \mathrm{~mm}$ br., oft netzartig verbmuden, goldgelb. Anf faulem llolz mol Blättern, sehr selten. H. serpula (Ácop.)

2. Plasmodien purpurrot. Sporangien kenlig bis fast zylindrisel, sitzend od. gestielt. gehäuft, mit stiel 1,3-2,5mm hoch, dunkelmot, rot-od. grïnbram. Sporen warzig. Anf fanlem Ilolz, zerstrent.
(Fig. 18.)
H. rubiformis (lers.)

Plasmorlinm weilidels. spromengen kenlig od. kreiself. gestielt. herdig, mit stiel $1-3 \mathrm{~mm}$ hoeh, bram od. griugell. sporen feinwarzig. Anf faulem Ilolz, zerstrent. H. rlavala (Pers.)

\section{Gattmug: Cormuia Rostafinski.}

Fporangien sitzend. Kapillitimulasern ein Netzwerk bildend. mit Ringfasern. śporen netzig.

sporangien gebogen od. rerzweigt, ca. $0,3 \mathrm{~mm}$ hr. of. etwas kuglig, goligell. Aut Lolse, selten. (Fig. 1\%.)

$$
\text { C. serpula (Wiegand) }
$$

\section{Familie: Ireyriaceae.}

Sporangien einzeln ml. herdig, sitzend oul. westielt. Kapilitium pin vollkommenes Netzwerk bildend, mit Verdickungen in Forn ron llabringen, Zähnen od. Warzen.

$$
\text { Bestimnungstabelle der Gattungen. }
$$

A. Sporangien sitzend.

a) Sporangienwand bleibend, ohme eckige Knötrhen.

\section{Iachuobolıs.}

b) Sporangienwand doppelt, anfen mit dunklen, cokigen Körnchen.

2. Perichacha.

B. Sporangien gestielt. Oberer Teil der spo. rangienwandlung schwindend.

3. Areyria.

\section{Gattung: Lachnobolus Fries.}

Sporangien gehänft. Sporangienwand einfach, olne Kü̈rhen. Kapillitimmfasern mit dicht stehenden Wärzches. 


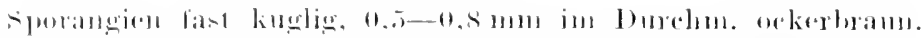

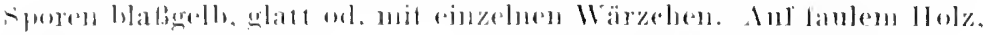

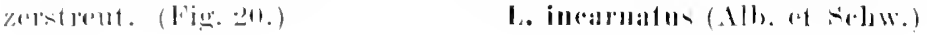

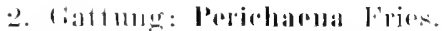

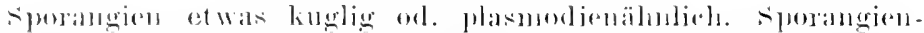

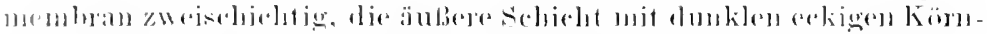

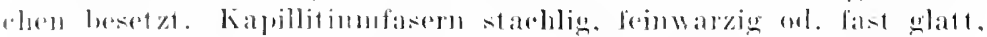

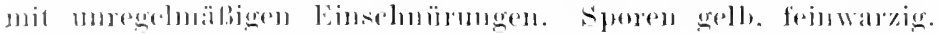

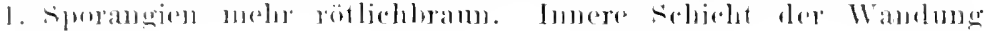
ulat.

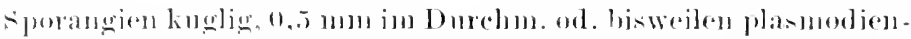

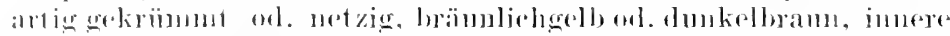

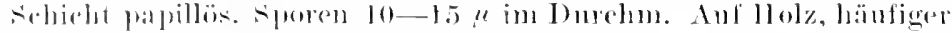

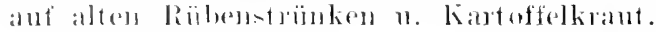

l'. verminulario (sohwein.)

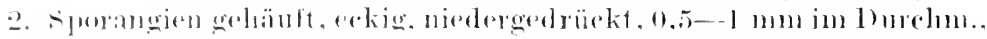

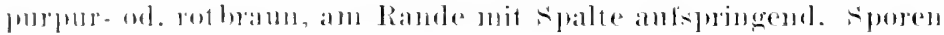

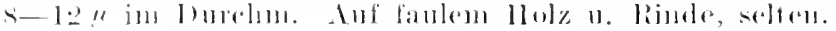

\section{P. lepronat libert}

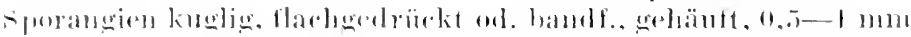

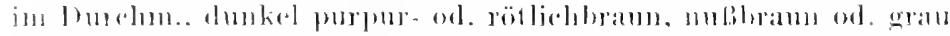

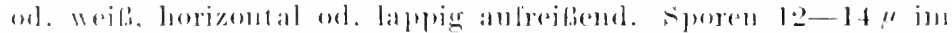

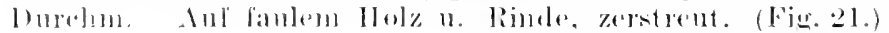

P. forticalis (liatsinl $)$

\section{Hattmuge: Ireyria Wiger.}

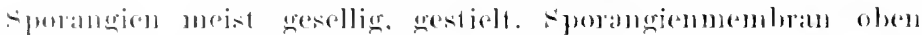

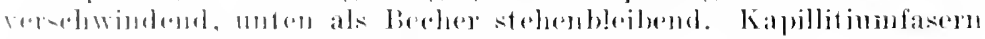

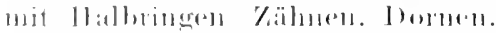

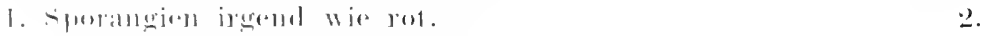

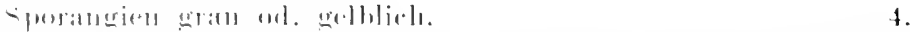

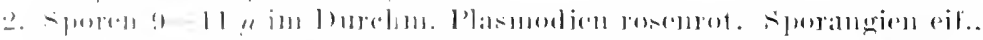

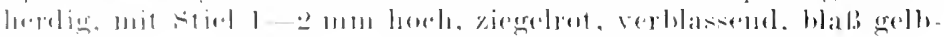

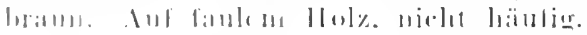

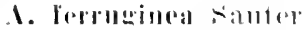

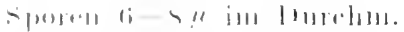

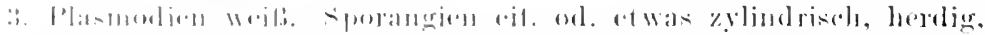

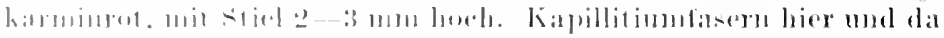

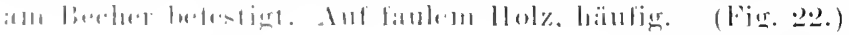

\section{1. punieral lerk.}

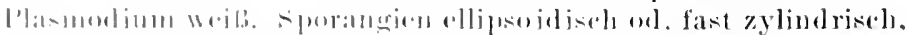

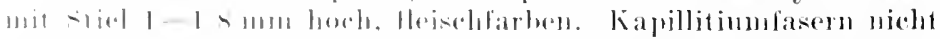

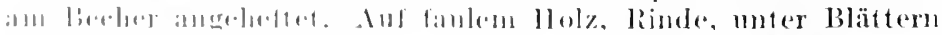

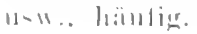

1. inralinata l'ers. 
4. Plasmodinm grau. sporangien eif. bis zylindrisch, blatigran od. gramötlich, seltner gelb, mit Stiel $0,8-4 \mathrm{~mm}$ lg. Kapillitiumfasem an Becher befestigt. Anf faulem 11 olz u. Pflanzenresten, zerstrent.

A. cinerea (Bull.)

Plasmodium weißlich, Sporangien zylindrisch, herdig 1, i-2.2 mu la.. bäunlichgelb. Kapillitumfasern frei rom Becher. Auf fanlem II.1\%, zerstreut.

A. Imtin, (Bnll. $)$

\section{Familie: Physaraceae.}

sporen dmbelvindet. Kalkablagerungen in kleinen amorphen kömchen in der sporangien wandmo, oft in blasenf. Amschwellmgen des Lapillitims, im stiel od. der columella. Sporangien getrennt. oelten zu Ïthalien rereinigt.

$$
\text { Bestimmungetabelle der fiattunderte }
$$

1. Sumangien zu einem $\ddot{t}$ halium zuxanmenfliebend.

1. Fulien.

P. Sporangien getrennt voneinaurles.

a) Kapillitinufasern rin grobes Netzwerk bildend. das wan\% mit kalkkörmelsen erfüllt ist.

b) Kapillitionfasem ein foines Netzwerk bildend, das keine Kalkablagerungen wh. solche nur in den Yetzecken ent. lıilt.

1. Kapillition in den Xetzecken mis unregehmäbigen Anshwellungen, in drinen Kalkkömchen abgelagert sind.

1. Fporangien ungestielt. Jhasmodienartig (vol.auch Physarmm2)

2. sporangien gestielt knplig wh. becherf.

a) sporangien wie lackiest aus. sehend, eif. meist hängend.

B) Sporangiennicht wielackient anssehend, fast immer auf. recht.

$\S$ sporangien - becherf. Kapillitium ans dicken, unregelmäBigen Anftreibungen mit Kalkablager. rumgen bestehend, "lie durch wenige hervortretendle feine Stränge rerbumden werden.
2. Barllanmial.

\section{Cienliowlia.}

\section{Leocarpm.}

Ђ. Craterium. 


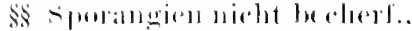
linglise rif. ad. plasmodirlation (I'. livalye 1 . liclermal). Kapollitimm ans loinen fiäien bestrhemel.

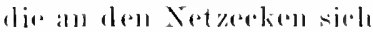

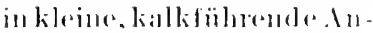

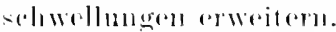

\section{fi. Plivarum.}

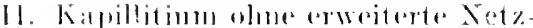

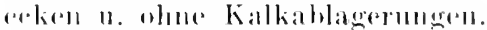

1. Kalkablagermugen mor in der symrangienwamblum.

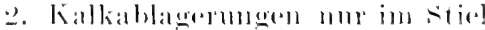
11. in lep Kolmmellat.

\section{Clonmbrionlermal.}

s. IIiarhai.

1. Cattunas: Fulien Hallor.

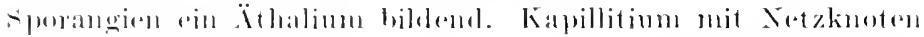
11. daria kalbahlagermengen.

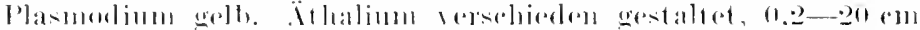

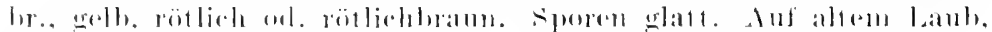

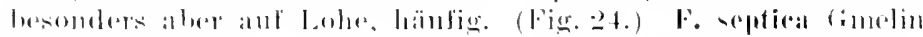

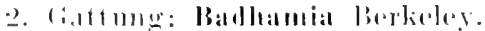

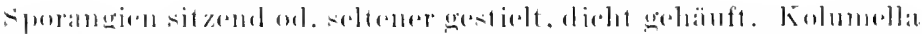

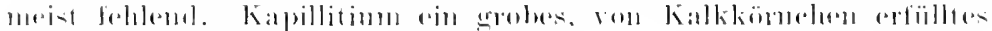
Not\%urele liblemel.

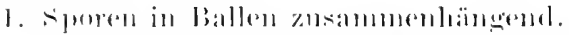

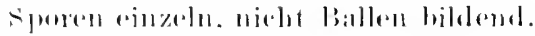

3 .

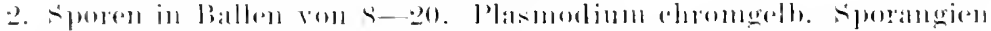

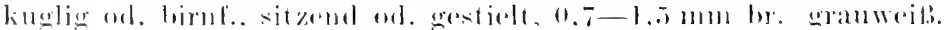

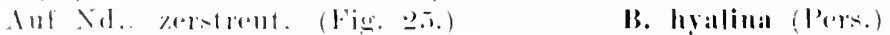

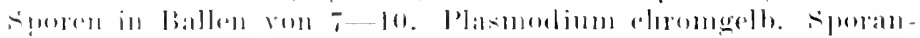

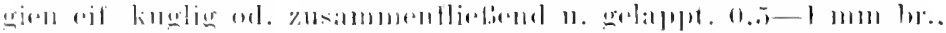

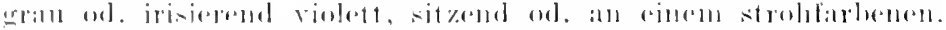

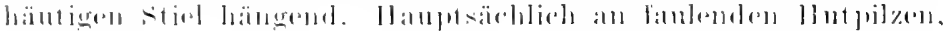
$\%+1,1+111$.

B. ntriculariv (linll.)

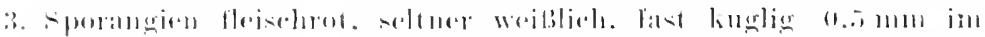

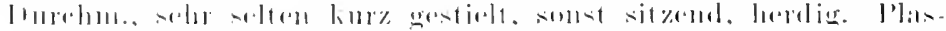

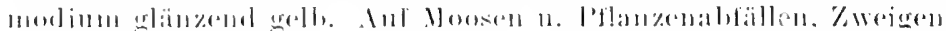

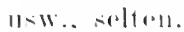

B. lilarina (l'r.)

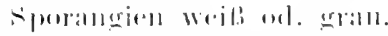

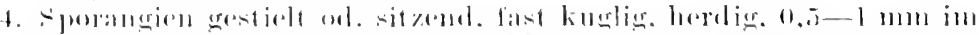

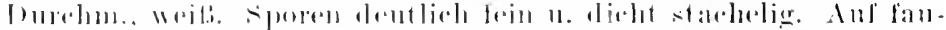
lom llal\% seltall.

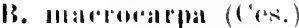

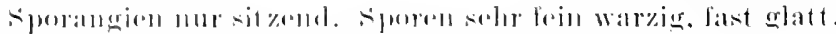


binf. anf eincm winzigen, bramnen stiel, dunkelgran bis violett irisierend. An faulenden Blättern, sehr zerstreut.

B. foliceolal Lister

Plasmodinm weiß. Sporangien fast kuglig, $0,4-1.2 \mathrm{~mm} \mathrm{im}$ Durchm., moist leedig, weils od. grat. An Unmenrinde n. über Laub, selten.

B. panieca (Fr.)

3. Crattung: Cienkowskia Rostafinski.

Sporangien plasmolienatig, verzweigt, bandantig. Kapillitimn ein lockeres Netzwerk ron staren Fäden mit vielen freien, gehogenen u. seharf zugespitzten Ästen bildend, dio mit flachen kalkhaltigen durchbolnten Platten in Verbindung strhen.

Sporangien $0.5 \mathrm{~mm}$ hr., gelhbram, blab querstreifig, rot fleckig. sporen fein stachelig. Anf faulem Holz, selten. (Fig. 26.)

\section{C. reticulata (Alb. et seliw.)}

4. Crattung: Leocarpus link.

Spurangien wie lackiert ausselend, mit 2 Membanen, die äubere knorpelig $n$. kalklattig, die innere lyalin. Kapillitim + in 2 systeme getremnt, das eino ein Netzwerk von staren, hyalinen Fäden bildend, das andere grob verzweigt $u$. mit brannen Kalkkönchen. sporen stachelig.

Plasmodium orangegell). Sforangien $2-4 \mathrm{~mm}$ lg. kuglig on. obovat, meist kur woibsticlig, meist geluanft u. hängend. ['her Blättern, Moosen, Stengelı usw., häulig. (Fig. 27.)

L. Iratgilis (Dicks.)

\section{Gattmug: Craterimm Trentepolıl.}

sporangien festielt, anfeeht hecherf., mit einem diinneren Deckel od. fast kuglig, rauh, Wandmeg mit Kalkköntelen u. knorpelig, wenigstens am frounde. Kapillitim mit grolin Kalkknoten, die dureh + verzweigte hyaline Fäden verbunden sind. In der Mitte des sporangiums mehr Kalkknötehen, so daß eine drt f'olnmella zustande kommt.

Plasmodimm gelb. Sporangien gestielt, aufreeht herhert.. ().7 his $1,5 \mathrm{~mm}$ hoch mit stiel, glatt, oeker-bis muliham orl. griülich brantul. Auf faulem Hlolz, Laub usw., zerstreut, (Fig. 2s.)

\section{L. minutum (Lepes)}

Plasmodimm gebb. Fporangin grestiolt, eit. ml. kreiself., I mm loeh mit Stil. rothraun mit weifen Kalkablagermegen u. gellen Warzen auf der oheren Ilälte. Auf faulen Laul, nicht selten.

('. leucoepplatum (l'ers.)

\section{Gattung: Physarum Person.}

Sporangien gestielt, sitzend or. plasmorlinartig. Wandumb doppelt, Kalkkörnchen gruppenwoise eingelagert. Kapillitimu „in hyalines Netzwerk mit kalkhaltigen Netzknoten.

Lindau, Kryptogamenflora II. 1. 2. Aufl. 
1. Norpanterien sitzend.

2.

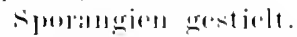

i.

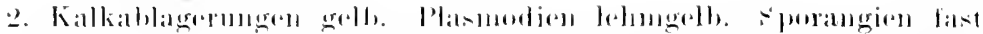

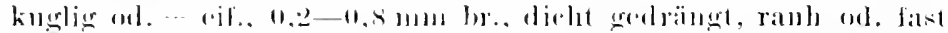

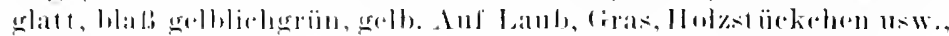
zorstremt.

I. virenern- Ditul.

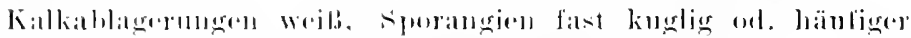

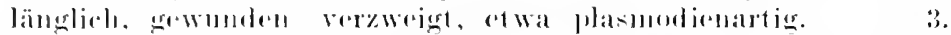

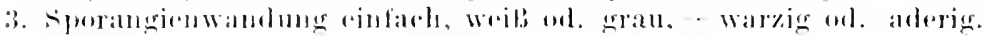

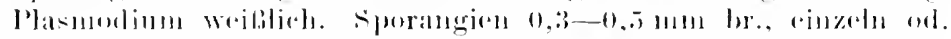

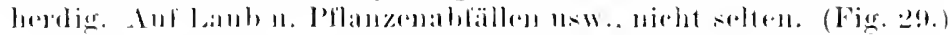

P. rimerenul (Batsill)

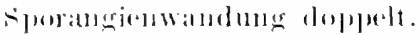

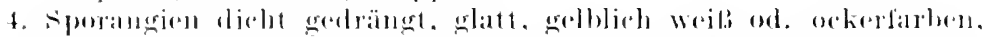

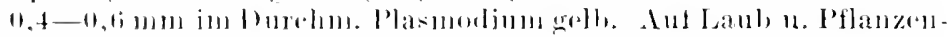
ahfii]l+11. \%(1) $=11013 t$

l'. eontextum Pers.

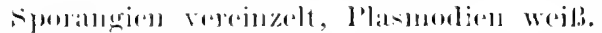

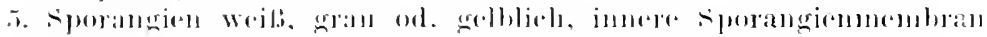

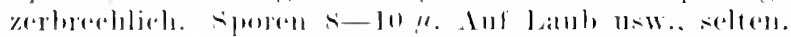

l'. -immanm (Bull.)

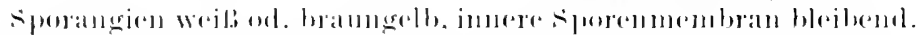

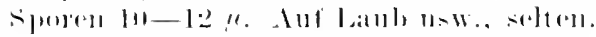

P. didermal lion.

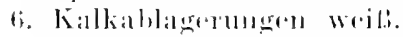

Kalkablagerumgen nirbit wajli.

si.

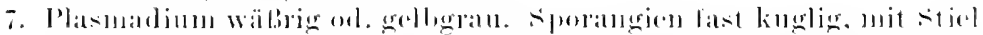

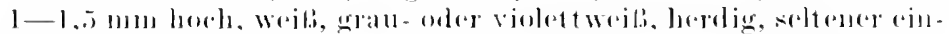

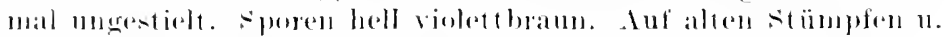

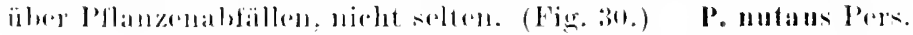

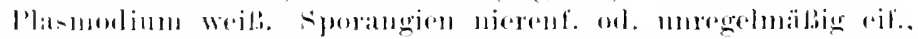

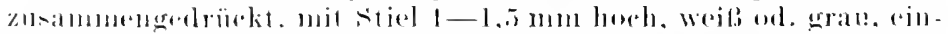

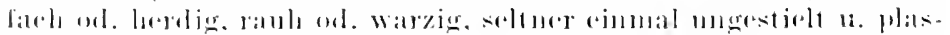

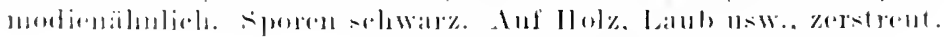

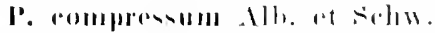

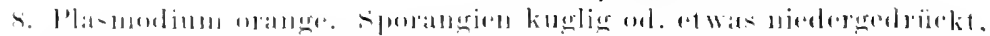

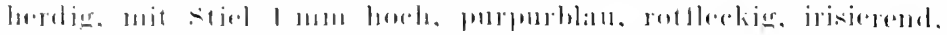

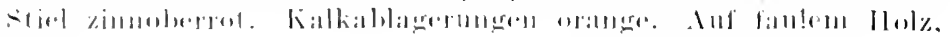
s.lin.

P. pittallumm Ditul.

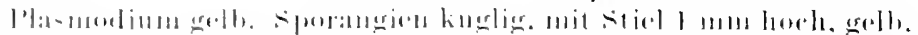

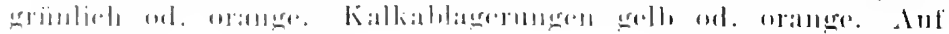

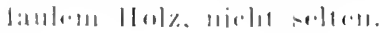

I'. viride (limel.)

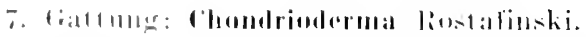

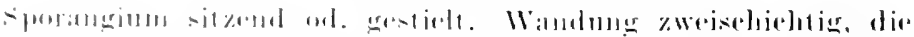

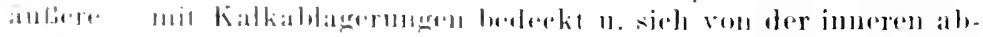

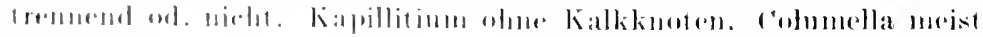
ballikuelie. 


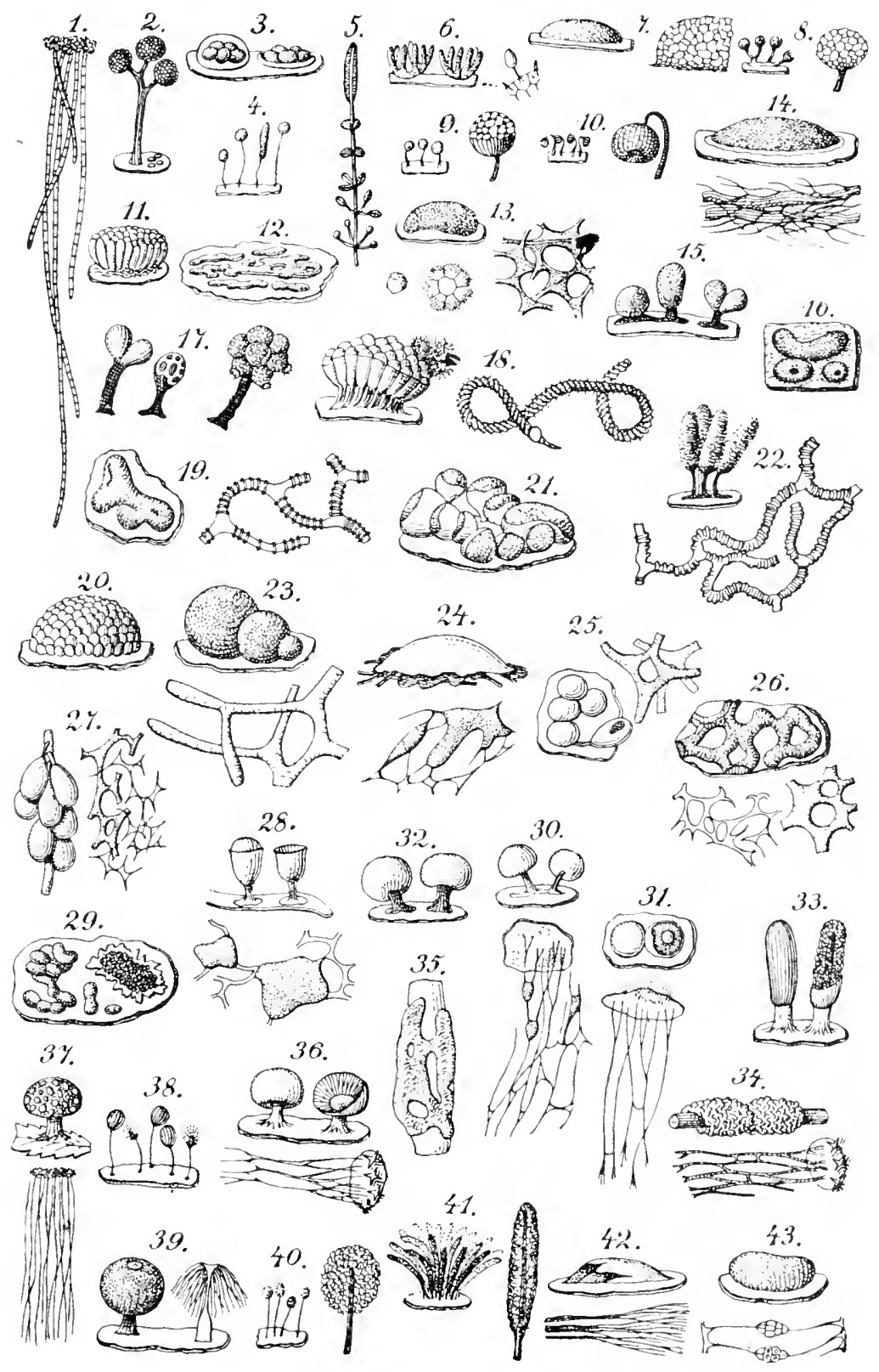




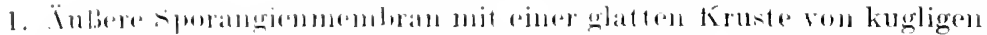

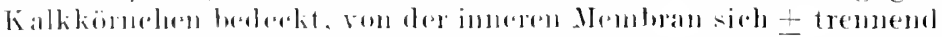

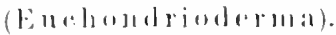

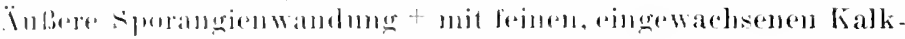

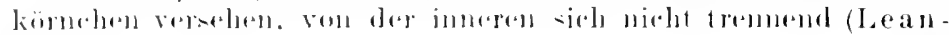
:

2. Simoralugient woili.

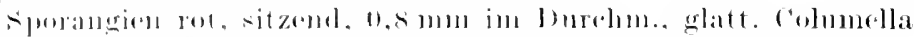

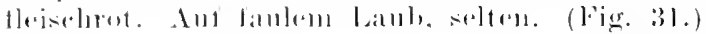

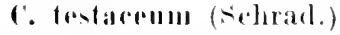

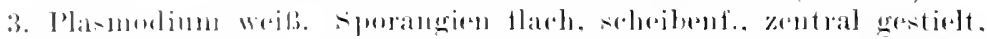

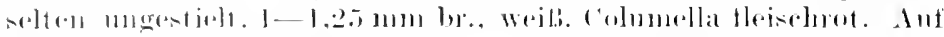
lamlan latub. niclat saltall.

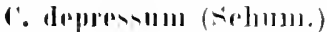

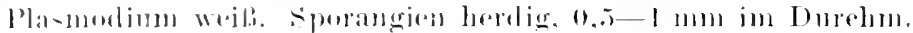

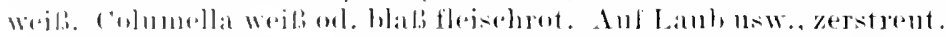

('. smmmarioidss (Fries)

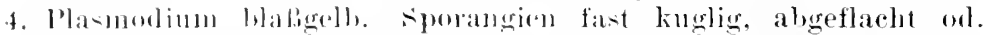

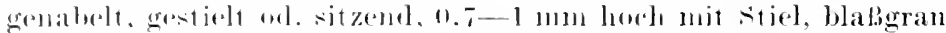

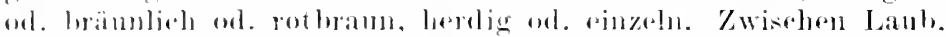

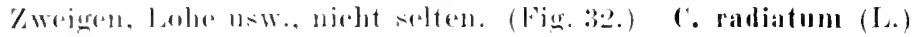

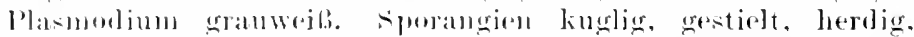

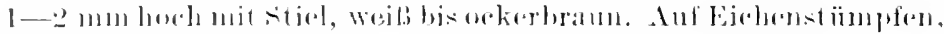
sillem.

(. Iloriformo (Bull.)

\section{h. Crattomes: Mialdora Fries.}

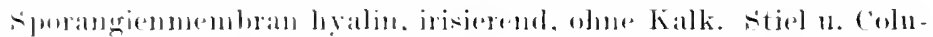
mella mit Kalkablagrermende. Kapillitimm riu purjumes Netzwerk

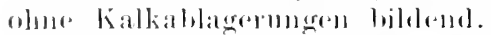

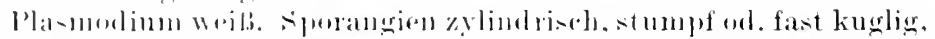

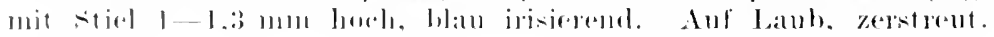
(ligr. :3:3.)

1). Iencopoula (Bull.)

\section{Familie: Didymiacear.}

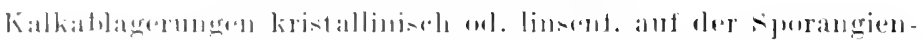

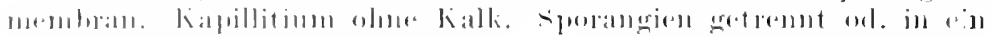

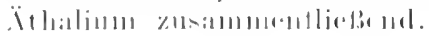

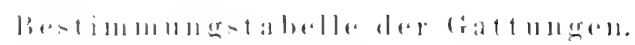

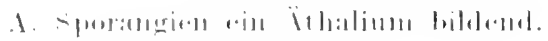

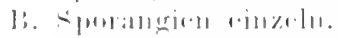

(1) Kislikiristill, -10111.

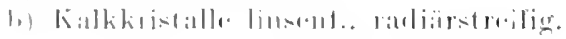

1. Nimunaria.

․ Iridyminm.

3. I.piniloulroma.

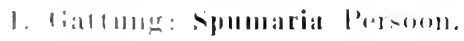

liallihi-1:all. - -11.1ul.

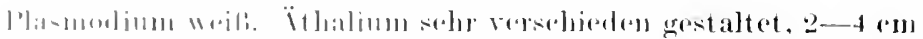

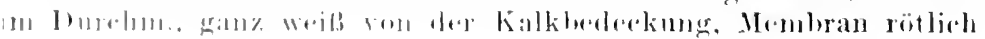


od. weiß. Kapillitimn weit netzf., purpmbram. Anf Laub, Moosen, Gräsern usw., hänfig. (Fig. 34.) s. alba (Bull.)

\section{Gattung: Didynuimm Sehrader.}

sporangien gestielt, sitzend od. plasmodienähnlich. Kalkkistalle zerstrent anf der Oberfläche. Kapillitium netzf. mit Verdickmngen, aber ohne kalk.

1. Sporangien niemals plasmodienälnliclu. stets gestielt. sporangien niemals gestielt, stets plasmodienähnlich or. pol. sterf.

Sporangien sitzent or. plasmodienähnlich od. westielt, nipmals aber damn scheibig od. der stiel hormartig.

‥ I'lasmodium gran. Sporangien rereinzelt, seleibig, anf zentralem Stiel. 0,4-11,8 mm mit stiel hoch, wanweis, mit einzelnen bramen Kristallhaufen. Stiel blabbram od. schwarz, längsstreifig. Colnmella \pm fehlend. Anf Laub. Hoos usw., selten.

\section{I). colarus (Alb. et seliw.)}

Plasmolium grau. Syorangien halbkuglig, genabelt, herdig. 1-1.5 mm mit stiel hoch, weil.s. Stiol tief dunkelgrünbram bis orange, hornatig durchscheinend, längstreilig. Colmmella halb. knglig. Auf laab. zerstreut.

D. nistipes (Link).

3. Plasmorlimm farblos or. blabgedb. Suorangien kissent. od. unregelmäßig verlängert n. plasmodienartig, bis 2 mm lang, glatt. weili, aulen mit einer zuxamnenhängenden, porzellanartigen Lage von Kalkkristallon ïberzogen. Sporen $11-1+\mu$ İles Lanb. Stengeh usw. zerstreut.

I. difforme (Pers.)

Plasmodium lelmogelb. sporangien niedergedrürkt, ansgehreitet plasmodienähnlich, 2-s mm br., od. netzf.. wurmf., gran. andeu mit zerstrenten Kristallablagerumgen. Sporen 7-9 ". Inf Laul, zejstrent. (1ig. 35.)

D. Complanatum (Jatseh)

4. Plasmodium grau. Sporangien halbkuglig. tief genabelt, gestielt, herdig, 0,5-1 mm hoch. od. fast sitzend u. zusammentliebent. weib ol. gran, auben mit zerstrenten branroten kristalluanfen. Stiel u. Colnmella dunkelhram. Anf Laub, Rinde nsw., nicht selten.

b. farinaremu sehrad.

Plasmodimm granweil. Sporangien luabkuglig, wenabelt, gestielt od. sitzend, $1,5-1 \mathrm{~mm}$ hoch, of. ausgebreitet plasmodienähnlich, herdig, schneeweiß durch die lockej zusammenhängenden Kristan ablagermgen od. gran, wenn die Kristalle spälicher anfsitzen. stiel u. Colnmella woil. Anf Laub, hänfig. (Fig. 36.)

D. semamulosmu (Alb. et sehw.)

\section{Gattung: Iepidoderma de Bary.}

sporangien gestielt, Membran knorpelis, zweiseluchtig, mit ober. fläehliehen Kristallablagermoen. Kajillitim verflorhten, ohne Kalli. 


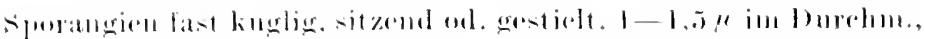

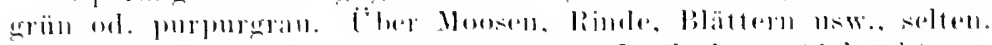
(lig. 37.$)$

I.. ligrimum (s.luall.)

\section{Familie: Stemonitarerar.}

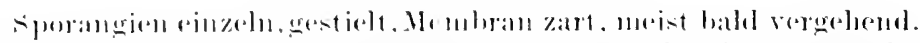

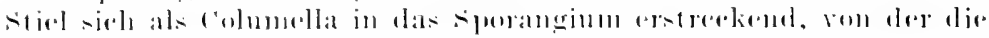

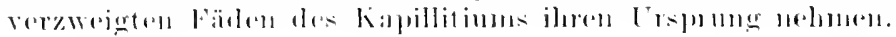

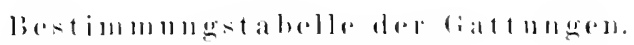

1. Stelelur bis e.1

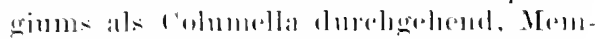

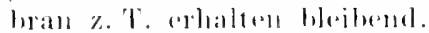

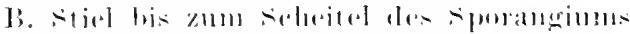

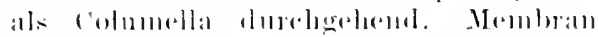
reröanglirlı.

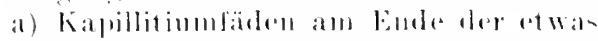

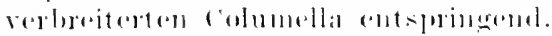

b) Kapillitiuntatelu mella (not-pringandel.

1. Kappillitimmfarelu nifelu notzl. an1

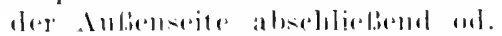

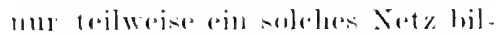

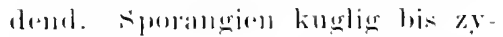
lindriscls.

1. Lamprombrima.

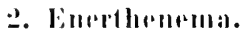

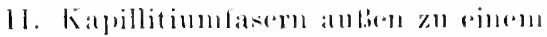

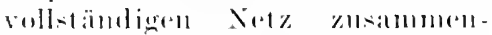

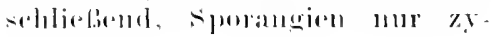
linulinish.

\section{3. ('orlatrichas.}

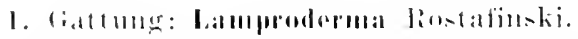

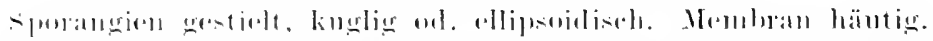

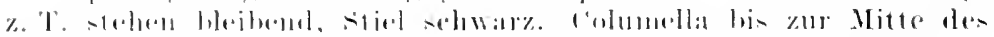

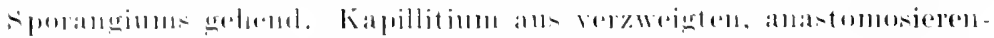

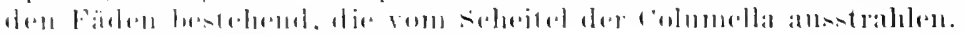

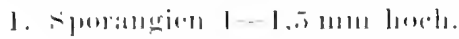

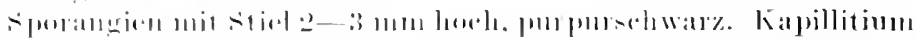

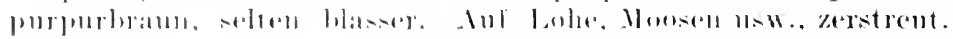

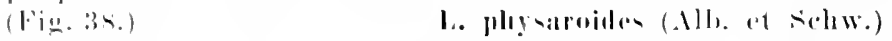

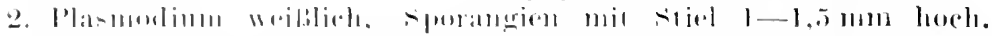

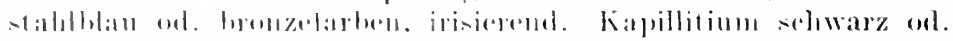

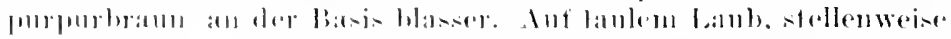

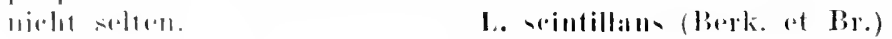

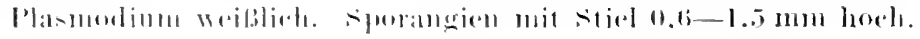


violett od. bronzefarben. Kapillitium farblos, seltner dunkler, an Her Basis nicht blasser. Auf faulem IIolz, Laub usw., zerstreut.

L. arcyrioides (somm.)

\section{Gattung: Enerthenema Bowman.}

sporangien gestielt. Colnmella durchgehend, vom scheitel ihres erweiterten Endes entspringend.

Plasmodium weißlich. Sporangien kuglig, nit stiel $1-1.5 \mathrm{~mm}$ hoeh, selıwarz. Stiel u. Kapillitinu schwarz. Anf faulem Holz, selten. (Fig. 39.).

E. papillata (Pers.)

\section{Gattung: Comatricha Preud.}

Sporangien zylindriseh his kuglig. herdig od. einzeh. Cohmella bis etwa zur spitze siel erstreckend, anf ihrer ganzen Länwe die Kapillitiunfasern entstehend, Iie sich netzf. veremigen, aber kein oberflächliches Netzwerk bilden. Stiel schwarz.

Plasmodiun weidslich. Sporangien kughig bis zylindriseh, mit Stiel 1-6 mun hoch, purpurhraun. Kapillitium purpurbranu. Sporen fast glatt, 7-11" Anf faulen Holz, zerstrent. (Fig. 40.)

\section{(C. nigra (Pers.)}

Plasmodium weißlich. Sporangien zylindrisch, stmmpf, nit stiel 2-3 mm hoeh, silbrig, dann brann, hertig. Kapillitiun blaf braun. sporen mit wenigen Wärzehen, 3.5-7 duf faulen Holz, loäufig.

\section{C. typhina (Wiggers)}

\section{Gattung: Stemonitis Gleotitsch.}

sporangien zylindrisch, gestielt, herdig. Stiel durchgehend, Kapillitium anf der ganzen Länge der collumella ausstralılend $u$. auch an der Oberfläche ein Netzwerk bilfend. Stiel schwarz.

1. Sporen mit wenigen Wärzehen rersehen.

Plasmodinn weiß. Sporangien purpunsehwarz, 1 it Stiel $2-5 \mathrm{~mm}$ hoch, meist büschelig. Kapillitiun dunkelbram, an der Oberfläche mit einigen Netzmaschen. Sporen gran od. rotviolett, stachlig, mit \pm netzf. Oberfläche. Auf laub, llolz, Abfälen. läufig. (Fig. +l.)

S. Ioscal Roth

2. Plasmotium gelblich weis. Sporangien purpurbrann, mit stiel (i-12 mm hoch, zuerst büsehlig. Kapilhitium purpurbrann, an der Oberfläche mit rundlichen Netzmasehen und anhängenden Resten der sporangienwand. Sporen blaf rötlich purpurn, fast glatt. Auf faulem llol\%, seltuer.

s. Halceidal (List.)

Plasmodium zitronengelh. Sporangien kurz gestielt, zimmet. brann 5-7 mun mit Stiel loeh. Kapillitiom bram, an der Oberfläche selı feine eekige Netzmaschen bilıtend. Sporen bla fibräunlich. spärlich warzig. Auf Laub u. Holz. nicht selten. 


\section{Famile: Imamrochataceare.}

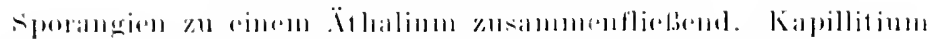

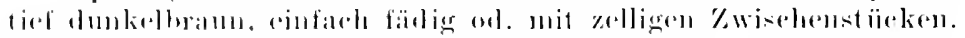

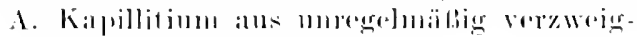

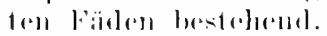

\section{Amanroreharta.}

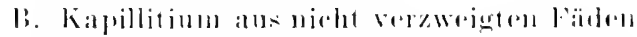
bestehand. die im verlinf zollige \%wi-

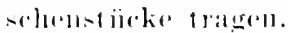

\section{Brofililia.}

\section{Aattmong: Amamrochaneto Romatimslit.}

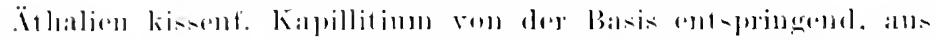

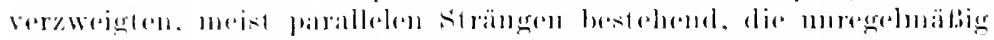

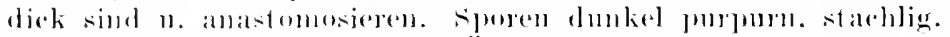

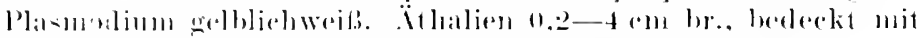

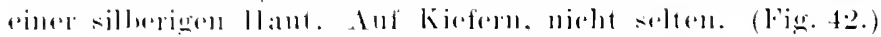

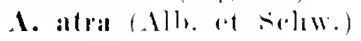

\section{Ciaftumg: Brofollial liostalinski.}

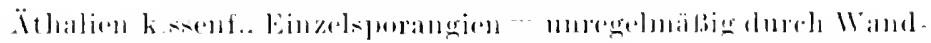

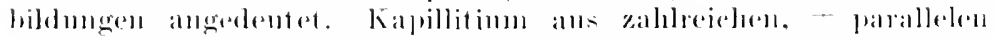

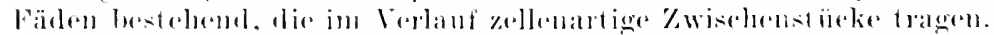

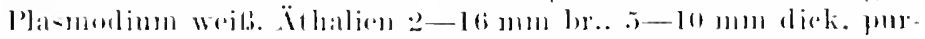

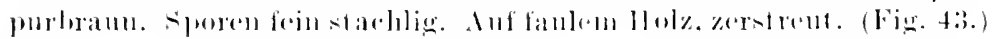

B. III villa (Fr.)

\section{Abteilung: Humycotes (Fadenpilze).}

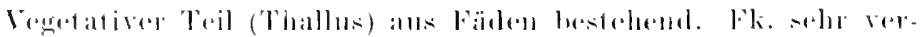

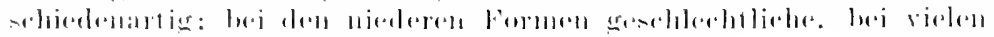

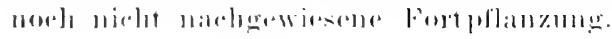

\section{Klasse: Phycomycetes.}

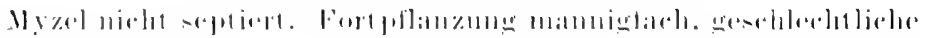

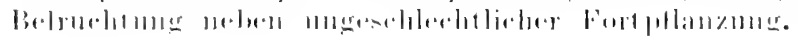

\section{Unterklasse: Oomyertes. 1. lirilu: Chytridiintare.}

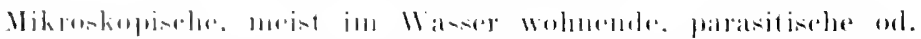

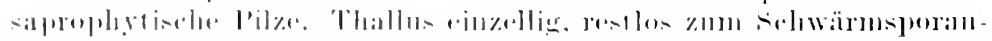

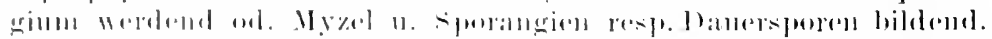

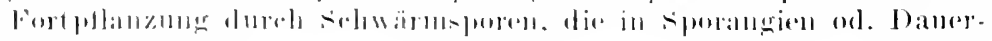

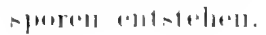


Bestimmungstabelle der Familien.

A. Thallus nie myzelartig: sondern anfangs ans nacktem Plasma bestehend, das sich rist kurz vorder Fruktifikation mit einer llant nmgib". ol. von Anfang an mit feiner Hant, bei ler Reife ein Sporangium orl. eine Danerspore ol. einen Hanten derselben billend.

a) Th. lange naekt, amöboid, bei der Reife als ganzes od. in einzehen stücken zum sporangimm ot. zur Danerspore werdend. Schwärmsporen zweigeilslig.

b) Th. sehr frïhzeitig mit Membran umgeben. Schwämsuoren fast stets eingeillig.

1. Th. sich in ein einziges sporangimm resp. Danerspore nmwandelud. Parasitiseh, meist aut Algen.

II. Th. meist knglig, gefärbt, bei der Reifo in eine Danersure umgebildet oul. narh Zerfall des Plasmas eine Anzahl ron sporangien bildend. Parasitisch, meist in Lanilpflanzen.

B. Th. in ein meist feines, diunfädiges Myzel n. in sporangien n. Danersporen gesliedert, rom Infang an mit Membran

a) Myzel dïnntïdis, zart, wurzelartign verzweigt, mit spitzen Enden, wenig ansgerlehnt $u$ mit den sporan gien (wenigstens anfangs) in oflener Verbindmo. Sporangien fist stets einzeln, selten mehrere durch Durehwachsung gebiklet. Danersporen ähnlieh wie die sporangien. Mrist l'ara. siten.

b) Myzel mit stammartiger IIanptarhso od. sehr reich rerzweigt u. weit ausgedehnt.

I. Myzel aus Hauptstamm u. Seitenzweigen bestehend, ron den sporangien dureh Wand abgetremt. sporangien terminal, moist einzeln sapuphyten.
(Myxochytrilimeate)

1. Wormuinacoar.

2. (1)pidiacear.

3. Symohytrialcaite.

(Ilycoehytridiingar)

4. Rhizidiarous.

5. Ilyphorhytriatoalo 


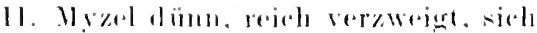
weit enstreckemel. stets mit interkalatru onl. terminalen Jnselewel. lumeren rersellen, dis in 2 lis

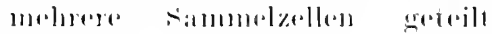
wrrelen. Parasiten u. Sajuro. plintin

fi. Clablescliytrianeale.

\section{Familie: Woroninarear.}

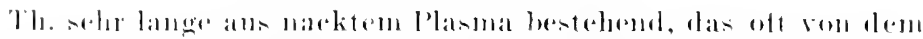

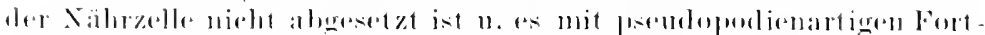

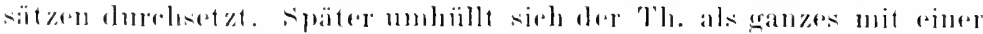

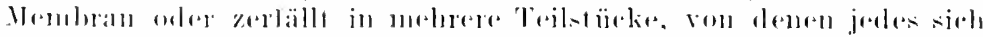

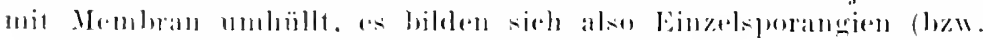

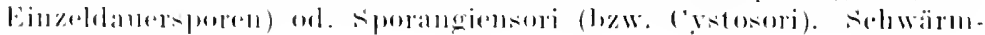
-porem zwrigerililig.

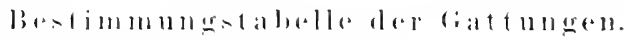

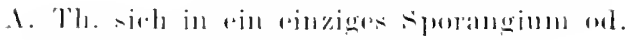
l)anelismore

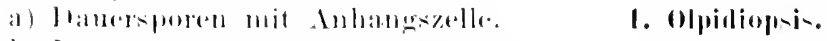

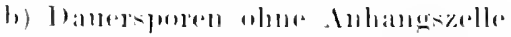

2. Premlolpislium.

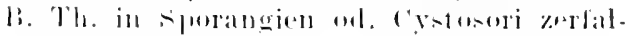
lonil.

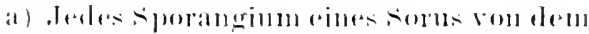

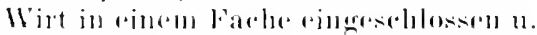

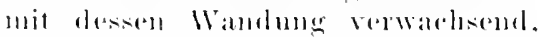

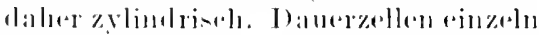
tarliling.

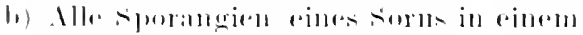

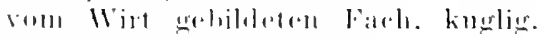
1):111\%\%ellen in II:alen.

\section{Rozulla.}

\section{t. Noromina.}

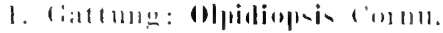

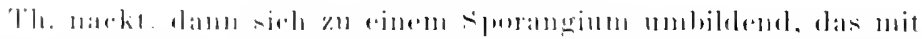

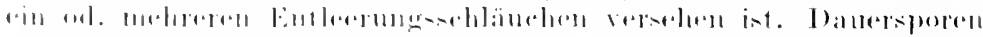

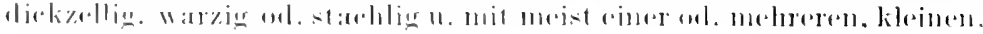

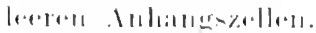

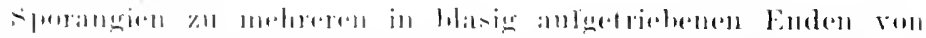

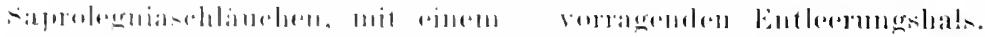

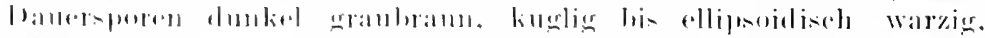

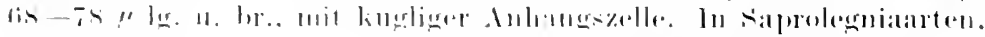
lı̈illtig.

(1. -atprolesuiar ('olm

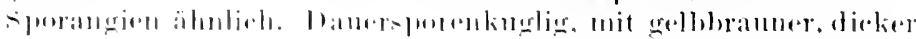


Membran 1. spitzen Stacheln, $60-40 \mu$ Durchm., mit kugliger od. ellipsoidischer Anhangszelle. In Achlyaarten, selten. (Fig. 44.)

0. ninor A. Fiseh.

\section{Gattung: Psemdolgidium A. Fisch.}

Ton vor. Gath. durch das Fehlen der Anhangszellen bei den Danersporen verschieden.

In Saproleguiaarten, nicht selten. (Fig. 45.)

In Achlyaarten, ebenso.

P. saprolegniae (A. Br.)

In Aphanomycesarten, ehenso.

I. Prsilorme (Cornu)

P. aphanomyis (Cormu)

\section{Gattung: Rozella Comn.}

Der Inhalt der schwämspore tritt in die Mrirsolle llureh den feinen Inlektionsschlauch ein n. teilt sich nach vollendetem Wachs. tum in viele Einzelpartien, die die Wirtszelle mit einer Wand roneinander abschliefs. Tede so abgeschlossene Plasmaportion ungibt sich mit einer Wand, welche mit den von der Wirtszelle gebildeten Wandungen eng verwädlst, u. wird zum sporangimm. Dauersporen lose in den Fäthern einzeln liegend hrann, klemstachelig.
In saprolegnia, zerstrent.
R. septigena Comm

\section{Crattung: Woronina Comn.}

Der eingedrungene Parasit wirl im ganzen dureh Wandungen inoliert mol bildet in Fach einen sporangien-od. Cystosorus.

In saprolegnia, nicht selten. (Fig. 46.) W. polyeystis Cornu

In Vanclieria terrestris n. sessilis, seltuer.

$$
\text { W. glomerata (Cornu) }
$$

\section{Familie: Olpidiaceae.}

Th. zelur frïlızeitig od. von Anfang an mit Membran ungeben 11. vom Plasma des Wirtes abgegrenzt, bei der Reife sich in ein einziges sporanginm (hzw. Danerspore) unwandelnd. Sehwärmsporen ein. geislig.

Bestimmnugstabelle der Gat tungen.

A. Danersporen mit Anluangselle.

1. Pseudolpialiopsis.

B. Danersporen ohne Anliangszelle.

a) sporangien frei in der Xährzelle liegend.

I. Sporangien mit vielen Entleernugsschläuchen.

1. Sprorangien sehlanchf., Entlee. rumgsschläuche kurz, in Reihen stehend. 


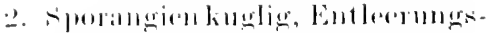

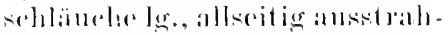
lonel

\section{Plootrandalus.}

11. Smorangion mit weniernu (1-3)

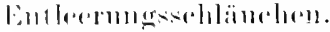

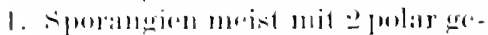

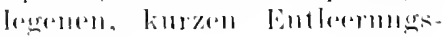
papillon.

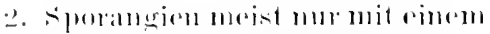

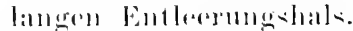

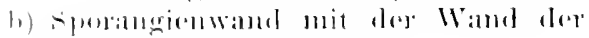

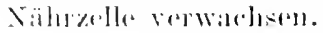

\section{Sinhareritar.}

\section{Olpldium.}

\section{Plrolpioliun.}

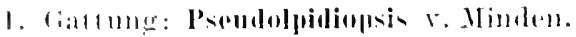

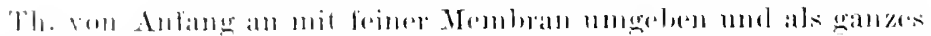

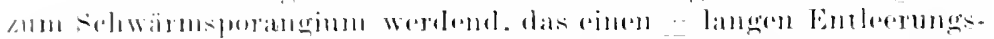

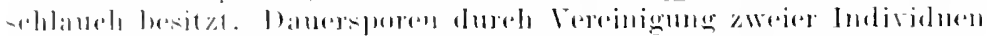

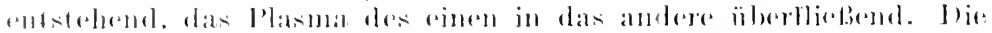

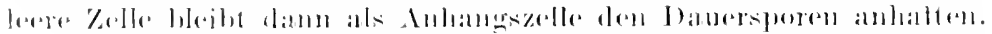

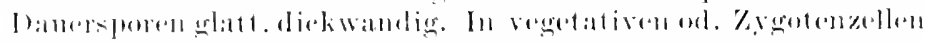

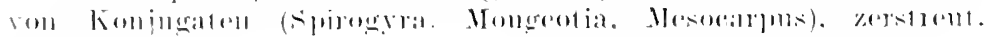
(lin. 17.$)$

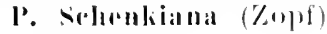

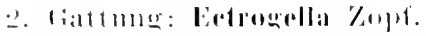

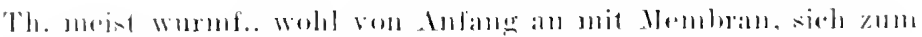

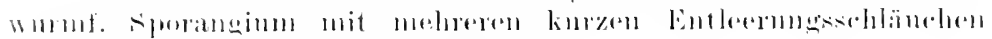

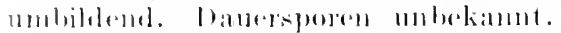

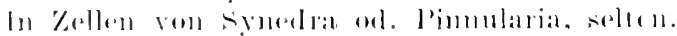

E. hacillariarearmul \%(1)

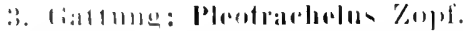

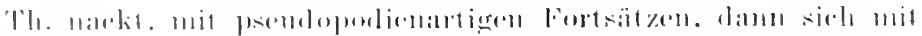

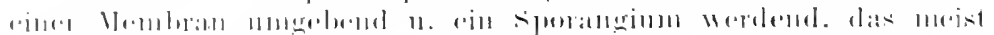

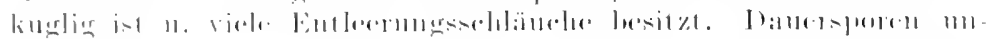
|whillull.

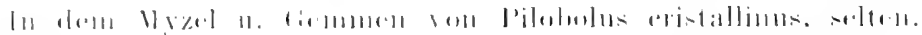
(l’ie. Is.)

l'. rulands \%opl

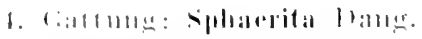

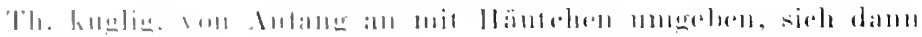

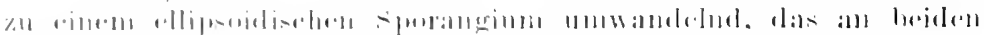

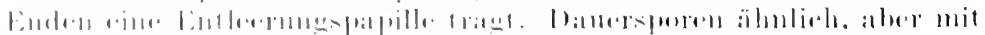

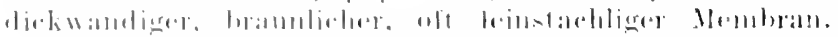

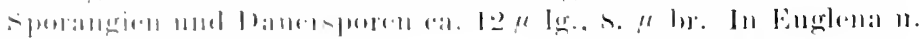

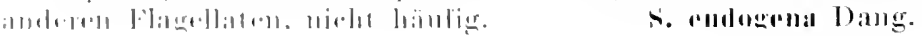




\section{Gattung: Olpidium A. Bramu.}

Th. nackt, sich später mit Nembran umgebend n. zum sporengimm (bzw. Danespore) werdend. Sporangien kuglig od. ellipsodisch. feinwandig, mit einem langen Entleerunghals. Danersporen knglig. glatt wl. warzig.

1. In vegetativen hellen ron Phanerogamen vorkmment. 2.

In Pollenkïrnern u. Pilzsporen vorkommend. 3.

In Algenzellen vorkommend.

In tierisehen Eiern vorkommend. 7 .

2. In den Lellen des Wurzelhalses junger Kohlptlanzen, die dadureh fanlen $n$. unfallen (schwarze Beine des Kohl), bri zu dichtem stande in den Frühbeeten, nicht selten. F. (Fig. 49.)

O. brassicar (Worom.)

In den Zellen von Blättern, Blatt- n. Blütenstielen von Trifolimm repens, solowielen n. Auftreibmugen vermalchent. Seln zerstrent.

(o. trifolii steluoet.

In den zellen von Lemma minom noyluriza, selten.

o. Iemuale (Fiscli)

3. In den Uredosporen ron Pnecinia-Arten selten.

o. Iredinis (1.agh.)

In Pollenkörnern.

4. Spwrangien $\mathrm{zu} 1-12$ in einem Pollenkorn. Zoosporen 4-5 " in Durehm. Damersporen mit glater, doppelt kmomierter, dicker Membran. Anf Pinuspollen in Wasser, selten. (1ig. 50.)

\section{0. pemdulum $\mathrm{Zopl}$}

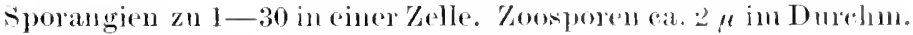
Danersporen mit einer eng anliegenden Justuhan 11 . Weit davon abstelenden, glatten Aubenluant. Anf in Wasser liegenden Pollenkörnern der verschierlenestı Pflanz'n, hïnfig.

0. Inxurians (Tomasch.)

5. Entleermughals der Sporangien nicht blasig anshwellend. 6.

Entleerungshals der sporangien vor dem Austritt ans der Nältrzelle blasig anschwellend, dann wieldr verengt. Danersporen mit glatter Membran n. weiter, blasenf. Miille. In Kellen von ver. schiedenen Desmidiaceen hänfig. O. endugrnmm 1. Branm

6. In Zellen von Zygnmma, selten. O. zyænemiona Magn.

In Zellen rom Spirogyra, Cladophora, Vaucleria, nicht seltum.

0. entopleytum (A. Bramu)

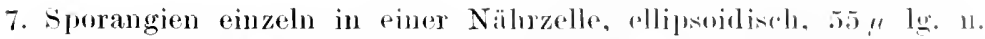
30 p br., mit sehr langem Entleermoshals. In Rotatorieneiern. seltell.

(). IIaterospertum (Nowak.)

Sporangien zu 12 u. mehr in einer Nälnzelle, knglig bis ellipsoi disch, 30-70 C jo Durelnn., mit selur kuryms, schmabell. Ent leermgshals. In Rotatorieneiem zerstrent. O. srengimm (Nowak.) 


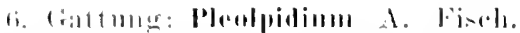

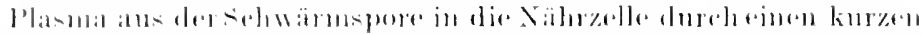

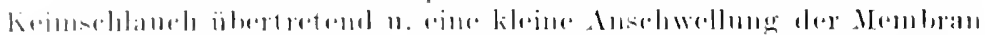

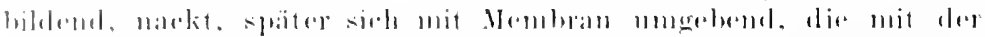

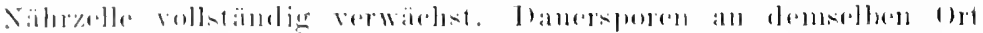

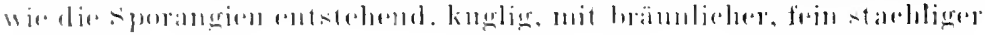
114mlin:all.

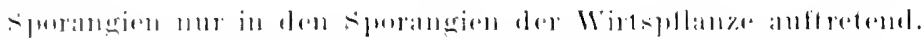

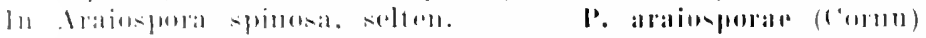

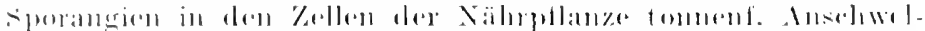

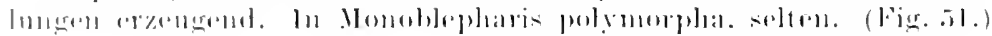

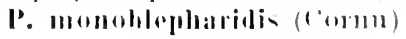

\section{Familie: Syurhytriareare.}

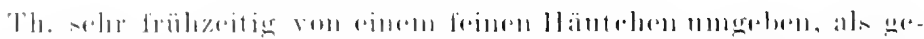

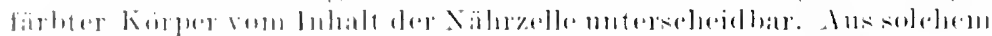

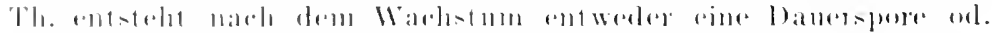

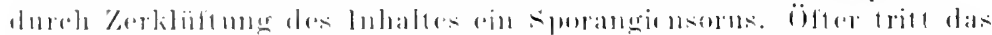

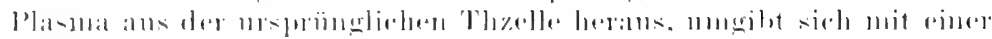

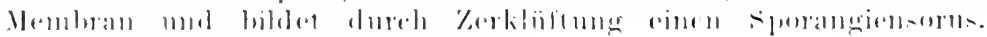
sill

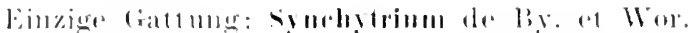

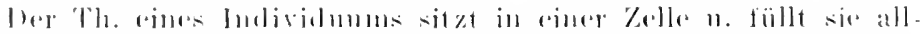

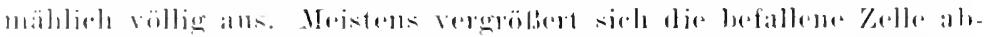

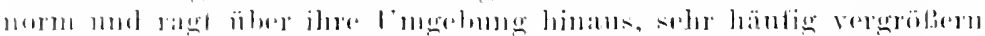

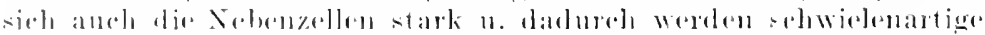

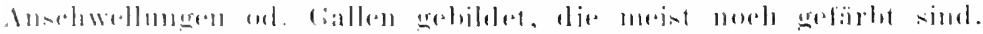

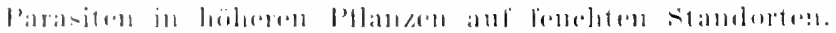

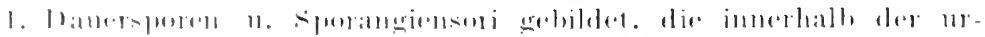

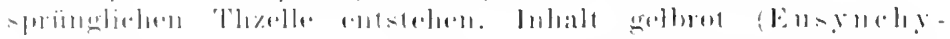

11 i 11111

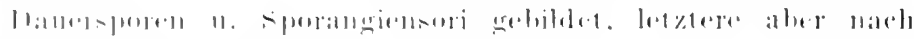

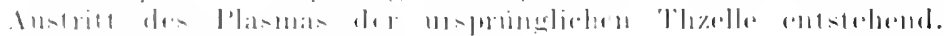

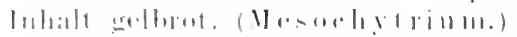

3.

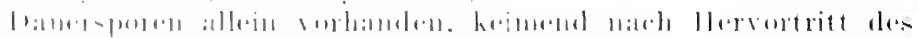

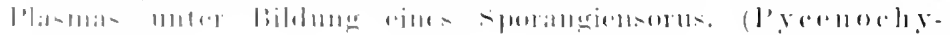
(1) 1113111 .

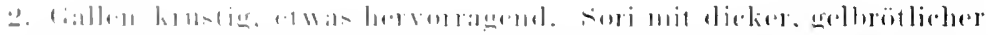

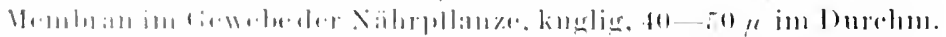
|

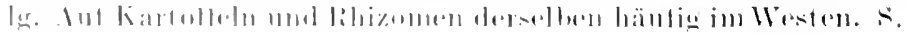

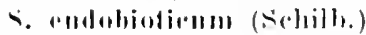

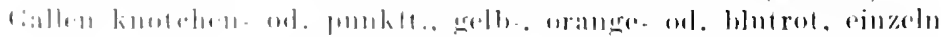

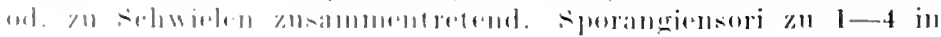


der Nährzelle, etwa kuglig, $40-250 \mu$ im Durclum., rot. Danersporen knglig, bram, 50-80 $\mu \mathrm{im}$ Durchm. Schwärmsporen rot. An allen oberirdischen Teilen von Taraxacum officinale, zerstrent.

S. taraxali de By. et Wor.

Gallen ähnlieh. Sporangieusorus 60-100 $\mu$ im Durehm. Danersporen ähnlich, 66-82 $\mu \mathrm{im}$ Durchm. In den Blättern von Oenothera biemuis, niclıt häufig.

s. fulgens sehroet.

3. Gallen einzeln, als goldgelbe Punkte erscheinend od. zu streifen u. Krusten vershmolzen. Hervortretende Plasmakörper rot. 100-170 $\mu$ in Durehm. Dauersporen mit bramer Jembran 1. rotem Inhalt. Sehwämsporen rot. Auf allen oberirdischen Teilen ron succisa pratensis, nicht selten. (Fig. 52.)

$$
\text { S. succisar de by et Wor. }
$$

Gallen länglich halbkuglig, einzehn punktf. oder zn Krusten zusammenfliebeud, gelbrot od. kastanienbram, je nach dem Vorhandensein ron sporangiensui od. Danersporen. Ilerrortretender Plasmakörper rot, 80-150 "l in Durehm. Dauersporen 11. Schwärmsporen ähnlich. An den oberirdischen Teilen von Stcllaria media n. nemorum, nicht lıänfig.

\section{S. Stellauian Furk.}

4. Inhalt der Danersporen gelb od. rotgelb (Chrysorluytimm) $\therefore$.

lulalt der Danersporen farbles (Leucochytrium) @.

万. Danersporen die ganze Nährelle voll anfülleml. (tallen halbkuglig oder zylindrisch, zusammengesetzt.

ii.

Danersporen lowe in der Xährzelle liegend. Gallon klein. einfach. nur aus vergröberten Epidermiszellen bestehand.

6. Crallen knötchent., orange- od, goldgelb. gleichmälig verteilt. selten zusammenfliflend. Danersporen mit kastanienbrannes Ifembran u. goldgelbem Inhalt. Bei der Keimung tritt das Plasma in Form einer umrandeten Blase hervor n. zerfïllt in zalulreiche sprrangien, diw durch Platzen der Membran frei werden. An häufigsten auf Lysinachia nummularia, aber daneben anf zahl rejchen anderen Pflanzen fenchter stantorte, hänfig.

\section{s. anuenum sinot.}

Gallen habkuglig bis zylindriseh, einzehn od. zusanmenfliobent. anf dem Scheitel mit einem Büschel einzelliger II are. Daus' sporen ähnlich. Auf den oberirdiselen Teilen von l'otentilla tormentilla seh zerstrent.

s. pilifionm Thomas

7 . Gallen haarartig vorspringend.

Gallen flach punktf.. sehwefel- bis goldgelb. mur aus einces pinzigen, wenig vergröberten Zelle bestehend. Daursporen zu 1-3 locker in der Nährzelle, goldgelb, 28-200 " in 1) mrlm. Auf den oberirdischen Teilen von Gagea-Arten, nirht selten.

\section{S. laptum sebloret.}

8. Gallen aus haarartig answachenden Epidermiszellen bestelend, die oft krustige Knötchen bilden, gelbrot bis schwarzlyaun. Daner. sumen meist einzeln, 70-136 $\mu$ ju Durchm., mit bramer Wen- 


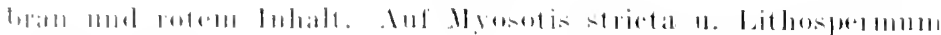

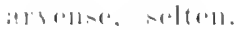

S. ImyoutidivKiblu

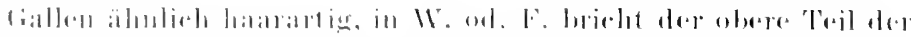

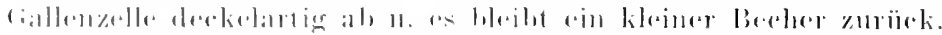

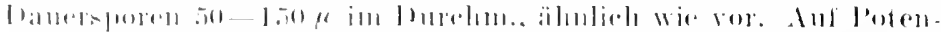

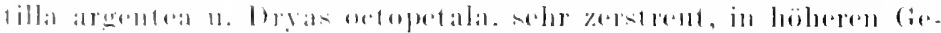

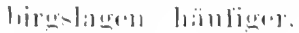

s. porrotillare (sichoret.)

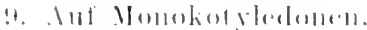
111.

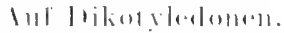
11.

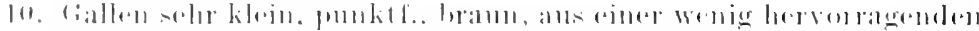

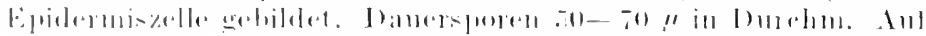

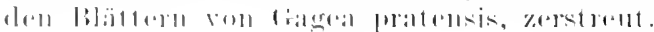

S. puncetatum sirluroet.

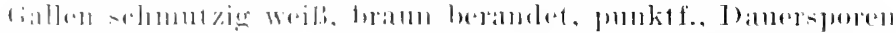

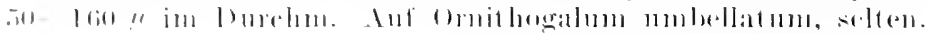

S. Nirmlii linb.

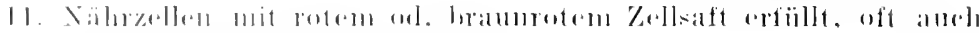
nesele dir bellathlouten Kellem.

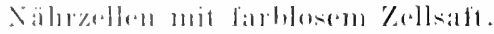

13.

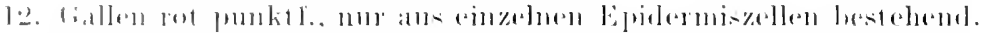

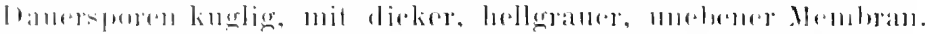

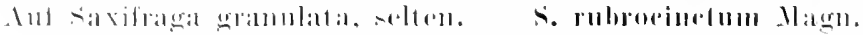

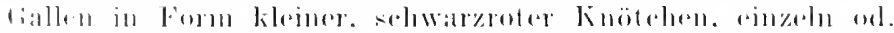

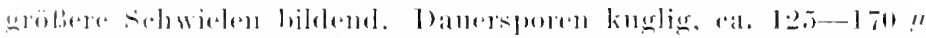

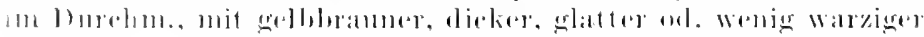

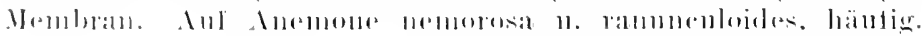

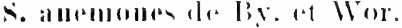

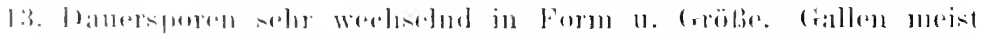

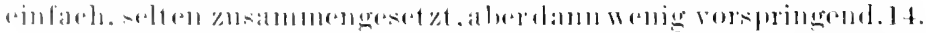

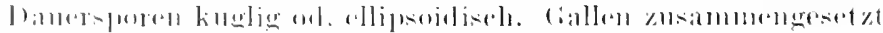

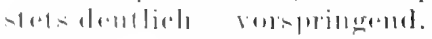

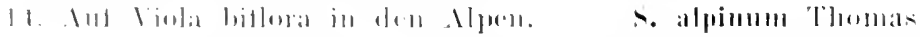

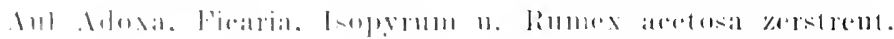

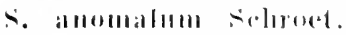

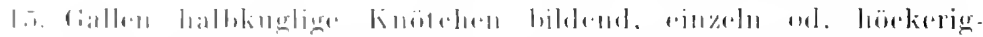

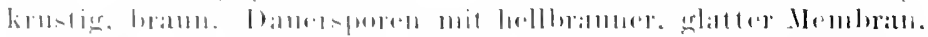

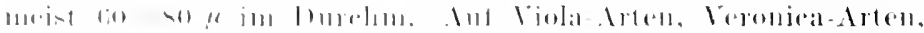

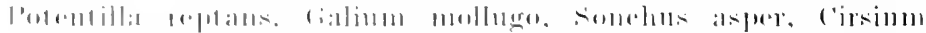

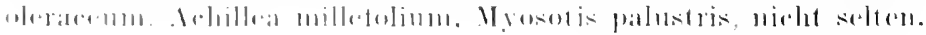

s. elohomum selorort.

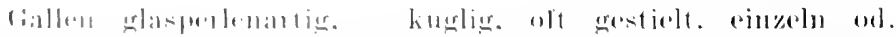

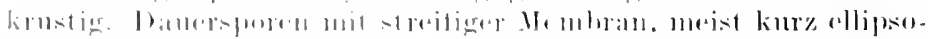

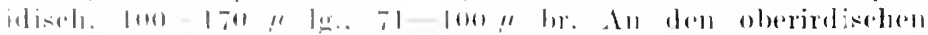

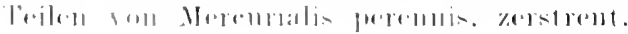

S. morrarialic (Lib.) 


\section{Familie: Rhizidiaceae.}

IIyzel dünn, zart, meist wurzelartig, mit spitzen Enden, wenig ausgedehnt, meist nur anf eine Nährzelle beschränkt, mit den spo. rangien meist bis zur Reife in offener Verbindung. Sporangien stets in der Einzahl, selten mehrere durch Durehwaehsung nacheinander. Danersporen meist wie die sporangien entstehend.

\section{Bestimmungstabelle der Gattungen $\mathbf{l}$ ).}

A. sporangien u. Dauersporen in der Yährzelle entstehend (Entophlycteae).

a) Dauersporen glatt. Sporangien 1. Dauersporen ohne subsporangiale Blase.

1. Eutophlyetiv.

2. Diploplilyctiv.

B. sporangien u. Dauersporen aulierhalb des substrates gebillet, selten letztere intramatrikal.

a) Myzel nur aus dem zarten Stiel (Keimschlauch der spore) u. einem winzigen seheibigen Haust or bestehend( $\mathrm{H}$ a r poehytrieae).

3. II arpochytriun.

b) Myzel verzweigt,fädig, zart od. gröber. wemn $n m$ hanstorienartig. dam gröber u. größer.

I. Myzel äuferst zart, wurzelartig. wenig ansgedehnt, seltener ans büschligen Hanstorien bestehend (Rhizophidieae).

1. Myzel anf ein nuverzweigtes, nadel- od. bläschenf. Haustor beschränkt.

2. Myzel stets verzweigt wurzelartig.

a) Sporangien ohme subsporangiale Blase.

Sehwärmsporen hüpfend, Geißel nachsehleppend. $\S \S$ Schwärmsporen nicht hüpfend, GeiBel vorn befestigt.

$\beta$ ) Sporangien mit einer sub-

\section{Phlyctidium.}

\section{Rhizophidium.}

\section{Latrostinu.}

1) Da sich die Unterfamilien nur durch minimale Untersehiede elarakterisieren, die oft noch variieren, so vergleiche man bei der Bestimmung die Abbildungen.

Linda u, Kryutogamenflora Il, 1. 2. Aufl. 
sporamgialen, moist intramatrikalun lilar.

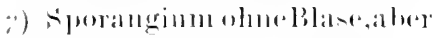
mit derutieherm stiel.

\$ spentangirell mit selueited.

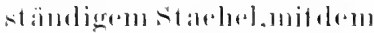
stirl inoffener Verbindmum.

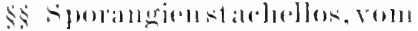
stiel durele rint 1 rimint.

\section{Phlỵtuchytrium.}

\section{จ. Abelidiun.}

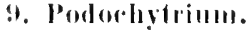

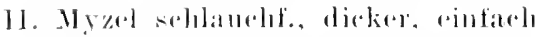

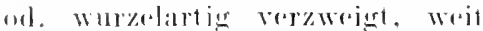
ansegedeloul, selfenerestratlat rikal

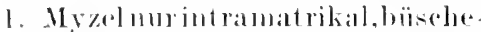
lierfabliy od. eliek mehlaurhl.

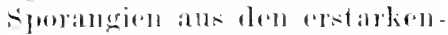

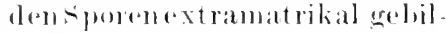
de1, 1):merefuren intramatrikal (c) li y lidirace).

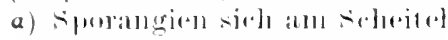

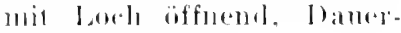
sporest starlilier.

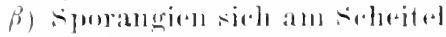

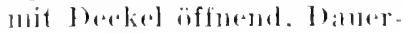
sporeme grlatt.

111. I)anguallia.

11. ('hytrilimm.

2. Myzol intramatrikal, plalllworzelartig od. rxtramatrikal

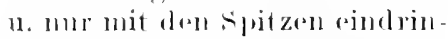

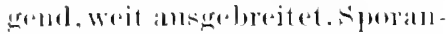

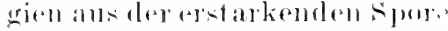
axtranatrikal erohilelet od. als

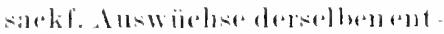

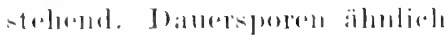

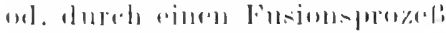

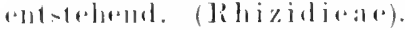

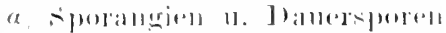

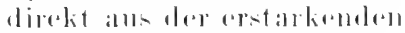

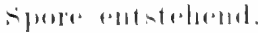

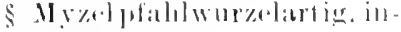
lrallatrikal.

1․ Rhiriliunt.

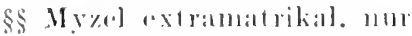

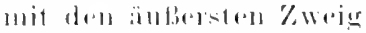

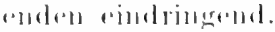

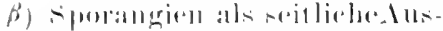

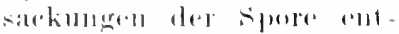

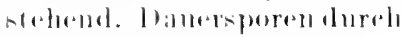
F'llime grabilelet.

\section{Polyphacus.}




\section{Gattung: Entophlyetis A. Fiseher.}

Die keimende schwänmspore nmgibt sich mit einer Membran u. sendet einen feinen Keimschlauch in die Nährzelle, der am Ende zum sporanginm anschwillt $u$. von dem ein feinfädiges, wnrzelartiges Iyzel entspringt. Der Keimfaden wird zum Entleerungshals des sporanginms. Danersporen intramatrikal, wie die sporangien entstehend, mit dicker, glatter, gelblicher od. brämlicher Hembran.

In Gloeococens mucosus, zerstreut. F.

E. apiculata (A. Braun)

In Vaucheria n. Spirogyren, zerstreut. E. rhizina (Schenk)

In vegetativen Zellen rou Spirogyra crassa, selten.

E. bulligera (Zopf)

In ('ladophora. selten. (Fig. 53.) E. Cienkowsiana (Zopf)

\section{Gattung: Diplophlyetis Selnoet.}

Wie ror. Gatt., aber die gekeimte Spore verschwindet, u. minterhalb. les Sporangiums bildet sich zuerst eine blasige Anschwellung, von der die Rhizoiden ausgehen. Dauersporen wie bei ror. Gatt., aber stachlig.

In toten od. alsterbenden Zellen ron Xitella-Arten u. Chara polyacantha, selten. (Fig. 54.) D. intestina (Schenk)

3. Cattung: Halpochytrimm lagerheim.

Die zur Ruhe gekommene schwänspore bildet eimen feinen, an Ende plattenartig anschwellenden Keimfaden u. bilet sich selbst zu einem langen, spindelf. gebogenen sporangium um. Danersporen unbekanut.

Sporangien $80-150 \mu$ lg. u. $4-6 \mu$ br. Anf Spirogyra, Zygnema 11. Gedogoninm, selten. (Fig. 5i).) H. Hedenii Wille

\section{Gattung: Phlyotidium A. Braun.}

Die srhwämspme entsendet in die Nährelle ein unverzweigtes, meist kurzes llaustor $u$, bildet sich zu einem versehieden gestaltigen sporanginm mit einem oler mehreren Entleerumgshälsen nu. Dauer-poren kuglig, dickwantig, ebenso gebildet.
Anf Vlothix zomata, selten.
P. Iaterale A. Braum

\section{Crattung: Rhizophidium Schenk.}

Wie ror. Gatt., alur ein zartfädiges, verzweigtes Wurzelsystem gebildet. Sporangien mit ein od. melneren, meist etwas vorspringenden Löchern sich öfnent. Dauersporen ebenso gebildet, mit bräun. licher Membran.

1. Sporangien (besonders die gröberen) sich stets nit 2-5 Löchern öffuend, die als Papillen ot. Tïptel erkennbar sind.

Sporangien sich stets nur mit einem Loeh öfnend.

2. Sporangien kuglig od. fast kuglig. 


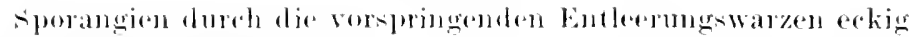

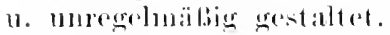

3. Anl 1 lgeru.

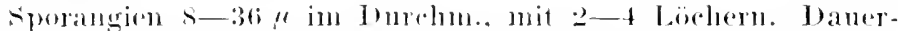

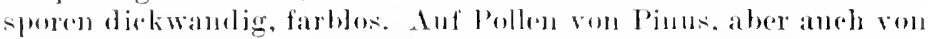

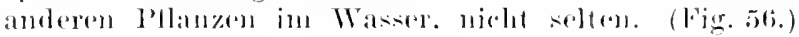

\section{R. polliniv (1. B)'ann)}

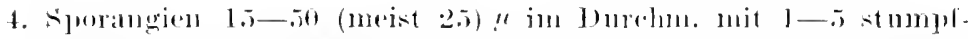

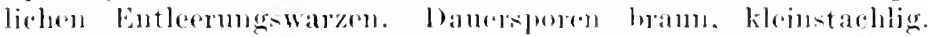

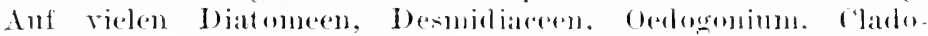

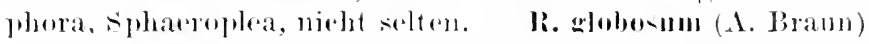

sporangien bis 12 " jul Durchun. hald zusammenfallend.

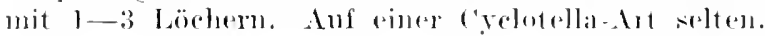

R. ryolutollan Zojof

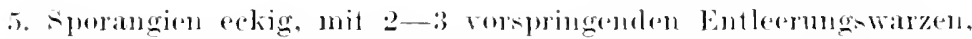
$20-25 \mu \mathrm{im}$ Durelum. Iuf dem spitzender Fädru rom oseillatoria

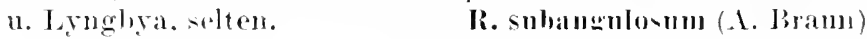

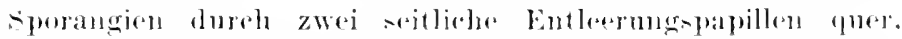

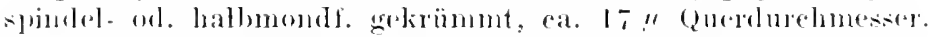
Auf chlamydomomals pulvisculus n. obtusa. seltem.

\section{R. tram-rer-am (.1. Jiramo)}

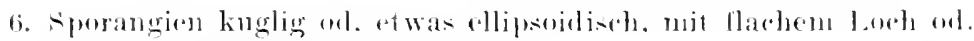
mit - vorigestrecktem llaks.

sporangeres spindelf. onl. exkig.

7. Auf Algeil n. Fligellatem.

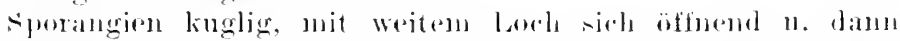

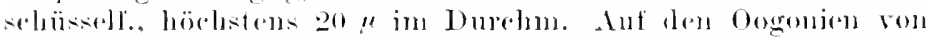

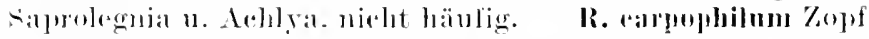

s. Sperangion nur mit Entresmespapille.

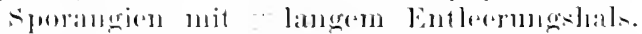

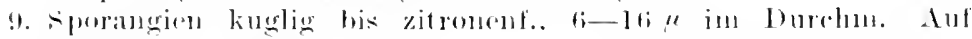
Hagellatru, soltedl. Mr.

R. ar.uformo" $(\%, 1,1, f)$

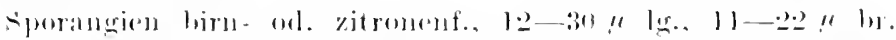

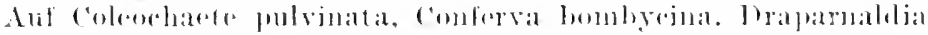

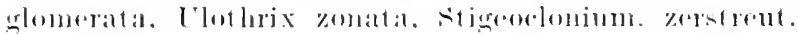

\section{IR. II!nillatum (.1. liraum).}

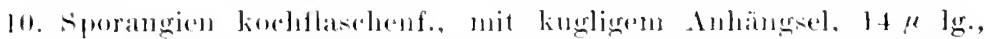
11 a hr. Anf ('hlamydomomas, selten. R. appendiculatum (Zopt)

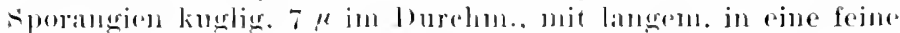

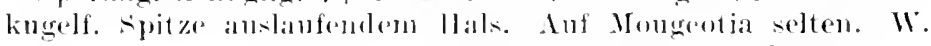

li. ampullatemun (A. Bramu)

11. Finorangien spindelf.

sporangigin eckigh.

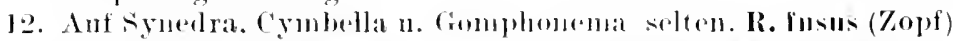

Auf Melosira, selten.

R. Iasemula (A. Bramu)

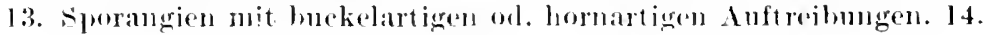


Sporangien st umpfeckig kuglig od. birnf., $10-15 \mu \mathrm{im}$ Durchm. Auf Chroococcus turgidus in Moortümpeh des Riesengebirges.

R. agile (Zopf)

14. Sporangien ei-, birn- od. spindelf. im Umris, mit mehreren buckelartigen Hervortreibungen, ca. $11 \mu$ lg., $8 \mu$ dick. Auf Desmidiaceen, Diatomeen, Palmellaceen u. Rotatorieneiern in Moortümpeln des Riesengebirges. R. gibbosum (Zopf)

sporangien zuerst kuglig, dam mit \pm zahlreichen, ungleich lg. oft gespaltenen. homartigen Fortsätzen, darlurch sternf.lappig erscheinend, 19-13 $\mu$ im Durchm. Auf Sphaerozyga circinnalis, selten. S. R. cornutum (A. Bram)

\section{Gattung: Latrostim Zopf.}

Sporangien aus der erstarkenden Spore entstehend, mit vielen zarten Würzelchen, seitlich sich mit einem Loch öfnend. Danersporen mit sehr dicker, fein radial streifiger Wandung 1 . riesigem Fettropfen.

In den Oogonien rom Vaucheria sessilis n. terrestris, selten. F.

I. comprimens Zopf

\section{Gattung: Phlyctochytrim Schroet.}

Die zur Rule gekommene Schwämspore treibt ins Innere der Xährpflanze einen feinen Schlauch, der an Ende blasig anschwillt 11. an der Blase feine Würzelchen bildet. Sporangien ans der spore hervorgehend, durch ein meist scheitelwärts gelegenes, oft gezähntes Loch sich öfnend. Dauersporen unbekamnt.

1. Mündnng der sporangien ganz ungezähnt.

Iründung der sporangien mit knopfiger Verdickung od. zahnf. Vorsprïngeu.

2. Auf Oedogonium, Bulbochaete, spirogyra, Zygnema. Closterium u. Cladophora, zerstrent. Auf Hydrodictyon ntriculatum, selten.

P. Schenkii (Dang.)

$$
\text { P. hydrodictỵi (A. Bramu) }
$$

Auf Ruhezuständen von Euglena, selten.

$$
\text { P. euglenae (Schenk) }
$$

3. Auf Zygnema crnciatum u. stellinum, zerstreut. W. F.

Auf Oedogonium rivulare, selten. W. (Fig. 57.)

$$
\text { P. zyguematis (Rosen) }
$$

P. quadricorne (de By.)

Auf Apirogyra orthospira, selten. P. dentatum (Rosen)

8. Gattmug: Obelidium Nowakowski.

Die ausgekeimte schwärmspore schickt in die Nährzelle 5-7 kräftige, verzweigte Rhizoiden $u$. bildet sich zu einem Sporangium mit Stiel u. solidem, spitzem Stachel am scheitel 1m. Sporangien unter dem Scheitel mit Loch sich öffnend. Dauersporen unbekannt.

Sporangien 32-56 $\mu$ lg., S-15 $\mu$ br. Anf leeren II üllen von Mückenlarven, selten, (Fig. 58.) 0. mucronatum Nowak. 


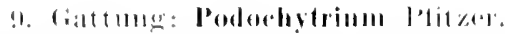

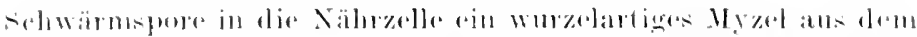

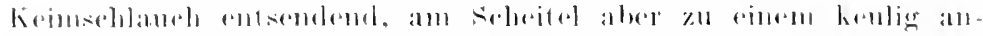

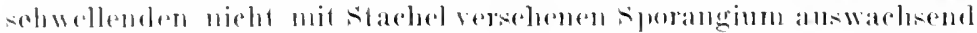

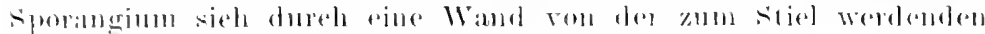

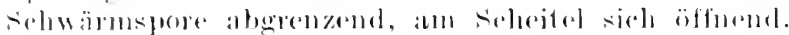

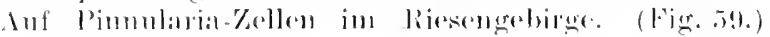

l'. ralsatwan l'lit\%.

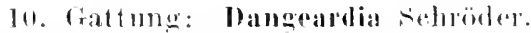

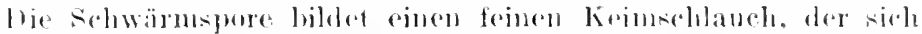

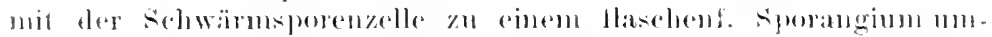

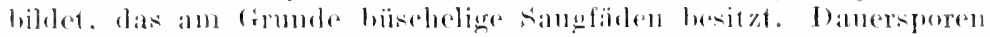
intramatrikal, ohne sangwirzelelen, mit dieker, stachediger Membran.

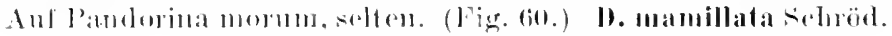

\section{Gattulle: Chifridium .1. Brallt.}

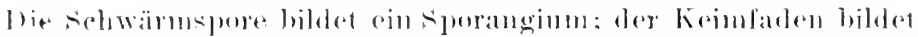

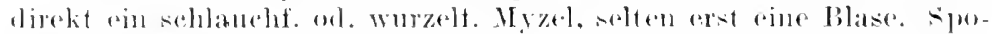

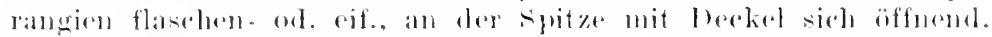
l)aneleporem intramatrikal.

1. Olune sulmomalluialo Base.

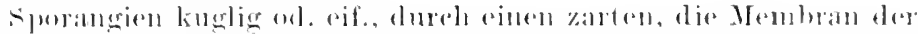

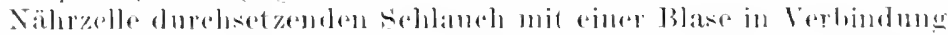

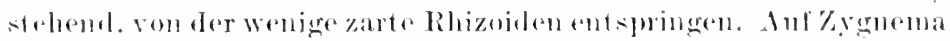

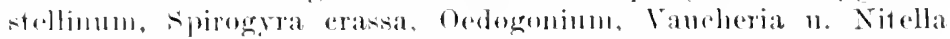
flexilis, zerst jermi.

('. Iatenaria Selenk

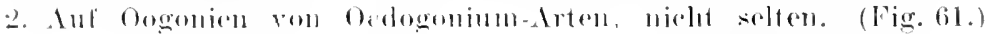

$$
\text { (C) ollat 1. Bramill }
$$

Auf Mescrearpus selteme

(c. Imesocarpi (lisch)

Aul lisillamia zeloral, sellell.

1. Ppitlomian Jowak.

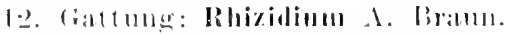

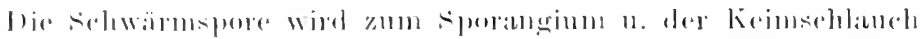

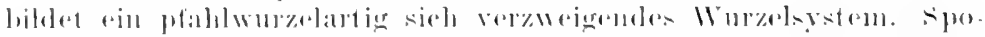

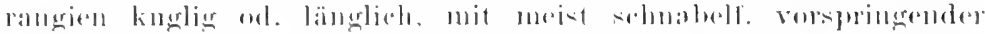

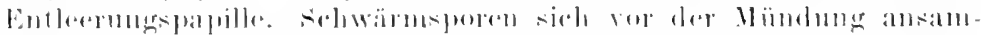

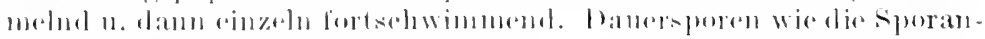

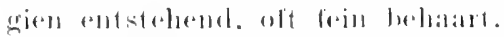

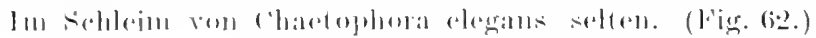

R. III!)ophilum A. Bram

\section{3. (iall11110r: Rhizoplalyetis A. Fischorer.}

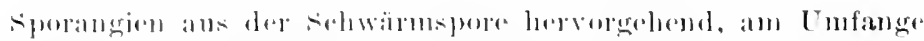

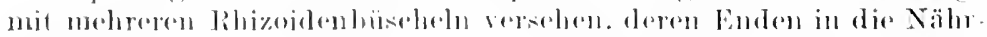

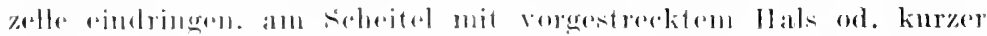

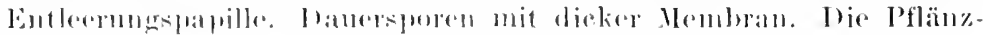



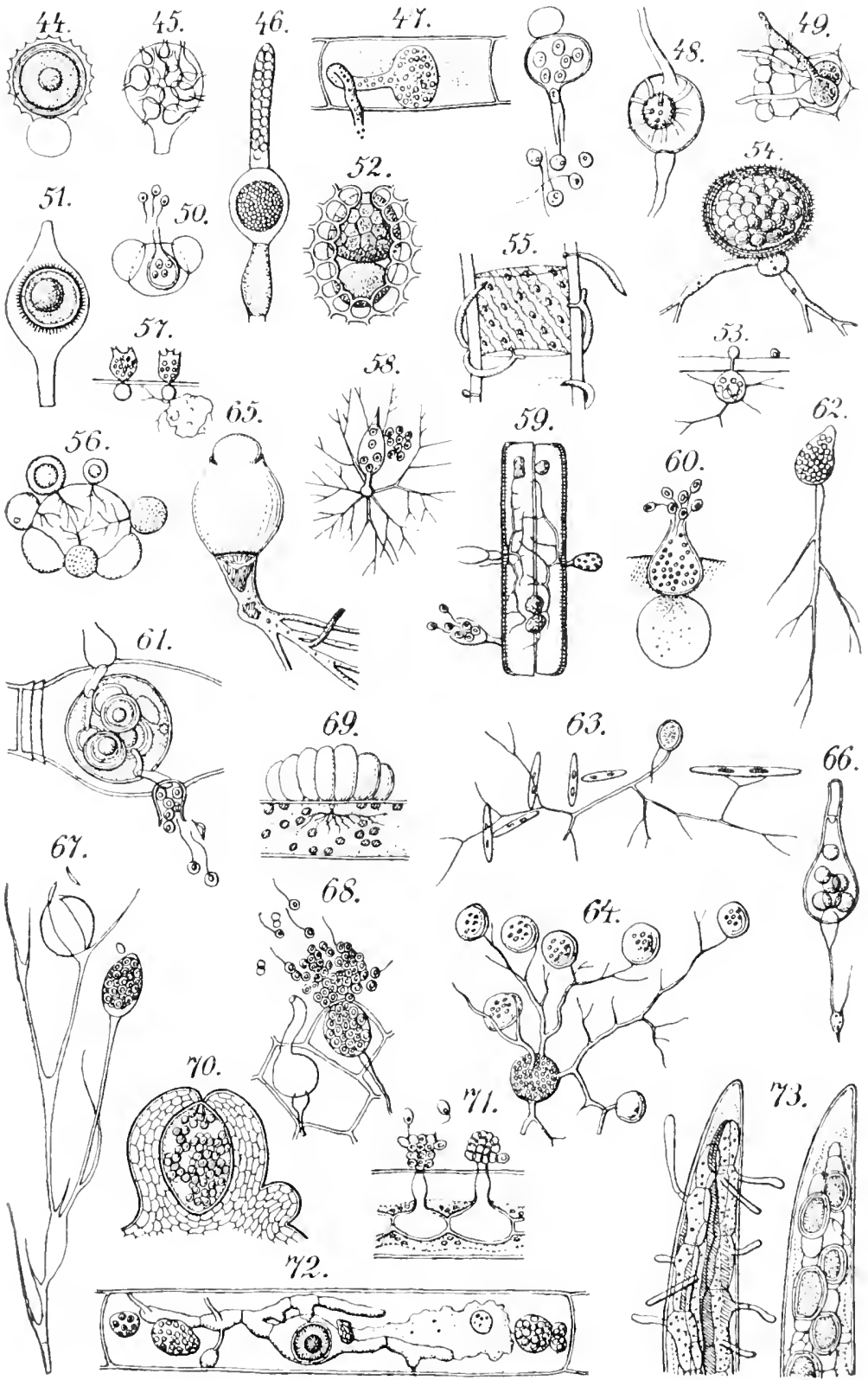


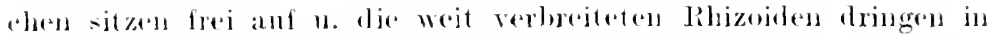
melirere Nöilnzellen rin.

Auf J)iatomeen ju salzwasker, selten. (lige (i3.) R. Bramnii (Zopt) Auf Mastignthrix arruginea, die Zellen gelly fä̀bend, selten. R. Illastigotriobis (Nowak)

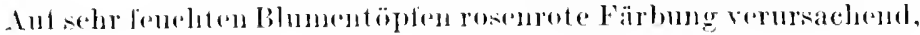
seltell.

R. rosea (de By. ex llor.)

\section{4. (raltung: Polyphasus Towakowski.}

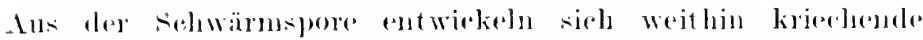
Rhizojlen, die nur mit den äubersten Eurles in die Nährzellen eindringen. Eluenfals an der Schwänspore tritt ein schlaush heraus, der in beliebiger Form anschwilt, alles Plasma in sich anfuimmt $u$. sich dureh eine Wand absehlielst: ans ihn wird das spenamerium,

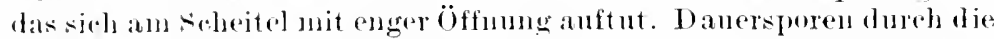

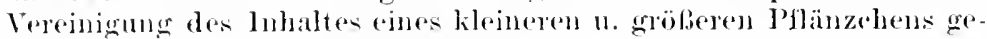
bilket. kleglig, glatt ocl. feinstachlig.

duf Rolnezuständen von Euglona viridis, zerstreut. (Fig. (i4.)

P. euglenae Nowak.

\section{Familie: Hyphochytriaceac.}

Mrze] weitlunig, schlauchf., ans Ilauptathse u. wurzelf. in substrat sich ansbreitendem 'Teil bestehend. Sporangien dureh Quer' wand abgetrennt. in linzahl an einen seitenzweig terminal gebildet, mit Decked sich offnend. Sehwärnsporen eingeiblig. Saprophyten.

Einzige (iattmer: Macroeluytrimm v. Mindren.

sporangien nur eines an jedem Pflänzehen. br. ollipsoidisch, bis $900 "$ "lg. $11.750 "$ bs. Inf faulenden, in Wasser licgenden Früchten

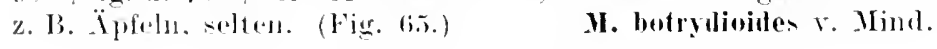

\section{Familie: Cladochytriaceac.}

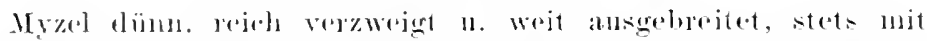

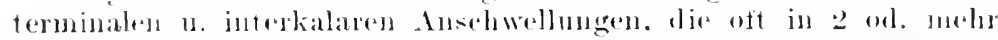

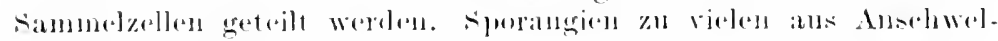

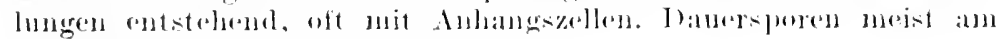

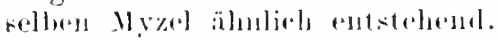

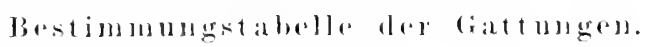

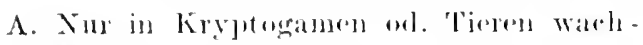
semal.

a) Sporangien interkalat wal. torminal

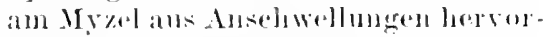
gehend, night reihenweise hintereinander. Ant cluateplestat.

I. Selowärmsporen unhegerilelt, stark alüiboid.

1. Amochoshytrium. 
II. Schwärmsporen eingeißlig, nicht amöboid.

b) Sporangien durch ziemlich gleich

2. Nowakowskiella.

lange, kurz zylindrische Fadenstïcke roneinander getrennt. Auf Tieren

u. Nitella

B. Nur in höheren Pflanzen vorkommend.

a) Danersporen unbekamnt. Sporangien mit Entleerungshals. Keine Gallen bildend.

\section{Cladochytrimm.}

b) Dauersporen bekannt. Gallen od. Verfärbungen bildend.

I. Dauersporen knglig od. ellipsoidisch, seltener einseitig abgeflacht. Anhangszellen an beliebiger Stelle mit kürzerem schlauch angeheftet

II. Dauersporen kuglig, stets einseitig flach $u$. vertieft $u$. hier mit einer an kurzem stiel befestigten Anhangszelle.

\section{Catenaria.}

\section{Physoderma.}

\section{Urophlyctis.}

1. Crattung: Amoebochytrimm Zopf.

Ilyzel dünn, weit verbreitet im Substrat, mit interkalaren An-chwellungen. Sporangien aus der erstarkentlen spore n. ans den interkalaren Anschwellungen hervorgehend, flaschenf., mit ziemlich langem Entleerungshals. Schwärmsporen grof, stark amöboid beweglich, unbegeiBelt. Dauersporen unbekaunt.

In schlein von Chaetophora saprophytisch, selten. (Fig. 66.)

A. rhizidiuides Zopf

\section{Gattung: Yowakowskiella Schroet.}

Myzel reich verzweigt, weit ausgebreitet, mit Anschwellungen, besonders an den Verzweigmngsstellen. Sporangien terminal od. interkalar aus Myzelanschwellungen entstehend, durch Wand abgegrenzt, mit Deckel sich öffnend. Schwärmsporen kuglig, eingeiplig. Sekundärsporangien durch die leere IIülle des Primärsporanginms durch. wachsend.

Danersporen unbekamnt. Im schleim von (haetophora elegans, relten. (Fig. 67.)

x. elegans (Nowak.)

3. Gattung: Catenaria Sorokin.

Myzel intramatrikal, ans zylindrischen, einzelligen Fäden bestehend, die an den Enden wurzelartig anslaufen. später spindel-od. tomnenf. Anschwelhngen zeigend, die durch dünnere, l-2 zellige Fadenstücke getrennt sind. Sporangien aus diesen Anschwelhngen hervorgehend, nit kurzem Entleerungshals. Schwärmsporen kuglig, ringeiblig. 
In Anguillula, Infusorieneysten, Räblertiereiern u. Nitella, selu zerstrent.

(1. ancuillulae Sorok.

\section{Crattoug: Chdochytrimm Nowakowsi.}

Iryel im Zellgewebe pon Zelle zu Zelle ziehend, reieh verzweigt. sporangien terminal of. interkalar im substat am Myzel gebildet. entweder direkt ans den Anschwellumgen hervorgebent od. erst nach Zerfall der Anseliwellungen in 2 sammelzellen, von denen die eint zum sporanginu wim, die andere dagegen als lese Anlangselle beibt. Entleerungshals zylimbriseh od. Arhubbelf. Damersporen um. belianut.

Im Grewe ron Acorus, Iris psendacorus, Glveria fluitan wachsend w. ameh darans hervortretend, gerstreut. (Fig. fis.)

C. temue Nowal.

\section{fi. Gattung: Phrsoderma Wallr.}

Myzel dïnfädig, von Zelle zn Zolle zielend, oft einfache oul. ans 2-3 Zelleu bestehende sammelzellen bildend. Sporangien weniu bekannt, extramatrikal, wie eis Rhizophidjun-sporangim mit Rhizoiden aufsitzend. Danersporen meist allein hekannt, knglier ofl. ellipsoidisch, selten einseitig llach, meist mit riner Mnlangszelle in Verbindung, mit glatter, bramer Membran. Keimumg mit oder olmes Deckel, mater Scliwärmsporenbildumg. Nur Verfärbmingen oul. pustelf. or. schwielenf. Anselwellungen erzengend.

1. In Monokotyledomen.

In Dikotyledomen.

2. Anf Alisma plantago n. ramunenloides bräunliche, kreisl. onl. längliche Pusteln od. Flecken hervorhringend. hänfier. (Figr. (i!).)

\section{1'. manculare Wallr.}

Auf den Blätern ron Butomus umbellatis blabgelbe, dam lunkle flecken erzengend, zerstrent. P. Intomi schroet.

Auf Plemm pratense, Dactylis glomerata u. Tritiem repens hellbranue, parallele Längst reifen in den blättern bildend, zerstreut.

P. erantuis (Biiseren)

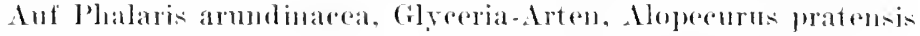

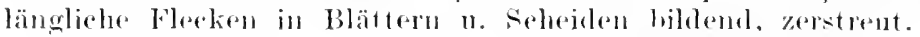

P. Gerhardid schereet.

Auf seipus maritimus sehwarze Flecken od. Ftreilen bildend. selteil.

lP. Schoroteri lirieger

Auf soirpus palustris tlache selowielen bildend. selten.

P. heleocharidis soluroet.

An den blätern von Iris psendacoros brämlich sehwäzlielee Flecken bildend, selten.

l'. iridis (ale By.)

In den oberiolisehen Teilen von Allium sehoenoprasm sehwarzbramere sehwielen bildend, selten.

P. allii Krieger

An Acorus ralamus hrame längliche Flecken erzengend, selten. 
3. Auf Ranunculaceen, Umbelliferen, Potentilla anserina, Nasturtium amphibium Pusteln. Sehwielen u. Verkrümmungen od. Verkümmerungen bildend, zerstrent. P. rawans Seluret.

Auf den langgestielten Wasserblättern von Ramnculus flammula sehwarzbrame Pustehn od. Flecken bildend, selten.

P. flammulae (Büsgen)

Auf den Blattstielen n. Blättern flache od. punktf. Schwielen erzeugend, selten.

P. Magnusiamum Krieger

Auf den Blättern u. Blattstielen von Menyanthes trifoliata weis. liche, rötliche, zuletzt dunkelbraune Schwielen bildend.

P. menyanthis de By.

An Blättern, Blattstielen u. Stengehn flaehe rötliche bis dunkelbraune Schwielen bildend, selten. P. speciosmm Sehroet.

An den Stengeln von Mentha aquatica dicke, sehwarzhrame schwielen bildend, selten.

P. menthae seluroet.

\section{Gattung: Urophlyctis schroeter.}

Myzel dünn, reich verzweigt, nit Anschwellnngen versehen, entweder in einer sich stark vergrößernden Wirtszelle lokalisiert od. sich über viele Zellen ausbreitend, oft große Gewebepartien ganz zerstörend. Sporangien sehr selten, anfsitzend, aber stets im Gerebe eingesenkt. Dauersporen durch Kopulation zweier Ansehwellungen entstehend. kuglig od. ellipsoidiseh, einseitig abgeflacht $u$. hier mit einer Anhangszelle (wenigstens in der Jugend) in Verbindung, mit bramer, glatter Membran. Parasiten in ober- od. mnterirdisehen Organen höherer Pflanzen, z. T. große Gallen, Deformationen usw, verursachend.

1. Myzel auf eine sich riesig vergrößernde Wirtszelle beschränkt bleibend, nicht in die Nachbarzellen übergehend.

Myzel in die Nachbarzellen unter eharakteristiselen Dureh. brechmigen der Membranen ühertretend, große IIohlräume dureh Zerstörung der Zellen entstehend.

3.

‥ Glashelle, knotige od. perlähnliche Gallen mit dunklem Kern auf den oberirdisehen Organen ron ('arum earvi erzengend, zerstrent. (Fig. 70.)

U. Kiriegeriana Magnus

In Rübenwurzeln riesige knollige, lepraartige Ansehwellungen bildend, vielleieht im Westen des Grebietes. I. Ieproidea (Trabut)

3. In oberirdischen Organen.

In unterirdisehen Organen.

$\therefore$.

4. Auf Blättern u. Stengeln von Chenopotimm glaueum, rubrum. urbicum u. Atriplex patulum. Lastatum Auftreibungen u. Verkrümmungen verursachend, zerstrent. C. pulposa (Wallr.)

Auf den Blättern u. Stengeln von Rumex acetosa, arifolins $u$. maritimus rotbraune, halbkuglige, kleine Pusteln bildend, selten. T. major seluroet.

5. An den W'urzeln von Rumex sentatus knollige Answïchse bildend, selten.

U. Riibadameni Magnus

An stengelgrund und den oberen Wurzelteilen ron Medicag"n 
sativa erbsengrolie Anschwelhungen, die zu tranbigen Gebilden zusimmentreten, arzeugend, selten. $\quad$ C. alfalfae (Lagh.)

\section{Reihe Ancylistineae.}

Myzel intramatrikal, schlauchf.. selten verzweigt, durch Querwände in Zellen zerfallend, die entweder zu sporangien od. zı Oogonien u. Antheridien werden. sporangien mit Entleerungssehlanch. Antherilien n. Oogonien abwecherelnd entstehend, dureh einen Kojulationsschlauch in Verbindung tretend. Oosporen stets in der Ein. zahl, mit schwärmern ol. Keinschlanch auskeiment. Sehwärmer zweigeilitig.

\section{Einzige Familie: Ancylistaceace. Bestinmungstabelle der Gattungen.}

A. Th. restlos in sionangien od. Gesehlechts. zellen zerfalleml. Sporangien n. Oosporen nur schwärms

a) sohwärmsoren im sporangimn gebilket u. sich vor de’ Miündung häıtend.

b) Inhalt der sporangien in einer Blase austretend u. erst damn in schwärm. sporen zerfallend.

I. Th. ganz unverzweigt.

11. Th. nnit Seitenästehen od. Anst iilpungen

1. Mehlyogeton.

‥ Myzorytium.

\section{Iagenidium.}

B. Thglieder u. Oosporen veget at iv in I yphen anskeimend. Schwärms poren ganz fehlente.

\section{Incylistes.}

1. Gattung: Aehlyogeton Schenk.

Th. sehlanucht., mit Querwänden. Jede Zelle wird zumu s'jeram-

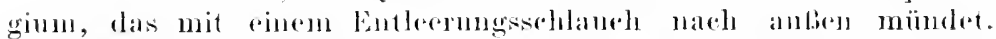

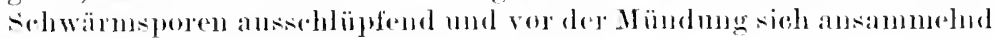
u. häutend. Greschlechtszellen unbekanut.

In Cladophorarollen. selten. (Firg. TI.)

1. entophytum sedernk

\section{Gathug: Myzorytium schenk.}

Wir vor. Galte, aber der Inhalt der sporangien in einer Blase

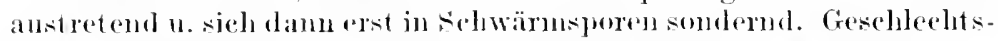
zellen nebeneinander, Oosporen in stohwinmsposen anskeimend.

In den Zellen ron ronjugaten, Oedogonium u. Cladophora, nicht selten.

if. proliferum schenk

In Anguillula, zerstrent.

II. vermicolmm ('opf) 
3. Gattmog: Lagenidium Schenk.

Th. schlauchf. mit kurzen Seitenästchen u. Ausstïlpungen, ebenso in Sporangien od. Gesehlechtszellen ohne Einschüurmg zerfallend. Schwärmsporenbildung beim Sporanginm wie hei vor. Gat. 1 ung. Antheridien zylindrisch, schlauchf., Oogonien meist \pm kuglig, beide auf derselben od. auf verschiedenen Pllanzen.

In den vegetativen Zellen von Spirogyra, Mesocarpus, Mongeotia, nicht selten. (Fig. 72.)

In den Zygoten ron spirogyra, zerstreut.

L. Rabenhorstii Zopf

C. entoplytum (Pringsh.)

In Dedogonimm Boscii, selten.

L. syneytiorum Kleb.

In größeren Diatomeen, zerstrent. L. enceans Zopf

In Pinnspollen, selten. $\quad$ L. pysmaeum Zopf

\section{Gattung: Aneylistes Pfitzer.}

Th. sellanehf., muverzweigt, in einzelne Teilstiicke zerfallend, jerles die Wandmig durchbohrend, answachsend $u$. in neue Zellen einAringend. Diözisch. Oosporen mit Keimsehlanch keimend.

In Closterium-Zellen, zerstrent. (Fig. 73.)

A. Costerii Pfitz.

\section{IIl. Reihe: Monoblepharidineae.}

Myzel dünn, wenig verzweigt, Sporangien zylindrisch, Schwärm sporen fertig ausselwärmend, eingeililig. Oogonien an der spitze ler Fäden gebildet, mit einer Oospore. Antheridien zylindrisch, unterhalb der Oogonien, in ihnen eingeislige Spermatozoiden gebikdet. die am sich öfnenden scheitel des Oogons eindringen u. die Oosphäre. hefruchten. Oospore kuglig, meist warzig, mit schlaueh anskeimend.

\section{Einzige Familie: Monoblepharidaceae. \\ Gattung: Monoblepharis Cornu}

Oogonien einzelı od. zu mehreren, oft reihenweise, Antheridien als kleine Zelle am Oogon ansitzend, seltener unter demselben. Anf mutergetanchten Zweigen, selten. (Fig. 74.)

M. polymorpha Cormu

Oogonien reihenweise, vicle hintereinander. Antheridien an of. unter den Oogonien, bisweilen reillenweise $u$. damn getrennt von des Oogonien. Ebenda. M. matandrat (Lagh.)

\section{Reihe Saprolegniineac.}

Myzel schlauchf., verzweigt, nur zur Abgrenzung der Fruktifikationsorgane mit Querwänden. Schwärmsporangien \pm lgg., zylindriscl. Schwärmsporen zweigeißlig. Oogonien an kurzen seitenästrn. gewöhnlich mit mehreren Oosplı̈̈ren. Antheridien fädig, unterhalb dè Oogonien od. an anderen Individuen (diözisch) entstehend, in di^ Oogonien hineiuwachsend $\mathbf{u}$. sich verzweigend. Die Befruchtung er- 
folgt durch Austreten der Kerne ans den Antheridiabästen n. Verrinigurg mit denen dey Oosphären. Wasserpilze anf Tieren u. Pllanzenrisitis.

Bestimmumatabelle der Familien und Gattmong.

A. Myzel ïlerall eleich dick. ganz mugeglied lert.

Fant. Saprolegniacear.

a) Schwärmsporen aus dem sporangium

alussehwirmend.

I. Spormgrenkeulig, Sehwärmsporen

in mehresen Reihen liegend.

1. Schwirmsporen sich nach dem Austrittsofort zerstrement, Sporangien durehwachsemel.

2. Schwämsmowen side ror der Öflnmogesammelnd u. damm elst ankschwärmend. sperangien nicht durchwarchsend.

3. Schwärmsporen nicht duroh (s) gemejusame öflumug anstretend, sonder'n jede einzelne dic Mrmbran durehtohlirend.

IJ. sporangien fädig, schwärmsporen nur in einer Reihe liegend.

1. Schwärmsporen nach dem Ams tritt sich zerstreuemel.

2. Schwärmsporen nach dem dustritt zucest als Köppehen lieg(e) blejbend.

b) Sichwämsporen bereits jum sporangimm mit keimschlaneh keintemel.

B. Myzel dureh Einsehnürmugen in einzelue P'artion abuetrilt.

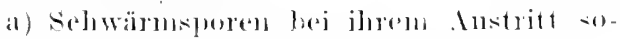
fort sirh entferment.

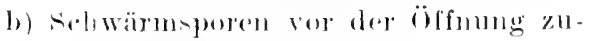
arst liecoen bleibend.

1. Saprolegnia.

a. A hlilya.

3. Dictyuchus.

\section{万. Aphanmmyer.}

i. Iplanes.

Fam. Leptomiturear.

7. Leplomilus

S. Ipoularitya.

1. Ciattung: Saprolegnia Xoes.

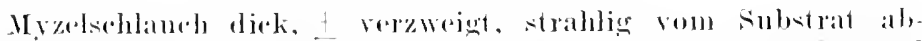

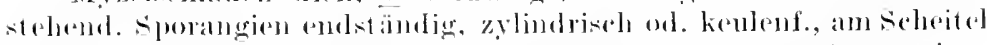

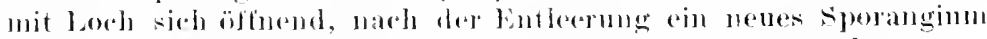

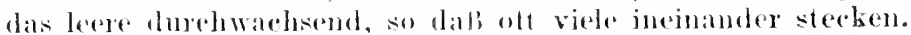

1. Oogonien morensternartit mit Vorsprüngen vesehen, eimeiig. Antheriden an Ende von fisten. die dieht an Oogon entspringen. sporangien durchwachsend. Auf toten Fliegen im Wasser, selu zerstreut.

S. asterophora de By. 
Oogonien nicht mit Vorsprüngen, vieleigg.

2. Oogonien an Ende der väulen, seltener an Seitenästchen hintereimander entstehend, bei der Reife abfallend. Antleridien unb. kannt. Sporangien durelnwachsend od. dureh zymöse Sprossungsich ernenemb. Auf Fliegen usw. sehr selten. (Fig. 75.)

S. monilifera de $3 y$.

Oogonien nieht abfallend. Sporangien nur durehwathend.

3. Antheridien stets vorbanden, selten fehlend.

Antheridien felulend, höelsst selten vorhanden.

4. Antheridien unmittelbar untre dem Oogon entspringend, oft nur lie scheidewand sich in das Oogon rerstïlpend, nie an Nebenästen. Oogonien terminal, \pm kuglig od. interkalar, tommenf. Auf toten lnsekten in Wasser, anch anf toten Krebsen, verbreitet.

\section{s. hypogyna (Pringsh.)}

Antheridien entfernt vom Oogon entspringend, am Ende langer. oft windender, ä̈mnerer Nobenstämme od. -äste.

万. Rasen sehlaff abstehend, Oogonien terminal od. interkalar, einzeh od. mehrere hintereinander, an den IIautfäden. Antheridien sehr zahlreich, anf Nebenästen, die an dïnneren, besonderen Ilanptasten entspringen. Oosporen his $20 \mathrm{in}$ einem Oogon, knglig. Anf lnsekten in stehenden Wasser, häufig. S. dioica de By.

Rasen bis 1 cm br.. straff abstehend ankerhalb des Wassers. Gogonien am Ende knryer Nebenäste, die traubig ans den llauptstanm entspringen. Antheridien am Ende von Nebenästen, the aus dem Itauptstamme in der Nähe des Oogons entspringen. Oosporen meist zu :-10 im Oogon, kuglig. Anf toten Insekten, Fischen, Krebsen im Wasser, hänfig. S. monoiea (Pringsh.)

1. Rasen bis 1,5 em by., stratf abstehend auBerlualb des Wassers. Oognnien teminal, einzeln an IIaupt-u. Nebenästen, nicht traubig. Oosporen fast stets zahlreieh im Oogon. Wie vor., hänfig. (Fig. 76.)

s. Thureti de By.

Rasen bis 1 em br., sehlafi, Fäden am Ende mit keuligen Spo. rangien, später in meluere, durch Wände abgegrenzte Teilstücke gegliedert, die zu reihenweise liegenden sporangien, Oogonion od. Dauerzellen verden. Oognien reihenweise ans den Ans.hwellungen hervorgehend. Antheridien sehr selten vorhanden. Gosporen zu mehreren in Oogon. Auf toten Insekten, in Wasser. zerstrent.

S. torulosa de By.

\section{Gattung: Iehlya Nees.}

sporangien nicht durehwachsend, somdern unterhalb des entleeten Sporangiums seitlieh ein nenes emporwathsend. Sehwärm-poren sich vor der Öfnumg sammelnd, sich häntend u. dann erst fortschwämend. Alles übrige wie bei vor. Gatt. Rasen meist mit starr abstehenden $\ddot{A}$ ster.

1. Oogonien dureh Ansstïlpungen unregelmäbig stachlig. Autheri- 


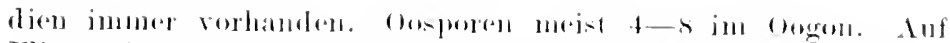

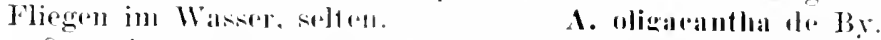

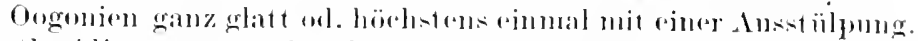

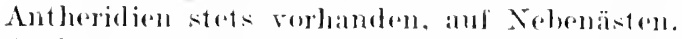

2. Anfleridien niemals an denselben Hauptsehlänlen wie die

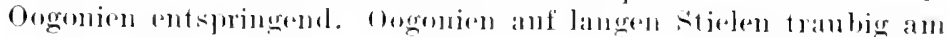

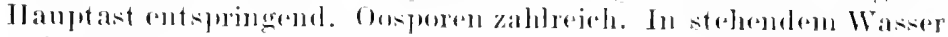
anf Insckten 11- h.. hänlig.

1. probiliera Xeres

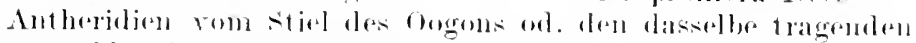

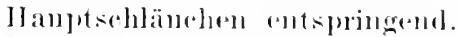

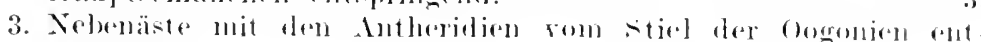
springerent.

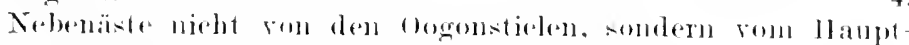
schlameh sellest entspringemd. stint stiele am Traofalem tranbig dicht stehend. Antherieliena jedem Ougon 1-2. ans wnverzweigten Nebenästen.

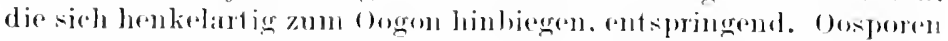
zu 1-6. An' 'Tieren n. pllanzliehen Abfallotoffen in Wasses'. häulig. (Fig. T.

A. raremona IIj]deb.

Oogonien wie bei res. Art. aber die stiele viel dijnner. hakies

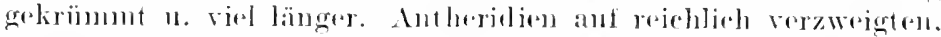

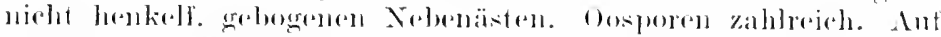
lnseliten in Waser. seltent.

1. aracilipes de $\mathrm{Br}$

5. Oogonien an kurzen, oft hakig gekrïnmentesticken, die tranlieg

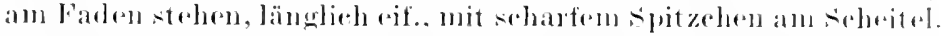

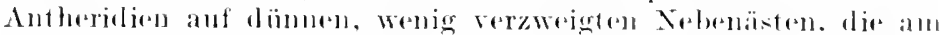

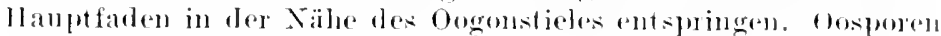

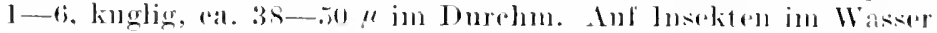
seltent.

1. aproulata de liy.

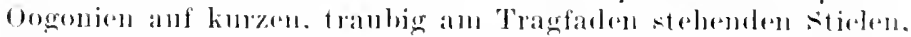

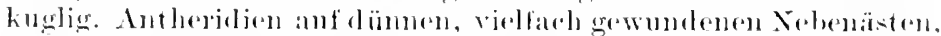

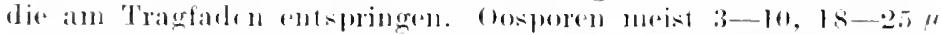

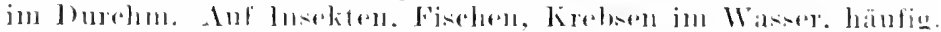

d. polyumalia lliblub.

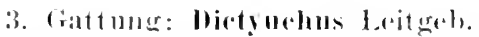

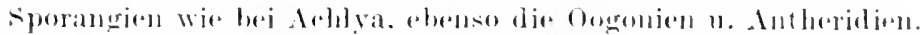

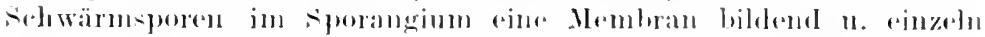

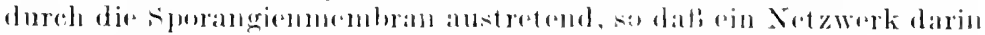
zurïckbleibt.

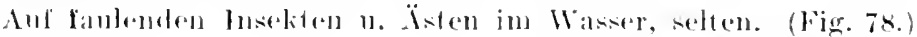

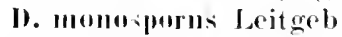

4. Galtunger: Ieptolegnia de By.

Rasen schlaff. Áporangien terminal, fäligr. Ashwärmsporen ein. roilig liegend, am solucitel ansschlüpfend, mit 2 endständigen Geibehn, damm zur Ruhr kommenul, sich häntend n. mit 2 seitliehen Geilieh 
weiter sehwärmend. Oogonien eineig, sonst wie bei saprolegnia, ebenso die Antheridien.
In Gebirgsseen, sonst selten
L. caudata de $\mathrm{By}_{\text {. }}$

\section{Gattung: Aphanomyces de By.}

Rasen sehr feinfädig, wenig verzweigt. Sporangien fädig, Schwärm sporen einreihig, vor der Mündung sich sammehd, u. nach II äutung fortschwimnend. Oogonien eineiig. Antheridien wie bei Achlya. 1. Oogonien glatt. Auf Insekten im Wasser, selten.

\section{A. laevis de By.}

Oogonien mit warzen-ol. staehelf. Ausstïlpungen.

Mrzel parasitisch, in Spirogrren lebend, Sporangien u. Oogonien außerhalb der Wirtszellen. Oogonien an kurzen Fädehen. Anthe ridien am Ende von Vebenästen. Oosporen einzeln, knglig. Selten.

3. Oogonien feinwarzig rauh.

A. phycophilus de By.

Oogunien mit großen, stumpf kegelf. Aussackungen, zerstreut. (Eigr. T!.)

A. stellatus de By.

6. Gattung: Aplanes de $13 \mathrm{r}$.

sehwärnsporen nicht sehwämend, sondern in sporangium auskeimend n. mit dem Keinsehlaneh die Wandung durchbohrend. Alles übrige wie bei Saprolegnia. Oosporen zahlreirh.

Auf Insekten u. Pflanzenteilen im Wasser, selten. (Fig. 80.)

A. Braunii de Br.

\section{Gattung: Leptomitus Agardh.}

Fäden verzweigt, in regelmäligen Zwisehenränmen ringf. eingeschnürt. In jedem Glied mehrere Zellulinkörner, die das Faden. glied absehließen können (bewegliche scheidewände). sporangimm zylindriseh, endständig, oft mehrore ïbeseinander. Schwäms poren mit 2 endständigen Geibeh. Oogonien unbekamnt.

Grobe flutende, weibe, später sehmutzig grane Rasen (Lämmerschwänze) an Holz $n$. Steinen bildend, nu in stark versehmutztem Wasser (Rieselfelder, Abwässer ron Zueker-u. Stärkefabriken usw.). häufig. (Fig. 81.)

L. Iacteus $\mathrm{A}$.

8. Gattung: Apolachlya Pringsheim.

Fäden wie bei vor. Gatt. Aporangien terminal, kuglig od. bimt. schwärmsporen sieh vor der Mündung sammelnd n. nach lläutumgr fortsehwimmend. Oogonien unbekannt.

Zwischen fanlenden Characeen, anch in Abwäsoru, selten. (Fig. S.2.)

\section{A. pirifera Zopt}

\section{Reihe: Peronosporineae.}

Myzel schlauehf., meist in den Interzelhlaren der Nährpflanzen 11. mit Uanstorien versehen. Konidienträger verschierlen. Konirlin 
entweder zu schwärmsporangien werdend od. nit Keimschlauch keimend. Oogonien an kurzen Seitenzweigen, stets eineiig. Antheridien an Seitenzweigen, kurzzellig, sich in das Oogon einbohrend. AnBer wenigen Arten aussehließlich Parasiten von Landpflanzen.

Bestimmungtabelle der Familien u. Gattungen.

A. Schwärmsporangien vorhanden, die ihren

Inhalt in eine Blase entleeren u. darin tlie schwärmer bilden. Daneben oft Konidien. die mit Keimsehłanch austreiben. Wasserbewohner ol. Parasiten in fenchter Luft

a) Schwärmsporangien fadenf,, nicht breiter als die Fäden.

b) Sehwärmsporangien kuglig od. zitronenf.

B. Besondere Sehwärmsporangien fehlend. Nur konidien vorhanden, die sich zu Sehwärmsporangien umbilden od. nit Keimschlauch austreiben. Ansschließ. lieh Parasiten anf höheren Landpflanzen.

a) Konidienträger keulenf., unter der Epidermis entstehend, Konidien reihenweise gebildet.

b) Konidienträger über der Epidermis herrortretend, verzweigt. Konidien an den Enden der Äste einzeln gebildet, abfallend.

I. Konidien sofort schwärmsporen bilkend od. erst den Inlablt entleerend, der dann zu schwärmern wistl.

1. Konidienträger unverzweigt, nach Bildung der 1. Koniclie weiter wachsend $u$. damn auch bisweilen mit einigen /weigen.

2. Konidienträger vor Bildung der Konidien fertig verzweigt, meist baumf.

a) Auf Gramineen, die Blätter u. Blütenstände stark um. billend. Oospore fest mit der Oogonwandung verwachsen.

B) Nieht anf Cramineen, keine

Fam. Pythiaceae.

1. Nematosporangium.

2. Pythium.

Fam, Albuginaceace 3. Albugo.

Fam. Peronosporaceae.

4. Phytophthora.

5. Sclerospora. 
Verbildungen hervorrufend.

Oosporefrei im Oogron.

\section{Plasmopara.}

11. Konidien nur mit Keimschlauch keimend.

1. Konidien mit Scheitelpapille, durch die der Keimschlauch austritt.

\section{Bremia.}

\section{Peronospora.}

1. Gattung: Nematosporangium A. Fischer.

Schwärmsporangien fädig, nicht breiter als die Myzelfäden, oft nicht durch Wand abgetremnt. Konidien fehlen.

Schwärmsporangien nicht abgegrenzt durch Scheidewand. Oosporen mbekamnt. Parasitisch in Zellen ron Spirogyra, Cladophora, Vaucheria, Bangia atropursurea, selır zerstreut.

X. gracile (Schenk)

Selıwärmsporangien durch Wand abgegrenzt. Oogonien terminal od. dicht unter dem Astende gebildet $\mathrm{u}$. deshalb wie geschnäbelt aussehend. Auf Fliegen u. Mehwürmern im Wasser, sehr zerstrent.

N. monospermum (l'ringsh.)

2. Gattung: Pythium Pringsheim.

Schwärmsporangien kuglig od. zitronenf., breiter als die Fäden. Konidien wie die Sporangien, abfallend, meist mit Keimschlanch keimend. Oogonien kuglig, Antheridien kurz keulig.

1. Oogonien stachlig.

2.

Oogonien glatt.

3.

2. Sporangien \pm kuglig. Keine Konidien vorhanden. Oogonien meist terminal, durch zallireiche radiale, kegelf. Ausstülpungen stachlig. Antheridien von benachbarten Asten entspringend. Saprophytisch in abgestorbenen Pflanzenteilen in Waser, auch in feuchter Luft rasenbildend, zerstreut.

P. megalacanthum de By.

Sporangien n. Konidien mbekannt. Oogonien meist interkalar, kuglig, mit stachelspitzigen Ausstïlpungen, nicht so dichi stachlig wie bei vor. Antheridien aus angrenzenden Fadenstücken entstehend. Saprophytisch in abgestorbenen Pflanzenteilen, auch Kartoffeln, nicht selten.

3. Konidien ganz fehlend.

P. hydnospormm (Mont.)

Konidien vorhanden.

4. Sporangien kuglig od. br. eif., nach der Entleerung durchwachsend od. seitlich ein neues Sporangimn bildend. Oogonien intramatrikal. Antheridien meist 2, auf ebenso vielen kleinen am Tragfaden des Oogons entspringenden Nebenästen. Auf toten 11 . sekten u. Pflanzenteilen in Wasser, zerstrent.

P. proliferum de By. 
sporangien msw. We vor. Oogonime extramatrikal. Antheridien

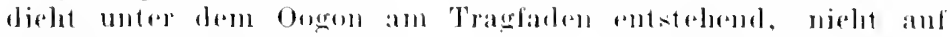
Nobenästen. Wie vor. W. lerax de By.

5. In l'llanzen.

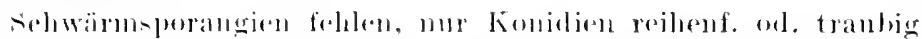

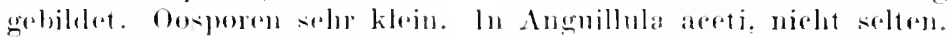

P.ancuillularacetisateb.

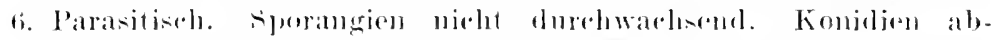

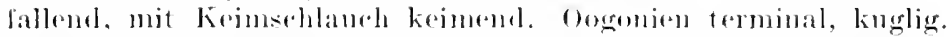

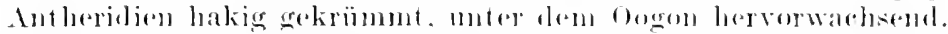

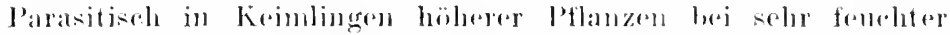

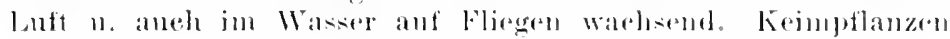
mofallend u. famlemel, häufigr. (Figr. sis.)

\section{P. Mr Bayamom llesse}

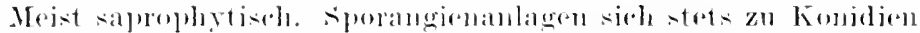

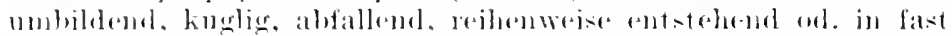

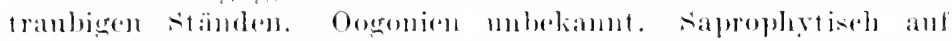

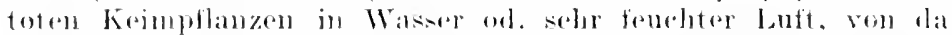

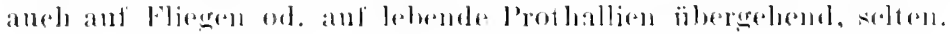

P. intermedium de liy.

\section{B. Frattuly: Albuen firay.}

l'arasitish, Hyzel inferzellular, Hanstorien kuglig-blasenf.

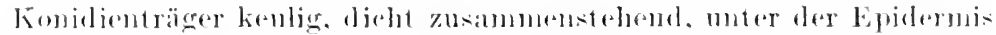

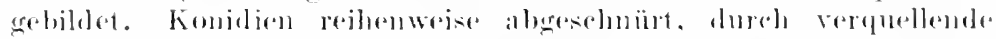

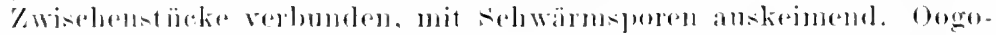

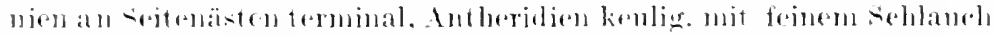

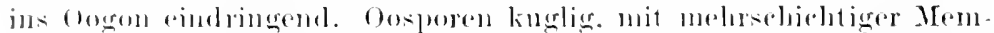

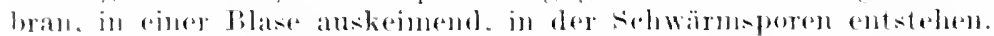

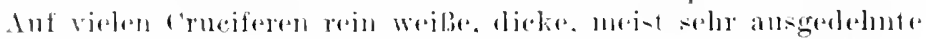

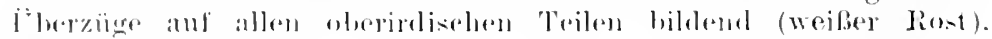

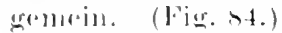

1. Candida (P'rers.)

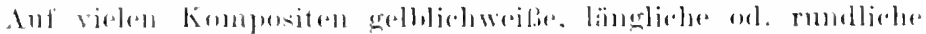
laterer bilrlend. löinlien.

A. tragopozoniv ( P'ers.)

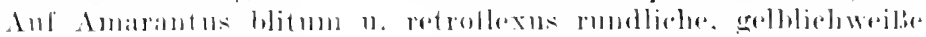
latger bildemel. selturer.

A. Iliti (biv. Bermlı.)

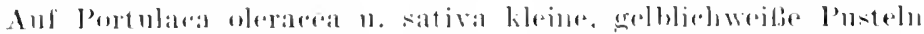
bildreld, zerstrimt.

1. portularare (I) $C^{*}$.)

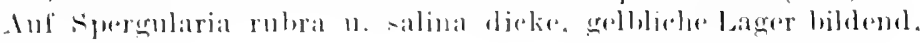
zoritrint.

I. Iopigoni de Jiy.

4. Cattolle: Inytophthoral de liy.

larasiton. llanstorien fädig. oft feblend. Fondienträger erst

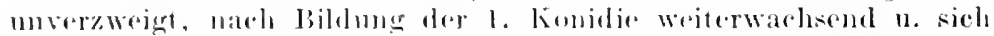
spärlieh ver\%weigend. Kondelien selawirmer bildend. Oosporen mir

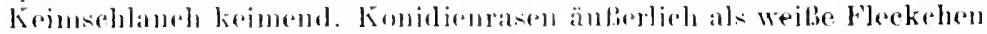
bemerkbar. 
(3)

84.

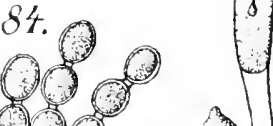

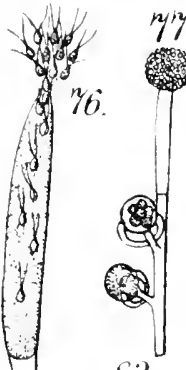
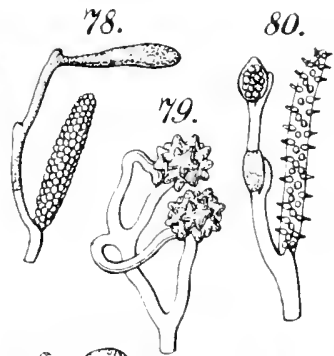

83. a a a

(i)

vices 89.

N) $79 \frac{S}{89}$.

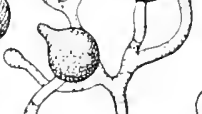

(1)

86 .

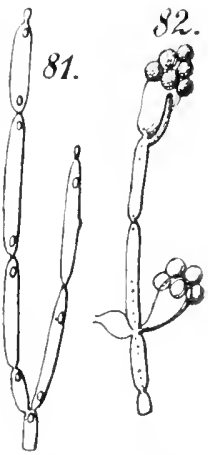

$8 \%$

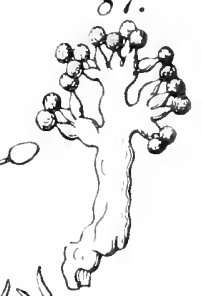

ivi)

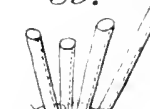

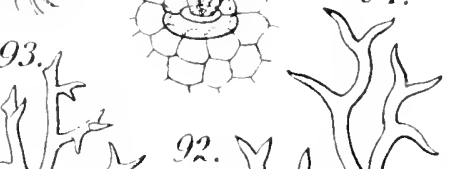

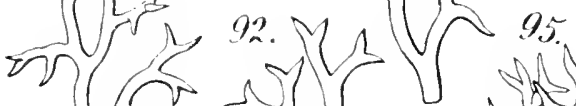

290 .

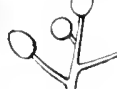

$9 \%$

99. $\mathrm{r}$

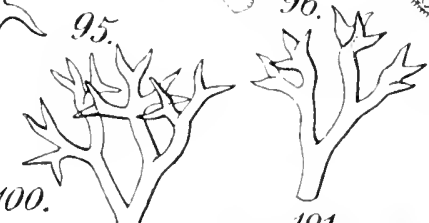

(a) $100 . \int_{104}^{101}$

98

.

10<smiles>C1=CC=[Se]=C1</smiles>

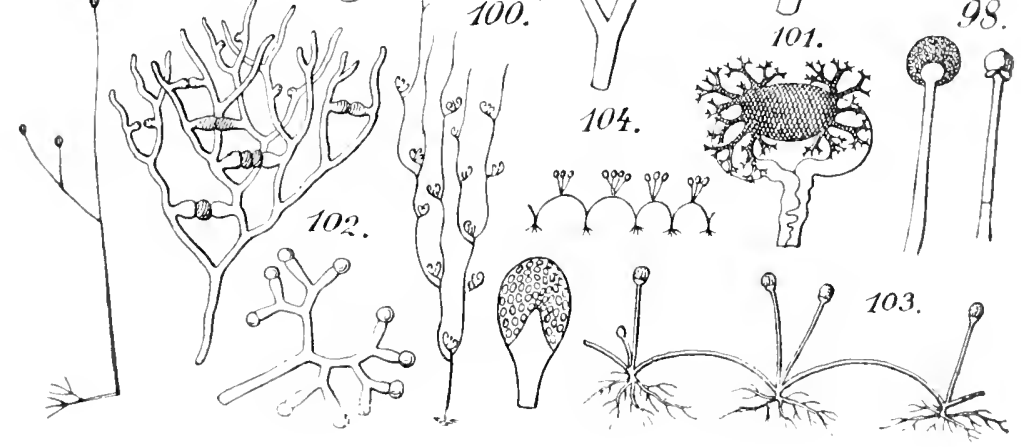


Oosporen bräunlieh. Konjdien zitronenf., $50-60 \mu \mathrm{lg} ., 35 \mu \mathrm{hr}$. u. größer. Auf vielen krautartigen I'flanzfu. namentlieh ihren sänlingen, besonders schärlich auf G(xächshauskakteen, sämlingen der Waldbäume in Pflanzginten nsw, stets die Ptlanzen verniehtend, läufig. (Fig. 85.) P. 'at Pormm (Cohnct Leb.)

Oosporen mbekamnt. Konidien ähnlich. aher viel kleiner. meist $27-30 \mu \mathrm{lg} . .15-20 \mu$ br. Auf Solanum-Arten, Authorreres viscosal 11. Selizanthus Grahami. Auf Kartoffeh die gefüreletete Kartoffel. fäule hervorrufend, in nassen Jahren nicht solten. (Figr. 86.)

P. inlestans (Mont.)

\section{Gattung: Selerospera Sehroet.}

Parasiten. Konidienträger niedrig, Verzweigungen kurz gabelig od. dreiteilig, erst an der Spitze des Trägers beginnend. Konidien mit Schwärmsporen keimend. Oosporen mit der Oogonwandung verwachsend.

Auf Setaria-drten die Blütenstände u. Blätter verbildend. zerstreut. (Fig. 87.)

s. eraminionala (sace.)

\section{Gattung: Planmopara Sehrort.}

Parasiten. llaustorien bläschenf. Konislenträser büselılig zu den spaltöfnungen bervorbrechend, rasenbildend, mit bämehenf.. oft spärlicher Verzweigung. Endästchen gerade, meist abgestutzt. Konidien mit Scheitelpapille, sehwämsporenbildend od. den Inlialt als Cranzes ausstobend, woraus dann die schwïmer hervorgehen.

Auf Anemone-Arten, Isopgrum, Aeonitum napellus niedrige, fleckenf., weiBe Rasen bilkend, nieht selten. F. S. (Fig. 88.)

\section{P. pyomaea (Ünger)}

Auf Geranium-Arten schneeweiße, fleckenf. Rasen bildend, häufig. F. S.

P. pusilla (de $\mathrm{Br}$.)

Auf dru Kotyledonen ron Impatins nolitangere, die Unterseite überzieliend, selten. F.

P. ohluerus sehroet.

Auf Epilobium palustre n. parvifolium weile, \pm große Rasen bildend, zerstrent. S.

P. epilobii (Rahenh.)

Muf Blättem 1. Früchten der Wriustöcke, gröliere u. hohe. weibliche Rasen bildend, oft häufig u. sehr schätlieh. S. Il. (Falscher Mrliltau.) (Fig. 89.)

P. vitiolala (Berk. ot Curt.)

Anf Umbelliferen sehneeweibe, niedrige liasen bildend, läufig. F. F. II.

l'. nivea (Ung.)

Auf Rhinanthen diehtr, weife, oft dir ganze Blattunterseite ïberzirlende Rasen bildend, hänfig. F. S. P. Jensa (Rabh.)

\section{Gattung: Bremia liegrel.}

Parasiten. IIaustorien blasen- od. keulenf. Konidienträger wiederholt dichotom verzweigt, letzte Anszweignug in eine schalenf. Platte erweitert, die seitlieh rinige spitzehen trägt, an denen je einc Konidie sitzt. Konidien mit Endpapille, mit Keimsehlaneh keimend. 
Auf Salat, Cichorien, Cinerarien u. anderen Gewächshauskompositen großen Schaden stiftend, zarte, weiße Rasen bildend, häufig. (Fig. 90.)

B. lactucae Regel

\section{Gattung: Peronospora Corda.}

Parasiten. Haustorien meist fadenf., 士verzweigt. Konidienträger aus einfachem Stanm, mehrmals dichotom verzweigt, Endäste spitz. Konidien olne Scheitelpapille, seitlich mit Keimschlauch keimend. Oosporen kuglig, glatt od. skulptiert, mit Keimsehlauch keimend. Kleine, meist weife od. graue Rasen bildend, selten weit ausgedehut, meist anf der Blattunterseite hervorbrechend.

1. Membran der Oosporen mit warzen- od. leistenf. Verdickungen besetzt (Calothecae).

Membran der Oosporen glatt od. höchstens gefaltet (Leio. thecae).

2. Auf Polypetalen.

Auf Sympetalen.

3. Auf IIolosteum umbellatum, nicht selten. F.

P. holostei Casp.

Anf Arenaria serpyllifolia u. Moehringia trinervia, nicht selten. F. S. H.

P. arenariae (Berk.)

Auf Alsine, Cerastium, IIonckenya, Spergula, Scleranthus. Stellaria (besonders media), häufig. F. S. H.

P. alsinearum Casp.

Auf Dianthus, Silene, Melandryum, Agrostemma, nicht selten. F. S. II.

P. dianthi de By.

Anf Vicia, Lens, Pisum, Lathyrus, häufig. F. S.

P. viciae (Berk.)

Auf Linum eatharticum, selten. S.

P. lini schroet.

4. Anf Erythraea, Chlora, zerstreut. S. P. chlorae de By.

Auf Ifyosotis, Omphalodes, Symphytum, Lithospermum, nicht selten. F. S.

P. myosotidis de By.

Auf Asperngo procumbens, selten. F. S.

P. asperuginis Schroet.

Auf Asperula, Galinm, Sherardia, nicht selten. F. S. H.

P. calotheca de By.

万. Wand des Oogons dick, mehrschichtig, nach der Reife nicht zusammenfallend (Parasiticae).

Wand des Oogons dünn, zusammenfallend.

6. Auf Corydalis-Arten, zerstreut. F.

P. corydalis de By.

Auf Cruciferen, besonders Capsella, oft mit Albugo candida zusammen, häufig. F. S. (Fig. 91.) P. parasitica (Pers.)

7. Auf Monokotyledonen. Auf Allium cepa u. fistulosum, zerstrent.

P. Schleideni Unger.

Auf Polypetalen.

Auf Sympetalen. 


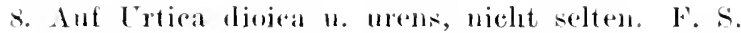

Auf clenopodiun, Atriplex, sinnacia, hänfigr.

P. nrticate (Lib.)

P. offusa (Grev.)

Auf Beta vulgaris, zerstrent u. sohäblieh. S. (Figr. 92.)

P. Scharhtii Fuck.

Inf spergula arvensis u, pentandra, häulig. F. S.

P. ohovata Bon.

Auf Ranumenlus, Ficaria, Jrosurus, nichi sellen. F. . Il.

P. lieariace T'ul.

Auf Eranthis hemalis, selten. F.

P. eranthidis Pass.

Auf Papraver, lüufig. F. S.

P. arhoresecus (lierk.)

Ant Fumaria, zerstreut. F. S.

P. affinis Robmann

Anf ('lurgosplenimu alteruifolimu n. Saxifraga gramulata, selten. li. is.

P. Clorysosplenii Fuck.

Auf Potentilla, Fragaria, Alohimila, Agrimonia, Sanguisorba, loterium, Pulus, nicht seltem. F.s. II.

P. potentillate de $\mathrm{Br}$.

Auf kultivierten Rosen. zersteut. F. S. P. sparsu Berk.

Auf 'Trifolinm, Medieago, Melibotus, Lotus, coromilla, Onomis, nivlut solten. F. S

P. trifoliorum de $\mathrm{BS}$.

Auf feranimm, Erodiun, nicht selten. S.

P. (onglonurata Fuck.

Iuf Euphorbia-Arten zerstrent. S. (Firg. :33.)

Auf Viola-Arten, selten. F. S. P. violae de $\mathrm{Br}$

9. Anf Anagallis, Androsace, J'rimmla veris, nicht selten. F. S. Il.

P. Candiula Fuck.

Auf Valeriamella, zerstreut. F. S. P. valeriamellat Furk.

Auf Vinea minor, selten. F.

P. vincale sehroet.

Auf Lamimn, Salvia. Stachys, Calamintla, Thymms, zerstremt. F.... II.

P. Iamii A. Biraum

Auf Veronica-Arten, hänfig. F. S. II. I. erinal I'nger

Auf Linaria, Digralis, zersterut. F. S. (Fig. 9.4.)

l'. linariae lenek.

Auf Antirrbinum oromtimm, selten. S. H.

P. antirhini singert.

Aut Blätern von mipsacus-drten, nicht häufig. F. . 11.

l'. dipsari 'Tul.

Auf den Blütruköplen von Dipsans pilosus. Knautia, Suerisa. nicht häufig. \&.

l'. violuceal lierk.

Anf Phytemma spieatum u, nigrmu, selten s.

P. phytomuatis Fuck.

Auf Bläterı, Hälblätern n. Stemgeh ron Anthemis, Matricaria, Tanacetun, zerstrent. F. S. H. (Jig. 9.5.)

l'. Ieptopperma de By. 
Auf den Blütenköpfen von Anthemis, Chrysanthemum, Matricaria, selten. S. II. (Fig. 96.) P. ralli de By.

\section{Unterklasse: Zygomycetes.}

\section{Reihe: Mucorineae.}

Myzel stets reich entwickelt, verzweigt, unseptiert, höchstens an den Fruchtorganen mit Scheidewänden od. spärlich im Alter gekammert. Sporangien od. Kondien vorhanden. Geschlechtliche Fortpflanzung dnrch Vereinigung zweier gleicher Aste erfolgend, die rameten vereinigen sich zur Zygospore u. bleiben durch die suspensoren mit dem Myzel verbumden. Auch Azygosporen gebildet. Chlamydosporen $u$. sehr kleme Myzelkonidien bisweilen vorhanden.

$$
\text { Bestimmungstabelle der Familien. }
$$

A. Ungeschlechtliche Fortpflanzung nur durch Sporangien (höchstems Myzelkonidien vorbanden).

a) Sporangien mit Columella. Zygo. sporen nackt od. locker mmhüllt.

b) Sporangien ohne Columella. Zygosporen mit dichter II iille.

\section{Mncoraceae.}

2. Mortierellaceac.

B. Ungeschlechtliche Fortpflanzung durch Konidien.
a) Kondien einzeln entstehend.
3. C'haetocladiaceae.
b) Konidien reihenweise entstehend.
4. Piptocephalidaceae.

\section{Familie: Mucoraceae.}

Bestimmungstabelle der Gattungen.

A. sporangienmembrau gleichmäßig, zerfließend od. zerbrechend, nicht kutikularisiert. Sporangien nicht abquellend od. abgeschleudert.

a) Sporangien alle gleichartig, vielsporig (Incoreac).

I. Myzel ohne rhizoidentragende Ausläufer, sporangienträger einzeln am Hyzel entspringend.

1. Sporangienträger nnverzweigt od. verzweigt, aber nicht gablig. Zygosporen am Myzel, nicht an besonderen 'Trägern.

a) Substrat-11. Luftmyzel gleich. Zygosporen am sinbstratmyzel.

\$ sporangienträger gran ol. brännlich, meist weil, 
Hatt. Sispensorendornen.

Jos.

+ sporangionträger stets mit sporamginu ah. seluliebend.

†† Sporangienträgrer steril embligend. sporangien an den îsten nirkend. SS sporangrienträger grüulicl ol. olivenfarben, metall. glänzend. Suspensoren mit dornigen Anlıängse]n.

ק) Substrat myzel farblos, Iuft nyyzel loraun, dornig. Zygosforen mur am Liftmyzel.

2. Sporangientrïger gablig, baumf. verzweigt. Zygosporen an be. sonderen Trä̈gern.

J]. Myze] mitrhizoidentragenden Ans. länferu. Sporangienträger meist hïschlig

1. sporangienträger nur an den Ausläuferknoten entstehend. Zygrosporen nackt.

\title{
6. Rhizopus.
}

2. Sforangienträger aufdem Scheitel der Ansläuferintermodien biischlig entstehend. \%ygo. sporen mit dorniger lï̈lle.

3. Pliy+oinyor.

4. Spinallus.

j. Sporodinia.

1. Hneor.

․ ('irciurlla.

\author{
6. Rhizopus.
}

7. Ilsidia.

b) Ëporangien mit zerfliebender Menbran u. violen sporen. Sporangiolen mit niclit zerfliebender Membran, wenigen sporen u. meist felnlender (olmumella. (Tha moldioge.)

1. Finrangiolen auf gerablen sticlen.

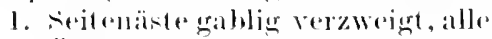
İto mit strorangiolen ahscluliclisemel.
จ. Thamnilimun.
a. Chactosiylun.

2. Sritruats steril horstenf. entigend, an ilurer angeselawollemen Mitte die wirteligr gestellten sporangiolen tragenel.

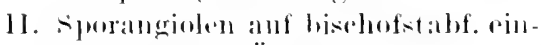

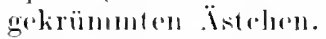

10. Helicostylum.

R. Sperangienmembran in oberen Treil nieht zerfliefend ad. zerbredend, sondern kutikularisiert, an der Basis anfyuellbar, 
alle sporangien gleichartig, vielsporig (Piloboleae).

a) Sporangienträger schlaff, oben nicht geschwollen, Sporangien unter $\mathrm{Zu}$ rücklassung der Columella abquellend. 11. Pilaira.

b) Sporangienträger steif aufrecht, oben angeschwollen, Sporangien mit der Columella abgeschleudert.

\section{Pilobolus.}

1. Gattung: Mucor Micheli.

sporangienstiele einfach od. verzweigt, an fler spitze in ein sporangium endigend. sporangienwand zerfließend od. zerbrechend. Suspensoren glatt.

1. Sporangienträger unverzweigt, selten einmal eine gelegentliche seitliche Auszweigung. 2.

Sporangienträger traubig verzweigt, momopodial. 4 .

Sporangienträger zymös verzweigt, \pm sympodial, wieklig. 5.

2. Sporangienstiele lg., jedenfalls über $1 \mathrm{~mm}$, Rasen nicht rosenrot.

sporangienstiele bis $1 \mathrm{~mm}$ hoch, sporangien kupferfarben. Rasen rosenrot. Im Waldboden hänfig. (Fig. 98.)

\section{Ramannianus Möller}

3. Sporangienwand sehr schmell zerfließend, wenig Quellsubstanz vorhanden, Columella mit orangegelben Inhalt. Auf Mist, sieh zersetzenden organischen Stoffen, ïberall gemein. (Fig. 97.)

I. mucedo L.

Sporangienwand langsam zerfließend, viel Quellsubstanz ror. laanden, Columella farblos. Auf Pferdemist, häufig.

II. mucilagineus Brel.

4. Verzweigung rein traubjg, Seitenäste stets kürzer als die Ilauptaxe. Mit Chlamydosporen. Sporangien gelblich bis hellbräunlich. Auf Mist u. faulender Substanz, überall häufig. (Fig. 99.)

I. racemosus Fresen.

Verzweigung doldentranbig, Nebenäste so lg. wie die Hauptaxe. sporangien fast schwarz. Auf Weisbot, anch pathogen im Kaninchen.

M. pusillus Lindt

5. Columellawandung ganz glatt.

6.

Columellawandung mit einigen geraden od. gebogenen Aus. stïlpungen. Sporangien schwarz od. dunkelbraun, feinstachlig. Auf Pferdemist, Brot, Kartolleln usw., häufig.

M. spinosus van Tiegh.

6. Rasen dunkelgrau. Ältere zuerst gebildete Sporangien zerfließend, jüngere u. kleinere fest. Auf Pferdemist u. faulen Kartoffeln, zerstrent.

II. circinelloidles van Tiegh.

Rasen schwarz. Alle Sporangien nicht mit zerfließlicher, sondern zerbrechlicher Wandung. Auf Brot, Kleister, zerstrent.

I. brevipes Riess 


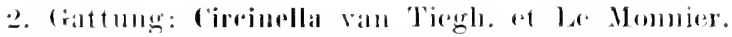

sporatugenträger weiterwachsend, steril all der spitze, seitliels sporangien in versehiedoner Amordumber tragend, nickend.

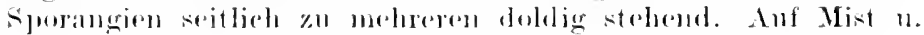
P'llatmonteidell, seltell. (Figr. 100.)

('. Imberlata van Tiregh. e. L L Momm.

3. Crattung: Plugeomyres kimze.

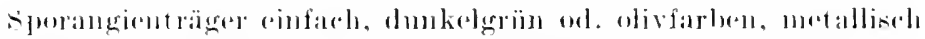

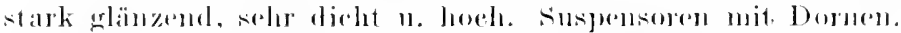

Aul bligen sulstanzen, aneh auf Brot, Mist nsw., in ofen Jabu. ratorien, nivht selten. (Fig. 101.)

P. nitem (Agardls)

4. (rattumg: Spinollus van Tiegh.

substatmyzel farblos, olne Doruen. Lufturgel brants, filzig.

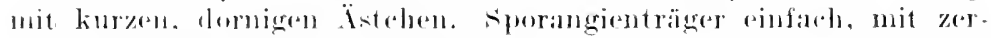

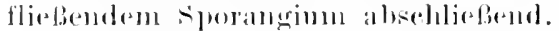

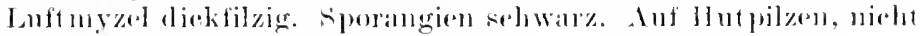
sitell. $\therefore$ II. S. luvierer (Liuk)

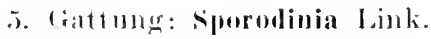

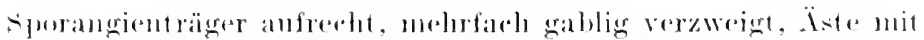

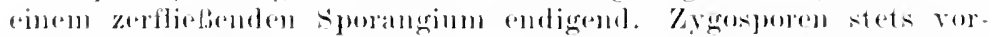

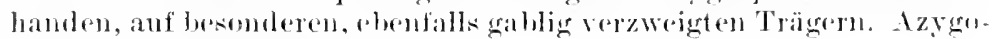
sperem oft rorlianden.

Inf fleishligen llutpilzen, zerstrent. (ligg. 102.)

\section{S. aspergillu (s.01\}.)}

\section{(i. Crattumg: Rhizopus Ehremberge}

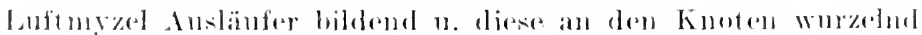

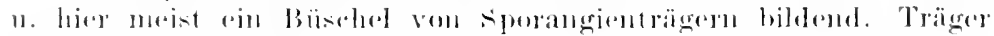

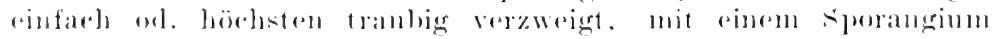

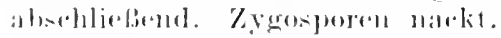

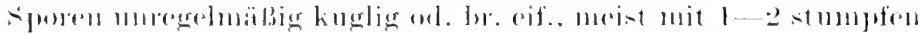

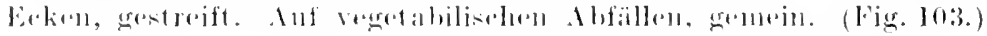

R. nimpiean, lihreub.

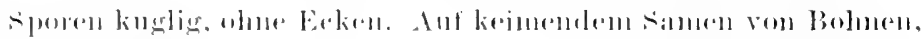
Elibill 11. Mais.

R. Mrandu Eirlam

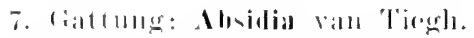

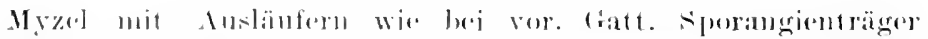

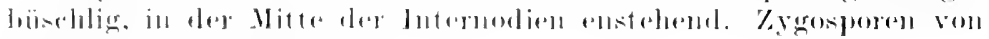

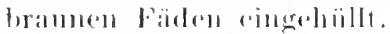

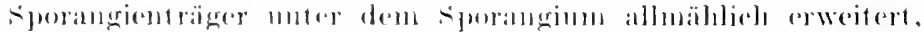

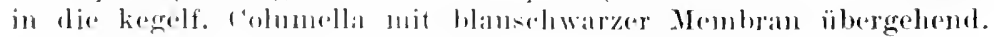

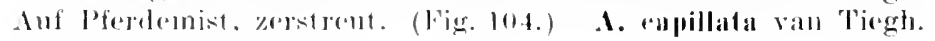




\section{Gattung: Thamnidium Link.}

Sporangienträger mit großem . Sporangium abschließend, unterhalb einzelne od. quirlig gestellte Äste tragend, die mehrfach gabel teilig sind u. an den Enden kleine Sporangien (Sporangiolen) mit wenigen sporen tragend. Zygosporen nackt.

Auf Pferdemist, Brot, Kartoffel, Pilzen usw., nicht selten. (Fig. 105.)

T. elegans Link

9. Gattung: Chatostylum ran Tiegh. et Le Monn.

Sporangienträger wie bei vor. Gatt., aber die Seitenäste steril endigend $n$. die sporangiolen quirlig in der Mitte tragend.

Auf Mist, zerstreut. (Fig. 106.)

$$
\text { C. Fresenii van Tiegh. et Le Monn. }
$$

10. Gattmong: Helicostylum Corda.

sporangienträger mit Sporangimm abschließend, mit verschieden angeordneten Seitenästen, die bischofstabf. eingekrümmt sind $и$. am Ende mit einer Sporangiole abschliefen.

Auf verschiedenen faulenden Substraten, selten. (Fig. 107.)

H. elegans Corda

\section{Gattung: Pilaira van Tiegh.}

Sporangienträger cinzeln, schlaff. Sprrangienwand im oberen Teil schwarz, kutikularisiert, nicht zerfließend, im unteren farblos, zart, verquellend u. damit das Sporanginm von der Columella lösend. Columella br., knopff.

Auf Mist von Pflanzenfressern zerstreut. (Fig. 108.)

P. anomala (Cesati)

\section{Gattung: Pilobolus Tode.}

Sporangienträger einfach, einzeln, straff bleibend, muter dem sporangium aufgeselıwollen. Sporangienwand kutikularisiert, fest. schwarz. Sporangien mit großer Gewalt abgeschlendert.

1. Sporen orange gefärbt. 2 .

Sporen farblos, ellipsoidisch, ca $5-10$ a $\lg$. Auf Mist voll Pflanzenfressern, häfuig. (Fig. 109.) P. cristallinns (Wiggers)

2. Sporen kuglig od. ellipsoidisch, $12-20 \mu$ lg. Ebenda, aber seltuer.

P. Kleinii van Tiegll.

Sporen kuglig, mit derher, zweischichtiger Mombran, $8-1+\mu$ in Durehm. Auf Mist, seltner. P. oedipus Montagne

\section{Familie: Mortierellaceac.}

Sporangien olme Columella. '/ygosporen in ein Gewebegehäuse eingeschlossen. Träger einfach od. verzweigt, nit sporangrien abschliebend. 
Einzige (rattumg: Mortierella commans.

1. Sporangientrïger verzweigt.

sporangientrïger morerzwigt. Sporangien weiß. Sporen ellip. soidisch $6 "$ lg.. 5 " br. Iuf l'ferelemist, nicht häufig. (Fig. 1]0.)

ll. Rostafinskii Brof.

2. Ilauptstamm mit sporangien absehliebend, Scitenäste abstelend, einzehn od. wirtelig, mit kleineren sporangien absehliebend. Auf Mist, morlomelen pflanzenteilen 11 . holzigen stehwämmen, seltent.

ll. polyrephata rowenans

sporangientrïger zymös verzweigt, seitenäse sich bogig ab. krümmend n. dann senkecht aufwachsend, den llauptstamm ïberwipfelut, das ganze kandelaberartig. Sporen etwa kuglig, ca. fi" im Durchm. Anf Mist, molernden Pflanzen u. Ilutpilzen, seltcrn.

M. cambelabrun van Tiegh. et Le Momm.

\section{Familie: Chactocladiaceac.}

Konjdenträger verzweigt, ähnlich den seitenästen von Chartostylum, meist rankend. Kondien ainzeln an den letzten spitzehen der Zweige sitzend. Zygosperen nackt.

\section{Einzige Gattmon: Chantorlatimn Fresentus.}

Konidien kuglig, 6,5-l0 1 in Durchm. Parasitisele ant den

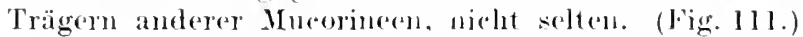

\section{Jomesii Fresen.}

In allen Teilat kleiner, kondien nur $2-5 \mu \mathrm{mm}$ 1)urchm. Ebenda, abor seltuer.

C. Brofeldi vanT jeght. at le Momm.

\section{Familie: Piptocephalidaceae.}

Kondienträger einfach od. verzweigt. Kondien reihenweise arejildet. Zygosporen naekt.

\section{Gattmon: Piptorephalis de bary.}

Konidienträger oben melorfach gablig, später gelorämit u. mit vielen Querändern, Astenden mit einer otwa kugligen Ansehwelmmeg. an deren Iföcliern die Konidientedten sitzon.

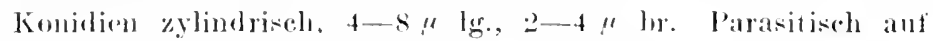

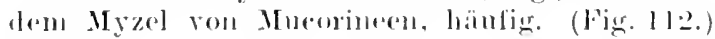

\section{l'. Freveniana de $13 y$.}

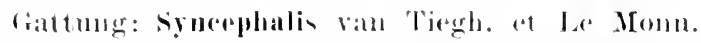

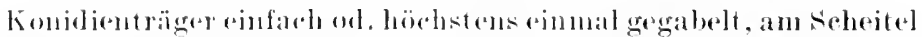
kantig od. kuglig angeschwollen. Anf der Jlase stehen Zellen von

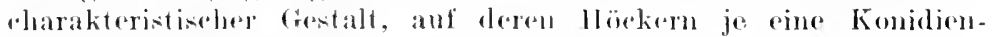
bettes sitzt

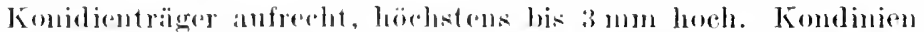
zylindrisele tomnenf., s- $10 / 1$ ] gr., i $\mu$ br. Auf M[ucorineen u. Mist, von da anf andere substrate ïlerehend, nicht selten. (Fig. 113.)

s. cordata van Tiegli. ot Ie Momn. 
Konidienträger aufrecht, oben bogenf. gekrümmt od. eingerollt, bis $0,2 \mathrm{~mm}$ hoch. Konidien spindelf. od. ellipsoidisch, $10-12 \mu \mathrm{lg}$., $4-6 \mu$ br. Parasitisch auf Mucorineen auf Mist, seltner. (Fig. 114.)

s. cormu ran Tiegh. et Le Monn.

\section{Reihe: Entomophthorineae.}

Myzel reich entwickelt, schlauchf., parasitisch, später geteilt. Konidien am Ende von schlauchartigen Trägern gebildet u. abgeschleudert, einzellig od. auch keine entwickelt. Zygosporen durch Vereinigung des Inhaltes ron zwei Zellen im Innern des Substrates gebildet, häufiger Azygosporen vorkommend. Keimung dureh Keimschläuche.

Bestimmungstabelle der Gattungen.

A. In Insekten lebend.

a) Konidienträger unverzweigt. Zygosporen unbekannt, Azygosporen vorkommend.

b) Konidienträger verzweigt. Zygosporen u. Azygosporen vorkommend.

B. In Pflauzen od. auf Mist.

\section{Empusa.}

2. Entomophthora.

a) Myzel schwach entwickelt, in den Zellen.

3. Completoria.

b) Myzel reich entwickelt, nicht in den Zellen.
I. Auf Pilzen.
4. Conidiobolus.
II. Auf Mist.
5. Basidiobolus.
III. Auf Laub n. Erde.
6. Endogone.

\section{Gattung: Empusa Cohn.}

Myzel im Innern ron Insekten, die einfachen Konidienträger hervorbrechend. Konidien kuglig od. eif., weit abfliegend. Azygosporen im Innern, dickwandig, braun.

Auf der Stubenfliege, sie im Spätsommer abtötend. (Fig. 115.)

Bei Raupen Epizootieen erzeugend.

E. muscae Colin

Auf Jassus sexnotatus.

E. aulicae Reich.

Auf Aphis-Arten.

E. jassi Cohn

E. Fresenii Nowak.

\section{Gattung: Entomophthora Fresenins.}

Myzel im Innern von Insekten, als Luftmyzel austretend 1. das Insekt an der Unterlage befestigend. Konidienträger verzweigt. Zygo- od. Azygosporen im Innern gebildet.

Auf Raupen. (Fig. 116.)

Auf Mücken (Chironomus).

Auf Aphis-Arten.
E. splıaerosperma Fresen.

E. conica Nowak.

E. aphidis Hoffm. 
3. Cattunge completoriat lohote.

Hyzel in den \%ellen. Konidienträger seblanehf, die Zellhaut

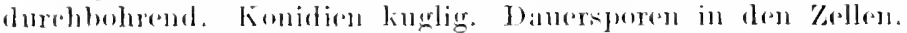

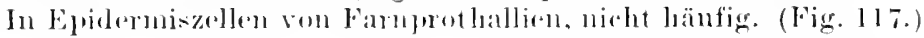

('. complens Lohide

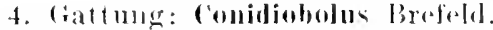

Mrzel parasiticels. Komblenträger einfarh, ant bude kenlig.

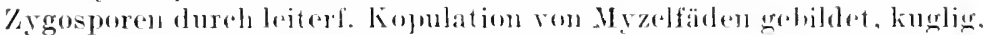
mit moluseluichtiger Membran.

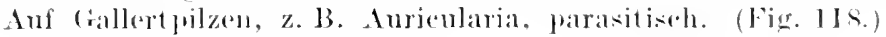

(.) ulripulosus liref.

\section{Gattunge Basidiobolus Eidam.}

Myzel diek, zuletzt vielzellis. Komblenträger einfach. am Eude

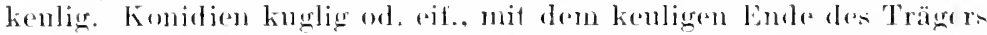

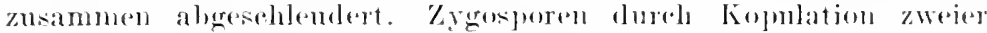
benachbarter \%ellen entstehend, kugligr, dirkwaldig.

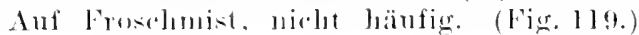

\section{B. ramarmm livlam}

\section{Ciatlung: lindowomo link.}

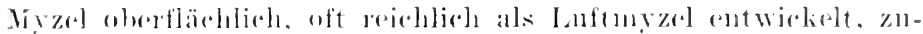

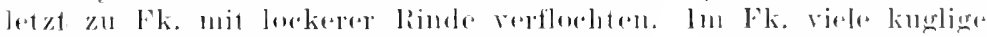
sporalligirll.

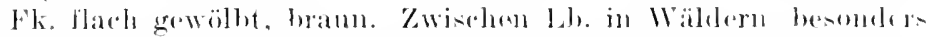

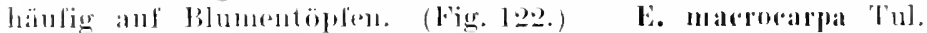

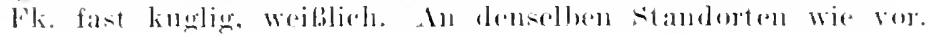
E. pisilorani, link

\section{Klasse: Mycomycetes.}

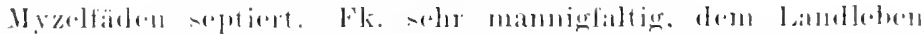

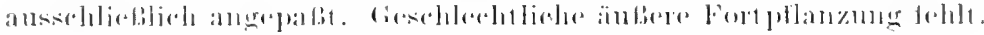

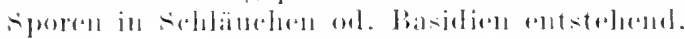

\section{Cunterklasse: Ascomyredes.}

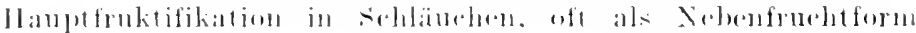
kinidien.

\section{Reihre: Irrmiascineare.}

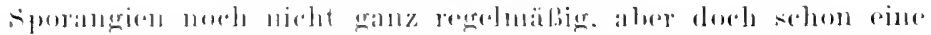

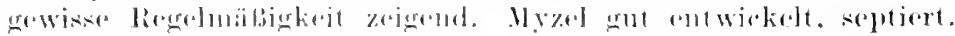

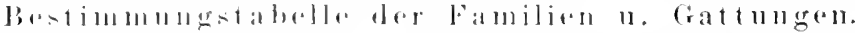

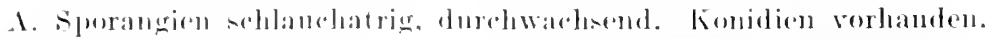
Fam. Ascoidearene. 
B. Sporangien keglig od. ellipsoidisch, frei stehend od. im Innern des Substrates. Konidien fehlend.

a) Sporen regellos im Sporangimm entstehend.

b) Sporen wandständig im ansgetretenen Endospor entstehend, kopulierend.

c) Wie Protonyces, aber die sporen nicht kopulierend.

Fam. Protomycetaceac.

\section{?. Volkartia.}

\section{Protomyces.}

4. Protomycopsis.

1. Gattung: Ascoidea Brefeld.

Myzel oberflächlich, große Klmmpen bildend, dick, reich septiert. Sporangien terminal, wie bei saprolegnia durchwachsend. Sporen zahlreich, hutf, in einer Ranke entleert. Konidien terminal u. seitlich ansitzend, länglich.

In Schleimflüssen ron Rotbuchen dicke bräunliche Massen bildend. S. Bisher nur in Westfalen gefunden. (Fig. 120.)

\section{A. rubescens Bref. et I indau}

2. Gattung: Volkartia R. Maire.

Bildet anf den Blättern des Wirtes granweiße Úberzüge und verursacht leichte Kräuselungen und blasige Anftreibungen. Fertile Hyphen unter der Blattepidermis ausbildend $u$. linglige oul. länglich ellipsoidische Chlamydosporen erzengend.

Auf IIeracleum sphondylinn. V. umbelliferarum (Rostr.)

3. Gattung: Protomyees Unger.

Myzel interzellnlar, parasitisel, mit Haustorien. Chlamydosporen mit dicker Wandung im Verlauf der Fäden gebildet, auskeinend in ein blasiges sporangimm, das die Sporen durch Zerreißen plötzlich ausschleudert. Sporen regelmäßig paarweise kopulierend.

Dicke Schwielen an stengeln, Blättern usw. ron Umbelliferen bildend, besonders auf Aegopodiun häufig. (Fig. 121.)

\section{P. macrosporus Ung.}

Ïnnliche Schwielen an Taraxacum bildend, seltner.

P. pachydermus $v$. Thïm.

4. Gattung: Protomycopsis Magnus.

Wie Protomyces, aber die Sporen nicht kopulierend.

Grauweige Blattschwielen auf der Blattunterseite, seltener an den stengeh bildend, im Hochgebirge anf Chrysanthemum.

P. lencantheni Magnus.

\section{Reihe: Exoascineae.}

Myzel gar nicht entwickelt $n$. daher Zellen einzeln od. reichlich entwickelt, verzweigt. Schläuche durch Umbildung einer Zelle cnt stehend od. pinzeln am Myzel od. in Lagern.

Lindau, Kryptogamenflora II, 1. 2. Aufl. 


\section{Bestimmungstabelle der Familien.}

A. Mrzel felilend. Zellen einzeln od. Sprofkolonien bildent, sporenbildung in Jumern einer regetativen Zelle.

B. Myzel stets vorhanden.

a) Schläuche einzeln an den Myzelzweigen entsteluend.

Fant. Saccharomycetaceae.

b) Sehlïnche lagerartig dicht nebencinander stehend.

1. Saprophytiseh auf Ifolz.

II. Parasitisch jn Blättern.

Fan. Endomycetuceae.

Fan. Ascocorticiaceae. Fam. Exwascacene.

\section{Familie: Saccharomycetaceae.}

Hefen. Myzelzellen einzeln of. zn S̈proßkolonien zusammenhängend. Sporenbildung in Tnnern einer Zelle, nach vorheriger Kopulation mit einer anderen Zelle od. olme dieselbe. Sporen sehr verschielen gestaltet. - I) ie (rattungen lassen sich nu untersehejelen, wenn man ihre sporenbildung kennt, die mejst erst in der kultur erfolgt. Für den Anfünger genügt die kenntnis der fattung șa charomyees Meyen, die sprolikolonim besitzt u. die hugligen od. eif. Sporen zu 2-6ev. mit vorheriger kopulation in ciner Zelle bildet.

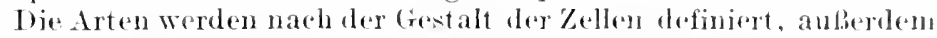
werden zahlreiche liassen bej den Arten unterschieden, die durch bestimmte Gärumgspozesse charakterisiert sind. Als sammelspezies haben die Bierhefen (S. cerevisiae Mey., Fig. 123), die Weinhefen (S. ellipsoideus Reeli), die Kabmbefen (s. myoodema Reeb) 11. a. zu getten.

\section{Familie: Endomycetaceac.}

Myzel oberflächlieh, schimmelartigr. Schlämche terminal, 4 his seporig. sporen einzellig. Oft chlanydosporen u. Konidienketten vorhanien.

\section{Crattung: Eromaseas lidiam.}

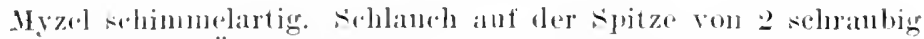

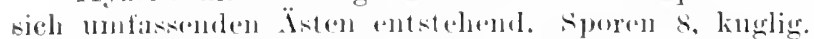

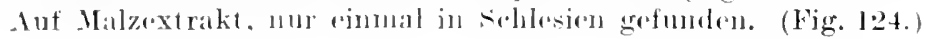

E. allus Eid.

\section{Cattumg: Eudomyces Reed.}

Myzel selimmelartigr. morist parasitiesend. Selnäuche einzehn terminal an Soitenästen gebildet, 4 pporigr. Sporen einzellig, hyalin, versehieden gestaltet. Konidienketten n. Chlamydosporen vorhanden.

schnceweibe Rasen anf dem lamenlen von Armillaria mellea bildend. Sporen hulf. Zerstrent. (Fig. 125.) E. decipiens (Tul.) 

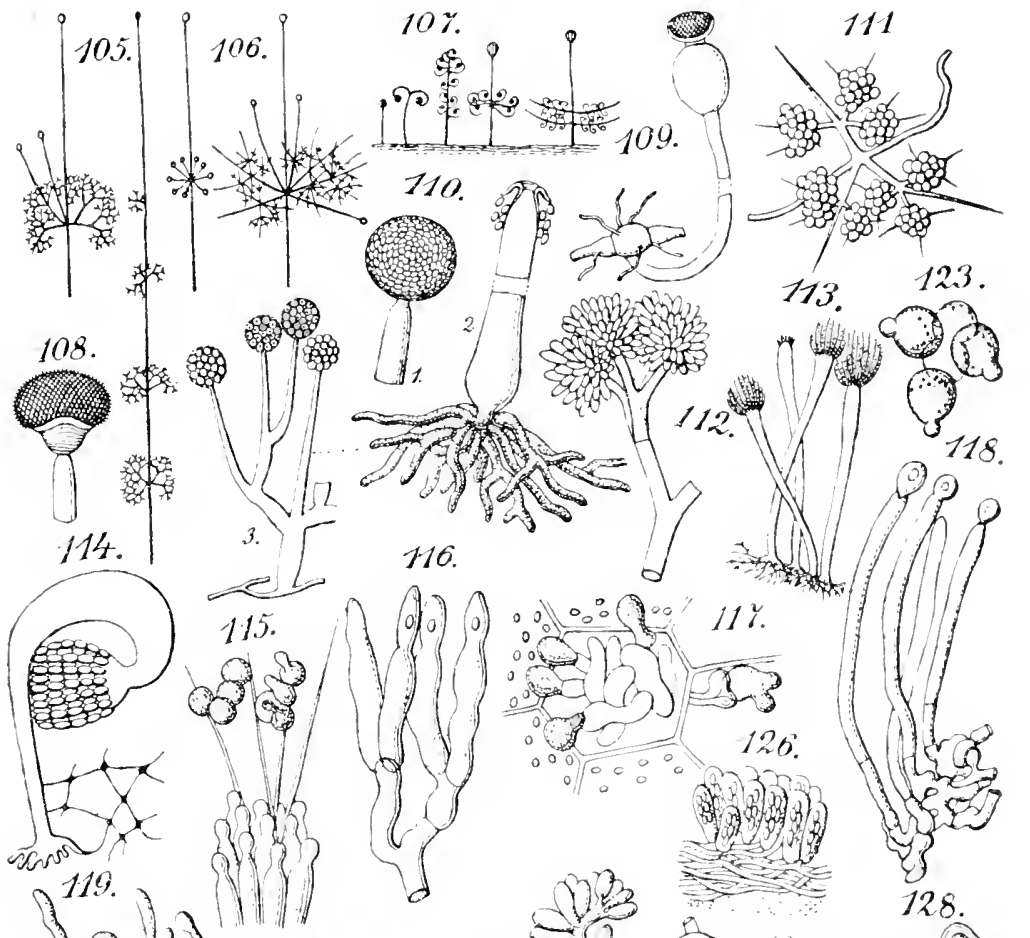
2171 120. (115)
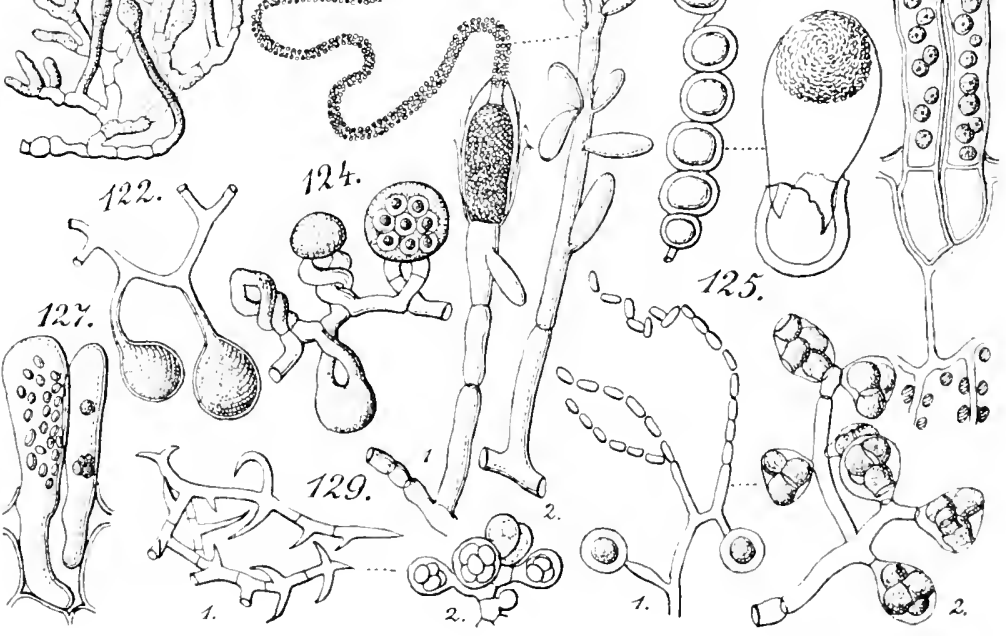
In selaleinfluls ron Eichen dicke wejle l'olster bildend. Sporen ellipsoidiseh, warzig. Bisher nur in Thïringen.

\section{Maguusii Judw.}

\section{Familie: Ascocortiaceac.}

Vegetatives Myzel oberflälhlich zart, anf iln die schläuche dicht nebencinander lagerartig stohend. Fuoness s, einzellig, hyalin.

Einzige Gattung: Ascocorticimm linel.

Grauwoils bis rötlich, 3-6 em lin., 0,5-l cul br. Auf der Rinde von Kirferustimplon, nicht länfig. (Fig. l:26.)

A. alhilum liref. et r. Tav.

\section{Familie Exoascaceac.}

Myzel parasitisch, oinjälurig od. peremnerend u. damn hexenbesenbildend, unter der Kutikula or. fror Epidermis wachsend. Sehläuche aus Mrzelzellen lagerf. emporwachsend. Sporen 4. 6, 8, einzellig, livalin, oft im seblamel schon hefenartig sprosiend.

Bestimmungstabelle der Cattmugent.

A. Das ganze sublintilulare Myzel fast rest.

los in sirhläucles sich muwandelud.

B. Nur die Euden des interzellularen Mrzels

zu sichläuchen sich $1 \mathrm{~m}$ wandelud.

J. 'Taplırina。

2. Magrusiella.

\section{Crattumgr: Taphrina Fr.}

Sehläuehe die Kutikula durelıbechend n. rin freistelendes Lager bildemd. Iläufig Verbiegmegen 11 . Ansbenlungen der Blätter od. Hexenbesen an Zweigent ryangend.

1. Auf Farmen (Cnterg. Taplurinopisis).

Auf Hölexent Pflanzen.

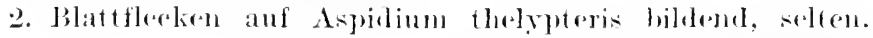

'T. Intescens Rostr.

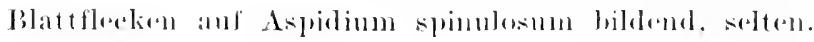
'T. lilicinal Restl'.

3. Anf Julifuren (Lutregr. Eutaplotiua).

$\because$.

3.

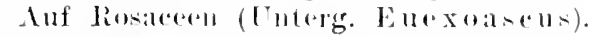

4. Auf Sillicaterent

12.

Auf Brotulacerent.

ก.

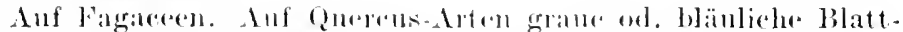
flecken arzengend, seltent.

'T' roerulesceus Tul.

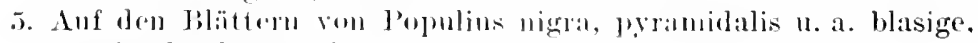

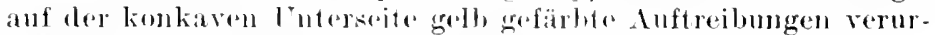
sachend, nicht sellen. (lig. 1:27.)

'l. alurea (l'ers.)

Auf den Frmelitkoten von Pupulus- Irten.

(i.

6. Auf P. tremula. Inäufig.

Auf P. alha, nicht seltem.
T. Joluansoni sadeb.

'T. rhizophora Johans. 
7. Auf Betula.

8.

Auf Alnus.

10 .

Auf Carpinus, hexenbesenbildend, zerstreut.

T. carpini Rostr.

8. Hexenbesen bildend.

Blattflecken bei Betula-Arten verursachend, nicht sclten.

T. betulate (Fuck.)

9. Schläuche oben \pm abgermulet. Auf B. pubescens n. carpathica, zerstreut.

T. betulina Rostr.

Schläuche oben rechteckig. Auf B. verrucosa, zerstreut.

T. turgida Sadeb.

10. Auf den Blättern von Alnus incana grane Überzüge erzengend u. hexenbesenbildend, nicht selten.

Auf den Blättern von A. glutinosa.

T. epiphylla Sadeb.

Auf den Zapfenschuppen von A. incaua u. glutinosa Deformationen erzeugend, zerstreut.

T. alni incanae (Külın)

11. Blattflecken rundlich, gelblich od. weiß. Stielzellen der Schläuche zwischen die Epidermiszellen nicht eingesenkt, Schläuche 41 bis $55 \mu \mathrm{lg}$. Zerstreut.

T. Sadebeckii Johans.

Blattflecken grauweiß, ausgedelnt auf den vergrößerten Blättern. Stielzellen zwischen die Epidermiszellen eingesenkt, Schläuche $31-37 \mu \mathrm{lg}$. Zerstrent. (Fig. 128.)

12. Auf Crataegus od. Pirus.

T. Tosquinetii (Westend.)

Auf Prunus od. Persica.

13.

Auf Potentilla silvestris Flecken u. Anschwellungen der Achse u. der Blätter erzeugend, selten. T. potentillae (Farl.)

13. Anf Crataegus oxyacantha u. monogyna an den Blättern Flecken u. Terkrïmmungen erzeugend, zerstreut.

T. cratacgi Sadeb.

Auf Pirus communis u. japonica blasige Auftreibungen an den Blättern verursachend, zerstreut.

T. bullata (Berk. et $\mathrm{Br}$.)

14. Auf den Blättern.

Auf den Früchten.

15. Auf Persica rulgaris, seltner anch Amygdalus Blattkräuselungen verursachend, nicht selten.

T. deformans (Berk.)

Auf Prunus-Arten auf Blättern $u$. hexenbesenbilklend. 16.

16. Auf Prunus insititia u. domestica graubereifte Blattflecken unterseits verursachend u. Hexembesen, zerstrent.

T. insititiae (Sadeb.)

Auf Prumus cerasus u. avium Blattdeformationen u. hexenbesenbildend, zerstreut.

T. cerasi (Fuck.)

17. Deformationen der Früchte (Narrentaschen) bei P. domestica u. padus verursachend, häufig.

T. pruni Tul.

Narrentaschen bei P. spinosa u. insititia erzeugend, zerstrent.

T. Rostrupiana (Sadeb.) 


\section{Grattung: Magnusiclla satleb.}

Schläuhe ummittelbar an den Euden der Mryelzweige, meist zwischen den Epidermiszeling gebilıtet, vorher kein schlanchbildendes Gewebe entstehend.

Sporen ellipsoidisch, $7-8 \times 4 \mu$. Auf Potentilla silvostris, zerstreut. F. S.

M. potentillae (Farlow)

\section{Roilue: Plectascineae.}

Fk. meist t kuglig, klein od. grob, von einer aus lockeren Fäden gebildeten od. festen Itülle (Peridie) ungeben, die unregelmäßig aufreißt. Fclıläuche an den die Fk. ausfüllenden Fäßen an Seitenzweigen ganz unregelmäßig entstehend, meist \pm kuglig, die Sporen später moist pulverig.

\section{Bestimmungstabelle der Familien.}

A. Peridie nur aus wenigen lockeren Fïden bestehend, daher die schläuche durch. scheinend.

1. Gymmoascaceae.

B. Peridie fest, geschlossen.

a) Fk. oberirdiscl.

I. Fk. ungestielt, klein.

2. Aspergillucene.

II. Fk. gestielt, viel größer.

3. Onygenaceae.

b) Fk. interirdisch.

I. Peridie nach dem Innern seharfabgesetzt. Sporen bei der Reife pul. verig.

4. Elaphomyectaceae.

II. Peridie nach imnen nicht selıarf abgesetzt, in das schlauchbildende frewebe übergehend. Sporen bei der Reife nicht pulverig.

\section{Terfezincene.}

\section{Familie: Gymmoascaceac.}

Peridie locker, fädisg. Selüiurhe das ganze lunere des Fk. ausfüllend, kuglig, 8 sporig.

$$
\text { Bestimmungstabelle der Gattungen. }
$$

A. Fiaden der Peridie dünn, gleichartig.
a) Sporen farblos od. lebhaft gefärbt.
1. Arachiniotus.

b) Sporen braun.

2. Amauroascus.

B. Peridie aus dickwandigen Fäden bestehend, die verbunden 1 . an den kndauszweigungen besonders gestaltet sind. a) Iste der Peridienfäden in Zacken od. Stacheh auslaufend.

\section{Gymnoaseus.}


b) Äste spiralig eingerollt.

c) Äste kammf.

1. Gattung: Arachniotus Schroeter.

Fk. kuglig. Peridie ans feinen, spinnewebartigen Fäden verwebt.

Fk. weiß, bis $2 \mathrm{~mm}$ br. Sporen hyalin. Auf Mist u. faulenden organischen Substanzen, selten.

D. candidus (Eid.)

Fk.1 mm br. Fk. u. Sporen goldgelb. Auf faulenden Vegetabilien, selten.

A. aureus (Eid.)

2. Gattung: Amauroaseus Schroeter.

Fk. u. Peridie wie bei vor. Gatt. Sporen braun. Anf altem Mist, selten.

A. niger Schroet.

3. Gattung: Gymnoascus Baranetzky.

Fk. kuglig. Peridie ans dickeren Fäden gebildet, die am Ende od. an den Zweigen in Haken ausgehen.;

Fk. gelb bis orangebräunlich, bis $0,5 \mathrm{~mm}$ br. Auf Mist, zerstreut. (Fig. 129.)

G. Reessii Bar.

\section{Gattung: Myxotrichum Kunze.}

Fk. kuglig. Enden der Peridienfäden spiralig gerollt.

Fk. gelb bis orange, bis $0,7 \mathrm{~mm}$ br. Auf Mist, selten.

I. uncinatum (Eid.)

Fk. graugrün, ca $1 \mathrm{~mm}$ br. Auf faulendem Papier, Pappe, nicht selten. (Fig. 130.)

M. chartarum Kze.

\section{Gattung: Ctenomyces Eidam.}

Fk. kuglig. Peridienäste teils in kammartige Anhängsel aus. laufend, teils schraubig gerollt.

Auf faulenden Federn, einmal gefunden. (Fig. 131.)

C. serratus Eid.

\section{Familie: Aspergillaceae.}

Fk. klein, oberirdisch, ungestielt. Peridie fest, häutig bis fleischig, urregelmäßig zerfallend bei der Reife. Sporen einzellig.
A. Fk. mit zottiger Bekleidung.
1. Cephalotheca.

B. Fk. kahl.

a) Sporen ohne Stacheln.

I. Konidien in Ketten entstehend, außerdem Büchsenkonidien vorhanden.

\section{Thielavla.}

II. Konidienträger mit blasiger Endanschwellung, auf der einfache od. 
verzweigte Sterigmen stehen, die sporenketien bilden.

3. Aspergillus.

III. Konidienträger pinselig verzweigt, an den Endästen Ketten von Konidien.

b) Sporen mit einzelnen langen, feinen stacheln besetzt.

\section{Penicillium.}

5. Amylocarpus.

1. Gattung: Ceplualotheca Fucked.

Fk. kuglig. Peridie \pm kolnlig. Sporen bran.

Fk, mit schwefelgelben Zotten besetzt. Anf faulenden cichencu Brettern, selten.

C. sulfurea Fuck.

Fk. mit krausen, verzweigten, sehwarzen llaaren bedeckt. Auf faulem llolz, selten.

C. trabea Fuck.

\section{Gattung: 'Thielavia Zojef.}

Fk. kuglig, braun. Schläuche nit 8 lramnen. Sporen. Fonidien jn kurzen Ketten, in die eckigen sehwarzen Sporen zerbrechend, daneben farblose Büehsen, in denen längliche, hyaline Sporen entstehen.

An Wurch von Legmminosen farasitisch, anch an anderen Pflanzen, besonders Topfpflanzen in Gewäıhshäusern, nicht selı(n. (Fig. 132.)

T. hasionala Zopf

\section{Gattung: Ispergillus Michedi.}

Fk. mit zelliger Peridie. Sehlïuche \& sporig. Nur von wengen Arten sind Fk. bekannt, von den meisten mu die Konjoliontrïger, die uns hier nicht angehen. Viele bilden statt der Fk. Sklerotien.

Fk. ohne Blasenhïlle, sehwefelgelb, bis 90 " br. Sterigmen der Konjdienträger unverzweigt. Sporen linsenf., an Rande nit einer Rimne, $8-10 \mu$ br. Auf allen möglichen faulenden Substanzen, Konidjenasen gran- bis olivengriin, genein, die Fk. nicht so hänfig. (Fig. 133.)

1. glaueus (l.)

Fk. mit Blasenhïlle. Sterignen verzwejgt. Fk. schwarz, bis 0,3 nmm jul Durehm. Auf IImmmelnestern, oft spontan auf allem mögliehen Substraten in der Kultur anfletend, nicht selten.

\section{A. nidulars (Eid.)}

4. Gattunc: Penicillim Limh.

Fk. ju Sklerotion od. frej gebildet. Schlänche mit $4-8$ rundiehen sporen.

Fk. ju Sklerotien entstehend, änlerst selten. Cremejn alagegen anf allen möglichen Substraten die blangrïnen Konidienrasen. (Fig. 134.)

J. crustaceum (L.)

Fk. frei entstehend, gelb lis orange. Konidienrasen graugrïn bis graubrann. Auf organisehen Substanzen, selten.

\section{P. Inteum Zuk.}




\section{Gattung: Amylocarpus Cinrey.}

Fk. kuglig, blaßgelb. Sporen kuglig, hyalin, mit einzehen, langen, feinen Stacheln besetzt.

Anf faulem $\mathrm{Holz}$ an der Meeresküste, sehr selten. (Fig. 135.)

A. encephaloides Currey

\section{Familie: Onygenaceae.}

Fk. kopfig, \pm lg. gestielt. Peridie bei der Reife sich lappig öffnend od. ringf. sich ablösend. Schlänche 8 sporig. Sporen einzellig, hyalin, glatt.

Einzige Gattung: Onygena Persoon.

Fk. hell- bis rotbraun, auf faulenden Hufen od. seltener Hörnern von Ziegen, Schafen, Rindern, zerstreut. (Fig. 136.)

0. equina (Willd.)

Fk. hellbraun, auf faulenden Federn, Gewölle, Haaren, zerstrent. o. corvina Alb. et Schw.

\section{Familie: Elaphomycetaceae.}

Fk. unterirdisch, groß, knollig. Peridie dick, nach imnen scharf abgesetzt. Schläuche regellos rerteilt od. zu größeren Gruppen angeordnet, die durch radial verlanfende, sterile Adern getrennt werden. Sporen bei der Reife pulverig, zu 2-4 im Schlauch, diekwandig, kuglig, sehwarz.

\section{Einzige Gattung: Elaphomyces Nees.}

Fk. gelb- bis rötlichbraun, innen von netzig anastomosierenden sterilen Adern durchzogen. In Lb.-, seltener Ndwäldern, hänfig.

E. variegatus Vitt.

Fk. ebenso, aber innen nicht geadert, sondern gleichmäßig. Ebenda. (Hirschtrïffel.) (Fig. 137.) E. cervinus (Pers.)

\section{Familie: Terfeziaceae.}

Fk. unterirdiseh, groß, knollig. Peridie nach imnen nieht scharf abgesetzt. Schläuche gleichmäßig od. in bandf. Anordnung verteilt. Sporen bei der Reife nicht pulverig, kuglig, staehlig od. netzig.

$$
\text { Bestimmungstabelle der Gattungen. }
$$

A. Fk. im Innern ohne sterile Adern, Schläuche gleiehmäßig verteilt.

B. Fk. im Innern mit sterilen Zonen, Sehläuche in gewundenen Bändern stehend.

\section{Hydnobolites.}

2. Choironyces. 


\section{Gattung: Hydmobolites Tulasme.}

Fk. mit llöekern 1 . Wülsten zwischen denen Gänge in das Inuere gehen.

Fk. 1,5 cm in I) urchm., weiblirh, wa. gelblich. In Lbwälesu, zorstreut. (Fig. 13s.)

II. cerebriformis Tul.

\section{Crattung: Choiromyees Vittadini.}

Fk. unregemäßig knollig, glatt, his fanstgrob, loll gelbbraun. In l,b. - N. Nitwildern, stellenwejse nieht selten. EBbar. (Fig. 139.)

(. maeandriformis Vitt.

\section{Reile: Pyrenomycetes.}

Fk. kuglig od. flaschenf., geschlossen od. sich an einem Punkte offnend. Fchlänche am frunde des $1 \mathrm{k}$. entstehend.

\section{Tnterreihe: Perisporineae.}

Gehäuse kuglig, nicht mit Loch sich öfnend, sondern die șporen durch Verwitterung od. mregelmäligen Zerfall des Geläuses frei werdend od. Fehänse flach schildf. u. dann am seheitel mit Loeh sich öffnend.

Bestimmungotabolle der Familien und Crattungen.

A. Crehäuse kuglig, allscitigr geschlossen.

a) Luftmyzel wejo. Gehäuce schwarz, mit irgendwelchen Anhängseln. Parasiten. Sebenfruclitformen. Oirlinm¹).

I. Fk. nur einen selnauch enthaltend.

1. Anhängsel färlig, an Ende stets ungetejt.

2. Anhängrel an Ende wiederholt diehoton verzweigt.

Fam. Erysiphaceae.

k. stets webrere Sohlïuche ent haltend.

1. Anhängeel an der spitze niemals spiralig coingerollt.

a) Anhängsol ganz unverzwejgt ol. unrengluälier verzweigt. \$ Anllärusel myzelartig, kriechrest, nicht starr abstehemel, nicht orl. unregelmailig verzweigt.

$\S \S$ Anluänerel starr abste. hrind, inade, muverzweigt.

1. Sphaerotheca.

2. Podosphaera.

\section{Erysiphe.}

\section{Phyllatinis.}

1) Auf kurzem, aufrebtem Stiel steht aine Reihe eif. Sporen. 
$\beta$ ) Anhängsel am Ende mehr. fach dichotom verzweigt.

2. Anhängsel an der Spitze \pm spiralig eingerollt.

b) Luftmyzel schwarz. Geläuse ohne Anhängsel, schwarz.

I. Sporen einzellig.

1. Fk. einzeln stehend.

2. Fk. am Rande eines behaarten Stromas stehend, auf Blättern.

II. Sporen zweizellig.

1. Luftmyzel sehr kräftig ausgebildet, auf Blättern.

2. Luftmyzel fehlend. Auf toten Wurzeln.

III. Sporen mehrzellig.

1. Luftmyzel fehlend, Sporen vierzellig.

2. Luftinyzel sehr stark entwickelt, Sporen mauerf.

B. Gehäuse schildf., nur die obere Hälfte deutlich ausgebildet, am Scheitel mit Loch sich öfnend.

a) Sporen zweizellig.

I. Sporen hyalin.

II. Sporen braun.

b) Sporen vierzellig.
5. Microsphaera.

6. Uncinula.

Fam. Perisporiaceae.

7. Anixia.

8. Lasiobotrys.

9. Dimerosporium.

10. Zopfia.

12. Capnodium.

Fam. Microthyriaceae.

13. Microthyrium.

14. Asterina.

15. Micropeltis.

1. Gattung: Sphaerotheca Lév.

Luftmyzel weiß, Ủberzüge bildend, mit kleinen Haustorien eindringend. Gehäuse dunkel, einschichtig, mit langen, gebogenen, meist einfachen Anhängselu. Schlauch groß, einzeln, 4-8 sporig. Sporen hyalin, einzellig. Parasiten.

Auf Hopfen, aber auch auf Rosaceen, Kompositen, Dipsacaceen, Epilobium, Geranium, Viola usw., häufig. (Fig. 140.)

Auf Rosen schädlich (Rosenmehltau), häufig.

$$
\text { S. humuli (DC.) }
$$

\section{S. pannosa (Wallr.)}

Auf Stachelbeeren die jungen Triebe u. Früchte vernichtend (Stachelbeermehltau), in Deutschland eingewandert.

S. mors uvae (Schwein.)

\section{Gattung: Podosphaera Kunze.}

Wie vor. Gatt, aber die Anhängsel aufrecht, am oberen Teil des Gehäuses sitzend, an der Spitze mehrfach regelmäßig gabelteilig. 
Auf Prumus, Crataegus, spiraea, Vaceinium, häufig. (Fig. 14l.) l. oxyacunthae (l)r.)

Auf Apfelbäumen an jungen Trieben, nicht häufig

\section{l. leucotricha (Ell. et Ev.)}

\section{Gattulg: Erysiphe Jledw.}

Juftuyzel wie bei vor. Cratt. Anhängsel jun Grunde od. etwa in der Mitte des Geläuses entspringend, myzelartig, wenig of. nicht verzweigt. Schläuche zu mehreren in Fk., $2-8$ sporig, sporen einzellig, liyalin.

1. Anlängsel am Grunde des Gehäuses entspringend u. mit dem IIyzel + verwebt.

Aubängsel melır in der Mitte entspringend, mit dem Myzel sich nicht verwebend, höchstens sich miteinander flockig vorklebend. 4. 2. Fk. in ein wolliges Myzel + eingesenkt. Nur anf Gräsern vorkommend, gemein.

E. graminis DC.

Fk. nieht in ein wolliges Iyzel eingesenk1. Nur auf DikotyleIonen.

3.

3. Auf l'flanzen der verseliedensten Fanilien. Sehläuche $3-8$ sporig. IIäufig. (Fig. 142.)

E. polygoni DC.

Auf Labiaten. Schläuche 2 sporig. Iläufig.

F. waleopidis DC.

Luf Kompositen. Schläuche 2 sjorig. Iläufig.

E. cichoriacearum DC.

4. Anhängsel vollstäudig bram. Auf cornus sanguinca, zerstreut.

Anhängsel ganz od. in oberen Tejl farblos.

E. tortilis (Wallr.)

5. Auf Caragana arhorescens, zerstreut. E. caraganae (Magn.)

Auf Astragalus glyeyphyllos u. cicer, zerstreut.

Auf Vicia silvatica $u$. cassubica, selten.

$$
\text { E. astragali (I) (C) }
$$

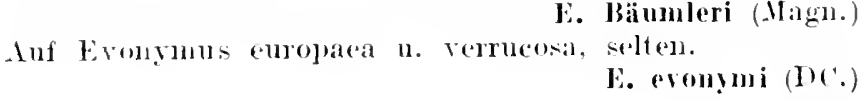

4. Crattung: Pleyllactinia lice.

Greäuse an ler l3asis mit mehreren graden, mrerzweigten, strallig abstehenden, am Crumle plattenf. crweiterten Anhängseln. Sonst wie vor. Gatt.

Auf den Blättern von St äuchern, bänmen z. B. Corylus, Carpinus, Quereus, Fagus, Betula, Almus, Fraxinus, lierleris, llippophaë, nicht selten. (Fig. 143.) I'. corylea (I'ers.)

5. Gattung: Mierosplanera lév.

Anhängsel von der Mitte bis zur fipitzedes Gehäuscentspringend, autrecht od. strahlig abstehend orl. nicderliegend, an der spitze melir- 
fach gabelteilig, die kurzen Endäste plattig verbreitert. Schläuche zu mehreren in Fk., mit 2-8 hyalinen, einzelligen Sporen.

Auf Berberis vulgaris, zerstreut. (Fig. 144.)

Auf Ribes grossularia, häıfig.

Auf Lycium-Arten, zerstreut.

M. berberidis (DC.)

M. grossulariae (Wallr.)

I. Mougeotii Lév.

Auf Alnus, Lonicera, Rhammus, Viburnum, Betula, Syringa u. a., nicht selten. (Auf Quercus-Arten form. quercina Neg.).

I. alni (DC.)

\section{Gattung: Uncinula Lér.}

Anhängsel einfach od. am Ende 2-3 gablig, stets die Enden \pm spiralig eingerollt. Sonst wie vor. Gatt.

Auf Salix u. Populus, nicht selten.

Anf Ulmus montana, u. campestris, selten.

U. salicis (DC.)

Auf Prumus-Arten, nicht selten. U. clandestina (Biv.)

Auf Acer-Arten, häufig. (Fig. 145.) U. prumastri (DC.)

Auf Vitis. Die Oidienform O. Tuckeri häufig, Fk. nur sehr selten beobachtet.

U. necator (Schwein.)

\section{Gattung: Anixia Iloffm.}

Fk. frei oberflächlich, nur mit Haftfasern befestigt, kuglig. schläuche mit 8 kugligen, hyalinen sporen.

Auf faulem Kiefernholz, an fenchten Wänden, selten. (Fig. 146.) A. parietina (Schrad.)

\section{Gattung: Lasiobotrys Kunze.}

Fk. am Rande eines flachen, dünnen, schwarzen, behaarten Stromas. Schläuche zylindrisch mit 8 einzelligen, ellipsoidischen grünlichen sporen.

Auf Blättern von Lonicera-Arten, selten. (Fig. 147.)

\section{Ionicerae (Kunze)}

\section{Gattung: Dimerosporium Fuckel.}

Luftmyzel brann, kräftig entwickelt, mit ïber Krenz vierzelligen Konidien an den Ästen. Fk. eingesenkt im Myzel. Schläuche ellipsoidisch, mit 8 zweizelligen, hyalinen sporen.

Auf Blättern von Ligustrum vulgare im südlichsten Teil des Gebietes. (Fig. 148.)

D. pulchrmm Sace.

10. Gattung: Zopfia Rabenh.

Fk. oberflächlich, kuglig niedergedrückt, Schläuche groß, sackf., mit 4-8 zweizelligen, beidendig spitzen, schwarzbramen sporen. Auf faulenden, in Ilaufen liegenden Spargelwurzeln, selten. (Fig. 149.)

Z. rhizophila Rabenl. 


\section{Gattung: Perisporimu Fries.}

Fk. oherflächlich, lose angeheftet, kuglig. Schläuche keulig nit länglich zylindrisehen, 4 zelligen, schwarzhramen, in die 'Teilzellen zerfallende sporen.

Auf stroh, Mist, Stricken n. anderen Alifallstoffen, nicht selten

P. vulgare Corla

\section{Crattung: Capmodium Mont.}

Lufturzel feste selowarze ¿̈berzüge bilelend (Rufitau). Nebene fruehtfornen häufig u. sehr mannigfach (Kondelen ron verschiedener (restalt, Coremien, Pykniden). Fk. sehr selten, chas keulig. Spos'n manerf. geteilt, brann.

Auf den versehiedensten Bämmen u. Sträuchern als RuBtau die Blätter ïherziclend. (Fig. 150.)

(. salicinum (Pers.)

\section{Crattung: Mierotlyrium thesm.}

luftuyzel felult. Fk. flaed sehildf., an liande otwas fasrig. (rhäuse häutig. mit Offnung ams scheitu. Spowen länglich, zweizellig, hyalin.

Auf Pteridium aguilinum, seltener Aspidium filix mas. selten.

Auf faulenden Nadeln, selten.

M. litigiosum saec.

Auf weiken Blätern von Betula. Carpinus, selten. (Fig. 151.)

Il. microscopicum Desm.

Auf Stengelu rou Cytisus u. frenista, selten. M. cytisi Fuck.

\section{Crattung: Asterina Lév.}

Wiv vor. Gatt., Gehäuse sich sternf. öfnend. sporen 8, zwerzolligr, bramn.

Auf Veronjea officinalis, seltan. A. reronicar (Libedt)

15. Crattumer: Mieropeltis Mont.

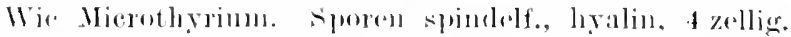

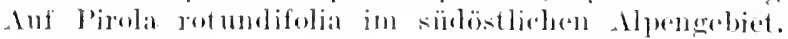

II. rarniolir:a Rehn

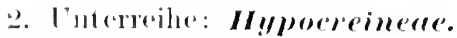

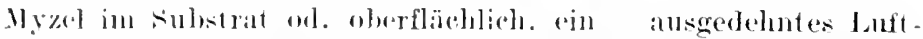
myzel bildemal od. zn eimem stroma sich verflechtend. Fk. frei, kuglig ad. flasehenf., orl. im luftmyzel od. Stroma eingesenkt. Geläuse meist weich lederig, floischig. od. häutig. nie solwwarz, stets anders ge fïrbt (auber Mazzantia). Miindung meist warzenf., seltener länger alligezogens. 

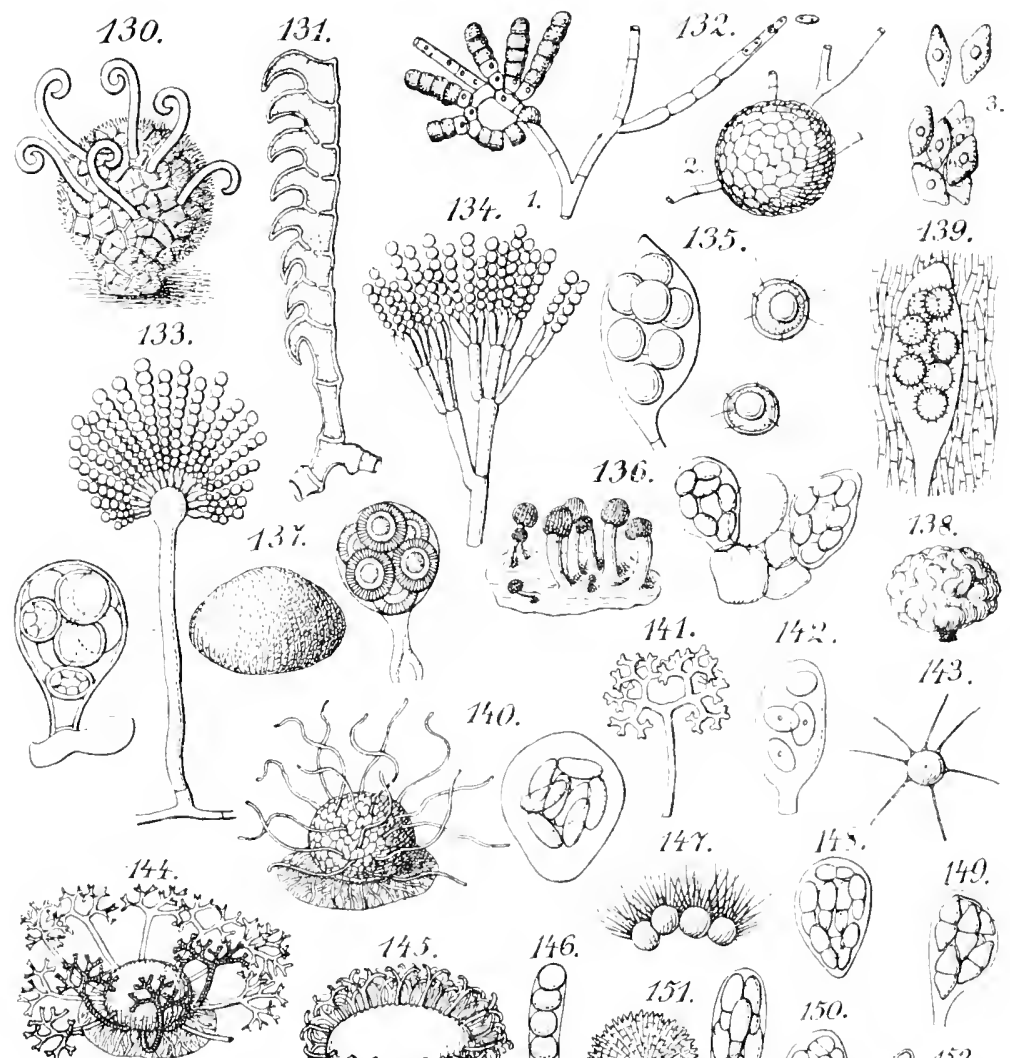

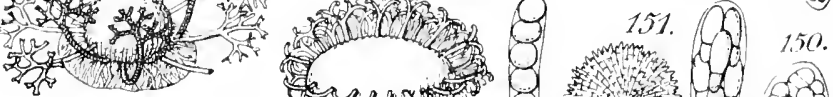

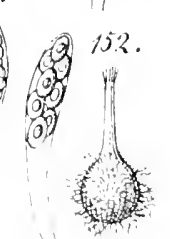

153. 154. 100 . 00 of

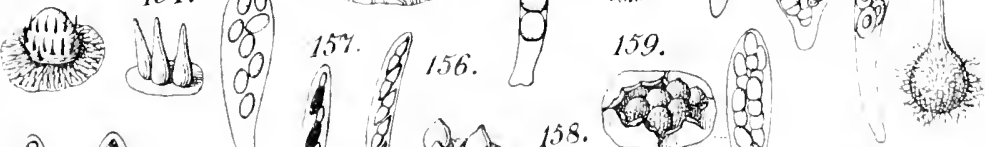

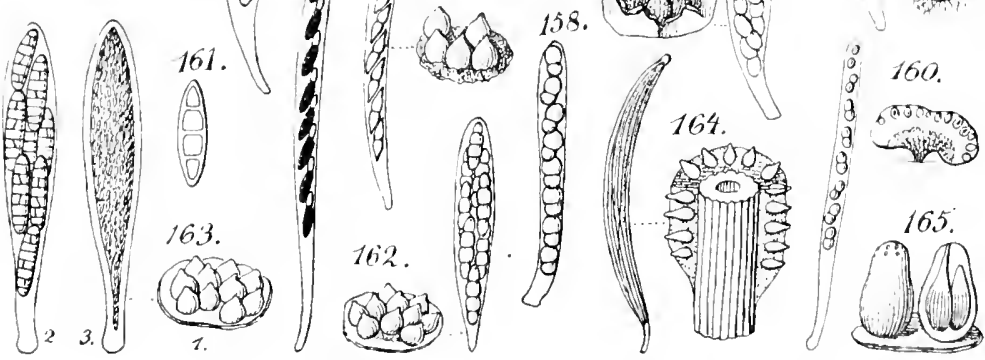




\section{Einzige Familie: Hypocreaceac. Bestimmungstabelle der Gattungen.}

A. Sporen einzellig.

a) Fli stet-ohne Stroma, höehstens mit Luftmyzel.

I. Sporen braun.

II. Sporen hyalin od. höchstens leicht

1. Melanospora. rötlich.

1. Sporen ohne Anluängsel.

a) Fk. eingesenkt.

$\$$ Fk. minter der Epidermis emgesenkt.

\$§ Stroma bedeckt, dann her. rorbrechend, schwarz, inne'n wejls.

p) Fk. rollständig frei auf te! substrat stehend.

\$ Mï̈ndung kegelf. of. flach, dem Gehïuse gleichfarbig. $\S \S$ Mïndung punktf. od. eingedriickt, am Rande dunkler getärbt als das Gehäuse.

2 . sporen bejelendig mit borstenf. Lnhängsel.

b) Fk. einem deutlich ausgebildeten Stroma eingesenkt.

I. Stroma der Blattsubstanz ein. gesenkt.

II. Stroma oberflärhlich auf Mist.

B. Sporen zwejzellis.

a) Stromar gänzlich fehlend, höchstens

Ln'tuszel (Nectria) vorhanden.

1. Crelıäuse bläulich od. i jolett.

IJ. Gehäluse rötlich, getlolich, nie blïılich.

1. Fk. parasitiscle auf Nyctalis asterophoral.

2. Fk. nicht lont washend.

b) Stroma vorhamdsos.

1. Stroma dieht filzirg-fälig.

2. Stroma fleischigr.

a) Wenn Konidienträger rorlatuden, diam nielit stilbumintig.

s sporen nielit im sehlauch in die Trilzdlen zerfallend.

2. Hyponeetria.

3. Mazzantia.

\section{Nectriella.}

5. Thelocarpou.

6. Eleutheromyces.

s. Selinia.

9. Lisea.

10. Pyxidiophora.

1: Nectria.

11. Hypomyces.

12. Nectria. 
$\$ s$ Sporen im Schlauch in die

Teilzellen zerfallend.

B) Konidienträge gestielt mit

13. Hypoerea.

Köpfchen (Stilbum), stets vorhanden, an ihrer Basis die $\mathrm{Fk}$.

C. Sporen 3- und mehrzellig, quergeteilt, nicht fälig.

a) Gehänse lebhaft gefärbt, im durch. fallenden Lichte nicht blau.

b) Gehäuse dunkier, im durchfall. Lichte blan.

D. Sporen mauerf.

E. Sporen lg. fadenf.

a) Stroma fehlend.

b) Stroma stets vorlanden.

I. Stroma die Stengel ringf. um. gebend.

II. Stroma abstehend.

1. Stroma klein, ungestielt.

2. Stroma gestielt.

$\$$ Stroma nicht aus einenı Sklerotium hervorwachsend, auf Tieren u. Pilzen.

$\$$ Stroma aus einem Sklerotium hervorwachsend, auf Gräsern.

\section{Calonectria.}

16. Gibberella.

17. Pleonectria.

18. Barya.

19. Epichlö̈.

20. Oomyces.

21. Cordiceps.

22. Claviceps.

1. Gattung: Melanospora Corda.

Fk. ganz frei od. mit Luftmyzel, Gehäuse weich, bräunhich, mit papillenf. od. vorgezogener u. mit Borsten besetzter Mündmg. Sporen ellipsoidiseh od. zitronenf., einzellig, brann. Selır zerstreut.

1. Anf Pilzen.

Anf Blättern, Nadehn, Holzstïckchen usw. auf der Erie. 3.

2. Auf Fomes igniarins, Polyporus adustus u. ähnl. Fr. $0,4 \mathrm{~mm} \mathrm{im}$ Durchm. mit ca. $2 \mathrm{~mm}$ langem Schnabel. Sporen zitronenf.

I. lagenaria (Pers.)

Anf größeren Scheibenpilzen. Fk, bis $0,35 \mathrm{~mm}$ im Durchm. mit papillenf. Schnabel. Sporen ungleichseitig zitronenf.

3. Fk. lg. geschmäbelt u. gewimpert.

II. Zobelii (Corda)

Fk. mit papillenf. Mündung, gelblich, einem weißen Faden. geflecht aufsitzend. Sporen zitronenf. M. teleboloides (Fuck.)

t. Sporen br. ellipsoidisch-scheibenf., beidendig abgerundet, ohne II yphengeflecht. Zerstreut. (Fig. 152.) II. chionea (Fr.)

Sporen br. ellipsoidisch, beidendig hyalin spitzig. Mit IIyphen. geflecht. Selten.

II. leneotricha Corda

Linda $u$, hryptogamenflora II, 1. 2. Aufl. 
2. Gattung: IIyponectria Sacca'do.

Fk. einzeln, unter der Epidermis stehend, kuglig, rötliçı̈.lh. Sporen ellipsoidiseh, einzellig.

In Buxusblättern, selten.

II. buxi (DC.)

3. Gattung: Mazzantia Montagne.

Stroma bedeckt, dann hervorbrechend, seliwajz, innen weil., mit wenigen kugligen Fk., die mit der Mïndung vorragen. Sporen einzellig, hyalin.

Auf dürren Stengeln von Galium-Arten, zerstrent. (Fig. 168.)

II. Ealii (Fr.)

Auf dürren Stengeln von Aconitum napellus, in den IIoehalp»n.

II. naprlli (Ce-ati)

4. Gattung: Nectriella Saceardo.

Fk. frei aufsitzend, gesellig, mit Mündungspapille, gelb od. röt lich. Sporen kurz spindelf., einzellig.

Auf welkenden Buxusblättern, zerstreut. (Fig. 153.)

I. Ronssebiana (Mont.)

5. Gattung: 'Thelocarpon Nylander.

Fk. frei, gesellig, mit punkft., ringsum dunkler gefärbten Öffnung od. eingedrücktem Scheitel, gelblieh. Sporen ellipsoidisch, einzellig. An bearbeitetem IIolz, selten.

'T. Laureri (Flot.)

Auf Solorina u. Baeomyces, selten.

T. epibolum Nyl.

6. Gattung: Eleutheromyces Fuckel.

Fk. frei, kuglig mit kegelf. Ilalsteil, bräunlich. Spore» (Hlipsoidisch, einzellig, beidendig mit borstenf. Anlängsel.

Auf faulenden Ihutjilzen u. Polyporus betulinus, nieht häufigr. (Fig. 154.)

E. subulatus (Tode)

\section{Gattung: Polystigun DC.}

Strona fleischig, dem Blattgewebe ringewachsen, rot on. rolbraun. Fk. eingesenkt, nur mit den Miindmigen herrorragend. Sporen ellipsoilisch, einzellig.

Parasit auf Prumus lomestica, spinosa u. insititia mit rotem Stroma, häufig. (Fig. 155.) P. rubrum (1'ers.)

Parasit auf Prumus palus, mit bräunlichem Stroma, seltner. P. ochraceum (Wahlenb.)

\section{Gattung: Selinia Karst.}

Stroma fleischig, oberflächlich, rot, mit roströtlichem Filz. Fk. zu wenigen im Stroma eingesenkt. Sporen ellipsoidisch, einzellig. Auf trockenem Schaf-u. Kuhmist, selten. S. pulchra (WVint.) 
9. Gattung: Lisea Sace.

Fk. frei, rasig, knglig. Gehäuse blau od. violett. Sporen länglich eif., zweizellig.

An dürren Buxusästchen, nur in Westdentschland, selten.

L. buxi (Fuck.)

10. Gattung: Pyxidiophora Brefeld et v. Tavel.

Stroma n. Chlamydosporen fehlen, sonst wie Hypomyces, Konidienträger büchsenf., im Innern die Konidien reihenweise bildend. Anf $x$ yetalis asterophora zerstreut. P. asterophora (Tul.)

\section{Gattung: Hypomyces Fries.}

Stroma wollig od. filzig-fädig. Fk. eingesenkt od. aufsitzend, kuglig, mit : kegelf., zugespitzter Mündung. Gehäuse lebhaft gefärbt. Sporen zweizellig, beidendig zugespitzt, hyalin bis hellbräunlich. Fast stets finden sich am Stroma Konidienträger mit quirliger Verzweigung и. 1-2 zelligen Sporen (Verticillium, Diplocladium, Dactylium) u. Chlanydusporen (einzellig Sepedonium, mehrzellig Myco. goue). Fast nur auf Hutpilzen, ihr IIymenium deformierend.

1. Perithecien nicht bekannt, nur Mycogone-Sporen vorhanden. 2.

Perithecien bekannt, aber nicht immer vorhanden, daneben stets die oben genannten Nebenfruchtformen.

3.

2. Hyphenfilz rötlich. Auf Clavarien n. dem Champignon, nicht selten.

H. Linkii Tul.

Hyphenfilz bräunliclı. Auf größeren Discomyceten, zerstreut.

H. cervinus $\mathrm{Tul}$.

3. Hyphenfilz weiß u. so bleibend. Auf Lactaria deliciosa, selten.

H. deformans (Lagger)

Hyphenfilz anfangs weiß, dann aber stets irgendwie gefärbt. 4 .

4. Hyphenfilz rot, grüngelb od. purpurviolett.

Hyphenfilz ocker-, orange- od. goldgelb.

5.

6.

5. Hyphenfilz rosa bis rot. Auf faulenden Arten von Russula, Agariens, Stereum, Polyporus n. von da auf Moos u. Blätter übergehend, zerstreut.

I. rosellus (Alb. et Schw.)

Hyplıenfilz blaß ziegelrot. Anf Lactaria-Arten, nicht selten.

H. laterins (Fries)

IIyphenfilz schmutzig grüngelb. Auf Lactaria- u. Russula-Arten, seltener.

H. viridis (Alb. et Schw.)

Hyphenfilz schmntzig purpurviolett. Auf Fuligo septica, selten.

II. violaceus (Schmidt)

6. Hyphenfilz ockergelb, bis fast orangegelb. Auf Russula-Arteu, nicht häufig. (Fig. I56.)

H. ochraceus (Pers.)

Hyphenfilz znletzt intensiv orangegelb. Auf Polyporus adustus u. ähnl., selten.

H. aurantius (Pers.)

Hyphenfilz intensiv goldgelb. Auf Boletus-Arten, häufig. (Fig. 157.)

H. chrysospermus Tul. 


\section{Gattung: Nectrin Fries.}

Stroma fehlend od. fleischig od. nur als fädige Unterlage aus. gebildet. Fk. einzeln od rasenf., auf dem Substrat, auf dem Stroma od. zwisehen dom Fadengedlecint sitzend, \pm kuglig. Gehäuse weich häutig. gelblich, rot od. brämulich, Mümdıng warzen-od. kegelf., Sporen hyalin od. rötlich, zweizellig, ellipsoidisch, beidendig stumpf od. zugespitzt.

1. Sporen warzig, rotbräulich. Auf alten, verfaulten Polyporus. Arten, selten. r. cosmariospora ces. ct de Not.

Sporen glatt.

2. Stroma fehlend.

Stroma als fleisehige Unterlage ou. Hyphenfilz vorhanden. 6.

3. Auf Flechten.

Nicht auf rlechten.

4. Fk. gesellig, auf einem fleiseluroten Fleck vorbrechend. Auf Anaptychia ciliaris, zerstrent.

N. Fuekelii Sace.

Fk. hervorbrechend, einzeln. Auf Peltigera canina, zerstreut.

N. lichenicola (Ces.)

5. Fk. frei, zerstreut, rotgelb-bräunlich. Auf fanlenden Graminen. blättern, zerstreut.

N. eraminicola lierk. et Br.

Fk. frei, einzeln od. gesellig, blut rot. Auf Ustulina u. Diatrype stigma, nicht selten.

r. episphacria (Tode)

Fk. einzeln, zimnoberrot, zwischen den Fasern stehend. Auf fenchtem Papier. zerstrent.

N. churticola (Fuck.)

6. Fk. in u. auf einer fasrigen Unterlage, orangerot, zusammenfallend $u$. fast schüsself.

Fk. einem fleiselugen Stroma aufsitzend.

N. peziza (Tode)

7. Anf Pandanus-Arten in Gewächshäusern, zerstreut.

N. pandani Tul.

An Ästen 11. Stämmen von Nolhölzern, nicht selton.

N. eueurbitulu (Tode)

Auf Dicotyledonen.

8. Auf Stengeln von Aconitum u. 'irsinm spinosisimmm, suwie anf Kuhkot, in den llochalpen nicht selten. Froma l-2 mm in Durchun., rot.

Nur auf Sträuchern u. Bäumen.

9. Fk. dunkelrot, in Alter schwarz. Fporen $9-1.2 \mu \mathrm{lg} ., 3-3,5 \mu$ br., Auf dünnen llasehuBästen, sltern auf Weide u. l'appel.

\section{N. coryli Fuck.}

Fk. höchstens brämulich od. dunkler werdend, niemals schwarz.

10.

10. Fk. zu wenigen rasig vereinigt, rot mit braner Mündungspapille, zuletzt sehüsself. cingefallen. Auf dïrren Stämmehen von Efeu, seltner. (Fig. 1\%8.)

X. sinopica liries

Fk. viel dichter u. zu vielen zusammenstehend.

11. Stroma polsterf. od. halbkuglig, rot. Fk. selur dieht darauf stehend. 
rot, später mehr bräunlich. Auf sehr vielen Sträuchern u. Stäm. men besonders immer auf Ribes u. Betula, im H. die Stromata konidientragend, in F. perithecientragend, gemein. (Fig. 159.)

N. cinnaharina (Tode)

Stroma polsterf. Perithecien lebhaft rot, durch den dunklen, glänzenden Mündungskegel au-gezeichnet. Häutig auf Zweiggabeln von Salix purpurea, auf Eichen- und Weidenrinde u. anderen Lb., aber nicht auf Buche. $\quad$. galligena Bresad.

Stroma polsterf., hervorbrechend, goldgelb, viele nebeneinander. Fk. sehr dicht gedrängt. Besonders auf Fagusästen, aber auch auf anderem Lb., häufig.

N. ditissima Tul.

\section{Gattung: Hypocrea Fries.}

Stroma fleischig, polsterf. od. + ausgebreitet. Fk. dem Stroma eingesenkt. Sporen meist hyalin, zweizellig, innerhalb des Schlauches in die Teilzellen zerfallend, daher der Schlauch seheinbar 16 sporig.

1. Stroma polster-od. scheibenf., scharf begrenzt am Rande. 2.

Stroma flach, weit ausgebreitet. 4.

2. Stroma nicht rot.

Stroma rot, dann rotbraun, durch die Mündungen der Perithecien punktiert. Teilzellen der Sporen fast kuglig, 3-4 $\mu \mathrm{im}$ Durchm . Auf Holz u. Rinde von Lb., nicht selten. (Fig. 160.)

$$
\text { H. rufa (Pers.) }
$$

3. Stroma rundlich od. länglich, am Rande frei, scliwarz-olivengrün bis schwarzbraun. Teilzellen fast kuglig, ca 4 " im Durchm. Auf faulenden Stämmen (Quercus, Salix usw.), nicht selten.

H, contorta (Schwein.)

Stroma polsterf od. lalbkuglig, gelb od. grünlichgelb. Teilzellen ungleich groß, 4 bzw. $3 \mu \mathrm{im}$ Durchm., kuglig bzw. eif,, oliven. farbig. Auf faulendem $\mathrm{Holz}$, über Blättern, nicht häufig.

\section{H. gelatinosa (Tode)}

4. Auf Pilzen.

Stroma sehr weit ausgedehnt, Moose, Holz, Erde nsw. überziehend, zitronengelb, am Rand weißfasrig, von den dunkleren Mündungen des Fk. punktiert. Teilzellen kuglig, bzw. eif., 4,5 bzw. $5 \mu \mathrm{im} \mathrm{Durchm.} \mathrm{Zerstrent} \mathrm{in} \mathrm{Wäldern.}$

H. citrina (Pers.)

5. Stroma krustig, flach, gelb. Teilzellen eif., 3,5-4,5 $\mu \mathrm{lg}$. Auf Polyporeen ( $\mathrm{P}$. betulinus) zerstrent. H. fungicola Karst.

Stroma krustig, gelb od. bräunlichgelb. Teilzellen kuglig, bzw. eif., $4 \mu$, bzw. $4 \times 3 \mu$. Auf Clavaria ligula u. Spathularia flavida in feuchten Ndwäldern, selten.

H. alutacea (Pers.)

\section{Gattung: Sphaerostilbe Tulasne.}

Stroma polsterf., fleischig, die Konidienträger (gestielte Keulen) tragend, an dereu Grund die Fk. stehen.

Konidienpilz goldgelb-rot, Fk. rotbraun. Auf İsten von Ulmus

u. Fraxinus, selten.

S. aurantiaca Tul. 


\section{1.). Crattung: Caloneretria de Notalis.}

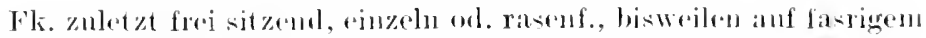
llyplenfilz. Fporen länglich, 4 zolligr, lıyalin.

lk. rot. In Rindenrisin voll Aeer. selten. (lig. l61.)

$$
\text { 1. Mecora (Wallr.) }
$$

16. Galtumg: Gibherella Farratrdu.

Strona fleiselig od. fohlend. Fli. frej anfitzend, rinzeln od. rasig. Gehänse durelseheinend blan od. violett. Sporen ellipsoidisch od. spindelf., hyalin, vierzellig.

1. An llahnen 11. stengeln.

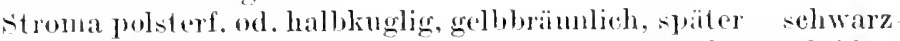
blau. Fk. rasig, sehr dunkel. im durchfalleudun Lichte stahlblau. sporen is-2:" "lg., $7-8$ " br. Auf diirren Isten ron Sambueus nigra u. racemosa, alleh von Sarothammus, Cytisus, salix u. a., zerstreut (Figr. I62.) (t. pulicaris (Fries)

2. Fk. rasenf., verwachsend u. häntige Krusten bildend, blau. Sporen $18-30(20-24) "$ lg. 4-6 " dick. Auf Krïnterstengeln u. be. sonders Grashalmen, zerstrent. N. Saubinetii (Mont.)

Fl. gehäuft. sehmut $\%$ gr blau. Fporen $2.5-32$ !" lg., 7 " dick. Auf faulenden Kolilstengeln, zerstrent.

\section{(i. cyanogena (Desm.)}

\section{Gattung: Pleonectria saceardo.}

Stroma fleisehig od. fehlend. Fk. geläuft. frej. Fporen ellipsojolisch od. spindelf., hyalin, mauerf. geteilt.

Fk. Jötlichlorann, rasig auf einem gellichen. polsterf. Stroma aufsitzenul. Duf diirren lierberitzenästen, zerstrent. (Fig. 163.)

$$
\text { P. Lamlyi (Desm.) }
$$

\section{1h. Crattunge: Barya Fonekel.}

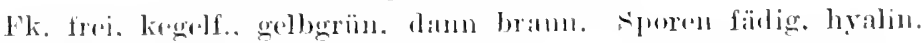
Anf fanlenter bortia moriformis, selten.

\section{3. parrasitirar liuck.}

\section{Crattung: Vipichlogi Fries.}

Stronta flach, fleisehig, die Ilalmescludelof. nukledend, weiß,

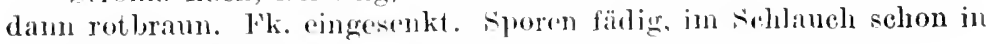
Teilzellen zerfallend.

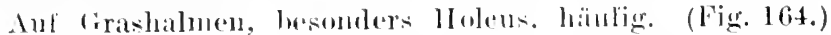

$$
\text { F. typhina (lers.) }
$$

20. Gattumg: Oomyces berli at Br.

Stroma rötlich, kegel-orl. sackf., senkrecht abstelend, mit 1 bis

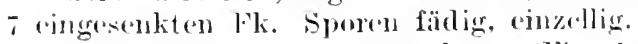

An trockenen (iräsern, solten. (l’iks. 1(i.i.)

1. earneoalbus (Lib.) 
21. Gattung: Cordiceps Fries.

Stroma aufrecht, \pm lg. gestielt, oberer Teil keulig od. kuglig. fertil. Sporen fädig, im schlauch in Teilzellen zerfalllend.

1. Auf unterirdischen Pilzen schmarotzend.

Auf in der Erde liegenden Insekten, Ranpen od. Puppen schma. rotzend.

2. Stroma mit blaßgelbem Stiel u. rötlich-schwarzer Keule. Auf Elaphomyces-Arten, zerstrent. (Fig. 166.)

c. ophioglossoides (Ehrh.)

Stroma mit dunkelgelbem Stiel u. brannem, fast kugligem Kopf. Ebenda, aber seltner.

C. capitata Holmsk.

3. Stroma goldgelb od. gran.

Stroma rot.

4. Stroma mit gelbem stiel u. lebhaft goldgelber Keule. Auf Insektenlarven, zerstrent.

C. entomorrhila (Dicks.)

Stroma mit sehwarzbramem Stiel u. granweifem, spüter bräunlich violettem, fast kugligem Köpfchen. Auf Käferlarven u. Laufkäfern, zerstrent.

C. cinerea (Tul.)

5. Stroma lg. gestielt, fertiler Teil keulig, gelb-od. pur' urrot. Auf Puppen u. Raupen von schmetterlingen, häutig. H.

\section{C. militaris (L.)}

Stroma leicht ockergelb, krustig u. sich darans fädig, bis $4 \mathrm{~cm} \mathrm{lg}$. erhebend. Fk auf dem Stroma einzeln od. rasig, blaß röttich. Auf toten Schmetterlingen, besonders Sphingiden, nicht häufig.

C. sphingum (Tul.)

\section{Gattung: Claviceps Tul.}

sporen den Blüten anfliegend, unterhalb des Fruchtknotens sich ein hornartiges, lg. vor agendes Sklerotinm entwickelnd, das in der Jugend Konidienlager (Sphacelia) trägt. Die zn Boden gefallenen Sklerotien entwickeln im F. auf langen Stielen kuglige Sklerotien, in denen die Perithecien mit den Schläuchen sitzen Sporen fädig.

1. Sklerotien in den Blüten von Heleocharis u. Scirpus gebildet, nicht häufig.

C. nigricans Tul.

Sklerotien in Gramineen.

2. Sklerotien in den Bliiten des Getreides, groß, dunkelviolett. Stromata rötlich, häufig, besonders in nassen Sommern (Fig. 167.)

c. purpurea (Fr.)

Sklerotien auf Phragmites, Molinia, Nardus u. and. Gramineen, wie ror. Art, aber in allen Teilen kleiner, seltner.

\section{C. microcephala (Wallr.)}

\section{Unterreihe: Dothideineae.}

Myzel im Inwern der Nährpflanze, en sklerotienartiges, senkrechthyphiges Stroma im Innern bildend, das nach außenhin meist fest u. schwarz abgeschlossen ist, im Innern aber aus weißem, weichem 
Gewebe besteht. Durch Zerreißen der deckenden Gewebsschichten wird dam das Stroma frei. Neben diesen typisehen Falle kommen auch solehe vor, wo das stroma eingesenkt bleibt od. von Anfang an oberflächlich steht (stets schwarz). Fk. dem stroma eingesenkt, typiseh nicht durch besondere Wandung von der Stromasubstanz getrennt. Mïndmng rundlich od. länglich, oft durch Verwitterung der deckenden Schichten unregelmäBig aufgerissen.

\section{Einzige Familie: Dothideaceate.}

Bestimmungstabelle der Gattungen.

A. Aseotrom eingewachsen 1 . vorbrechend.

a) Sporen 2 zellig, hyalin

J. Dothidella.

b) Sporen 2 zellig, bram

2. Systremma.

B. Stroma zwisehen Epidermis $u$. Palis. saden bedeckt bleibend

a) Sporen 2 zellig, hyalin

b) Sporen 4 his melirzellig, braun

c. Stroma zwischen Kutikula u. Epidermis bedeckt bleibeud. Paraphysen 0 . Sporen hyalin, gleich- bis 2 zellig

D. Stroma dem Mesophyll eingelagert

a) Sporen 1 zellig, hyalin

b) Sporen 2 zellig, hyalin

c) Sporen 4 zellig, braun

3. Scirrhia.

4. Rhopograplus.

\section{Euryachora.}

6. Phyllachora.

7. Endothella.

8. Homostegia.

E. Loculi isoliert dem Mesophyll eingelagert, perithecienartig, Sporen messerförmig, braun

\section{Curreya.}

\section{Gattung: Dothidella spaj.}

stromata vorbrechend $u$. krustig, mit eingesenkten Perithecien. Ohne Paraphysen. Sporen zweizellig, hyalin.

Auf dürren $̈$ sten von 13 erberis, zerstseut.

I). berberilis (Wahlenb.)

Auf $\ddot{A}$ sten von Ribes (besonders von li. rubrum) zerstrent. (Fig. 170.)

1). ribesia (Pers.)

Auf Ästen ron Daphne nezereum, in den $\mathrm{Al}_{\mathrm{l}}$ en.

1). mezerei (Fries)

2. Gattung: Systremma Theil. et Syd.

Stromata rorbrechend u. krustig, mit eingesenkten Perithee en. Ohne Paraphysen. Sporen zweizellig, braun, meist die Zellen etwas ungleioh.

Auf dürren İsten von Sambueus, Syringa, Arer, Rhamnus, Morus u. a., nicht selten.

s. natans (Tode) 
Auf dürren Ästen von Buxus semperrirens, selten. (Fig. 171.) s. puccinioides (DC.)

Auf noch hängenden Ulmenblättern, nicht selten.

S. uhmi (Schleich.)

3. Gattung: Scirrhia Nitschke.

Stromata strichförmig, vom obe flächlichen Clypens bedeckt, zuletzt in einem linienförmigen spalt aufreißend. Paraphysen fehlen. Sporen länglich zweizellig, hyalin.

An dürren Blattscheiden von Phragmites, zerstreut. (Fig. 173.) S. rimosa (Alb. et Schw.)

An Wedelstielen ron Pteridum, zerstreut. (Fig. 174).

s. aspidiorum (Lib.)

4. Gattung: Rhopographus Nitschke.

Stromata wie bei Scirrhia. Paraphysen vorhanden. Sporen 4 bis mehrzellig, braun.

An Wedelstielen von Pteridium, zerstreut. (Fig. 175.)

B. filicinus (Fries)

5. Gattung: Euryachora Fuckel.

Stromata zwischen Kutikula u. Epidermis bedeckt bleibend. Paraphysen fehlen. Sporen farblos, zweizellig.

A uf faulenden Birkenblättern, zerstreut. (Fig. 172.)

E。 betulina (Fries)

Auf Stengeln u. Blättern von Sedum maximum, purpureum u. thelephium, im Gebirge. $\quad$ E. thoracella (Rutstr.)

6. Gattung: Plyllachora Nitschke.

Stromata dem Mesophyll eingelagert, bedeckt bleibend. Paraphysen vorhanden. Sporen einzellig, hyalin.

Auf Blättern von Gramineen, häufig. (Fig. 169.)

Auf Blättern von Trifolium-Arten, nicht selten.

P. graminis (Pers.)

P. trifolii (Pers.)

7. Gattung: Eudodothella Theiß. et Syd.

Stiomata wio bei Phyllachora. Paraphysen vorhanden. Sporen farblos, zweizellig.

Auf dürren Juncushalmen, zerstreut.

E. junci (Fries)

\section{Gattung: Homostegia Fuckel.}

Stromata wie bei Phyllachora. Paraphysen vorhanden. Sporen vierzellig, braun, bisweilen mit einer Längswand.

Auf den Th. von Panmelia saxatilis, besonders im Gebirge. (Fig. 178.)

H. Piggotii (Berk. et Br.) 


\section{Gattung: Curreya Saccardo.}

Loculi peritherienartig, olne echtes Ostiolum, zerstreut od. eng gelagert, unter der Epidermis eingesenkt, durch hyphiges Stroma verbunden. Paraphysen vorhanden. Sporen mauerf., länglich, braun.

Auf Kiefernzapfen, zerstreut. (Fig. 177.)

C. cono.um (Fuck.)

\section{Unterreiho: Psendosphaerimeae.}

Stromata klein, cingewaehsen, perithccinmähnlich, nit mehrere nebeneinander stehenden Loeuli, die je cinen Ascus enthalten.

\section{Einzige Familie: Pseudosphacriaceae von Höhn.}

Vie vorige.

Einzige Gattung: Dothiora Fries.

Stroma eingesenkt, später die deckenden substratschichten unregelmäßig zerreißend. Fk. nicht regelmäßig aufspringend, sondern lappig aufreißend. Sporen länglich, hyalin, quer mehrzellig, stets noch mit mindestens einer Längswand. Holzbewolnnend.

An dürren Ästen ron Populus tremula, zerstrent. (Fig. 176.)

D. sphacroides (I'ers.)

An dürren Ästen von Sorbus aucuparia, selten.

J. sorbi (Wahleub.)

\section{ז. Unterreihe: Sphaeriineae.}

Myzel in-od. außerhalb des substrates, cinfach füdig od. zu stromatischen Gebilden verflochten. Stroma verschieden, flach ausgebreitet bis senkrecht abstehend. Fk. frei, einzeln od. rasig od. im Substrat od. dem Stroma ganz od. teilweise eingesenkt. Crehäuse sehwarz, meist kohlig, brüchig od. seltener lederig zähe, Mündung papillenf., halsf. vorgezogen od. selır lg.fïdig, meist rund, selten zusammengedriickt. Schlänche am Grunde des Fk. hervorwachsend, meist zylindrisch. Paraphysen vorhanden. Sporen selu versehieden. Nebenfruchtfo:men als Konidienträg(e), Pykniden od. Konidienlager häufig vorhanden.

\section{Bestimmungstabelle der Familien.}

A. Fk. fiei stehend od. zuerst eingesenkt im substrat u. damn-hervortretend. Stroma felnlend, cin fädiges nyphenge. flecht bisweilen vorlianden, sehr selten ein kuntiges stroma vorhanden, auf dem die lik. sitzen.

a) Fk. yon Anfang an oberflächlich. 
I Gehäuse dünn, fast einschichtig, am Scheitel mit Haarschopf.

1. Chaetomiaceae.

II. Gehäuse lederig od. kohlig, seltener häutig, stets dentlich mehrschich tig. Fk, frei od. in einem Hyphengeflecht sitzend, kahl od. behaart. Paraphysen vorhanden.

b) Fk. zuerst dem Substrat eingesenkt, später $\div$ hervortretend.

I. Gehäuse weich, häutig. Fk. meist auf Mist, bisweilen ein Stroma vorhanden Sporen stets dunkel gefärbt.

II. Gehäuse derber, lederig bis brüchig kohlig. Selten auf Mist.

a) Fk. einzeln od. herdenf. wachsend.

§ Mündung lg. schnabelf.

$\S \S$ Mündung kurz, höchstens warzig od. keglig.

+ Mündumg rund.?

† Mündung seitlich zu. sammengerlrïckt, spaltenf.

B) Fk. sich meist unterrindig entwickelnd n, hervorbrechend, stets rasig, seltener auch von Anfang an oberflächlich, fast immer auf einem fädigen od. krustenf. Stroma aufsitzend.

B. Fk. dem substrat eingesenkt u. ohne Strom od, von einem schildf. stromatischen Gewebe (Clypeus) bedeckt od. in einem Stroma sitzend.

a) Fk. dem Substrat eingesenkt, Mündung durchbrechend od. durch Verwitterung der oberen Schichten des Substrates frei werdend.

I. Fk. bis $0,5 \mathrm{~mm}$ grof, häutig od. lederartig.

1. Mündung kurz, oft undentlich.

a) Ohne l'araphysen.

B) Mit Paraphysen.

8. Mycosphaerellaceae.

9. Pleosporaceac.

2. Mündung verlängert schnabelf. 11. Gnomoniaceae.

II. Fk. iiber $0,5 \mathrm{~mm}$ groß, dick lederig od. kohlig.

10. Massariaceac. 
b) Fk. einzeh rom einem Clypeus bedeckt od. nugeben.

c) Fk. einem stroma eingesenkt, meist 12. Clypeosphaeriaceae. zahlreich.

I. Substanz des Stromas von den der Nährsubstanz nicht deutlich geschieden, oft uur durch Saum. linie od. Verfärbung des substrates erkembar.

1. Tor den Perithecien sich Pykniden entwickelnd.

2. Tor deu P'. sich Konidienlager entwickelnd.

13. Valsaceat.

14. Melanconidaceae.

II. Substanz des Stromas deutlich von der des Nährsubstrates verschieden, uur aus Hyphen bestehend.

1. Schlauchsporen klein, zylindrisch, gewöhnlich auch gekrüinmt.

2. Schluchsporen niemals zylindrisch.

a) Schlauchsporen ein- bis mehrzellig, wenn einzellig nur hyalin. Konjlien in Stromahöhlumgen gebildet.

B) Schlauchsporen einzellig,

16. Melogrammataceac. stets dunkel gefärbt. Ko. nidien meist frei auf dem jungen Stroma.

15. Diatrypaceae.

Best immungstabelle der frattungen.

1. Familio Chactomiaceac nur die Gattung. 1. Chatominn.

Z. Familie sordariaceac.

A. Sporen einzellig, mit oul. whe lyaline

Allhängsel

a) Ohne strontha.

2. Sortaria.

b) Mit stromal.

13. Sporen zwoizollig.

3. Ilypocopra.

4. Delitivelin.

C. Sporen yuer mehrzellig.

5. Sporormia.

D. Sporen mauerf.

6. Pleophragmia.

3. Familie splateriaceac.

A. Sporen einzellig.

a) Sporen hyalin, gelogentlich auch rinmal \%weiteilig.

I. Sporen ellipsoidisch. Fk. unter 1/4 $\mathrm{mm}$ grob.

7. Trichosphuerin. 
II. Sporen zylindriscl. Fk. ïber $1 / 4 \mathrm{~mm}$ groß.

8. Leptospora.

b) Sporen ellipsoidisch, braun.

I. Ohne Anhängsel.

II. Mit Anhängseln.

9. Rosellinia.

10. Bombardia.

B. Sporen zweizellig.

a) Fk. behaart.

I. Sporen eif. od. kenlig.

11. Coleroa.

II. Sporen spindelf.

12. Niesslia.

b) Fk. kahl.

I. Gehäuse glatt.

13. Melanopsamma.

II. Gehäuse grobhöckerig.

14. Bertia.

c. Sporen quer drei- u. mehrzellig.

a) Fk. behaart od. in einem Hyphen.

filz steckend.

I. Sporen farblos, zuletzt gleichmäßig bräunlich.

1. Sporen spindelf.

2. Sporen zylindrisch-wurmf. od. ellipsoidisch.

15. Herpotrichia.

16. Lasiosphaeria.

II. Sporen bramn, Endzellen hyalin 17. Chaetosphaeria.

b) Fk. kahl, auch olme IIyphenfilz.

I. Sporen hyalin.

II. Sporen brann.

18. Zignö̈lla.

19. Jelanomma.

4. Familie Ceratostomataceae.
A. Sporen einzellig hyalin.
B. Sporen einzellig, bram.
C. Sporen quer vielzellig.

20. Ceratostomella.

21. Ceratostoma.

2.. Ceratosphaeria.

$\therefore$ Familie $A m p$ hisphaeriaceae.

A. Sporen quer zwei-od. mehrzellig.

a) Sporen zweizellig, braun.

b) Sporen vierzellig, aber im Schlauch

in zweizellige Teile zerfallend, braun.

23. Amphisphaeria.

c) Sporen mehr als zweizellig, nicht zerfallend.

I. Sporen hyalin.

II. Sporen braun.

B. Sporen manerf.

2.). Nelomastia.

o6. Trematosplacria.

27. Strickeria.

6. Familie Lophiostomataceae.

A. Sporen einzellig, braun.

B. Sporen zweizellig.

25. Lophiella.

a) Sporen hyalin.

b) Sporen braun.

99. Lophiosphzera.

30. Schizostoma. 
C. Sporen quer mehr als 22 zellig.

a) Sporen hyalin.

b) Sporen bram.

D. Sporen manerf.

31. Lophiotrema.

32. Lophiostoma.

33. Platystomum.

34. Nitschkia.

3.). Gibhera.

36. Ofthia.

37. Gibberidea.

39. Cucurbitaria.

8. Familie Mycospliaerellaceac.

A. Sporen zweizellig.

a) Sporen in zwei gleiche Zellen geteilt.

I. Sporen hyalin.

1. Fk. in kleine Gruppen muter der Oberhant lebender libäter sitzend.

2. Fk. im Gewebe tiefer sitzend, in abgestorbenen Pflanzen teilen.

1I. Sporen braun.

b) Sporen in zwei ungleiche Zellem geteilt, untere kleiner.

B. Sporen quer mehr als zweizellig, hyalin.

a) Auf Flechten schmarotzend.

b) Nicht auf Flechten.

3\%. stigmatea.

40. Iycosphaterla.

41. Tichothecium.

4․ Guignardia.

43. I'harcidia.

44. Splıaerulina.

4.j. Physalospora.

46. Venturiat.

47. Didymella.

4๑. Dilymosphaeria.

49. Dilophia.

b) Sporen-mit Anhängaceln.

I. Sporen lïnglish.

1. Aporen hialin.

2. Spor n bramn.

II. sporen taidigr.

1. Fk. behaart.

2. Flk. kahl.

1). Sporen manerf., hyainn bis hram.

1. Fk. behaart.

II. Fk. kahl. io. Metasphaeria.

il. Leptosphaeria.

i2. Ophiocharta.

53. Ophioholus.

54. Pyrenophora.

5.). Pleospora. 
10. Familie Massariaceae.
A. Sporen einzellig.
B. Sporen zweizellig, braun.
C. Sporen quer mehr als zweizellig.
56. Enchnoa.
57. Phoreys.
a) Sporen hyalin.
58. Massarina.
b) Sporen braun.
59. Massaria.
D. Sporen mauerf., brann.
60. Pleomassaria.

11. Familie Gnomoniaceae.

A. Sporen einzellig.

a) Schläuche achtsporig.

I. Mündung kurz abgestutzt.

61. Phomatospora.

II. Münrlung schnabelartig ausgezogen.

1. Mit stromaartigem Gewebe. 62. Mamiania.

2. Ohne Stroma.

b) Schläuche vielsporig.

B. Sporen zwei bis vierzellig, Schläuche achtsporig.

63. Gnomoniella.

64. Ditopella.

65. Gnomonia.

12. Familie Clypeosphaeriaceae.

A. Sporen einzellig.

B. Sporen mehrzellig.

66. Anthostomella.

a) Sporen hyalin bis gelblich.

I. Sporen ellipsoidisch bis spindelf. 67. Hypospila.

II. Sporen fädig.

b) Sporen braun.

68. Linospora.

69. Clypeosphaeria.

13. Familie Valsaceae.

A. Sporen einzellig.

a) Sporen hyalin, gekrümmt.

70. Valsa.

b) Sporen braun, nicht gekrümmt.

B. Sporen quergeteilt.

a) Sporen hyalin.

71. Anthostoma.

b) Sporen braun.

C. Sporen mauerf.

72. Diaporthe.

73. Rhynchostoma.

74. Fenestella.

14. Familie Melaneonidaceae.

A. Sporen einzellig.
a) Sporen ellipsoidsch od. kurz spin-
b) Sporen lg. zylindriseh, wurmf. ge- krümmt.
75. Cryptosporella。
76. Cryptospora.

B. Sporen zwe zellig.

a) Sporen hyalin.

I. Pykniden vielkammerig mit

hyalinen, einzelligen Sporen. 77. Valsaria.

II. Konidienlager flach mit dunkel. braunen, einzelligen Sporen. 78. Melanconis.

b) Sporen braun.

79. Melanconiella. 
C. Sporen quer mehr als zweizellig.
a) Sporen hyalin.
80. Calospora.
b) Sporen bram.
81. Pseudovalsa.

15. Familie Diatryaceac.

A. Schläuche bis achtsporigg.

a) Stroma nur bei den konidjenlagern entwickelt, nicht bej den lik.

s:. Culosphaeria.

b) Stroma bei den Fk. stets entwiekelt.

1. Stroma weit ansgedehnt.

83. Diatrype.

1I. Stroma scheiben- od. jolsterf.

B. Schläuche vielsporis.

84. Quaternaria.

8.s. Jiatrypella.

16. Fantilie Melogram mateae.

A. Sporen einzellig byalin.

s6. Botryosphaeria.

3. Sporen zweizellig braun.

87. Myrmaceinm.

C. Sporen quer melir als zweizellig, braun. 88. Melogramma.

17. Familie Xylariaceae.

A. Stroma krustigr od. scheibeni. kuglig od. habkuglig, stets ungestielt

a) Stroma selhwarz, im Alter sehr brïchigr u. immen mit llohlränmen. S9. Cstulina.

b) Stroma soluwarz od. anders grefärbt. auch in Altri olne IIolilräume.

1. Stroma zuerst eingesenkt, jung fleisehig. Konidienlager auf der Stromaoberfläche unter dem Periderm gebildet, später abfallend.

90. Nummularia.

I1. Stroma gewöhulieh von Anfang an oberflachlich u loblzig od. loohlig. Kondidendager obere flälolich. pulverig.

1. Stronna mit konzentrisehen Lagen

2. Stromal nicht konzentrisch seschichtet.

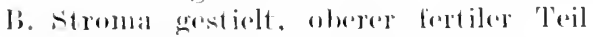

91. Haldinia.

\$... IIypoxylou.

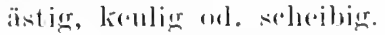

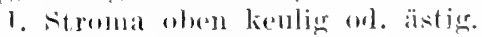

11. Stromat obese solucilier.

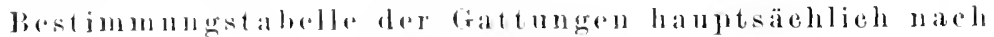
din silnoril.

1. sporen rinzelligr.

sporen quer meht als zwoizellig, hisweilen bei den fadont. 
Sporen die Zellen nur durch Öltropfen angedeutet.

60 .

Sporen mauerf., mit mehr als 2 Querwänden u. mindestens einer Längswand.

2. Spore hyalin (höchstens gelblich).

89.

Sporen dunkel gefärbt.

3. Fk. mit Borsten od. Haaren besetzt.

19.

Fk. ganz kahl (höchstens am Grunde mit wurzehden Il yphen).5.

4. Fk. frei aufsitzend.

Fk. eingesenkt bleibend.

7. Trichosphaeria. 56. Enchuoa.

5. Fk. lg. geschmäbelt $u$ der Schnabel weit hervortretend.

6.

Fk. mit kegel-od. papillenf. Mündung, wenn lg. geschnäbelt, dam im Stroma eingesenkt $u$. mit dem schnabel nicht hervortretend.

8.

6. Fk eingesenkt bleibend, Sclmabel als lange Spitze hervortretend.7.

Fk. zuletzt ganz freistehend, Schnabel färlig, sehr lg.

20. Ceratostomella.

7. Fk. ohne Stroma eingesenkt.

63. Gnomoniella.

Fk. unter einem seheibigen Pseudostroma eingesenkt.

6ะ. Mamiania.

8. lk. nicht einem Stroma eingesenkt.

Fk. einem Stroma eingesenkt.

9. Schlänche mit 8 (seltener weniger) sporen.

Schlänche vielsporig.

64. Ditopella.

10. Fk. von Anfang an oberflächlich entstehend, Sporen zylindrisch, oft gekrümmt.

8. Leptospora.

Fk. anfangs eingesenkt, dam herrortretend od. so bleibend (wemn, wie bei Nitschkia bisweilen ron Anfang an oberflächlich. dann (lie Fk. schüsself. zusammensinkeud).

11.

11. Fk. nicht schüsself. einsinkend, nicht rasig gehäuft.

12.

Fk. schüsself. einsinkend, rasig gehäuft. 34. Nitschkiı.

12. Schlänche keulig. Sporen länglich, abgestumpft, größer.

45. Physalospora.

Schläuche dümn zylindrisch, Sporen ellipsoidisch, viel kleiner.

\section{Phomatospora.}

13. Stroma valseenartig, d.h. scharf begrenzt, klein, kegel- od. polsterf.

14.

Stroma diatrypeenartig d. h. weit ausgedehnt, ohne besondere Gestalt.

18.

14. Fk. im Stroma stehend, Konidienfrüchte in demselben Stroma vorhergehend od. gleichzeitig od. wenn getremt, dann Fk. in einem Stroma.

Fk. gruppenf. im Periderm ohne Stroma nistend, aber die Konidienfrüchte in einem valseenartigen Stroma.

\section{8.. Calosphaeria.}

15. Sporen ellipsoidisch od. spindelf., nicht gekrümmt. 16.

Sporen länglich, gekrümmt od. zylindrisch wurmf. 17 . Linda 11. Kryptoganenflora II, 1. ?. Aull. 
16. Kondienfrïelite im stroma in Lagern gebildet, die später frei liegen.

75. Cryptosporella.

Konidienfrïhte Pykniden im Stroma. s6. Botryosphaeria.

17. Sporen kleiner, wurstf, gekrimmit. Fo. Valsa.
Sporen viel länger, wurnf.
76. ('ryptospora.

18. Fk. u. Pykniden in demselben Stroma. 70. Valsa.

Fk. u. Konidien auf verschiedenen Stromata, entweder Lager od. vielkammerige Pykniden vorhanden. \$3. Diatrype.

19. Fk. irgendwie dentlieh behaart.

Fk. kahl.

20.

21.

20. Mündung des Fk. mit langem Haarsehopf. 1. Chatominm.
(rehäuse mit Borsten.
؛. Rosellini:.

21. Sohläuche arlıt-(seltener virr-)sporigr.

Schläuche vielsporig. $\mathrm{Fk}_{\text {。 }}$ im stroma eingesenkt.

8.5. Diatrypella.

22. Stroma ganz fehlend, höchstens ein Jyphenfilz vorhanden. 23. Stroma rorhanden.

23. Mïndung der Fk. kegel. od. warzenf., nie lg. ansgezogen. 25. Mündung der Fk. verlängert.

24. Mündung nur $\mathrm{lg}$. halsf. Mistbewolmer, ․ Sordaria. Mïndung fadenf., Holzbewohner. DI. Ceratostoma.

25. Mündung rund.

Müudung breitgedrüıkt.

28. Lophiella. 24.

26. Aporen beidendign mit hyalinem Amhämgset. 10. Bombardia. Sporen olme Anhängsel. \$. Rosellinia.

27. Stroma flaeh krustio, oberflächlich, auf Wist, Grehäuse hı̈utig. 3. Hypocopra.

Stroma eingesenkt od. frei, auf $1 \mathrm{Holz}$ (wemn anf Mist [l'oronia] dam anfreeht). Crehänse nicht häntig.

28. Stroma sieh anf ein schwarzes sehildf. Psendostroma beschiinkend.

dit. Anthostomella.

Stroma nicht so.

29.

30.

29. Stroma diatrypeen- od. valseenartig.

Stroma frei vou Anfang an owl. durehthrehend u. dann frei-
ehend.

30. Sporen ellipsoidisch.

71. Anthostoma.

sporen zylindrisel gebogen. Kondienlager anf besomderem Stroma. S4. Quaternaria.

31. Stroma halbkuglig, polsterf., von Anfang an frei od. herrorbrechend 11 . dam frei.

Stroma senkreeht abstehend, keulig, füdig usw.

32. Stroma innen olne konzentrisele sohiehtmug. 32. 35 .

stroma innen mit konzentriseher sohiehtung.

\section{Daldinia.}

33. Stroma anfangs lederig-fleisehig, später kohlig-brïchig, mit Ifohlräumen, Fk. sehr groß. 
Stroma von Anfang an holzig od. kohlig, ohne Hohlräume. Fk. viel kleiner.

34.

34. Konidienlager unter der obersten Stromaschicht gebildet, Stroma scheibig od. napff.

90. Nummularia.

Konidienlager auf dem Stroma gebildet, Stroma halbkuglig, kuglig, polsterf. od. durch Zusammenfließen krustig.

\section{Hypoxylon.}

35. Stroma einfach kenlig od. verästelt. 93. Xylaria.

Stroma gestielt, oben br. scheibig. 94. Poronia.

36. Sporen hyalin.

Sporen dunkel gefärbt.

37 Fk mit Haaren od Borsten rersehen.

38 。

Fk. kahl.

40.

38. Fk. von Anfang an frei, nie eingesenkt.

39.

Fk. zuerst eingesenkt dann \pm vortretend, Borsten meist nur am scheitel des Fk.

46. Venturia.

39. Schlänche am Scheitel verdickt. Sporen zylindrisch, spindelf.

12, Niesslia.

Schläuche am scheitel nicht verdickt. Sporen ellipsoidisch.

11. Coleroa.

40. Fk. von Anfang an frei stehend.

Fk. ganz eingesenkt bleibend od. zuerst \pm eingesenkt $u$.

\pm hervortretend.

42.

Fk. in einem stroma.

41. Gehäuse mit groben warzenf. Verdickungen. 14. Bertia.

Gehäuse ganz glatt.

13. Melanopsamma.

42. Miindung stets rund, Fk. eingesenkt bleibend.

43.

Mündung flach zusammengedrückt, Fk. \pm hervortretend.

Q9. Lophiosphaera.

43. Schlïuche am Ende verdickt u. mit Kanal rersehen.

65. Guomonia.

Schläuche nicht rerdickt od. wenn verdickt, ohne Kianal. 44.

44. Sporen gleich zweiteilig.

45.

Sporen in eine untere, sehr kleine u. obere, viel größere Zelle geteilt.

42. Guignardia.

45. Fk. mit nur flacher od. papillenartiger Mündung.

Fk. eingesenkt mit der warzen- od. kegelf. Mündung die deckenden Schichten durchbrechend. 47. Didymella.

46. Fk. unter der Kutikula od. Epidermis sitzend.

\section{Stigmatea.}

Fk, in tieferen Sehichten eingesenkt. 40. Mycosphacrella.

47. Fk。 in einem Stroma eingesenkt.

48.

Fk. unter einen schildf. Pseudostroma sitzend.

48. Stroma diatrypeenartig.

67. Hypospila.

72. Diaporthe.

Stroma valseenartig. 
49. Kondienfriehte gakanmmerte Pykniten.

Nur Konidienlager vorhanderi.

50. Paraphysen fehlen.

Paraphyen vorhanden. .j).

7. Mrlanenuic.

7.. Diaporthe.

7. Valsaria.

51. Fk. nicht bohaart.

Fk. mit Ilatron bedeckt, in einem Filz sitzrnd.

3.j. (iibhera.

52. Mündungen rmul.

Mïndung breitgedrïckt.

30. Silizotoma.

53. Fk. frei (welten ringesenkt) anf Mist.

rk ohno stroma zuerst z ringrasenkt.

4. Ioliturhia.

Fk. im sitroma sitzend.

54. Auf Flechten parasitiseh.

Nicht auf Flochten

41. 'Tirhotleceium.

55. Fk. rasigg gehäuft, hedeckt, damn hrrvorbrechend.

36. Otthia.

lk, nichi rasieg gehäuft, meist einzehn.

56. Fk. nur anfangs $†$ eingesenkt entstehend. dann fast völig trei.

2:3. Amphisphacria.

Fk. bedockt bleibend. nur ntit der Mïndunglervorkommend. 57.

57. Grhäuse dimn, fast nur an stongeln.

Geläuse fester, kollig. nur an isten.

58. Nitroma valseenartig.

4.. Itilymosplateria.

5. Ploreyso

Ftrona diatryeenartig. unseheinbar.

59. Kondienlager vorlanden.

7:3. Rhynehostuma.

$5 \div 1$.

Vielkammerige Prkniden vorhanden.

60. Sporen hyalin od. gellylich.

7). Melanconiolla.

s. Myrmareimm.

sporen almkel gefärbt.

(6)

is.

61. Jk. behatet on borstig.

(i).

Fk. stets kahl

64.

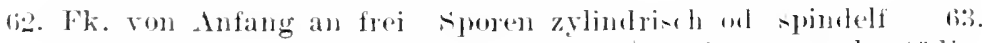

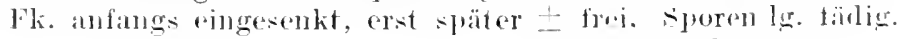

50. Ophioehata.

63. Fporen spindelf.

15. Horpotrichia.

sporen zylindrisch, abgerundet. Wurmf. urekriummt.

16. Isaviopharria.

if. Mündung stets ruma.

Yïmbung zusammelıgedrigk1.

31. I.opliniotrema.

1i.i.

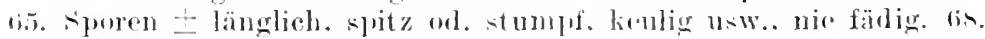

sporen fädigr.

tig. Stroma fohlt ganz, Fk. mus ringugenlit.

I'lu den Fk. ein schwarzes schildf. l'sendostroma enthaltend.

(is. Limospora.

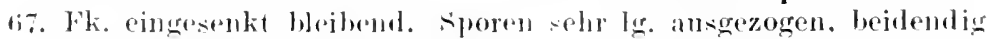
mit langran dünnem dnhängser.

4!). Nilophia.

l'k. ringresankt, damn nach Zerstirmug des Nährgewebes fa-1 ganz frei. Fporen lg. fädig.

53. Ophiobolus. 
68. Fk. sehr lg., sehnabelf. ausgezogen.

22. Ceratosphaeria.

Fk. mit warzen- od. kege f. Mündung, nie schnabell. vorgezogen; weun die Mündung verlängert, dann Fk. in einem Stroma sitzend.

69. Parasiten anf Flechten.

69.

Nicht auf Flechten sitzend.

43. Pharcidia.

70. Kein Stroma vorhanden.

Stroma od. Pseudostroma vorhanden.

71.

76.

71. Fk. von Anfang od. zuletzt ganz frei stehend.

72.

Fk. eingesenkt bleibend, nur die Mündung hervorragend. 73.

72. Fk. ron Anfang an oberflächlich, höchstens an der Basis etwas eingewachsen. Mü̈ndung fein durchbohrt. 18. Zignoella.

Fk. zuerst ganz eingesenkt, dann \pm frei werdend, aber die Basis stets eingesenkt bleibend. Mündung mit viel größerer Öfnung.

25. Nelomastia.

73. Paraphysen rorhanden.

74.

Paraphysen fehlen

74. Sporen olnne Gallerthülle.

Sporen mit Gallerthiille.

75. Mündung flach od. kurz warzig.

Mündung halsf. verlängert.

75 .

76. Fk. unter sinem schildf. Pseudostroma sitzend.

Ein echtes Stroma rorhanden.

50. Metasphaeria.

58. Hassarina.

14. Sphaerulina.

65. Gnomonia.

67. Hypospila.

77. Stroma valseenartig, Konidienlager rorhanden.

So. Calospora.

Stroma valseen - od. diatrypeenartig, gekammerte Pykniden vorhanden.

72. Diaporthe.

78. Stroma fehlend, höchsten die Fk. in einem Hyphenfilz sitzend. 79.

Stroma od. Pseudostroma rorhanden. 87.

79. Mündung stets rund.

Mündung breitgedrückt.

32. Lophiostoma.

80 .

80. Fk. ron Anfang an freistehend, wenn eingesenkt, dann auf Mist

81 .

Fk. anfangs eingesenkt, dann \pm frei bis oberflächlich. 84 .

Fk. eingesenkt bleibend u. nur mit der Mündung vorragend. 86 .

81. Fk. in einem Hyphenfilz nistend.

Fk. nicht in einem llyphenfilz.

82. Nur auf Mist.

17. Chaetosphaeria.

5. Sporormia.

Niemals auf Mist.

83. Mündung warzen- od. kegelf., kurz.

Yündmng fädig verlängert.

19. Helanomma.

22. Ceratosphaeria.

84. Sporen im Schlauch in 2 zweizellige Stücke zerfallend, daher der Schlanch scheinbar mit 16 sporen. $\quad 24$. Ohleria.

sporen nicht zerfallend.

85.

85. Fk. cinzeln stehend. Mündung mit weiter öffnung.

26. Trematosphateria. 


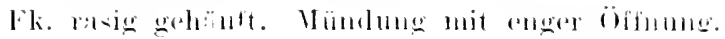

86 Gehäuse lederig häutig

Gehäuse härter kohlig u. briichig.

:35. Gibherilluas.

51. Ieptosphatia.

5.). Massaria.

87. Fk. muter einem Pseudostroma stehenıl. Ho. Clypesphaeria.

Fk. in einem valseenartigen strona ringesenkt.

88.

88. Konidien in deutlich angsebildeten Lagern.SI. Pseudovalsa.

Konidien in vielkammerigen Behältern. Ss. Melogramma.

89. Sporen hralin (bisweilen bei der Reife dunkler).

sporen dumkel gefälot (bisweilen erst bei völliger Taife fäibt).

90. Jïindung stets rumd.

Nïndhng zusammengedrückt.

90.

ge-

92.

91.

91. Gehäuse häutig. Paraphysen fehlen.

33. Platystomum.

Gehäuse brüchigr kohlig. Paraplysen vorhanden.

92. Gehäuse borstig behaart

27. Strickeria.

Gehäuse stets kahl.

j4. Iyrenophora.

6. Pleophramian.

93. Nur auf Mist.

Niemals anf Mist.

93.

94. Mündnug stets rund.

IÏ̈ndung zusammengedrückt.

33. Platystomum.

95. Fk. rasig gehäuft, zuletzt ganz freistehend. 3S. Cueurbitaria.

Fk. einzeln od. wenn in Gruppen, dann bedeckt bleibend. 96.

96. Fk. stets einzehn stehend, ohue stroma.

Fk. in einem stroma gruppenf. ot. bei Fehlen desselben in kreisf. Crmppen in Periderm.

74. Fenestella.

97. Fk. cingesenkt, dann später frei hervortretend od. durch die Ver. witterung der deckenden schichten des Nährsubstrates . frei werdend. sporen olne Gallerthïlle.

Fk. voun Periderm belcekt bleibent, nur mit der warzenf. Iïndung durchbrehend. Eporen mit deutheher Gallerthülle. b(1). Pleomassaria.

98. Fk. eingesenkt $u$. dam später fist frei hervortretend. 27. Ntrickeria.

Fk. eingesenkt u. so bleibend od. hinfiger durch Verwitterung der Schichten des Nährsubstrates frei hervortretend.

\section{5. leospora.}

\section{Crattung: C'batotomium Kunze.}

Fk. oberflächlich anf rinem fïligen Myzel sitzend, an der kurzen, nicht vorgezogenen Mündung mit einem Han seloppl hesetzt. Gehäuse diun. Sporen bram, fast kughge, oft beinahe zitronenf. Paraphysen O. Konidien an den Myzelfäden od. an den schopflaaren.

1. Schopfliaare diehotomisch verzweigrt. 
2. Sporen breit ellipsoidisch, beidenkig kurz zugespitzt. Auf faulenden Pflanzenteilen, Mist, Papier, nicht selten.

$$
\text { C. comatum (Tode) }
$$

Sporen etwas stark abgeflacht, ron oben \pm kreisf., ron der Seite schmal elliptisch. Auf fenchtem Papier u. Pappe, zerstreut. (Fig. 179.)

C. chartarum (Berk.)

3. Schopfhaare wenig gewnden, an den Enden bischofsstabf. eingerollt. Sporen länglich ellipsoidisch, beidendig kurz zugespitzt. Auf Mist, nicht selten. (Fig. 180.) C. murorum Corda

Schopflıare ganz unregelmäßig eng spiralig gewunden. Sporen lanzettlich. Auf Pferdemist, selten, (Fig. 181.)

\section{C. spirale Zopf}

\section{Gattung: Sordaria Ces. et de Notaris.}

Fk. eingesenkt od. oberflächlich, häutig. Schläuche 4-8 sporig. Sporen braun, init Gallerthïlle oder Anhängseln, ellipsoidisch, seltner kugel- od. scheibenf. Paraphysen vorhanden.

1. Sporen ohne Anluängsel.

Sporen mit Anhängsel.

2. Sporen flach scheibenf. Auf Mist ron Pflanzenfressern, nicht häufig.

S. discospora Anersw.

Sporen nicht flach, sondern kuglig od, ellipsoidisch. 3.

3. Schläuche oben abgeflacht $u$. verdickt.

Schläuche oben abgerundet kaum verdickt. Sporen ellipsoidisch 15-20 $\times 9-11 \mu^{\circ}$. Auf Mist, faulendem Papier u. Pflanzen. teilen, häufig. (Fig. 182.)

S. fimicola (Roberge)

4. Sporen ellipsoidisch, $24-32 \times 16-20 \mu$. Auf Hasen- u. Kaninchenkot, sowie Mist anderer Pflanzenfresser, häufig.

S. macrospora Auersw.

Sporen fast kuglig, $18-25 \times 15-18 \mu$. Auf Mensehen- u. Hundekot, nicht häufig.

S. Lumana (Fuck.)

5. Schläuche vielsporig. Sporen beidendig mit Anhängsel, 24-34 $\times 16-19 \mu$. Auf Mist von Iłasen, Kühen, Pferden usw., zerstreut. S. pleiospora (Wint.)

Schläuche mit 8, seltener weniger Sporen.

6. Sporen unten mit einem Anhängsel.

6.

Sporen unten mit zwei Anhängseln.

7. Oberes Anhängsel fädig.

10.

Oberes Anhängsel breit, gestreift, kurz. Auf Mist ron Pflanzen. fressern, zerstrent.

S. decipiens Wint.

8. Oberes Anhängsel dünnfädig, nur auf Mist.

9.

Oberes Anhängsel dickfädig. Sporen $34-45 \times 20-30 \mu$. Auf faulenden Kr räuterstengeh $u$. auch auf Mist, nichthäufig. (Fig. 183.)

S. brassicae (Klotzseh)

9. Fk. bis $400 \mu$ hoch. Sporen 17-21 $\times 9-12 \mu$. Auf Mist ron Pflanzenfressern, zerstreut.

S. minuta (Fuck.) 
lik. $6011-800 \mu$ hoch. Fjoren $2.2-30 \times 12-14 \mu$. Ebenda, zerst rent.

s. currulu de Bary

10. Fiporen $17-28 \times 10-12 \%$. Elemela, zerstrent.

s. eoproplita (Fr.)

sporen 4ti-60 y 25-30\%. Inf Kuh- 11. Iferdemist, nicht seltell. s. Iimiseda I'rs. re de Not.

\section{Gattmog: Iypucopra Fr.}

Fk. in einen solwwarzen, krustigen strona eingesenk1, somst wie Sordaria.

1. Stroma ausiedehute Krusten bildend.

stroma klein, nit wenigen Fk. Spren ellipoidisell-spindelf., $20-35 \times 12-15 \%$. Auf Ilasen- u. Kanineheukot, zerstrent. (Figr 184.)

H. meriluria Fries

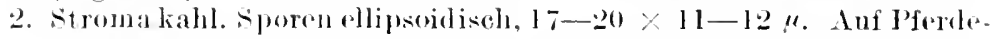

11. Kulmist, zerstreut.

II. limeti (Jers.)

stroma bramzottig. Sporen alipsojeliseh, 17-21 $1 \times 9-10 \mu$. Auf l'ferdemist, zerstreut!

H. equorum (Fuck.)

\section{Gattung: Wolitsohia duersw.}

sporen zweizellig, bram. Paraphysen vorhanden, komst wie sorelaria.

Sporen an der Wand tiof eingeschnür, zuletzt in 2 rif. filieder won:s $\times 16$ " zerfallend Auf Kot von Rohen, Ilasen, l'ferden usw. nicht häufig. (Fig. 185.)

I). Auerswallii luck.

sporen eingeschnüt, nicht zorfallond, im samzen $22 \times s, 4$. Auf llasenkot usw., zerstreut. I. minuta Fuck.

\section{Crattung: Sporormia de Notaris.}

sporen quer 4 bis melorzellig, hramuselowaly. sonst alles übrige wie bei siordaria.

1. siproren $4 z^{2} l l i x$.

sporen mehr als somlig. Aul Kuh- u. Sohafmist, sedten.

s. limetaria de" Not.

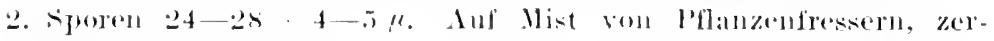
streut.

S. Illinima Anorsw.

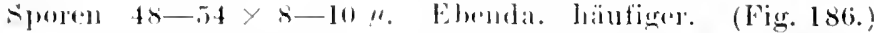

$\therefore$ intermodia duersw.

sporen $90-95 \times 14-17 \mu$. Vilemela, zerstrent.

S. mentoppora duersw.

6. Crattung: Pleophragmia Fuek.

siporen mauerf., gelbbram, somst wie sordaria.

Auf IIasenkot, nicht häufig. (Fig. 187.)

I. Ieporum Fuck. 


\section{Gattung: Trichosphaeria Fuck.}

Fk, oberflächlich, klein, mit winziger Mündung. Gehäuse dünn, behaart od. fast kahl Sporen einzellig, bisweilen der Inhalt 2 teilig, hyalin.

1. Fk. kahl od. höchstens mit einzelnen Borsten besetzt. Sporen einzellig, $5-8 \times 2-3 \mu$. Auf entrindeten Laubholzästen, zerstreut.

T. minima (Fuck.)

Fk. dicht behaart.

2. Fk. \pm kuglig, dicht gedrängt. Sporen einzellig, $5-8 \times 3-4 \mu$. Auf Lbholz-u. -rinde, zerstrent. (Fig. 188.) T. pilosa (Pers.)

Fk. niedergedrückt eif., dicht u. zusammenflieBend. Sporen 2 teilig, $8 \times 3 \mu$. Auf faulem Kiefernholz, nicht häufig.

\section{T. vermicularia (Nees)}

\section{Gattung: Leptospora Fuckel.}

Fk. behaart od. nur filzig bekleidet, Mündung klein, flach. sporen zylindrisch, beidendig abgerundet, oft wurmf. gekrïmmt, einzellig, seltner mit 2 teiligem Inhalt.

1. Fk. kahl od. nur filzig bescheidet.

2.

Fk. mit abstehenden Haaren besetzt.

3.

2. Fk. oberflächlich, meist große Krusten bildend am Grunde oft von Hyphenfilz nmgeben. Sporen grade od. unten knief. umgebogen, 19-22 $\times 3-4 \mu$. Auf alten Lbstïmpfen, häufig. (Fig. 189.)

L. spermoides (II offm.)

Fk. oberflächlich zerstreut od. herdenf. außen in der Jugend weis.-, im Alter graubraunfilzig od. kahl. Sporen unten etwas verschmälert $u$. umgebogen $35-50 \times 4-5 \mu$. Auf Lbstümpfen, nicht selten.

L. ovina (Pers.)

3. Sporen unten ohne Anhängsel. An faulenden entrindeten Lbästen, zerstrent.

L. canescens (Pers.)

sporen unten mit einem borstenf. Anhängsel. Auf faulem Holz, selten.

I. caudata Fuck.

\section{Gattung: Rosellinia Ces. et de Not.}

Fk, oberflächlich, frei od. von IIyphenfilz umgeben, \pm kuglig, mit \pm flacher Mündung. Gehänse kahl od. borstig. Sporen ellipsoidisch, einzellg, braun.

1. Fk. nicht mit IIaaren besetzt, aber oft von einem Hyphengewebe umgeben od. filzig bekleidet.

Fk. mit Borsten besetzt.

2. Fk. höchstens bis $0,4 \mathrm{~mm}$ im Durchm., krustig dicht, Gehäuse dïnn, brüchig. Sporen $10-12 \times 6-8 \mu$. Auf faulem IIolz, Rinde, Ästen von Lib., nicht selten.

R. pulveracea (Ehrl.)

Fk. über $1 / 2 \mathrm{~mm}$ im Durchm., Gehäuse dick.

3. Fk. am Grumde mit IIyphengewebe.

Fk. am Grunde ohne IIyphengewebe. 


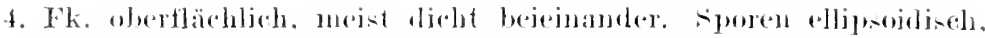
etwas moleichseitig, efwas zusammengedrübkt, $15-23 \times 6-7 \mu$. Auf faulen dsten u. Rijudeju vout Lh., lıäufig. (Fjg. l91.)

\section{R. ayuila (Fr.)}

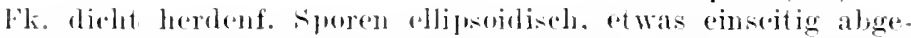
flacht. von dere seitre otwas spindelf. mit Randeisten n. beidendig

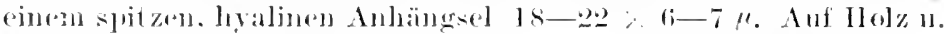
limele von Jis., zerstrent. R. Helenal (Fr.)

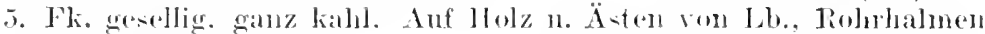
usw. nivlıt lö̈uligs R. mammiformis (P'Prs.)

Fk. zerstreut od. eqesellig. granweifflorkig. Anf fiammen 11. Zweigen rom L.l.. selten. R. araneosa (Pers.)

6. Fk. an Grumbe mit Ilyblenfilz, heronf. Fuoren elliposidischspindelf., $10-14 \times 5-6 \mu$. Auf clavaria-Arted, zerstreut.

R. elavariae (Thul.)

Fli. nicht mit llyphentilz am crmule.

7. Fk. meist linustig, mit selur zahlrejehen Borsten bedeckt. Sporeu schmal ellipsoidiseds, 12-18 $\times 6-9 \mu$. Anf faulen limele ven l,., zerstrent.

R. lifularia (frer.)

Fk. krustig, mit spärlichen kurzen Bursten besetzt. Siporen ellipsojdisch, etwas zusammengedrängt, 6-10 zerstreut.

li. velutina Fuck.

\section{Crattung: Bombardia Fries.}

Fk. oherflächlich, meis büschelig stehend. Sporen ellipsoidisch, schwarthaun, bejendig mit t langen, hvalinem Anhängsel.

Auf dem Himsulnitt von lb., njeht selten. (Fig. 191.)

B3. Iascicalata Fr.

\section{Gattung: Coleroa Fries.}

Fk. obertiälulich, meist herdenf., kuglig u. so bleibend, nuit

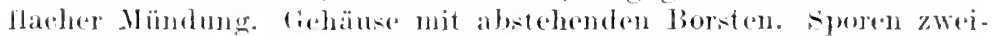

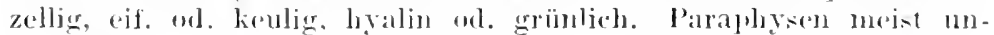
deutlirh.

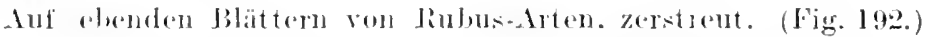

c. chatomimm (kze.)

Auf el. Dil. von Alehimilha vulgaris, zerstreut.

$$
\text { (. alchimillat (Grev.) }
$$

Auf lob. BI. Los l'otentilla anserina. niclut luäufigr

\section{2. (iattung: Nimslia Anersw.}

$$
\text { c. potentillate ( } \mathrm{Fr} .)
$$

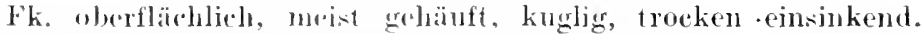
Gehäuse nit abstehonden borsten. sporen spindelf., zweizellig, hyalin. l'araphyien undentlich.

Borsten mindestens so $\mu$ lg. Sehläurhe ellipsoidisch. Anf faulenden Gras-u. Carexhabmen. zerstrent. Y. exusporioides (Desm.) 
Borsten höchstens $40 \mu \mathrm{lg}$. Schläuche zylindrisch. Auf faulenden Kiefernadeln u. von da auf Ästchen übergehend, zerstreut . (Fig. 193.)

r. pusilla (Fr.)

\section{Gattung: Melanopsanma Niessl.}

F'k. oberffächlich, kuglig od. länglich, Mü̈ndung flach od. warzenf., glatt, kahl. Sporen zweizellig, hyalin od. bräunlich.

Fk. krustig, später um die Mündung eingesunken. Sporen

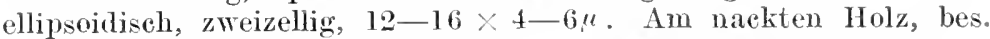
von Lbstümpfen, häufig. (Fig. 194.) M. pomiformis (Pers.)

\section{Gattung: Bertia de Not.}

Fk, oberflächlich od. mit der Basis etwas eingewachsen, herdenf., \pm kuglig. Gehäuse höckerig od. runzlig. Sporen ellipsoidisch, leicht gekrümmt, hyalin.

Auf Holz, Rinde von Lb., häufig. (Fig. 195.)

\section{B. moriformis (Tode)}

Auf dem Th. von Solorina crocea, im höneren Gebirge.

B. Lichenicola de Not.

\section{Gattung: Herpotrichia Fuckel.}

Fk. oberflächlich, 士 kuglig, gesellig. Crehäuse mit langen, kriechenden IIaaren besetzt, die einen Filz um die Fk. bilden. Sporen spindelt., mehr als 2 zellig, hyalin bis bräunlich

An faulenden Ranken ron Rubus idaeus, zerstreut.

H. rubi Fuck.

Auf faulenden Nadeln, Äst chen, IIolz usw., nicht häufig. (Fig. 196.)

H. pinetorum (Fuek.)

16. Gattung: Lasiosphaeria Ces. et de Not.

Fk, oberflächlich, herdenf., meist auf filzigem Ilyphengefleeht. Gehänse brüchig, behaart. Sporen zylindrisch, meist etwas gebogen, mit mehreren Scheidewänden, \pm hyalin.

1. Gehäuse mit steifen, meist kurzen Borsten bedeckt.

Gehäuse mit zottigen braunen Haaren. Sporen zylindrischwuxmf., mit 5-7 Querwänden, 55-62 $\times 6-7 \mu$. Auf faulen Lbstämmen, zerstreut. (Fig. 197.) L. hirsuta (Fr).

2. Sporen zylindrisch-wurmf., mit 6-8 Querwänden, $70-80 \times 7-8 \mu$. Auf faulen Lbbäumen u. $11 \mathrm{olz}$, zerstreut. L. hispida (Tode)

Sporen zylindrisch, gebogen od. am unteren Ende wurmf., $50-60 \times 4-6 "$. Auf faulem Holz, gestrent.

L, rhacodium (Pers.)

17. Gattung: Chactosphaeria Tul.

Fk. zwischen dichtem, braunem Filz sitzend, dicht gedrängt, kuglig. Gehäuse kahl. Sporen länglich, 4 zellig, die Endzellen beiderseits lyalin, die beiden Mittelzellen braun. 
Auf faulenden Ïsten u. IIolz weite, sanmetartige Uberzüge bildend, zerstreut.

C. tristis (Tode)

18. Gattung: Zignoëlla Sacc.

lkk. oberflächlich, höchstens am Gruncle etwas eingesenkt, kahl. sporen eif. his spindelf., mehrzellig, hyalin.

sporen $18-32 \times 5-8 \mu$. Auf llolz u. Rinde von Lb., zerstreut. Z. oroidea (Fr.)

sporen $19-20 \times 3-4 \mu$. Auf faulendem Eichenholz, selten. z. papillata (Fuck.)

19. Gattung: Velanomma Fuck.

Fk. obertlächlich meist rasig, $\pm \mathrm{kuglig}$, kahl. Hündung warzen• ol. kugelf. Sporen wie bei vor. Gatt., dunkel gefärbt.

An Isten, llolz, Rinde von Lb., lıäufig. (Fig. 198.)

I. pulvis pyrius (I'ers.)

An Rhododendron-Ästen im llochgebirge, nicht selten.

I. rhododendri liehm

20. Gattung: Ceratostomella Sace.

Fk. oberflächlich, bisweilen am Grunde eingesenkt, kuglig, Itindung haarf. ausgezogen. Sporen länglich ellipsoidiseh, einzellig hyalin.

Auf fanlem Holz ron Lb., besonders Fagus, zerstreut.

$$
\text { C. rostrata (Fr.) }
$$

Auf Nil., hesonders bearbeiteten hiefernholz, Blaufäule verursalchend. nicht selten. (Fig. 19?.) r.pilifora (Fr.)

21. Gattung: Ceratostoma Fries.

Wie ror. Gatt., aber sporen brann.

In Rissen der Rinde des Weinstockes, zerstrent.

C. viti, Fuck.

22.2. Crattung: Cerntosphaeria Niess].

Wir vor., abes die sporen lïnglich mit. nelne en Querwänden, hyalin.

Sporen 4 zellig, $18-21 \times 5-6 \mu$. Auf faulem IJolz, selten.

('. rhenana (Auersw.)

sporen 6 zellig, 21-28 $\times 5-6 \mu$. Iuf faulem Weidenholz, zer. streut.

(. pusilln (l'uek.)

23. Gatiung: Imphiophaterin ces. et de Sot.

Stroma O. Fk. im substrat zuerst \pm eingesenkt, dann fast freistehend. Gehäuse kahl, kohlig, Mündung warzenf. Sporen länglich, zweizellig brann.

sporenzellen fast gleich, an der Querwand etwas eingeselonürt, 
Ascomycetes.

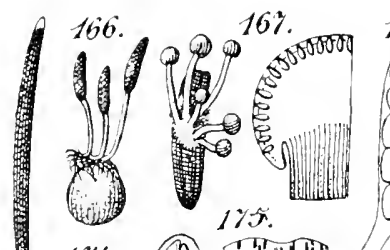

168. 169. 190. 191. 192. 173.

1\%.

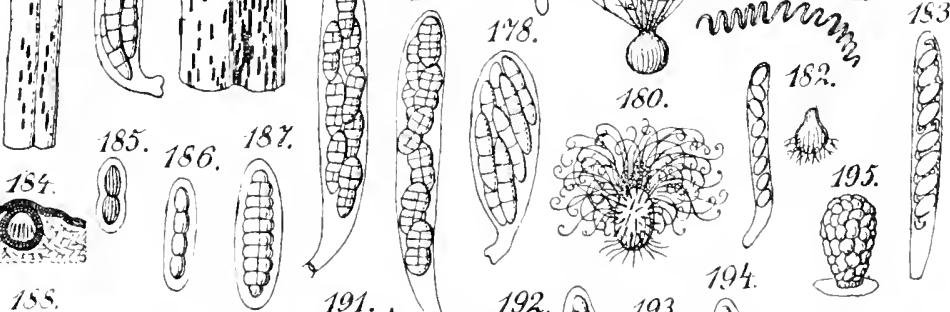

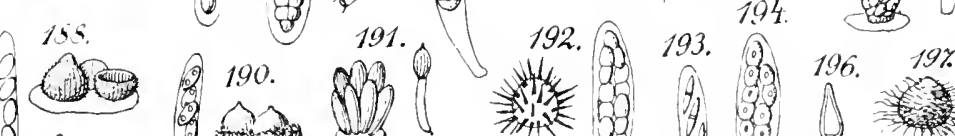

8 199.

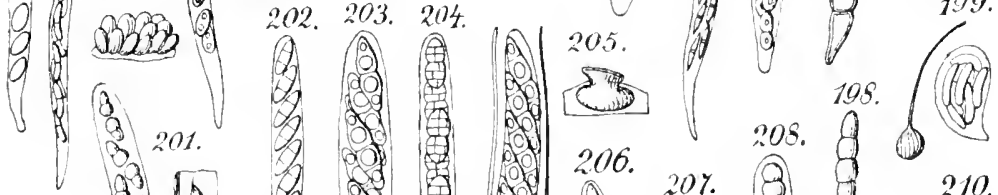

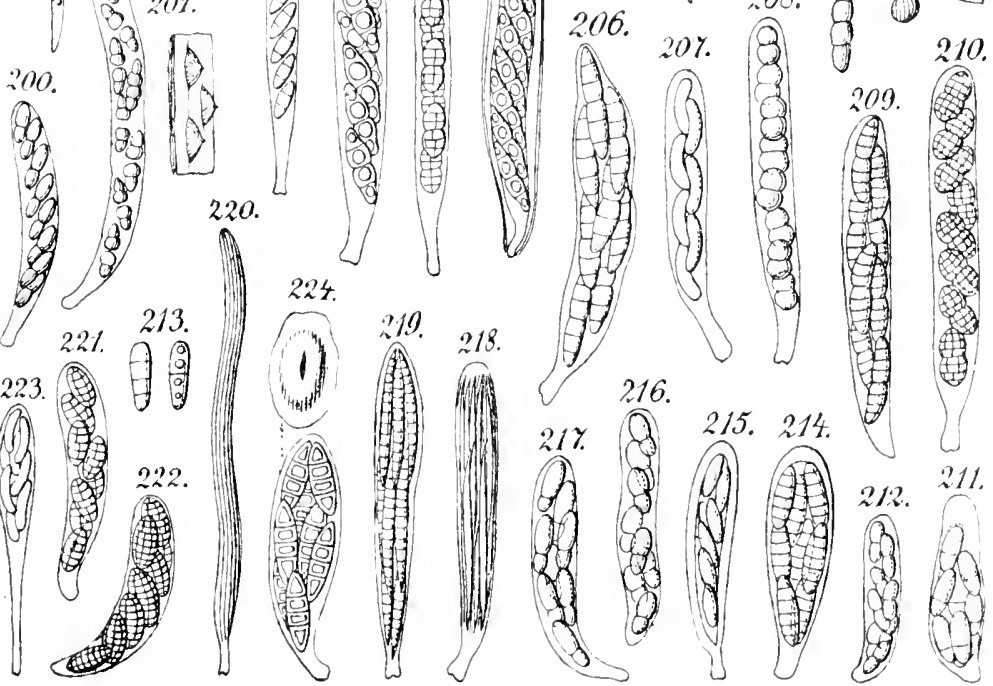


hellbraun, 17-26 6-8 ". Auf älterer Rinde ron Ulmus, Quereus, salix n. a., zerstrent.

A. umbrina (Pers.)

Obere sporenzelle breiter u. länger, an der Querwand tief ein. geschnürt, braun, $24-26 \times 8-10 \%$. Auf hartem Eichenholz, zerstreut. (Fig. 200.)

A. applanata (Fr.)

\section{Gattung: Ohleria Fuekel.}

Fk. herdig, anf einer dïnnen Unterlage, eingesenkt, dann fast frei hervorbrechend. Mündung papillenf. Sporen + zellig, im schlauch in zwei 2 zellige Teile zerfałlend, braun.

Auf faulenten strünken, nichıt häufig. (Fig. 201.)

(O. obducens Wint.

25. Gattung: Melomastia Nitsehke.

Wie folg. Gatt., aber die Sporen hyalin.

Auf dünnen Asten ron Lb. u. Sträuchern, nịcht selten. (Fig. 202.)

I. mastoidea (Fr.)

26. Gattung: Trematosphaeria Fuekel.

stroma 0 . Fk. eingesenkt, damn \pm hervortretend, kuglig niedergedrïckt. Mündlung warzenf., selır weit. sporen ellipsoilliseh od. spindelf., mehrzellig, braun.

Mündung sehr groß. Sporen $21-26 \times 6-7 \mu$. Auf hartem llolz von Lb. nicht selten. (Figr. 203.)

T. pertusa (Pers.)

Irundung kleiner, fast purpurrot, dann sehwarz. sporen $18 \times 6 \mu$. Auf entrindeten Erlenästen im Crebirge T. phaea (Rehm)

27. Gattung: Striclieria körber.

Stroma O. Fk. eingesenkt., dann fast frei, kahl. Mündung flach od. warzenf. sporen ellipsoidiseh, mauerf, gelbhraun.

J. Sporen mit neist 7 Querwänden u. mehrepen Längswänden. 2.

sporen mit meist 3 Querwänden u. einer Längswand, 1s-2 I $\times$

$7 \mu$. Anf der Rinde von Robinia, nicht selten.

S. Kochii Körb.

2. Fk. dieht gedräng: grofe strecken ïberziehond. An entrindeten Asten, bes. ron Eschen, zerstrent. (Fig. 204.)

S. obduceus (Fr.)

F'k. einzeln od. nur zu wenigen gelı̈uft. Auf dürren Ästen von Lonicera, besonders in den Mpen. S. imnavis (de Not.)

\section{S. Gattung: Iophiella Sace.}

Fk. einzeln, oberfläehlich, ohnestroma, am Girundeeingewachsen. Mündung zusammengedrückt. Sporen spindelf., einzellig, dunkel. braun. Paraplisken vorhanden.

Mündung gekerbt. An dïrren Ïsten von Prunus, Cornus, Fraxinus, Lonicera usw., selten.

L. eristata (Pers.) 
29. Gattung: Lophiosphaera Trevisan.

Fk. wie bei vor. Gatt. Sporen länglich, 2 zellig, hyalin. Auf Brombeerranken, nicht häufig. I. Fuckelii Sace.

30. Gattung: Sclizostoma Ces, et de Not.

Fk. wie vor. Sporen ellipsoidiseh zweizellig braun. Auf alter Pappelrinde, in siiddeutschland.

S. vicillum Sace.

\section{Crattung: Lophiotrema Sace.}

Fk. wie vor. Sporen länglich, quer drei- bis mehrzellig.

Fk. meist einzeln. Sporen 4 zellig meist $20-26 \times 5-8 \mu$. Auf dicker Weiden- oder Pappelrinde auch IIolz, zerstrent. (Fig. 205.)

L. nucula (Fr.)

Fk. meist herdig. Sporen 6 zellig, meist $26-30 \times 4 \mu$. Auf dürren Ïsten, namentlich Rubıs, selten. I. praemorsum (Lasch)

\section{Gattung: Lophiostoma Fries.}

Fk. wie vor. Sporen ebenso, aber braun.

1. Sporen ohme Anliangsel.

Sporen beidendig mit Anhängseln.

2. Sporen 4-8 zellig, $20-30 \times 5-8 \mu$. An dürren Kräuterstengeln, nicht selten. (Fig. 206.) L. caulium (Fr.)

Sporen 6 zellig, die Endzellen etwas heller, $40-45 \times 9-10 \mu$. Auf dicker Rinde von Quercus, Populus u. Juglans, nicht selten.

L. macrostomum (Tode)

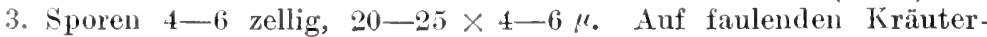
stengeln nicht selten.

I. insidiosum (Desm.)

Sporen 7-8 zellig, $32-38 \times 9-10 \mu$. Anf $\ddot{\text { Asten }}$ und II olz von Salix, seltwer.

I. appendiculatum Fuck.

\section{Gattung': Platystomum Trevisan.}

Fk. wie vor. Sporen mauerf., bram.

Sporen mit 5 Quer- u. 1-2 Längswänden. Auf dürren Ästen u. II olz von Lb., nicht selten. P. compressum (Pers.)

\section{Gattung: Nikschkia Otth.}

Fk. rasenf., unterder Oberhaut hervorbrechend, kuglig, trocken schüsself. zusammenfallend. Sporen zylindrisch, hyalin einzellig.

Sporen $9-11 \times 2-3 \mu$, mit 2 Öltropfen. Auf dürren Lbästen z. B. Tilia, Acer, Prunus, nicht selten. (Fig. 207.)

\section{N. cupularis (Pers.)}

Sporen $9-11 \times 2-2,5 \mu$, mit 4 Öltropfen. Anf nacktem 11 ol $z$ u. Lbrinde seltner. 


\section{Gattung: Gibbera Fries.}

Stroma tilzig, verschwindend. Fk. rasig ansitzend, mit einzelligen Borsten besetzt. Sporen ellipsoidisch, zweizellig, braun.

Auf Preifelbeerstengeln zerstreut. G. vaccinii (Sow.)

\section{Crattung: Otthia Nitschke.}

Fk. rasenf. unter der Oberhant vorbrechend, kahl. sporen wie ror.

An dirren isten von Crataegus oxyacantlat, selten.

(o. erataegi I'uek.

An dïren Rosenästen selten.

o. rosar Firek.

An düren Ïsten von Acer platanoides selten. (Fig. 208.)

(). aceris Wint.

37. Gattung: Gibberislea Fuckel.

Fk. rasenf. hervorbrechend. Sporen länglich spindelf. mit mehreren Querwänden, loram.

An dïrren Viscum- Isten, zerstreut. (Fig. 209.)

(a. visei Fuck.

38. Gattung: C'ucurbilatia Gray.

Fk. rasig od. dielit herdenf., auf einem filzigen od. krustigen Stroma, muter der Oberhaut vorbrechend, dann freistehend. sporen matuerf., bram.

1. Iuf Lb.

Sporen mit 3 Querwänden an der mittlerenstark, an den beiden anderen wenig eingesohnïrt, mit einer Längswand, 17-23
7-8.". An Nilrinde zerstreut.
(. pityophila $\left(\mathrm{Fr}^{\circ}\right.$.)

2. sporen mit 3-7 Querwänden.

sporen mit 8-9 (2ner- u. melneren Längswänlen. 26-36; 12 - $14 " \prime$, in ther Mitte eingeschniint. Auf diirren Berberis-Tsten läufig. (Fig. :210.)

(c. herberidis (Pers.)

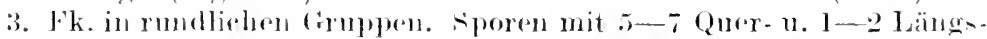

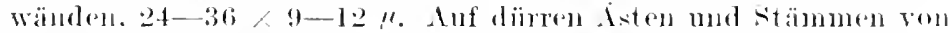
crtisus, wieht selten.

('. laburni (l'ers.)

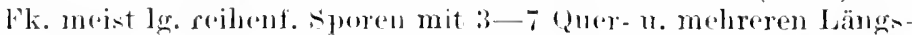

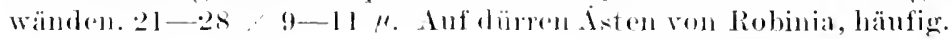
(․ plonsatal (Fr.)

\section{Gattmug: Stimmatea Fries.}

Fk. beteckt bleibend, nuter der Epidermis oder lintkma, mit der Öffumeg vorragend. Schläuche büsehelig. Sporen länglich. zweizotlig. hyalin bis grïmlieh. J'ajaphysen forhamben.

Auf der Oberseite lebender bläter von feranium Robertianum kleine Crmupen hildend, lüufig (Fig. 2l1.) S. robertiani Fries

Auf der Oberseite lebender libitter von fremanium silvaticum, im Crelbirge.

s. greranii Fries 
40. Gattung: Myeosphaerella Johanson ${ }^{2}$ ).

Fk. wie bei ror. Gatt., aber tiefer im Gewebe sitzend. Alles andere wie bei vor. Gatt., aber Paraphysen fehlend.

1. Auf Farnen.

Auf Monokotyledonen

2.

Auf Dikotyledonen.

2. Fk. in einem braunen Fleck zerstreut stehend. Sporen länglich keilf., kaum eingeschnïrt, $10 \times 3 \mu$. Auf lebenden Wedeln von Aspidium u. Asplenium, zerstreut.

I. filicun (Desm.)

Fk. nur oberseits, zerstreut. Sporen länglich, stumpf einge. schnürt, $8-9 \times 2 \mu$. Auf dürren Wedeln von Pteridium aquilinum zerstrent.

II. aquilina (Fries.)

3. Anf Liliaceen.

Auf Gräsern, Juneus, Typha.

4. Fk. in länghichen, £ schwarzbraunen Flecken stehend. Sporen eif. länglich, \pm ungleiehhälftig, schwach eingeschnürt, hyalin, 9-13 3 3-4 $\mu$. Auf toten Blättern von Convallaria, Polygonatum, nicht selten.

I. asteroma (Fr.)

Fk. dicht rasig, von der grauschimmernden Epidermis bedeckt. Sporen länglich, abgerundet, nicht einges chnürt, hyalin $16 \times 4-5 \mu$ Auf Blättern u. Schaften von Allium, nicht selten.

5. Auf der Oberseste der Blätter von Agrostis, selten.

$$
\text { II. allicina (Fr.) }
$$

I. agrostidis (Fuck.) Auf toten Stengeln von Scirpus lacustris, selten.

$$
\text { I. scirpi lacustris (Auersw.) }
$$

Auf toten Blättern von Typha latifolia u. minima, zerstreut.

6. Auf Blättern von Kräutern.

II. typhae (Lasch)

Auf́ Kräuterstengehn.

Auf Blättern von Sträuchern od. Bäumen.

Auf trockenen Hülsen von Cytisus laburnum u. alpinus, zerstreut.

I. leguminis eytisi (Desm.)

7. Auf toten Bl. von Stellaria holostea u. anderen Arten, nicht selten.

II. isariphora (D ssm.)

Auf toten Bl. von Brassica u. Armoracia, häufig.

II. brassicicola (Duby)

Auf dïrren $\mathrm{kl}$ von Fragaria, häufjg

Auf lebenden Bl. von Oxalis, nicht selten.

I. depazeiformis (Auersw.)

Auf dürren Bl. von Eryngium, zerstreut. I. eryngii (Fr.)

8. Auf dürren Stengeln u. Schoten von Cruciferen, nicht selten.

II. cruciferarum (Fr.)

1) Von den etwa 150 deutschen Arten, die meist auf eine od. wenige Näbrpflanzen beschränkt sind und sich durch geringe Merkmale unter. scheiden, konnten hier nur wenige aufgenommen werden.

Lindau, Kiyptogamenflora II, 1, 2. Aufl. 
Auf dïrren stengeln von Medicago, zerstreut.

11. cireumvaga (Desm.)

Auf dïrren Stengeln von Umbelliferen. N. leptoasea Auersw.

9. Auf faulenden 131. von Populus tremula. M. maeularis (Fr.)

Fk. meist locker, herdig. sporen $7-8 \times 2-4 \mu$. Anf Bl. von Quereus, häufig.

II. punctiformis (Pers.)

Fk. herdig, in eckigen, von den Nerven begrenzten Flecken.

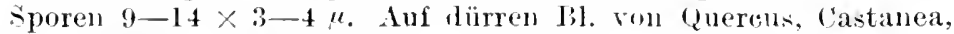
Acer, leseulus usw., läufig. (Fig. 212.)

I. maculilormis (P'rs.)

Auf faulenden Bl. ron clematis, nicht selten.

M. Vagabumla (Desm.)

Auf dïrren Bl. von crataegus, zerstreut.

II. crataegi (Fuck.)

Auf welken Pl. ron Hedera, zerstreut. M. hedericola (Desm.)

Iuf dürren Bl. von ligustrum vulgare, zerstrent.

II. ligustri (Desur.)

41. Gattung Tichothecium r. Flotow.

Wie vor. Gatt., aber sporen hram. Flechtenparasiten.

Auf dem Th. von Krustenflechten, besonders im Gebirge.

T. gemmiferum (Tayl.)

42. Gattung: Guiguardia Viala et Raraz.

Wie Ifrosphaerella, aber die sporen erst kurz vor der Reite durch eine Wand in eine nntere kleine u. obere grofe Zelle geteilt, livalin.

sporen $10-16 \% 4-6$. Auf faulen Eichenblättern, zerstrent.

ii. punctoidea (Cooke)

flooren s $x 3 ! "$. Anf dïren Eichenblïtern, zerstrent.

(i. Cookeana (Auersw.)

sporen $14-15<4-5 \mu$. Auf dïrren Blättern von larpinuzerstreut.

(i. ('arpinea (Fr.)

sporen $13-17 \% 3-4 \mu$. Auf diirron stengreln von Epilobium andrustifolium, nicht hïufig.

(i. 'pilobii Wallr.

43. Gattung: Phaceidia körbers.

lk. ringesenkt, dann hervorstehend, sonst wie Myeosphaerella. sporen länglich, zuletzt 4 zellig, hyalin. Flechtrnparasiten.

Auf den Apotheoien von Leenora subfusca u. anderen Arten, nicht sclten. (Fig. 213.) P. epicymatia (Wallr.)

44. Gattung: Sphaeruliun sace.

Fk. zuletzt wenig hervortretend. sporen melorellig, bisweilen auch mit einer Lāngswand, hyalin. 
Auf dürren Eichenblättern, zerstreut. S. myriadea (DC.)

Auf dïrren Asten ron Rosa u. Rubus, zerstreut. (Fig. 214.)

S. intermixta (Berk. et $\mathrm{Br}$. )

45. Gattung: Physalopora Niessl.

Fk. eingesenkt bleibend, nur mit der kegelf. Mündung hervortretend. Sporen länglich, stumpf, einzellig, hyalin.

Anf dürren Grasblätteru, nicht lıäufig. (Fig. 215.)

P. festucae (Lib.)

Anf dürren Himbeerranken, nicht häufig. P.idaei (Fuck.)

Auf faulen Ästchen von Cormus sanguinea, nicht häufig.

P. corni Sacc.

46. Gattung: Venturia Ces. et de Not.

Fk, eingesenkt, nur mit der IIündung od. teilweise hervortretend, am Scheitel mit steifen Borsten besetzt. Sporen 士 ellipsoidisch, zweizellig, hyalin bis olivengrün od. gelblichbraun. Paraphysen bald 0 . 1. Anf Kräntern.

Auf Blättern von Bäumen.

3.

2. Sporen 12-1 $4 \times 4 \mu$. Auf Blättern vou Rumex-Arten, zerstrent.

V. rumicis (Desm.)

Sporen $10 \times 3,5 \mu$. Auf Blättern von Epilobium-Arten, zerstreut. V. maculiformis (Desm.)

3. Auf Rosaceen, Nebenfruchtformen Fusicladim.

4.

Anf Betula-Arten, nicht selten (Fig. 216.)

V. ditriclıa (Fr.)

Auf Populus tremula, zerstreut.

Auf Fraxinus, zerstrent.

V. tremulae Aderh.

V. fraxini Aderh.

4. Auf Birnenblättern, Nebenfruchtform F. pirinum, hänfig.

V. pirina Aderh.

Auf Apfelblättern, Nebenfruchtform F. dendriticum, lı̈ufig.

V. inaequalis (Cke.)

Auf Kirsehblättern nieht selten.

V. cerasi Aderh.

Auf Blättern vou Crataegus, zerstreut. V. crataegi Arerh.

\section{Gattung: Didymella sace.}

Fk. nur mit der Mündung vorbrechend, kahl. sporen \pm eiförmig, zweizellig, hyalin. Paraphysen vorhanden.

Auf Wedelstiplen von Aspidium felix femina, Ptridium $n$. Struthiopteris, selten. D. mierospora (Niessl.)

Auf dürren Carex-Blättern, zerstreut.

D. proximella (Karst.)

Anf Kräuterstengeln, besonders von Urtica, nicht selten. (Fig.21 7.)

Auf Stengeh von Bryonia alba, zerstrent.

D. superflua (Auersw.)

D. bryoniae (Fuck.)

Auf Epilobium-stengeln, nicht selten.

D. fenestrans (Dnby.) 
48. Gattung: Itidymosplateria Fuckel.

Wie vor. Gatt, aber sporen braum.

1. Oberlant ïber den I'k. nuverindert. Aut dürren Stengeln größerer Kräuter, zerstreut.

1). (comoidea Niessl

Oberhaut dureh die IIyphen geschwärt n. einen dunklen Fleek bildend.

2. An düren Kräuterstengehn, zerstrent. D. bruneola Niessl

Anf berindeten noch lebenlen $\ddot{A}$ sten von buberis, zerstreut.

J). Pidlrumidis (Fr.)

49. Crattung: Dilophia Sace.

Fk. bedeckt blejbend. sporen lg. spindelf., quereneteilt, beidendig mit fädigem Inhängsel, hyalin.

tuf dïrren (rrakhalmen, zerstrent. (Fig. 2l8.)

(I). Eraminis (Fuek.)

\section{0) Gattung: Metasphatria Sa(ce. $\left.{ }^{1}\right)$}

Fk. bedeekt, mit kurzer Öffumeg. Fporen ellipsoidiseh bis länglieh, stmupf oul. spitz, drei bis melrzellig, hyalin. Paraphysen vorlauden.

1. Auf Monokotyledonen, Sporen mit 2-4 Querwänden. 2.

Anf Dikotyledonen, Sporen mit $2-4$ Querwänden.

2. Auf Typha angustifolia, nicht bäufigr.

1l. Iacustris (Fuck.)

Auf dürren Stengeh ron Polygomatum, zerstrent.

11. Bellyurkii (Westend.)

3. Auf hïren strugehn von Seneeio nemorensis u. Fuehsii, zerstreut.

M. IIIIruspora (Fuek.)

Auf Iiätern von Iedera helix, zorstreut.

M. Leliciuala (l) e.sm.)

Auf biattern von Vinea, zerstrent.

I. vincale (Fr.)

51. Ciattung: Leptespharria ('ase at de Sut.

Wio vor. Gatt., aber die sporen equll, bis catboramn.

1. Anf Momokntylutonen.

2.

Auf loikutyleclonen.

2. sporen nit 2-4 Querwïnden.

sporen mit 5 nud mobr Querwinden.

3.

4.

3. Auf dïrren ligaslabluten u. Inzula, hïufier.

I.. [ulmurum Auersw.

Auf dürress Pliragmites-llaluen, zerstrent.

Auf 'Pylua latifulia, zorstrent.

I. arumdinacea (sow.)

L. typharum (Desm.)

1) Von dieser und der folgenden Gattung kommen zusammen gegen 150 Arten im Gebiet vor, von denen mur die allerwichtigsten aufgenommen werden konnten. 
4. Sporen 6 zellig. An dürren Cladodien u. Ästehen von Ruscus, zerstreut.

L. rusei (Wallr.)

Sporen $7-8$ zellig. An faulenden Halmen von Scirpus lacustris, nicht selten.

L. Sowerbyi (Fuck.)

Sporen 8-10 zellig, 35-46 $\mu$ lg. An dïrren Grashalmen.

L. culnifraga (Fr.)

Sporen $8-10$ zellig, $30-35 \mu$ lg. An Roggenstoppeln, nicht selten.

L. herpotriehoides de Not.

5. Sporen $4-5$ zellig.

6.

Sporen mehr als 5 zellig.

7.

6. Sporen mit 3 Wänden, an ihnen schwach eingeschnürt, 20-30 $\times 4,5 \mu$. An dürren Kräuterstengeln, besonders von Urtica $u$. Angelica, häufig.

L. doliohum (Pers.)

Sporen mit 4 Wänden, an ihnen eingeschnürt, 2. Zelle etwas dicker, $24-36 \times 3-6 \mu$. An dürren Kräuterstengeln, besonders von Umbelliferen, häufig.

L. modesta (Desm.)

7. Sporeu mit 6-10 Wänden, $36-50 \times 5-6 \mu$. Auf dürren Kräuterstengeln, besonders von Urtica, nicht seiten.

\section{L. acuta (Moug. et Nestl.)}

Sporen mit 5 Wänden, in der Mitte oft eingesclinürt, $30-42 \times$ 4-5 $\mu$. Auf dürren Cruciferenstengeln, nicht selten.

\section{L. maculans (Desm.)}

Sporen mit 5 Wänden, $35-40 \times 3,5-4 \mu$. Auf dürren Kräuterstengeln, besonders von Compositen.

L. ogilriensis (Berk, et Br.)

Sporen mit 7 Wänden, in der llitte tief eingeschnürt, vierte Zelle meist dicker, $30-35 \times 3,5 \mu$. Auf dürren Stengeln von Eupatorium cannabinum, zerstreut.

I. agnita (Desm.)

Sporen mit 7-10 Wänden, die 4. Zelle etwas dicker, 35-40 $\times 3,5 \mu$. An dürren Stengeln von Tanacetum u. anderen Compositen, nicht selten. (Fig.'219.) I. dolioloides (Auersw.)

\section{Gattung: Ophiochacta Sace.}

Fk. nur mit der Mündung hervortretend, später nach Entfernung der Oberhaut fast frei, an der Mündung od. ganz nit Borsten bedeckt. Sporen fädig, quergeteilt, gelblich bis hyalin, oft in die Teilzellen zerfallend.

Auf dürren Grashalmen, bes. Getreidestoppeln, nicht selten.

o. herpotricha $\left(F_{r}\right.$. $)$

\section{Gattung: Ophiobolus Riess.}

Wie vor. Gattung, aber die Fk. kahl.

1. Fk. auf einem rötlichen od. purpurnen Flecke sitzend. Auf Stengeln größerer Kräuter, besonders an Kartoffelstengeln, häufig. (Fig. 220).

o. porphyrogenus (Tode)

Fk. auf keinem od. höchstens einem schwärzlichen Flecke sitzend. 
2. Auf Crtia-stengeln, zerstreut. O. erythrosporus (liess)

Auf legmminosenstengeh (Astragalus, (nobryehis usw.), nicht selten.

O. rudis (Riess)

Am Frunde von dïrren Frehinm-stengeln, zerstreut.

O. Cesatianus (Mont.)

Auf diirren Compositenstengeln (Cardums, Carlina, Cirsium), nicht sclten.

(1. areminatus (Sow.)

54. (Gattung: Pyrenophora Fries.

Wie folg. Gatt., aber Fk. an der Mündung od. ganz mit borsten bed eckt.

1. Gehäuse lederartig-d̈̈m, Mündung mit Borsten besetzt. 2.

Crehäuse dick, sklerotienartig. allseitigg oll. nur die llünthung borstig.

2. Sporen mit 7 Querwänden u. I Längswand. Anf Apenpflanzen, Sedum, Saxifraga, Primula, Rhododendron in den Alpen.

\section{P. ('hrysospora Niessl.}

sporen mit 6-S Querwändeu u. 1 Jüngswaind. Auf kräuterstengehn u. Vitisranken, nicht in Horhgebirge.

3. Fehäune vollständig mit Borsten bedeckt.

$$
\text { P. coronata Niessl }
$$

Gehäuse nur an der Mündung mit Borston. Sprom mit o Querwänden n. 1 Längswand. Auf dïrren Blättrm von Il oleus lanatus. njcht selten. P. phacocomes (Reb.)

4. Sporen mit 3-5 Querwänden u. 1 Längswand, 35-45 $\times 20-30 \mu$. Auf Gras- 11. besonders Getreidehalmen. zerstrent.

P. relicina (Fuck.)

sporen mit 3 Querwänden u. 1 Längswand, 44-50 × 17-20 $\mu$. Ebonda, zerstreut.

P. trichostoma (Fr.)

\section{Gattung: Pleospora liabenh.}

Fk. zues's bedeckt, dann \pm hervortretend, kahl, sporen Iänglich bis eif., manerf., gelb od. braun gefürbt.

1. Auf Monokotyledonen.

Auf Dikotyledonen.

3.

2. sporen mit 5 Qurwin̈den u. 1 längswand. Auf Gräsern, nicht selten.

P. Vagans Niessl

Sporen nit 7 (quer- 1. 1-4 hängswänlen. Anf carex-Arten, bis in die Alpen.

P. diseors (Mont.)

3. Auf Kräutern.

4.

Auf Sträuchern.

5.

4. Sporen mit :5 Queswïnden u. ringesehnürt, dir 4 mitteren Zellen nit jo 1 Längswand, $15-21>8-10 \mu$. Auf Kränterstengeln, häufig, oft mit folg. Art. (Fig. 22.2I.) P'. vulgaris Niessl

Sporen mit 7 Querwänden, ringeschnürt, nit 2-3 Längswänden, 24-40 × 12-16 4 . Auf Kräuterstengeh, Fruchthüllen, häufig. (Fjg. 222.) P. lierburum (Fr.) 
5. Sporen mit 5 Querwänden u. 1 Längswand. Auf dürren Ranken von Clematis vitalba, zerstreut.

P. elematidis Fuck.

Sporen nnit 6 Querwänden u. 1 unvollständigen Längswand. Auf dïnnen Berberiszweigen, zerstreut

P. orbicularis Auersw.

\section{Gattung: Enchnoa Fr.}

Stroma 0 . Fk. eingesenkt bleibend, behaart. Sporen läng!ich, einzellig, hyalin bis bräunlich.

Auf dürren Eichenästen, nicht häufig. (Fig. 223.)

E. infernalis (Kze.)

\section{Gattung: Phoreys Niessl.}

Wie vor. Gatt. Sporen ellipsoidisch, braun, zweizellig.

Auf dürren Quereus-ïsten, zerstreut.

P. bufonia (B. et B.)

Auf dürren Ästen von Prunus cerasus u. domestica, zerstreut.

P. vibratilis (Fuck.)

Auf dürren Tiliaästen, zerstreut. P. Curreyi (Tul.)

\section{Gattung: Massarina Sacc.}

Wie vor. Gatt., Fk. nur mit der Mündung vorbrechend. Sporen länglich, hyalin, quer mehrteilig.

Auf dürren Fagusästen, seltner Betula, zerstreut.

M. eburnea Tul.

59. Gattung: Massaria de Not.

Wie ror. Gatt., aber die sporen braun.

śporen $48-54 \times 19-23 \mu$. Auf dürren Ulmenästen, zerstreut.

I. foedans (Fuck.)

Sporen $50-74 \times 14-20 \mu$. Auf dürren Birkenästen, zerstreut. M. argus (Berk. et $\mathrm{Br}$.)

Sporen 44-52 × $16 \mu$. Auf dürren Ästen von Acer pseudoplatanus, zerstreut. I. pupula (Fr.)

Sporen $80-103 \times 21-23 \mu$. Auf dürren Acerästen, bes. A. campestre, seltner. (Fig. 224.) I. inquinans (Tode)

60. Gattung: Pleomassaria Spegazzini.

Wie vor. Gatt., aber die Sporen ellipsoidisch, grof, mauerf., braun. An dürren Betulazweigen, zerstreut.

P. siparia (Berk et $\mathrm{Br}$.)

An dürren Ästen von Rhamnus frangula, zerstreut. (Fig. 225.)

P. rhodostoma (Alb. et Schw.)

An dürren Ästen von Lycium barbarum, zerstreut.

P. varians (Hazsl.) 
61. Crattung: Phomatospora sace.

Fk. eingesenkt, meist auch später nur mit der warzenf. Mindung hervorragend. Sporen sehr klein, einzellig, hyalin.

An dürren Kräuterstengeln . Grashalmen, selten.

J. Berkeleyi Sace.

6:2. Crattung: Mamiania Ces. et de Not.

Myzel ein fleckenf., selwwarzes Pseulostroma ïber den Fk. bildend. Fk, eingesenkt bleibend, mit sehnabelf., kurzer Mündung vorragend. Sporen ellipsoidisch, einzellig hyalin. Auf Blättern schwarze Flecken bildend.

Auf Carpinus, häufig. (Fig. 226.) M. fimbriatn (Pers.)

Auf Corylus, seltner.

M. coryli (liatseh)

\section{Gattung: Gnomoniella Sace.}

Stroma 0 . Fk. cingesentit bleibend u. nur mit der lg. zylindrischen Mündung hervortretend. Sporen ellipsoidisch, hyalin, einzellig. Auf faulenden Alnusblättern, zerstreut. (Fig. 227.)

(x. tubiformis (Tode)

64. Gattung: Ditopella de Not.

Wie ror. Gatt. Sehläuche vielsporig. Sporen einzellig, hyalin. Auf dürren Alnusästchen, häufig. (Fig. 228.)

1). Iusispora de Not.

65. Gattung: Gnomonia Ges. et de Not.

Wije Gnomoniella, aber die Sporen länglielı, lıyalin, 2 od. 4 zellig.

1. Sporen zweizellig.

sporen vierzellig.

2.

2. Auf düren blättern von Juglans regia, zerstreut.

Auf faulenden Corylusblïttern, zerstreut.

(i. leptostyla (Fr.)

(i. vulgaris ces. et de Sot.

Auf dürren Kirschbaumblättern, zerstrent. (Fig. 229.)

(A. erytlirostoma (l'ers.)

Anf diiren Blattstielen von Aeer psendoplatanus u. negundo.

fi. cerastis (Riess)

3. Auf dïrren Stengeln von Epilobinm hirsutum, selten.

(i. riparia Niessl

Auf faulenden Blättern von Rubus frutieosus, selten (Fig. 230.)

G. chamacmori (Fr.)

66. Gattung: Anthostomella sace.

Myzel über den Fk. cin kleines, sehwarzes Pseudostroma bildend. Fk. cingesenkt, nur nit der kurzen, kegelf. Mïndung vorragend. Sporen ellipsoidisch, einzellig, bram. 
Sporen am Grunde mit schnabelf., hyalinem Anhängsel, 24 bis $33 \mu \mathrm{lg}$. Auf dürren Rubusranken, zerstrent.

\section{A. appendiculosa (Berk.et Br.)}

Sporen ohne Anhängsel, ea. $10 \mu \mathrm{lg}$. Auf dürren Ranken von Rubus, zerstreut. (Fig. 231.)

A. elypeata (de Not.)

\section{Gattung: Hypospila Fr.}

Pseudostroma vorhanden. Fk. nur mit der Mündung hervortretend. Sporen länglich, mit 1-3 Querwänden, hyalin.

1. Auf dürren Eichenblättern.

Auf welken Blättern von Dryas octopetala, selten.

$$
\text { H. rhytismoides (Bab.) }
$$

2. Sporen mit 1, später 3 Querwänden, $17-23 \times 4 \mu$. Häufig. (Fig. 232.) H. pustula (Pers.)

Sporen am untern Ende mit 1 Querwand, $12 \times 3,5 \mu$. Seltner. H. bifrons (DC.)

\section{Gattung: Linospora Fuek.}

Pseudostroma vorhanden. Fk. mit schnabelf. Mündung vor'tretend. Sporen lyalin, meist geteilt, hyalin bis gelblich. Auf faulenden Blättern von Salix (bes. eaprea), nieht selten. (Fig. 233.)

L. capreae (DC.)

Auf faulenden Blätterı von Populus tremula, selten.

L. populina (Pers.)

69. Gattung: Clypeosphaeria Fuekel.

Pseudostroma vorhanden. Fk. mit der kegelf. Mündung hervortretend. Sporen länglieh, meist mit 4 Querwänden, braun.

Auf dürren Spargelstengeln, zerstreut.

C. asparagi (Fuek.)

Auf dürren Stengeln von Epilobium angustifolium u. Rubus, zerstreut. (Fig. 234.) C. Notarisii Fuek.

\section{Gattung: Valsa Fries.}

Stroma entweder ausgebreitet, nieht seharf begrenzt (diatrypeenartig) od. undeutlich (wenn das Substrat wenig verändert ist) und bisweilen ganz fehlend od. seharf begrenzt, rundlich, kegel-od. polsterf. (valseenartig), entweder eingesenkt $u$. dann hervorbrechend od. oberflächlieh, häufig im Substrat durch eine sehwarze Saum. sehicht begrenzt. Fk. im Stroma eingesenkt, versehieden gelagert, nur nit den Mündungen vorragend, meist mit lg. Hals. Sehläuehe 8 od. vielsporig. Sporen einzellig, gebogen (wurstf.), hyalin, seltener bräunlich.

1. Stroma fehlend od. nur angedeutet.

Stroma diatrypeenartig.

Stroma valseenartig. 
2. Stroma fehlend, Fk. in der IIolzsubstanz gebildet (Endoxyla). 7. Stroma meist nur angedentet, Fk. in der Rindensubstanz gebildet (Cryptosphaeria).

3. Schläuche 8 sporig (Eutypa). 8. Sehläuche vielsporig (Cryptovalsa). 17 .

4. Schläuche 8 sporig.

Sehlänche vielsporig (Valsclla). 18.

5. Stroma von einer festen, hornartigen beekenf. Sehicht nuschlossen. die mit dem Periderm verwachsen ist. Fk. mit den Mïndungen durch die weiß gefärbte Selseibe des Stromas hervorhrechenel (Leucostroma).

Stroma nicht von einer solchen Sehicht umsehlossen, höchstens durch eine Sammsehicht begrenzt.

6. Strona in Ilokzï̈rper entstehend u. die linde durchbrechend, Sulstanz verschieden rom Nährsubstrat (Eutypella). 24.

Stroma im Rindenparenehym entstehent, olne Saumsehicht, das Substrat nur wenig verändexnd (Euvalsa). 27 .

7. Mündungen groß, vorragend, braun, zuletzt fast sehïsself. Sporen braun. An Tannenholz, seltent.

V. opereulata (Alb. et Schw.)

Mündungen klein, fast kuglig, schwarz. Sporen bräunlich. An morsehem Kiefernholz, zerstrent.

V. parallela (Fr.)

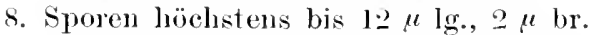

Sporen $14-18 \times 3 \mu$. Stroma angedeutet, sehr weit sich ausbreitend of. seltner eng begrenzt. Fk. meist licht gleiehmäbig verteilt. Auf toten Eschenzweigen, nieht selten.

\section{V. ellnomia (Fr.)}

9. Stroma angedentet, dem Rindenpareneliym eingesenkt, ganze Äste überzichend $u$. die Kinde zu einer von den Mündungen rauh punktierten Krnste umwandelnd. Fk. sehr dicht. Auf troeknen Zweigen ron Fagus, nicht selten.

V. myriocarpa Nke.

Stroma ausgebreitet, seltuer eng begrenzt, der Rinde eingesenkt md liese oft bis auf den llolzkörper sehwärzend. Fk. mejst dicht stehend. Auf toten Ästen von Populus, nicht seltan.

V. populina (Pers.)

10. Mï̈mbugen der Fk, mit melneren, meist 4 Furehen 11.

Möndungen ganz oluse Furehen.

11. Stroma stets weit ansgebreitet, ganze Äste äberyiehend. 12.

Stroma fleekenf., meist klein, oft viele beieinander n. zusammenfliebend, die Rinde anftreibend. Mündungen halbkuglig, glänzend schwarz, schwach gefurcht. Auf dürren Ästen n. Sträuchern von deer campestre u. pseudoplatams, zerstrent.

V. subtecta (Fr.)

12. Oberfläche des stromas selnwarz, von den großen, dicken, tief 4 furehigen Mündlungen fast stachlig. Auf nacktem Holz u. Isten ron Fagus, ('arpinus, Quereus, nicht selten.

V. spinosa (Pers.) 
Oberfläche des Stromas meist schwarz, von den stumpfen, kleineren, 2-5 (meist 4) furchigen Mündungen rauh. Auf Holz u. Rinde ron Lb., bes. Acer pseudoplatanus, nicht selten. (Fig. 235) V. eutypa (Ach.)

13. Stroma im Innern schwarz gefärbt od, ungefärbt. 14. Stroma im Innern gelbgrün, meist weit ausgedelnnt, oberfläch. lich, das Holz auftreibend. Mündung klein, stumpf kegelf. Auf Hol $\%$ u. Ästen von Fagus, Crataegus, Prunus spinosa, Rosa u. a., häufig.

V. flavorirescens (Hoffm.)

14. Oberfläche des Stromas nicht rauh. da die Jündungen kaum rol ragell.

Stroma aus rundlichen, bis $4 \mathrm{~mm}$ br. Polstern bestehend, oft aber weit zusammeniließend od. ausgebreitet, von den kleinen, zahlreichen lündungen rauh, außen u. innen schwarz. Aul naclem Holz, Stümpfen, seltner Rinde von Lb. z. B. Acr campestre, nicht solten.

V. scabrosa (Bull.)

15. Stroma fast stets weit ausgebreitet.

i 6.

Stroma meist unregelmäßig fleckenartig, oft zusammenfließend, die Oberfläche des Substrates unregelnäßig auftreibend, zuletzt schwarz, Mündung halbkuglig od. kegelf. Auf $\mathrm{Holz}$. Rinde von Lb., z. P. Quereus, Prunus padus u. spinosa, Robinia usw., häufig.

$$
\text { V. lata (Pers.) }
$$

16. Stroma weit ausgebreitet, rundlich od. schmale parallele Streifen bildend, das Holr auftreibend, durchgängig schwarz. Mündungen klein, fast kuglig. Auf festem Holz von Quereus, Fagus, u. a. nicht selten.

V. milliaria (Fr.)

Stroma weit ausgebreitet, seltner unterbrochen fleckenf., sehr düun, das Holz nicht od. wenig auftreibend, glanzlos, braun bis schwärzlich an der Oberfläche, darunter eine ungefärbte Zone n. unter dieser die geschwärzte Schicht mit den Fk. Mündung punktf., kaum vorragend. Anf entrindeten Zweigen von Icer campestre, zerstreut.

V. leioplaca (Fr.)

17. Stroma in der Rinde nistend, die Holzoberfläche u. das Innere der Rinde schwärzend, die Rindenoberfläche unverändert lassend. Mündungen mit 4 Furchen, groß, abgerundet. An dürren Zweigen ron Acer campestre, zerstrent.

V. protracta (Pers.)

Stroma ähnlich, weit ansgebreitet. Mündungen undeutlich furchig, \pm vorragend, kegelf. od. gestutzt. Auf dürren Weinstöcken, zerstreut.

V. ampelina Nke.

18. Stroma klein, flach gewölbt, mit weißen Scheibchen das Periderm durchbohrend, mit $2-4$ Fk. Auf dürren Zweigen von Cornus sanguinea, selten.

V. Laschii Nke.

Stroma kegelf. gestutzt, oft mehrere zusammenfließend, mit meist 5-6 Fk. u. weiß bereifter Scheibe. Auf dicken, toten Zweigen von Salix caprea, selten.

V. fertilis Nke.

19. Stromata fest mit dem Periderm verwachsen $u$, daher beim Abziehen des Periderms an diesem haften bleibend. 
Stromata niedergedriickt pustelf., mit der linde fest ver. wachsen, daher mit dem Periderm nicht abzichbar, mit kleiner sehmutzig weiber Scheibe u. 6-12 l'k. Mündungen gestutzt, stumpf. An toten Ïsten von P'rumus spinosa, nicht selten.

\section{V. pincta Fr.}

20. Schläuche 4 u. 8 sporig.

schläuche mur 8 sporig.

21. Stroma linsenf., Seheibe auffallend weiß, meist gesellig in großer Zahl ganze Zweige iiberziehend. Auf abgestorbenen Ästen von Populus, hänfig. (Fig. 236.)

V. nivea (Pers.)

Stroma niedergedrückt kegelf., mit weniger auffallender scheibe. An abgestorbenen Ästen ron Rhammus frangula, häufig.

V. Auerswnldii Nke.

22. Sporen höchstens bis $14 \mu \mathrm{lg}$.

Sporen 16-18 $\times 3-6 \mu$. Stroma niedergedrückt kegelf. Auf toten Zweigen von Ahms, nicht selten.

\section{V. diatrypa Fr.}

23. Stroma flach kegelf. Sporen $10-12 \times 2,5-3 \mu$. Auf toten Zweigen von Prunus-Arten, Sorbus, häufig.

V. leucostoma (Pers.)

Stroma niedergedrüickt kegelf. Sporen 9-14 $22 \mu$. Auf toten Ästen von Salix-Arten, nicht selten.

V. translueens (de Not.)

24. Sporen höehstens bis $8 \mu \mathrm{lg}$. $(6-8)$.

stroma kegelf. od. fast halbkuglig. Mündungen \pm - lg., runzlig od. furehig. Sporen 8-12 $2 \times 2 \mu$. Auf abgestorbenen Ästen von Ulmus campestris n. effusa, häufig. V. stellulata Fr.

25. Stroma aus kreisf. Basis polster-od. kegelf., mit kreisf. Scheibe durehbrecheud.

Stroma aus länglicher Basis stumpf kegelf., mit länglieher Scheibe quer durehbrechend. Auf toten Zweigen von Prunus jpinosa, zerstrent.

V. prunistri (Pers.)

26. Fk. selır zahlreich in Stroma. sporenführender Teil der sehläuehe $40-48 \mu$ lg. Auf toten Zweigen von sorbus, nicht selten.

V. sorbi (Alb. et solhw.)

Fk. ti-s in stronat. Sporenführender Teil der schläuche 24-32 " lg. Anf toten Zweigen ron l'runus padus, selten.

\section{V. padi karst.}

27. Fk, einreihig in einem scharf ungrenzten (ansgenommen die Basis) Stroma liegend. Mündungen bündelf. vereinigt od. kurz beibend u. dann dicht gedrängrt 11 . ohne Beteiligung des Stromas rine Art seheibe bildend. (Monostichae).

28.

Fk. kreisf. in der von der Rinde äuferlich nicht verschiedenen Stromasubstanz lagernd. IÏ̈ndungen meist nur am Rande einer seheibe hervorbrechend, die in ihrer Substanz versehieden ist von der, welche die Fk. umschlieft (Circinatae). 33. 28. Auf Ni. 
Auf Lb.

31.

29. Fk. höchstens bis $19 \mathrm{im}$ Stroma.

30.

Stromata gleichmäßig zerstreut, fast halbkuglig, nach Verschwinden des Periderms frei werdend, mit 20-30 Fk., auf der Oberfläche hänfig mit grünem Pulver. Mündungen meist sehr klein, eine flache, schwarze Scheibe bildend. Auf Ästen u. Stäm. men von Pinus silvestris, seltner Juniperus communis, häufig.

$$
\text { V. pini (Alb. et Schw.) }
$$

30. Stromata vereinzelt, ähnlich, aber nur mit $3-4 \mathrm{Fk}$., ohne grünes Pulver. Pyknidensporen doppelt so lg. wie bei vor. Auf toten, dicken Zweigen ron Juniperus communis, selten.

V. cenisia de Not.

Stromata ordnungslos zerstreut, mit 5-15 Fk., mit dem Mün. dungsbüschel das Periderm durehbohrend. Mündungen sehr kurz, einen traubenf. Körper bildend. Auf Ästen u. Stämmen von Picea excelsa, zerstrent. V. abietis (Fr.)

31. Mündungen verhältnismäBig kurz. 32.

Mündungen his $1,5 \mathrm{~mm}$ l@., dünn, bündelf. nach oben auseinander gebogen. Stroma flach pustel- od. kegelf., mit, 5-20 Fk. Auf trockuen Ästen von Quereus, Rosa n. a., nicht selten. (Fig. 237.)

V. ceratophora Tul.

32. (Die hier zusammengefaften Arten unterscheiden sich nur durch feinere Merkmale, die dem Anfünger nicht sofort in die Augeu springen. Die sichere Bestimmung kann nur dureh eine ausführlichere Flora erfolgen). Sämtlich an toten Ästen in der Rinde.

Auf Salix, zerstreut.

V. Schweinitzii Nke.

Auf Fagus, nicht häufig.

V. decorticans (Fr.)

Auf Prumus spinosa, zerstreut.

V. microstoma (Pers.)

Auf Crataegus oxyacantha, zerstreut. V. Hoffmanni Nke.

Auf Acer campestre, zerstrent.

Auf Vitis, zerstreut.

V. exigua Nke.

Auf Cornus alba, selten.

V. vitis (Schwein.)

V. coronata (II offm.)

33. Stroma sehr dentlich u. abgegrenzt.

Stroma nicht erkenntlich, uur aus der grauen od. bräunlichen Scheibe bestehend, die von den kurzen Mündungen der 3-9 kreisf. beieinander liegenden Fk. durehbohrt wird. Auf dürren Ästen von Salix, Populus u. Betula, nicht selten.

V. germaniea Nke.

34. Schläuche 4 od. 8 sporig.

Schlänche nur 8 sporig.

36 .

35. Schläuche nur 4sporig. Scheibe durch einen Ris im Periderm hervortretend. Fk. 10-15 im Stroma. Sporen 18-22 ×5-6u. Anf dürren Ästen von Rosa u. Rubus, zerstreut.

V. sepincola Fuck.

Stromata zahlreich, gleichmäßig über weite Strecken verteilt. das Periderm durchbrechend od. sternf. sprengend, mit 4-20 Fk. 
speren der spur. Schlabehe $16-24$ 3-6. der tsporigen

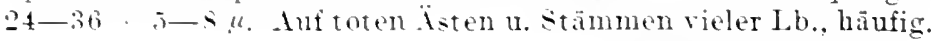

V. ambieuv (Pers.)

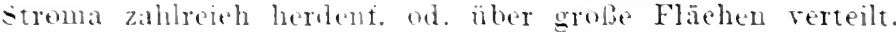
das Periderm dureliboluend. mit B-I: Fk. sporen der sspor.

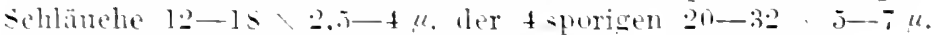
duf toten isten n, stimmen von silix. nieht selten.

in. Aut \゙d.

$$
\text { V. salicina (Pers.) }
$$

liti l.b.

3.- Stromata dielote weite strechen bedechend. puntelt. dureh da- terni. zersprengte Periderm vorbrechend. Mümbng mit glan. zend shwarzer Papille an scheitel. Sportn l:2-16 ‥s-3 tut toten 7weigen von Larix n. Pinus silvestris. zerstrelt.

V. Curreyi The.

stromata änlieh. aber das beridern nicht sternf. zerriseth.

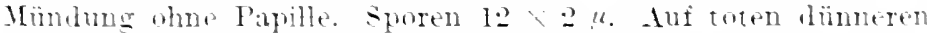
Zweigen rom thies peetinata. zerstrellt.

\section{Frienii ( $\mathrm{Pubr}$ )}

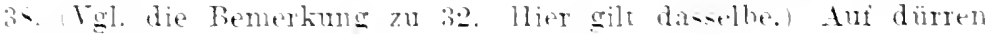
istell.

Iuf Populus.Arten. zerstrent.

Aut Fagus, zerstreut.

Auf leer pouboplatamus. solten.
I. -ordida İke.

V. pustulata Auerom.

V. peudoplatani $\mathrm{Fi}_{\mathrm{i}}$.

\section{Fallumg: Inthustomil Nit-ehte.}

stroma diatryeen-od. valsernartig. Fh. eingesenkt. num nit den Himdungen herforbrehend. sporen ellipsidiseh. einzellig. duntw celärbt.

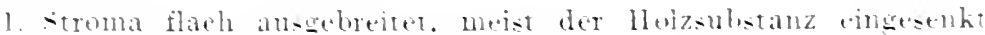
aliatrypenartig). (Fuanthostoma.) -

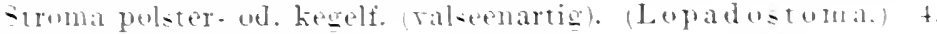

$\therefore$ sporen minter ls

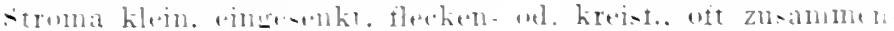

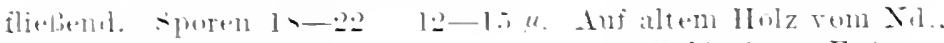
stloer Lb.. zerstreut.

1. eubiculare (Fr.)

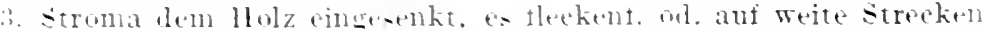

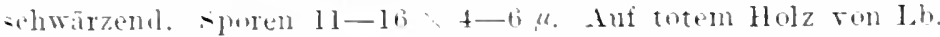
1. leer. Fraximus. Pemulus) zerstuent. (Fig. 23s.)

A. molanoter (Berk. et Br.)

strona nnseheinbar. angesent die llolzoberfläehe sehwärend.

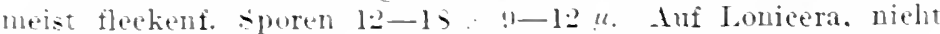
selten.

1. xylostei (Pers.)

4. Stroma hegel- ml. pustelf., in der linde vingewachsen. mit $6-s$ Fh.

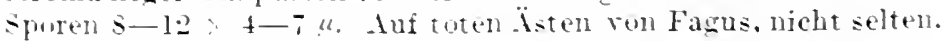


Stroma pustel-od. halbkegelf., auf dem $\mathrm{Holz}$ frei sitzend od. in die Rinde hineinragend, mit 8-42 Fk. Sporen $10-14$ y $5-6$ u Auf toten Lbästen, bes. Llmus, zerstreut.

A. gastrinum (Fr.)

72. Gattung: Diaporthe Nitschke ${ }^{1}$ ).

stroma diatrypeen- od. valseenartig, oft unscheiubar u. nur durch schwarzen Randsaum kenntlich. Sporen ellipsoidisch, zmeizellig, hyalin.

1. Stroma diatrrpeenartig, die Nährsubstanz kaum rerändernd. stets mit schwarzem Randsaum.

Stroma valseenartig, oft fehlend. Fk. in kleinen rundlichen Gruppen beisammenstehend. (Chorostate).

2. Fk. in der Holzsubstanz sitzend. (Euporthe). 19.

Fk. im Rindenparenchsm sitzend. (Tetrastagon).

3. Auf Kräuterstengeln. Sporen zwischen 10 u. $14 \mu \mathrm{lg}$.

Auf Ästen u. Holz ron Lb.

4. Auf Cmbelliferen

Auf Kompositen.

Auf Chenopodium, Solanum tuberosum, Medicago, Oenothera usw. Stroma tief schwarze Flecken bildend. Nicht selten.

\section{Tulasnei Nke.}

5. Stroma ¿ große Flecken bildend, braun od. grau, später schwarz. Auf Angelica u. Chaerophrllum, zerstreut.

\section{Berkeleyi (De-m.)}

stroma meist sehr weit ausgebreitet, braun, später schmutzig schwarz. Auf Heracleum, zerstreut.

D. inquilina (Wallr.)

6. Fk. fast immer reihenweise stehend. Auf Solidago virgaurea, nicht selten.

D. linearis (Nees)

Fk. ziemlich dicht stehend, selten reihenteise. Auf tchilleal. Artemisia, Anthemis, Cichorium usw. zerstreut.

D. orthoceras (Fr.)

Fk. ordnungslos zerstreut. Auf Lappa, Tanacetum, Cirsium. Carduus us $\pi$.. zerstreut. D. aretii (Lasch)

-. Auf Polypetalen.

Auf Sambucus racemosa. Stroma meist ausgebreitet, sehwarz. zerstreut.

D. spiculosa (Alb. et schw.)

8. Auf Leguminosen.

Nicht auf Leguminosen, Stroma fast stets weit ausgebreitet. 10.

9. Stroma ausgebreitet od. durch Verschmelzung kleinerer Gruppen zusammenfließend, die Holzoberfläche schwarz färbend u. oft

1) Ćber 100 deutsche Arten, die zum Teil sehr selten sind. Hier können nur die häufigsten behandelt werden, die streng an das Substrat angenaßt erscheinen. Man suche also die sichere Bestimmung der Cnterlage zu erhalten. 
klein-warzige, rauhe, hier und da unterbrochene Krusten bildend. Fk. meist vereinzelt. Auf Cytisus laburnum, zerstreut.

D. medusaea Nke.

Stroma kleine, isolierte or. zusammenfließende Flecken bildend, selten weit ausgebreitet. Fk. dieht herdenweise. Auf Robinia psendacacia, zorstreut.

1). fasticulata Nke.

10. Fk. weitläufig zerstreut. Auf Populus u. Salix, häufig.

1). forabilis Nke.

Fk. gesellig hervorbrechend. Auf Umus zerstrent.

D. eres Nke.

Fk. mejst zerstreut od. dicht gesellig. Auf Carpinus, nicht häufig.

I. sordida Nke.

Fk. zn 3-8 zusammengedrängt, kantig. Auf Spiraea-Arten zerstreut.

1). sorbariae Nke.

Fk. in Längsreihen stehend. Auf Acer campestre, zerstrent.

D. protracta Nke.

Fk. zerstreut stehend. Auf Rhammus frangula, zerstreut.

D. nigricolor Nke.

Fk. gleichmäfig locker zerstrent. Auf lledera, seltener.

D. pulla Nike.

Fk. gesellig, meist aber zu 2-i zusammenstehend. Auf Cornus sanguinea, seltuer.

D. crassicollis Nhe.

11. Auf Kräuterstengeln. Stroma nicht ausgedehnt, klein. $1 ?$.

Auf Isten von 1 b.

12. Stroma rundlich. Auf Polygonatum, zerstreut.

I. pardalota (Miont.)

Stroma sehmal lanzettliel. Auf Filipendula ulmaria, nicht selten.

D. lirella (Noug. et Nestl.)

13. Stroma weit ausgebreitet, meist ganze Iste ungebend u. überziehend.

Stroma fleckenf., oft zusammenfließend, aber die einzelnen Flecken dureh sehwarzen Randsamm kenntlich. Auf Rubusranken, zerstrent.

I). insignis Fuck.

14. Auf leguminosen.

Nicht at Iseguminosen.

16 .

15. Schläuche $120-180 \mu \mathrm{lg}$. Sporen $15-20 \times 8-10 \mu$. Auf Saro. thannus, Genista, Ulex. verbreitet. D. inuequalis (Currey)

Schläuche $60-70 "$ lg. sporen $14-16 \times 4 \%$. Auf Crtisus laburnum, zerstreut.

1). rudis (Fr.)

Schläuche $60-70 \mu \mathrm{lg}$. Fiporen $14-15 \times 3-4 \mu$. Auf Saro. thamnus, nicht selten. $\quad$ b. sarothamni (Auersw.)

16. Auf Sympetalen.

Auf Polypetalen.

17. Sporen länglich od. stumpl spindelf. Auf Syringa vulgaris, zerstreut.

1). resecans Nke.

Sporen sehr schmal spindelf., spitz. Auf Viburmum opulus $u$. lantana, zerstreut.

D. Beckhnusii Nke. 


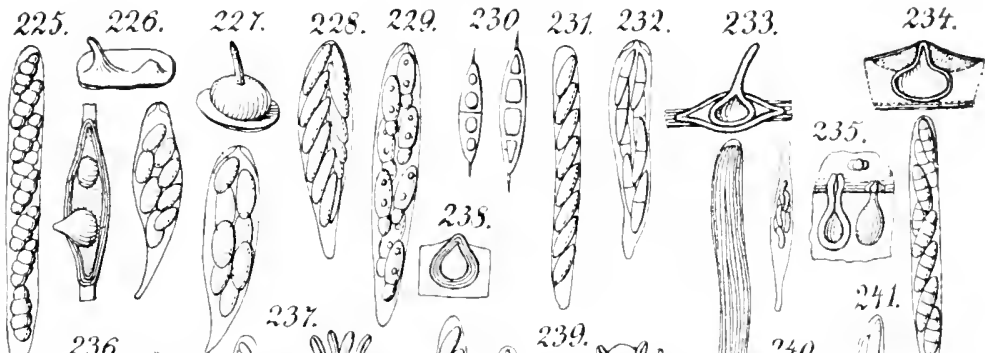

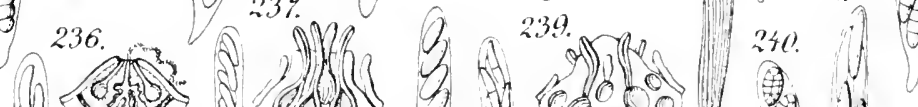

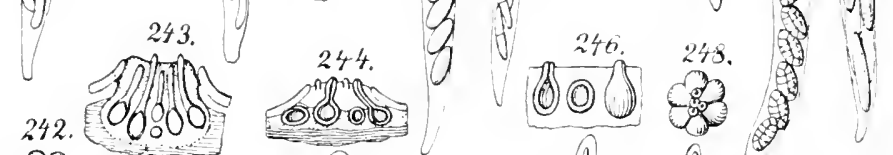

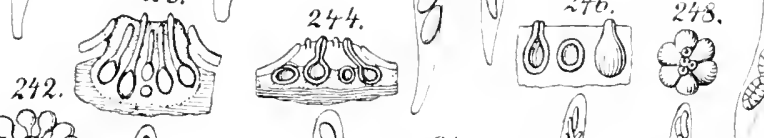

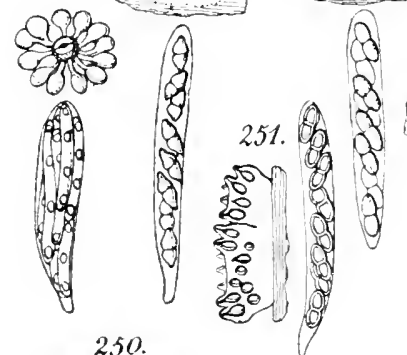

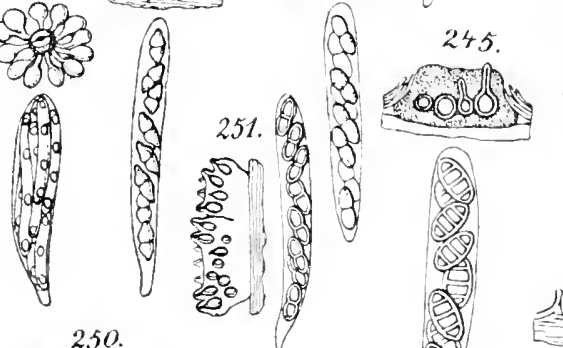

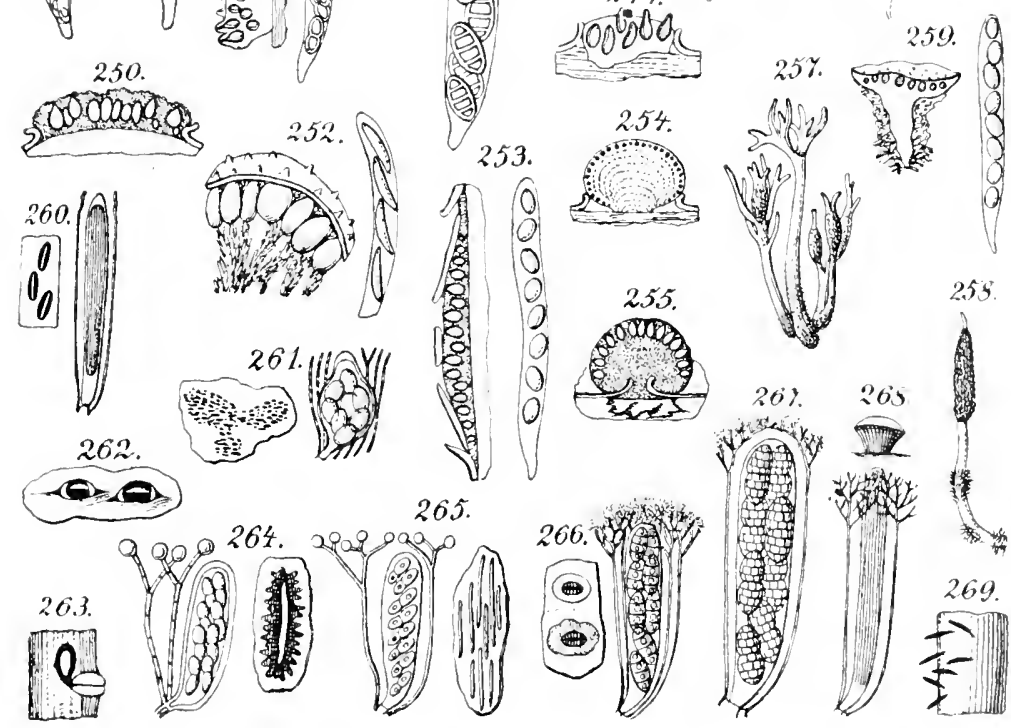


18. Auf Salix, bäufig.

ID. spina Fuck.

Auf lopulus tremula, häulig.

I). putator Nke.

Anf Corylus, zerstrent.

I). revellens Nkie.

Anf Betula, hïnfig.

D. exasperans Nke.

Anf Querens, zerstrent.

I). insularis Nke.

Auf Rubus, häufig.

Auf Evongmus, zerstrent.

I). restellata $(\mathrm{F} r)$

1). Laschii Nkte.

Auf Tilia, häntig.

b. relata (Pers.)

Auf cormus alba n. sanguinet, zerstrent. lo. rorni fuck.

19. Sporen ohne Anluängsel (Euchorostate).

Sporen beidendig mit Anhängseln. (Chorostatella). 23.

20. Auf liosaceen.

Nieht auf Rosacren.

21. sporen $16-18 \times 4.5 \%$. Auf Crataegus wxatcantha, zerstreut.

1). crataegi Fuck.

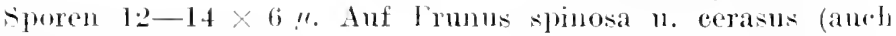
lihammus), zerstrent. D. librosa (lers.) 22. Inf Salix, nicht selten.

D. salicellat (Fr.)

Anf Corylus, selten.

Auf Carpinus, zerstrent.

11. conjumata (Nees)

D. betuli (l'ers.)

Auf Querens, läulig. (Fig. 239.) 1). leiphamia (Fr.)

Auf Berberis, zerstreut.

D. detrusal (Fr.)

Anf Ribes grossularia u. rubrum, zerstreut.

D. strumella (Fr.)

Auf Robinia, seltuer.

D. oncostoma (Duby)

Auf Leer perendoplatanns, seltner. 1). pustulata (1)esm.)

Auf Rhammus cathartica (u. l'rums) D). Tibrosa (l'ers.)

23. Auf ('orplus.

Nicht auf corylus.

24. Stroma liach, anßen gelb bestäubt, zerstreut.

1). -ullureal Furk.

Stroma nur anl die seheibe beschränkt, nicht bestïubt, seltuer.

1). fessera (ro)

25. Auf salix, mieht selten.

D. Trisella (T'ris.)

Auf Querens, zerstrent.

1). taleola (Fr.)

Auf Rubus idarens ne truticosis, zerstrente.

1). nidulans Nierst

- Iuf Rhamnus frangula, seltuer.

II. syllemenia (Fr.)

73. Gattung: Rhymehostonta Kallst.

stroma diatrypeenartign, unseheinbar. Miindung schmabell. sporen ellipoidiseh, zweizalig, bramn.

An bearbeitetem Nilholz, zerstreut R. apiculatmm (Currey)

7t. Gattung: Fenestella Tul.

Stroma valseenartig. of wenig entwiekelt. Fk. meist kreisf. gestellt. Mündungen dureh ane seheibe hervorbrechend. Sporen lïnglich, manerf., dunkel gefärbt. 
Sporen $10-40$, $14-20$ " Auf toten Lbästen, bes. von Alnus u. Crataegus, nicht selten.

l'. princeps Tul.

Sporen 19-25 $\therefore 10-12$ ". Auf Lbäster. (Fig. 240.)

r. vestita (Fr.)

7.5. Gattung: Crytosporella Sace.

Stroma valseenartig. Fk. kreisf. gestellt, in der Rindensubstanz, mit den Mründungen die scheibe durchbrechend. Sporen ellipsoidisch bis kurz spindelf., hyalin, einzellig.

1. Scheibe schwarz.

Scheibe gelbrot oder ziegelrot, herrorbrechend. Auf toten Ïsten von Carpinus, zerstrent.

C. aurea (Fuck.)

2. Sporen $30-60 \therefore 7-9$ ". Auf Ulmenästen, nicht selten. (Fig. 24l.)

c. hypodemia (Fr.)

sporen $14-17 \times 4-45 \%$. Auf Populus pyramidalis, seltner.

C. populina (Fuck.)

76. Gattung: Cryptospora Til.

Wie ror. Gatt, aber die sporen zylindrisch-wurmf., hyalin, einzellig.

Auf Alnus, lräufigg. (Fig. 242.)

Auf Betula, luäufig.

Auf Corylus, ierstreut.

C. suffusa (Fr.)

C. betulae Tul.

(. corylina ('Tul.)

77. Gattung: Valsaria de Not.

Stroma ralseenartig, mit schwarzer Saumselicht. Sporen hyalin, zweizellig. Konidienlager vielkammerig.

Auf Lindenästen, häufig. (Fig. 243.) V。 tiliae (Pers.)

78. Gattung: Melanconis Tul.

Stroma ralseenartig. Fk. nit langem $\mathrm{Hal} \sim \mathrm{u}$. aus der scheibe vorbrechenden Mündungen. sporen länglich, lı̣alin, zweizollig. Konidienlager flach.

1. Sporen ohne Anhängse!

Sporen mit borstenf. Anhängseln an beiden linden. Auf Ïsten von Alnıs, häufig.

II. alıi Tul.

2. Stroma eine gelbe od. gelbbrame, krümliche Masse darstellend. mit 6-10 Fk. Auf Ästen ron Carlinus, zerstreut.

\section{Xanthostromal (Ifont.)}

Stroma innen nicht so.

3. Sporen 22-25 $\times 10$ ". Auf Juglans, zerstrent.

M. carthusiana Tul.

sporen 7-20, 6...7, Auf Betula, nicht selten. (Fig. 244.)

II. stilbostomia (Fi.) 
7!) liattung: Mrlanconiolla silre.

Wie vos. Gatt., aber dir syores bram.

Auf Carpinus, zerstrellt.

11. porliallit (1'il.)

80. Crattullg: lalosporal Filfer.

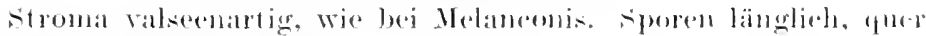
molir als zweizellig. hyalin.

Iuf Acer psemdoplatamus, zerstresti.

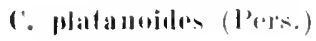

s1. Crattung: Psendovalsa Ces. ot dr Not.

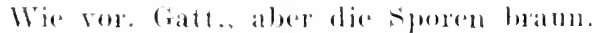

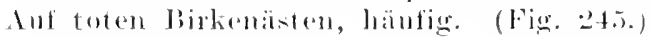

Ant foten

l'. helulare (solumm.)

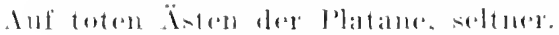

P. irroulatio(1)(.)

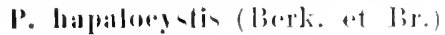

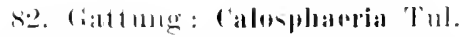

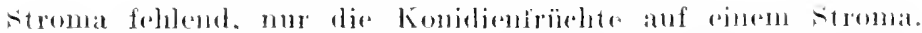

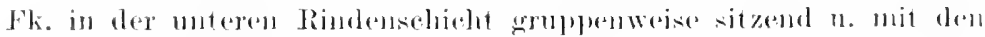

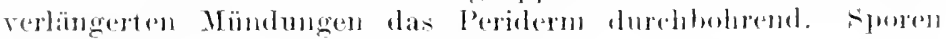
zylindriseh, gekrimmm, hyalin, einzellig.

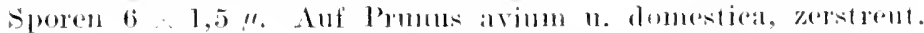

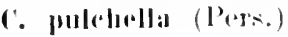

sporen s-1:2 :2". Auf bitula, zerstroul.

('. purillal (II:allenlo.)

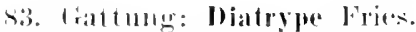

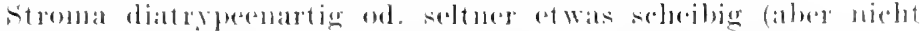

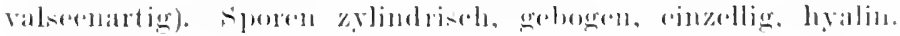

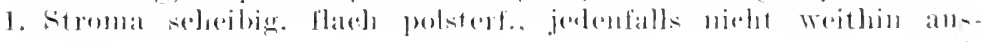
gerlelint.

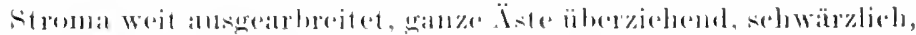

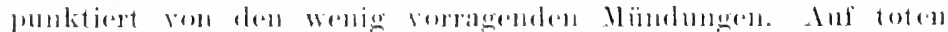

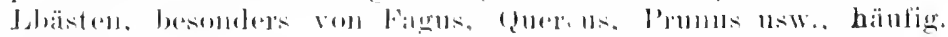
(lig. 2t6.) D. -liema (1luffm.)

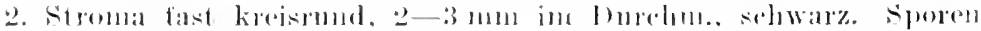

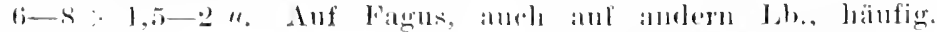
$(1+2+7$.

1). Iiscilormis (110fim.)

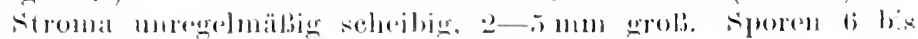

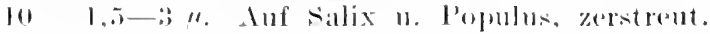

I). bulluta (Hofful! 
84. Gattung: Quaternaria Tul.

stroma valsenartig, an der Basis meist rerschmelzend $u$. ein von schwarzem Grenzsaum umschlossenes Lager bildend. Fk. meist zu + im stroma. sporen zylindrisch gebogen, einzellig, lräunlich.

sporen 14-20 4 "I. Anf Fagus, nicht selten. (Fig. 248.)

Q. quaternuta (Pers.)

sporen 24-32 6-8\%. Auf Ulmus campestris, seltuer.

Q. dissepta (Fr.)

8.5. Gattung: Diatrypella Ces. et de Not.

stroma valseenartig, in der Rinde nistend. Schläuche langgestielt, vielsporig. Sporen zylindrisch, gebogen, einzellig, bräunlich.

1. Mündnngen über der stromascheibe dentlich hervoragend, daher die Sehpibe rauh.

2.

Mündungen nicht od. wenig hervorragend. sporen 5-8 $/ \mathrm{lg} .3$.

2. Sporen 8-12 $\times 2-3 \mu$, selir stark gekrümmt. Anf toten Eichenästen, häufig. (Fig. 249.) D. quercina (Pers.)

sporen $6-7 \times 1,5 \mu$, weniger gekrümmt. Auf Fagus, seltner Quoreus, nicht selten.

1). aspera (Fr.)

3. Oberfäche der Stromascheibe glatt on. nur wenig umeben.

Stromabberfläche uneben u. höckerig. Auf Lbästen, bes. Alnus, Corylus, Carpinus, hänfig

1). veruciformis (Elmh.)

4. Stroma mit rundlichem Grunde.

Stroma mit länglichem Grunde, quer durchbrechend. Auf Birnenästen, zerstrent.

1. favarea (Fr.)

5. Fk. 15-30 im stroma. Mïmbungen kegelf., punktf. Aut Eichenästell, zerstreut.

D. pulvinata Nke.

Fk. zn 3-8 !n stroma. Mïndmmgen knrz, dick, strahlig gefurcht. Auf Alnus, häufig. D. Toceiaeana de Not.

86. Gattung: Botryosphatra les. et de Not.

stroma valseenartig, im Perilerm angelegt, zuletzt freistehend. Fk. eingesenkt, dann kuglig vorgewälbt. sporen ellipsoidisch, einzellis, hyalin.

sporen $30-40 \div 14-18 \%$. Auf Eichenästen. (Fig. 250.)

B. melanops (Tul.)

\section{Gattumg: Myrmacium Nitschke.}

Stroma meist valseenartig, klein, sonst wie bei vor. Gatt. sporen ellipsoidisch, zweizellig, bramn.

Stroma schwarz. Fporen $15-18 \times 8-9 \%$. Auf Lb., nicht lıäufig.

I. insitivm (Ces. et de Not.)

Stroma rostrot, immen blas. Sporen $15-16 \times 9-10 "$. Anf T.b., nicht häufig. (Fig. 251.)

II. Inbricosum ( $1+1$. ) 
Ss. Cattung: Melogramma Fires.

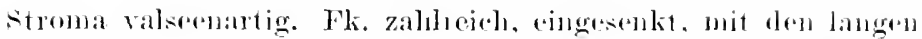

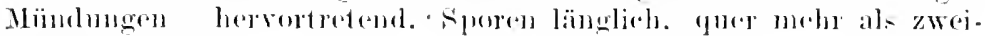
zellig. braum.

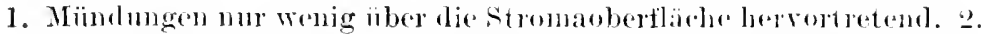

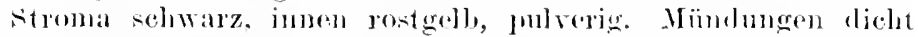
gedrängt, borstig hervortedend, spores fadenf.. fast hyalin. Auf Corylus, seltuer Quereus, zorstreut.

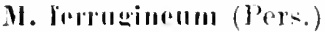

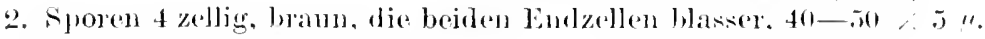
Auf carjinus, zerstrout.

I. Bulliardi Tul.

sporen 8 zellig, braun, die bedon Endzellen blasser, jt bis $70 \times 8 "$. Auf Rinde am Grumde der Stämme n. Wurzeln ron Fagus. zarstrout.

11. spinilormu (llallr.)

8!) Crattung: Ustulina 'T'ul.

stroma oberläehlich. unregelmäfig. oft weit ausgebreitet. mit

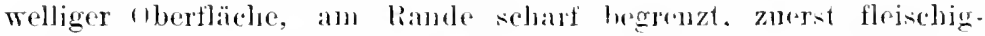

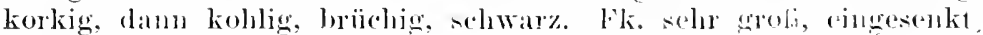

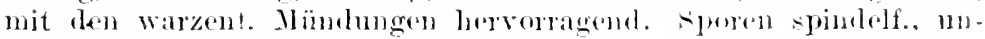
gleielsecitig, einzellig, schwarz.

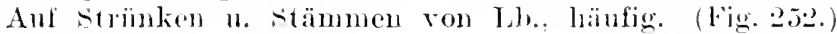

I. maxima (llaller)

\section{Gattumer: Nummularia 'T'ul.}

Stromat meist thach schejhen-od. schiisself. scharf begrenzt, im unteren Tejl ringesenkt, kohlig, shwarz. Fk, rinschichtig, ringesenkt. Syoren ellipsoidiceh. oft cinseitio flach, cinzellig. schwarzbann.

Stroma innen schwarz, krustent., rund od. länglich. Auf Fagusästen, njelut selten. (lig. 253.)

x. Bulliardi Tul.

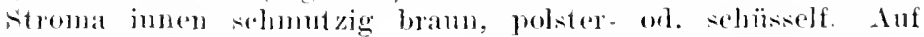
Eichenä-ten, zelstrent.

I. surenenturiata (Tole)

\section{Caltlung: Daldinia de Not.}

stroma oberfläblich, frei. ervol, schwarz. innou faserig mit

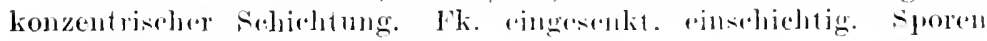
ellipsoirliselh, einzellig, bramu.

Auf Lb., namentich Buche n. Erle, ult an wasehlagenem Holz

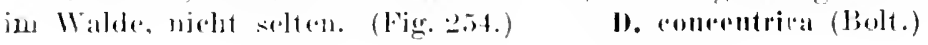

\section{Crattung: Hypoxylou Bulliarl.}

Stroma rutwoder iranz oberflächlieh onl. zuerst. bedeckt u. dann frei, seltner mit den firunde eingesenkt, holzig ad. korkig, kuglig, halbkuglig od. krustig, schwarz, luaun od. rot. Fk. meis ein. schichtig, eingesenkt, kamm mit den Mümdungen hervorragend. Sporen ellpsoidisch ad. spindell. oft etwas eiuseitig abgeflacht, einzelljg, sehwarzbraun. 
1. Stroma völlig frei, oberflächlich.

Stroma mit dem unteren Teil dem Substrat $\_$tief eingesenkt (Endoxylou).

2. Mründungen der Fk. 亡 warzenf. herrorragend (Epixylon). 4 .

Mündungen flach, durehbohrt, nabelf. (Euhypoxylon). 7 .

3. Stroma klein, länglich, schwarz. Sporen $17-23 \times 5-7 !$. Auf entrindeten Lbästen, bes. Buche, zerstreut.

H. semiimmersum Nke.

Stroma länglich, bis $6 \mathrm{~mm}$ lg., wenig rorragend, braun, später schwarz. Sporen $26-38 \times 10-14 \mu$. Auf entrindeten Ästen, von Lb.s bes. Eiche, Buche, Pappel, seltner auf Rinde, häufig.

II. udum (Pers.)

4. Stroma flach ausgebreitet.

Stroma - kuglig od. rundich-höckerig.

5. Stroma meist langgestreckt, bis $2 \mathrm{~cm}$ lg. $u .6 \mathrm{~mm}$ br., durch Zusammenfließen meist lange, schmale Krusten bildend, schwarz, glanzlos. Auf morschem Weidenholz, seltner an anderen Lb., hänfig.

I. serpens (Pers.)

Stroma mehr rundlich, nie so schmal, glatt, braun-, später ganz schwarz. Auf Holz n. Rinde von Quereus u. Corylus, nicht selten.

H. unitum (Fr.)

6. Stroma gewölbt, halbkuglig od. kuglig, meist verschmelzend. Mündungen höckerig-warzig hervorragend, rotbraun damn schwarz. Sporen $10-12 \times 4-5 "$. Auf Holz 1 . Rinde ron Lb., bes. Alnus u. Petula, häufig. H. multiforme Fr.

Stioma ähnlich, sehmutzig biaun, damn schwäızlich, glatt. Sporen $12 \times 6$ ". Auf dicker Fagusinde, häufig.

\section{H. cohaerens (Pers.)}

7. Stroma ausgebreitet.

8.

Stroma typisch halbkuglig od. kuglig, sehr selten (auf Holz) etwas ausgebrejtet.

s. Stroma fleckenf., meist aber sehr weit krustig ausgebreitet, anfangs lebhaft brämnlich rot, dann schwärzlich. Auf Holz, seltner Rinde von Fagus, Acer, Fraxinus usw., häufig.

\section{H. rubiginosum (Pers.)}

Stroma sehr weit ausgebreitet, parallel verlaufende, $1-2,5 \mathrm{~cm}$ br., lange Streifen bildend, anfangs grünlich od. gelblich bis hell purpurrot, im Alter schwärzlich. Auf Fagusholz, selten.

H. purpureum Nke.

9. Stroma anfangs - braum, später schwarz.

10.

Stroma auch später irgendwie braun.

11 .

10. Stromata dureh das Periderm brechend, damn frei, polsterf. bis kuglig, meist zusammenfließend, dick krustig, in der Jugend goldgelb, dann rostrot, endlich schwarz. Fk. unregelmäßig traubig gehäuft. Auf toten Ästen von Salix, scltner Quereus
u. Acer, zerstreut.
I. botrys Nke.

Stromata herrorbrechend u. oberflächlich, halbkuglig od. fast 


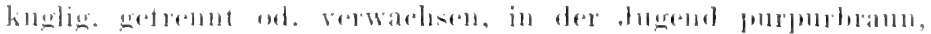

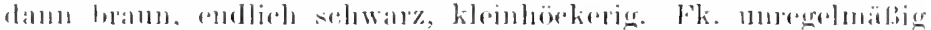

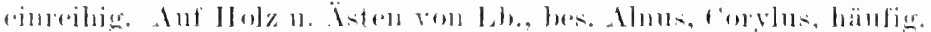

II. funcum (l'ars.)

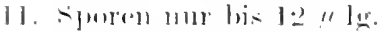

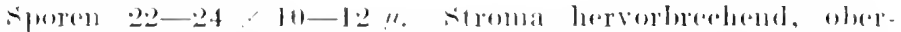

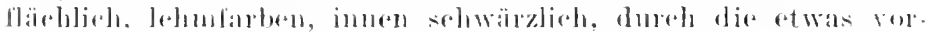

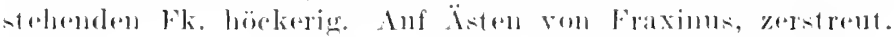

11, argillaterum (l'(rs.)

12. Stroma inmon sohmutgig braun.

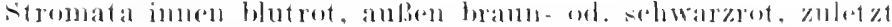

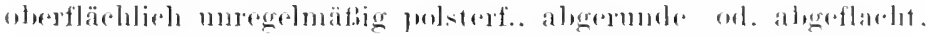

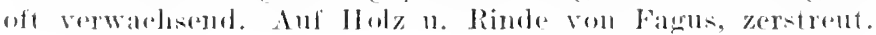

H. I 11 ilum, (') 1 l.)

13. Stromata zuledz frej. halbkrusting od. kuglig. hänfig anf lloly

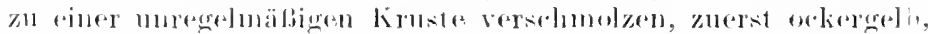

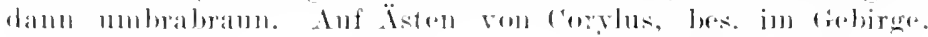
zersirelle.

II. IIridum Nkte.

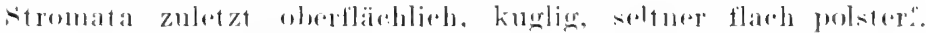
ol. auf Holz langeresterekt krustig, zuerst ziereteot dann dunkel.

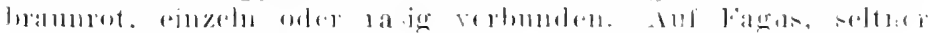
anderen J,b., häufig. (Fig. 25.5.) H. anceimrmu (13ull.)

\section{Cattung: Xylaria llill.}

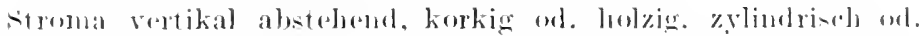
koulig. oinfach oul, verästelt, selowary, mit sterilem stiolteil. Fli.

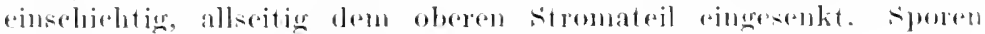
ellipargliseh, oft ungleichseditg, rinzellier. selowar.

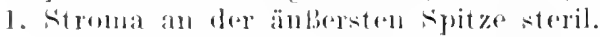

strouma lis zur spitze F'k. lragemel.

2. Stromatiol zottig (Xylodal tyla).

stomataled kahl (Xylostyla).

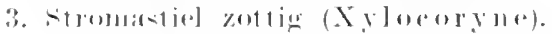

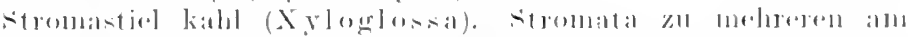

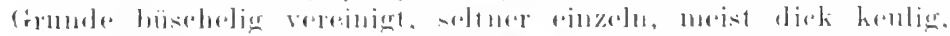

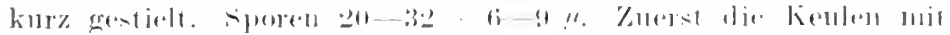

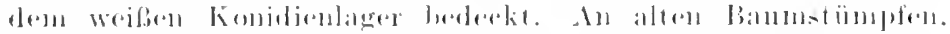
hällfigr. (lige.2.iti.)

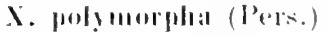

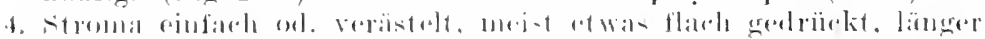

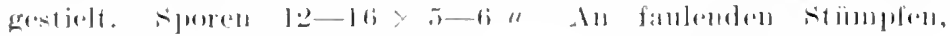

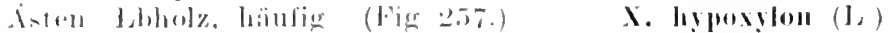

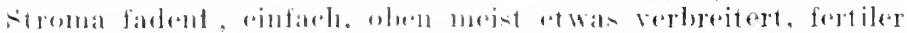

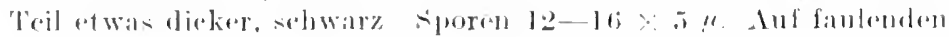
Fruchthiillen ven Fanus, nicht selten. (Fig 2.ss)

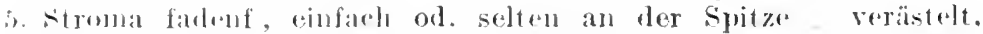

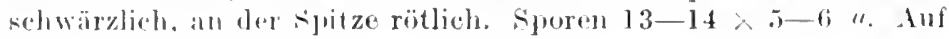


Stielen n. Nerven abgefallener Blätter, auf stengeln u. Astchen zerstrent.

X. filiformis (Alb. et Schw.)

Stroma rasenf. u. am Grunde oft knollig verdickt, daraus nach abe? mehrere einfache ol. wenig verästelte fingerdicke Keulen hervorkommend, kurz gestielt, runzlig, schwarz. Sporen 18 bis $20 \because 5-6 \mu$. An behamenem $11 \mathrm{olz}, 1$ fählen od. Strünken, nicht solten.

X. divitata (L.)

6. Stronna meist = herdenweise wachsend, zylindrisch, einfach, oben oft lıornf. gekıümmt, wollig behart. Sporen $8-9 \times 5 \mu$. Auf faulenden Ästen St mmen u. Holz von der Unterseite hochwachsend, selten. $\quad \mathbf{X}$. rorniformis (Fries)

Stroma einzelı, selten zu $2-3$ am Crunde verbunden, ver schiedenartig gekrümmt, einfach, erdfarbig, später schwarzlich, rissig gefeldert, nuten dicht rötlich zottig. Sporen $11-14 \times 5-6 \mu$. Anf Ästen ron Aeer pseudoplatanus u. Carpinus, ron der Unterseite hochwachsend, selten.

x. longipes Nke.

\section{Gattung: Poronia Willd.}

stroma zuletzt teller-od. napff., gestielt, mit weiler, an den schwarzen Fkmündumgen punktierter Scheibe. Fk. eingesenkt. Sporen br. ellipsoidisch, einzellig, sehwarz, mit Schleimhülle. Sporen 26 10-14\%. Anf altem Pferdemist zerstre it. (Fig. 259.)

P. punctata (L.)

\section{Unterreile: IIysteriinere.}

IIyzel hell od. dunkel gefärbt, in Substrat, selten stromabildungen erzengend. Fk. frei od. erst bei der Reife hervorlorehend, länglich, selten rundlich, gerade od. verbogen, bsweilen muschelf. gewäbt od. bandartig od. fast stäbchenf., abstehend. Gehäuse lederig ol. kohlig, am Seheitel sich mit einem RiB öffnemd u. die längliehe schuile entblöfend. Schlänche meist 8 sporig. Sporen versehieden. Paraplysen vorlianden.

Bestimunugstabelle der Familien u. Gat 1 ungen.

A. Fk. eingesenkt. Gehäuse mit den bedeckendens chichten verwachsen, lederig.

a) Sporen einzellig, hyalin, zu 4 im Schlauch

h) sporen zweizellig, hyalin, zu 8 im sehlanch.

Fam. Hypodermataceale.

c) Sporen fädig, einzellig, lıyalin, zu 8 iu Schlamel.

H. l'k. zuerst eingesenkt, damn hervor

1. Hypodermella.

2. Hypoderma.

3. Iophoderminm. meclend. Gehäuse frei von den Substrat schichten. läutig ol. kohlig.

a) Gehäuse häutig, schwarz. sporen eif.

Fan. Dichanenarour. 4. Nichaenis. 
b) Gehäuse dick, fast korkig, gran od. schwarz. sporen fädig.

I. Fk. kuglig, kegelf. aus der Rinde hervortretend 11 mit sehmalem Ril. sich öffnend.

II. Fk. kuglig, tief eingesenkt, mit sich senkrecht ansetzondem, lü. flaschenf. Hals warzig hervortretend.

Fan. Ostropaceac.

\section{i. Ostropia.}

6. Roherger.

C. Fk. von Anfang an frei. (ieluänse kohlig od. häutis.

a) Fk. flach od. muschel-od. bandf. abstehend. Scheibe linienf., seltner rundlich.

Fam. Hysteriaceac.

I. Fk. mit flachem Grumde aufsitzend. linienf., flach.

1. sporen zweizellig (seltnes vierzellig), hyalin, eif.. spintelf., länglich.

a) Gehäuse häutig, Paraphysen wonig veristelt.

B) Gehäuse kohlig, Paraphysen ein dickes Epithecimm bildend.

2. Sporen 4-6 zellig, zuletzt brauı, länglich.

7. Inlographum.

3. Sporen mauerf.. zuletzt gefärbt

II. Fk. abstechend kahn, muschelod. bandf.

1. Sporen spindelf. $4-8$ zellig, braun

\section{Mytiiilimm.}

12. Iophimu.

13. Arrovpermum.

1. Cattmog: llypodermella v. Tubeuf.

Fk. wie bei folg. (ratt. Fehläuhe tsporig. sporen pinzellig, länglich keulig, mit schloimhïlle.

Auf Nadeln von larix in den Alpen.

II. Larieis $v$. Tub.

Auf Pinusnakln, zorstrent.

H. sulcigena (Link)

\section{Crattung: Hypoderma DO.}

Fk. ringewalehsen, länglich. Gohäuse lederig, schwarz, mit leinem Längsipalt anfspringend. sporen spindel- od. stäbchenf., zweizellig, liyalin. Paraphysen oben hakig ofl. korkzicherf. gebogen. 
Sporen $18-20 \times 4 \mu$. Fk. 1-1,5 mm lg. An dürren Stengeln bes. von Humulns, Epilobinm, Aconitum, Solidago usw., zerstreut, H. commune (Fr.)

Sporen $21-24 \times 3-4 \mu$. Fk. $1-2 \mathrm{~mm}$ lg., parallel längs stehend. An faulenden Ranken, Astchen usw., bes. von Rubus, zerstrent.

H. rirgultorum DC.

\section{Gattung: Lophodermium Chevallier.}

Fk. eingewachsen, länglich, gew ölbt. Gehäuse häntig, mit Längsriß die Deckenschichten anfreißend. Sporen fadenf. od. lg. keulenf., hyalin. Paraphysen oben hakig od. korkzieherf. gebogen. 1. Anf Coniferennadeln.

Auf abgefallenen Blättern von Berberis, Crataegus, Pirus bis ins Hochgebirge, zerstreut. $\quad$ L. hysterioides (Pers.)

Auf Stengeln u. Blattseheiden von Phragmites $u$. anderen Gramineen. bis ins Hochgebirge, nicht selten.

L. arundinaceum (Schrad.)

2. Auf faulenden Nd. von Pinns silvestris, Picea, Abies bis ins Hochgebirge, gemein (Schüttepilz). (Fig. 260.)

L. pinastri (Schrad.)

Auf dürren Nd. von Juniperus Arten bis ins Gebirge, nicht selten.

L. juniperinmm (Fr.)

Auf Nd. von Abies pectinata, zerstreut (Weißtannenritzenschorf). $\quad$ L. nerrisequium (DC.)

\section{Gattung: Dichaena Fries.}

Fk. sehr klein, länglich od. rundlich, quer gestellt, in großen Flecken zusammenstehend. Schläuche umgekehrt birnf., $4-8$ sporig. Sporen ellipsoidisch, , inzellig, dann klein vielzellig.

An glatter Rinde junger Eichenstämme, zerstreut.

D. quereina (Pers.)

An glatter Rinde junger Fagusstämme, zerstreut. (Fig. 261.)

D. faginea (Pers.)

\section{Gattung: Ostropa Fries.}

Fk. kuglig, eingesenkt, dann kegelf. hervorbrechend, mit Längsriß sich öffnerd. Schläuche lg. zylindrisch. Sporen zu 8, tädig, vielzellig, hyalin. Auf trockenen Ästen von Lb., zerstreut. (Fig. 262.)

o. cincrea (Pers.)

\section{Gattung: Robergea Desmazières.}

Fk. kuglig, ziemlich tief eingesenkt, mit einem horizontalen Schnabel der grauen Scheibe etwas hervortretend. Schlänche u. Sporen wie bei vor. Gatt.

An Lbästen, selten. (Fig. 263.)

R. unica Desm. 


\section{Gattung: Iulographum Ljbert.}

lkk. linienf., oberflächlich sitzend, nit feinem Längsrils sich affuend, schwarz, sehr klein. Sehläuche kenlig ol. eif. Sporen zweizelligr. hralin.

Aut fanlenden Blättern von Ifedera, llex, Rhodmendorn, selten. (1.ig. 264.)

1. ragum Desm.

\section{Gattung: Gilonium Mühlenb.}

Fk. linienf., mejst ziemlich lg.. gewölbt. mit langenn Ril.s sieh öthent, schwarz. Sehläuche keulig, ssporig. Sporen hyalin, zweizellig. selten 4 zellig. Paraphysen oben ein Epithecium bildend.

Fk. nicht auf einem IIyphenfilz sitzend. Auf entrinletem, feurlitem Holz von Corylus, Prumus, Alnus, Fagus, Quereus, zerntreut. (Fig. 20.5.)

(i. lineare (Fr.)

Fk, in einem Hrphenfilz sitzend. Anf der Rinde alter Kiefern. stämme, solten.

fi. graphicum (Fr.)

\section{9. (rattung: Hysterium Tode.}

Fk. flach auisitzend, länglich bis linienf., gewölbt, mit Längsrif sich offnend, schwarz, kohlig. Schläuche keulig bis zylindrich, 8 sporig. Sporen keulig, quer 4-, seltner 6 zellig, zuerst hyalin, damn braun. Paraphysen ein gefärbtes Epithecium bildend.

Fk. meist zerstrent, länglich bis rundlich, 1-2 mulg., 0,5 bis $1 \mathrm{~mm}$ br., zart längsgestreift. im Alter oft scheinbar gesticlt. Sporen

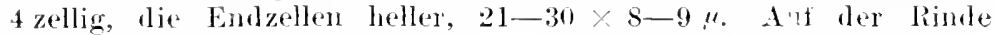
ron Quereus, Betula, Popnhus u. a., nicht selten. (Fig. 266.)

\section{II. pulieare Pers.}

Fk. meist gehäuft, oft parahlel, länglich, zart längsstreifig, l-3 $31 m$ lg., $0,5-0,8 \mathrm{~mm}$ br. Sporen gleichmägig hellbrann gefärbt. 18-21 5-6". Auf der Rinde von Quereus, seltner Betula 11. a.. nicht selters.

H. angu-tatum Alb. et sichw.

\section{Crattung: Ilysterographimm corda.}

lk. wie bei ros. Gatt., stark gewälht. speren ellipsoidlsch, mauerf., hyalin, später geth his braun werdend. Parapleysen ein Epithecium biklend.

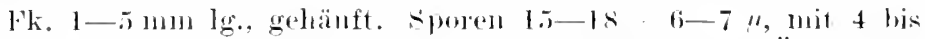

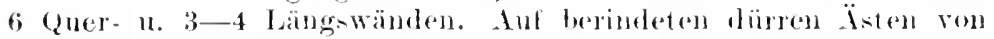
Rosa, Prunus, zerstreut. II. curratum (Fr.)

Fk. meist gesellig, 1-2,5 $\mathrm{mm}$ lg. Sporen $36-40 \times 15-200 "$. mit 3-4 Querwänden u. 2-3 fach längstrilig. An berinteten Ïsten vou Fraxinus, seltuer anf Coryhts, lagus, luglans u. a., zerstreut. (1)ig. :21;7.)

II. fraxini (Pers.)

\section{1. (iattung: Mytilitlium Fuby.}

Fk.sehnal aufsitzend, kahn od.musehelf, obenschmalschneidenf., gekrümmt, mit Längsrils aufspringend. schłäuche zylindrisch, 
8sporig. Sporen spindelf., 7-8 zellig, hyalin. reif brann. Paraphysen fädig.

Sporen zuletzt s zellig. Auf den Blattnarben (u. berindeten Ïstchen) ron Larix, Pinus punilio n. cembra, in den Alpen.

11. gemmigenum Fuek.

\section{Gattung: Lophinm Fries.}

Fk. muschelf. od. anfrecht bandf., zusammengedrückt n. oben eine schmale, mit längsrif sich offnemde sehneide bildend. Sporen fädig, quergestielt, hyalin od. gelblich.

Fk. muschelf., bis $1,5 \mathrm{~mm}$ lg. 11 . ea. $0,7 \mathrm{~mm}$ hoch. sporen $1: 20$ bis 150 "lg. Auf 11olz u. Rinde ron Pinus silvestris u. Abies, seltner an Lb.. selten. (Fig. 268.)

L. mytilinum (Pers.)

Fk, bandi.. 1.5-3 $\mathrm{mm}$ hoch, 0,5-I $\mathrm{mm}$ lg. Sporen $150-320 "$ " lg. Auf Rinde vom Pirus communis. Prumns spinosa, Alnus, seltell.

I. dolabriforme Wallr.

\section{Gattung: Acrospermum Tode.}

Fk. sich von der [nterlage stiftf. frei erhebend. an scheite] mit feinem Längsspalt, kurz gestielt. Sporen fädig, sehr lg.

An dürren stengeln nit $1-3 \mathrm{~mm}$ hohen Fk. zorstrent sitzend, zerstreut. (Fig. 269.)

A. compressuni Tode

\section{$\therefore$ Reihe: Discomycetes.}

l'k. napf-, schïssel-ol. krugf., stets bei der Reife weit geöfnet. schläuche mit Paraphysen ein IIyneninm billemb. Als Neben. fruchtiormen Konidien vorkonmend.

\section{Unterreihe: Pladeidimere.}

Myzel hyalin od. dunkel, häufig ein nit dem substrat verwalchenes Strona bilılend, Fk. anf fädiger Lnterlage frei od. häufiger dem Substrat ol. Stroma eingesenkt, meist dann später - herrorbrechend, länglich od. rundlich, zuerst vällig geschlossen, daun die Substrat- 1. Hüllsehichten rundlich aufreißend u. lappig zurürkschlagend, wodureh die rundliche od. längliche Scheibe frei gelegr wird. Gehänse lederig od. fleisehig. Paraphysen dies sehläuche meist überragend 1 . ein dichtes Epitheeium bildend. Iypothecium versehieden dick.

$$
\text { Bestimmungstabelle der Familien. }
$$

A. Gehäıse weich, fleischig, hell gefürbt. nicht seluwarz. Scheibe meist hell gefärbt, von den Lappen des Geläuses umgeben.

B. Gchäuse lederig od. kohlig, stets schwarz

\section{Stictidalepate.}


a) Fk. eingesenkt, dann weit hervortretend. Hypothecium dick.

2. Tryblidiaceae.

b) Fk. im Nührsubstrat (bzw. Stroma) eingesenkt bleibend. IIspothecium dünn, wenig entwickelt.

\section{Phacidiaceae.}

\section{Familie: stictidaceate.}

Gohäuse aus langgestreskten Zellen bestehend, hell gefärbt. Scheibe flach, wachsartig, hell, seltner dunkel. Hypothecium düm, farblos.

$$
\text { Bestimunngstabelle der Gattungen. }
$$

A. Sporen ellipsoidisch, länglich,spindelf od. zylindriseh, nicht fädig.

a) Sporen einzellig.

I. Scheibe lireisf.

1. Paraphysen oben kenlig angeschwollen, stumpf.

"8) Sporen ellipsoidisch ïber $20 "$ ] g. $17.10 " 1 / \mathrm{br}$.

1. Ocellaria.

B) sporen ellipsoidiseh od. eif., selten länger als 10 ".

‥ Naevia.

2. Paraphysen oben lanzettich zugespitzt.

3. Stegia,

1I. Scheiben länglich.

1. Paraphysen füdig, rerzweigt, oben etwas keulig angeschwollen.

t. Briartia.

2. Paraphysen oben reich rerzweigt, ein Epitheejum bildend.

5. Propoli.

1.) sporen ques in 2-6 Zollen geteilt.

I. Scheibe jundlieh od. wenig läng. lich

1. Paraphyeen Lialiog. koin Ejpithe. cium bilelend.

6. P'hratemonatevia.

2. Paraphysen versweigt, ein Epithecium bildent.

11. Schejbe lo. linjenf.

7. Cryptodiseus.

s. Xylogramma.

B. sporen fälig, viclzellig.

a) Schläuche kenlig, stumple zugespitzt, gestielt.

9. Niemateyelus.

b) Schläuche zylindrikeh, viel länger, oben abgerundet, fast ungentielt.

I. Paraphy̌sen fädig, lamm keulig.

11. Paraphysens ein Epitheeium bildend

10. stictis.

11. Schizoxylon. 


\section{Gattung: Ocellaria Tulasne.}

Fk. eingesenkt, dann vorbrechend $u$. das Substrat lappig aufreißend. scheibe weich, goldgelb, dick berandet. Sporeu ellipsoidisch, hyalin. Paraph ysen verzweigt, nach oben etwas verbreitert. Schlauchporus $\boldsymbol{J}+$.

Scheibe $0,5-3 \mathrm{~mm}$ br. Sporen $21-30 \times 9-12 \mu$. An dürren Ästen vou Populus, Salix, IIippophaë bis in die Hochalpen, zerstreut.

o. ocellata (Pers.)

\section{Gattung: Nalevia Fries.}

Fk. zuletzt lappig aufreißend, hervortretend. Scheibe feucht hellgefärbt, trocken etwas dunkler. Sporen länglich od. eif., hyalin, kleiu. Paraphysen fädig od. gabelteilig, oben oft etwas verbreitert u. gefärbt.

1. Auf IIonokotyledonen. 2.

Auf Dikotyledonen. 3 .

2. Scheibe blaßbrännlich, $0,2-0,4 \mathrm{~mm}$ br. Sporen $9-1 \mathrm{I} \times 3-4 \mu$.

Schlauchporus $J+$. Auf duirren Halmen von Junens effusus, selten.

N. pusillal (Lib.)

Fk. in Längsreihen. Scheibe gelbrötlich, $0,3-0,4 \mathrm{~mm}$ br. Sporen 7-8 $\times 3$ ". Schlanchporus $J-$. Auf der Unterseite dürrer Blätter von Garex hirta, zerstreut. Y. seriata (Lib.)

3. Scheibe gelbwei $, 0,25 \mathrm{~mm}$ br. Sporen $7-8 \times 3-3,5 \mu$. Schlauchporus $J+$. Anf der Luterseite faulender Eıchenblätter. selten. (Fig. 270.) N. minutissima (Auersw.)

Scheibe gelblich od. rötlich, 0,3-1 mm br. Sporen $12-17 \times$ 6-8 4 . Schlanchporns $J$ - Auf dürren Stengehn von Solidago virgaurea, sehr zerst ent. $\quad$ s. minutula (Sace. et Malbr.)

\section{Gattung: Stegia Fries.}

Fk. mit Klappe od. Deckel, seltner mehrlappig aufreißend. Scheibe weich, wachsartig, Schläuche keulig, oben abgerundet. Sporen länglich, hyalin. Paraphysen oben lanzettlich zugespitzt. Schlauchporus o + .

Sporen $10-12 \times 3,5-4,5 \%$. Seheibe blaßs. Anf dürren Grasblätteru u. Carex in den Ilochalpen. (Fig. 271.)

\section{s. subvelat:i Rehm}

\section{Gattung: Briartia Sacc.}

Fk. eingesenkt, dann die Oberhaut des substrate - mit Läugsriß zerreißend. Scheibe sehmal, zart berandet, rot. Schläuche 4 bis 6 sporig. Sporen länglich, stumpl, gerade od. etwas gebogen, hyalin. Schläuche $\mathrm{J}$ -

Ant dïrren Stengeln von Chenopodinm album, selten. (Fig. 272.)

B. purpurascens Rehm 


\section{Crattunes: Propolis Frits.}

Fk. ringesenkt, dann hervorberelenel u. die Ibecke lappig zer.

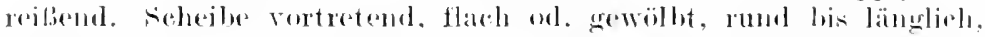

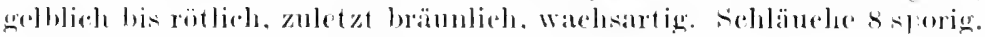

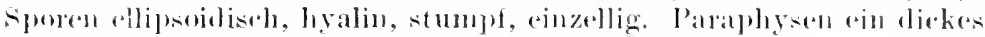
Epitleerium bildend. Sthläurle d-

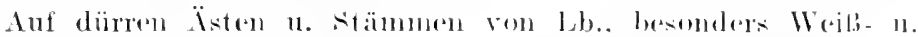

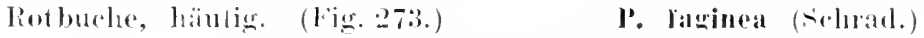

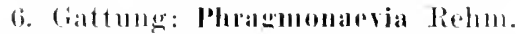

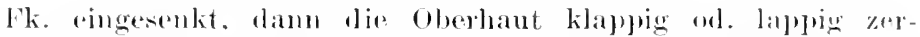

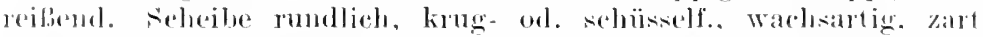

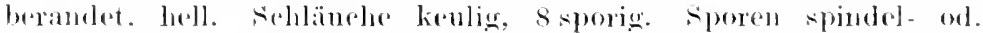

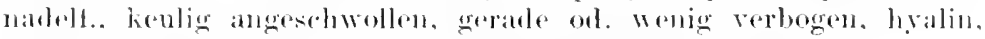

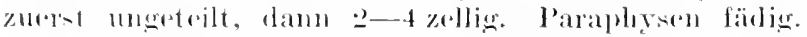

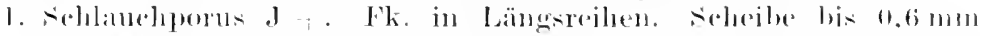

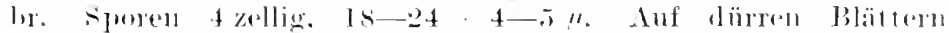

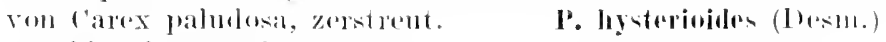

sehlanu(b)

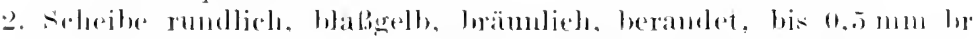

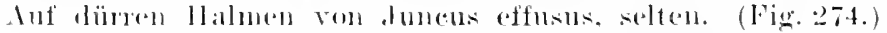

D. emergens (Karst.)

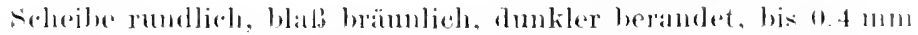

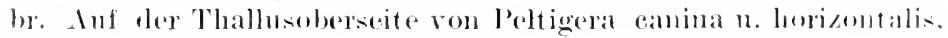
zoristrent.

l. peltierrae (Xyl.)

\section{Crattung: Cryptoliscus c'orela.}

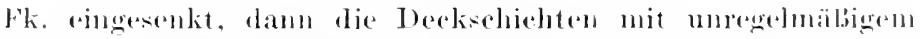

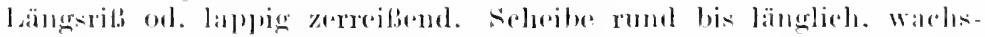

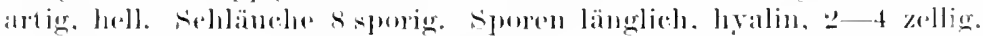

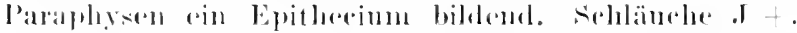

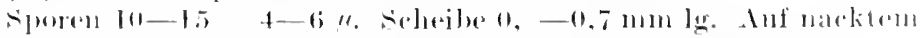

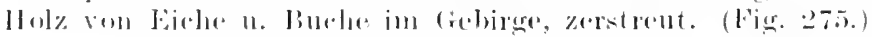

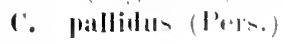

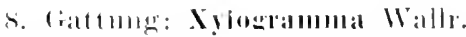

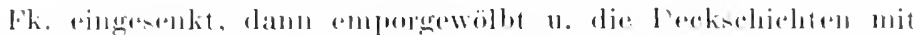

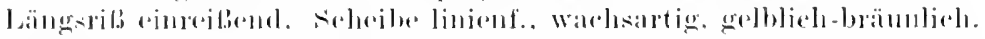

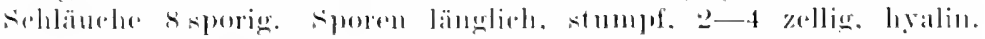

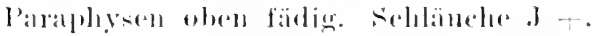

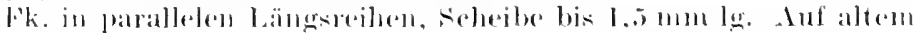

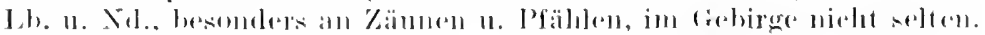
(1)ig. 27 (i.)

X. sticticum (Fr.)

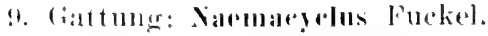

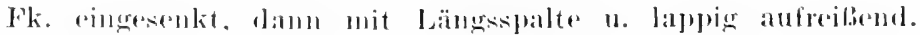

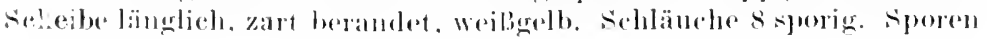


fadenf., vielzellig, hyalin. Paraphysen oben verästelt. Schläıche $\mathrm{J}+$.

Auf abgefallenen Kiefermuadeln, zerstrent. (Fig. 277.)

X. niveus (Pers.)

\section{Gattung: Stictis Persoon.}

Fk. eingesenkt, damn lappig anfreißend u. durchbrechend. Scheibe eingesenkt bleibend, krugf., meist dick berandet. Schläuch $\theta$ zylindrisch, 8 sporig. Sporen fadeuf., vielzellig. Paraphysen oben wenig verzweigt. Schlänche meist .J + .

Auf berindeten Ästen ron Apfelbänmen, Weiden usw. Scheibo rötlich od. gelbbräunlich, bis $0,7 \mathrm{~mm}$ br. Sehr zerstreut, bis in die Alpen. (Fig. 278.)

S. radiata $(\mathrm{L}$. $)$

Auf Ästchen von Quercus, Acer, Alnus, Popmlus, Rhammus usw. Scheibe gran od. grünschwärzlieh, weif bestäubt, $1-2 \mathrm{~mm}$ br. Zerstreut, bis ins Hochgebirge.

S. mollis (Pers.)

An dürren Stengeln von Rubus, Spiraea, Eupatorium. Viburnum nst. Scheibe 4 lappig, schneeweils, bis $0,6 \mathrm{~mm}$ br. Selten,

\section{s. stellata (Wallr.)}

An taulenden Grashalmen, sow vo varex, Luzula, Iuncus Scheibe grau bis bläulich schwärzlich. bis $1 \mathrm{~mm}$ br. Zerstreut.

s. armulinacea Pers.

\section{Gattung: Schizoxylon Persoon.}

Fk. eingesenkt, dann knglig hervortretend u. sich zuerst punktf., dam weit rundlich öfnend. Scheibe krugf., dann flach, schwärzlich grün. Schlänche 8 sporig. Sporen fädig, vielzellig. Paraphysen ein durch J sich blämendes Epithecimm bildend.

Scheibe bis $1 \mathrm{~mm}$ br. An dürren Kräuterstengeln z. B. Oenothera, Scrophularia, Lappa, Galeopsis, Artemisis, Genista usw., zerstreut.

S. Berkeleyanum (Dur. et Lér.)

\section{Familie: Tryblidiaceac.}

Fk, eingesenkt, dann hervorbrechend u. weit hervortretend, gestielt or. nicht. Gehäuse meist schwarz, lederig od. kohlig, über der Scheibe sich als Ilaut spannend, die am Scheitel rmdlich auf. reißt u. Iappig zurückklappt. Hypothecium dick. Sehläuehe 8 sporig.

$$
\text { Bestimmungtabelle der Gattungen. }
$$

A. Fk. sitzend, becherf., mit groben Jappen anfspringend.

a) Sporen quer $2-4$ zellig.

b) Sporen mauerf.

B. Fk. kugel- or. kreiself., gestielt, braun od. sehwarz, mit feinen Zähnen aufreibend.

Linda 11 , Krytogamenflora 11, 1. 2. Autl.

1. Tryblidiopsis.

2. Tryblidium. 
a) Fk. einzehn stehend, nicht auf einem stroma.

I. Schlänche $J$... Fk. selur wenig über das substrat hervortretend.

I1. Nur Schlauchporus $J+$. Fk. zuletzt frei aufsitzend.

b) Fk.gehäuft auf einem strom astehend

\section{Olontotrema.}

\section{Heterosphaeria.}

5. Neleroderris.

\section{Gattung: Tryblidiopsis Karsten.}

Fk. kuging, eingesenkt, dam linsenf. u. frei aufsitzend. lapply aufreibend. Gehäuse lederig, schwarz. Seheibe weibgelb, krugt. eingesenkt. sporen länglich spindelf. Hypothecium weis onl. schwach bläulichgrün, dick. Paraphrsen oben ästig.

Fk. 1-3 nm br. Sporen hyalin od. schwach gelblich, Is-:$\times 6-7 \mu$. An dïrren, berindeten, noth hängenden xiefrrn- od. lärehenästchen, zerstreut. (Fig. 279.) T. pinastri (Pers.)

\section{Crattung: Tryblidimn Rebentiseh.}

Fk. ebenso. Scheibe rundlich, flach. Gehänse hornig luterig. schwarz. sporen länglich ellipsoidisch. hyalin od, getblich, manert. laraphrsen oben ästig. Ilypothecinm dick, neist schwach gelblich.

scheibe $1,5-3 \mathrm{~mm}$ br. sporen $30-4.5 \% 12-1.5 \%$. Inf les Rinde alterer Eichen, hesonders im Gebirge, zerstent, schwer sichtbal. (Fig. 2su.)

T. ealiciforme liebent.

\section{Gattung: Odontotrema Sylander.}

Fk. kuglig, eingesenkt, dam durehbrechend, trocken oben ein. sinkend, am scheitel sich mit Loch öfnend u. dam klayplg antreibend. scheibe krugf. eingesenkt, weibrötlich. Gehäuse laderigr. schwarz. Sporen 2, dann + zellig, hyalin. schläuche $J+$ t

scheibe $0,5-1 \mathrm{~mm}$ br. Sporen $9-12>\therefore-5 \mu$. An entrinderent Ilolz von Pieca, Juniperus. Pinms exmbra in den Alpen, nieht salten. (Fig. 281.$)$

(o. hemisphaterioum (Fr.)

\section{Fattung: Inotompharia tireville.}

Fh, eingesentit, kuglig, dann hervorbredsend n. frej anfsitzend. mit zähnigen lappen sternf. aufspringend. Seheibe krugf. ainge senkt, weiblieh. Gehänse häntig lederig, schwarzbrann. Sporsis länglich, zulotzt 2 zellig, hyalin. Paraplyysen fätligr. oben elwa lanzettf.

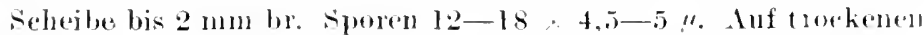
strogehn ron Tombelliferen, besonders Danems, Anethmm, zerstrent. (Fig. 2s:2.)

H. patrila (Torle)

\section{Crattung: Seleroderris Fries.}

Fk. ans einem unterrindigen Stroma rinzeln oel. grehäuft hexror brechend, anfangs kughg, dann krugf., me-ist etwats gestielt. mit 
kleinen, unregelmäßigen Lappen aufreißend. Scheibe blaß gefärbt. Sporen nadelf. od. verlängert spindelf. 4 zellig hyalin. Hypothecinm blaß. Paraphysen fädig.

Fk. als kleine gestielte Bïschel hervorkommend $1-4 \mathrm{~mm}$ br., bis $15 \mathrm{~mm}$ hoch. Sporen nadelf.. oben stumpf. nnten spitz 30 bis $36 \times 3-4 \mu$. Sehlauchporus $J+$. An abgestorbenen Ästen von Ribes nigrum u. rubrum zerstreut. (Fig. 283.) S. ribesia (Pers.)

Fk. als schwarze Kruste dicht nebeneinander stehend 0.5 bis $1 \mathrm{~mm}$ tr. sporen verlängert spindelf., $30-33 \times 3-4 "$. Schlanchporus .J-. An dürren Stengeln von Euphrasia officinalis, selten.

\section{S. ageregata (Lasch)}

\section{Familie: Phacidiaceare.}

Fk. in die Nährsubstanz od. in ein Stroma eingesenkt, unten flach aufsitzend. Gehäuse häntig lederig od. hart kohlig, schwarz, entweder oben ron dem bedeckenden $s$ : bstrat frei u. dasselbe lappig anfreißend $n$. zugleich selhst Iänglich od. rundlich sich am scheitel lappig öfnend od. aber mit dem deckenden substrat fest verwachen n. mit ihm zusammen lappig od. mit Längsrif anfspringend. Scheibe rundlich od. länglich. schläuche 8 sporig. sporen verschieden. Paraphysen fädig od. oben ästig u. ein Epithecium bildend.

$$
\text { Bestimmungstabelle der Gattungen. }
$$

A. Gehäuse nicht mit den deckenden sub. stratschichten verwa hsen. Fk. geschlossen zwischen den Lappen des substrates hervortretend " dann erst lappig aufspringend.

a) Sporen länglich, einzellig. hyalin.

b) sporen längliøh, spindelf., quer mehr zellig.

I. Scheibe rund.

II. Scheibe länglich, durch Längsriß frei werdend.

e) Sporen manert.

1. Psendophacidium.

\&. Coccophacidium.

3. Clithris.

4. Psendographis.

B. Gehäuse mit der deckenden Nährsub*tanz rerwachsen $u$. mit dieser lappen. od. spaltenf. aufreiBemu.

a) Fk. einzeln stehend, ohne Stroma.

1. Sporen Iänglich, lzellig.

1. Fk. rundlich.

a) Paraphysen kein Epithecium bildend.

j. Plaacidium.

p) Paraphysen ein Epithecium bildend.

b. Trochila.

2. Fk.unregelmäPig, länglich, spal - 
tenf. lappig anfreifend. Kein Epithecium

II. Sporenlänglich, zwoi- his vie zelligs.

\section{T. Cryptomyees.}

1. Fk. rmollich, von der Nitte des Scheitels aus sich lappig ïft. nend, Sporen zwri-bis vituzellig.

2. Fk. länglich, am Scheitel sich länglich lappig öfnend. Sporen zweizellig.

III. Sporen fädig od. nadelf., ungleich zweizellig.

b) Fk. zu melireren einem stroma einge bettet, spaltenf. anfreibend.

I. Sporen einzellig, ejf., lyyalin.

II. Sporen einzellig, fädig od. nadelf.. luyalin.

\section{s. Splraeropezia.}

9. Srhizothyrium.

11. Cocenmyees.

\section{Psemdorhytisma.}

!2. Rhytisma.

1. Gattung: Preudophacidium Karsten.

Fk. eingesenkt, geschlossen, linsenf., dann die deckenden Sub. stratschichten lappig zerreißend u. rom Scheitel aus lappig anfreißend. Scheibe rund, flach, blaf. Gehäuse lederig lı̈utig. schwarz. Sporen länglich, stumpt, hyalin, einzellig. Paraphșsen fädig.

Scheibe $1-1,5 \mathrm{~mm}$ br., blabviolett. Sporen $10-16 \times 4-5 !$. An dürren Ästen von Ledum palustre, selten.

\section{P. Iedi (Alb. et schw.)}

Scheibe 1-2 mm br., blas. Sporen $12-15 \times 4-6 "$. An dürren Asten ron Rhododendron ferugineum in den Alpen.

\section{P. rhododendri Relum}

\section{Gattung: Coccophacidium Rehm!}

Fk. kuglig eingesenkt, dann die deckenden Schichten lappig zerreibend u. sich auf dem scheitel mehrlappig öthend. Gehäuse häutig kohlig. Ss.lueibe brämnlich. Sporen nadelf., beidendig spitz, oben breiter, zuletzt bis 1:2 zollig, hyalin bis gelblich. Paraplysen fädig.

Sclueibe 1.5-3 1101 br. sporen 55-80 $\% 4.5 " 1$ br. An dürren Kiefernästen, zerstrent. (Fig. 284.) ('. pini (1lb. et schm.).

3. Gattung: Clithris Fries.

Fk. eingesenkt, länglieh, die Deckschichten nit Läugsriß spaltend $u$. lappig zurïckschlagend, gewölbt, daun sich oben mit I,ängsriß u. Lappen öffuend. Scheibe länglich, blaf. Sporen fädig od. verlängert spindelf,, zuletzt vielzelligr, hyalin. Paraplı̣sen fädig, oben haken-od. pfropf nzielierf. Eebogen.

Fk. meist quer ïber den Ast relagert, aulen bereift, $5-20 \mathrm{~mm}$ lg. Sporen bis $90 \times 1,5 "$. Anf diirren, dümeren Eichenästen, häufig. (Fig. 285.)

c. quercina (Pers.) 


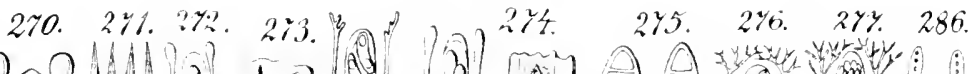
(3)

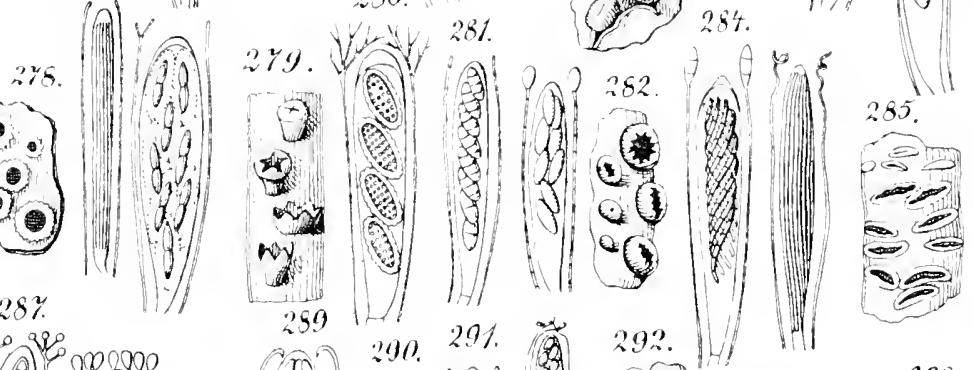
gio 98000000

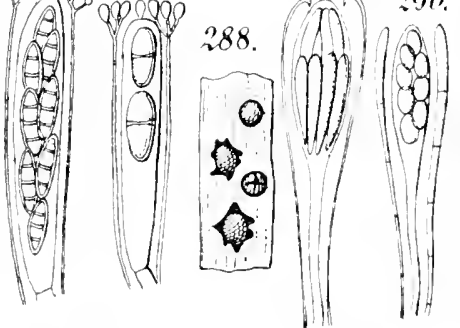

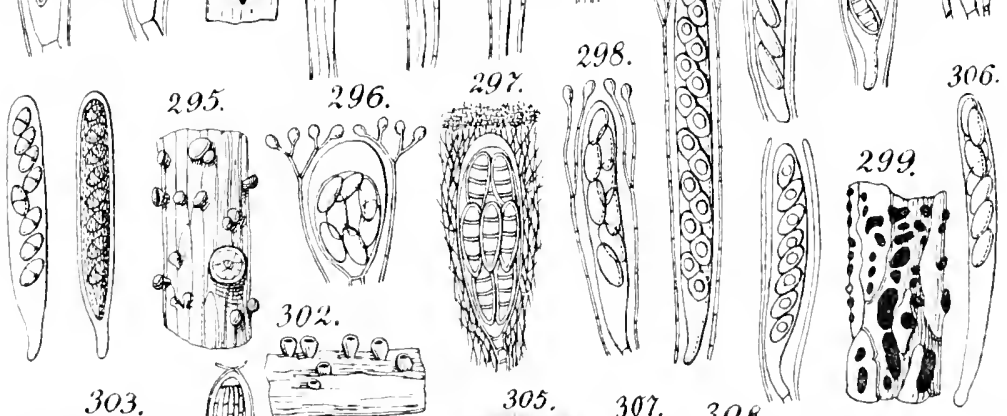

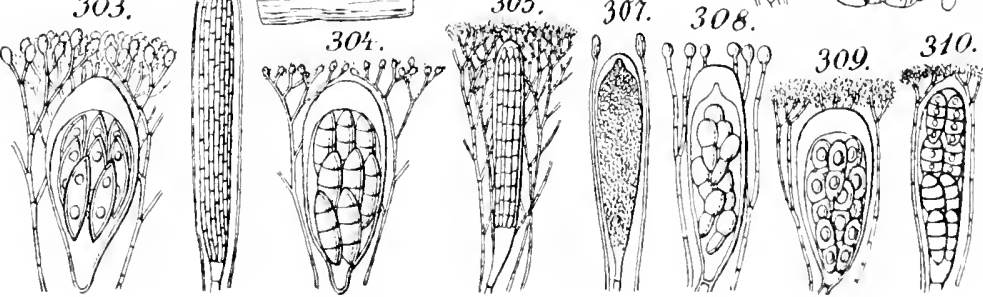


lkk. länglich, spitz, auben nicht bereift, 2--.j $10 m$ lg. Seheibe grïnlichgelb. Sporen verlängret spindelf., $40-50 \times 2,5 \mu$. An berindeten, dümmen, noch hängenden Astelen von Pieea u. Iarix in dielnten Gebirgswälırn.

C. rerispa (Pers.)

\section{Gattung: Pseudoeraphis Nylambler.}

Fk. rmullich od. Iänglich, ringesenkt, das substrat lappig zer. reibend, hervortretend 11 . dam anf lem solnoitel länglich zackig sich offuend, kohlig, schwarz. Seheibe gelbrötich. sjoren manert. Parapligsen oben ästig. Sporen J $\mathrm{J}$.

Scheibe 1-2 nm br. Sporen 21-3.1. 10-14". Aut for Rinde alter Abies bis ins llochebebirac, zerstrent.

\section{P. Matima (Ach.)}

\section{Gattumg: Phardiom Fries.}

Fk. rmolich linsenfo, eingewaehsen, oben von lex litte ans mehrlappig anfspaltend. Sporen ei-ol. spindelf. Paraphssen fädig. Sehlauchporus $\mathrm{J}+$.

Auf faulenden Kiefermadeln. Fk. J-1,8mm ir. Singen spintlelf., abgermulet, $12-14 \times 3,5-4 "$. Kerstrent.

\section{P. Iarerum Fr.}

Auf des Enterseite lebender liäter von Galium, Asperula, Rubia. Fk. bis $0,8 \mathrm{~mm}$ br. Sporen läuglich kenlig, $10-12 \times 2,5-3 "$ ". Zerstrent.

P. repandum (Allb et schw.)

\section{Gattmeg: Trochiba Fries.}

Fk, ringesenkt, dann sich hervorwöbend u. nit einem fängs-

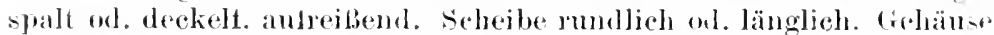
schwärzlich. Sproren länglich, einzellig, hyalin. Paraphysen ein

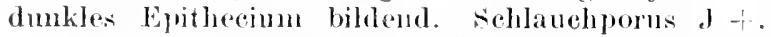

Anf der Cntreseite von Ftrublättren. Selneibe nit $3-4$ zalten

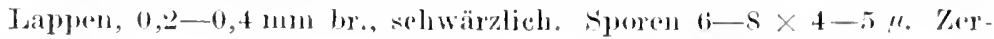
streut.

'T. eraterium (DC)

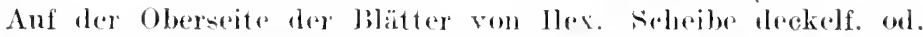
klappig frei werdend, gran od. brïunlieh, $1.3-1 \mathrm{~mm}$ br. siporen 9-11 $13,5-4.5 \mu$. \%erstent. (Fig. 2st.) 'T. ilieis (Cherv.)

Aut Blattstielen von Aecr pendoplatanus, fesenlus u. Ailanthus, Scheibe meist durch längssualt entblölit, gelblicl grau, $0,5-1,2 \mathrm{~mm}$

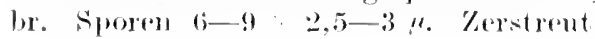

$$
\text { T. protiolaris (Alb.et seluw.) }
$$

\section{Gattung: Cryptomyers cireville.}

Fk. eingesenkt, abgeplattet, an sulucitel moregremälig sich spaltend. Scheibe tlach. Gehäuse liohlig, sehwarz. Sporen läuglich. rinzellig, loyilin.

Fk. $1-10$ (en lg., $5-15$ nm br., krustig. Salneibe gelbbrämulich. 
Sporen 20-: 6 ; $10-13 \%$. Paraphysen ein Epithecium bildend. An absterbenden Weidenästen, selten. C. maximus (Fr.)

Fk. den Nerven folgend, streifig, $0,5-3 \mathrm{~mm}$ lg., $0,25 \mathrm{~mm}$ br., schwarz. Sporen $8-10 \times 5-6 \%$. Anf der Tnterseite ler Wedel ron Pteridium, zerstrent.

C. pteridis (Rebent.)

\section{Gattung: Sphaeropexia saccardo.}

Fk. eingewachsen, linsenf., ron der Mitte aus lappig aufspringend. sporen länglich, 2-4 zellig, hỵalin. Paraphysen meist oben ästig. schlanchporus $\mathrm{I}+$.

Scheibe blaf, ca. $0,4 \mathrm{~mm}$ br., sporen 4 zellig, $15-1 \mathrm{~s} \times 5-6 "$. Anf noch liägenden Blättern ron Empetrum nigrum in den Alpen. (Fig. 28\%.)

S. empetri (Fuck.)

Scheibe strohgelb, ca $0,4 \mathrm{~mm}$ br. Sporen $2-4$ zellig, 15 bis $17 \times 4-5$ ". Auf der Oberseite dïrrer Blätter von Andromeda, selten. S. andromedae (Fr.)

\section{Gattung: Sehizothyrium Desmaz.}

Fk. eingewachsen, rundlich od. länglich, mit Längsriß lappig spaltend. Schläuche zuerst mit s, später m:t oft weniger sporen. schläucle . -

Scheibe bräunlich, $0,3-0,4 \mathrm{~mm}$ br. sporen meist nngleich zweizellig, $12-1+\times 5-6 \mu$. Paraphysen ein grünliches Epithecium bildend. Auf lebenden Blättern ron Achillea ptarmica, zerstreut. (Fig. 28s.)

S. ptarmicae Desm.

Scheibe gelblich, bis $0,9 \mathrm{~mm} \mathrm{lg}$. sporen $8-9 \times 2,5-3$ ". Paraphỵsen fädig. Auf der Oberseite ron Wedeln ron Pteridium, zerstreut.

S. aquilinum (Fr.)

\section{Gattung: Coceomyces de Notaris.}

Fk. linsenf., mehrlappig aufspringend. scheibe rundlich, gelhlich. Sporen nadelf, oben meist breiter u. stumpfer, zuletzt vielzellig, lyalin. Paraphrsen fädig, oben hakig gekriimmt.

Scheibe $1-3 \mathrm{mn}$ ! br. Sporen $35-7 ., \times 2-3,5 \mu$. Auf famlenden Blättrrn ron Eichen u. Buchen, seltner Birken, zerntreut. (Fig. 2s9.)

(. coronatus (Schum.)

\section{Cattung: Pseudorhytisma Juel.}

Fk. in einem das ganze Blatt durehsetzenden sklerotinartigen Gewebe sitzend, das anBen mit schwärzlicher Haut abgegrenzt wird, rundlich od. länglich verbogen, mit Längsriß lappig aufreißend. scheibe blas röticlı. Sporen hyaliu, eif., einzellig. Paraplysen fädig.

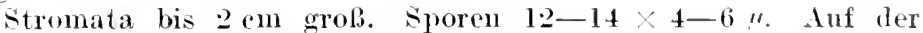
Unterseite der Blätter von Polygonum bistorta u. viviparum in Gebirge, nicht selten. (Fig. 290.)

P. histortae (DC.) 


\subsection{Crattung : Rhytioma Fries.}

stroma flach ausgebreited, nutrer der Blattoberhaut gelagert, auben schwarz, innen wejl., Fli. zu nehreren, eingesenkt, länglich gebogen od. rundlich, mit längslil.; aufreibend. Sporen fädig od. nadelf., hyalin, meist einzellig. I'araphysens fädig.

Auf der Oberseite faulender Acerblätter, auf den hängenden Blättern nur Konidienlager entwickelnd, die Fk. 'rst an den 'aulenden Bl., F., gentein. (Fig. 291.)

Auf der Oberseite von Weidenblättern, hänfigr.

R. acerinum (Pers.)

R. salicimun (Pers.)

Auf der Oberseite der Blätter von Andromeda, zerstreut.

R. andromedae (l'ers.)

Auf der Oberseite der Blätter von Empetrum, im Ilochgebirge.

R. empetri Fries

\section{Luterreihe: Pezizineae.}

Myzel fädig, verzweigt, septiert, saprophytiseh orl. f arasitisch. Fk. meist von Anfang an frei, seltner erst eingenenkt, dann aber stets völlig frei hervortretend, selten aus einem sklerotiun hervor. wachsend, sitzend od. grestielt, zuerst kugrlig gesehlossen, dann von einer kleinen Mündung am seheitel aus sich öfnend, nie latplig, bei der Reife flach teller-od. seheibenf., becher-od. krugt. Ilymenium den oberflächlichen Teil des Fk. geschlossen überziehend, stets mit Paraphysen. Gehäuse um den granzen lk. napff. lierumgehend, seltwer nur an der Unterseite ausgebildet.

\section{Bestimmungstabelle der Familen.}

A. Gelläuse napff., den ganzen Fl. unten

u. seitlich ungebend.

a) Fk. leder-od. hornartig od. knorpelig.

Paraphysen ein Epithecium bildend.

I. Fk. zuerst eingesenkt, dann her. vorbrechend, oft zuerst mit einer Membran geschlossen.

11. Fk. von Anfang an frei (bei den Flechtenparasiten meist zuerst ein. gesenkt), nieht von einer llaut iiberdeckt

b) Fk. fleiselnig od. bei de: kleinen For-

\section{Conangiaceac.}

2. Patellariaceae.

men häulig, zart. I'araphysen kein Epitheciun bildend.

I. Iypothecium merst seliwach entwickelt (mit Ausnalnue der großenFormen), vou dem Gehäuse in der Struktur versehiolen. Sporen $u$. 
Hymenium meist nicht die sehöne regelmäßige struktur zeigend wie bei II, sondern alles viel kleiner.

1. Gehäuse von paraplectenchymati $\approx$ chem Gefüge (Zellen rundlich, eckig, oft dunkelwandig. grau.

2. Gehäuse von prosoplectenchymatischem Gefïge (Zt llen langgestreckt, parallel verlaufend), tast nur hellwandig.

II. Hypothecium gut entwickelt, eben so wie das Gehäuse locker paraplectenchymatisch.

1. Schläuche bei der Reife einzeln über die scheibe her vortretend.

2. Schläuche bei der Reife eine gleichmäßige Sehicht bildend, nicht hervortretend.

B. Fk. eine gut ausgebildete fleisehige Unterlage zeigend, aber die Seitenwand des Gehäuses ganz fehlend od. kaum entwickelt.
3. Mollsiaceae.

4. Helotiaceae。

\section{Familie: Cenangiaceac.}

Fk. zuerst eingesenkt, dann vollständig hervorbrechend, selten mit Stroma, lederig od. hart homartig od. seltner weich gallertig (dann nur große Formen), dunkel od. heller gefärbt, sich rundlich öffnend $u$. zuletzt scheibig od. krugf. Scheibe bei einigen zuerst, dureh eine Haut versehlossen, die verschwindet. Gehäuse para- od. prosoplectenehymatiseh. Sporen verschieden, hyalin bis schwarz. Paraphysen ein Epithecium bildend. Flechtenparasiten od. Saprophyten.

\section{Bestimmungstabelle der Gattungen.}

A. Fk. in frisehem Zustande weich gallertig, trocken hornartig.

a) Fk. frisch im Innern tropfbar gallertig, sehr groß, auf dem Boden.

1. Sareosomal.

b) Fk. frisch im Innern gallertig, kleiner. auf IIolz.

B. Fk. im frisehen Kustande nieht gallertig, 2. Bulgaria. sundern leder- od. hornartig od. wachsartig.

a) lik. zu mehreren einem Stroma aufsitzend, hervorbrechend.

1. Sporen zu $8 \mathrm{im}$ schlauch nicht sprossend.

3. Dermatca. 
11. speren in sinlalueh sprossend. daler der selnbueh dieht mit kleinen siporen roffïlt

b) Fk. keinem stlonla autsitzent, einge-

4. Tympanis. senkt, dann lervorherelumel, meist einzelu.

1. Parasiten anf Fleeleten.

1. speren rinzellig.

2. sporen zweizellig.

3. Sporen quer vien bis sireliszellig

11 Nicht auf Flechten, anf llolz $u$. Rimble.

1. Siporen einzellig.

a) Fk. cinzeln stelend, bis (1., mm hr., mit unvollkom menem fiehäuse an der seite s. Agyrium。

b) Fk. bïschelig herrorbrechend, ïber I nm br., nut vollkommenem Gehäuse.

2. sporesu zweizellic.

r) siporen hvalin.

p) siporen brauls.

5. Pluacopsis.

(j. conida.

i. Colidiun.

3. sporen fädig viclzeligg.

\section{Cenangium.}

10. Crumenula.

11. Pseadotryblidium.

1‥ Fodronia.

\section{Gattung: Sareosumal Caspary.}

Fk. kuglig his zylindriseh banchig, frisch innen tropthar gallertig. Scheibe rundlich sicls öfuend, flach sehïsself., dick brandet. matt sehwärzlich. sporen ellipsoidisch.

Von Nuli- his liartoffelgrible zwisehen Jlos u. Nol, seltru. s. grobesmm (schunidel)

\section{Ciattung: Bulgaria Fries.}

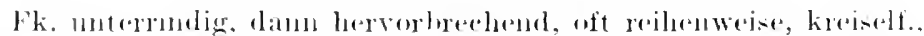

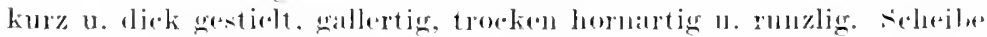

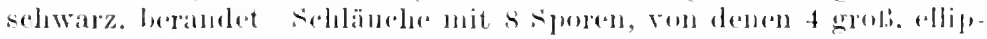

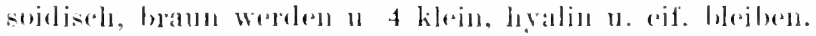

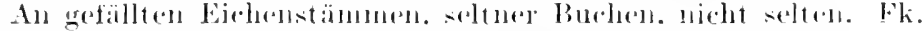

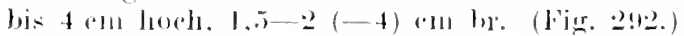

B. polycuraplia (forler)

\section{Ciatlunge Mormatea Fires.}

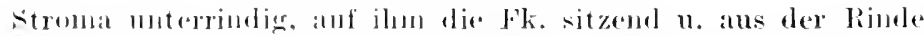

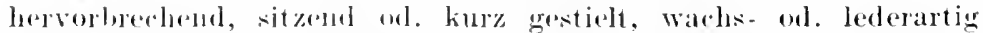

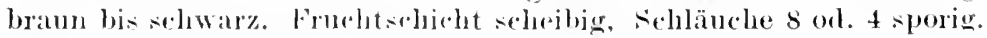
Sporen zuerse rinzellig, damn quer 4-li zellig. hyalin od. bräunlich. Paraphysen ein Ephitheriun bildend. Schlanehperns J T. 
1. Sporen einzellig, selten später zweizellig.

sporen zwei u. mehrzellig.

3.

2. Stroma gelblichgrün. Fk. grüngelb bestäubt, trocken bräunlichschwarz, 2-4 $\mathrm{mm}$ br. Scheibe gelbrötlich bis bräunlich. Sporen $15-18 \times 3-5 \mu$. An dürren Asten von Prunus avium, nicht selten. (Fig. 293.) D. cerasi (Pers.)

Stroma undeutlich. Fk. gehäuft durchbrechend, rostbraun bestäubt, dann schwarzpurpurn, $0,5-1,5 \mathrm{~mm}$ br. Scheibe schwärzlich, dick berandet Sporen $10-14 \times 3-4 \mu$. An dürren Ästen von surbus aucuparia, zerstrent.

D. ariae (Pers.)

3. Fk. außen gelb od. gelbbräunlich, nicht schwarzbraun, kurz gestielt. Scheibe hell.

Fk. außen olivenbraun od. sehwärzlich, seheibe braunschwarz. 5 .

4. Stroma ockergelb. Fk. gelb, trocken dick weif bestäubt, bis $1 \mathrm{~mm}$ br. Scheibe blafgelb. Sporen bis 4 zellig. $18-20 \times 10-12 \mu$. An dürren Stämmehen von Fagus u. Carpinus, besonders in Gebirge.

D. (arpinea (Pers.)

Stroma gelblich. Fk. außen gelbbräunlich, trocken weif bestäubt, $0,5-2 \mathrm{~mm}$ br. Scheibe zimmetbraun. Sporen zuletzt 4 zellig, $20-27 \times 5-7$ \%. An dürren, berindeten Eichenästen. nicht häufig.

D. cinnamomea (Pers.)

5. Stroma dünn, gelblich. Fk, meist in Längslinien durchbrechend, kurz gestielt, oliven braun, weißlich bestäubt. kurz gestielt. Scheibe schwärzlichbraun. Sporen zuletzt meist 4 zellig, $15-20 \times 6-8 \%$. An dürren berindeten Ästen von Rhamnus trangula, zerstreut. (Fig. 294.) D. frangulae (Pers.)

Stroma braun od. sehwarzgrün. Fk. büschelig hervorbreehend, gestielt, schwärzlich, bram bestäubt, $1-211 \mathrm{~m}$ br., $1 \mathrm{~mm}$ hoch. Scheibe braunschwarz. Sporen zuletzt zweizellig, $12-15 x+$ bis $4,5 \mu$. An dürren Ästen von Zwetschen, Aprikosen, Schlehen zerstreut.

D. prunastri (P'ers.)

\section{Gattung: Tympanis Tode.}

Stroma unterrindig, wenig entwickelt. Fk. einzeln od. gehäuft hervorbrechend, meist kurz 11 . dick gestielt, schwarz, homartig. Scheibe rundlich, schüsself. Schläuche zuerst 8 sporig, später mit winzigen, zahllosen Sporen erfüllt, J-. Paraphysen ein Epitheeium bildend.

Auf dürren berindeten Ästen von Coniferen bis ins Hochgebirge, zerstreut. Scheibe schwarz, bis $1 \mathrm{~mm}$ br. (Fig. 295.)

\section{T. pinastri Tul.}

Auf dürren Weidenästen, bis in die Alpen, zerstreut. Fk. trocken weils bestäubt, schwarz, bis $1,5 \mathrm{~mm}$ br.

T. saligna Tode

Auf dürren, berindeten Ästen von Alnus incana u. viridis bis in die Alpen, zerstreut. Fk. schwarz, seltner weils bestäubt, bis $0,5 \mathrm{~mm}$ br.

T. alnea (Pers.)

Auf dürren berindeten Ästen ron Crataegus, Prunus donestica, 
Pirus malus, sorbus, alture Populus tremula u. Sambucus, zerstreut. Fk. schwarz, dick mehlig bestäubt, bis $1 \mathrm{~mm}$ br. scheibe trocken graublaul.

T. comspersa (Fr.)

Auf dïrren istchen von fraxinus excelsior u. ormus, selten. kk. schwarz, glänzend. 1 mu br.

T. Fraxini (schu.)

5. Crattung: Pluaropsin Tul.

Fk, "ingesenkt, gehïutt hervorbrechent, schwarz, wachsartigr. Scheibe unberandet, zuletzt gewölbt. Sporen länglich, einzellig, hyalin. ][äufig flieben mednrere Fk. zu sehwarzen Polstern zi sanmen. Auf dem Tli. von Chlorea vulpina in den Alpen, niclit selten. (Fig. 296.)

P. vulpina Tul.

\section{Gattung: Conida Massal.}

Fk. gehäuft hrrorbrechend. Scheibe flach od. gewölbt, unberaudet sthwarz. sporen keulig od. länglieh, zweizellig, hyalin bis gelblich.

Auf den Apothecien von steinbewohnenden Flechten der Gattungen Lecausora, Placoslinm, Caloplaca murorum usw., bes. im Gebrirge.

C. remens (Tul.)

Auf dem Th. von Pliyscia stellaris u. Xanthoria pariet na, zerstreut.

C. destruens Riehm

7. Crattung: Celidimm Tul.

Fk. gehäuft, + hersorbrechend, schwarz. Scheibe flach, unberaudet. Sporen länglich, abgerundet, 4 zellig, hyalin.

Auf der Seheibe, seltuer dem 'Tlı. von Lobaria pulnonacea, zerstreut. (Fir. 29\%.) C. stictarmm (de Not.)

Auf der scleibe von stembewohnenden Lecanora sordida, coniojs, subfusca, fermer von L. pallida auf Baumiuden, zerstreut.

Auf der scheibe von Xanthoria parietina, selten.

$$
\text { C. varians (Dav.) }
$$

C. varium ('Tul.)

Auf den Th. von Baconnece- Irten, selten.

\section{(C. ericetorum (Flot.)}

\section{S. Gattung: Agyrium Fries.}

Fk. gesellig, aber nicht biincluelig, hervorbrechend od. von Anfang an br. aufsitzend, wachs-, trocken hornartig. sohribe hell, rund. lich, unberandet. Schläuche 8 sporig. sjooren ellipsoidisch, hyalin, einzellig. Paraphysen eine Art Epitheeinm bildend. Schläuche $J+$.

Fk. bis 0,5 mm br., rötlichbraun. Sporen $10-15 \times 5-8$ !" Auf entrindeten llolz u. Äston von Rosa, Pinus bis in die Alpen, selten. (Fig. 298.)

A. rufum (Pers.)

Fk. bis 0,5 mmn br., grau - bis gelblichweil. Sporen 4,5-6 61,5 bis 2,5 ". Auf entrindetem I'inusholz im Gebirge, sehr zerstreut. 


\section{Gattung: Cenangium Fries.}

Fk. einzeh od. gehäuft, hervorbrechend, ungestielt, leder-od, wachsartig, braun bis schwärzlich. Scheibe sich rundlich öffnend. krug-, dann schüsself., berandet. oft eingerissen. Schläuche 8 sporig. Sporen zylindrisch bis spindelf., oft etwas gebogen, lyyalin, einzellig. Paraphysen ein Epithecium bildend.

1. Auf Coniferen.

Nicht auf Coniferen.

2. Fk. büschelig hervorbrechend, $5-15 \mathrm{~mm}$ br., rotbraun u. dick kleiig bestäubt. Scheibe zimmetbraun. Sporen $6-10 \times 2-2,5 \mu$. An dürren berindeten Ästen ron Alnus viridis n. incana, Corylus, im Gebirge zerstreut.

C. furfuraceum (Roth)

Fk. bïschelig hervorbreehend, $5-20 \mathrm{~mm}$ br., graubräunlich, filzig 1 . mehlig. Scheibe rotbräunlich. Sporen $12-15 \times 3,5-4 \mu$. An faulenden, berindeten Ästen ron Popnlus tremula, nicht hänfig.

C. populneum (Pers.)

3. Fk. büschelig hervorbrechend, krngf., dann sehüsself. u. lappig berandet, dunkelbraun. Scheibe bräunlichgelb, $1,5-3 \mathrm{~mm}$ hr. Sporen $10-12 \times 5-7 !$. An berindeten Asten von Kiefern. lıänfig. (Fig. 299.) (. abietis (Pers.)

Fk. gesellig die Oberhant durchbrechend, braungelb, $1-3 \mathrm{~mm}$ br. Scheibe gelbbrämnlich. Sporen $12-14 \times 3.5-4,5$ ". Auf faulenden Kiefermmarleln, selten.

C. acicola (Fuck.)

\section{Cattung: Crumenula de Notaris.}

Fk. gesellig od. vereinzelt, herrorbrechend, meist kurz gestielt, außen feinhaarig, trocken gefaltet, brannschwarz. Scheibe blaßgrau. Schläuche 8 sporig. Sporen verlängert spindelf., oft etwas gebogen, zweizellig, hyalin. Kéein Epithecium.

Fk. $1-3 \mathrm{~mm}$ hoch. Sporen häufig einzellig, aber mit 2 öltropfen, 18-27 $\times 3-3,5$ ". An der Rinde älterer Kiefernstämme, selten. (Fig. 300.)

c. pinicola (Rebent.)

\section{Gattung: Pseudotryblidium Rehm.}

Fk. hervorbrechend, sitzend od. oft kurz u. dick gestielt, matt schwarz, trocken etwas runzelig. Scheibe kaum berandet. Schläuche 4-8 sporig. Sporen ei- od spindelf., stumpf, 2-4 zellig. hyalin, damn braun Epithecium dick, bramn.

Fk. bis $1 \mathrm{~mm}$ hoch u br. Sporen $15-18 \times 6-8$ ". Auf glatter Rinde von Abies, zerstrent bis ins IIochgebirge. (Fig. 301)

\section{P. Neesii (Flot.)}

\section{Gattung: Godronia Mongeot.}

Fk. meist einzeln, hervorbrechend, meist kelchf., kurz gestielt. Scheibe krugf., scharf berandet. Schlänche 8 sporig. Sporen lädig, quer vielteilig, hyalin. Paraphysen fädig. Schlauchporus $\mathrm{J}+$. 
Fk. einzeln we gesellig. 0,5-1,5 mm br. 11. hoch, brämlieh nehwarz. Soheibe gramweil. An diuren Isteben vou Alums, betula, symphoricarpus usw., zerstrent. (Fig. 302.)

(i. ureeolus (Alb. et schw.)

Fk. einzeln, brannsehwarz, l-l $5 \mathrm{~mm}$ hoeh, $1 \mathrm{~mm}$ hr. s.hejhe brann. An stimmeheu von Calluma vulgaris, selten.

1i. erisue (lir.)

\section{Familie: Patellariacrar.}

Fk. vou dnfang an meist oberflächlich (bej den Parasiten zuer-1 (ingesenkt), leder- od. hornartig, meist dunkel gefälbt, balbkuglig wl. länglich. Scheibe zuerst kuglig gesehlossen, nivht vou eiure llaut berleckt, sich ron der Mitte ans rumllich orl. längliels öffuend. Hypothecinm dmbel gefärlat. Epithecims stets entwickelt.

Bestimmusgetabelle Ier ciattumgen.

A. Nur parasitisch auf Flechten.
a) sporen rinzellig.
1. Nesolectiaia.
h) sporen zwrizellig.
I. Sporen hyalin.
2. Sintulat.
1J. Siporen zuletzt braun.
3. Nhrothallu.

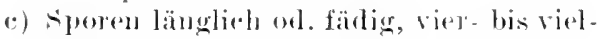 zellig
1. Sporen allipsodisels, meist vierzellig, hyalin, Jann bran.

f. I, promgrapha.

11. Sporen färlig. vielzellig. hyalin, in den sehlänehen in die cinzelnen Zellen zerfallent.

\section{Baretrosprata.}

13. Nicht parasitiscle anf Flecliten, somdern allf $110 \mathrm{lz}$ usw.

a) Siporen ail onl. zwrizellig.

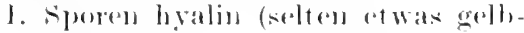
likli).

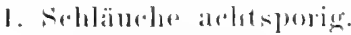

a) Ilypothereinm n. Cohäuse zart, klejuzellice. Sproren rinod. zweizellig.

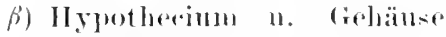
dick. groborllig. siporen nur finzelligr.

6. Iatellea.

2. Selolauche violsporig. sporem kuglig.

II. Sporen hyalin, dann hranu, nur zweizellig.

1. Sichejbe rond.

9. Larsthia. 
2. Scheibe länglieh od. unregelmäßig.

10. Melaspilea.

3. Scheibelinienf., bisweilen sternf.

11. Hysteropatella.

b) sporen melrr als zweizellig.

I. Gehänse u. Iypothecium dünn. Sporen länglich, vier-bisachtzellig. 12. Durella.

II. Gehäuse u. IIypothecium diek.

1. Fk. sitzend.

a) Scheibe stets berandet u. so bleibend.

13. Patellaria.

B) Scheibe zuerst berandet, später gewölbt u. unberandet 14. Pragmopora.

2. Fk. kurz gestielt.

15. Lahmia.

\section{Gattung: Nesolechia Massalongo.}

Fk. hervorbrechend, rundlich, schwarz. Seheibe rund, zart berandet, zuletzt gew ̈̈bt u. Rand verschwindend. Sporen hyalin, einzellig. Fruchtsehieht $\mathrm{J}+$.

Auf der Oberseite des Th. von Cetraria glanea, Parnelia saxatilis, conspersa, caperata, furfuracea bis ins Hoeligebirge. (Fig. 303.)

N. oxyspora ('Tul.)

Auf der Oberseite der Thallusschuppen vom Cladionaarten, zerestreut. No oxysporella (Nyl.)

Anf Candelaria vitellina an Felsen, in den Alpen besonders hä!ıfig.

N. vitellinaria $\left(\mathrm{N}_{\mathrm{r} l} \mathrm{l}\right)$

\section{Gattung: Scutula Tulasne.}

Fk. sitzend, gehäult od. rinzeln, schwarz. Scheibe schüsself., zart berandet. sporen eif. od. länglich spindelf., zweizellig, hyalin. Fruchtschicht $\mathrm{J}+$. Al

Anf dem Thl von Peltigera canina u. rufeseens bis in die

\section{Gattung: Nhrothallus de Notaris.}

Fk. zuletzt hervorbrechend, sehwarz. Seheibe flach, zulctzt unberandet. Sporen ellipsoidiseh, zweizellig, reif bram.

Auf der Oberseite des Th von Parmelia-Arten, cetraria wauca u. islandiea, Sticta, Usuea, zerstreut.

\section{A. parmeliarum (Sommerf.)}

\section{Crattung: Leciographa Massalongo.}

Fk. eingesenkt, dann herrorbrechend, schwarz. Seheibe zuletzt runflich od. seltner länglieh, sehmal berandet. Sporen zuletzt 4 zellig. reif braun. Funchtschicht $\mathrm{J}+$. 
An dem Th. vom Pertusaria. Oehrolecha an Rinden, zerstrent. L. inspersa (Tul.)

Auf dem Th. vout I'hpletis argena an Riunlen, seltuer. (Fig. 304.)

I. Zwackhii Jlan.

5. Crattung: Bactronpora Massalongo.

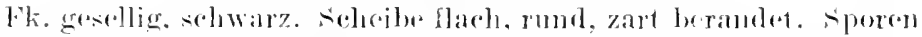
säbchenf., quer in viele Ze-llen im seidanch zertallend, hyolin.

Auf Flechtenth an alten Eiches, nicht hänfig. (Fig. 305.)

B. Iryina $\left.(\Lambda \cdot]_{1}\right)$

\section{f. Gattung: Patellea Fries.}

Fk. oberflïchlich, gehäuft, schwarz häufig. trocken verbogen. Scheibe zuletzi schïswelf., zart berandet. Sporen hyalin, einzelligr. später oft zweizellig. Gehämse selur zart, ans kleinen, schwarzen 7edlen besteliend.

Fk. gehänft anf butroten Flecken, bis $0,+$ mm br. Sporen ejt.

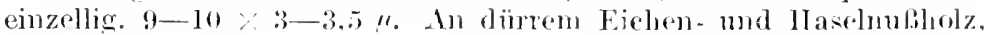
zerstrent.

P. sauguinea (l'ers.)

Fk. anf alugeblaften Fleckent. his 0,4 mm hr. Sporen ejt. od. kenlig, zuletze zweizellig. 6-9 3-3.;". Ebenda. seltuer. (Fig. 306.)

P. commutata (Furk.)

7. Gattung: Patinella Saceardo.

Fk. gehänft, dingesenkt, damn herrorbrechend, länglich, oft ge-

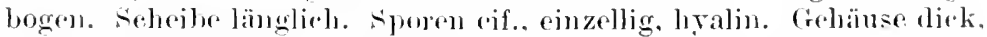
grohzellig, schwarz. Fruchteshieht.

Fk. $0,3-0.6 \mathrm{~mm}$ lg.. bis $0,5 \mathrm{~mm}$ br. An faulenden stümplen ron Jarix 11 . T'inus cembra in Crebinge, zerstrent.

\section{Hexella (Ach.)}

\section{Crattung: Biatorella de Notaris.}

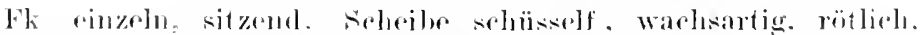

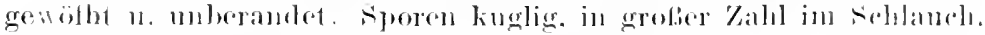

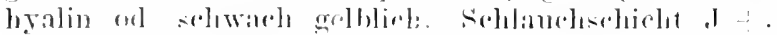

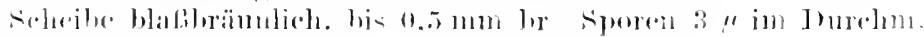

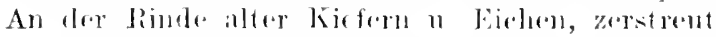

\section{B. piufoola (Mass)}

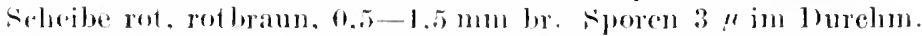
Auf frischem llarz von Pinus u l'icea, hesomlers in Gehirge hänfig. (lig. 307.)

B. resinae (Fr.

scheibe haunsehwarz. liv $0,4 \mathrm{~mm}$ br. Sporen 5-7 " im Durehm. Auf feuchtem Lahmbolem. keltem.

B. geophinua ( Nyll.)

9. Galtumg: Karselhia Körber.

Fk. oberflïchlich, sehwarz, trocken fest. Scheibe sehïsself., zuletzt gewölbt u. muberandet. Selblänehe s sporig. Sporen länglich 
keulig, zweizellig, hyalin, dann brann. Epithecium braun. Fruchtschicht $\mathbf{J}+$. - Von den deutschen Arten sind die meisten sehr selten, die Flechtenparasiten sind hier überhaupt nicht berücksichtigt.

Scheibe $0,5-1,2 \mathrm{~mm}$ br. Sporen $9-12 \times 4-5$ ". Auf fanlem, entrindetem Holz von Eichen, selten. (Fig. 308.) K. lignyota (Fries)

10. Gattung: Melaspilea Nylander.

Fk. oberfläehlich sitzend, selten zuerst etwas eingesenkt, schwarz, fest. Scheibe rundlich, oft länglich od. etwas unregelmäßig, flach, zuletzt kaum berandet. Schänche 8 sporig. Sporen keulig, 2 zellig, lange hyalin, dam bräunlich. Epithecium gefärbt, grïnlich od. bräunlich. Gehäuse zum Untersehied von vor. Gatt. viel weicher u. zarter.

Scheibe 0,5-3 $\mathrm{mm}$ br., schwarz. Sporen $15-18 \times 6-7 "$. An morscher Rinde roi Eichen u. Ulmen, selten.

\section{II. arthonioides (Fée)}

Scheibe $0,2-0,5 \mathrm{~mm}$ br., schwarz, trocken runzlig. Sporen 15-27 $\times 8-9 \mu$. Auf Rinde von Quercus, Tilia, Jnniperus, Larix, Pims pumilio u. cembra, besonders im Gebirge. (Fig. 309.)

I. proximella Nyl.

\section{Gattung: Hysteropatella Rehm.}

Fk. eingesenkt, dann hervortretend, linienf., oft verbogen $и$. sternf., später mehr elliptisch. Scheibe länglich, schwarz, Schlänche 8 sporigg. Sporen länglich bis kenlig, 4 zellig, hyalin, dann brämnlich. Epithecium brann. Schlauchspitze $\mathrm{J}+$.

Auf der Innenseite von abstehender Rinde ron Apfelbäumen sclten. (Fig. 3I0.)

H. Prosiii (Duby)

12. Gattung: Durella Tulasne.

Fk. meist gesellig anf abgeblaßten Flecken, schwarz, lederighäntig, trocken zusammenfallend. Scheibe flach, zart berandet. Schlänche 8 sporig. Sporen länglich spindelf., 4-8 zellig, hyalin. Epithecium gefärbt. Gehäuse sehr dünn u. Hypothecium fast farblos. Fruchtschicht $\mathrm{J}+$.

Scheibe 0,2-1 mm br., schwarz, etwas gerunzelt. Sporen 4 bis 6 zellig, 18-21 $\times 4-5 \mu$. Auf faulenden Ästen, bes. von Eichen, selten.

D. compressa (Pers.)

Scheibe $0,2-0,5 \mathrm{~mm}$ br., granrötlich od. bräunlich. Sporen 4 bis 8 zellig, 24-35 $\times 5-6 \%$. An Ästen von Eichen, Buchen, Brombeeren usw., selten. (Fig. 3Il.) D. connivens (Fr.)

\section{Gattung: Patcllaria Fries.}

Fk. oberflächlich, gesellig. schwarz, hornartig. Scheibe rumllich, flach, berandet. Schläuche 8 sporig. Sporen spindelf., meist et was keulig, 4 bis mehrzellig, hyalin. Epithecium brann. Gehänse diek, nicht zusammenfallend. 
Scleeibe 0,2-0,5 mu br., brannsehwarz, sporen 4 zellig, lis bis

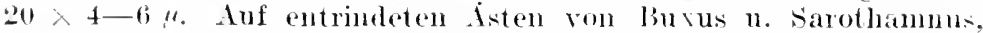
relten.

P. prosima Berk. et Br.

Scheibe $0,5-1,5$ mun br., schwarz, grün bestäubt, Spore!n \& 1 . mehrzellig, $30-45 \times 8-10 \%$. An trockenfaulem llolz von Lb., anch an holzigen stengeh, verbreitet, aher lejwht mit Flechtenapothecien zu verwediseln. (Fig. 312.)

P. atrata (11edw.)

14. Gattung: Prammopora Massalongo.

Fk. zerstreut. sitzend. Seheibe llach, zart herandet, später wp. wölbt u. unberandet, scliwarz, trocken hart u. ruszlig. Schlüuche 8 sporig. Sporen, spindelf. 2-8 zellig. hyalin, gratle. Epithecium grüuliehbrann. Gehäuse dick, posoplectenchymatisclı.

Sclieibe $02-1) .5 \mathrm{~mm}$ br. Sporen $15-20 \times 3-4 \mu$. An der Rinde von Kiefern u. antleren Vid. nicht selten. (Fig. 113.)

\section{P. ampluibola Massal.}

\section{Gattung: Lahmia Körber.}

Fk. znerst sitzend, dam kurz u. diek gesticlt, kreiself. Scheibe krug- bis schüsself., zart berandet, schwarz fest. Sclläuche \& sperin. sporen stäbchent. gewmeleu, 4-8 zellig, hyalin. Epithecium bräunlieh. Gehäuse paraplectenchymatiseh.

Fk. "1-0.4 hoch n. br. Sporen bei der Reife 30-45 $\times 4-5 "$ " In Rindentissen ron Populus alba u. tremula. Salıx, zerstremt. (Fig. 314.)

L. Kunzei (Flot.)

\section{Familie: Mollisiatenar.}

Fk. ron Anfang an frej dems bstrat anfsitzend od erst eingesenkt. damn bervorbrechend. stets br. 11. ungestrilt antsitzend, waldsartige weich od. gallertig. Gehänse an Grumde ans melur rumblichems. moist dunklen Zellen besteliend nath dem Ramele zu prosoplectenchymatirels

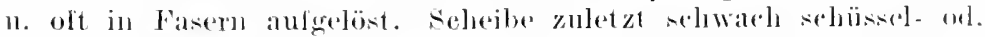

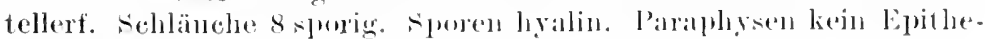
cium bildend.

$$
\text { Bestimnungstabelle der (iat1 nugent }
$$

A. Fk. gallertig knorpelig gell, ot. rot, trocken loornartig.

a) Sporen einzellig.

b) Suroren zuletzt quer melnzellig.

1. Orbilia.

¿. Calloria.

B. Fk, "achsartig, weich, bisweilen auchsehr diinn u. fast bäutig.

a) Fk, zuerst eingesenkt, dann hervorbrechend.

1. Fiporen einzellig. 
1. Fk, außen kahl.

a) Fk. wenig herrortretend, hell gefärbt.

$\beta)$ Fk.weit hervortretend, dmnkel gefärbt.

2. Fk. außen n. am Randeborstig.

II. Sporen quer mehrzellig.

1. Fk. hell gefärbt, wenig hervortretend.

2. Fk. dunkel gefärbt, weit hervortretend.

3. Peendopeziza.

4. Pyrenopeziza.

5. Pirottaca.

6. Fabraea.

†. Beloniella.

b) Fk. ron Anfang an frei anfsitzend.

I. sporen einzellig.

1. Fk. auf einem llyphengewebe sitzend.

2. Fk. nicht auf einem Hyphengewebe.

Il. sporen quer mehrzellig.

1. Sporen zuletzt zweizellig.

2. Siporen verlängert spindelf., 4-

u. melnzellig.

S. Tapesia.

9. Mollisia.

10. Niptera.

11. Belonidiun.

\section{Gattung: Orbiaia Fries.}

Fk einzelu od. herdig, zuerst kuglig geschlossen, dann tellerf. geöfnet, glatt, rot od. gelb, gallertig weich, trocken hornartig, Sporen länglich od. spindelf., einzellig, hyalin. Paraphysen oben \pm kuglig erweitert.

1. Nur auf faulendem Holz.

Auf abgefallenen Kiefermmadeln. Fk. gesellig, bis $0,5 \mathrm{~mm}$ br., bernsteingelb, dann umbrabraun. sporen spindelf., $5 \times 1 \mu$. selten.

o. succinea ( $\mathrm{Fr}$.)

2. Fk. meist gehäuft, oft zusammenfließend, Scheibe bis $0,3 \mathrm{~mm}$ br., rosa od. bernsteingelb, trocken eingerollt u. orangegelb al. rot. Sporen ellipsoidisch, $3-5+2-2,5 \mu$. Auf Lb., bis in die Alpen, nicht selten. (Fig. 315.) O. coceinella (sommerf.)

Fk. zerstrent. Schleife flach, zart berandet, dunkelrot, bis $1 \mathrm{~mm}$ br. Sporen fädig spindelf., $12-17 \times 1,5-2 \mu$. An entrindeten Asten von Eichen, Buchen, Rosen, Pinus cembra, Rhododendron, bis ins llochgebirge, zerstrent.

(o. vinosa (Alb. et schw.)

\section{Cattulng: Calloria Fries.}

Fk. wie bei vor. Gatt. Sporen länglich, spindelf. od. stumpt, 2 selten 4 zellig, hyalin.

Fk. lerdion, zusammenfließend. Scheibe gelb, orauge od. blutrot, trocken dick berandet $u$. verbogen. Sporen $9-14 \times 3,5-4 "$. An lürren Stengeln ron Urtica diojea, häufig. (Fig. 316.)

C. fusarioides (Berk.) 


\section{Crattung: Pseldopeziza Fuckel.}

Fk. kahl, anf verfärbten Blattflecken erst eingesenkt, dann sitzend hervorbrechend. Scheibe hell, zart berandet. Sporen länglich: einzellig. hyalin. Paraphysen oben stets verloreitert.

Fk. meist gesellig anf $1-3 \mathrm{~mm}$ br., braungelben Flecken. Scheibe grangell, bis $0.5 \mathrm{~mm}$ br., Sporen $10-14 \% 5-6 \%$. An lebenden Blättern ron Trifolimmarten, häufig. (Fig. 317.) P. trifolii (Bernh.)

\section{Gattming: Pyrenopeziza Fuekel.}

Fk. meist gesellig, anf geschwärzter Unterlage, braun brs braunschwarz, außen glatt. Seheibe krug- bis schïself., zart it. feinfaserig berantlet, hellfarbig. Sporen länglich od. spindelf., einzellig, hyalin. Paraphysen oben meist verbreitert. - Üher 40 höchst unscheinbare u. seltene Arten, die namentlich in den Alpen rorkommen. Hier können nur wenige, auch in der Ebene häufigere Arten berïcksichtigt werden.

1. An Ranken n. Strugehn.

Auf dürren Blättern von Eryngium campestre, zerstreut. Scheibe grau, dunkel berandet, bis $0,8 \mathrm{~mm}$ br. Sporen $15-18 \times 5-6 "$. ichlauchporus $\mathbf{J}+$. $\quad$ r. eryngii Fuck.

2. Schlanchporus $\mathrm{J}+$.

3.

Sehlanchporus $J$ - Scheibe rosenrot, weiflich berandet $0,5-1,2 \mathrm{~mm}$ br. sporen $8-10 \times 2,5 \%$. An faulenden stengelu von Artemisia absinthium, selten. P. absinthii (Lasch)

3. Anf dïrren Rebenranken, nicht selten bis in die Alpen. Scheibe grau. trocken bramsehwarz, $0,3-1 \mathrm{~mm}$ br. Sporen $7-9 \times 1,5$ bis 2,5 $\mu$ (Fig. 318.) l'. rubi (Fries)

Auf dünren stengeln von Artemisia rulgaris, selten. Scheibe graugelblich, trocken braunschwarz, $0.2-1,2 \mathrm{~mm}$ br. sporen $7-10 \times 1,5-2 \mu$.

P. artemi-ian (Latach)

Auf dïrren stengehn von salvia, Melittis, Ononis, Lotus, Prenanthes, chondrilla, Epilobium usw.. zerstrent. Selueibe gran od. schwach rötlich. trocken brann, 12 . weils berandet, bis $0.4 \mathrm{~mm}$ br. sporen $8-12 \times 1,5-3 \mu$.

P. ،ompromolu Relon

5. Gattung: l'irottaca Saece et speg.

Fk. gesellig, hervorbrechend, sitzend, bramn. Scheibe grau od. blänlich, dunkel berandet, sehiisself., nit Borsten an Rande. Sporen länglieh bis spindelf. anzellig, hyalin. Schlanchporus $J+$.

Scheibe bis $0.2 \mathrm{mnn}$ br. sporen $7-10 \times 1,5-2$ ". An dürren Stengeln von senecio, Aconitum usw, brsonders in den Alpen, selten. (Fig. 31!.)

P. Ealliea sace.

6. Gattung: Fabraea saceardo.

l'k. wie bei Psendopeziza. Sporen länglich, zuletzt 2 (selten 4) zellig. lı̣alin. Schlauchporus $J+$. 
Auf lebenden Blättern von Cerastiumarten, bis in die Alpen, zerstreut. Scheibe weißgelblich, bräunlich berandet, bis $0,5 \mathrm{~mm}$ br. Sporen $7-10 \times 3-3,5 \mu$.

P. cerastiorum (Wall'r.)

Auf der Unterseite lebender Blätter von Ranunculusarten, zerstrent. Scheibe hellgran, dunkler berandet, bis $0,8 \mathrm{~mm}$ br. Sporen ungleich zweiteilig, $12-15 \times 5-6 \mu$.

P. ranunculi (Fries)

Auf der Unterseite lebender Blätter von Astrantiaarten, besonders in den Alpen, zerstreut. Scheibe weifgelblich, bräunlich berandet, bis $0,4 \mathrm{~mm}$ br. Sporen bis 4 zellig, $15-18^{\circ} \times 4-5$ ". (Fig. 320.)

P. astrantiae (Ces.)

\section{Gattung: Beloniella Saceardo.}

Fk. gesellig, hervorbrechend, sitzend, schwarzbraun, kahl. Scheibe zuletzt schüsself., zart u. feinfaserig berandet, grau od. röt. lieh. Sporen \pm verlängert spindelf., reif $2-4$ zellig, hyalin. Paraphysen oben wenig rerbreitert. Schlanchporus $J+$.

Scheibe blaßgrau, meist lünglieh, $0,2-0,5 \mathrm{~mm}$ lg. u. $0,2-0,3 \mathrm{~mm}$ br. Sporen 15-20 $\times 3-4 \mu$. An dürren Grashalmen, z. B. Mrolinia, Calamagrostis in lichten Waldungen, zerstreut.

\section{B. graminis (Desm.)}

Scheibe rundlich, gelbweißlich od rosa, $0,3-0,8 \mathrm{~mm}$ br. Sporen $15-24 \times 2-2,5 "$. An dürren Stengehn vou Gahiumarten, nicht häufig.

B. galii veri (Karst.)

Scheibe grauweiß, $0,3-0,8 \mathrm{~mm}$ br. Sporen $21-27 \times 3-3,4 \%$ 。 An stengeln von Cont urea, Cirsium, Artemisia us., bes. im Gebirge, nicht häufig.

B. brevipila (Rob.)

\section{Gattung: Tapesia Persoon.}

$\mathrm{Fk}$ gesellig, auf einem \pm ausgedehnten, \pm dicken, brau gefärbten Hyphenlager sitzend, glatt, wachsartig, aufen brüunlich. Scheibe flach, hellfarbig, zart berandet od. faserig sporen ellip. soidisch od. spindelf., grade od. sehwaeh gebogen, einzellig. Sehlauchporus $\mathrm{J}+$. Die Unterscheidmng der Arten ist ohne Vergleichsmaterial kaum möglich.

1. Auf Holz u. Rinde.

Auf Grashalmen (z. B. Phragmites), nicht häufig. Scheibe weißlich od. bläulich weißlich, $0,3-2 \mathrm{~mm}$ br. Sporen $8-12 \times 1,5$ bis $2 \mu$.

T. hydrophila (Karst.)

2. Scheibe grau od. gelblieh weif, trocken bräunlichgelb, $0,2-2 \mathrm{~mm}$ br. Sporeu verlängert spindelf., 9-12 $\times 2,5-3 \mu$. Paraphysen oben 2 " br. Anf Ästen von Eichen, Birken, IIainbuchen u. a., zerstrent.

T. lividofusea ( $\mathrm{Fr}$.)

Seheibe grauweiß od. weißgelblich, trocken grau bis bräunlich, 0,3-2 $\mathrm{mm}$ br. Sporen verlängert spindelf. od. zylindriseh, 8 bis $15 \times 2-2,5 \%$. Paraphysen oben bis $4 \mu$ br. Auf faulenden Ästen von Lb. (selten $\mathrm{Nd}$.) bis ins Hochgebirge, zerstreut. (Fig. 321.)

'T. fusca (Pers.) 


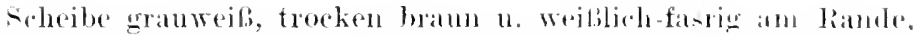
$0.5-1,2$ mm br. Sporen lïnglich stumpf, 7-ll 2-2.., I". An düren Ros'uästen, zerstrent.

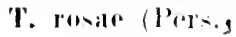

\section{Crattung: Mollisia liues.}

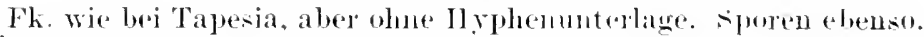

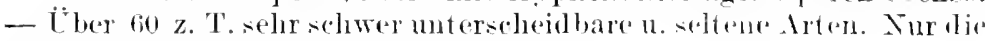
häufigsten kömuen hier genannt werden.

1. Auf Dikotyeledonen.

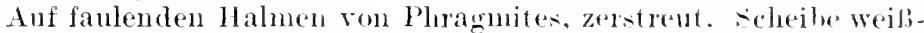
lich od. weiBgelblich, trocktn schwach gollgelb, $1.2-1.2$ mm br. sporen verlängert kenlig hi-schwach spindelf.. \&-10 . 2..5-3 ".

\section{II. alrundillarea (I) ('.)}

2. Auf llolz u. Rinule.

3.

Auf stengehn u. Blättron.

3. Schlauchporus. . †

4.

Schlanchporus of - Seheihe gratuweils. oft rexhogen. troeken braun, rumzlig. $0.3-1.5110 \mathrm{~m}$ hr. Paraphysen oben $2-3$ " br. Auf Lb., besonder's Eiche, Buche, Biskr, Ilasel usw., bis ins Iloch. gebirge, nicht selten.

M. limuiroolal (Pliill.)

4. Scheibe weif-od, bleigrau. zart weils berandet, oft rerbogen, trocken nelu wan bis schwärzlich, nit ringerolltem Rand, 0.2 bis 2 $110 \mathrm{~m} \mathrm{br}$. sporen länglich, stumpf, sehwath gebogon on. meist gerarle, 6-9 $2-3$ ". Paraphysen obell 3-5 "l br. An faulem $110 \mathrm{z}$ u. A.sten vou Lh., besouders an feuchten stellen. häufig bis in die Alpen. (Fig. 322.) M. rincrea (batsch)

scheibe bläulichgrau, blasser beranded. trocken mehr graugelb, $0: 2-4$ mu br. Fporen spindelf.. 12-14 33 ". Paraphysen oben

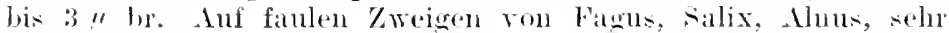
zerstrent.

M. eaceia (Fuck.)

seheibe srau, zart berandet, trocken sraugelblich u. Weilblich

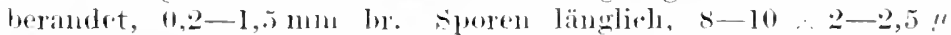

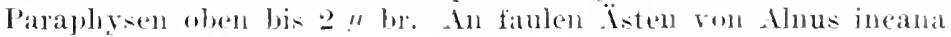
12. glutinusa, nicht selten.

M. home-uada (Tul.)

5. Aul stengelus.

(i.

Auf faulenten Birkenblätern, zexstrut. Scheibe blas weifröllich, zart 11. gekerbt beraurlet, troeken fast sehwärzlich, 0,2 bis 0,4 mm hr. sporen länglich, 4-12 3 ". Parallysen oben bis 3 " hr. (Fig. 323.)

31. Letuliecola (Fuck.)

6. Fk. auf selowäzlichen Flecken sitzend. Scheibe srawweil., zart berandet, trocken schwarzhraun, ejugerollt. $0,2-0,5 \mathrm{~mm}$ hr.

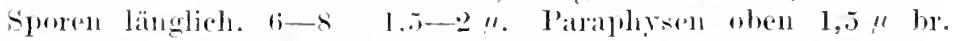
Aul düren Kräuterstengeln. zelstreut. M. atrata (Pers.)

scheibe graubräunlich or. gelblichgrau, dunkler u. etwas ge-

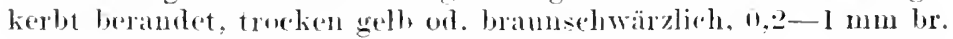


Sporen länglich od. länglich keulig, 6-9 $\times 2-2,5$ ". Paraphysen oben 2 " br. Auf faulen Stengeln von Polygonumarten, zerstreut.

I. polyeoni (Lasch)

\section{Gattung: Niptera Fries.}

Wie Mollisia, aber die Sporen bei der Reife zweizellig. Schlanchpor'us $\mathrm{J}+$

1. Anf Dikotyledonen.

Auf Halmen von Poa, Calamagrostis, bis ins Hochgebirge, selten. Scheibe schwach rötlichbraun, etwas berandet, bis $1 \mathrm{~mm}$ br. sporen spindelf, $10-12 \times 2-2,5 " \quad$ N. poae (Fuck.)

2 An Stengeln

$\therefore$.

Auf faulem $\mathrm{Holz}$ von Betula, Fagus, Quercus, zerstreut. Scheibe weiBlich od. weißgelblich, zart berandet, $0,3-2 \mathrm{~mm}$ br. Sporen fast stäbchenf, stumpf, $10-15 \times 2-3 "$ (Fig. 324.)

x. ramealis Karst.

3. Scheibe blaß grauweiß, blasser berandet, $0,3-1,5 \mathrm{~mm}$ br. Sporen keulig od. länglich spindelf., 12-1 $8 \times 2-2,5$ "!. Am Grunde fauler Stengel ron Cirsimm, Lappa, nicht häufig.

N. carduormm (Rehm)

Scheibe wäBrig gran, heller berandet, $0,2-1,3 \mathrm{~mm}$ br. Sporen länglich, $7-14 \times 2-3 \mu$. An dürren Himbeerranken, selten.

S. dilutella (Fr.)

\section{Gattung: Belonidium Mont, et Dur.}

Fk. wie bei Mollisia, nur die Sporen quer 4 zellig. Die meisten Arten sehr selten.

Scheibe blafgran, bis weifgelblicl, $0.3-1.5 \mathrm{~mm}$ br. sporen zuletzt 4 zellig, $22-25 \times 5-7$ ". An dürren IIalmen von Scirpus lacustris u. Phragmites, selten.

B. lacustre ( $\mathrm{Fr}$.)

\section{Familie: Helotiaceat.}

Fk. oberflächlich von Anfang an, selten hervorbrechend, bisweilen aus einem Sklerotium entstehend, sitzend od. gestielt, bis. weilen auf einer Hyphenunterlage stehend, wachsartig od. häutig, seltner gallertig. Scheibe zuletzt stets krug- od. flach schüsself. Schläuche 8 sporig. Sporen verschieden. Paraphysen fädig, meist oben verbreitert, kein Epithecium bildend. Gehäuse ans dïnnen, hellfarbigen, paraplectenclymatisch verhundenen Zellen besteliend.

$$
\text { Bestimmungstabelle der Gattungen. }
$$

1.Fk. gallertig, knorpelig, trocken hornartig.

a) Sporen einzeliig, kleine Formen.

I. Scheibe an Rand gezackt. Anf Equisetum.

1. Stammaria. 
II. Shejbe glatt. Nicht auf Equise. tum.

b) sporen zuletzt mehrzellig, große l'ilze.

2. Ombrophila

3. Coryne.

B. Fk. wachsartig, flejwhig, dick od. häntig, troken nie loornartig.

a) Fl. fleisehig-wachsartig. friseh zerbrechlich, trocken lederartig u. sich nieht zusammenschliebemol, neist grob.

l. Fk. niclut aus einem Silerotion int-pringend.

1. Fk. aulien filzig behaart.

2. Fk. aufen kahl.

(e) substrat aulfällig grün verlärlot.

B) Substrat nicht grün verfärbt.

\& sporen einzellig.

$\$ \S$ Sporen quer mehrzellig.

1I. Fk. auf einem Sklerutium entspringend.

4. Sarcoseypha.

5. Chlorospleninm.

6. Cihoria.

7. Rutstroemia.

8. Selerotinia.

b) Fk. warhsartig, zähe o. l. hiutig, meist nur klein.

I. Fk. anBen behaart.

1. Fk. auf einem ansgehreiteten IIyphengewebe sitzend.

a) Sporen einzellig.

9. Eriopeziza.

f) Sporen quer mehrzellig.

10. Arnehnopeziza.

2. Fk. ohne ausgebreitetes $11 y$ phengewebe.

(c) Sporen kuglig.

11. Lachnellula.

ק) sporen chlipsoidiseh od.länglich.

\$ Scheibe mit schwarzent

Haaren beset $z$ t.

$\$$ scluejhe an Ramele kahl

ar. wenigstors nicht

orhwarzhorstig.

* Parapliysen an der spitze stmmpf.

$†$ Crehäuse, diün, zart.

sporen meist nur einzellig, seltuer zulet: zweizellig.

th Crehäuse dick, derb.

sporen zuletzt stets zwoizellig.

13. Dasyseypha.

1․ Desmazierella.

14. Lachuella. 
* Paraphysen ander spitze

lanzettlich.

† Sporen nur einzellig. 1.5. Jachmmm.

Hiporen zuletzt, $q u \times r$

Il. Fk. außen kahl.

$$
\text { mehrzellig. 16. Erinella. }
$$

1. Sporeu kuglig.

2. Sporen ellipsoidisel bis spindelf.

17. Pilya.

a) Sporen nur einzellig (nur bei

18 zuletzt oft zweizellig).

$\S$ Scheibe an Rande ge zälnnt.

18. Cyathicula.

$\S \S$ Scheibe am Rande glatt.

$\beta$ ) Sporen zuletzt quer mehr. zellig.

\$ Fk. nur sitzend.

20. Belonium.

$\S \S$ Fk. dentlich gestielt od.

am Grunde wenigstens

stielartig zusammenge-

zogen.

* Gehäuse häutig, dünn. Stiel kurz u. zart.

** Gehäuse dick. Stiel diek

19. Hymenoseypha.

21. Belonioseyphá.

22. Helotium.

3. Sporen fädig.

(i) Fk. gestielt.

(j) Fk. sitzend.

ฉ3. Gorgoniceps.

24. Pocillum.

1. Gattung: Stammaria Fuckel.

Fk. zuerst eingesenkt, meist in Büscheh rorbrechend. Scheibe knug-, daun sehüsself., zackig berandet, orange od. t rot. Sporen länglich, einzellig, hyalin. Schlauehporus $\mathrm{J}+$.

Seheibe bis $1 \mathrm{~mm}$ kr. sporen $15-2 !) \times 5-7 \mu$. An faulenden Halmen ron Equisi tum auf feuchten Stellen, nieht selten. (Fig 325.)

E. enuiseti (Ilotfin.)

\section{Gattung: Ombrophila Fries.}

Fk. einzeh ol. geseilig, ober lächlich, mit dicken, langem Stiel, gallertig, trocken lornartig, auffällig gefärbt. Sporen ellipsoidiseh, einzellig, hyalin.

1. Seheibe violett od. purpuru

Sehube weil lich od. blal, brämnlich.

2. Scheibe purpurn od. blaß violett, $0,4-10 \mathrm{~mm}$ br. Stiel $4-15 \mathrm{~mm}$ lg. Sporen $10-12 \times 3-4 \mu$. Schlauchspitze J - Auf faulem Ilol\%, Ästen, Blättern an sumpfigen Stollen, zexstreut. (Fig. 326.) o. clavus (Alb. et Schw.) 
Sclucibe lila od. blafs violett, 1-2 ntm br.. mugestielt. Sporen

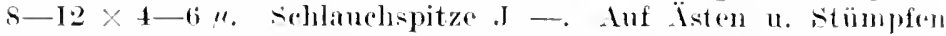
von Eichen n. Kiefe:n, nicht häufig. (O. liacina (Wulf.)

3. Scheibe weiblich od. WeiBgran, $1-41 m$ br. Stiel bis 1 , 5 mm lo.

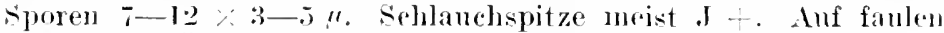
Blättern n. Astehen in teuchten Wählern. nicht häufig.

6. Umbonatal (l'(r's.)

Scheibe blasbräunlich. 2-4 mm br. Stiel $2-4 \mathrm{~mm}$ lg. Siporert $6-9 \times 3,5-4 "$. Sehlanchspitze J - An tanlenden Früchten ron Alnus, selten.

(1. Bateumleri Rehun

\section{:3. Crattung: Coryue 'T'ulasue.}

Fk. gasellig. bïschclig gehäuft. oherflächlieh, zuerst kuglig gø. schlossen, dann rundlich sich offnend, gestielt, gallertig, trocken hornartig. Scheibe krug- bis tief schïsself., sporen spindelf., : his $4 \mathrm{ze}^{2}$ lligr, hyalin. Schlanchporus .J $\div$.

Fh. bis 1,is em horeh, fleisch-al. violettrot wie die sebeibe. Ibaneben stielartige, glejels gefärbte. oft verzweigte Konidienkenleluen. Auf dem llirnselunit von Buchen- u. Eichenstümpfen, an femelnt. liegenden $\ddot{A} s t(n)$ bis ins llochgebirge, ïberall nicht selten. (Figr. 327.)

\section{(. sarcoides (Jacy.)}

\section{Crattung: Sareoncypha F'ries.}

Fk. meist büscluelig zusammenstehnd, gestielt, anben lein zottig. scheibe zuletzt schïssell. sporen ellipsoieliceh od. längliøh, lyalin, slatt.

Fk. meist ainzeln. selumutzig rötlieh weils. Sticl his 3 an lg.. z. T. in der Erole eingesenkt. Selejbe zimnober-ol. scharlatehot, zuletzt wellig onl. eingerissen berandet, 1-5en br. Fporen $311-411$

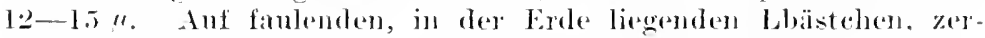
strent. (Fig. 32s.) S. rocoineal (Jacq.)

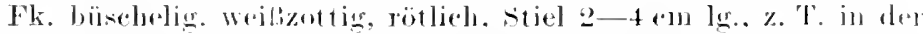

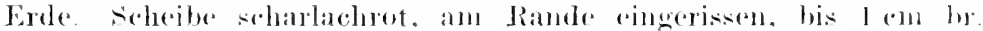

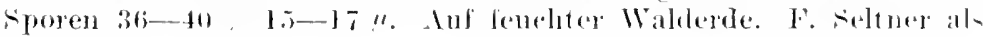
rous.

S. protracta (l'r.

\section{万. Crattungू: ('hlorosplenimu Fries.}

Fk grsellig. wenig gestielt, fast sitzelut, wachsartig, spangriü.

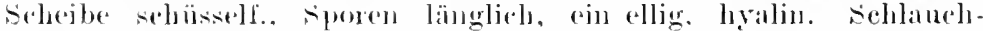
porus $J+$. Auf spangrïu verdïhten llolzflerken sitzend. diese Flecters bïufig, Fk. solten.

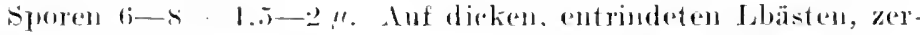
strent.

spored1 10-1t 2,5-3,i," Hbendal. (Fig. 3:20.)

C. acruginosuu (Oed.) 


\section{Gattung: Ciboria Fuckel.}

Fk. neist einzeln, groß, anßen glatt, lg. u. zart gestielt. Scheibe trichter-, später schüsself. Sporen ellipsoidisch, einzellig, hyalin. schlauchporus $J+$ A AuBerlich wie Sclerotinia aber nicht aus einem Sklerotium hervorkommend.

Fk. umbra- bis kastanienbraun, Stiel bis $3 \mathrm{~cm} \mathrm{lg}$. Scheibe etwas 'lunkler, 0,5-1,5 cm br. Sporen 6-7,5 $\times 3-3,5 \%$. Auf faulenden Zapfen ron Abies im Gebirge.

C. rufofusea (Weberb.)

Fk. gesellig, bräumlich, Stiel $1-4 \mathrm{~cm} \mathrm{lg}$. Scheibe blaßbräunlich, $4-10 \mathrm{~mm}$ br. Sporen $8--12 \times 4,5-5,5 \mu$. Auf faulenden Kätzchen vou Alnus u. Salix, sehr zerstrent.

C. amentacea (Balb.)

Fk. blaßbrämlich, Stiel $2-8 \mathrm{~mm}$ lg. Scheibe nmbrabraun, $2-8 \mathrm{~mm}$ br. Sporen $9-10 \times 5-6 \mu$. Iuf faulenden Kätzchen von Populus tremula n. alba, selten.

c. caucus (Rebent.)

\section{Gattung: Rutstroenia Karsten.}

Wie vor. Gattung, Stiel gewöhnlich im Boden eingesenkt. Sporen Iänglich, 2-4 zellig, hyalin. Schlauchporus $\mathrm{J}+$.

Fk. hellbraun, Stiel $3-12 \mathrm{~mm}$ lg., Scheibe kastamienbraun, 2-10 mm br. Auf faulenden. in Boden liegenden J̈stchen u. Früch. ten von Eichen, Birken, Erlen, bis in die Alpen, sehr zerstrent. (Fig. 330.)

R. firma (Pers.)

Fk. oft gesellig, ockergelb, feinfasrig längsstreifig, Stiel $1-5 \mathrm{~mm}$ lg. Scheibe braun, $2-8 \mathrm{~mm}$ br. Sporen $15-18 \times 7-9$ ". Auf in Boden liegenden Ästchen von Fagus u. Carpinus, selten.

\section{R. holaris (Batsch)}

Fk. + olivengrïn, oft schwärzlich streifig, Stiel $1-3 \mathrm{~mm} \mathrm{lg}$. scheibe dunkel olirgrün, $2-7 \mathrm{~mm}$ br. Sporen $14-18$ ‘-7". Auf abgefallenen Ïstelien von Abies. selten.

R. elatina (Alb. et Schw.).

\section{Gattung: Sclerotinia Fuckel.}

Fk. wie Ciboria, stiel meist lg., oft unten dicht haarig, stets aus einem Sklerotium hervorkommend, das durch Umbildung ron Früchten, Stengelı usw. erzeugt wird. Sporen ellipsoidisch bis länglich, einzellig, hyalin, oft 4 gröbere nnd 4 kleinere in Schlauch. Schlauchspitze J +. - Ton mehreren fuchtbewohnenden Arten sind Konidien bekannt, welche im F. die jungen Blätter befallen u. auf kurzen Trägern reihenweise entstehen. Die Sklerotien nachen eine Ruheperiode im Wiuter durch u. keinen im F. zu einem orl. mehreren Fk. aus.

1. Früchte von Ericaceen zu sklerotien unbildend. 2. Nicht auf Fricaceen.

2. Iuf Vaccininn vitis idaea, besonders in Gebirge, nicht selten. (Fig. 331.)

s. uriula (Weimm.)

Auf Taccinium oxycoccus, zerstreut.

s. oxycocei IVoron. 
Auf Vacrinimm myrtillus, häufig. (Fig. 33:2.)

Auf Vaccinium uliginosum, zerstreut.

S. hackarum (schroet.)

s. megalospora Worom.

Auf Rhododendronfrïchten, in ten Aipen.

S. rhododendri Finch.

3. Auf Früchten von Rosacen.

Nicht auf Rosareen.

4. Auf Frürhten ron Prunus cerasus, selten. S. cerasi Woron.

Anf Frïchten von Pirus gommunis a. malus, zerstrent.

s. fruetigena schroet.

Anf Frïchten von Prumis padus, selten.

s. padi Woron.

Auf Frijchten ron Sorbus ancuparia, selten.

S. anchpariae Woron.

5. Auf Frïchten.

Nicht auf Früchten, sondern Wurzeln od. Stengeln usw.

6. Auf Eicheln, selten.

s. pseudotuberosa Rehm

Auf Alnu-frïchten, selten.

s. alni Maul

7. Anf Rhizomen von Anemone nemorosa, zorstrent.

S. tuberosa (Hedw.)

Auf Wurzelu von Brassica, Raphanus, Beta usw.. nicht selten.

s. Libertiam Furk.

Auf faulenden Weinblättern, hänfig.

S. Fuckeliana (de By.)

Auf kultivierten Kleearten, zerstrent

S. ciborioides (lloffm.)

Auf jumgen Blättern ron ('alanthus nivalis, selten.

s. galanthi r. Keissl.

Auf fanlenden Halmen von Carex stricta, selten.

S. Durienana (Tul.)

\section{Tiattumg: Eriopeziza Saccarto.}

lk. gesellig. anf einem diehten, filzigen Gewebe sitzend, auben filzig, wachsartig. Scheiben shüsself., zant, weißhadrig berandet. sporen länglieh, hyalin, einzellig. Sehlanuhporus J t.

Scheibe $0,15-0,3 \mathrm{~mm}$ br. Wiinlich gran, trocken sohwärzlich,

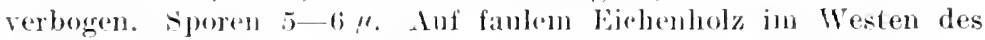
(ieblietes, zerstrent. (Fing. 333.)

E. encisa (Pers.)

\section{Cattung: Arnchnopeziza Fuckel.}

Fk. gesellig, anf zartem, weibem Hyphenfilz sitzend, auBen mit goldgethem Filz, scheite schüself, mit etwas eingebogrenem Rand. sporen länglich, reif $2-4$ zellig. Schlanchporus $\mathrm{J}+$.

Scheibe gelblich, trocken rot. od. gollgelb, $0,3-2,5 \mathrm{~mm}$ br. Sporen $15-20 \times 5-5 \%$. An faulenden Blättern, Ästehen, Frïchten von Quereus u. Fagus, zerstrent. (Fig. 334.) A. aurelia (Pers.) 
311. 312

313. 314

315. 316. 31\%. 318. 319.

W(A

320. (2) $\theta$

(a)

332<smiles>C1=CC2CCCCC2C1</smiles>

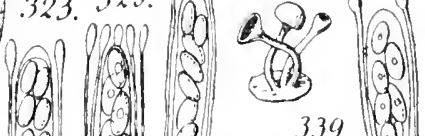

(?)
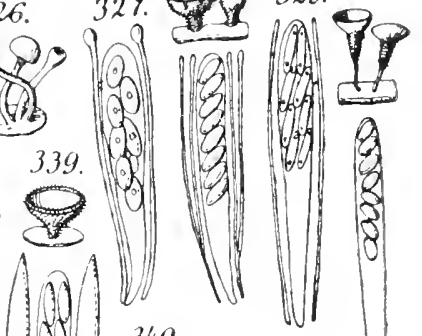

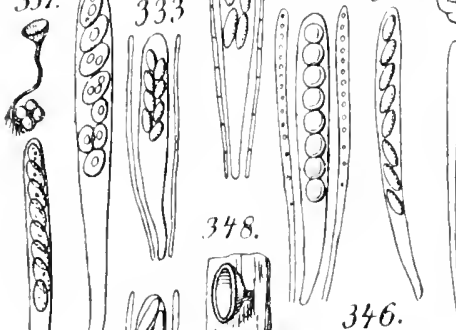

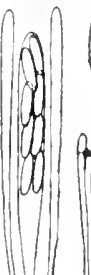

9) $\begin{array}{rr}342 \\ \quad 341.030\end{array}$

(a) 10.335

$(2)$

, 


\section{Gattung: Lachmellula Karsten.}

Ink gesellig, hervorbrechend, sehr kurz gestielt, auben weil.sfilzig. Scheibe orangefarben. sporen kuglig, hyalin. Schlanth. jorus e t

Siliel $1 \mathrm{~mm} \mathrm{lg}$. Scheibe bis $4 \mathrm{~mm}$ br. Fporen $4-6 \mu$ im $\mathrm{burchm}$ An dürren Isten von Larix. Pinns cembla u pmilio in den 11 och. alpen, nicht selten (Fig 335). I. ehrysophthalma (Pers.)

\section{Gittung: Desmazierella Tibert.}

Fk. sitzend, schwarz, mit starren braunen Haten bedeckt. an Crrunde mit zahlreicheren, welligen Haaren. Scheibe gelbbram. lu. u. zerstreut belaart, besonders an Rande. sporen ellipsoidisch. hyalin. Paraphysen oben dunkel gefärbt, weit die scheibe als llatre ïbersagend.

Falueibe bis 5 mm br. Sporen $18-20 \times 9-10 \%$. An faulendem Kiefermudeln, seltem.

b. aleirola lil.

\section{Crattung: Dasysegpha Fics.}

Fk. sitzend od, etwas gestiel1, nocist von Anfang an oberfläehtidh.

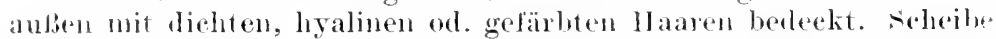
flach, zalt berandet. Sporen ellipsoidiseh, stumpt od. spitz, lyalin. meist einzellig, selien zuletzt zweizellig. sohbarhporns .I .

1. Auf Koniferen.

Nicht auf Koniteren.

2. Aulere Ilaare des Fk. hyalin, kurz gestielt.

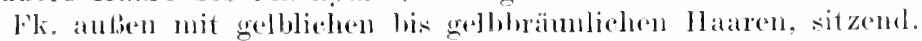

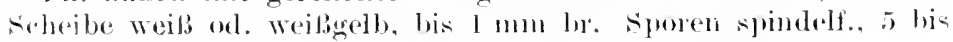
s. I,5-5 ". Auf faulen liefermuldelu, selur zorstrent.

\section{b. pulverulenta (Lib.)}

3. Fk. meist einzeln, hervorbrechend, woibfilzig, stiel bis l mm In.

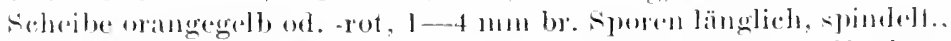

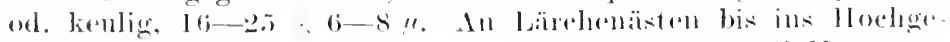
birge, läufigh. (ligg. 3360.)

1). Williommiii Hart.

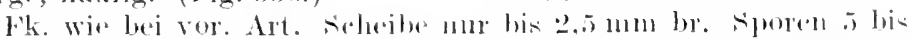

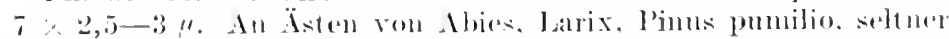
als rol.

1). (alleilormis (Willd.)

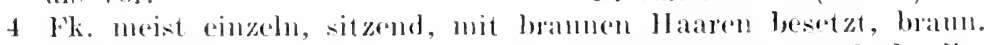

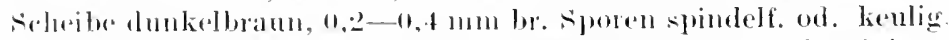

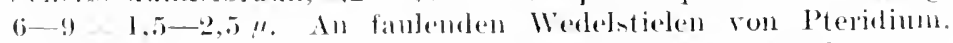
zerstreut. I) pleridis (Alb.et sehw.)

Fk. grä̈utt auf greschwä\%tril Flecken, selur kurz gestielt, gedbod. dumkelbratu, braungell, behalart. Scheibe gelb, 1 -2 111 br. sporell $5-6 \times 2,5-3 \%$. Auf faulenden llol\% von Eichen, Buchen, Filen, Pajpeln, usw. his ins lloelggebirg. zerstrent.

I). rerina (Pers.) 
14. Gattung: Lachnella Fries.

Fk. sitzend, außen gefärbt, behart, Gehäuse dick. Scheibe flach, zart berandet. Sporen spindelf., spitz od stumpflich, hyailin, zuletzt stets zweizellig Äuberlich sonst wie Dasyseypha. Schlauchjorus $\mathrm{J}+$.

Fk. meist gesellig, hell- bis dunkelrot, zottig von bräunlichen Haaren. Scheibe hell- bis braunrot, $0,7-2,5 \mathrm{mmbr}$. Sporen 14 bis $16 \times 2,5-3,5 \mu$. An entrindeten Ästen von Ligustrum. Fraxinus, (arpinus, selten. (Fig. 337.) L. flammea (Alb. et Schw.)

Fk. gesellig, außen weißlich od. gelblichrötlich, filzig braunhaarig. Selheibe rötlich od. gelbbräunlich, bis $0,7 \mathrm{~mm}$ br. Sporen 15 bis $18 \times 3,5-4 \%$. An Pinde ron Populus, zerstrent. (Fig. 338.)

L. cortiralis (Pers.)

Fk. gesellig, bräunlich, rostbram filzig. Scheibe blaß, $1-1,5 \mathrm{~mm}$ br. sporen verlängert-keulig, 9-12 $\times 2,5$ " An dïrren Ästen von Lonicera-Arten, seltener Clematis n. Cynanchum, besonders im Mittelgebirge, zerstreut

L. harbata (Kze.)

\section{Gattung: Lachumm Retz.}

Fk. änßerlich wie bei Dasyseypha. Sporen einzellig, hyalin, selten zuletzt zweizellig. Paraphysen die schläuche überragend, lanzettf. zugespitzt. Sehlauchporus $\mathrm{J}+$.

1. IIaare des Fk. farblos.

II aare des Fk. gefärbl.

2. Fk. gestielt.

Fk. sitzend, weiblich, zottig. Scheibe weiblich od. gelblich, $0,5-1.5 \mathrm{~mm}$ br. Sporen $9-17 \times 1,5-2 \mu$. Auf faulenden stengehn von Senecio, Adenostylis, Eupatoriun, Sambucus ebulus usw., selten.

L. mollissimum (Lasch)

3. An Ästen u. IIolz (seltner Früchten).

An Blättern u. Stengehn.

4. Fk. herdig, gelbweißlich, dicht weibfilzig, Stiel $0,5 \mathrm{~mm}$ lg. Scheibe gelb od. rötlich, $0,5-2 \mathrm{~mm}$ br., trocken etwas dunkler. sporen $6-10 \times 1,5-2 \%$. An dürren Eichenïsten, seltner an Buchen 1 . Crataegus, sowie deren Fruchthüllen, zerstrent. (Fig. 339.)

L. bicolor (Bull.)

Fk. gehäuft, friseh wie 'Tan glänzend, auBen gelblichwcil.' bis goldgelb, mit farblosen glänzenden Haaren, sticl $(1,5-1$ - 11 lg. Scheibe gelblich, bis $1 \mathrm{~mm}$ br. Sporen $6-10,1,5-2,5 ! "$. Auf faulenden, entrindeten Eichenästen, selten.

I. cristallimm (Fuek.)

Fk. einzeln od. gesellig, zart elfenbenweils, farblos flammig, Stiel $0,3-3 \mathrm{~mm}$ ]g. Scheibe etwas gefärbt, seltner gelblich, bis $1 \mathrm{~mm}$ br. Sporen $6-10 \times 1,5-2,5 \mu$. Auf Ästen von Lb. im feuchte.1 Laube, besonders auf Bucheckeru in fenchten Wïltem, häufig.

L. virgineum (Batselt)

5. Anf Blättern. 
Fk. herdig, seluneeweid, angedrückt feinzottig, stiel his 0,5 mm

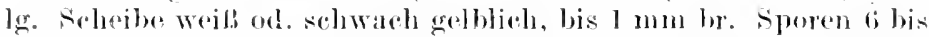
$8 \times 1-1,5 !$. An dïrren Rubusstengeln, von Iontaria bulbilera, Alenostylis in Vorgebirge lis in die Alpen, zerstrent.

L. nivellum (Hedw. f.)

6. Fk. meist einzeln, durchscheinend weiblieh, foin woifoflammig. stiel bis $0.5 \mathrm{~mm}$ lin. Solseibe röllich ofl. gelblielı, bis $0,2 \mathrm{~mm}$ br. speren 4-5 1.5.". Auf baulenden Blättern von Eicluen,

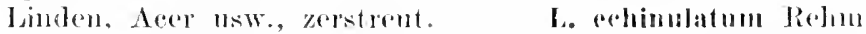

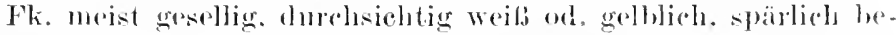
haart, stiel bis 0,5 mm lg. Selueibe gelblich, bis 0,5 mm! br.

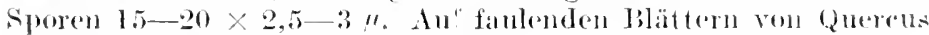
u. Castanca, sehr zerstrent. (Fig. 340.) L. ciliare (seluard.)

7. Fk. sitzend.

Wh irestielt.

8. An kräisterstemgeln.

9.

Fi. ejnzeln od. gesellig, olivenbramn, zottig ven gelben Hadren.

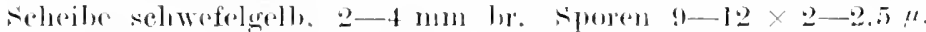

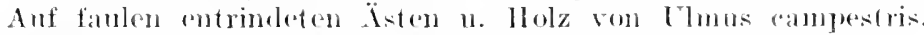
scitin.

I. flavoluligineum (Alb, st selaw.)

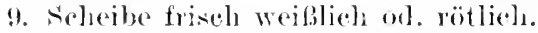

Flk. gesellig, kastanienloram, brammottig. Acheibe blabecolb.

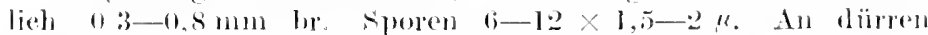

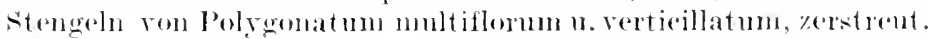

I. nidulus (Sclum. et lize.)

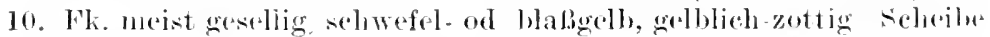

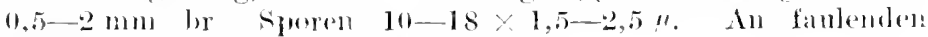
sienceln gröiderer Kränter. zerstrent.

\section{Iencophateum (l'ers.)}

Fk. zerstrent, selewelelgell, troeken brämlinh, mit gedhen od.

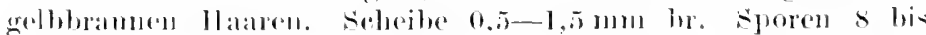

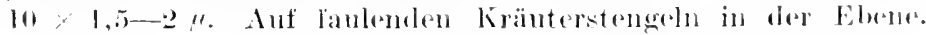

I. sulturemm (Priss.)

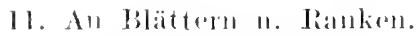
$1:$.

A1! Graslablacm.

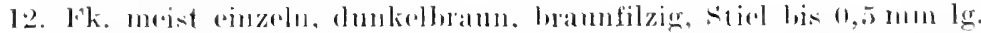

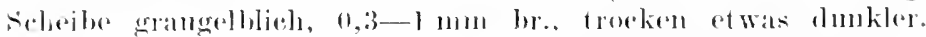

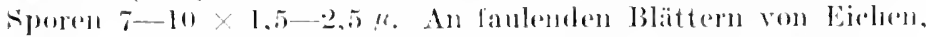
Rot- u. Ilamburlem, nieht häufigr. l. Fuserseens (Jers.)

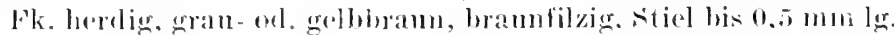

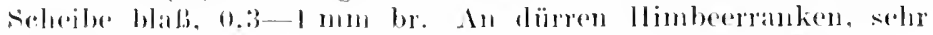
zerstivint.

L. Mandestiumm (J3ull.)

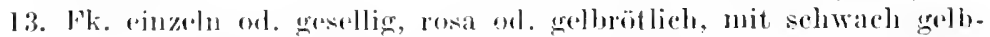
liehen Ilatren, stiel bis $0.3 \mathrm{~mm}$ lg. Scheibe rot od. purpurn, $0,5-1.21111$ hr. Sporen $6-10 \times 1,5-2,5 \mu$. An diisren Halmen voll Phragmites. Ilolens, an sitroh. selur zorstrent.

I. eontroversum (Cooke) 
Fk.einzehn od. gesellig, sehwach gelbbräunlich, kleiig-filzigdureli braume Härchen, Stiel bis $0,5 \mathrm{~mm}$ lg. Scheibe blaf, 0,5-1 mu h. sporen $8-12 \times 1,5-2 "$ Auf faulenden Grashalmen 7. B. secale, Elymus, amch ron Jumcus, sehr zerstrent.

\section{I. patens (Fr.)}

\section{Gattung: Frinclla Saceardo.}

Fk. meist herdig, fast sitzend, aufen behaart. Scheibe schwaph bräunlich od. rosa. Sporen t-s zellig, fädig. hyaliu. Paraphysen lanzettf., die Schlänche überragend.

Fk. weiblich, gelblich od. rötlich, Haare oben hyalin, muten gehlich. Scheibe $0,2-1 \mathrm{~mm}$ br. Sporen 35-45 $\times 1,511$. An dïrren Ilalmen von .Tuncus, zerstrent. (Fig. 341.) E. juncieola (Fuck.)

\section{Gattung: Pitya Fuckel.}

Fk. gesellig, sehr kurz gestielt, flockig-weiflich. sporen knglig, glat, hralin. Paraphysen oben etwas verbreitert.

Fk. Weif, flockig, Stiel oft $0,5-1,5 \mathrm{~mm} \mathrm{lg}$. ol. fast fellend. Seheibe orangerot od. goldgelb, 2 -20 $12 \mathrm{~m}$ br. Sporen 2 " im Durchin. An trockenen Ästehen od $\mathrm{Td}$ von Picea n. Abies im Gebirese, zerstrent. (Fig. 342.)

P. rulgari, Fuck.

\section{Cattung: Cyathicula de Notaris.}

Fk. meist zerstrent, gestielt, glatt. Soheibe zuletzt flach, am Rande mit regemäligen, borsigen Zähnchen. sporen längliph, zulotzt zweigellig, hyalin. Paraphysen fädig. Schlauchporus .J -

Fk. weiBhich bis gelblich, stiel $1-6$ mm lg. Scheibe schwach rosi, $0.5-3 \mathrm{~mm}$ lor. Sporen 1.5-18 3-4,5". An dürren Pllanzensengeln (Lrtica, Clematis, Heraclemm, Lappa, Arenostylis, Cirsimm, Rulbeckia), bis ius IJochgebirge, zerstreut. (Fig. 343.)

\section{l. eorounata (Bull.)}

\section{Cattumg: Hymenostypha Frics.}

Fk. sitzend od. gestielt, glatt orl. flammig behant, Wallsilliw häutig, mit dïmnem Gehänse. Scheibe krug-endli»h srhüsself., an Rande zart feinfaserig. sporen ellipsoidisch, stumpe orl. spitz, en. zellig, hyalin. Paraphysen fäligr, kaum reloreitert. - Die (ialtumw unfalit in ler hier angenommenen Lmgrenzmng äber lon moist seltene Arten de: Gebietes, von denen nur die häufigsten anfqenomnen werden können. Vo 1 dem äuberlich ganz gleidh ansschenden Jelotiun dureh die einzelligen sporen getremt.

l. Fk. sitzend ganz ohne Stiel (Unterg Pezizellal).

Fk. mit Stiel (Unterg. Plitalea).

2 Nicht auf Farmen schlauchporus J +.

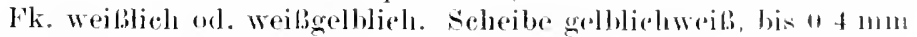
br. sporen $5-9 \times 15-2 "$ " sehlanchporus meist .I-. Inf 


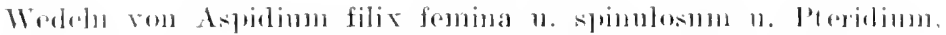
siltill.

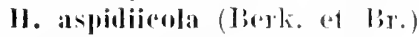

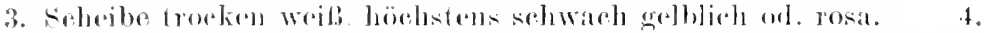

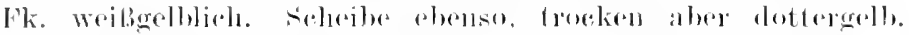

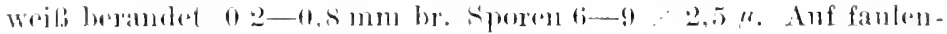

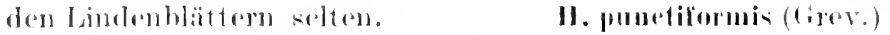

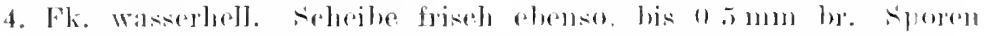

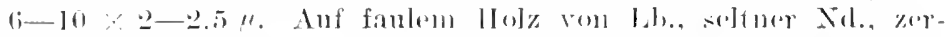
streul. (Fig $34+$ )

II. hyalian (Pers.)

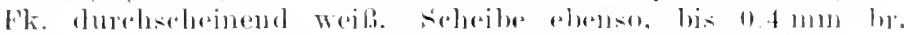

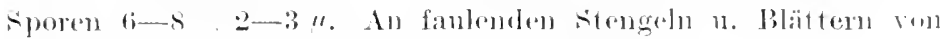
Epilobium angustifolium u. hirsutum, selten.

I. punctoislos (Karst.)

5. Anf Komiforen.

(i.

Ant (rianinexpe.

7.

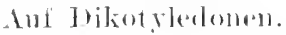

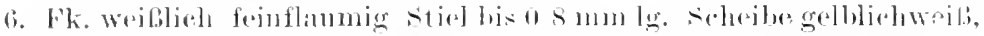

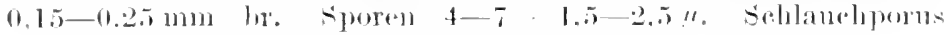

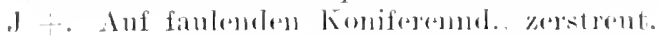

H. a10แ11 ( 111 . ol sehw.)

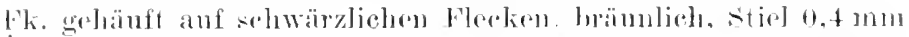

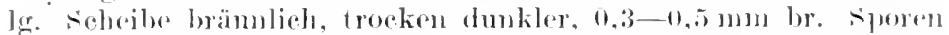

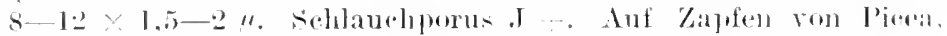

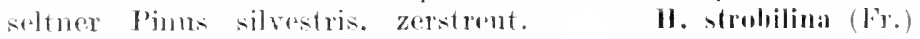

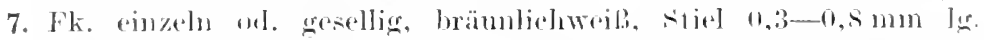
scheibe hramuleh, an Raute zart erestreift w. Weiblich bestïnht,

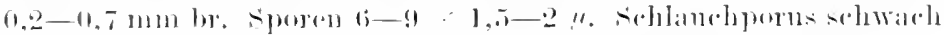

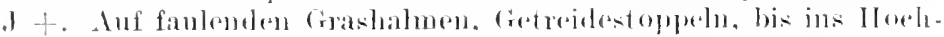
untirige.

11. ('uluiluma (1)esm.)

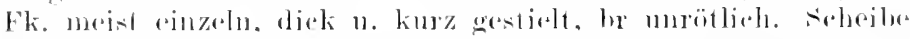

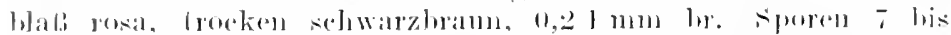

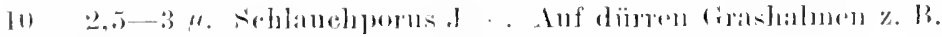

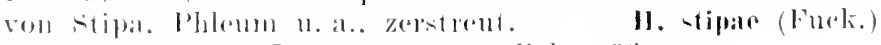

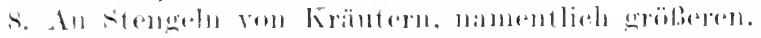

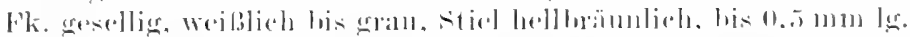

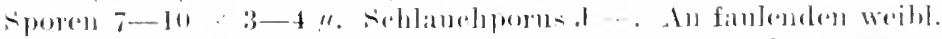

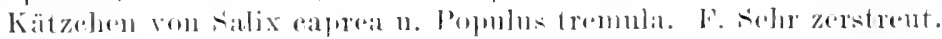

11. amlanti ( $33 a 1 \leq 0+1)$

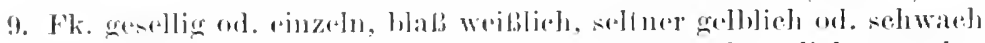

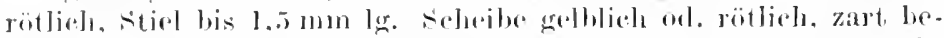

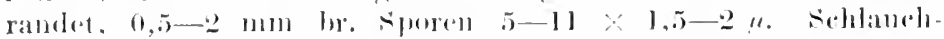

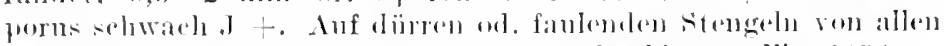

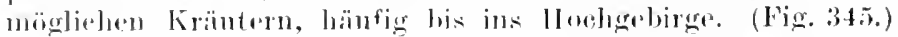

II. cyathoidea (Bull.)

Fk. gesellig, bals weiglich orl, grelblich, oben senkrecht frin dichtstreifig, Stiel hasser, bis $1 \mathrm{~mm}$ lg. Sehejbe gelblich od. Jötlich, $0,3-1,5 \mathrm{~mm}$ br. Sporen $7-9 \times 1,5-2 . "$. Schlauchporus 
kaum J - Auf stengeln ron Urtica, seltner ron Tmbelliteren od. Kompositen, viel seltner als ror. H. urticae (Pers.)

\section{Gattung: Belonium Saceardo.}

Fk. sitzend, glatt, auBen bestänbt od. feinflaumig. Selseibe flach, wachsartig. sporen 4 zellig, lyalin. Schlauchporus $.1+$.

Fk. gesellig, gelbbräunlich od. graugelb. Scheibe weiblich, grau

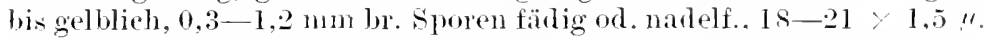
Auf fanlenden Kieferumadeh im Westen des Crebictes.

\section{B. pineti (Batsch)}

\section{Cattung: Belonioseypha Rithn.}

Fk. einzeln od. gesellig. kurz u. dick gestielt, anliten glatt, trocken fein bestäubt. sporen zylindrisch od. keulig. 4 zellig. hralin.

Fk. gelblich ol. rötlichweils, stiel bis 1 mm lo., trocken weisgrïnlich, bestänbt u. nach dem Rand foin längssteeifig. Selopbe blafs bis rötlich. J,s $1.2 \mathrm{~mm}$ br. sporen mit schleimhïlle mmgeben, 21 bis 40 4-5". An dïren aufrechten Grashahmen z. B. Molinia, scale, Festuca, selten. (Fig. 346.) B. rexata (de Not.)

\subsection{Gattung: Holotimu Fries.}

l'k. einzeln od. cesellig, herrorbrechend, seltner rou $\operatorname{lnfang}$ an olerflächlich sitzend, + gestirlt, glatt od. feinflammig, warhsartio, trocken verbogen. Scheibe flach, zart berandet. Sporen ellipsoidisch. stumpl od. spitz, zurist ein-damn zwri-oder seltner vierzellig, hyalin. Paraplysen wenig verbreitert. - Über 30Arten im Gehiet. dir meisten davon selten $u$. lokalisiert.

I. Fk. meist gehänft, kurz gestielt. Scheibe sehr bald flaeh. Aporen länlich, gerade. einzellig, selten später zweizellig. :2.

Fk. cinzeh orl. biinchelig, fast stets lg. u. dick gestielt, Scheibe meist lange krugf., dam flar.h. sporen keulig on. spindelf.. oft gobogen, einzellig, später 2-4 zellig.

2. Fk. gesellig, bisweilen zusammenfliefend, oft unterrindig ent. stellend u. lie Rinde abluebend od. auf nacktem Holz von Anfaug an oberflächlich, weiblich, selur kurz gestielt. scheibe zitronen-orl. berasteingedb, (1.5-3 min br.. trocken meist goldgelb. sporen lïnglich stumpf $5-1+$. 3-4 "solten zweizellig. Schlauchporus kamm J -. Auf faukn Isten n. 11olz ron Jh., besonders Fagns, nicht srolien. (Fig. 347.)

H. ritriumu (Hodw.)

Fk. herdig selor kurz gestielt, weiblich bis gelblich. Acheibe blab- ofl. orangegelb, $0,3-3 \mathrm{~mm}$ bl. sporen $10-15: 2-3: 4$, zuleut zweizellig. Schlauchporus meist. J + . Auf faulemen stengeln gröberer Krinter, Lrica, Eupatorimu, Sambucus ebulus, Erigeron, Salvia, Cynanchun, Dahlia usw., Jis ins Hodngebirge. zelstrent. (Fig. 348)

H. herbarum (Pers.)

3. Auf I-ten ron bämuen (anch Fuchthïllen u. Zapfon)

Auf stengeln u. Ranken von Kräutern. 


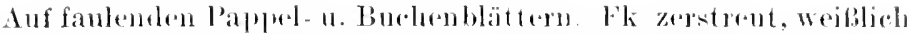
od. gelblieh, stiel his $0.8 \mathrm{~mm}$ lg. Scheibe ebenso geföb:, trocken bis goldgelb, $0,3-1,2$ mm br. sporen krulig od. spindelf, alogestumpet, zuletzt \%weizellig, $10-15 \times 3-3,5 !$. Selfen.

\section{II. phyllophilum (Desm.)}

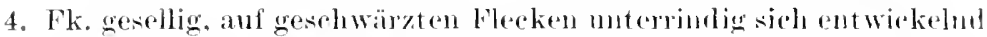
11. dam hervorbeehend gelbheh od. gelbhränulich, sticl l-lo mun

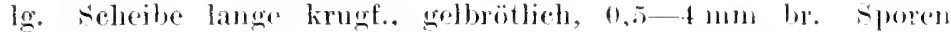
spindelf od. kenlig. 15-20 4-6" (selten etwas länger), zuletzt zweizellig. Schlauchporus schwaeh ot. Au! fanlenden Istrhen von Alnus. Queseus, Fraximus, Salix, Fruehthïllen vou kichen, Buchen, Ilasehiissen, Kiefernzapfen, nicht selten.

\section{H. virwultorum (Tahl)}

Fk. gesellig hervorbrechend, gelbbräunlich, stich $0,5-2,5$ m1n lg. blasser. Scheibe $11.5-5 \mathrm{~mm}$ br., rost-orl. gelbbrimlich. Sporen

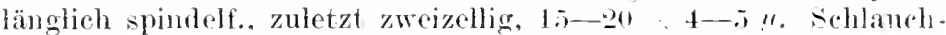

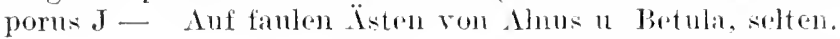

II. -ublenticulare Fries

5. Fk, gesellig, gelblichweib, trocken bräunlich, stiel 0.3 mm lug. seheibe geblichweis, $0,2-1,2 \mathrm{~mm}$ br. sporril spindelf., etwas spitz, zuletzt meist 2 zellig. 15-20 24 !. Suhlonehporus kaum $\mathrm{J}+$. An dïren Ilopfenranken, ziemlieh selten.

II. lommuli (t,asch)

Fk. herelig, meist anf sehwärzliehen lecken, gelblich bis mäun.

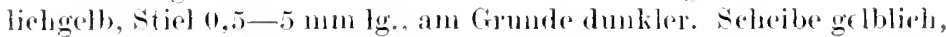
$0.3-3 \mathrm{~mm}$ br. Siporen spindelf. or. keulig. zuletzt z-4 zellig. 18-25 4-i". Achlauehporus sehwarh I Auf balenden

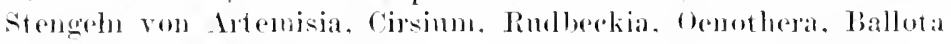
usw, zerstremt. (Fig. 34t.) Il, seulula (I'ers.)

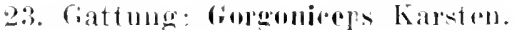

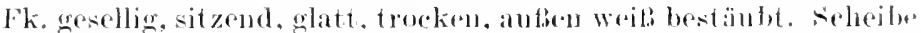
flach. Speren stäbchenf., oft schwate keulig. zuletzt bis lo zellig. hyalin. Selulauelporus .J + .

Fk. weiglich, scheibe $0,2-1), \pi$ mu br., obenso gefäbt. Sporen

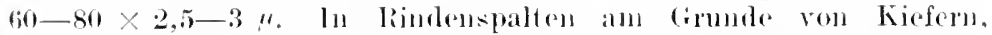
selture an Kapfen, selten. (Fig.3ion.) B. aridula Karst.

\section{Crattung: Ponillum de Vutalis.}

Hk. einzoln, kur\% gestielt, hecherf., glatt, blabbratul. Fiporen fädig, meist riuzellig. Paraphysen uft verbreitert u.braun.

Seheibe flach, blabhram, $0,2-0,7$ mm br. Sporen 120 bis $140 \times 1$ ". Anf der Untersoit" dïrrer Bläter von Eichen, selten. P. Cesatii (Mont.) 


\section{Familie: Iscoholaceate.}

Fk. ron Anfang an oberflächlich, sitzend, fleischig, zuerst geschlossen, dann die flache ofl. etwas gewölbte, zart berandete scheibs enthlöbend. Gehänse oft sehr dünn, kanm ausgebildet, sonst aber mit rem Iypothecium zusammen deutlich zellig. Schläuche bei der Reife sich streckend u. sich einzeh über die scheibe erhebend, meist mit Deckel aufspringent. Sporen einzellig. Fast mu mist bewohnende kleine Pilze.

$$
\text { Bestimmungstabelle der Gattungen. }
$$

A. sporen immer farblos.

a) Schläuche 8 sporig.

1. Ek. behaart.

II. Fk. kahl.

h) Schläuche vielsyorig.

I. Nur ein Sehlauch im Fk.

II. Mehrere Schlänche in Fk.

B. sporen riolett od. bram.

a) sporen kuglig.

b) Sporen deutlich länglich.

1. Lasiobolus.

$\because$ Ascophanus.

3. Talebolus.

4. Rhyparobius.

I. Sporen im schlanch zn einem Rallen verklebt.

6. Saccobolus.

1I. sporen frei unter sich.

7. Ascoboius.

\section{Gattung: Latsiobolus saccarde.}

Fk. auben mi staryen, spitzen, hyahinen od. geblichen Haaren besetzt. Schläuche mit Deckel sich öffnend. Sporen ellipsoidiseh.

Scheibe gelbbrännlich, $0.3-1 \mathrm{~mm}$ br. Fk. außen gelblich od. rötlich bis braungelb. Sporen $28-30<1 \cdot-15 \mu$. Auf llist ron Kühen, Pferden, ferner von schaten, Rehen, Ziegen, Itirschen usw. bis in die Alpen, nicht selten. (Fig. 351.) L. equinus (Müll.)

Scheibe gelbrot, $0,5-2 \mathrm{~mm}$ br. Fk. aufen ebenso. Sporen 24-27 $\times 10-15 \mu$. Auf Afist, faulenden Abfällen von Znckerfabriken. zerstreut.

L. pulcherrimus ( 1 r.)

\section{Gattung: Ascophanus Boudier.}

Fk. kahl, weich, sonst wie ror. Gatt. Die meisten Arten sehr selten $u$. im Gebiet num wenige Male gefunlen. Dir genamnten Arten bläuen durch Jod ihre schlänche.

Scheibe weils od. seltner gelblich, $2-3 \mathrm{~mm}$ br. sporen glat od. mit einzehen Wärzchen besetzt, $32-36 \times 14-16 \%$. Auf Mist von K̈̈hen, Ilirsehen a anderen Pflanzenfressern, zerstreut.

Scheibe gelb- od. brämulichrot, meist feinfasrig berandet, $1-3 \mathrm{~mm}$ 


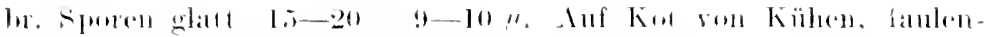

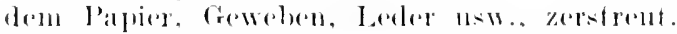

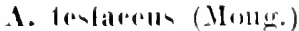

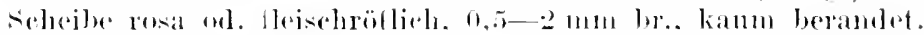
Sporen körnelig rauh, 15-21 9-12u. Aul Mist rou Kïlem.

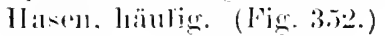

l. armens (l'ers.)

3. Craftura: Trelebolus Tinte.

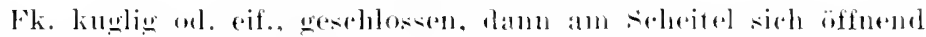

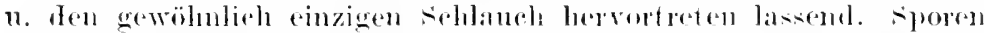

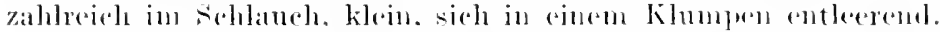

Fk. 0.3-11,4 mm grof. Sporen 5,8-7 3-3.5 1. Anf Kot rom

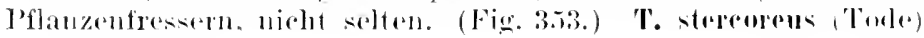

\section{t. Gattung: Rhyparohius Boudier.}

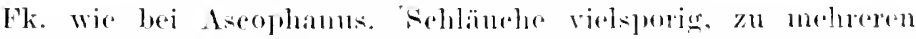

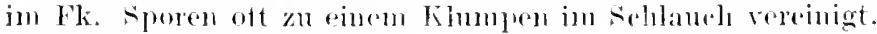

1. Schlinule o -

Fk. schuntzigweil bis grauvioleft selocibe etwas dunkler,

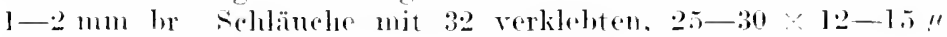

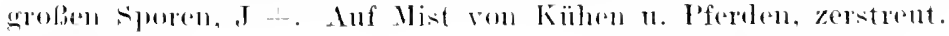
(Fig. 354.)

R. Pellefisri (c'r.)

2. sirheibe nitelit rot.

3.

Fli. u. Scheibe flejsch- od. rosemrot, $0,1-0.2$ mm hr. sehläuche mit selu zallheichen, $6 \times+4$ grofien sporen. Auf Mist ron

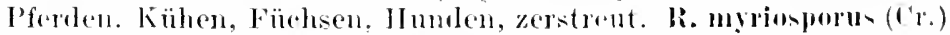
3. Sehläurle mit melur als 10 sporen.

Fk. 11. Sehoibe weif. bis gelblich. $0,3-1$ num br. Sohläuche nit 16 sporen von $10-13 \times 6-8 \mu$. Besondors alt Kuhnist, selfen.

R. sexdecinsporus (Cr.)

4. Fk. 11. Selueibe selumutzigweif bis gelblich. $0.1-0.311 m$ bu.

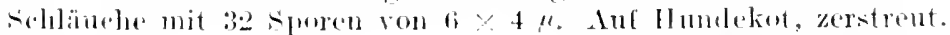

li. animu- (Auersw.)

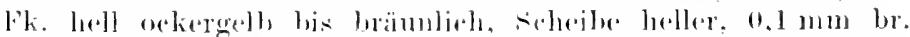

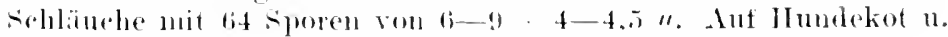

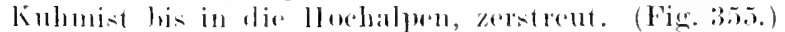

R. (rustaceus (Fuck.)

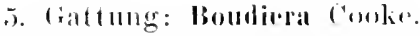

Sicheibe oft zuletzt gewalbt. meist unberandet, sonst wie Asco. bolus. Siporen kuglig, foin punktiert, zuletzt violett.

Fk. u. Scheibe schmutzigbram, $0.5-0.7 \mathrm{~mm}$ ln. Sporen 12 bis 15" im Durehm. Aut altem Itmelr- u. Fuchsliot, stelten.

B3. nineroseopira (Cr.) 
6. Gattung: Saccobolus Boudier.

Fk. wie bei Ascobolus. Sporen ellipsoidisch, glatt, durch Gallerte vereinigt $u$. eineu Klumpen im schlauch bildend, zuletzt violett. Schläuche $J+$.

1. Fk irgendwie gelb.

Fk sehwach riolett, durchscheinend, scheibe $0,5-1,5 \mathrm{~mm}$ br. sporen einseitig etwas abgeflacht, $15-18 \times 6-8 \%$. Anf Mist von Kühen, Kaninchen usw, bis in die Alpen, zerstreut. (Fig. 356.)

s. violascens Boud.

2. Fk. berustein - od. goldgelb, scheibe schwarz punktiert, $0,5-1 \mathrm{~mm}$ br. sporen $20-25 \times 9-12 \mu$. Auf Mist ron Kïhen, Hirschen, Ziegen, schafen usw. bis in die Alpen, zerstrent.

\section{E. Kéverni (Cr.)}

Fk. weingelb, scheibe meist blasser, $0,2-0,5 \mathrm{~mm}$ br. sporen etwas ungleichseitig, violett, zuletzt braun, $12-15 \times 6-8$ ". Auf Mist von Kühen, Schafen, Hasen, selten.

s. depauperatus (Berk. et Br.)

\section{Gattung: Ascobolus Persoon.}

Fk. kuglig ol. birnf., glatt ol. kleiig bestäubt, Feheibe flach, meist deutlich berandet, schwarz punktiert. Schläuche mit Deckel sich öfnend. Sporen ellipsoidisch od. spiudelf., violett, zuletzt bram, glatt, parallel längsstreifig od. warzig, mit Gallerthof, getrennt voneinander.

1. Sporen nicht warzig verdickt

Fk. gesellig, außen kleiig-schuppig, brämnlich. Scheibe grünlich. gelb, 3-6 mu br. Sporen stumpf warzig, $18-22 \times 12-14 "$. Auf Brandstellen im Gebirge, selten.

A. atrofuseus Phill, et Plowr.

2. Fk. auben kleiig bestäubt od. flaumigr.

Fk. dicht gedrängt, außen glatt, geblich od. bräunlich, trocken schwarzbraun, scheibe $0,2-0,5 \mathrm{~mm}$ br. Sporen fein längsstreifig, $21-25 \times 8-12 \mu$. Auf Mist ron Pflanzenfressem, häufig.

A. claber Pers.

3. Fk. gesellig, gelb od, gelbbräunlich od. blaßgrüntich, am Rand u. auben weis kleiig, scheibe $0,5-5 \mathrm{~mm}$ br. Sporen zart längsstreifig, $21-30 \times 11-1 \pm \mu$, mit einseitiger Gallerthüllo. Auf Kot ron Pflanzentressern, nicht selten. (Fig. 357.) A. stercorarius (Bull.)

Fk. meist gesellig, wie eingesenkt scheinend $u$. hervorbrechend, bräunlich, etwas tlaumig. Scheibe grünlich od. gelbgriin, $1-1,5 \mathrm{~mm}$ br. Sporen glatt od. mit wenigen Längsstreifen, $45-70 \times 25-40 " 1$, mit b. eitem Schleimhof. Inf Mist von Kühen, seltuer von anderen Ptlanzenfressern, zerstreut. (Fig. 358.) A. immersus l'ers.

\section{Familie: Przizaceate.}

Fk. oberflächlich (selten in der Erde - eingesenkt), sitzend od. gestielt, auBen kahl od. behaart, fleischig. zuerst geschlossen. dam am 


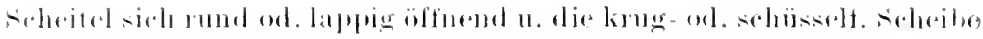

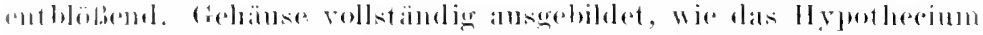

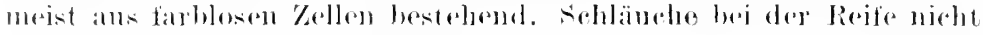

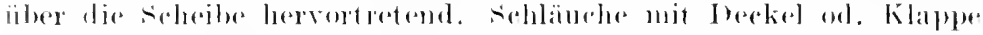

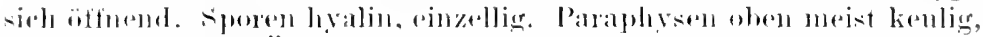

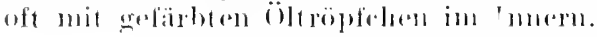

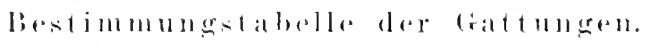

A. sporen linglig.

a) Fk. allien belatart.

I. Ilaare lang, spitz. Fk. Jebhalt gar tijlst.

\section{Sibarespora.}

11. Hatre kurz, tein, Fk, dunkal grefïllit.

2. Peculoplectania.

3. Plirariella.

b) Fli. andien kahl.

B. sporen ollipsoblisth, maist stmmpt, seltner spitz.

a) Flk. anben mit langen, Wolligen orl. starren suitzen IIarren.

I. Haare borstent., lang. Fli, rumelich anfreibend.

4. Lachnea.

II. Ilaare wollig. Fk. lapplig aufreibend, in Boden steckend.

5. Saremplatera.

b) Fkanufen kahl onl. hördstens kleiger od. flanming.

I. Fk. regelmälijg. rundlich antreibend.

1. lk. hej Vetletzung nicht milahelud od. hächstens aine farblose Flïsigkeit abscheidend.

a) sehläucles . I

s lk. gestielt.

s.t. Fitzend.

b) sichläurelse d -

$\$$ sporent grate, solturer hiokkevigr od. Warzign.

* l\%. mil + langem stiol, mindestemsdoutliels stied artigr zusalmmlengezogent. tstitel kurz, diek, mit

lexisten 11. Vertiefun-

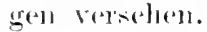

6. Tarzetta.

․ Plicaria.

tritel kurz, diek, glat1.

kk. becher- inl. kelchif. bleibend.

Fk. zuletzt gamz flacle ausgebreitet.

5. Iretabula.

9. (inopyxis.

10. IIseina. 
t+† Stiel lang, dünn. Fk. anben völig suelulig, rauls.

** Fl. ganz nugestielt.

11. Marropudia.

1‥ Humaria.

ș sporen bei der Reife nuit netzf. V'e dickungen.

13. N1יuria.

2. Fk. bei Ve letzung eine gefärbte Flïsigkeit abscheidend. 14. Cialactinia.

Il. Fk. mregelunäbig halbiert ohrf. 1.5. Otillea.

\section{Gattung: Sphaerospora Saccardo.}

Fk. sitzend. sich rundlich öfnend $u$. zuletzt flach ausgebreitet, anlien mit einfachen, spitzen llaren beleckt. sporen knglig. warzig.

Fk. aulsen gelbrötlieh, braumbehart, $3-8$ mm br. seheibo orange- ol. seharlachrot. Sporen I8-20" im Inrchn. Auf tonigen Waldboden, selu zerstrent. (Fig 359.) s.trechispora (Berk. et Br.)

\section{Gattung: Psemuloplectania Fuekel.}

F'k. wir bej vor. Gatt, außen filzig behaart, dunkel gefärbt. sporen glatt kuglig.

Fk. gesellig, braunschwarz. Scheibe glänzend schwarz, 1, $5-3 \mathrm{~cm}$ br. sporen 10-14" in Durchms. Zwischen Nateln u. Moos auf dem Bollen, bis ins Howhebirge, zerstrent. F. (Fig. 360.)

P. nimpella (Pers.)

Fk. einzelı, schwarzbraun, braunfilzig, oft mit stiel. Scheibe granschwarz, 2-5en br. Sporen 10-1+ "im Durchm. An fanlenden stïmpfen vom Abies, selten.

P. Mrelatella (Fr.)

3. Gattung: Plicariella Sacoardo.

Fk, wie bei vor. (katt, anlien kahl n. gratt. Siporen kuglig, glatt od. Warzig.

1. Sehläuche $\mathrm{J}-$.

Schläuche $\mathrm{J}+$. Fk. purpurn. Scheibe schwärzlich-rußbranu, 1-3 vu br. Sporen glatt, 7-9 $\mu$ in Durchm. Auf Brandstellen, selten.

P. fulieinea (Schum.)

2. Siporen glatt.

Fk. einzeln, mennigrot. Scheibe ebenso gefïrbt, weilshch be-

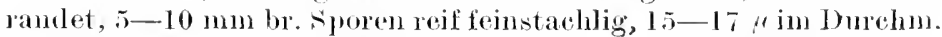
Zwischen Moosen auf Maueru, selten. D. miniata (Cr.)

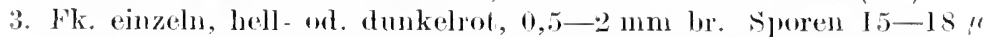
im J)urehm. Au" feuchter, beschatteter Erde, sehr zorstrent.

\section{P. eoustellatio (Besk. et $\mathrm{Br}^{\circ}$ )}

Fk. herdig, warlsugelb, zuletzt griulich ge'leckt. Seheibe meming-

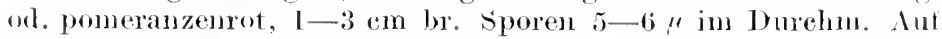
Tammentudeln an Bolen, in Gebirgo, selten.

l'. Pulgentic (Pors.) 


\section{Gatmog: Iabhuea Fries.}

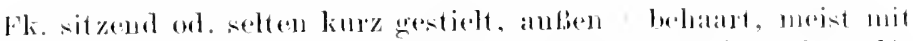

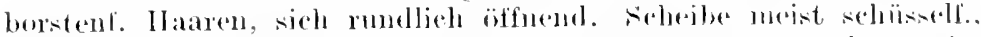

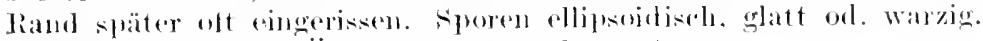

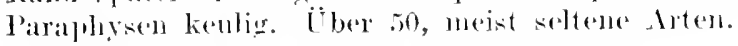

1. Speren glatt.

Fporen warzig onl. raul. Fk. sitzond.

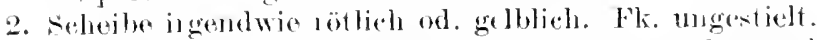

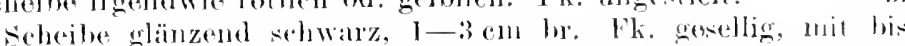

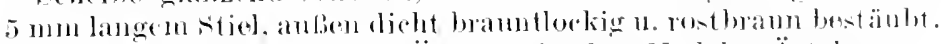

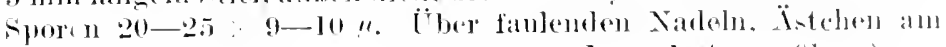
Boden, zerstrout.

I. medantoma (Now.)

3. Aut Brandstellen.

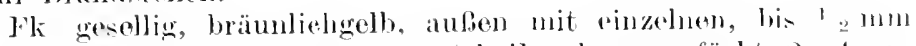

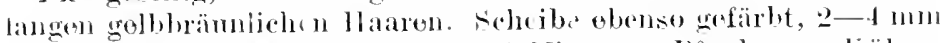

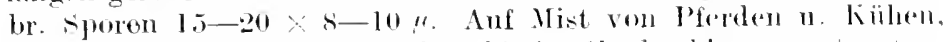
auclo anf mistgetränktem Hoden, bis ins Hochgobirgo, zerstrant

1. stereo. cal (Pers.)

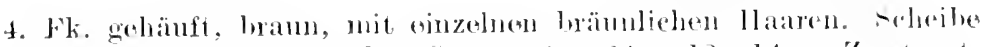

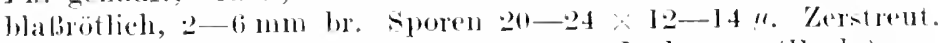

1. brunea (luak.)

Fk. gosellig, bräunlich, an liant mit vinzelnen Ilaaren bestzt. Selotibe schmutzig orangegelb od. brämulehrot, $1-4$ mm hr. Suroren $15-18 \times 7-8, "$. Zerstreut. I. melaloma (Alb. et sellw.)

5. Sichejbe blabgran od. hlats getblich.

seluejbo rot.

ii.

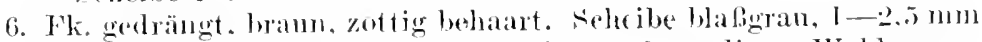
br. Sporen $18-24 \therefore 8-9 "$, rauh. Iuf sandigen Waldwesen, zersictite

I. Eregaria Relum

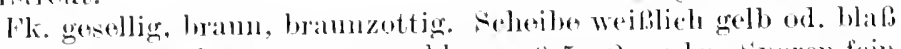

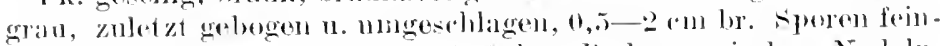

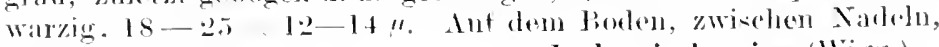

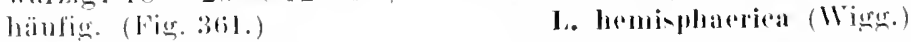

7. Auf dente Eralboden.

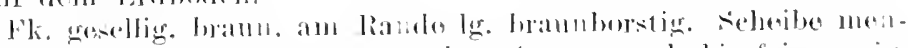

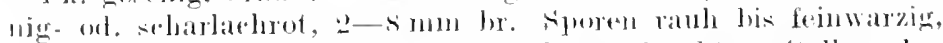

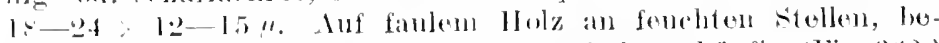
sonders in linwaldshänsern, his in die Ilochalpers. häufig. (Fig. 362.)

l. senteliata (1.)

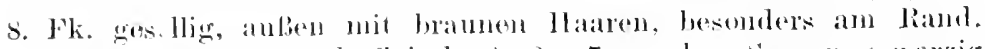

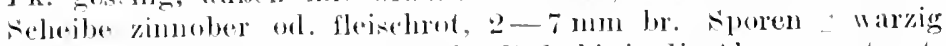
raul, $18-24$. 12-15". Anf der Erele bis in dio Alpon, zorstrent.

l. "Imbrormu (lir.)

Fk. gesellig, götlichblam, foinflammigr. an kande bramberstig.

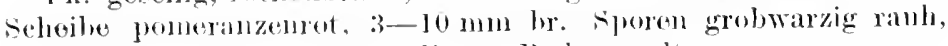
$15-20 \times 4-10 \%$. Luf sandigom Bolen, solten.

L. (hateri (smitlı.) 
5. Crattumg: Sarcosphaera Auerswald.

Fk. dem Erdboden eingesenkt, zuerst geschlossen, damn lappig aufreißeud, außen - lang behaart, zuletzt etwas über den Boden herrortretend, Paraphysen keulig. Schlänche $\mathrm{J}+$.

Fk. schmutzig weiß, braumbehaart, $1-5 \mathrm{~cm}$ br. Scheibe blaß, krugf. Sporen $22-24 \times 12-14 \mu$. Im Sande, selten.

\section{S. sepulta ( lro)}

Fk. weißlich od. rötlich, feinfilzig. $5-10 \mathrm{~cm} \mathrm{br.} \mathrm{u.} 5 \mathrm{~cm}$ hoch. Scheibe hell- od. schmutzigviolett. Sporen $17-20 \times 9-10 \mu$. In Ndwäldern unter Nadeln, im Gobirge, zerstreut (var. macrocalix Riess mit Sporen von $15-18 \times 7-8 \mu$ ). (Fig. 363.)

\section{s. coronaria (Jacz.)}

\section{Gattung: Tarzetta Cooke.}

Fk. außeu glatt, mit langem, dümem, dem Boden oingesenktem Stiel. Scheibe trichterf., wellig od. gekerbt berandet. Schlauchspitze $\mathrm{J}+$.

Fk. 1-2,5 cm br., strohgelb od. gelbbräunlich, Stiel $2-5 \mathrm{~cm} \mathrm{lg.}$ Scheibe gleichfarbig. Sporen 12-15 6 - 8 ". Auf fettem Boden, auch in Gewächshänsern, selten. (Fig. 364.)

\section{T. rapulum (Bull.)}

\section{Gattung: Plicaria Fuckel.}

Fk. meist gesellig, sitzend, glatt, sich rundhich öffnend. Scheibe zuerst krugf., dam zuletzt ganz flach, am Rande eingerissen. Sporen glatt od. warzig. Schläucho $J+$.

1. sporen glatt.

sporen warzig.

2. Auf Erde u. Steinen.

Nicht anf diesen substraten.

3.

4.

3. Fk. blabiolett, am Grunde wejBlich-filzig. Schoibe violett, $0,5-2 \mathrm{~cm}$ br. Sporen $10-12 \times 5-6 \mu$. Auf der Ercke an Brandstellen, selten.

1. violacea (Pers.)

Fk. auken otwas filzig, nit ganz kurzem Stiel, Scheibe hell ockerfarbig, $1-3 \mathrm{~cm}$ br. Sporen $13-18 \times 8-9 "$. An feuchten Mauern и. Blumentöpfen, selten. P. Inuralis (Sow.)

4. Fk auBen mehlig bestäubt, oft faltig an crundo, Scheibe ganz flach an Rande neist nungeschlagen u. lappig eingerisson, bränn lich, sehr zerbrechlich. $2-10 \mathrm{~cm}$ br. Sporen $14-18 \times 8-10 !$. An fanlenden Lb.- u. Nistïnpfen, zerstrout.

P. repanda (Wahlenb.)

Fk. umbrabramu, foinrunzlig. Schoibo gelbbräunlich, $0,4-2 \mathrm{~cm}$ br. Sporen 15-18 ×9-10 ". Auf Mist von Kühen. Ilirschen, Rehen usw., zerstrent.

P. fimeti (lwok.)

5. Fk. kastanienbram, etwas grubig. könig. Seheile umbral raun 


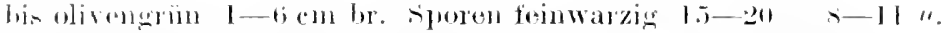
Auf scluatigom sambigem IValdboden u. Wegen zorstrent.

P. badia (J'rrs.)

Fk. crelbbrämlich. weil kloigg hetäubt. scheibe rub- bis zimmetbrans, wellig verbogen u gingerissen, J-5 cm br, sporen

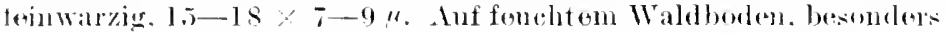
in (rehirge, zerstrent (Fig. 36.i.) P. puntulata (Itelw.)

\section{Crattung: Acetahula Fries.}

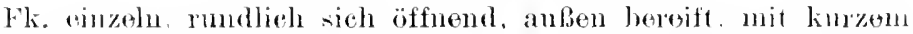

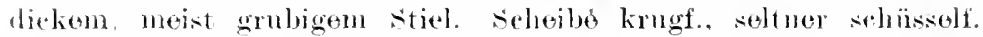
am Rand oingorissen. Fyoren glatt. Paraphysen ästig, oben farbig.

Fk. granw.iB, bereift, stiel 4-10 mm br. sehoibe rauchgrau, 2 -5 ('m br. sporen $18-2+\% 12-14$.". Paraphysen oben bräunlich. Auf fonchtom schattigen $\mathrm{W}^{2}$ aldbodon bis ins IIochgebigg, nicht salten. (Fig 366) ) A. -ulcata (Pers.)

Fk. woilslich, mit radiären, sich verzweigenulen leiston, stiel

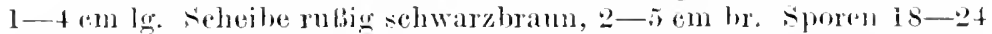
$\times 12-154$. Paraphysen oben brann. Yebar. Inf seluttigenn Waldboulen, zerstreut.

1. vuluaris Fuck.

\section{Gattung: Geopyxis Persoon.}

Fk. meist gosellig, rundlich sich öfnend, kurz gostielt. Scheibe kruefe, soltuer flach 11 . an Rande oingerissen. Sponen watt. Paraplıven ästigr, oft oben gefärlt.

1. Schejbe rot od. last sehwarz.

schoibo heller od. dumkler bram.

2. Fk, gesellig, schmutzig orkergolb, otwas kleigg bestäubt, stiel 1-j mm lg., zottig. Scheibo mennig-od. fleiselurot, selten arelir-

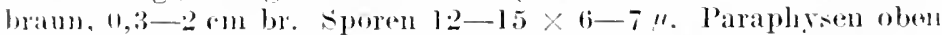

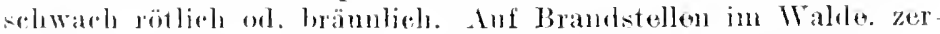
slints.

(i. carbonaria (Alb, ot schw.)

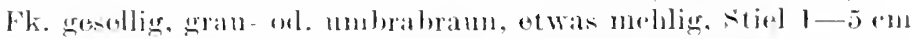

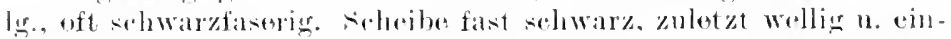

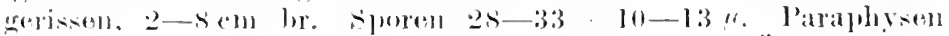

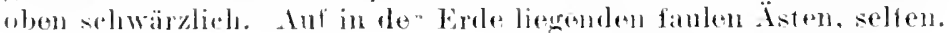

(i. raterium (schw.)

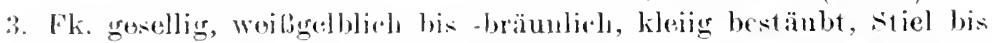
$3 \mathrm{~mm}$ lg., cingesenkt. Sclosibe dottergelb, zulotzt schüsself.. an

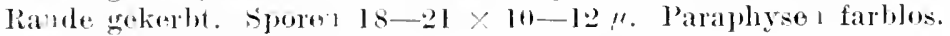
Auf sandigen, sommigen Maldboden, zerstreut. (Fig. 367.)

A. cupularis (L.)

Fk, oinzoln, woilslich otwas kloiicr bestäubt, stiel blassor.

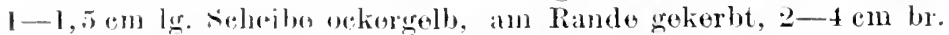
sporen ls-20 ll-13\%. Paraplissen farblos. Auf fouchtem Waldborlen, sentuer stionpfon, selten. (i. (atinus (IIolmsk.) 
10. Gattung: Dincina Fries.

Fk. einzeln, glatt, dick u. kurz gestielt, mullich sich äfnend. scheibe zuletzt flach sehüsself., meist eingerissen n. verbogen. Sporen glatt. Paraphysen oben kenlig n. gefärbt.

Fk. weiß od blafgelb, fein kleig. Stiel bis $1 \mathrm{~cm}$ lg., bisweilen mit Falten. Scheibe ockergelb, zuletzt $\cdots$ kastanienbrann, $1-5 \mathrm{~cm}$ br. bisweilen auch viel größer. Sporen $21-24 \times 12-13 "$. Paraphrsen when kastanienbram. Anf schattigem Waldboden n. anf fanlem IIolz. zerstrent. EBbar. (Fig. 368.)

I). vellosa (Pers.)

Fk. rosa bis gelblichweif. glatt, stie? $0.5-1 \mathrm{~cm}$ lg., tief gefureht. scheibe graubraun, $2-10 \mathrm{~cm}$ br. sporen spindelf., spitz, $27-31$ 11-12.". Paraphỵsen brämlich. ¿nf Watdboden, am Grunde alten xistïmme, zerstrent.

1). ancilis (Pers.)

\section{Gattung: Vacropodia Fuckel.}

Fk. einzehn, mit langem stiel, anfen ranh behaart. Scheibe zuletzt schüsself. Sporen glatt. Paraphỵsen oben keulig. gefärbt.

Fk. g' au od. weibgran mit iem $1-4 \mathrm{em}$ langen stiel bräunlich rauhhaarig. Scheibe graubran. $1-3 \mathrm{em}$ br. sporen $18-2.5$ 10-12 ". Paraphysen oben s.hwach gelblich. Anf grasigen, waldigen Anhöhen, sehr zerstrent. (Fig. 369.) M. macropur (lers.)

\section{Gattung: Humaria Fries.}

Fk. meist gesellig, sitzend, rundlich sich offnend. kahl. Schoibe zuletzt sehüsself. ol. auch gewöbt. Sporen wlatt od. rauh. Paraphysen wabelig, oben meist verbreitert 11 . oft mit gefärbten öltrüpflien gefiillt.

1. sporen ganz glatt.

Fk. gesellig, weibrötlich od. getblich seheibe orangegelb on. mennigrot, $0,5-1 \mathrm{em}$ hr. Sporen ellipsoidsels, fein körnigg rauh, $21-27 \times 12-154$. Paraphysen mit gelbrötlichen Tröpfehen. Anf dem Boden zwischen Voosen, besonders an Wegabstichen, lı̈̈ufìg. (Fig. 370.)

H. rutilan ( Fr.)

2. Sporen ellipsoidisch, stumpf.

Fk. gesellig. orangefarben od. goldgelb, etwas flammig. Seheib: ebenso gefärbt, heller berandet, $2-5 \mathrm{~mm}$ b. Sporen spindell., spitz, $18-25 \times 8-10$ ". Paraphysen mit getbliehen öltröpfehen. Auf dem Waldboden od. Wegen, zerstrent.

H. Insispora (Berk.)

3. Scheibe gelb od rot.

Scheibe nieht so gefürht.

4. Anf Erile.

s.

$\therefore$.

Auf Mist.

(i.

i. Fk. zerstrent, pomeranzenrot. Scheibe ebenso gefürbt, weiblich flockig berandet, 1-5 mm br. Sporen $18-20 \therefore 9-10$.". Paraphysen mit rötlichen öltröpfchen, zerstrent.

H. lencolomil (lledw.) 


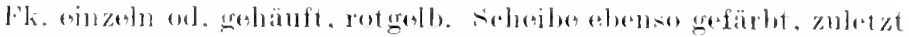

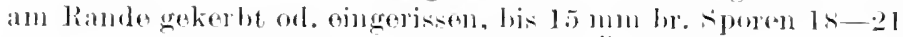

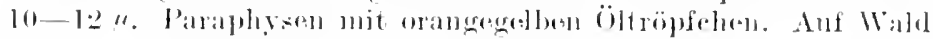

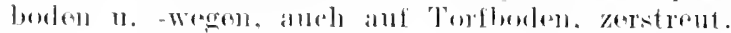

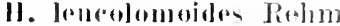

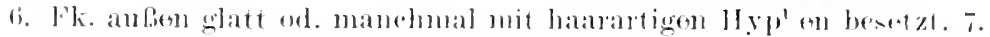

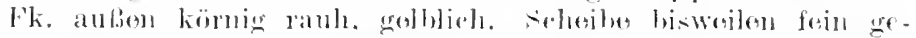

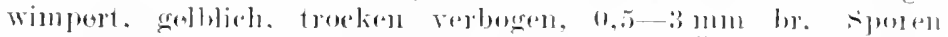

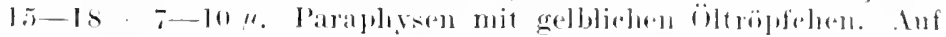

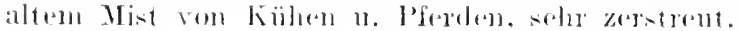

H. [ramulala (Bull.)

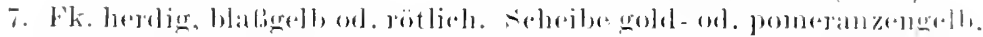

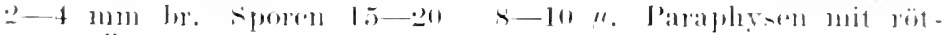
linhen (i)triptehese. Iuf faulem Kot ins Walde, selten.

\section{H. subhirsuta (sohmm.)}

Fk. dichstehend. gelblich, am Gimde mit farblosen llybluen besetzt. Scheibe schmutzig gelb, zart u, woilswimperig herandet.

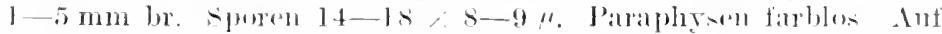

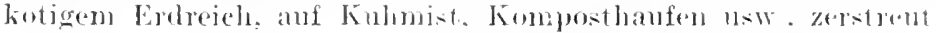

Il. teleboloider (Alh. et sehw.)

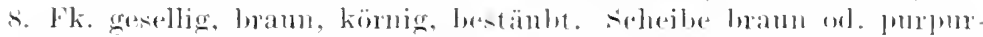

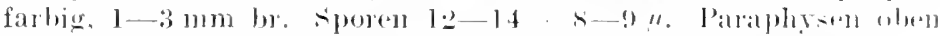

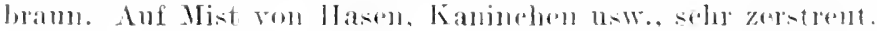

II. Irportim (l'urk k.)

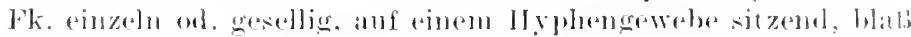

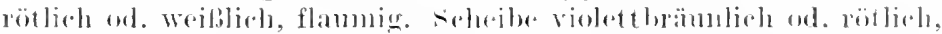

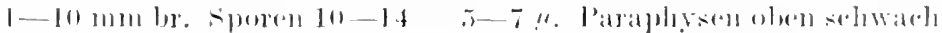

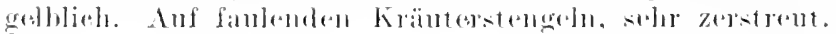

\section{Iorrata (karst.)}

\section{Tratcumg: Alenria Furkel.}

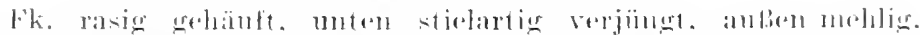

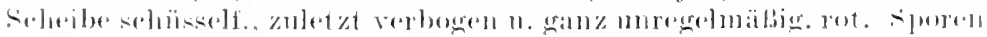

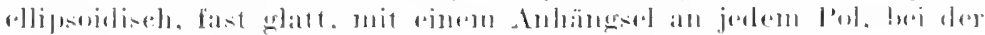

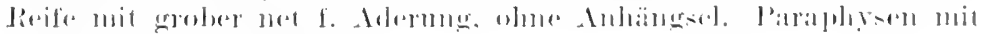

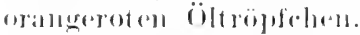

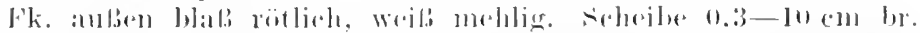

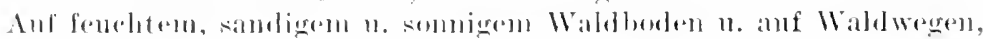
loälige. (vigr. 371.)

A. aurantia (11iill.)

\section{Crattung: dialatetinia looke.}

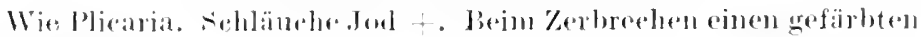
saft rinteremel.

Fk. sit\%ond, mubrabrann, foinkörnier. mil bäulinl-bramnem saft. Scheibe sehwäzlind violett, fi-8 mm br. Sporen glatt, lis 7,5 1 . Auf famlenden stïmmen u. anf Erde, selten.

(i. sanioua (Sehrad.) 
Fk. gehäutt, sitzend, gran od. gelblich, glatt, mit gelbem saft, Scheibe brämtich violett bis bramn, $2-3 \mathrm{~cm}$ br. Sporen feinwarzig, $18-20 \times 8-10 "$. Auf Waldboden, selten.

(i. suecosa (Berk.)

\section{Gattung: Otillea Persoon.}

Fk. einzeln or. bïsehelig, sitzend, bis zum Grunde seitlich anfsespalten, an den Iändern rerbogen od. eingerollt, oft olnf., glatt. sposen ellipsoidisch. Paraphysen oben - hakis gekrïmmt, farblos. sohlüuche meist $\mathrm{J}$ -

1. Archeibe brann ar. brämnliclı.

Fk. einzeln od. büschelig, gespalten od. olnf., anlsen gelbbränn lich, kleiig ranh. 2 -5 cm hoch. his $3 \mathrm{br}$. Scheibe gelblich-orange. farben od. mehr rötlieh. Sporen $10--15 \times 5-6 \mu$. Auf dem lioden ron Lhwäldern. zerstreut. (Fig. 372.) 0. onotial (Pers.)

2. Fk. gesellig, gespalten od. ohrf., anBen hellbram, am Grunde wriblich zottig. I.5-6em br. scheibe dumkelbranu. Sporen

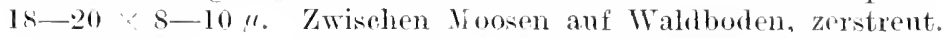

O. cochleata (L.)

Fk, herdigg, gespalten oder oluf., gelbbrännliel, narl unten zotlig gelbwris. $1-4 \mathrm{~cm}$ hoch, I-3 cm br. Sehejbe bräunlich. sporen la-15 6-8 4 . Anf dem Boden ron Ndwädren, bis ins llochgebirge, nicht selten

o. leporilia (liatscli)

\section{Familie Pyromemataceac.}

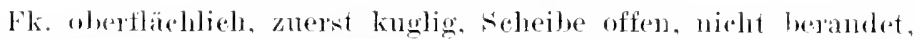
sätre flach orl. gewöbt. Grhänse an den seiten ganz follend od. ludimentär ansgebildet, nur als Hypothecium - lick. Fonst im iubrern Anssehen etwa wie IImmaria.

\section{Bestimnungstabelle der lrattungan.}

1. Fk, einzelu stehend.

13. Fk auf eine fädigen I'ntedage gedrängt strhend.

\section{Pilopezia.}

2. Pyromenta.

I. Tattung: Psilopezia Berk.

Fk, einzeln, fleischig-gallertig, flach, meist gerölht. Cishäuse bei ler lieife ganz fehlend, Iypothecium gut ansgebildet sporen ellipsoidisch, glatt, einzellig, lyalin. sehr fencht od. in Wasser lobende l'ilze.

I. Paraphysen oben braun.

Fk. habbkuglig, 2-3 mm br., Seleibe fleischfarben. Sporen whe Öltropfen, $18-20 \times 10-12 \mu$. Parapliysen farblos u. zart warzig. An faulenden Zeugstïcken in einer Wasserleitungsinn, in den Alpen, nur einmal gefunden, aber sicher nicht selten.

P. aquatica (Lam. ef l) 


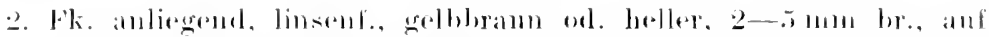

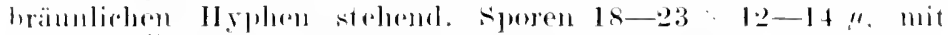

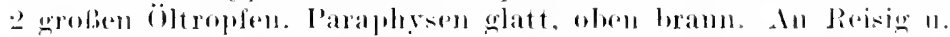

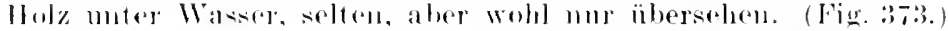

P. obcardii (Kalchlr.)

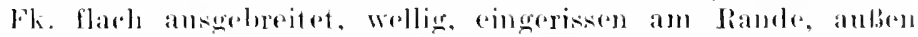

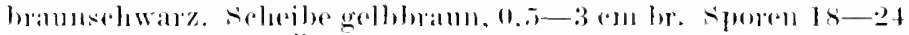

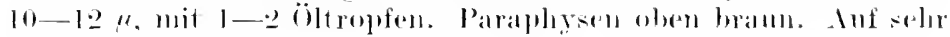

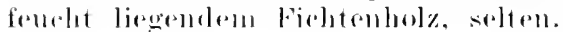

P. rhizinoide (Rahh.)

\section{‥ Gattung: Pyromema Carms.}

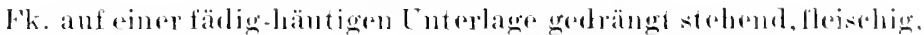

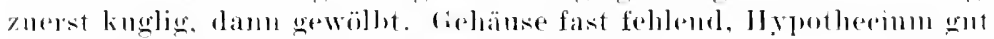

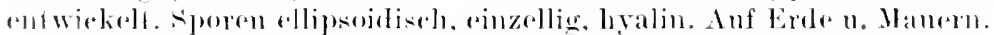

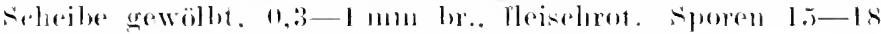

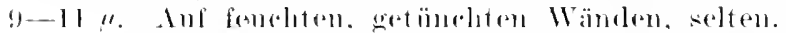

P. Homertiemm (sow.)

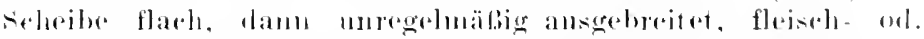

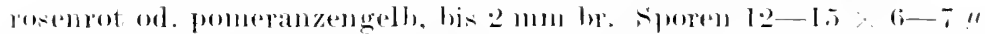
Inf fenchten Waldbobfen, hesomder's brandstellen bis in die Voralpen, zersterent. (Fig. 374.) P. omphalodes (Bull.)

\section{Intropilu: Tuberineate.}

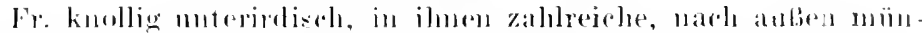
dende diänge od. westhlossende Kammern, deren Wände von Jyme-

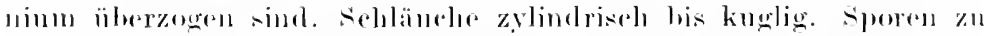
l-8 im simblanch. meist netzig oll. Warzig, selten glatt, meist dmukel

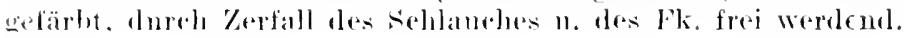

\section{Finzige Familie Tuberacuat.}

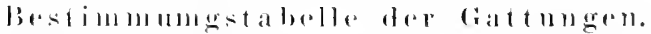

1. Syoren allipsodiseh, glatt

I. Balvilmial.

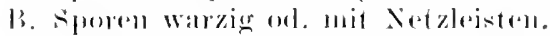

a) Fk. mit rintem finzigent, hisweilen rer-

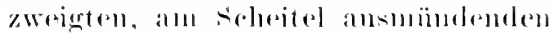
Holilraum

2. (itillia.

1) Fk. mit zahlorivhen (jängen n. Kammortl elmelssetzt.

1. Cänger an molurerent l'muklen der

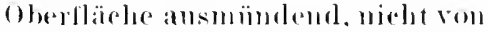
llyphers refiille. Sporess knglig. grobwartig.

11. Cränge whenso nads anlion mïn3. Hyluolria.

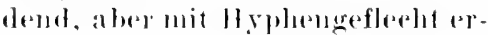
fiillt. 
1. Schläuche kenlig bis zylindrisch, 8 sporig, palissadenartig angeorduet. Sporen knglig. warzig.

2. Schlänche mehr kuglig, mehr regellos gelagert, meist $1-4$. sporig. Sporen neist ellipsoidisch, netzig od. stachlig.

\section{t. Pachyphloeus.}

5. Tuber.

\section{Gattmog: Balsamia Vittadini.}

Fk. knollig, von zahlocichen, nuregelmäbigen, nicht nach auben mündenden Kanmern durchsetzt, deren Wände von dem Ilymeninm bekleidet sind, welches ans palissarlenartigen Parajliysen n. regel-

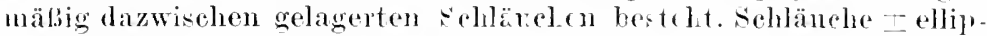
soidin.h, 8 sporig. Sporen ellipsoidiseh, glatt, hyalin. Geruch reif muangenelum.

Fk. etwa nubgrolj od. gröber. fein papillös od. fast glatt, rust. farbig. Schlänche die Paraphysen nicht ïberragend. Sprren $25-42 \times$ 10-IS " In der Hnmsschicht von Buchenwählern od. im sanel nnter Parkracen, selten, aber wohl übersehen, II. W. (Fig. 375.)

B. rulatris Viti.

Fk. mur haselnnBgrols, rötlich - bis violettbram, diclıt mit kloinen phyzonalen böckern besetzt. Kammern kleiner n. Kammerwände llümer als bo i vor. Art. Sehlänche die l'araphysen meist ïberragend. sporen 20-28 $\times 12-17 \mu$. Enter Buchen n. Haselnüssm in Itumus, selten. S. H.

B. fragiformis Tul.

\section{Crattumg: Gemea Vittadini.}

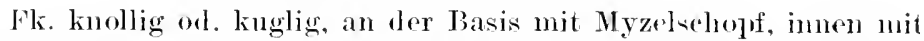
-inem llohlranm al. mit einem System von Gängen. die durch Tejlnug des Raumes entstanden sind, alle gemeinsam am scheitel ansmiindend. Ilymeninm ans palissadenf. gestellten Schlänchen 1. P'araphysen bestehend, letztere ïber den Schläuchen eine Art Rindenschicht bildend. Schlänche zylindrisch, s spo ig. Sporen ellipsoidisch, hörkrig od. stachlig, farblos. Geruch meist widerlich.

I. Ilohlraum des Fk. durch Vorsprünge geteilt u. daher cin Fysten von Gängen entstehend.

Fk. mit einfachem, zentralem 1lohlramm, anBen sehwarzhrann mit bramen IIaaren, innere Rinde des Ifohlrammes bram, glatt, bis I cm br. Sporen 28-35 x I9-28" grobwarzig. In der Hnmnssehicht sandiger Böden muter Buchen, Kastanien, Tammen, zerstreut.

(A. hispidula lierk.

2. Fk. knollig, unregelmälig faltig.

Fk. \# regelmäBig knglig, löchstens mit rinigen soichten Falton. anßen schwarz mit kleinen, polygonal mmmuleten Warzen, bis I em br. Sporen halbknglig höekerig, $28-3.5 \times 21-28 \mu$. In Linda u, Kryptogamenflora II, 1. 2. Aufl. 


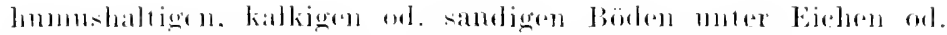

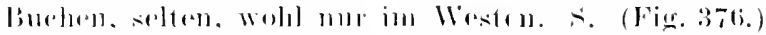

\section{(i. sphaterira 'Tul.}

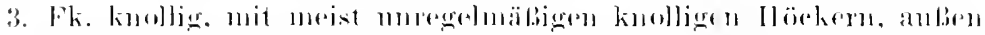

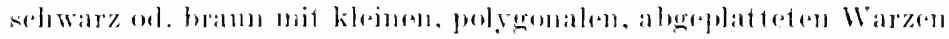

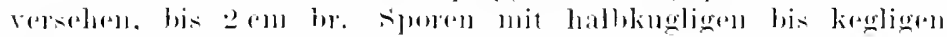

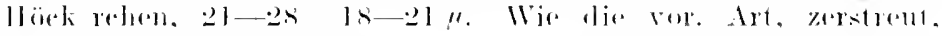

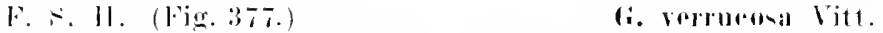

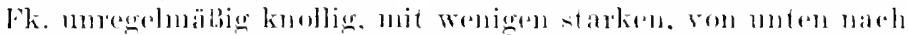

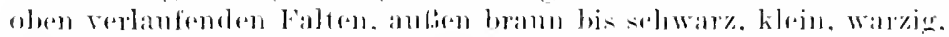

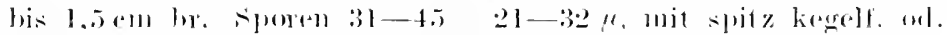

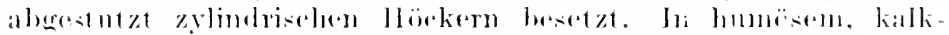

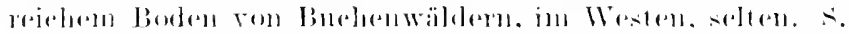

(i. lintzrhii lirek. +t lis.

\section{Eattumg: Hyaluotria lierk. a bre.}

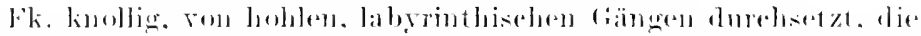

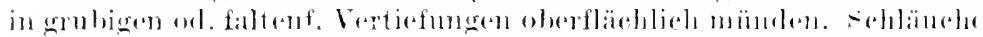

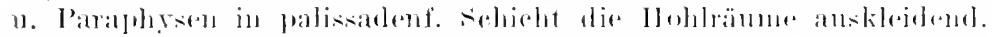

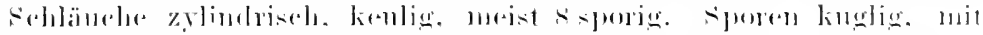

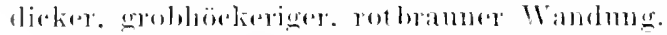

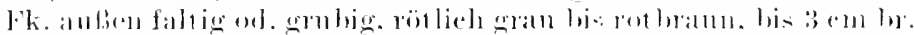

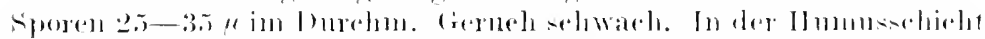

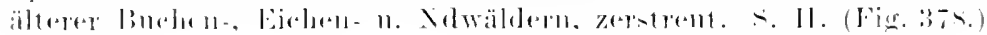

T. Tulanomi lingli. (1 lir.

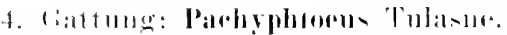

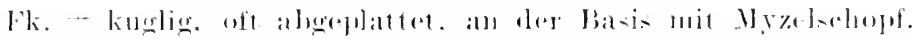

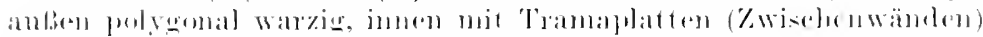

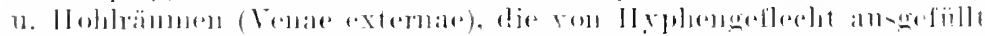

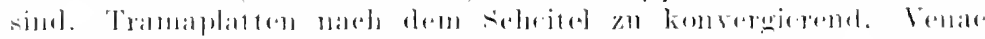

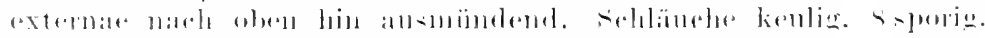

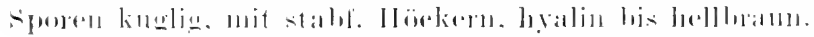

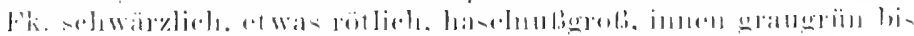

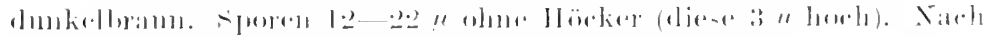

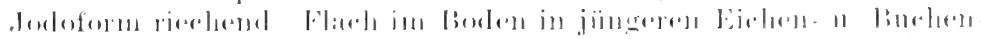

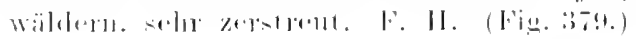

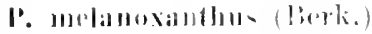

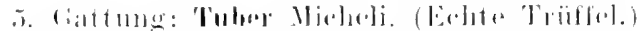

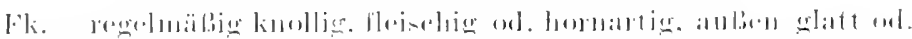

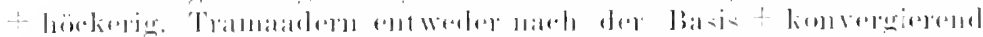

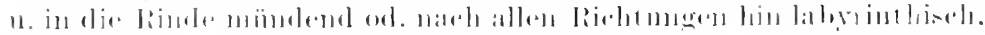

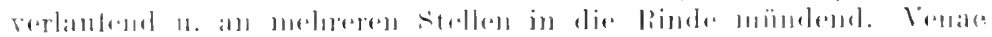

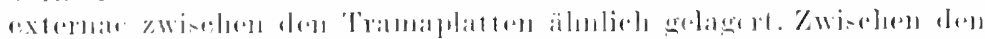

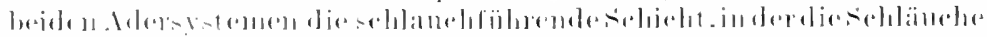

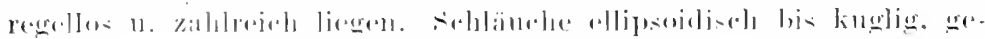


359. 360.361 .362$.

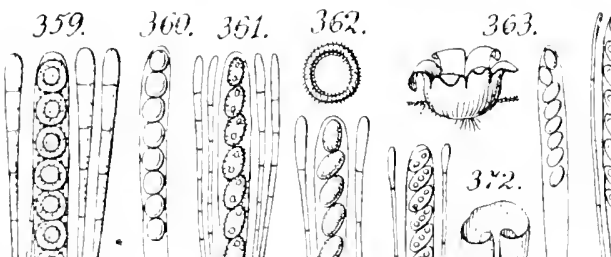

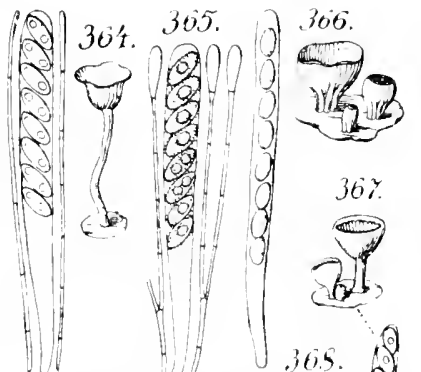

6

H.

3 il

.

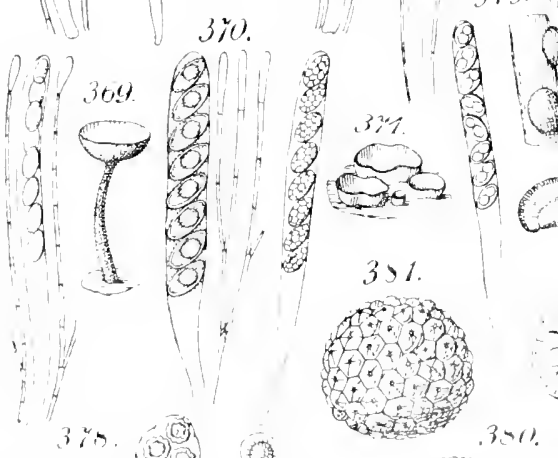

4 (1)

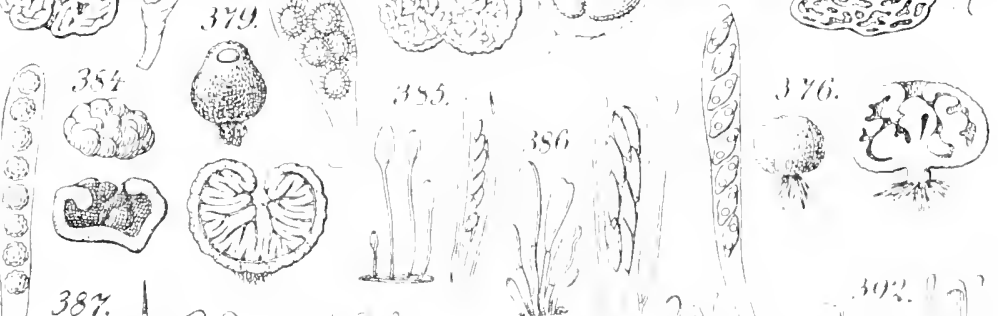

38\% 1 Whe

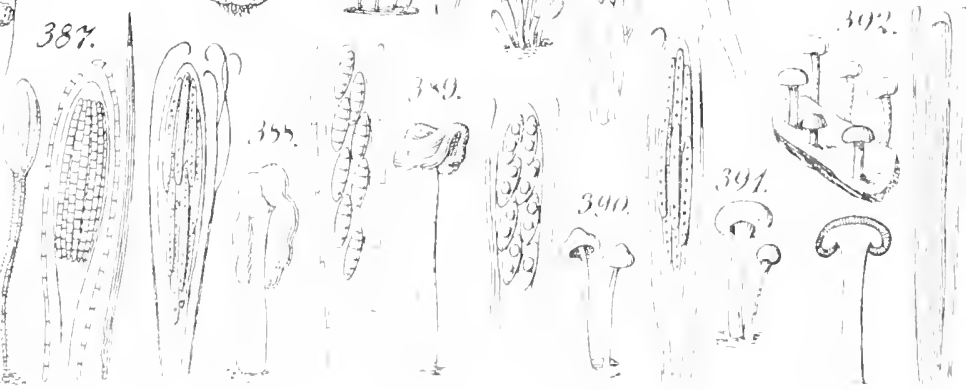




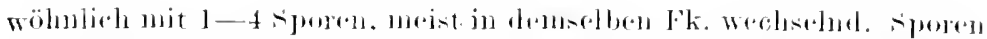

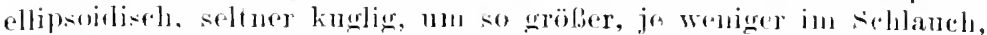

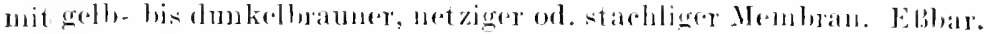
1. sporen stachlis.

sporen netzmalshig.

3 .

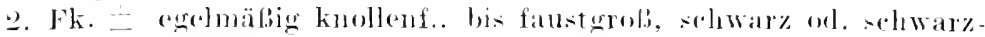

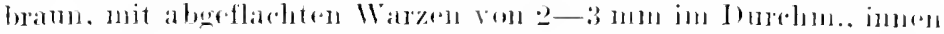

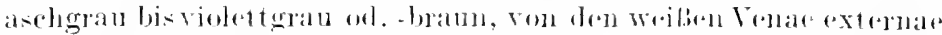

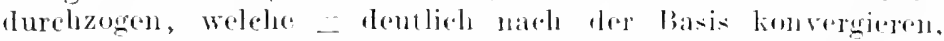

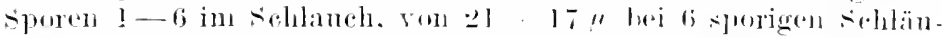

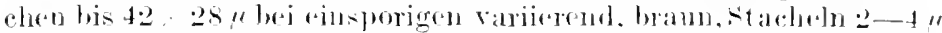

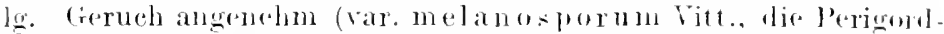
trïfel, ist im Imern schwarzviolett bis rotlicherlewarz mit zahl-

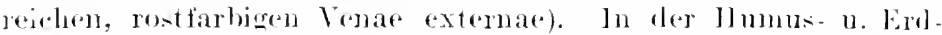
schicht muter Eichen 11 Buchen, im Westen. H. W. (Wig. 3so.)

T. bromale Vitt.

Fk. = rmodlich, bis nubgrols, youtlehbrams, mit dureh scharfe Furches getrennten polxgonales Warzes, innes hrampätlich.

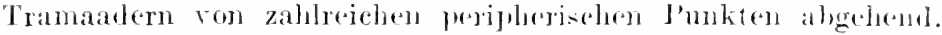

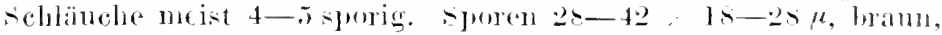

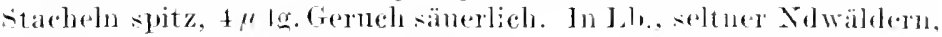
zo rotrent, ziemlich tief im Bowlen

T. rufum J'ieo

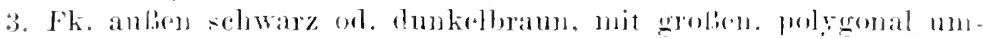
schriebenen. vorragemden 11 arzene.

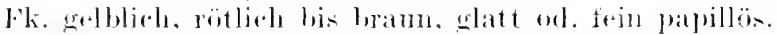

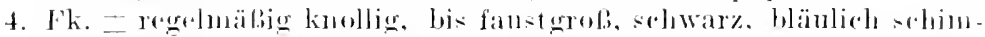

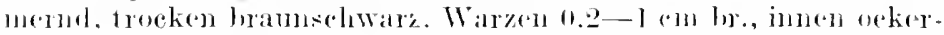
gell, bis bräunlich. Tramadern molemtlich. Sporen zu $1-6$.

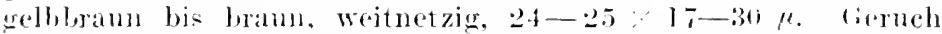
angenclins. (var. mosentericum Vitt. hat als dunkle Linien sichthare Tramaderus). In der Jumusclsielet moter Eichen, Burben 11. anderens l.b., zerstrout. S. II. (Wig. 381.)

\section{T. artivmm litt.}

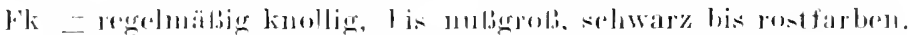

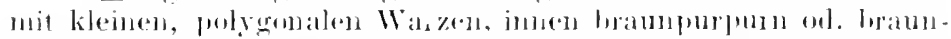

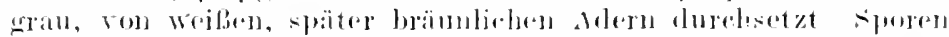

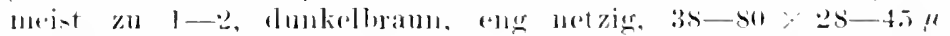

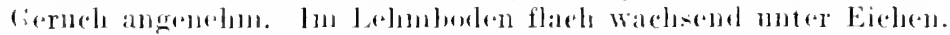

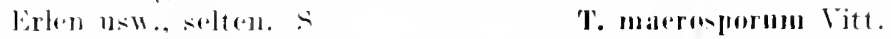

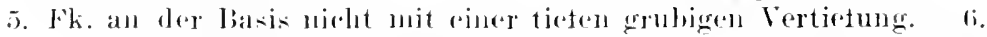

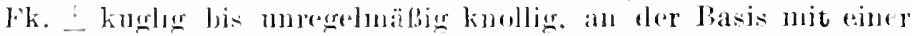

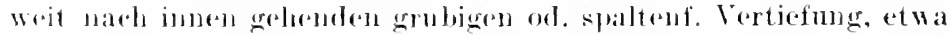
wabunligroli, glatt bis foin papillös, ofkergelb, später rot- bis duukeliranu. Venae extermae nach der Giruhe an der basis komver-

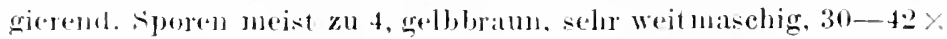
$20-30 \%$. Geruch angenehum. In der Ilumusschicht von Eichen-u. licel ruwäldern, zerstreut. (Fig. 38\%) T. exeavatum Vitt. 
6. Fk. knollig. his hatsehnuggrob, oft etwas platt gedrïckt, glatt, znerst weiß, danu graugelb bis rötlichbram u. weibleckig, innen rötlich-od. gelblichbraun. Sporen zu 1-4, gelbbraun bis braun, engnetzig, 28-52 24-45". Geruch rettichartig. ?n der IIu. muschicht von Eichen. und Buchenwäldern, auch in Komposterde, nicht hänfig. S. II.

T. puberulum Berk. et Br.

Fk. - rundlich, oft niedergedrückt orl. höckerig-faltig, bis nußgrols, glatt od. kleiig, weis, daun bräunlich mit rötlich-violetten Flecken, imen braunpurpurn mit weißen Adern, sporen zu 1--4, gelbbraun, weitnetzig, $30-45 \% 90-30 \mu$. Geruch sïuerlich. ln der Humusschicht lehmhaltiger Böden von Lbwäldern, selten.

T. Aryophilum 'Tul.

\section{Interreilte: Helcellineat.}

Fk. hut-, keulen od. krustenf.. fleischig bis fleischig-wachsartig. gestielt wh. nicht. Hymeninm von hnfang an frei, den Fls. ganz od. in seinem oberen Teile iiberziehend, glatt od. nit Runzehn n. Falten aus dicht nebeneinanderstehenden schläuchen n. Paraphysen bestehend.

Bestimmungstabelle der Familien.

A. Fk. ungestielt, scheibig-kmstig od. gewölbt.

1. Rhizinaceae.

P. Fk. hut-od. keulenf., I lang gestielt.

a) Hymeniumtragender 'T'eil des Fk. kemlen- od. kopff., meist glatt, schläuche am scheitel mit Lreh sich offnend.

$\because$ dieoglosiaceare.

b) Ilymeniuntragender Tcil des Fk. hutt.. oft mist unregehmäBiger Faltelung.

B. Helvellaceate.

\section{Familie Rhizinaceac.}

Fk. magestielt, scheibig krustig od. fast kuglig mit dem llymenium anf der Anbenseite, zerbrchlieh. Schlänche nuit Deckel auf. -pringent. Achliel.t sich wahrselecinlich eng an die Pyromenatareell ant.

\section{Gattungs: IRhizina Tries.}

Fk. krustenf. ansgebrejtet. mit wurzelartigen Fortsitzen ant der

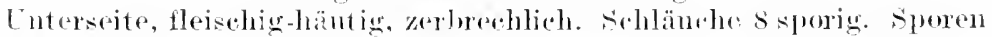
hyalin, einzellig. Paraphysen olen brann, kenligr u. cint bitheeium bildend.

Fk. bis 9 mm br., 2-3 mm diek, oben kastanienbran, unten weiblieh od. gelblich bis bräunlich, mit Fasem dieht besetzt. Storen -pindelf., beidendig stmmpflich zogespitzt, 30-40 × $-10 \mu$. Iuf somnigen Waldboden, Waldwegen, bes. von Kieferwäldern. bis iu die N Nenen, nicht selten. (Fig. 383.)

R. inflatal (schiteff.) 


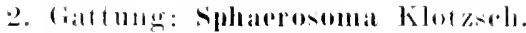

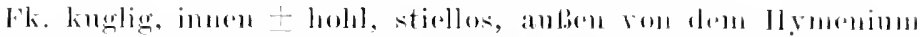

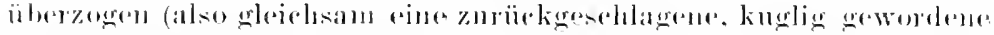

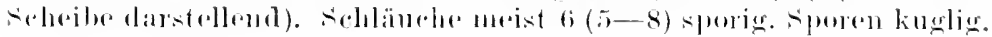
warzig. lıvalin bis hräumlielı.

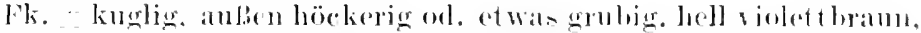

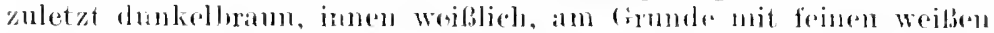

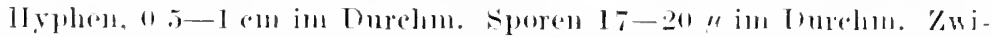
schen lleideliraut n. Nadeln in Nowäldern. nielıt häufig. (Fig. 394.)

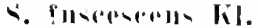

\section{Familie: Geoglossarmar.}

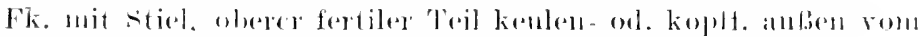

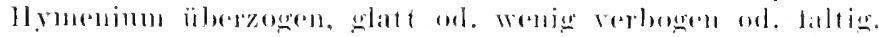

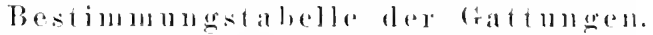

A. Fertiler 'Teil des Fk. keulien, also mur rine

Anselewellomed des stiele bildemel.

a) sporeu farblos. anzellig. selten zulotzt zwrizellig.

1. sporen spindelf. onl. länglieh ellip. srialineh.

1. Fk. andh al, lor.ant.

l. Mitrula.

2. l'k. errïn onl. seluwirzlich.

‥ Mirrengumum,

11. Sfuren maldelf. onl. fïilis. mit schleimbort.

\section{Sinathularial.}

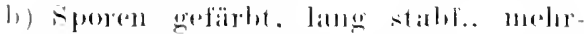
zallim.

3. (inowhan-1111.

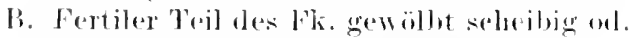

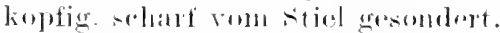

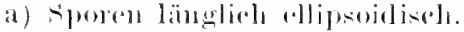

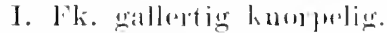

1]. l'k. Wacelisartign.

5. Iontial.

ti. Curlumiolla.

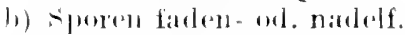

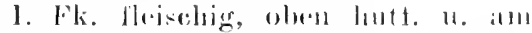
Rantrle mongerollt.

l'. Fk. watelsartig. oben selueibien. laturl anelute.

\section{Frimuia.}

s. Vibrimial.

\section{Crattunge: Mitrula l'ersound.}

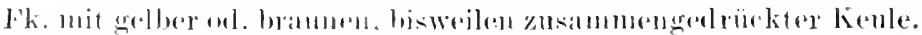

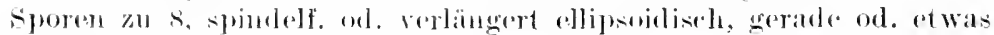

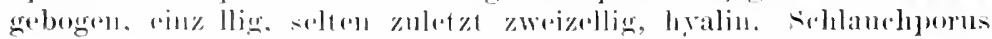
J + . 
1. Fk. ïber 1 en horll.

Fk, einzeln, 5-6 mm hoch, Keule rundlich eif., blali dotter-od. rotgelb, 0,5-1 mm lg., stiel gell. Sporen narlelf., $12-14 \times 2,5 \mu$. Auf faulenden Kiefermadeln, selten. H. pusilla (Nees)

2. Fk. einzeh od. gesellig, 1,5-6 cm hoch, Keule oif. bis kopff., orangefarben od. gelb, Stiel blaßgelb od. weißlich. Sporenspindelf., kaum spitz, 12-18 $83-4 \%$. Anf Nd.. anch Blättern u. Astchen an feuchten Waldstellen, nicht selten. M. phalloides (Bull.)

Fk. einzelı, 1-2 cm hoch, Keule eif. od. länglich, orangegelb bis rostfarbig, 2-4 mm lg., Sticl fädig, gelbbram. Sporen schmal spindelf., spitz, $14-17 \approx 2-3 \%$. Auf faulenden No. im Walde, nicht selten. (Fig. 38.5.)

I. cucullata (Batsch)

\section{Gattung: Microglossmm Gillet.}

Fk. wie bei ror. Gattung, grïn od. sehwärzlich. Sporen hyalin, cinzellig, selten zuletzt 2 ad. 4 zellig. Schlauchporus .J +

Fk. moist büschelig, bis 4 (ou hoch, Keule $3-8 \mathrm{mmlg}$, olivengrün, innen fast spangrïn, Stiel heller, klebrig-schuppig. Sporrus spindelf., einzellig, zuletzt anch 4 zellig, 15-18 $\times 4-5 \mu$, liyalin. Auf fenchtem Waldboden, zerstrent. (Fig. 386.) M. viride (Prers.)

Fk. gesellig od. büschlig, 3-4 em hoch, olivengraugrïn, oft flath, stiel gelbhrämlicl. Sporen länglich ellipsoidiseh, einzellig, $12-15 \times$ ¡-6". Anf Waldboden, solten. M. ulivacenu (Pers.)

\section{Gattung: Geoglonsmm l'ersonm.}

Fk. selowary od. schwarzhram, Keule flach, undeutlich vom sticl abgegrenzt. Sporen zu 8 , stäbchenf., ahgerundot, geraele od. etwas gebogen, quer 4-16 zollig, zuletzt braun. Schlaudlporus d t. 1. Kenle glatt.

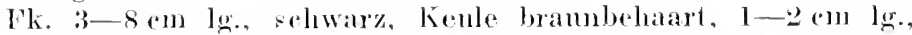
flarl, stiel rumb, ramhharig. Sporen $14-16 \%+1 \mathrm{~g}, 100-120 \times$

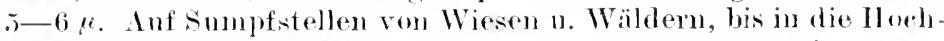
alpent. S. 11 . (Fig. 387.)

fi. Hirsutum l'ars.

2. Fk. frisel auben klebrig od. sechleimig.

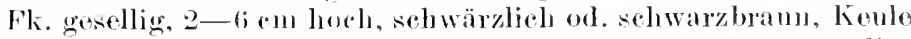
1-3 coll lo., flach, stiel glatt wh. ctwas selouppig. Sporen zylin. drisch, meist an einen Ende etwas rerjüngt. 8 zellig, Paralnysen oben rosenkranzf., brämbleh. An grasigen stellen in Wäldern 1. anf Wiosen, gerstreut. (A. oplioglossojdes (I.)

3. Fk. selowarz, sehleimig, 3-5 em hoelh, Kenle zylindrisel. sporen 4 zellig, $60 \times 4-5$ C. Paraphysen oben koplf., hame. Anl lirde. sill ("il.

(x. viseosmun Pers.

Fk. 3-6 em hoch, selowäzlich, klebrig, Keule zumgenf. orl. lanzettlieh, sporen tzellig, $60-80 \times 5-6 \mu$. Paraploysur obrul birnt. Inf waldigen Il ïgeln, seln zorstrent.

(i. erutinosum l'res. 


\section{Gattung: Spathularia l'ersoon.}

Jk. wie vor. Kenle ej-ol. spatelf., zusammengedriickt u. leiderseits am stiel etwas herablaufend. sporen zu s, fäelig od. nadelf., ron einem selıleimlıof umgeben, einzellig, hralin. l’araplyysen färlic, oben lhakig od. korkzielerartig trebogen, hyalin.

Fk. 4-6 cm loeh, keule gold-od. orangegelb, meist spatelf., flach, kamm- od. Wulstartig bejderseits herablanfend. Stiel weilslich ol. gebllich. Sporen oben etwas breiter, 45-70 $62-3,1$. Anf dem Boden in Xiwäldern bis ins Hochgebirge, zerstreut. S. H. (Fig. 3ss.)

S. Clavata (schaeff.)

\section{Gattung: Leotia Hiller.}

Fk. gallertartig, klebrig, fertiler Teil hutf., rumdlich gewölbt, an Rand eingerollt, unten frei. Sporen zu s, spindelf., zuletzt $2-4$ zellig. hyaliu bis grüulich. Paraphssen oben keulig. grïn.

Fk. gesellig bis büschelig, $3-10 \mathrm{~cm}$ lg. Ilut grïnlicligelb bis dunkelbramgrün, stiel $2-8 \mathrm{~cm}$ lg., gell, kleinschuppig. Sporen $18-25 \% 5-6 \mu$. Auf feuchtem, lehnigen Waldboden, zerstrent. (Fig. 3s!.)

L. gelatimosa Ifill.

\section{Cattung: C'udoniella Saccarto.}

Fk. wathsartig fleischig, nicht klebris, IInt zuerst s.lueibis, dann am Rand eingerollt $u$. verbogen. sporen zn 8, spindelf. spitz, einzellig. zuletzt 2-4zellig. lyalin. Paraphysen oben etwas ver breitert, livalin.

Fk. gesellig, 0,j-l cu hoch, IIut weils bis bräunlich, stiel weili. sporen 1.j-20 $204-j \mu$. In hollen Eichenstämmen, Fdelkastanien, anf faulem Filuolz, zerstreut. (Fig. 390.) C. aceicularis (Bull.)

\section{7. rattung: Codonia Fries.}

Fk. fleisclig. Ilut hutf., oben flach gewölbt, am Rand ringerollt u. etwas gefaltet, frei. Fporen zu 8. nadelf. zuletzi vielzellig. livalin. Paraphrsen fädig, oben meist gebogen.

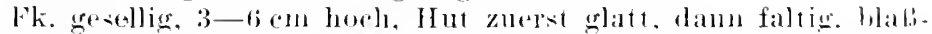

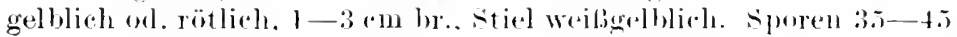

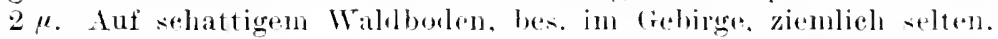
(Fig. 391.)

C. riprinans (l't+is.)

\section{s. Gattung: Vibrissea Fries.}

lk. wachsartig. Hut scletibenf.. frei, am Rimble etwas umgeschlagen. Śporen zu s, fallenf., zuletzt vielzellig, luyalin. Paraplysen wenig rerbreitert, fas farblos.

Fk. gesellig, bis l,jem lowh, II utscheibe linsenf., etwas ungtsschlagen. gelb oll. orangerot, $2-5 \mathrm{~mm} \mathrm{br}$. Stice weiblich bis grünliel od. scluwäzlich. Sjoren bis $200 \% 1 \mu$. Anf faulem Ilolz u. Kweigen in fiefendem IVasier, selten. (Fig. 392.)

V. truncorum (Alb. et scluw.) 


\section{Familie Helvellaceae.}

Fk. fleischig, stiel seharf abgesetzt, meist hohl, zerbrechlieh. II ut fast glatt $u$. verbogen od. mit Falten of. Vertiefungen versehen. schläuche mit einem Deckel aufspringend. Sporen ellipsoidisch, hyalin einzellig.

Bestimmungstabelle der Gattungen.

A. Hut ganz od. oben hohl, in der Regel mit der ganzen Fläche innen dem stiel gleich. sam aufsitzend $u$. mit ihm verwachsen.

a) llut durch Längs- u. Querleisten in vertitefte Zellen geteilt.

b) Hut mit gewundenen Falten ïberzogen.

B. Hut nur in der Mitte mit dem stiel verbunden, also nur aufsitzend.

a) Hut glockig.

b) Hut gelappt, nach dem Stiel zu umge. schlagen.

1. Horchella.

2. Hyromitra.

3. Verpa.

4. Helvella.

1. Crattung: Morelıella Dillenius.

Fk. fleischig, zerbrechlich, stiel zylindrisch, hohl. Hut seharf abgesetzt, dem Stiel meist ganz aufgewachsen, imen ganz od. nur oben hohl. Iymenium durch Leisten in netzf. Gruben geteilt. Sporen zu 8, ellipsoidisch, einzellig, hyalin od. gelblich. Paraphysen keulig. Elibar. Alle im F. (Moreliel).

1. Hut nur oben hohl. nnterer Rand frei rom stiel abstehend. 2 .

llnt ganz hohl, völig dem stiel aufgewachsen.

2 . Stiel glatt, nicht längsfurchig.

3.

stiel nach nuten oft verbreitert, mit gewundenen Längsfalten, weil.j orl. gelblich, (j-12 m $\mathrm{gg} ., 1,5-2 \mathrm{~cm}$ br. llut oben ziemlich seluarf zugespitzt, nnten bis $1 / 3$ ort. darïber frei, gelb-ort. olivenhraun, $2-3 \mathrm{~cm} \lg$, $2 \mathrm{~cm}$ br. Sporen $20-25 \times 12-15 \mu$, hrllgelblich. In lichten Waldwegen, zerstrent. M. rimosipes DC.

3. Stiel bisweilen an Grunde schwach verdickt, weiblich oh. gelblich. Kleig bestäubt, 2-3 mal so $1 \mathrm{~g}$. wie der Hut, 1,5-2 em br., lrolıl. Hut bis zux Hälfte frei, glockig kegelf., $2-3 \mathrm{~cm} l g ., 1,5-3 \mathrm{em} \mathrm{hr.,}$ braun. Sporen hyalin or. schrach relblich, $22-25 \times 12-14 \mu$. In Gebïschen, selten (Fig 393.) M. hybrida (Sow.)

stiel nach unten knollig verbreitert, kleiig bestäubt. weif, hohl, t-lo em u. melor lg., bis $4 \mathrm{~cm}$ br. Hut kegrelf., oft mehr kuollig

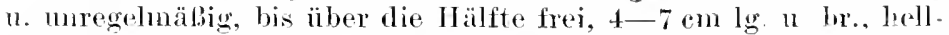
brau od. olivenbram. sporen etwas gelblich, $21-24<12 \mu$. Au schatigen stellen, selten.

H. rigat (Batseh)

4. Hut mehr kegelf., nach oben also deutlich verjü̈gt.

5.

llut ellipsodisch od. eif., den stiel kaun wulstio überragend. durch Längs- n. Querleisten in tiefe, muregelmäbig rechteckige 


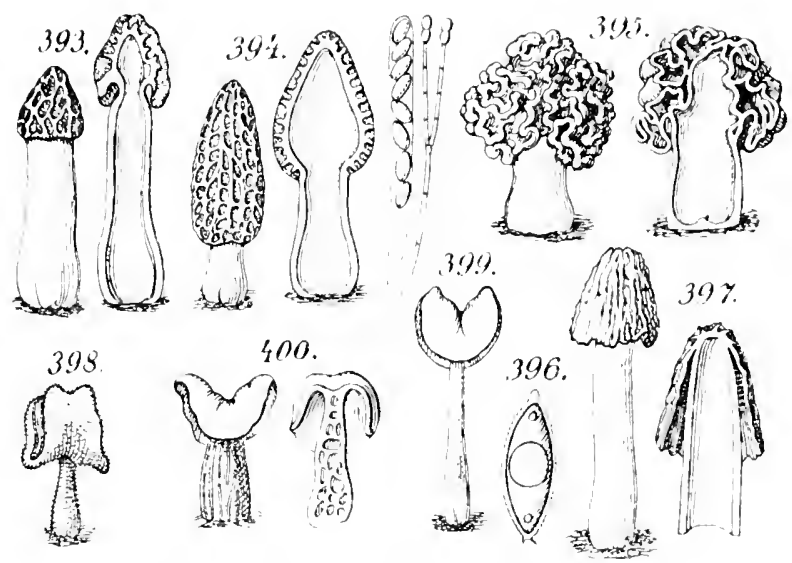

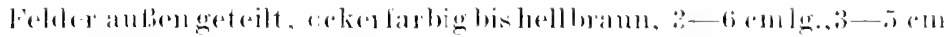

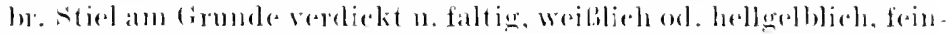

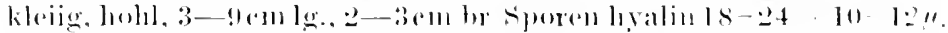

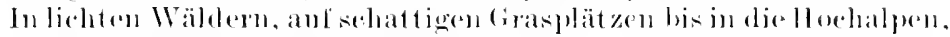

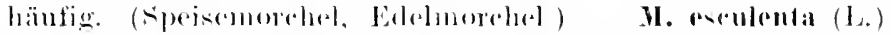

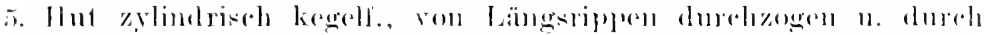

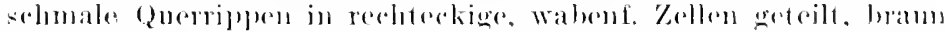

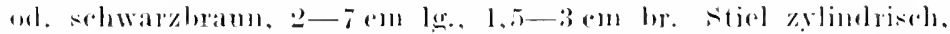

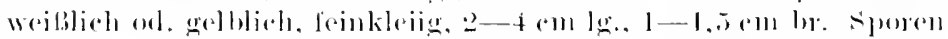

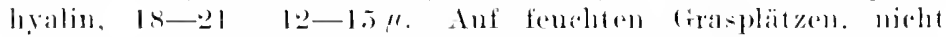

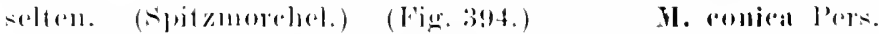

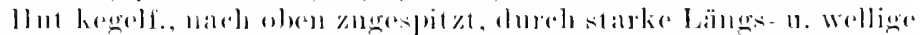

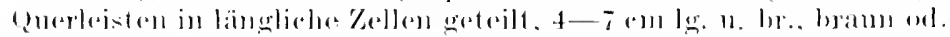

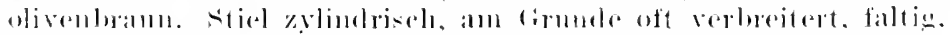

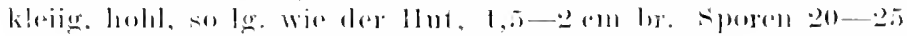

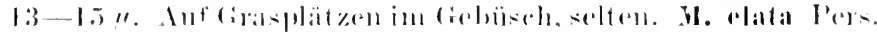

\section{Ciattome: Cigromitua bies.}

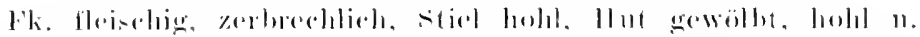

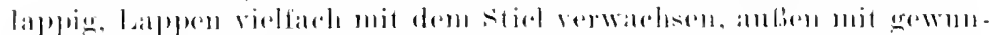

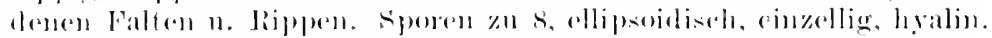

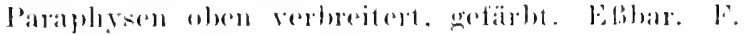

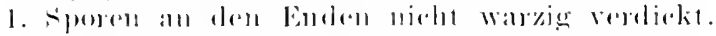

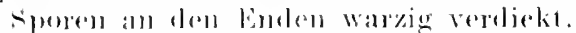

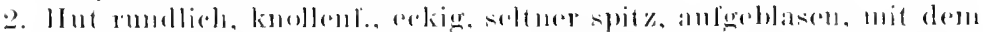

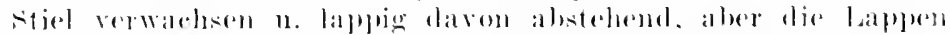

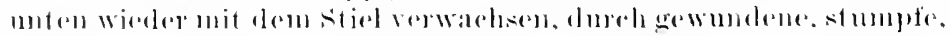

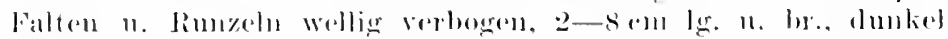

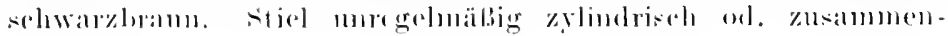


gedrïckt, oft grubig. weiblich, gelblich al. rötlich, schwach filzig, $3-9 \mathrm{~cm} \mathrm{lo.,} \mathrm{1,5-3} \mathrm{cm} \mathrm{br.} \mathrm{Sporen} \mathrm{ellipsoidisch,} \mathrm{18-24} \times 8-11$ !". In Kiefernwäldern anf sandigen Boden bis ins Gebirge, nicht selten (Stockmorchel, Faltenmorchel, Lorehel). (Fig. 3!5.)

(A. esculenta (Pers.)

IInt meist 2 spitzig, mit (2-4) heruntergeschlagenen, am Rande \pm mit dem stiel verwachsen, wllig od. faltig verbogenen Lappen, 5-12 cm lg̈. n. br., zimmet - bis kastanienbram. Stiel zylindrisch, an Grunde meist grubig, weiblich bis rötlich, feinfilzig, $4-10 \mathrm{~cm}$ lg., $1,5-3 \mathrm{~cm} \mathrm{br}$. Sporen ellipsoidisch, $18-24 \times 8-9 \mu$. In Ndwählern, zerstrent bis ins Gebirge. G. infula (Sclnaef.)

:. Int sehr unregelmäbig, rundlich od. knollig, kraus, fast ganz drm stiel angewachsen, mit breiten, stmmpfen Falten, 6-12 cm lg.. bis $30 \mathrm{~cm}$ br., hellolivenbram od. ockergelb. Stiel unregelmälig. grubig, weiBlich, feinfilzig, $3-6 \cdot m$ lg. $n$. br. sporen spindelf., zugespitzt, beidendig mit kurzen: warzigen Knopf, $30-40$. 12 bis $14 \mu$. In Wäldern, selten. (Fig. 396.) (C. qiăs (Krombh.)

Hut umegelmäbig, aufgebläht, zollig-eckig, moregelmäligg wellig gelaput u. zurückgescliagen, von stumpfen Rippen u. tiefen, schmalen, geschlossener Felderi durchzogen, 2-5 cm lg., $3-8 \mathrm{~cm}$ br., rot- bis dunkelbraun, an den Rippen kastanienbraun. Stiel etwas flach, oben meist breiter, grubig-furelig, bräunlich bis dunkel violett, 2-2,5 cm lg. u. br. sporen ellipsoidisch, an den Enden mit warzenf. Knopf, $30 \% 1 \% "$. In Fichtenwädern des Vurgebirses, selten.

(A. Alispectal (Krombli.)

\section{Gattung: Verpa Swartz.}

Fk. gestielt, fleischig, zerbrechlich. Ilnt kugel-, glocken-al. kegelf., mur mit der spitze dem Stiel angewachsen, muten frei, grat od. schwach gefaltet od. längsrumzlig. Stiel zylindrisch, oft verbreitert, zuletzt hohl, glatt ol. schmplig. Sporen ellipsoidiseh, rinzellig, hyalin ul. gelblich. Paraphysen oben etwas verbreitert u. gefärbt. Elbbar. F.

II nt glockig, anben mit dichtstehenden, parallelen, gewundenen, oft verzweigten $n$. durch Querleisten verbundenen liunzeln bedeckt. $2-4 \mathrm{~cm}$ lg., 2-3cm br., braun od. orkerfarbig. Stiel zylindrisch, wben etwas verjüngt, weiblich, filzig, oft kleigg schuppig. 7-1+cm les. $1.5-2 \mathrm{~cm}$ br. Sporen $60-80 \quad \because 17-22 \mu$. In lichten Wäldern, selton. (Fig. 397.)

V. bolsemica (krombh.)

1tut glockis, fingerlut - od, eif, oben oft eingedrïckt, frei herab-

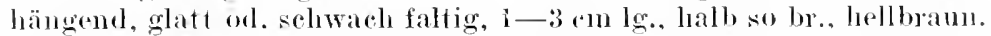
stiel zylindriscl, unten oft etwas rerdickt, glatt, mit einzeluen feinen

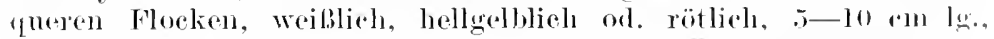
$1-1,5 \mathrm{em}$ hr. Sfuren $20-25 \times 12-18 \mu$. 111 l bwïlerm, soltell. V. ronical (Mill.) 


\section{Irattumg: Helvella I.}

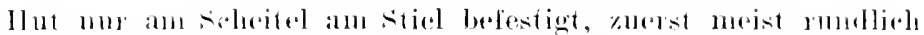

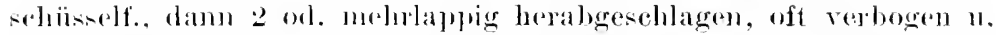

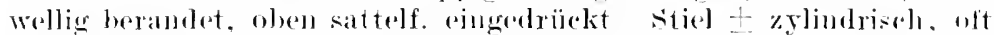
flammig, oft buclitig a tiof gefurcht, hisweilen hohl. Sporen ellip-

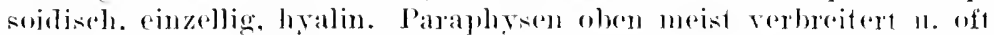
farbig. Elbbar. Meist $F$.

1. Stice nicht gefureht, mur bisweilen etwas grubig am firmele. 2 .

sticel stets längsfurchig.

2. Ilut n. Stiel bellatert. flammig.

Ilut u. stiel glat t.

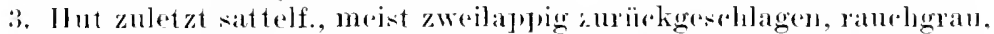
mit brämliehen llaaren besetzt, 1-1,j rm lg. u. br. Stiel hellgrall, zottig belaart, $1 \mathrm{~cm}$ lg., $1,5 \mathrm{~mm}$ br. Fpolen $15-18 \times 9-10 "$ " In lichten Wäldern, auf Frasplätzen, zerstreut (Fig. 398.)

\section{1. ephippimu Lér.}

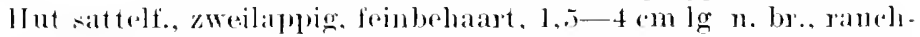
bramn, toocken sehwarz. Sitiel oft etwas zusimmengedrüelst. grau orl. seluwärzlich, dicht feinllammig, $3-50 m \lg ., 2-7 \mathrm{~mm}$ hr. sporen $15-20$ × $9-12 \mu$. In linhten ldowildern, bes. an Brandstellen, zesstreut. S.

H. atra Könit

4. Nitiel ganz glatt, nicht mehlig bestäubt.

$\therefore$.

llut sattelf., zwrilappig, wellig berauket, 1-2,5 em lg. u. lor.. rul.ibraun. Sticl mejst glatt, seltuer grubig. gelblich, melulig he.

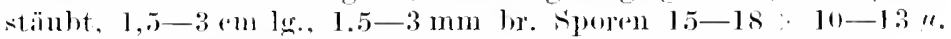
Auf lelinigene borlan, selten. H. pulla IJolmsk.

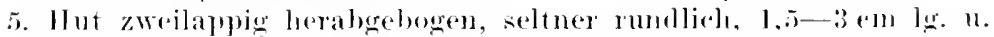

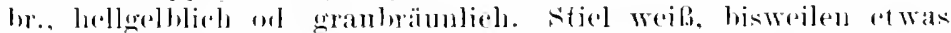

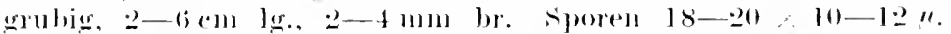

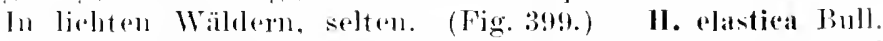

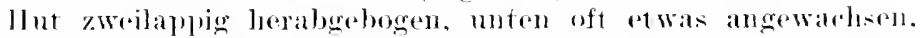

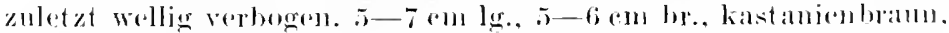

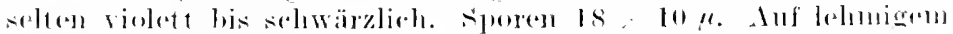

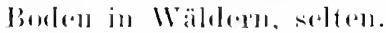

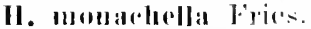

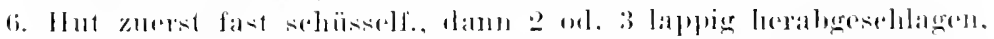

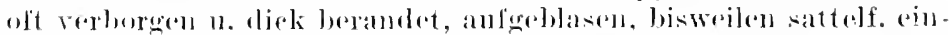

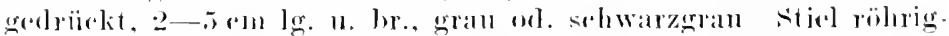

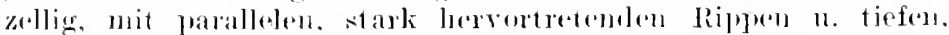

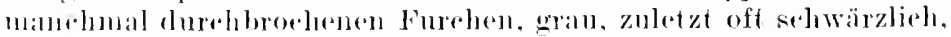

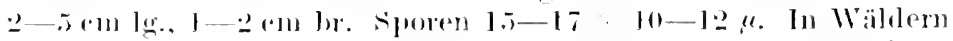

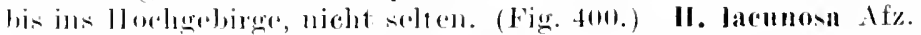

llut 2 bis + lappreg zurbükgeschlagen, wellig berandet u. lirans

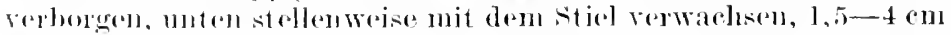

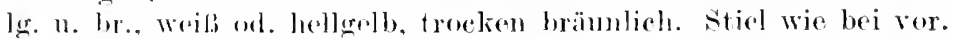

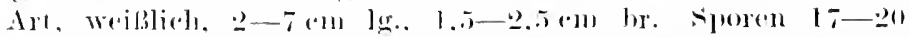

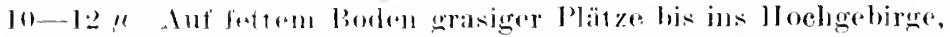
zerstrent.

II. rrisjal (s.opl.) 


\section{Verzeichnis der Gattungen. Arten und Abbildungen des systematischen Teiles.}

Jis in Klammen stehenden Ziffern bezedonen die Figurnummen. Inis Abbilanngen sind den Werken von Lister, Rehm, Winter, den natiofichen Pflanzentanilien, her Kryptogamentlona der Jark Brandenburg und enigen andesen wichtigeren Arbeiten in nolnmen.

alietis (Cenang.) 157.

-.. (Vals.) 125.

Abrothallus 159.

Absidia 60.

absinthii (Pyrenop.) 164.

aeerinum (Rhyt.) (291) 15:2.

aceris (Otth.) (208) 112.

- (Enc.) (145) 77.

Aeetabula 188.

Achlya 47.

Achlyogeton 44.

acicola (Cenang.) 157.

(Desmaz.) 174.

acicularis (Cudoniella) (390) 200.

Acrospermi $\mathrm{m} 141$.

ac'uforme (Rhizoph.) 36.

acuminatus (Ophiob.) 118.

atuta (Leptosph.) 117.

acuum (Hymenose.) 178.

aeruginascens (Chlorospl.) 170.

aeruginosum (Chlorospl.) (329) 170.

aestivum (Тиb.) (381) 196.

affinis (Pernosp.) 55.

(Trich.) 12.

aggregata (Sclerod.) 147.

agile (Rhizoph.) 37.

aynita (Loptosph.) 117.

agrostidis (Mycosph.) 113.

(Ceirr.) =agrostidis (Aycosph.).

Agrrium 156.

alba (Begg.) :3.

- (Spum.) (:34) 21.

albidum (Ascocort.) (126) 68.

Albugo 52.

albus (Erem.) (124) 66. alchimillae (Coler.) 106.

Alemria 190.

alfalfae (Trophl.) 44.

allii (Physod.) 42.

allicina (Ireosph.) 113.

ahnea (Trmp.) 15.5.

alni (Melanc.) 131.

- (Microsph.) 77 .

- (Selerot.) 172.

alni incanae (Taph.) 69.

alpinmm (Synchytr.) 3:2.

alsinearmm (Peronosp.) 55.

alutacea (Hypoc.) 8..

Amauroaseus 71 .

Amaurochacte 24.

ambiens (Vals.) 126.

amentaceae (Cibor.) 171.

amenti (Hrmenose.) 178.

Amoeboch frium 41 . ampelina ( $\mathrm{Vals.}$ ) 12:3.

amphibola (Pragmop.) (313) 161.

Amphisphaeria 108.

ampullacem (Rhizoph.) 36.

Amylocarpus 73.

aneilis (Disc.) 189.

Aneylistes 45 .

andiomedae (lihyt.) 152.

- (Npharrop.) 151.

anemones (Nyuchytr.) :32.

anguilulae (Catein.) 4:.

anguillular aeeti (1'hyth.) 5.2.

angustatum (Hrst.) 140 .

Anixia 77.

anomala (Pilair.) (108) til.

anomalum (Nrnchytr.) :3:. 
Anthostom, $\mathbf{1} \mathbf{2}$;

Anthostomella l:ot.

antimhini (Peromos].) it.

Aphanomseres 49 .

aphanomsicis (Psemelolp.) 27.

aphitlis (Entomophth.) (ii).

apiculata (Achl.) 4s.

(Entophl.) 3.;.

apiculatum (lihronch.) 1301.

Aplanes 49.

Aporlachlya 49.

a prenchiculatum (Lophiost.) 111 .

- (Rhizoph.) 36.

apenendioulosa (Anthostomella ) l Is.

applanata (Amphisph.) (20m) 110 .

aynatica (Psilope) lot.

a(puila (Rosell.) (ISW) Joti.

aquilina (Mroosph.) 11:3.

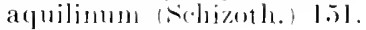

Arachoniot an: 7 l.

Ara(duojerziza 17:.

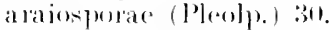

aranrosa (Rosill.) loti.

arlocescoms (Peromosp.) is.

artii (l)ials.) 1:2-

Arevia 14.

arevroicles (lamprod.) 23.

a renarias (Peromospe) .j.

a roillacea (rilor.) (s) 4 .

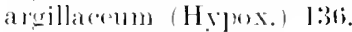

arems (Mass.) II!s.

ariae (1)(2mote) 15.).

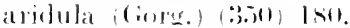

artemisiar (Prenole) ltit.

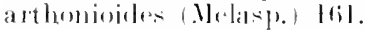

almortinarea (Leptosph.) Ilti.

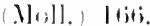

(sitiol. 145.

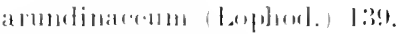

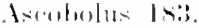

Areosenticinme tis.

Ancolilater ti.i.

Ascophandis IsI.

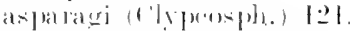

as

Asprerillus 7.2 .

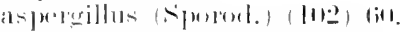

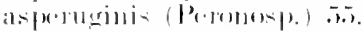

aspredicola llym:onrese) ITS.

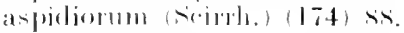

Astroma Ts.

astrome (IYomple) 11:3.

astemphora (Pxid. s:?. asterophora (siapol.) 46.

astragali (Erys.) 7ti.

astrantiale (Fabr.) (3201) 16.5

atra (Amamroch.) (42) 24 .

(He) 20114

at lata (Moll.) loti

- (l'atellar.) (312) 16:2.

atcofusem (Ascol). 1s:3.

aucoupariate (siderot.) 17.2.

Aurswaldii (Dedits(ch.) + Is.i) 104. (Vals.) l:24.

anlicace (1 mpe) (i).).

Aulographum 140.

aturantia (Aleur.) (37) I!K.

anrantiaca (cribr.) (9) !)

(siparest.) s.

aurantius (Hypom.) s:3.

aurea (1'rptosporella) l:3.

(Taph.) (l:27) (ix.

alurelia (Araclanolu) (:3:34) 172

allreum (siruchetr.) :3]

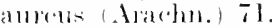

bacearum (sederet.) (:3:2) $17: 2$

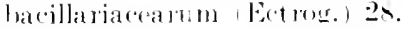

Bacillus :2.

Bacterinm 2.

Bactmejora latl.

Balliamia li.

batia (Plic.) Ist.

Bimuleri (Eryse) Ta.

(1)ulu.) i7n.

bialsatmia I!):

barlata (lachucll.) 17.5.

liarya sti.

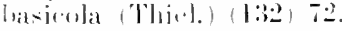

biardioludus bit.

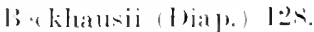

licesiatea 2

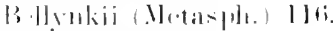

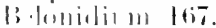

li fonidla | ti. .

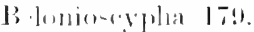

l) Junima lo 7 .

In me-llatal (Moll.) Ititi.

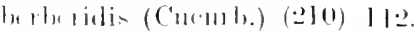

(bothichlas) st.

- (Miarajh.) (1+1) 7 .

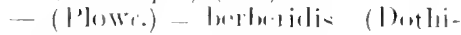
(lilla)

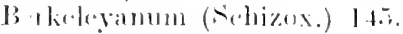

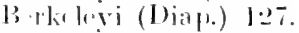

(liculat.) len. 
Bertia 10\%.

betulae (Cryptosp.) 131.

- (Psendor.) (:45) 132.

- (Taph.) 6!).

betuli (Diap.) 1:30.

betulicola (Moll.) (3:23) 166.

betulina (Emrach.) (172) s.9. - (Taph.) 6is.

Biatorella 160.

bicolor (Lachn.) (339) 175.

bifrous (Hyposp.) l:l.

bistortae (Pundorh.) (290) ijl.

bliti (Alb.) 5:2.

bobemica (Verp.) (3!17) :3.33.

bolatic (Rutstr.) 17l.

Bumbardia lo6.

lotrydioides (Nacroch.) (6.5) 40.

Butryoyhaeria 133.

botrys ( $\mathrm{H}_{y j}$ ox. $) 135$.

bestrytic (Trich.) (17) 12.

Boudiera lso.

Jrassiode (0)p.) (49) 29 .

- (Plasmod.) 6.

(Sord.) 10:3.

brassicicola (Mycosph.) 113.

Brammii (Aplan.) (sol) 49. (Rhizopht.) (6i:) : 8 .

Brefeldia 24 .

B efeldii (chactorl.) bi.

B:t mia 54.

beripila (Beleniolla) 165.

bue ripes (Muc.) ng.

Briardia 14:3.

hrumale (Tuh.) (:306) T!)6.

brmea (Larhorra) lsti.

lyrumeola (bidrmosph.) 116.

Inyomiae (I)idrmella) lli.

lutenia (Phore) 119.

Bulgaria 154.

l.ullata (Diatr.) 13:2.

-.. (Taph.) 69.

Bulliardi (Molowe) l:34.

— (Xumm.) (25:3) 1:34.

lulligera (Entoplol.) 35.

butomi (Thyoul.) 42.

huxi (Hyponectr) 82.

(Lis.) 8:?

(actormm (l'h.etopheth.) (sis) it.

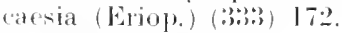

(Moll.) 16ti.

(acsium (Ayre) 15it.

(alami (Ihisol.) 4.. calieiformis (Dasysc.) 174.

caliciiforme (Tryibl.) (280) 146.

Calloria 163.

Calomectria 86.

Calosphaeria 132.

Calospora 132.

ralotheca (Peromosp.) 5.3.

cancellatum (Dict.) (10) 10 .

candolabrum (Mort.) 62.

candida (Alb.) (84) 5.

(Peromosp.) 5.5.

randidus (Arachn.) 71.

canescens (Leptosp.) 105.

canimus (Rhvp) 182

capillata (Abs.) (104) (601

(apitata (Cordic.) 8.

(apnorlinm 78.

capreae (Linosl.) (2:3:3) 121.

caragarae (Errs.) 76.

earhonaria (Geop.) ] $8 \mathrm{~s}$.

earduorum (Nipt.) 166.

carneoalbus (Oom.) (16.5) 86 .

(armens (Ascople.) (3.)2) 18.2.

(arminlica (Microp.) 7 s.

(arpinea (Dermat.) 15.5.

(tuign.) 114.

(arpini (Taph.) 69.

(arpophila (Xyl.) (2.s) 1:36.

(a) jophihm (Rhizoph.) :36.

(arthusiana (Mr.lane.) l:31.

(atenaria 41.

catimus (reop.) Ist.

(ancers (ciloor.) 17 tל.

(audata (Leptol.) 4!).

(leptosp.) 10.)

(aulium (Lophiest.) (206i) 111.

('cidium lofi.

('enangium lis.

couisia (Vals.) I25.

('rphalotheca 72.

cerasi (1)emat.) (29:5) lin.

- (selerot.) 17:.

(Taph.) 69.

(Vont.) 115.

(rastiormm (Fabre) lli.i.

cerastis (comom.) l:0).

C'ratiomyas s.

("ratophola (lak.) (20:3) las.

creatospharria bos.

('Patostoms los.

(cratostomedla los.

(crebri omis (llyluob.) (I:Se) 74.

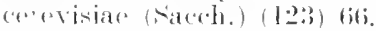


ecrina (1)asyse) 174.

('satianus (tphiol.) Ils.

Csatii (Poc.) 180.

(x) vinus (Elath.) (1:37) 73.

- (1) youn.) 8.3.

('hactoc'achiom tiz.

Chactomium 102.

chaetomimn (6'or) (192) 106.

('hactos hacria $\mathbf{1 0 7 .}$

Chastostyli on 6].

(hamar mori (Cnom.) 120.

dhartarum (chatom.) (179) 103.

(Mrxot.) (1:30) 71 .

chasticola (Neet.) 84.

('hateri (Laclunea) 186.

(hionca (Mclanospe) (1.5) 81 .

(hamidothrix 2.

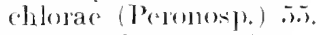

chlorosplenism 170.

( hoinomyees 74 .

Chondrioglema lis.

('homdromyees 4.

chrysophthalma (Lachnelhula) (3335) 174.

chrysosjermus (Hyjom.) (1.57) 8.3. chysosplenii (Peronosp.) 5.5.

(hrysospora (19urn.) IIs.

Chytridium 38.

('iboria 171.

(cilborioides (siclerot.) 172.

cichoriacearum (Erys.) 76.

rionkowskia 17.

('inkowkiana (Entoph.) (53) 3.5.

ciliare (Tachm.) (3401) 176.

cincta (Vaks) 124.

cinerea (Are.) 15.

- (cordic.) 85.

- Moll. (32) l66.

- (0.trop) (262) 139.

eineremom (l'hys.) (29) ls.

cinnabarina (Xect.) (I5.9) S.).

(innamomea (Dermat.) 15.).

circinans (cuklon.) (391) 2016.

(irejnella 60 .

cireinclloides (Muc.) 5e.

(ireumvaga (1) reosph.) 114.

citrina (11ypoe.) 85.

(.itrinum (Hel.) (347) 179.

Cladochytriun 4:.

('ladothrix :2.

clandestina (Inc.) 77 .

clandestinum (Jachu.) 176.

elavariar (Rosell.) 106. clavata (Hemitr) 13.

- (Spathul.) (388) 201.

clavatum (Podoch.) (59) 3s

Claviceps 87 .

clavos (bidrun.) 21.

- (cmlr.) (326) 169.

clematidis (Jleosp.) 119.

clemens (conida) 1.50 .

('lithris l 4 s.

closterij (Aneyl.) (7:3) 4.5.

crpeata (Anthostomella) (2:3i) i:l.

(lypeosphacria 1:21.

coecinea (raweose) (32s) 170.

(oocejnella (bo.) (3l.i) l(i:).

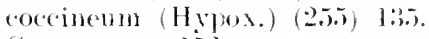

rocomyeres lis.

('occophacidium 14s.

cochleata (Otin.) 191.

coerulescens (Taph.) tis

cohacens (Hyjox.) 13.5.

coleroa lofi.

('omatricha 2:3.

comatum (1 hactom.) lo:?.

commone (Hyporl.) 138.

commutata (Patellea) (306i) Itir.

complanatum (1)ielym.) (:3i) : 3 .

complens (fompl.) (117) bit.

Completoria tit.

compresisa (1)ur.) I6l.

compressula (190mop.) 164.

compressum (Acrosp.) (269) 141 .

(Phiss.) ls.

(19latist.) 111.

- (Platyist.) 111.

comprimens (Latrost.) $: 37$.

concentriea (1)alel.) (254) l:34.

conglonerata (Peronesp.) i.t.

conica (Eutomophth.) 6:3.

(Horeh.) (30.4) 202.2

(Vipa) 2013.3.

fonida loti.

('onidiobolas 6it.

('oujuncta (1)iap.) 1:30.

commivens (1)mi.) (311) 16il.

(onojedea (1)idrmosph.) 114.

conosum (curi.) (177) (10.

conspersa ('Trup.) 156.

(onstellat io (Plicariella) I8.T.

contextum (l'hys.) 18.

contorta (Hy joe.) 85.

- (Trich.) (l6) 12.

controversum (lachn.) 176.

(Cookeana (Cuign.) 114. 
(eoprophila (sord.) 104

eordata (Syneeph.) (113) 6:2.

Cordiceps 87.

('orni (Diap.) 130.

- (Physal.) 115.

corniformis (Xyl.) 137.

cormu (Synceph.) (114) 6\%.

cormitum (Rihizoph.) 37.

Comuvia 13.

coronaria (Sacrosph.) (363) 187.

colonata (Cyath.) (343) 177.

- (Pyren.) 118

- (Vals.) 125.

coronatus (Coccom.) (289) 1.5l.

eorticalis (Perich.) (21) 14.

- (Laehnell.) (338) 175.

corvina (Onyg.) 73.

corvdalis (Peronosp.) 5. .

corvlea (Phyllact.) (143) 76.

corvli (Mam.) 120.

- (Nect.) 84.

corylina (cryptosp.) 1:31.

Coryne 170.

eosmariospora (Nect.) $8 t$. erassicollis (Diap.) 128.

erataegi (Diap.) 130.

- (Myeosph, ) 114.

- (Otth.) 112 .

- (Taph.) 69.

- (Vent.) 115.

Craterium 17.

craterium (Geop.) 188.

-- (Troeh.) 150.

Genothrix 2.

Cilibaria 9.

crispra (Clifhr.) 150.

- (Helv.) 204.

cristallinum (Lachn.) 175.

cristallinus (Philob.) (109) 61.

cristata (Lophiella) 110.

eroeatus (Chondrom.) (2) $t$.

cruciferamm (llyeosph.) 11:.

Crumenula 157.

('rustaeeum (Penie.) (134) 72.

erustae us (12hyp.) (355) 182.

Cryptodiscus 144.

Cryptomyees 150.

Cryptospora l:31.

(ryptosporella 131.

Cienomyees 71 .

enbienlare (Anth.) 126.

cucullata (Mitr.) (385) 199.

Cucurbitaria 112. encurbitula (Nect.) 84 .

Cudonia 200 .

Cudoniella 200.

culmicola (Hrmenose.) 178.

culmifraga (Leptosph.) 117.

eulmorum (Leptosph.) 116.

cupularis (Geop.) (367) 188.

- (Nitsehk.) (207) 111.

('ulreya 90.

C'urrevi (Phore.) 119.

- (Vals.) 126.

curvatum (Hrsterogr.) 140.

(urvula (Sord.) 104.

evanogena (Gibberell.) 8.i.

(ivathicula 177.

cyathoidea (Hymenose.) (34.5) 178.

erclotellae (Rhizoph.) 37.

eyti-i (Mieroth.) 78.

Daldinia 134.

Dangeardia 35.

Dasyserpha 174.

de Baryanum (Phyth.) (83) 5.2 .

decipi ns (Endom.) (125) 66.

- (Sord.) 103.

decora (Caloneet.) (161) 86.

deeoricans (Vals.) 125.

deerrata (Hum.) 190.

deformans (Hypom.) 83.

- (Taph.) 69.

Delitschia 104.

dentatum (Phlyctoch.) 37.

deusa (Plasmop.) 54.

depauperatus (Saceob.) 18:.

d pazciformis (Mycosph.) 113.

depressa (Perich.) 14.

depressum (Chondriod.) 20.

Delmatea 154.

Desmazierella 174 .

destruens (Conida) 1.56.

detrusa (Diap.) 1:30.

Diachea 20 .

dianthi (Peronosp.) 55.

Diaporthe 127.

diatrya (Vals.) 12t.

Diatrype 132.

Diatrypella 1:3:.

Dichaena 139.

Dictydium 10.

Dietyostelium 5.

Dietyuchus 48.

dideima (Plıss.) 18.

Didvmella liñ. 
Dirlymium 21 .

bidymosphacia 116.

lifforme (I)idym.) 21 .

discitata (Xyl.) 137 .

Dilophia 116.

dilutella (Nipt.) 166 .

Dimerosporium $7 \%$.

dioica (riaprol.) 47.

Diplophlyct is 35 .

dipsaci (Pronosp.) iti.

disciformis (Diatr.) (2075) 1:32.

Discina Is?.

(liscors (Pleosp.) 117.

(Hiscospora (sord.) lo:3.

(lissepta (Quaterus.) 1333.

ditisima (Nect.) s.j.

bitopella 1:0.

ditricha (Vist.) (2:Ifi) 11.

dolabriforme (Loph.) $1+1$.

dolioloickes (Leptusjo.) (21!) 117.

doliolum (Levtosph.) 117.

fomesticum (19ron.) 192.

Dothidea 87 .

Dothidella 88.

Dothiora 90.

drvina (Bactr.) (30.5) 160.

drophihm (Tub.) 197.

Jivella 161.

Iurieuana (sclerot.) 172.

ehurnea (Massarina) 119.

echimulatum (Lachn.) 17t.

Ectrogella 2 s.

effusa (Lindb].) (7) 9 .

(Perougese) कis.

Ela phomperes $7: 3$.

watal (Moreh.) 2012.2.

alastical (Holve) (3!)!9) 2(1.4.

clatina (P'stuclogr.) Jin.

- (Rutstr) 171.

Cegans (Helicost.) (I0T) 6il.

- (Novakowskirlla) (tio) 41 .

-. (Rhiz.) bit.

-. (Thamn.) (I0.j) (il.

Eleutheromyers 82.

"Mipnoidens" (Facell.) fif.

clongata (cuculd.) 112.

emelerens (Phraymom.) (274) 144.

empetic (lihyt.) 1.iz.

- (Sphacrop.) (287) 151.

Empusa 63.

encephaloides (Amyl.) (13:5) 73.

Enchnoa 11!. endolsioticum (sivellytr) :30.

Enclodothella 89.

(mologena (sphaerit.) 2s.

endogenum (Olp.) 29.

Endegone 6.t.

Endompees 6ti.

enceans (hagen.) 45.

Enerthene ma 2:3.

Entrorium 11 .

Entomophthora ti:

entomonhiza (corlice) st.

Entophlyctis :3.5.

eniophytum (Achlyog.) (71) 44.

- (Lagen.) 4.i.

- (1)]p.) 29.

"phippium (Holr.) (39s) 204.

epiblastematica (Ficut.) 1.ig.

"pilolum (Theloc.) \$2.

Ejuibloe sti.

(2)icrmatia (Phare.) (21:3) 114.

rpiclendrum (Lroogr.) (2.3) 11.

rpidermidis (bidymosh.) 116.

rpilobii (Guign.) 114.

- (Plasmoje) 54.

epiphylla ('laph.) 69.

epiphytica (Chlamydothr.) :3.

elisphaeria (Nect.) s4.

epithemiae (Chytr.) 38.

cquina (Onyg.) (1:36) $7: 3$.

equinus (Lasjob.) (3.5l) 179.

equiseti (stamn.) (:325) 169.

equorum (Hypor.) $/(14$.

"ranthidis (Teronosp.) .5.).

Eremascus 66.

('los (I)iap.) l:s.

ericale (codre) list.

ericetormm (celisl.) biti.

Erinclla $17 \%$.

Eirumeziza 17:2.

(r)ngii (Jyenth.) ]l:3. (I'veriop.) ltit.

Eresiplis: 76.

(rithrospons (Ophiob.) 118.

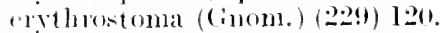

(ciulenta (Girom.) (395) 203.

- (Moreh. 2012.

(merlenae (Phlyetoch.) :37.

- (Polvph.) (6it) 40.

(unomia (Vals.) 122.

(1)phorhiae (Teronosp.) (93) 55.

Euryachora 8!.

eut vipa (Vals.) (235) 123.

evomymi (Erss) 76. 
exasperans (1)iap.) 130.

excaratum (Tub.) (382) 194.

exigua (Vals.) 125.

exosporioides (Niessl) 106.

Fabraea 164.

faginea (Dich.) (261) 139.

- (Prop.) (273) 144.

fallax (Trich.) 12.

farinaceum (Didym.) 21.

fasciculata (Bomb.) (191) 106.

- (Diap.) 128.

faracea (Diatryella) 1:33.

faroginea (Trich.) 12.

Ferrestella 130.

fenestrans (Didymella) 11.i.

ferax (Pyth.) :0

ferruginea (Are.) 14.

- (Gallion.) 3.

ferrugineum (Melogr.) 134 .

fertilis (Vals.) 123.

festucae (Physal.) (215) 11.).

fibrosa (Diap.) 130.

fieariae (Peromosp.) 5.5.

filicina (Taph.) 68.

filicinus (Rhopogr.) (175) s9.

filicum (Myeosph.) 113.

filiformis (Xyl.) 137.

fimbriata (Mam.) (226) 1201 .

finctaria (spor.) 104.

fimeti (Hypoc.) 104.

- (Plic.) 187.

fimicola (sort.) (182) 103.

fimiseda (Sorrl.) 104.

firma (Rutstr.) (390) 171.

flaceida (Stem.) 23.

flammea (Lachnell.) (337) 174.

flammulae (Physod.) 43.

flavofuligineum (Lachn.) 176.

flavofuseum (Lycos.) 11.

flavogenita (stem.) 23.

flavorireseens (Vals.) 12:3.

flexella (Patin.) 160.

flexuosa (Licea) ([2) 10 .

floriforme (Chondriod.) 20).

fordans (llass.) 119

foliicola (Badh.) 17.

forabilis (Diap.) 128.

tragariae (1lyeosph.) 113.

fragiformis (Bals.) 193.

- (Tubul.) (11) 10.

fragilis (Leoc.) (27) 17.

frangulae (Dermat.) (294) 15i). fraxini (Hysterogr.) (267) 140.

- (Tymp.) 156.

- (Vent.) 11.5.

Freseniana (Piptoc.) (11:2) 62.2 .

Fresenii (Chaetost.) (16(i) 61.

- (Emp.) 63.

Friesii (Vals.) 126.

fructigena (Siclerot.) 172.

Fuckeliana (iclerot.) 172.

Fuckelii (Lophiosph.) 111.

- (Nect.) 84.

fulgens (Pleotrach.) (48) 2ی.

- (Plicariclla) 18.5. (N'vnchytr.) 31.

fulisinea (Plicarictla) Is.s.

Fuligo 16.

fulvus (llyxoc.) 4.

fungicola (Hypoe.) 8.5.

furfuraceum (Cenang.) 15i.

fusarioides (Call.) (:3l6) $16 \%$.

fusca (stem.) (41) 23.

- (Tap.) (321) 165.

fuscescens (Lachn.) 176 .

- (Nphaeros.) (384) 198.

fuscum (Hypox.) 136.

- (Polvang.) 4.

fusiforme (Pseudolp.) 27.

fusiger (spin.) 60.

fusispora (Ditop.) (228) 120.

- (Hum.) 189.

Galaetinia 190.

galanthi (Sclerot.) 172 .

galcopsidis (Erys.) 76.

galii (Mazz.) (168) 82.

galii veri (Beloniella) 16.5.

Gallionclla 2.

gallica (Pirott.) (319) 164.

ralligena (Nectr.) 85.

gastrinum (Anth.) 126.

gelatinosa (Hypoc.) 8.).

- (Leot.) (389) 200).

gommifertom (Tichoth.) 114.

gemmigenum (Mytil.) 141.

Genea 193.

Geoglossum 199.

geophana (Biator.) 160.

(ieopyxis 188.

geranii (Eurvach.) geranii (stigmat.).

- (stigmat.) 112.

Gerhardtii (Physod.) 42.

sermanica (Vals.) 125. 
Gibbera 112 .

Gibberella 86 .

Gibberidea 112.

gibhosum (Rhitoph.) 3\%.

gigas (Gyrom.) (396) 203.

- (Moreh.) 201.

glaber (Ascol.) 18.3 .

glaucus (Asp.) (133) 72 .

globosum (Rhizoph.) 36 .

- (sareos.) 15t.

- (Srnehrtr.) 32.

glomerata (Wor.) 27.

Glonium 14t).

ghutinosum (Geogl.) 199.

Gnomonia l:0.

Ginomoniella 1:00.

Godronia 157 .

Gorgoniceps 180.

gracile (Nematosp.) il.

gracilipes (Achl.) 4s.

graminicola (Nect.) sit. (siclerosp.) (s7) it.

graminis (Beloniella) l6i.

- (1)iloph.) (218) 116.

- (Erys.) 7.5.

- (Phillaet.) (169) 89.

- (Physod.) 42.

granulata (Hum.) 190.

graphicnm (Glon.) 140.

gregaria (Lachnea) 186.

gresarium (Olp.) 29.

grisea (Peronosp.) 56.

grossulariae (Hicrosph.) 7 .

Guignardia 114.

(inttulina 5 .

Guttuinolsis is.

Grmuoascus 71 .

Givomitra 262.

hapalocystis (Pseudor.) 13:2.

Haypochytrium 3.5 .

Heclenii (Harpoch.) (55) 35.

hedericola (Mveosph.) 114.

heleocharidis (Physod.) 4?.

helicicola (Metasph.) 116.

Helieostylum 6l.

Helotium 179.

Helvella 204 .

hemisphacrica (Lachnea) (361) 186.

hemisphaericum (telont.) (281) 146.

Hemitriehia 1:3.

herbarum (Hel.) (348) 179.

- (Pleosp.) (2.2) 118. herpotricha (Ophioch.) 117.

Herpotrichia $10 \%$.

herpotrichoides (Leptosph.) 117.

Heterosphaeria 146.

hirsuta (Lasiosph.) (197) 107.

hirsutum (creogl.) (387) 199.

hispida (Lasioph.) 107.

hispidula (fien.) 193.

Hoffmanni (Vals.) 125.

Holmskjoldii (Aseoph.) 181.

holostei (Peronosp.) 5.).

Homostegia 89.

humana (Sord.) 103.

Humaria 1S:.

humuli ( $\mathrm{Hel}$.) 180.

- (Sphaer.) (140) 万.

hvalina (Badlh.) (25) 16.

- (Hrmenose.) (344) 178.

hrbrida (Noreh.) (393) 201.

Hydnobolites 74 .

hridnosporum (Prth.) 5l.

Hydnotria l!4.

hridrodictri (Phlyetoch.) 37.

hivdrophila (Tap.) 16.5.

Hymenoserpha $17 \%$.

Hypocopra 104.

Hipocrea 8.5 .

Hipoderma $13 \mathrm{~s}$.

Hypodermella 138.

hypodermia (Cryptosporella) (24l) 131.

hypogyna (saprol.) 47.

Hypomyces 8.3 .

Hiponertria 82.

Hyospila 121 .

Hypoxylon 134.

hypoxylon (Xyl.) (2.5) 136.

hysterioitles (Lophod.) 139.

- (Phramon.) 144.

Hrsterium 140.

Hyiterographium 140.

Histeropatella 161.

jassi (Emp.) 63.

idaei (Plivsal.) 115.

ignavis (Ftriek.) 110.

ilicis (Troch.) (286) 148.

immersus (Ascob.) (35s) 18.3.

inaequalis (1)iap.) 128.

- (Vent.) 115.

incarnata (Are.) 14.

inearnatus (Laehnob.) (20) 14.

infernalis (Enchm.) (223) 119. 
infestans (Phytophth.) 5t. inflata (Phizin.) (383) 197. infula (Grom.) 203. inquilina (Diap.) 127 . inquinans (Mass.) (2.24) 119 insidiosum (Lophiost.) 111. insignis (Diap.) 128. insititiae (Taph.) 69. insitivum (Mrrm.) 133. inspersa (Leciogr.) 160 . insularis (Diap.) 130 . intermedia (spor.) (186) 104. intermedium (Phyth.) 52. intermixta (sphaerul.) (2l4) Ils. intestina (Diplophl.) (54) 35. Johansoni (Taph.) 68. .Jonesii (Chaetocl.) (111) 6:2. iridis (Phrsod.) 42.

irregularis (Pseudor) 132.. isariphora (Iycosph.) 113. junci (Endodoth.) 89.

- (Scirr.) = junci (Endodoth.). juncicola (Erin.) (341) $17 \%$. juniperinum (Lophod.) 139.

Karschia 160.

Kerverni (saccob.) 18.5.

Kleinii (Pilob.) 61.

Klotzschii (Gen.) 194.

Kochii (strick.) 110.

Kriegeriana (Lrophl.) (70) 43. Kimzei (Lahm.) (314) 16:2.

laburni (Cucurb.) 112.

lacerum (Phac.) 150.

Lachnea 186.

Lachnella 175.

Lachnellula 174.

Lachnobolus 13.

Lachnum 175.

lacteus (Leptom.) (81) 48. lactucae (Brem.) (90) 5.5. lacunosa (Helv.) (400) 204 . lacustre (Belonid.) 166. lacustris (Metasph.) 116. laetum (Srnchytr.) 31. laeris (Aphan.) 49. lagenaria (Melanosp.) sl. lacenariae (Chyts.) 3s. Lagenidium 45 . lasenula (Rhizoph.) 36. Lahmia 162 . lamii (Peronosp.) 5.).
Lamproderma $\mathbf{2} \mathbf{2}$.

Lamyi (Pleonect.) (16:3) st. laricis (Hypodermella) 1:3s.

Laschii (Diap.) 130 .

- (Vals.) 123.

Lasiobolus 181.

Lasiobotrys 77 .

Lasiosphaeria 107.

lata (Vals.) 12:3.

laterale (Phlyct.) 3.5.

lateritius (Hypom.) 83.

Latrostium $3 \%$.

Laureri (Theloc.) 8. .

Leciographa 159.

ledi (Pseudoph.) 14s.

leguminis crtisi (Mroosph.) 113.

leioplaca (Vals.) 123.

leiphaemia (Diap.) (239) 130.

lemnae (Olp.) 29.

Leocalpus 17.

Leotia 200 .

Lepidoderma $\underline{2}$ l.

lepigoni (Alb.) .j2.

leporina (Otid.) 191.

leporum (Hum.) 190. - (Pleophr.) (187) 104.

leproidea (Trophl.) 43.

leptoasca (Ireosph.) IIt.

Leptolegnia 48 .

Leptomitus 49 .

leptomitiformis (Begg.) 3.

leptosperma (Peronosp.) (95) 56.

Leptosphaeria 116.

Leptospora 105.

leptostyla (Gnom.) 120.

leucanthemi (Protomvoof). (i.).

leucocephalum (Crat.) $1 \%$.

leucoloma (Hum.) 189.

leucolomoides (Hum.) $19($ ).

lencophaeum (Lachn.) 176.

leucopoda (Diach.) (3:3) : 2 ().

leucostoma (Tals.) 1:4.

leucotricha (Melanosp.) sil.

- (Podos.) 76.

Libertiana (siclerot.) 17:.

Licea 10.

lichenicola (Bert.) 10\%.

- Nect.) 84.

ligniaria (Rosell.) 106.

lignicola (Moll.) 166.

lignyota (Karschia) (30s) 161 .

ligustri (Jrcosph.) 114.

lilacina (Badl..) 16. 
lilarina (6mlur.) 170.

linasiar (lemonospe) (9) it).

lindbladia !

lincitre (cilom.) (26,5) 140.

lionerix (I)iap.) 1:27.

lini (Peromosp) is.

linkii (Hrpom.) s.3.

Linospora lel.

lirella (J)iap.) 12s.

Liscal s:3.

litigiosum (Nicroth.) Ts.

lividofusca ("Tap) ) 16i.j.

lomeipes (Xyl.) l:37.

lomicrae (Lasiob.) (147) 77 .

lopliculla 110.

Iophiosphaeria 111.

lophiostoma 111.

lophiotroma 111.

lophimm $1+1$.

lophodermium 1:39.

Juridum (Hypox.) l:36.

luteserems (Taphe) (ix.

lutem (Penic.) 7:.

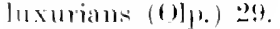

Lyogala 11.

licaperalon (lictice) (14) 11 .

matrandla (Monobl.) ti.

macoroaryea (Bathli.) 16.

(cilins.) !)

(Embos.) (1:2-2) tit.

Macereleytrimm 40.

Mareropodia Is:?.

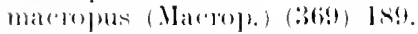

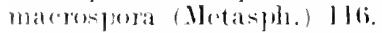

(some) los.s.

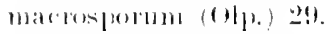

(Till.) 1!).

macrosports (Jomogra) sis.

(l'10toll1.) (121) 6.5.

macrostomum (Lophiost.) I1].

masulatix (Lejesols.) 117.

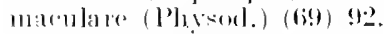

matularis (direosph.) 114.

maculiformis (Mycosph.) (2|2) 114.

(Vint.) 11.;.

matandiformis (choigoms.) (1:39) 74.

llagnusianmom (l'hsisol.) $4: 3$.

Magmusiolla 70 .

Magnusji (Endom.) tis.

major (cropl)l.) 4:3.

Hamiania 120.

mammiformis (liessell.) lo.j. mamillata (I)ance) (600) 3. mamillatum (Rhizol,h.) 36 .

Massaria $11 !$.

Massarina II!!

mastigotrichis (lihyolul.) 40.

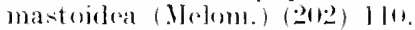

maxima (Brel.) (4:3) 24.

([s1.) (25) $1: 34$.

maximus (cretoum.) lis.

Mazmantia s:a.

molusica (l)iajo) les.

megalarauthmo (Pith.) il.

megalospora (selerot.) 17:.

(itpor.) 104.

medacna (Pscuelopl.) Is.s.

melaloma (Lachonea) lisi

Jelancomiclla 1:3:2.

Melancomic 131.

Melanomma los.

melanops (botryosh.) (2).su. 1:3:.

llelamojeamma $10 \%$.

Jelanospora sl.

melanestes (Anth.) (2:3s) lati.

melanoxauthus (l'achyphl.) :379) 194.

Melaspilea liti.

melastoma (lachonea) Isti.

Melogrammin 1:34.

Melomastial 110.

menthae (Phsedel.) 43.

menvanthis (ihrsolle) 4:3.

mescurialis (sinderte) :3:.

merelaria (Hejere) (Jist) lot.

mesocalpi (chytr.) is.

Jetasphareria 116.

mezerej (l)othidella) sis.

(I'owr.) m \%erei(l)othicledlat)

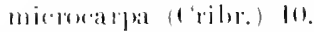

microcephalal (1'lavie) st.

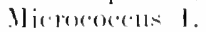

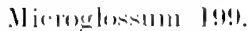

Micropeltis Ts.

mieroserejica (Bomel.) Is:.

micosecopicum (Jieroth.) (1.il) Ts,

Microspharema 76.

llicrosprisa 2.

microspora (1)idym.) 115.

(sicirlo) microspera (l)idym.).

microstoma (Vals.) Jet.

Microtlerium 78.

militaris (coldic.) st.

milliaria (Vals.) 1:3.

miniata (P'licariella) 185. 
minima (Apor.) 104.

- (Tyichosph.) 10.5.

minor (Olpidiops.) (44) 27.

minnta (Delitsch.) 104.

- (Sord.) 103.

minutissima (Naer.) (270) 143.

minutula (Naer.) 143.

minutum (C'rat.) (28) 18.

Mitrula 198.

morlesta (Leptosph.) 117.

mollis (Stiet.) 146.

Mollisia 166.

mollissimm (Lachn.) 175.

monachella (Helv.) 204.

monilifera (kaprol.) (75) 47.

monolylepharidis (Pleolp.) (51) 30.

Monoblepharis 45.

monoica (Saprol.) 47.

monospernum (Nematosp.) 5l.

monosporus (Dictyueh.) (78) 48.

Iorehella 201 .

moliformis (Bert.) (195) 107.

mors urae (Siphaer.) 75.

Nortierella 62 .

Mougeotii (Microsph.) 77.

mucedo (Nue.) (97) 59.

mueida (C'eratiom.) (6) 8.

mucilagineus (Nuc.) 59.

Nucol 59.

mucoroides (Dict yost.) 5.

mucronatum (obel.) (58) 37.

multiforme (Hypox.) 135.

muralis (Plic.) 187.

murorum (chaetom.) (180) 103.

museae (Emp.) (115) 63.

myorlerma (Hacoh.) 66.

mycophifum (Rhizid.) (62) 38.

MYeosphaerella 113.

myosotidis (Peronosp.) 5.T.

(Svnchrtr.) 32.

mriadea (Nphaerul.) 115.

miriocarpa (Vals.) 122.

myriosporus (Rhyp.) 18:.

Hymaceim 133.

Mytilidium 140.

mytilinum (Loph.) (268) 141.

Myxocoecus 4.

Mrxotriehmm 71 .

Mvzoertium 44.

Nacmacyelus 144.

Naevia 143.

napelli (Nazz.) 82. natans (Doth.) = natans (Nystr.).

- (Sphaerot.) (1) :3.

- (Systr.) 88.

necatoi ( $\mathrm{Cnc}) 77$.

Nectria 84.

Nectriella 82.

Nematosporangium 51.

Neesii (Psendotrybl.) (301) 157.

nervisequim (lophod.) 139.

Nesolechia 159.

nidulans (Asp.) 72.

- (Diap.) 1:30.

nidulus (Lachn.) 176.

Niesslia 106.

Niesslii (Nymchytr.) :32.

nigra (Comatr.) (40) $2: 3$.

niger (Amanroasc.) 71.

vigrella (Pseudopl.) (:360) 18.5.

nigrieans (Clavie.) 87.

- (Rhiz.) (103) 60.

nigrieolor (Diap.) 128.

nigripes (Didrm.) 21.

Niptera 167.

nitens (Ofigon.) 13.

- (Phyeom.) (101) (60).

Nitsehkia 111.

nivea (Plasmop.) it.

- (Vals.) (236) 124.

nivemm (Lactm.) 176.

niveus (Naemae.) (277) 145.

Notarisii (Cypeosph.) (234) I.21.

Nowakowskiella 41.

nuenla (Lophiot.) (20i5) 110.

Ninmmularia 1:34.

mutans (Are.) 15.

- (Phys.) (30) 18.

Ohducens (Ohler.) (201) 110.

-. (Plasmop.) 54. (Striek.) (204) 110.

Obelidium : :37.

oloovata (Peronosp.) 5.).

1)ellaria 14:3.

ocellata (6)(oll.) 143.

ochracea (Chlamylothr.) :2.

ochraeem (Polyst.) 82.

ochraceus (Hypom.) (15ti) 8:3.

Odontof rema 146.

oedipus (Pilob.) 6l.

ogilviensis (Lepetosplo.) 117.

GhJeria 110.

oligacantha (A.Jl.) 48. 
Oligronema 13.

olivaceum (Enterid.) (13) 11.

- (Nierogl.) 199.

"Ila (Chytr.) (61) 38.

(1)pidiopsis 26 .

()]pidium 29 .

()mbroplita 169.

omphalodes (Pyron.) (374) 192.

oncostoma (1)iajp.) 1:30.

onotica (Otid.) (372) 191.

Onverena $7: 3$.

oocardii (T'silop.) (373) 192.

()omyces 86 .

operculata (Vals.) 12:3.

()phiobolus 117.

Gphiochasta 117.

ophioglossoides (Cordic.) (166) 87.

- (Geogl.) 199.

orbicularis (T'leosp.) 118.

Orbilia 163.

orthoceras (Diaj). 127.

Ost ropa 139.

Utidea 191 .

()thia 112 .

orina (Leptosp.) 10.5.

oroidea (Zign.) 107.

oxyacanthae (Podos.) (141) 76 .

oxycoeci (s.elerot.) 171.

oxypora (Nesol.) (303) 59.

uxysporella (Nesol.) 159.

pachydermus (Protom.) 6.5.

Paclivphlocus 194.

padi (Sclerot.) 172.

- (Vals.) 124.

pallidus (croptod.) (275) 144.

pandani (Nect.) 84.

panicea (Badh.) 17.

jamosa (splaer.) 75.

papillata (Enerth.) (39) 23.

(King.) los.

parallela (Vals.) 122.

parasitica (liar.) 86 .

- (Peromosp.) (91) 5.5.

(Tetram.) 6.

pardalota (Diap.) 128.

parietina (Anix.) (146) 7 .

parmeliarum (Abroth.) 159.

patella (Heterosph.) (28:) 146.

Patellaria 161.

Patellea 160.

patens (Lachn.) 177.

Patinella 160.
I'elletieri (Rhyp.) (354) Is:

peltigerae (Phragmon.) 144 .

pendulum (0)

Penicillium 72.

Periehaena 14.

Perisporium 78.

Peronospora 5.5.

persimilis (Trich.) 12.

pertusa (Tremat.) (203) 110.

petiolaris (Troch.) 150 .

peziza (Nect.) 84.

Phacidium 150.

Phacopsis 156 .

phaea (Tremat.) 110.

phaeocomes (Prren.) 11s.

phalloides (Mitr.) 199.

Pharcidia 114.

Phlyctidim 35.

Phlyctochytrium 37.

Phomatospora 120.

Phoreys 119.

Phragmonaeria 144.

Phycomyces 60 .

phycophilus (Aphan.) 4!).

Phyllachora 89.

Phyllactinia 76 .

phyllophilum (Hel.) 180.

l'hysalospora 114.

physaroides (Lamprod.) (38) 22.

Physarum 17.

Physoderma 42.

phiteumatis (Teionosp.) iff.

Hhytoplathora 52.

Piercotii (Homost.) (178) s!?.

Pilaira 61.

pilifera (ceratostomella) (199) 117.

pilificum (Evoncluytr.) 31.

Pibobohus rii.

pilosa (Trichosph.) (J88) 10.5.

pinastri (Lophed.) (2601) 139.

- (Microth.) Ts.

- (Tryblicliops.) (279) 146.

- (1'Tum.) (29.5) 155.

pineti (Belon.) 179.

pinetorum (Herpotr.) (196i) 10..

pini (Coccoph.) (284) 148.

- (Vals.) 12.5.

pinicola (Biator.) 160 .

- (crum.) (3001) 157.

P'iptocephalis 62 .

pirifera (Apodachl.) (82) 49.

piriformis (Cribr.) 9.

pirina (Vent.) 115. 
Pirottaea $16 t$.

pisiformis (Endog.) 64.

Pitya $17 \%$.

pityophila (Cueurb.) 112.

Plasmodiophora 6.

Plasmopar'a 54.

platanoides (Calosp.) 132.

Platystomum 111.

pleiospora (Sord.) 103.

Pleolpidium 30.

Pleomassaria 119.

Pleonectria 86.

Pleophragmia 104.

Pleospora 118.

Pleotrachelus 28 .

Plicaria I8T

Plicariella 185.

poae (Nipt.) 167.

Poeillum 180.

Podochytrium 38.

Podospliaera 75

pollinis (Rhizoph.) (56) 36 .

polvandra (Achl.) 48.

Polvangium 4.

polycephala (Mort.) $6 \%$.

polveystis (Wor.) (46) 26 .

polygoni (Erys.) (142) 76 .

- (Moll.) 166.

polymorpha (Bulg.) (292) $\mathbf{5} 54$.

- (Monobl.) (74) 45 .

- (Xyl.) (256) 136.

Polyphagus 40 .

lolysphondylium 5.

polyspora (C'renothr.) 3.

Polystigma 82.

pomiformis (Nelanops.) (194) 107.

populina (Cryptosporella) 131.

- (Linosp.) 121.

- (Vals.) 122.

populnewm (C'enang.) 157.

Poronia 137.

porphyrogenus (Ophiob. (220) 117.

portulacae (Alb.) 52.

potentillae (Coler.) 106.

- (Magnusiell.) 70.

- (Peronosp.) 55.

- (Fynchytr.) 32.

- (Taph.) 69.

praemorsum (Lophiot.) 111.

Pragmopora 162.

princeps (Fenest.) 131.

prolifera (Achl.) 48.

proliferum (Myzoc.) 44. proliferum (Pvth.) sl.

Propolis 144.

Prostii (Hysterop.) (3111) 161.

Protomyces 65.

Protomyeopsis 65.

protracta (Diap.) 128.

- (Sareose.) 170.

- (Vals.) 122.

proxima (Patellar.) 162.

proximella (Didrmella) 115.

- (Melasp.) (309) 161.

prunastri (Dermat.) 155.

- (Enc.) 77.

-C(Tal2.) 124.

pruni (Taph.) 69.

Pseudographis 150.

Pseudolpidiopsis 28.

Pseudolpidium 27.

Psendomonas 2.

Psendopeziza 164.

Psendophacidium 148.

Pscudoplectania 185.

pseudoplatani (Tals.) 1:20.

Pseudorhytisma 151.

Pseudotryblidium $15 \%$.

pseudotuberosa (s'clerot.) 172.

Pseudovalsa 131.

pseudotuberosa (felerot.) 172 .

Pseudovalsa 131.

Psilopezia 191.

psittacinum (Phys.) 18.

ptarmicae (Schizoth.) (288) $15 \mathrm{l}$.

pteridis (Cryptom.) lin.

- (Dasyse.) 174.

- (Rhopogr.) $=$ filicinus (Rho. pogr.).

puberulum (Tub.) 197.

puccinioides $($ Doth.) = puceinioides (Systr.).

- (Sistr.) (171) s!.

pulchella (Calosph.) $1: 32$.

puleherrimus (lasiob.) IS1.

pulehra (Selin.) 82.

pulchrum (Dimerosp.) (148) 77.

pulicare (Hyst.) (266) 140.

pulicaris (Gibberell.) (16:) 86 .

pulla (Diap.) 128.

- (Helv.) 204.

pulposa (Crophl.) 43.

pulveracea (Rosell.) 105.

pulverulenta (Dasyse.) 174.

pulvinata (Diatryjella) 13:3.

pulvis pyrius (Melanom.) (198) 108. 
junctata (19rom.) (2.59) 187.

punctatum (sinchetr.) $3: 2$.

puncetiformis (Hymenose) lis.

(1)resph.) 114.

punctojilea (fuigne) 114

(Hrmemose.) 17s.

punicea (Asc.) (2.2) 14.

pmpula (Mar..) 119 .

purpuraserens (Briard.) (272) $14 \%$.

jurpurea (19avice) (167) 87.

pripureum (Hypox.) l35.

finsilla (t'alospli.) l:32.

(ceratosph.) Jus.

(licea) Io.

(llitr.) l!)!.

(Nar.v.) 14:3.

(Nies.el.) (193) 1117.

(Plasmope) 5t.

pusillus (Mhu, 59.

pustula (Hyposp) (28:2) l:2 1.

pustulata (Diaj\%) 1:30.

(Plic.) (::60.3) lss.

(Vals.) 1:2t.

putator (Diap.) 1:30.

lisomaca (Tlasmop.) (so) it.

firmaemom (Lagene) 4.i.

firenoperiza lit.

Pirmophora $11 \mathrm{~s}$.

Pyonema 1!2.

Pitlium il.

Pyoliephora si:

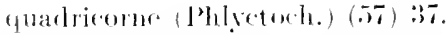

(Jllaternaria l:o:

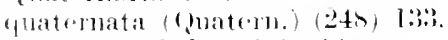

furcurna (clith.) (2).s) 14s.

(l)iatripellat (24!1) l:3:i.

(I)icl., l:3:?.

Rabmhorstii (Laturon.) (72) 45. racemosa (.Arhl.) (7T) $4 \mathrm{~s}$. garromosus (Mute) 5!!.

ratiata (Nict.) (27s) 145 .

radiatum (chondriod.) (3:2) 20 .

radii (Peromosp.) (!6i) 57.

Ramamnamo (.Mue.) (!s) 5!!. ramealis (Nipt.) (324) 16 .

ramigera (\%orel.) :3.

ranarum (Basidioh.) (1]!) fit. lanunculi (Falus.) lis.

rapulum (Tarz) (364) 187.
Recssii (crmn.) (129) 7l.

relicina (jyven.) Ils.

Jepancla (Ṕlic.) Is:.

repandum (Phac.) 150

resecans (1)iaj.) 128.

resinae (Biator.) (367) lfill.

Reticularia II.

reticulata ('icuk.) (26) 17.

revollens (Diap.) 130.

rhacodium (Lasiosph.) 107.

rhenama (Cratospli.) Ios.

rhizidioides (Amoehech.) riti 41 .

Rhizidium :ss.

Rhizina $19 \%$.

rhizina (Entophl.) 35.

rhizinodese (Psiloje) 192.

Rhizophirlium 3.5.

rhizophila (\%opf.) (149) ד.

lihizophlyetis : $x$.

rhizophora (Tajh.) (is.

Rhizopms 60.

thotodendri (Jlelanome) lus.

- (Psemeloph.) 148.

(sclerot.) 172 .

rhodostoma (Pleomass.) (2.2) 114.

lihopographus 89.

lihvenclostoma 130 .

lilivparoloins 18:.

Rhitisma 1.2.2.

rhytismoides (Hyposp) l2l.

ribesia (1)othirdella) (170) s.

- (1'lowr.) = ribesia (I)ethiel.).

- (Folerod.) (26:3) 147.

rimosa (sicirr.) (173) s?.

rimosipes (Morrh.) 2011.

riparia (finom.) 1:20.

liobereara l:39.

molertiani (stiem.) (2ll) ll:.

gosar (r)th.) 11:2.

- ('Tape) lifi.

resia (Guttul.) $\bar{~}$.

(lihizophl.) $41 \%$.

liosellinia 10.5 .

rescellus (11ypom.) s.3.

Rostafinskii (Mort.) (1)61) (i2.

postrllata (1)iap.) 1:30.

restrata (ceratostomella) Ins.

liostrupiana (Taph.) (69.

Reusseliana (Neetriella) (1.i:) $\$ 2$.

Rozella 27.

rubescons (Ascoid.) (1201) 6i.j.

rubi (Herpotr.) 105.

- (Pyrenop.) (31s) 164. 
rubiformis (Hemitr.) (18) 1:?. rubiginosum (Hypox.) 135. rublicosn (Myrm.) (251) 1:3:3. rubrocinctum (Eynchytr.) 32. rubrum (Polyst.) (15.5) 82. rudis (Diap.) les. (Ophiob.) 118.

Riibsameni (Crojhl.) 4:?. rufa (Cribr.) 9.

- (Hypoe.) (160) 85.

rufofusea (Cibor.) 171.

rufum (Agrr.) (298) 156. - (Tub.) 196.

rumicis (Vent.) 115. rusci (Leptosph.) 117. rutilans (Hum.) (370) 189. rutilum (Hypox.) 13\%. Rutstroemia 171 .

Siacharomyces 66 .

saecobohus 18:3.

S'aclebeckii (Taph.) 69. salicella (Diap.) 130. salicina (Vak.) 12ti. salicium (Capn.) (250) 7R. (Rhyt.) 152.

salicis (ine.) 77 .

saligna (Tymp.) 15.

sanguinea (Patcllea) 160. saniosa (Calact.) 190.

saprolegnia 46.

saprolegniae (Ohpidiojs.) $\mathbf{2 6}$. (Pseudolp.) (45) 27.

sarcoides (coryue) (327) 170.

Narcina $\mathrm{I}$.

Sarcoscypha 170.

Sarcosona 154 .

Sarcosphaera 187.

sarothamni (Diaj).) 128.

Caubinetii (Gibberell.) 86.

scaber (Aplian.) 49.

scabra (Trich.) 12.

scabrosa (Vals.) 12:3.

Schachtii (Peronops.) (92) r.5.

richenkiana (Pseudolpidiops.) 28.

schenkii (Phlyctorh.) 37.

Schizostoma ill.

Sichizothyrium 15l.

sichizoxylon 145.

Schleideni (Perouosp.) 5.5.

schoeteri (Thysod.) 42.

schweinitzii (Vals.) 12.). scintillans (Lampood.) ․․․

seirpi lacustris (Mycosph.) 11:3.

Sicimhia 89.

sclerroder: is 146.

Selerospora 54.

Siclerotinia 171 .

Scutula 159.

scutula (Hel.) (:249) 180.

scutellata (Lachnea) (360) Isto.

Selinia 8\%.

semiimmersmu (Нурох.) 1:3.

sepincola (Vaks.) 125.

septica (Ful.) (24) 16.

septigena (Roz.) 27.

sepulta (Sarcosph.) 187.

seriata (Naev.) 14:3.

serpens (Chondrom.) 4.

- (Hypox.) 135.

serpula (Comur.) (19) l:?.

(Hemitr.) 12.

seratus (Cten.) (13I) 7I.

sexdecimsporus (khyps) Is'.

sinopica (Nect.) 84.

simuosum (Phys.) ls.

siparia (Pleomass.) 11!).

sorbariae (Diap.) 1:s.

sorbi (Dothiora) 90.

- (Vals.) 124.

Sordaria 10\%.

sordirla (Diap.) 128.

- (Tals.) 126.

Sorosphaera 6.

sowejbyi (Leptosph.) 117.

sparsa (Perouosp.) in.

Sipathularia 200.

speciosum (Physod.) 4:i.

spermoides (Leptosp.) (Is!I) l15.

sphaeriea (Gen.) (376) 194.

Sphaerita 28.

sphaeroides (1)othioma) (176) !0.

sphaeropezia 151.

Sihaerosoma l98.

sphaerosperma (Entomophth.) (116) bi3.

Sphaerospora lkis.

Silhaerostilhe s.5.

Siphacrotheca 7.5 .

Sphacrotilus 2.

sphaerulina 114.

sphingmo (cordic.) s7.

spiculo a (1)iap.) 127.

spina (1)iap.) 1:30.

spincllus to 
-piniferum (Mologr.) $1: 34$.

- jinosa (Vals.) lez.

-joinosus (11uc.) is.

tivale (thaetom.) (181) 10.8.

- Pirosema 2.

ripirillum 2.

splemelens (Cribr.) ؛.

spodiaea (Melaneoniella) 13:.

sporodinia

cyorormia 104.

spumaria 20 .

-jumarioides (c hondriod.) 20t.

spuamulosum (D)idym.) (36) 2l.

itamnaria 169.

tergia 143.

-tellariae (srnchytr.) :31.

stellata (sitict.) i45.

sellatus (Aplan.) (7!) 4!.

tellulata (Vals.) 1:4.

sitemonitis 2?3.

stercorarius (Ascob.) (3.5.) 18:3.

- tercorea (Lachnea) 185.

-tercosens (Teleb.) (3.53) 1s:.

stictarmm (celiel.) (297) 1.0it.

-ticticum (Xylogre) (276) 144.

tictis 14is.

- tigma (1)iatr.) (29t6) 1:32.

stigmatea 112 .

- tilbostoma (Mclanc.) (244) Ji3.

stipae (Hromnose) $17 s$.

stemptococecus 1.

serickeria 110.

-trobilina (Hymmose. 17 s.

-trumella (Diap.) 130 .

subangulosum (Rhiznll.) :3.

-ublinsutat (Hum.) lat).

sublenticulage (llace) Isil.

-ubtecta (Vials.) 1:2.2.

subulatus (Elonth.) (1.it) s.2.

-ubvelata (ctor..) (271) 143 .

- uecenturiata (Nmmu.) li3.t.

-luceinea (1)b.) ldi3.

suecisae (simelutr.) (52) :31.

sucrosa (lialact.) lol.

suffusa (crotospo) (24\%) 1:31.

sulcata (Atret.) (366) list.

suleiena (Hyporl rumella) I33.

-ulfurea ('ephal.) 72.

(Diap.) 1:30.

sulfuremon (Lalclun.) 176.

siperflua (Didymella) (217) 11.5.

suspecta (Cyrom.) 2013.

cryorephalis fiz.
Finchytrimm 30.

sincetionm (bagen.) 45.

singenexia (Dialo) 130.

sistremma 88.

taleola (Diap.) 1:30.

Tapesia 16is.

'Tajulurina lis.

taranaci (Nynchytr.) :3l.

Talzetta 187.

teleboloides (Hum.) Igu.

(Melanosp.) 81 .

Telebolus 182.

tenmo (Cladoch.) (68) 42 .

tessella (1)iap.) r:3u.

tesiera (I)iap.) 130 .

testaceum (chombliod.) (31) 201.

testacens (Ascophl.) 1 $1 \times 2$.

Tetramya 6.

'Thamnidium (il.

thelena (liosell.) Io.5.

Thelocarpon s:?

Thielavia 7 .

thoracella (Eurvach.) s.t.

Thureti (saprol.) 4 .

Ticlotherium 114.

tigrimum (Lepicl.) (37) 2.2.

tiliae (Valiar.) (24:3) 131 .

Tocciacana (1)iatr: nellal) l:3:3.

tortilis (Erys.) 76 .

torulosa (tiaprol.) 47.

Tospumetii ('laph.) (l2s) tie.

trabea (cephal.) 71.

tragopogonis (Alh.) riz.

translucens (Vals.) 124.

transwersum (lihiosph.) 30.

trechispora (N)hatereste) (3.5th ls.

Termatosplateria 110.

tremulare (Vont.) 11.i.

Prichial 1:2.

Triehosphaceria $10 \%$.

trichostoma (Terest.) 115.

trifolii (0)p.) 2 !!

(Hhyllach.) s!!.

(Peimlop) (317) 164 .

trifoliorum ('eronosp.) 5.5.

trist is (chactosph.) los. (Nitsclik.) 111.

Trechila liso.

truncolum (Vibriss.) (3392) 200.

Tryblidiopsis 146.

Tryblidium 146. 
Tuber 194.

tubereulariformis (Nect.) 84.

tuberosa (siclerot.) 17.2.

tubiformis (Gnomoniclla) (2.27) 120 .

Tubulina 10.

Tulasnei (Diap.) 127.

- (Hydnot.) (378) 194.

turgidla (Taph.) 69.

turgidum (Antlı.) 126.

tussilaginis (Coleosp.) 219.

Tympanis 15.5.

typharum (Leptosph.) 116.

typhae (Nycosph.) 11:.

tyluina (Comatr.) $2:$.

- Epich.) (164) 86.

melum (Hypox.) 135.

Ulei (lroe.) 2]3.

ulmi (Euryach.) = uhmi (systr.).

- (Systi.) 89.

mulsellata (Circin.) (lon) 601).

mombelliferarum (Volk.) 6.5.

umbonats (Ombr.) 170.

umbrina (Amphisph.) 110.

umbromm (Laehnea) 186.

uncinatum (Mrxot.) $7 \mathrm{l}$.

Uncimula 77.

unica (Roh.) (263) 139.

mitum (Hrpox.) 135.

ureolus (Golr.) (302) 1.5.

uledinis (Olp.) 2 ?!

minula (sclerot.) (:331) 171.

Trophlyet is 4:?

urticas" (Hrmenose.) 179 .

- (Peronosp.) 5.5.

Tstulina 134

ntricalaris (Badh.) 16.

utriculosus (Conidiol).) (118) 64.

raccinii (Cibhera) 112.

vagabunda (Myeosph.) 114.

ragans (Physod.) t:3.

- (Pleospo.) 118.

vasum (Aulogre) Ito.

valerianellae (T'eronosu.) 5.).

Valsa 121 .

Valsaria $1: 81$.

valia (Trich.) (15) l.2.

varians (C'elicl.) 1.it.

- (Pleomass.) 119. variegatus (Elaph.) 7.8.

varium (Celid.) 1.ti.

velata (Diap.) 130.

velutina (Rosell.) 106.

Venturia 115.

venosa (Dise.) (368) 169.

vermicolum (Nyzoc.) 44.

rermicularia (Trichosph.) 10.5.

vermicularis (Perich.) 14.

veronicae (Asterin.) 7s.

- (Sorosph.) 6.

Verpa 203 .

verneiformis (Diatryerlla) $13: 3$.

verrucosa (fien.) (376) 194.

restita (Fenest.) (240) 131.

vexata (Beloniose.) (346) 17s.

vibratilis (l'hore.) 11 !).

Vibrissea 200.

viciae (Peronosp.) 5.).

vicinum (Sichizost.) 111 .

vincae (Hetasph.) 116.

-, (Peronosi.) 5.j.

vinosa (6).h.) 16.3.

violacea (1'(ronosp.) 5 (i

- (Plic.) 187.

violaceum (Polysph.) (5) i.

violacens (Hypiom.) 8.3.

violae (Peronosp.) 5.).

violascens (Hrpom.) 81.

- (Saccob). (3.56) $18 \%$.

virescens (Phis.) IS.

virginemm (Lachn.) 175.

virenlt olum (Hel.) 17!.

(Hrpod.) l:3s.

viricle (1licrogl.) (386) 19!).

- (Phys.) is.

riridis (Hroom.) 8.3.

visci (Gibiberid.) (209) II:?

viscosum (Geogl.) l!!!.

vitellinaria (Nesol.) 1.59.

vitellimm (1'olyang.) (:i) 4 .

viticola (Plasmop.) (\$!) it.

vitis (ceratost.) 108 .

(Vals.) 125.

Volkartia 6.i.

vulgare (lerisp.) 78 .

vulgaris (Acet.) 188.

— (bals.) (375) 198.

(4nom.) 120.

(Ciuttulinops.) 5.

(1'it.) 177.

- (Pleoplo) (2.2) 11

vulpina (l'hac.) (296) l.56. 
Willsommii (l)assere) (336i) 174.

Nommina 27 .

xanthustroma (Molance) lal.

Silaria lis6.

Vilescanma 144.

xlontri (Anth.) leti.
Kignorilla lOR.

Kolbelii (Melanosp.) 8l. Zoogrlor a 3.

\%olffia 77.

Kwarkhii (Leciogr.) (30) 16t). \%onematis (Phlyetoch.) 37. zirnomicola (c)p.) 29. 



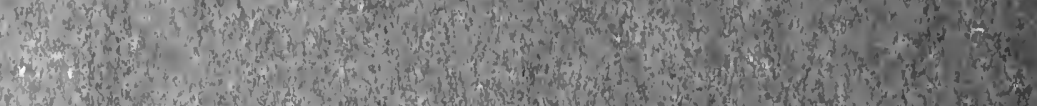

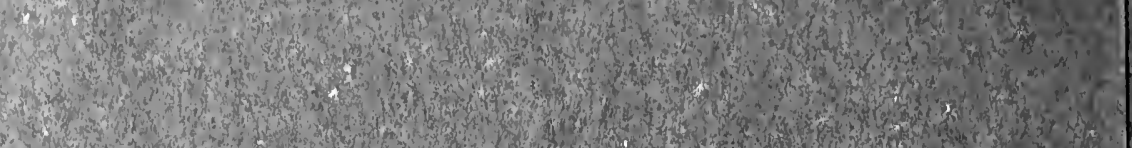
(2)

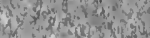

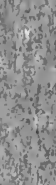
(3):

W.

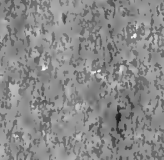

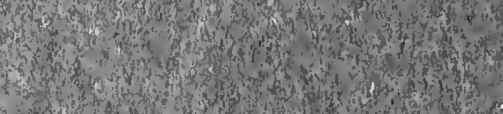

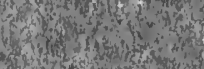

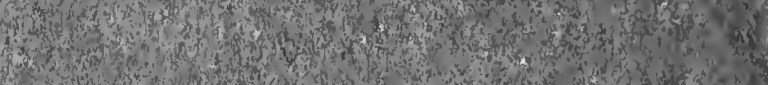

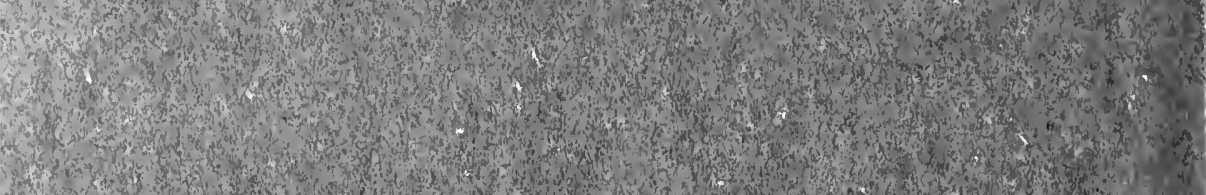

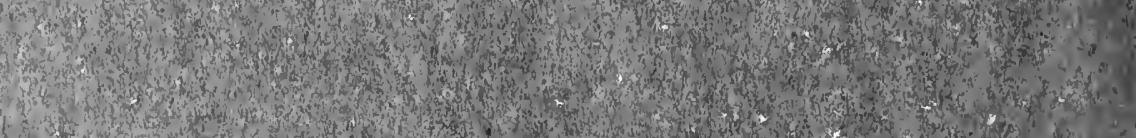

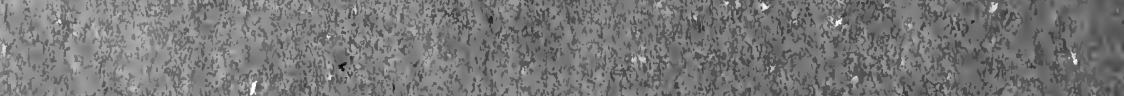
W.

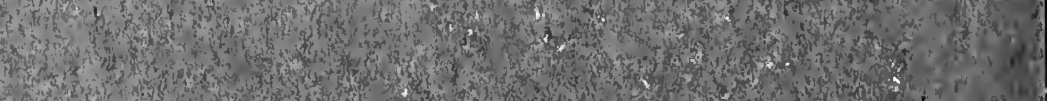
He

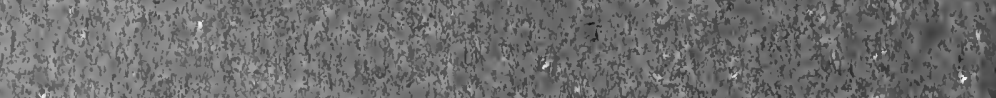
.

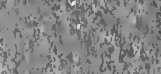
19. (x) पis. ris

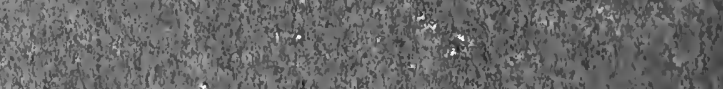

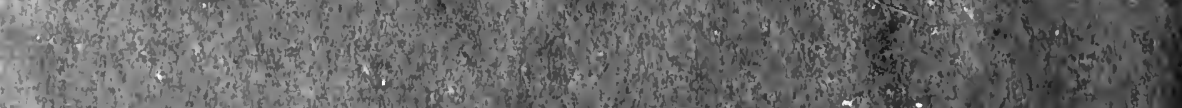

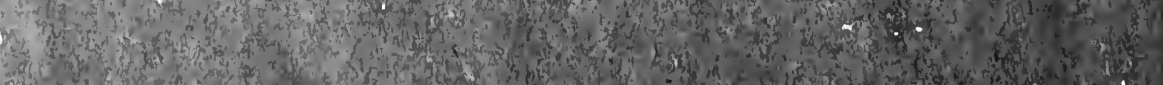
(3) (3)

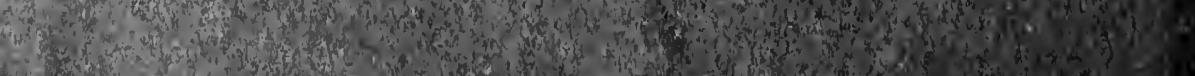

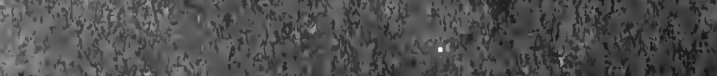

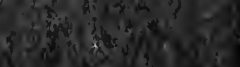

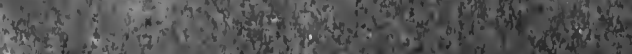

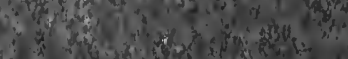


Lindau Gustav Die mikiosho

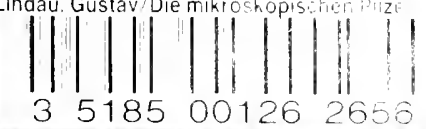

35185001262656
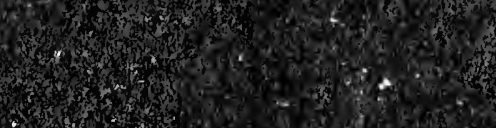

3. 2.6.

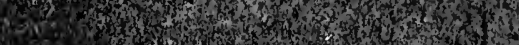

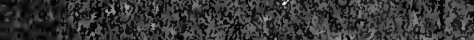
305.

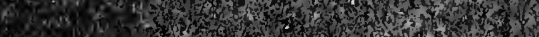

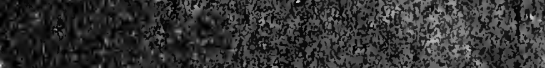
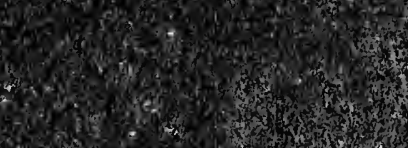

irion

20

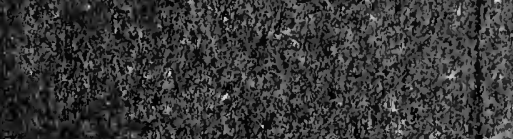

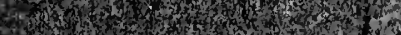

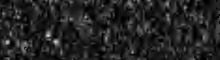

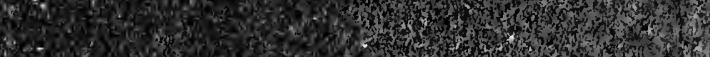
5. 5 (1)

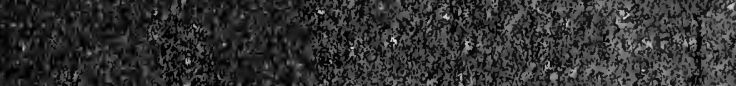

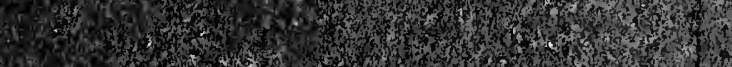
3.5.

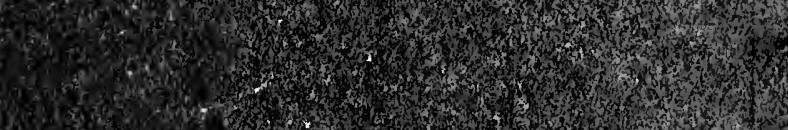

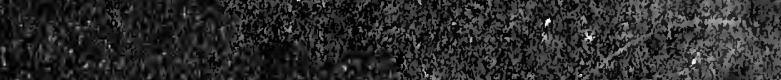

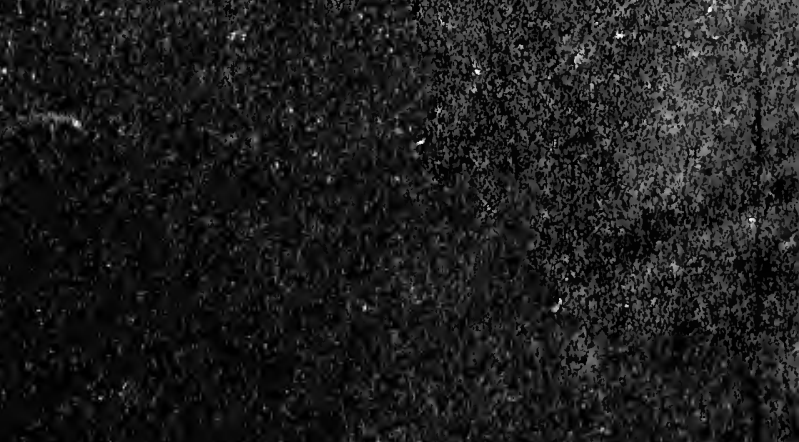




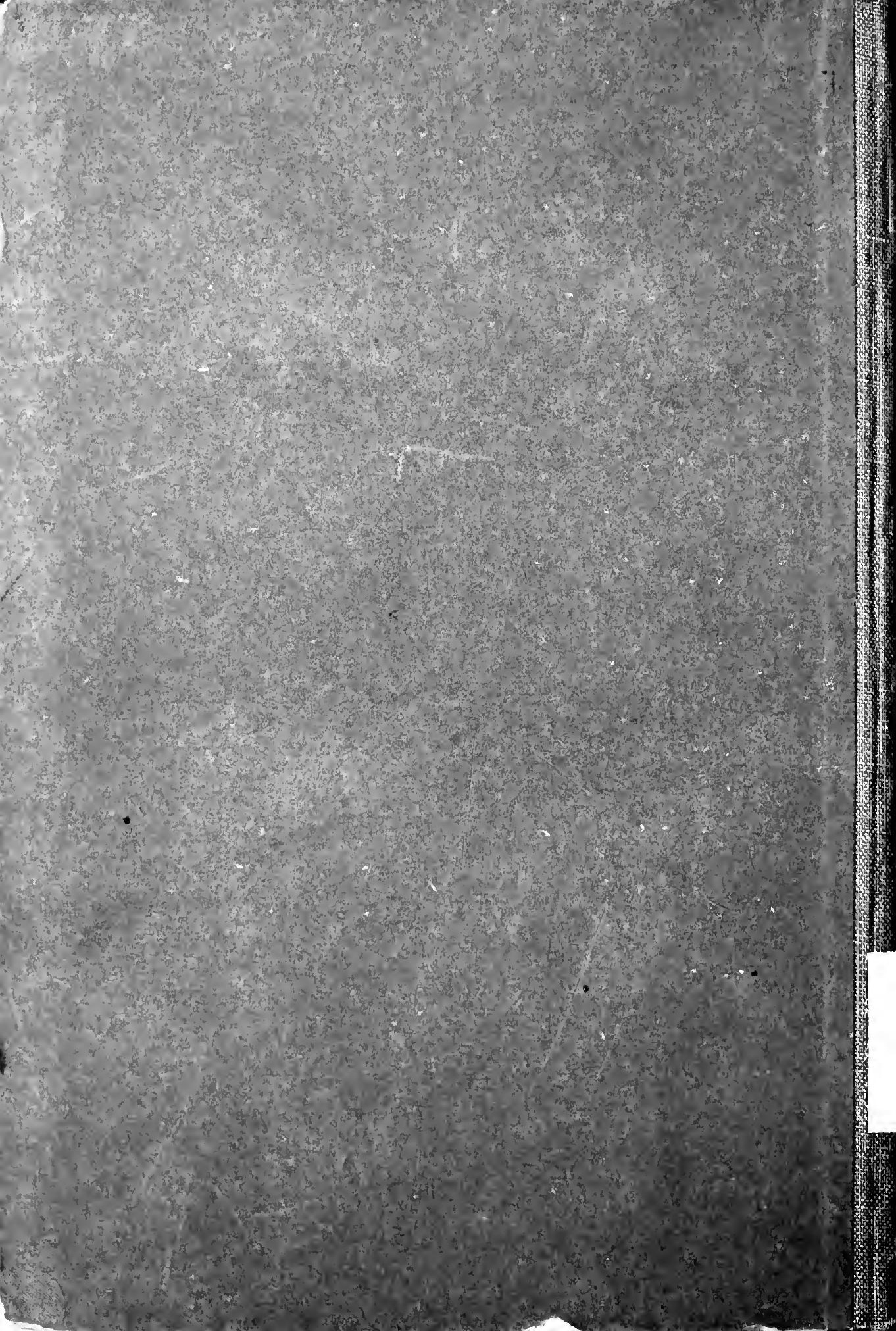

